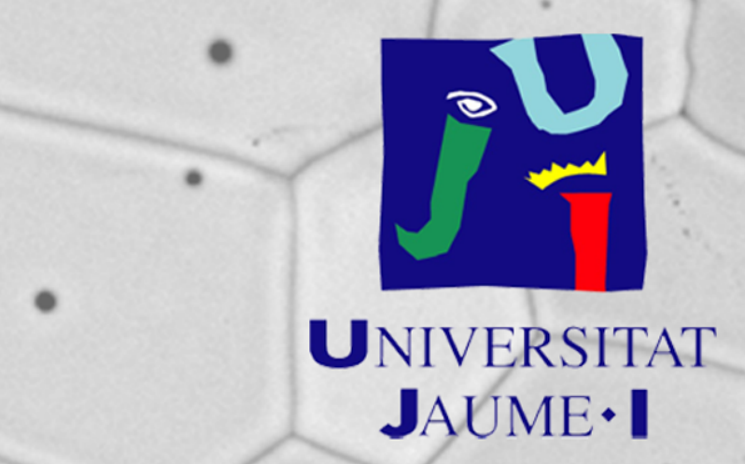

Escuela Superior de Tecnología y Ciencias Experimentales Departamento de Ingeniería Química

Estudio del proceso de sinterización de componentes cerámicos para pilas de combustible de óxidos sólidos

Tesis Doctoral

Adriana Belda Peña

- Dirigida por:

Dr. Agustín Escardino Benlloch

Dra. Ana Gozalbo Nebot 



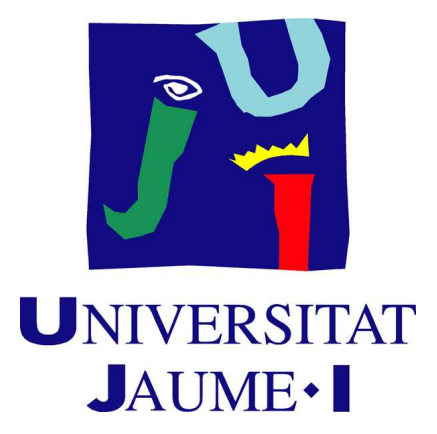

Escuela Superior de Tecnología y Ciencias Experimentales

Departamento de Ingeniería Química

\title{
Estudio del proceso de sinterización de componentes cerámicos para pilas de combustible de óxidos sólidos
}

\author{
Tesis Doctoral \\ Adriana Belda Peña
}

Dirigida por:

Dr. Agustín Escardino Benlloch

Dra. Ana Gozalbo Nebot

Castellón de la Plana, Noviembre de 2015 

Agustín Escardino BenLloch, CATEdRÁtico de INGENIERía QuímiCA dE LA UNIVERSITAT Jaume I de Castellón y ANa Gozalbo Nebot, Profesora titular de Ingeniería QUÍMICA DE LA UNIVERSITAT JAUME I DE CASTELLÓN

CeRTIFICAN: Que Dåa. AdRIANA BeLdA PeÑa ha realizado bajo su dirección, en los laboratorios del Instituto Universitario de Tecnología Cerámica, dentro del programa de doctorado del Departamento de Ingeniería Química de la Universitat Jaume I de Castellón, el trabajo que bajo el título "ESTUDIO DEL PROCESO DE SINTERIZACIÓN DE COMPONENTES CERÁMICOS PARA PILAS DE COMBUSTIBLE DE ÓXIDOS SÓLIDOS" presenta en esta Memoria y que constituye su tesis para optar la grado de Doctora en Ingeniería Química.

Y, para que conste a los efectos oportunos, firman el presente certificado en Castellón, a 28 de Julio de 2015.

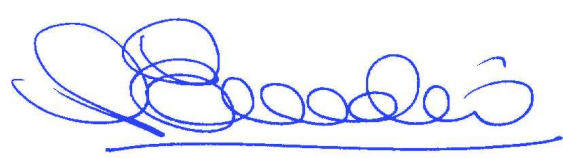

Fdo. Agustín Escardino Benlloch Catedrático de Ingeniería Química

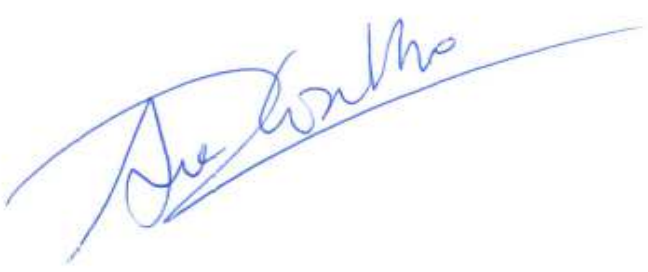

Fdo. Ana Gozalbo Nebot

Prof. Titular de Ingeniería Química 

"Creo que el agua se usará un día como combustible, que el hidrógeno y el oxígeno que la constituyen, utilizados aislada y simultáneamente producirán una fuente de calor y de luz inagotable". Julio Verne, La Isla Misteriosa (1875). 



\section{Agradecimientos}

Una parte de la investigación cuyos resultados se exponen en esta Memoria se ha realizado dentro del proyecto europeo SOFC 600: "Demonstration of SOFC stack technology for operation at $600^{\circ} \mathrm{C}$ ", durante el periodo de tiempo comprendido entre 2006 a 2010 y corresponde al desarrollo de la tarea que le fue asignada a la empresa NTDA (Nuevas Tecnologías para la Distribución Activa de Energía) dentro del proyecto global.

Dicha empresa tenía suscrito un convenio de Colaboración con el Instituto Universitario de Tecnología Cerámica de la Universitat Jaume I, a través del cual esta Institución participó en el desarrollo del citado proyecto europeo.

En consecuencia, quiero hacer patente mi agradecimiento a la Comisión Europea y a la empresa NTDA, por el soporte económico prestado. Asimismo quiero extender dicho agradecimiento al Instituto de Tecnología Cerámica, por haber apoyado incondicionalmente, después de finalizar el mencionado proyecto, la continuación de la línea de investigación que ha conducido a obtener una parte importante de los resultados que se exponen en esta Memoria.

También me gustaría reconocer la labor de mis compañeros más cercanos, por haberme animado todos y cada uno de los días; tanto los que están: Paula, Angel, Sonia, Lola, Javier, Yolanda, Vicente, Ma José y Ana; como los que ya no están trabajando con nosotros: Breogán, Noelia y Begoña. Y especialmente agradecer a D. Agustín, por esta nueva oportunidad que he tenido de trabajar y de aprender a su lado. 

"A mi familia y a mi Maestro, como ejemplo de esfuerzo y dedicación“" 



\section{Tabla de contenido}

Resumen..... 5

1 Introducción. 7

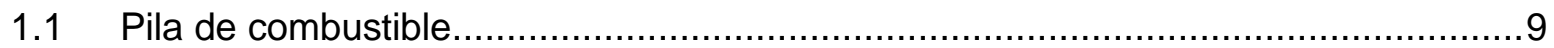

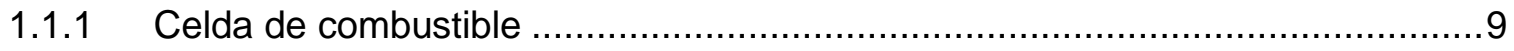

1.1.2 Tipos de celdas de combustible ........................................................... 10

1.1.3 Eficacia de una celda de combustible ...................................................... 12

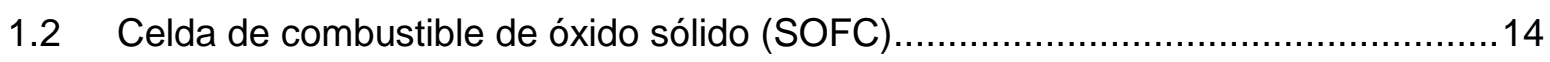

1.2.1 Principios termodinámicos ...................................................................... 14

1.2.2 Propiedades del electrolito de las SOFC ............................................... 16

1.2.3 Materiales a utilizar para el electrolito de las pilas SOFC ..............................16

1.2.4 Conductividad iónica del electrolito de las SOFC ........................................19

1.2.5 La conductividad iónica en monocristales ................................................20

1.2.5.1 La conductividad iónica en materiales policristalinos .................................21

1.2.5.2 Medida de la conductividad iónica de materiales policristalinos ...................24

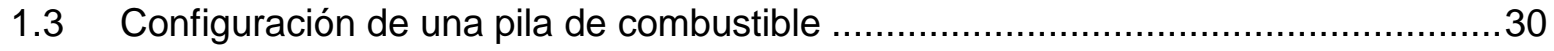

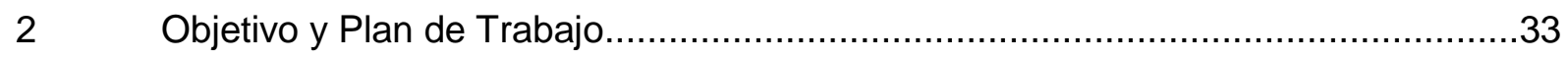

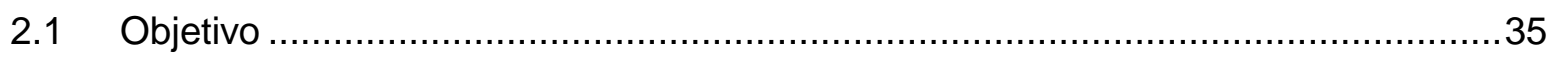

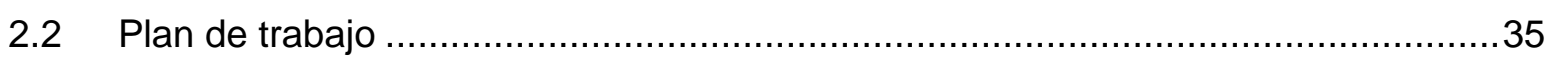

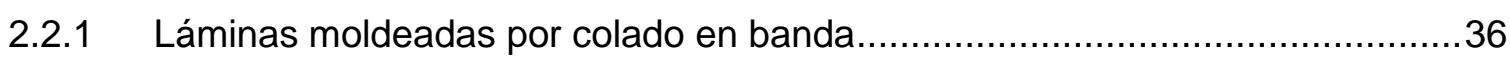

2.2.2 Probetas conformadas por prensado unidireccional.......................................37

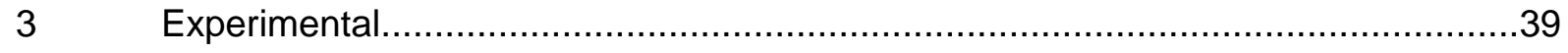

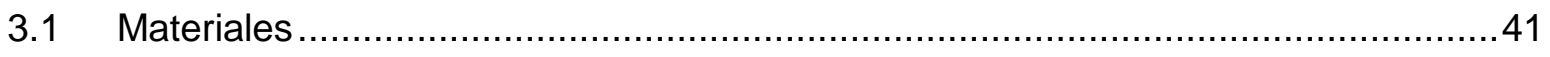

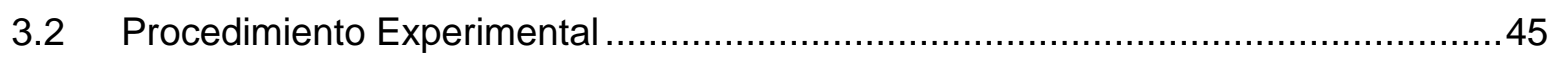

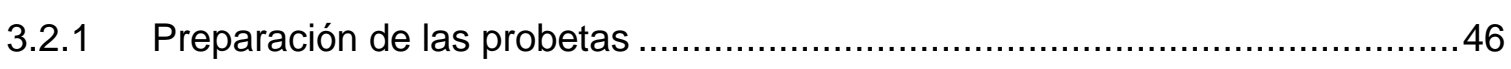

3.2.1.1 Conformado por prensado unidireccional ........................................... 46

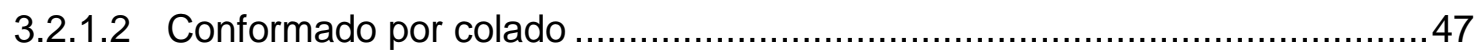

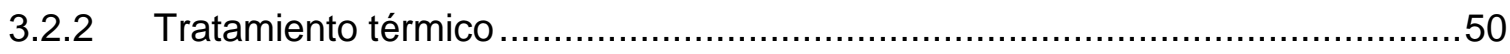

3.2.3 Preparación de las muestras de láminas sinterizadas..................................51

3.2.4 Determinación de las propiedades técnicas del producto resultante de la etapa de sinterización ......................................................................... 52

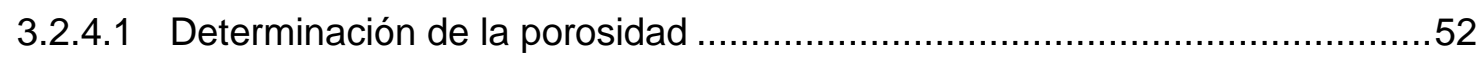

3.2.4.2 Determinación del tamaño de los microcristales (diámetro medio de

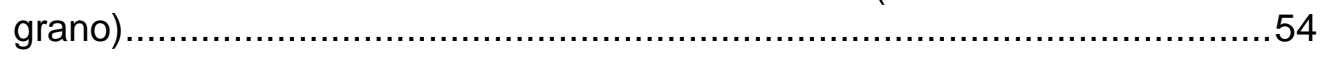

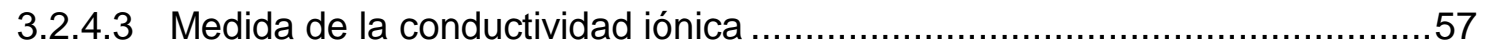


3.2.4.4 Determinación de la Resistencia Mecánica a la Flexión de las láminas sinterizadas

Resultados

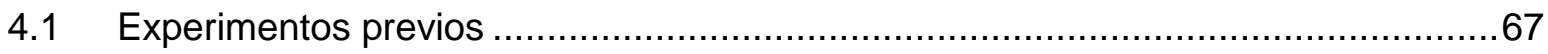

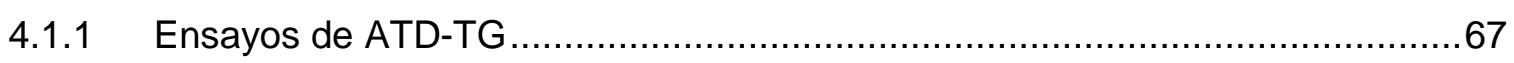

4.1.2 Ensayos con el Microscopio de calefacción ...................................................69

4.2 Optimización de las suspensiones de circona................................................. 70

4.2.1 Ensayos utilizando una mezcla de metil etil cetona e isopropanol como disolvente 72

4.2.1.1 Ensayos realizados utilizando terpineol como dispersante ........................72

4.2.1.2 Ensayos realizados utilizando Menhanden Fish Oil de Aldritch (MFO) como dispersante..................................................................... 75

4.2.1.3 Efecto de la proporción de dispersante (MFO) ....................................... 82

4.2.1.4 Efecto de la relación MEK/Isopropanol en el disolvente..............................84

4.2.1.5 Características de las suspensiones idóneas ...........................................86

4.2.2 Ensayos utilizando una mezcla de xileno-etanol como disolvente.....................86

4.2.2.1 Optimización de la composición de las suspensiones preparadas con mezclas xileno-etanol al $50 \%$, en masa.

4.2.2.2 Optimización de la composición de las suspensiones preparadas con mezclas xileno-etanol en la proporción másica 40-60.

4.3 Optimización de la etapa de eliminación de la materia orgánica contenida en las láminas coladas: Selección de la velocidad de calentamiento y de la

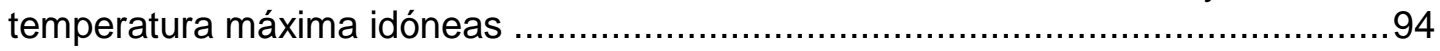

4.3.1 Criterio de selección: Aspecto visual de la lámina resultante ..........................94

4.3.2 Criterio de selección: Porosidad de la lámina resultante................................97

4.3.3 Montaje utilizado para conseguir mantener la planaridad de las láminas durante el desarrollo de las etapas de eliminación de materia orgánica y de sinterización............................................................................................ 100

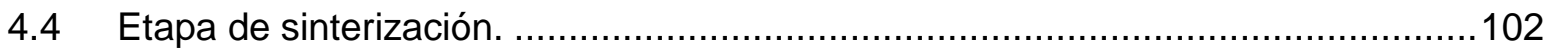

4.4.1 Experimentos con láminas coladas........................................................ 103

4.4.1.1 Influencia del ciclo térmico de sinterización sobre la porosidad de las

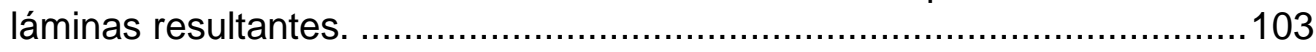

4.4.1.2 Influencia del ciclo térmico de sinterización sobre el diámetro medio de grano de las láminas resultantes.....................................................112

4.4.1.3 Resistencia mecánica de las láminas sinterizadas ................................117

4.4.2 Experimentos con probetas prensadas ....................................................117

4.4.2.1 Influencia del ciclo térmico de sinterización sobre la porosidad de las probetas resultantes.

4.4.2.2 Influencia del ciclo térmico de sinterización sobre el diámetro medio de grano de las probetas resultantes. 
4.4.2.3 Influencia del ciclo térmico de sinterización sobre la conductividad iónica de las probetas resultantes.

4.4.3 Probetas conformadas a partir de la composición $C$ - II ..............................124

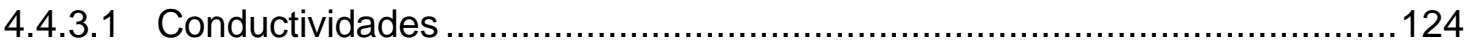

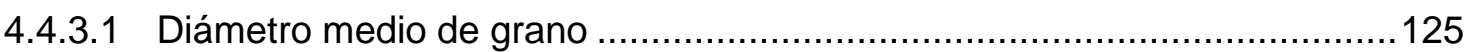

4.4.3.2 Resistencia mecánica de las láminas coladas sinterizadas ......................126

4.4.4 Probetas conformadas a partir de la composición $C$-III ...............................127

4.4.4.1 Conductividades .................................................................................. 127

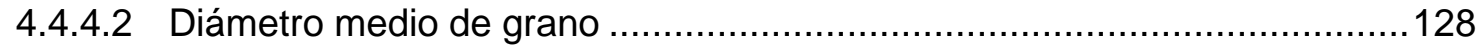

4.4.4.3 Resistencia mecánica de láminas coladas sinterizadas ............................130

5 Discusión de los Resultados

5.1 Composición C-I. Comparación de las propiedades estructurales de las piezas resultantes de sinterizar, a diferentes valores de $T_{S}$ y $t_{R}$, las láminas coladas y las probetas prensadas.

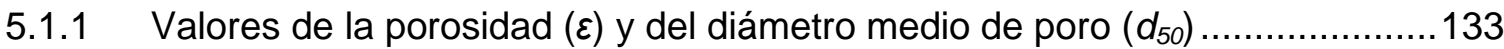

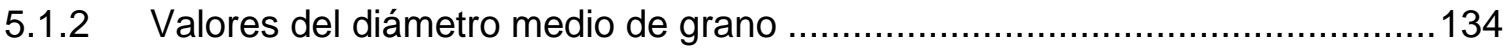

5.1.3 Variación de la porosidad y el diámetro medio de poro con la temperatura de sinterización y el tiempo de residencia ................................................... 135

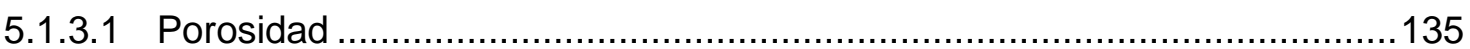

5.1.3.2 Diámetro medio de poro ............................................................... 137

5.1.4 Estudio cinético del crecimiento de grano. Variación del diámetro medio de grano con la temperatura de sinterización y el tiempo de residencia.........138

5.1.4.1 Muestras sinterizadas a partir de las láminas coladas con la suspensión $C-1-35$

5.1.4.2 Piezas prensadas

5.1.5 Variación de la conductividad total con la temperatura de sinterización y el tiempo de residencia.

5.1.5.1 Variación de la conductividad total con la temperatura de ensayo $\left(T_{\mathrm{e}}\right) \ldots \ldots 152$

5.1.5.2 Variación de la conductividad total con el diámetro medio de grano 155

5.1.5.3 Interpretación de los resultados obtenidos en base al Modelo de Brick Layer. Contribución de la conductividad en el interior de grano y en los límites de grano al valor de la conductividad total.

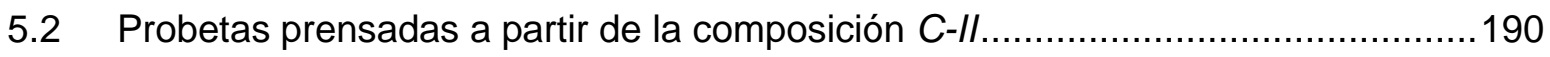

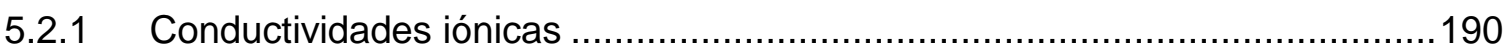

5.2.2 Consideraciones sobre la resistencia mecánica............................................194

5.3 Probetas prensadas a partir de la composición C-III..........................................195

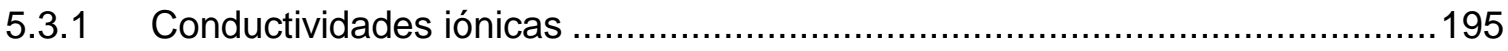

5.3.2 Consideraciones sobre la resistencia mecánica...........................................198 


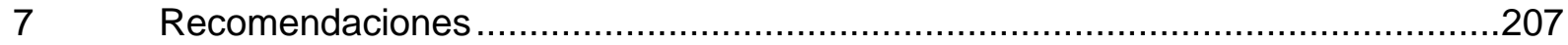

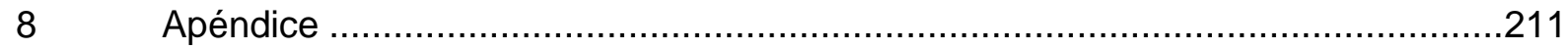

8.1 Resultados obtenidos al medir las conductividades de las probetas

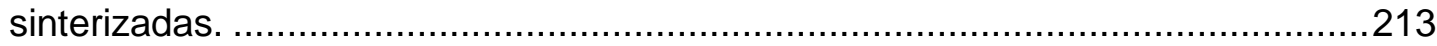

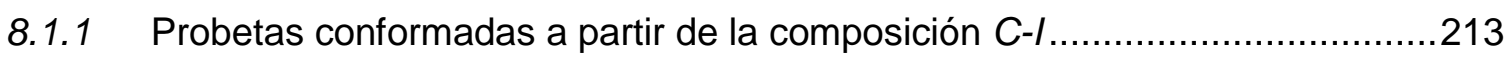

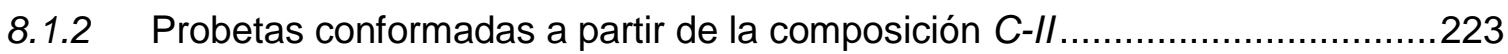

8.1.3 Probetas conformadas a partir de la composición $C$-III ...............................226

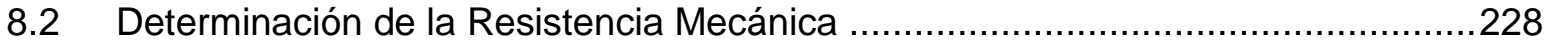

8.3 Publicaciones realizadas en el marco de esta investigación ................................229

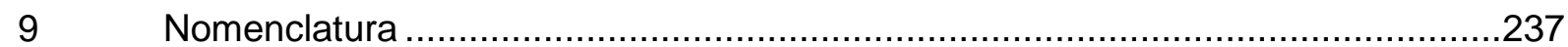

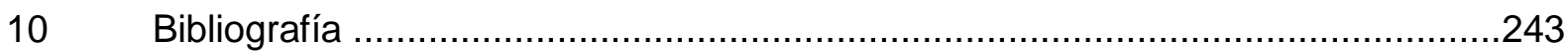




\section{Resumen}

El trabajo cuyos resultados, interpretación y discusión son objeto de esta Memoria, se ha desarrollado con la intención de obtener un producto apto para ser utilizado como electrolito en células de combustible de oxido sólido en configuración ESC capaces de operar, con una eficacia aceptable, en el intervalo de temperaturas comprendido entre 873 y $973 \mathrm{~K}$. Como material de partida se ha utilizado polvo de circona dopada con escandia y ceria o con itria $\left(10 \mathrm{Sc}_{2} \mathrm{O}_{3 .} 1 \mathrm{CeO}_{2.89 \mathrm{ZrO}_{2} \mathrm{O}} 3 \mathrm{Y}_{2} \mathrm{O}_{3 .} .97 \mathrm{ZrO}_{2}\right)$.

La mayor parte de la investigación se ha realizado con láminas y probetas cilíndricas

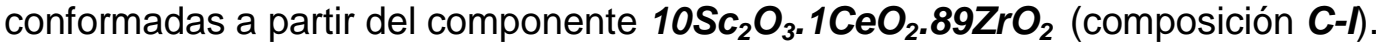

Con la intención de mejorar la resistencia mecánica de las láminas sinterizadas, se han realizado algunos experimentos adicionales con láminas y probetas conformadas a partir de otras dos composiciones: La denominada $\boldsymbol{C}$-II (constituida por $80 \%$ de

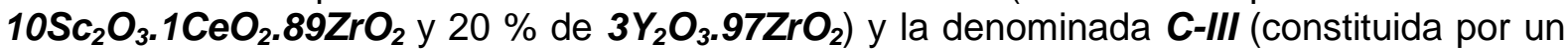
$98 \%$ de $10 \mathrm{Sc}_{2} \mathrm{O}_{3} .1 \mathrm{CeO}_{2.89} 8 \mathrm{ZrO}_{2}$ y $2 \%$ de $\alpha$-alúmina, proporciones másicas).

\section{Labor realizada con la composición C-I}

Se ha desarrollado y optimizado un proceso de sínterización de láminas, conformadas por

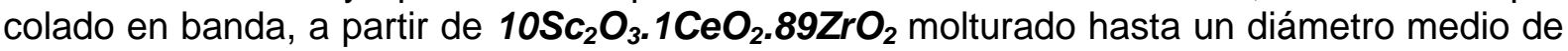
$0,097 \mu \mathrm{m}$. Este proceso ha consistido en:

a) Seleccionar los componentes, de naturaleza orgánica, necesarios para preparar una suspensión estable del material inorgánico de partida. Esta suspensión debía reunir las características adecuadas para que las láminas, conformadas a partir de ella por colado en banda, mantuvieran la planaridad y la ausencia de grietas, en crudo, después de secarlas.

b) Diseñar el ciclo térmico adecuado para eliminar los aditivos orgánicos contenidos en las láminas crudas, en una etapa previa a la de sinterización, sin que resulte afectada la planaridad y compacidad de las mismas.

c) Diseñar el ciclo térmico adecuado para desarrollar la etapa de sinterización de las láminas exentas de materia orgánica, con el fin de conferirles la mayor resistencia mecánica posible, junto con las propiedades de baja porosidad y alta conductividad iónica deseadas.

Se ha determinado la porosidad, el diámetro medio de poro y el diámetro medio de grano de las láminas sinterizadas, a diferentes condiciones de operación (temperatura de sinterización y tiempo de residencia a dicha temperatura).

Se ha ensayado la posibilidad de correlacionar, mediante una ecuación sencilla, los datos experimentales del diámetro medio de grano de estas láminas con la temperatura y tiempo de tratamiento, durante el ciclo térmico utilizado para su sinterización.

Dada la dificultad encontrada para medir la conductividad iónica de las láminas sinterizadas, debido al reducido espesor de las mismas (alrededor de $100 \mu \mathrm{m}$ ), se ha procedido a conformar probetas cilíndricas, por prensado unidireccional, de mayor espesor que dichas láminas, para utilizarlas con esa finalidad.

Estas probetas se han sometido a los mismos ciclos térmicos que las láminas coladas, para eliminar los componentes orgánicos y para proceder a su sinterización, habiéndose determinado asimismo la porosidad, el diámetro medio de poro y el diámetro medio de grano de las muestras sinterizadas. 
Se ha comparado los valores de la porosidad, el diámetro medio de poro y el diámetro medio de grano en las probetas sinterizadas y en las láminas sinterizadas conformadas a partir de la suspensión elegida, para comprobar si eran del mismo orden ya que, tratándose del mismo material, la conductividad iónica total podía resultar afectada por diferencias importantes entre dichas propiedades.

Mediante una ecuación similar a la propuesta para las láminas, se ha ensayado asimismo la posibilidad de relacionar los datos experimentales del diámetro medio de grano con la temperatura y tiempo de tratamiento, a lo largo del ciclo térmico que conduce a su sinterización.

Se ha determinado experimentalmente la conductividad iónica total de las probetas sinterizadas, a diferentes condiciones de temperatura de sinterización y tiempo de residencia a dicha temperatura, en el intervalo de temperaturas de ensayo comprendido entre 573 y $1273 \mathrm{~K}$.

Habiendo encontrado una cierta relación entre los valores de la conductividad iónica total y el correspondiente diámetro medio de grano, se ha intentado aclararla apoyándose en el modelo de Brick-Layer, que es el más frecuentemente utilizado para la interpretación de los resultados experimentales de conductividad iónica en materiales policristalinos.

Para ello, partiendo de la información experimental obtenida y en base a dicho modelo, se han calculado una serie de valores de la conductividad iónica en los límites de grano y en el interior de grano, a diferentes temperaturas de ensayo, en el intervalo comprendido entre 623 y $1273 \mathrm{~K}$, en el que no era posible determinar dichas propiedades experimentalmente.

Con estos valores calculados se ha tratado de explicar la mencionada relación entre la conductividad iónica total y el diámetro medio de grano.

Asimismo se ha determinado la resistencia mecánica de láminas sinterizadas de alrededor de $100 \mu \mathrm{m}$ de espesor.

\section{Labor realizada con las composiciones $C$-II y $C$-III}

Con la intención de tratar de mejorar la resistencia mecánica de las láminas sinterizadas, se han realizado algunos experimentos con dos composiciones ligeramente distintas a la $\boldsymbol{C}$-I: a) composición $\mathrm{C}$-II constituida por $80 \% \mathrm{10Sc}_{2} \mathrm{O}_{3} .1 \mathrm{CeO}_{2} .89 \mathrm{ZrO}_{2}$ y $20 \%$ de circona dopada con itria, de fórmula molecular $3 \mathrm{Y}_{2} \mathrm{O}_{3} .972 \mathrm{rO}_{2}$; b) composición $\mathrm{C}$-III constituida por un $98 \%$ de ${ }_{10 \mathrm{Sc}_{2} \mathrm{O}_{3} .1 \mathrm{CeO}_{2} .89 \mathrm{ZrO}}$ y un $2 \%$ de $\alpha$-alúmina. Las proporciones de los componentes de la mezcla, en ambos casos, son en masa.

Con ambas materias primas se han conformado probetas cilíndricas, por prensado unidireccional, que se han tratado térmicamente del mismo modo que las de la composición C-I aunque, en estos casos, sólo se han realizado experimentos a una temperatura de sinterización (1673 K), para dos o tres valores del tiempo de residencia, a fin de comparar los valores de la conductividad iónica resultante con los obtenidos para la composición $\boldsymbol{C}$-I.

Asimismo se han preparado láminas coladas, a partir de suspensiones preparadas con los mismos aditivos orgánicos que se utilizaron con la composición $\boldsymbol{C}$-I optimizada, a fin de medir la correspondiente resistencia mecánica. Estas láminas, de alrededor de $100 \mu \mathrm{m}$ de espesor, se han sometido a los mismos ciclos térmicos, para la eliminación de la materia orgánica y para sinterizarlas, que los empleados para la composición $\boldsymbol{C}$-I. 
"Y qué se quemará en vez de carbón?; -¡Agua!, ...iAgua para calentar las calderas de los vapores y las locomotoras, agua para calentar el agua!. Julio Verne, La Isla Misteriosa (1875).

\section{Introducción}




\subsection{Pila de combustible}

Una pila de combustible es un dispositivo que se comporta como una batería electroquímica primaria, ya que genera energía eléctrica como resultado de reacciones químicas, por las que determinados componentes se transforman en otros con menor contenido de energía química'.

A diferencia de las baterías electroquímicas galvánicas que operan en régimen discontinuo, ya que cuando se agota su carga se desechan (baterías primarias) o se han de recargar (baterías secundarias), las pilas de combustible operan en régimen continuo, puesto que los reactantes se alimentan continuamente al sistema y los productos de reacción, con un contenido de energía química más bajo, se extraen continuamente del mismo².

\subsubsection{Celda de combustible}

Las pilas de combustible están constituidas por un conjunto de celdas apiladas. El principio de funcionamiento de una celda de combustible es inverso al de la electrólisis del agua. Durante la electrólisis, el agua se disocia en dos componentes, hidrógeno y oxígeno, por acción de la corriente eléctrica, mientras que en una celda de combustible se obtiene energía eléctrica como consecuencia de la reacción entre esos dos gases para dar agua. La energía química del enlace $\mathrm{H}-\mathrm{H}$ de la molécula $\mathrm{H}_{2}$ se transforma en energía eléctrica, a la vez que se obtiene vapor de agua, como resultado de la oxidación electroquímica del combustible $\left(\mathrm{H}_{2}\right)$ y la reducción electroquímica del oxidante $\left(\mathrm{O}_{2}\right)$. El hidrógeno que se alimenta a la pila puede obtenerse por electrólisis del agua, 0 a partir de cualquier hidrocarburo o alcohol mediante el proceso de reformado catalítico. El oxígeno se suministra normalmente como corriente de aire ${ }^{3}$.

Dado que el único producto de reacción es agua, teóricamente no se produce emisión de contaminantes. Ahora bien, cuando las pilas de combustible se alimentan con hidrocarburos, con el fin de generar el hidrógeno necesario por reformado catalítico, se desprende $\mathrm{CO}_{2}$, aunque en cantidades inferiores al que se produce mediante los sistemas tradicionales de generación de energía eléctrica. En ningún caso se emiten óxidos de nitrógeno.

Una celda de combustible consta de un ánodo (electrodo negativo), un cátodo (electrodo positivo) y un electrolito consistente en un conductor iónico que permite la transferencia de iones entre los dos electrodos. (Figura 1.1). El combustible (hidrógeno) y el oxidante (oxígeno) se alimentan continuamente al ánodo y al cátodo respectivamente, donde sufren las transformaciones que se describe a continuación, dependiendo de la naturaleza del electrolito que se utilice ${ }^{4,5}$.

- Electrolito conductor de aniones:

$\begin{array}{lll}\circ & \text { Ánodo: } & \mathrm{H}_{2}+\mathrm{O}^{2-} \rightarrow \mathrm{H}_{2} \mathrm{O}+2 \mathrm{e}^{-} \\ \circ & \text { Cátodo: } & 1 / 2 \mathrm{O}_{2}+2 \mathrm{e}^{-} \rightarrow \mathrm{O}^{2-}\end{array}$

- Electrolito conductor de cationes:

- Ánodo: $\quad \mathrm{H}_{2} \rightarrow 2 \mathrm{H}^{+}+2 \mathrm{e}^{-}$

○ Cátodo: $\quad 1 / 2 \mathrm{O}_{2}+2 \mathrm{H}^{+}+2 \mathrm{e}^{-} \rightarrow \mathrm{H}_{2} \mathrm{O}$ 
En ambos tipos de electrolito, se produce la migración de la especie ionizada hacia el otro electrodo, y los electrones resultantes del proceso de ionización se trasladan desde el ánodo al cátodo por un circuito externo, constituyendo la corriente eléctrica. La transformación global producida, que es exotérmica, puede resumirse mediante el esquema de reacción correspondiente a la combustión del hidrógeno:

$$
\mathrm{H}_{2} \text { (gas,ánodo)+ 1/2 } \mathrm{O}_{2} \text { (gas, cátodo) } \rightarrow \mathrm{H}_{2} \mathrm{O} \text { (gas,ánodo) }
$$

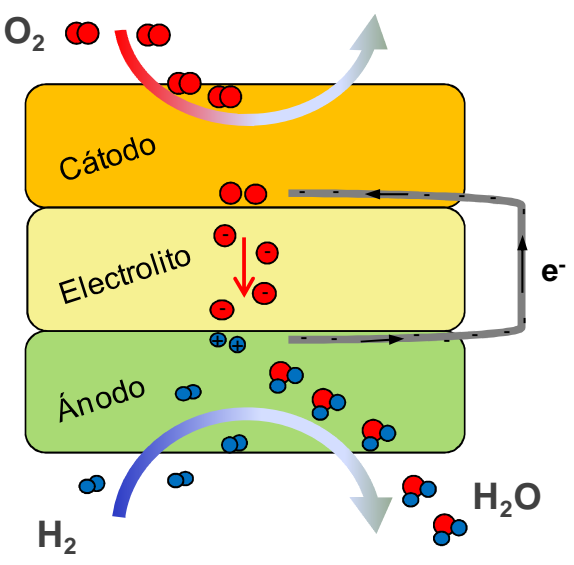

(a)

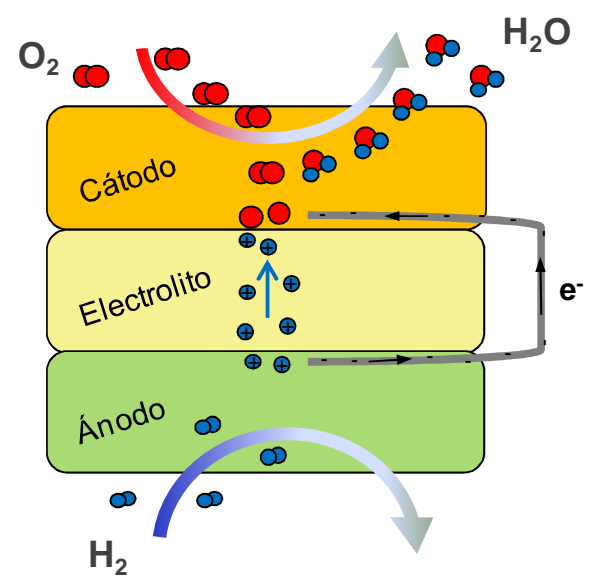

(b)

Figura 1.1. Esquema básico de una celda de combustible ${ }^{3}$ a) El electrolito es un conductor aniónico. b) El electrolito es un conductor catiónico (protónico).

\subsubsection{Tipos de celdas de combustible}

Las celdas de combustible se clasifican según el tipo de electrolito y la temperatura de operación. Los cinco tipos clásicos son: de membrana polimérica (PEMFC), de ácido fosfórico (PAFC), alcalinas (AFC), de carbonato fundido (MCFC) y de óxido sólido (SOFC) (ver Tabla 1.1)

Cada tipo de celda es apropiada para una aplicación concreta.

Las pilas constituidas por celdas PAFC fueron las primeras en comercializarse, seguidas por las constituidas por celdas MCFC y AFC.

En función de la potencia producida por cada tipo de pila, pueden ser utilizadas para suministrar energía a diferentes dispositivos. Las SOFC pueden suministrar hasta $200 \mathrm{~kW}$ en configuración tubular y entre 5 y $10 \mathrm{~kW}$ en planar, las PEMFC en torno a los $250 \mathrm{~kW}$, las MCFC 2MW, las PAFC $11 \mathrm{MW}$ y las AFC entre 10 y $100 \mathrm{~kW}$.

Las bajas temperaturas de trabajo de las pilas poliméricas las hace idóneas para aplicaciones de uso doméstico (ordenadores, teléfonos móviles, etc.) y para el sector automovilístico, aunque el principal inconveniente es la necesidad de usar hidrógeno de alta pureza como combustible. 
Tabla 1.1. Tipos de celdas de combustible

\begin{tabular}{|c|c|c|c|c|c|}
\hline & $\begin{array}{c}\text { PEMFC/ } \\
\text { DMFC }\end{array}$ & PAFC & AFC & MCFC & SOFC \\
\hline Electrolito & $\begin{array}{l}\text { Nafion® } \\
\text { Membrana } \\
\text { polimérica }\end{array}$ & $\begin{array}{c}\mathrm{H}_{3} \mathrm{PO}_{4} \\
\text { Matriz de } \\
\mathrm{SiC}\end{array}$ & $\mathrm{KOH}$ & $\begin{array}{l}\text { Carbonatos } \\
\text { fundidos de: } \\
\mathrm{Li} / \mathrm{K} \mathrm{Li} / \mathrm{Na} \\
\text { Matriz de: } \\
\mathrm{LiAlO}_{2}\end{array}$ & $\begin{array}{c}\mathrm{YSZ} \\
\left(\mathrm{ZrO}_{2}+8 \% \mathrm{Y}_{2} \mathrm{O}_{3}\right)\end{array}$ \\
\hline Electrodos & Carbón & Carbón & $\begin{array}{l}\text { Metales de } \\
\text { transición }\end{array}$ & $\mathrm{Ni}$ y $\mathrm{NiO}$ & $\begin{array}{c}\text { Perovskitas y } \\
\text { perovskitas/ } \\
\text { cermet NiO/YSZ }\end{array}$ \\
\hline lones & $H^{+}$ & $H^{+}$ & $\mathrm{OH}^{-}$ & $\mathrm{CO}_{3}^{2-}$ & $O^{2-}$ \\
\hline Combustible & $\mathrm{H}_{2}$ & $\mathrm{H}_{2}$ & $\mathrm{H}_{2}$ & $\mathrm{H}_{2}$ & $\mathrm{H}_{2}$ \\
\hline & Metanol & $\begin{array}{c}\text { Gas } \\
\text { natural } \\
\text { Butano }\end{array}$ & & $\mathrm{CO}$ & $\begin{array}{c}\text { Gas natural } \\
\text { otros } \\
\text { hidrocarburos }\end{array}$ \\
\hline Catalizador & $\mathrm{Pt}$ & $\mathrm{Pt}$ & $\begin{array}{l}\mathrm{Ni} / \mathrm{NiO} \\
\mathrm{Ni} / \mathrm{Ag}\end{array}$ & $\begin{array}{l}\text { Material del } \\
\text { electrodo }\end{array}$ & $\begin{array}{l}\text { Material del } \\
\text { electrodo }\end{array}$ \\
\hline$P(W / k g)$ & $400-1000$ & 90 & $9-240$ & 40 & 100 \\
\hline$T(K)$ & $298-393$ & $423-493$ & $298-473$ & $873-973$ & $973-1273$ \\
\hline $\begin{array}{l}\text { Eficacia } \\
\text { (HHV\%) }\end{array}$ & 40 & 40 & $30-40$ & 45 & $40-50$ \\
\hline
\end{tabular}

PEMFC: Polymer Electrolyte/ Proton Exchange Membrana; DMFC: Direct Methanol; PFCA: Phosphoric Acid; AFC: Alkaline Fuel Cell; MCFC: Melting Carbonate; SOFC: Solid Oxide.

HHV: High Heating Voltage

En la Figura 1.2 se muestra un esquema con los diferentes tipos de pilas existentes. 


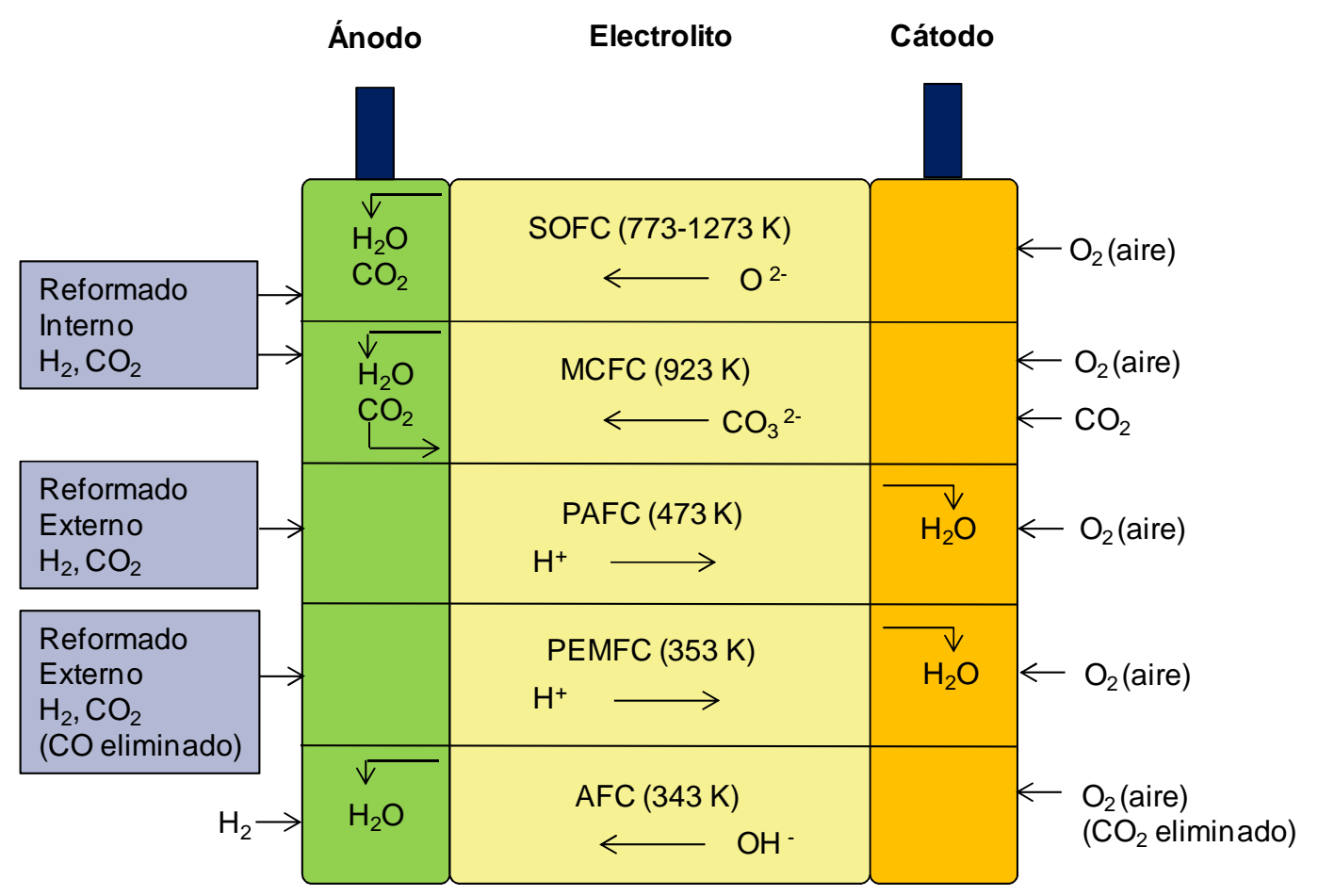

Figura 1.2. Esquema de una pila de combustible7. Resumen de los distintos tipos y funcionamiento.

\subsubsection{Eficacia de una celda de combustible}

El rendimiento o eficacia de una celda de combustible debe determinarse considerando las pérdidas que se producen, durante su funcionamiento, por diversas razones. Dependiendo del tipo de celda, se suelen obtener eficacias comprendidas entre un $35 \%$ y un $60 \%$.

La eficacia ${ }^{8}\left(\boldsymbol{\epsilon}_{F C}\right)$ es un término que se utiliza para cuantificar el funcionamiento de la celda de combustible y es igual al producto de la eficacia electroquímica $\left(\boldsymbol{\epsilon}_{E}\right)$ por la eficacia calorífica $\left(\boldsymbol{\epsilon}_{H}\right)$. La eficacia electroquímica es igual al producto entre la eficacia termodinámica $\left(\boldsymbol{\epsilon}_{T}\right)$, la eficacia voltaica $\left(\boldsymbol{\epsilon}_{V}\right)$ y la eficacia faradaica $\left(\boldsymbol{\epsilon}_{J}\right)$. Por tanto:

$$
\epsilon_{F C}=\epsilon_{E} \cdot \in_{H}=\in_{T} \cdot \in_{V} \cdot \in_{J} \cdot \in_{H}
$$

\section{i) Eficacia calorífica:}

La eficacia calorífica debe considerarse en los casos en los que el combustible contiene gases inertes e impurezas (por ejemplo $\mathrm{CH}_{4} \mathrm{O} \mathrm{CO}$ ) susceptibles de reaccionar con el oxígeno, además de las especies que son electroquímicamente activas (en el caso que se está considerando el $\mathrm{H}_{2}$ ). Se define como:

$$
\epsilon_{H}=\frac{\Delta H}{\Delta H_{\text {com }}}
$$


donde $\boldsymbol{\Delta} \boldsymbol{H}$ representa la variación de entalpía que experimentan las especies electroquímicamente activas disponibles en la celda para generar electricidad que, en este caso, sería la variación de entalpía de la reacción global (1.5), e $\boldsymbol{\Delta} \boldsymbol{H}_{\text {com }}$ es la variación de entalpía que experimenta el conjunto de las especies químicas presentes en la mezcla de gases que se alimenta a la celda.

\section{ii) Eficacia termodinámica:}

El cambio de energía libre o función de Gibbs de la reacción química que tiene lugar en la celda puede ser convertido totalmente en energía eléctrica. Por lo tanto, la eficiencia termodinámica intrínseca (máxima) de una celda tipo SOFC viene dada por la expresión:

$$
\epsilon_{T}=\frac{\Delta G}{\Delta H}=1-\frac{T \cdot \Delta S}{\Delta H}
$$

\section{iii) Eficacia voltaica:}

A medida que se va generando corriente en una celda de combustible, el voltaje se reduce debido a varios factores: aumento de temperatura, variaciones de presión, flujo y composición de los gases y material de la celda. La eficacia voltaica $\left(\boldsymbol{\epsilon}_{v}\right)$ se define como la razón entre el voltaje de la celda $\left(\boldsymbol{E}^{\prime}\right)$ y el voltaje de la celda en el equilibrio $(\boldsymbol{E})$ :

$$
\epsilon_{V}=\frac{E^{\prime}}{E}
$$

La diferencia entre el potencial reversible (o potencial de circuito abierto) y el voltaje de la celda se denomina polarización y se representa por $\boldsymbol{\eta}$ :

$$
\eta=E-E^{\prime}
$$

La polarización total de la pila es la suma de 4 tipos de polarizaciones: la de transferencia de carga 0 activación, $\boldsymbol{\eta}_{\text {act }}$, (suma de energías de activación necesarias para las reacciones electroquímicas que se producen: adsorción, transferencia de carga, desorción, etc.), la de difusión o polarización por concentración, $\boldsymbol{\eta}_{\text {dif, }}$ (la cual depende de las propiedades de transporte de materia del sistema, ya que los reactivos se deben difundir a través de los ánodos y cátodos porosos, por lo que se requiere una buena microestructura porosa interconectada), la polarización de reacción, $\boldsymbol{\eta}_{r e}$, (aparece cuando la velocidad de reacción para suministrar reactivos o eliminar productos en las proximidades de los electrodos es lenta), la polarización de resistencia u óhmica, $\eta_{\Omega}$ (causada por la resistencia a la conducción de iones a través del electrolito y de electrones a través de los electrodos y colectores de corriente, y por la resistencia de contacto entre los componentes de la celda).

$$
\eta=\eta_{a c t}+\eta_{d i f}+\eta_{r e}+\eta_{\Omega}
$$


Todas estas polarizaciones afectan al rendimiento de la celda de combustible, reduciéndolo. No pueden eliminarse pero pueden ser minimizadas escogiendo adecuadamente el material y el diseño de la celda. La temperatura, presión, composición del electrolito, y material de electrodo influyen también sobre la polarización.

\section{iv) Eficacia faradaica:}

Este término considera la posibilidad de que sucedan reacciones paralelas que originen corrientes más bajas de lo esperadas. Esta contribución viene dada por la razón entre la densidad de corriente producida y la disponible para la conversión directa del combustible:

$$
\epsilon_{F}=\frac{J}{J_{F}}
$$

donde $\boldsymbol{J}_{\boldsymbol{F}}$ sería la densidad de corriente producida si se convirtiera el $100 \%$ de combustible y vendría dada por la ecuación de Faraday:

$$
J_{F}=v \cdot F \cdot \Theta_{F}
$$

siendo $\boldsymbol{\Theta}_{F}$ el flujo molar del combustible.

\subsection{Celda de combustible de óxido sólido (SOFC)}

Su nombre de debe a que los componentes fundamentales de la celda son sólidos de naturaleza cerámica. Se basan en la propiedad que tienen ciertos óxidos inorgánicos, a temperaturas moderadamente altas $(873-1273 \mathrm{~K})$, de permitir el transporte, por difusión, de iones $\mathrm{O}^{2-}$ a su través ${ }^{9,10,11}$. Pertenecen, por tanto, al grupo de celdas con electrolito conductor de aniones.

Los materiales más comúnmente empleados para la construcción de este tipo de celdas son los siguientes ${ }^{12,13}$ :

- Electrolito: óxido de circonio (circona) estabilizado en su forma cúbica con óxidos de metales de transición de los grupos III y IV, tales como óxido de $\mathrm{Y}, \mathrm{Sc}, \mathrm{Ce}$, etc. El más usado es $\mathrm{ZrO}_{2}$ estabilizado con $\mathrm{Y}_{2} \mathrm{O}_{3}$ (YSZ).

- Cátodo: $\mathrm{LaMnO}_{3}$ dopado con $\mathrm{Sr} \rightarrow \mathrm{La}_{1-\mathrm{x}} \mathrm{Sr}_{x} \mathrm{MnO}_{3}$.

- Ánodo: cermet $\mathrm{Ni}+\mathrm{YSZ}$.

\subsubsection{Principios termodinámicos}

Como se ha indicado anteriormente, las SOFC son de electrolito conductor de aniones (iones $\mathrm{O}^{2-}$ ). En ellas se utiliza hidrógeno y oxígeno como combustible y oxidante respectivamente (Figura 1.3) ${ }^{14}$. 


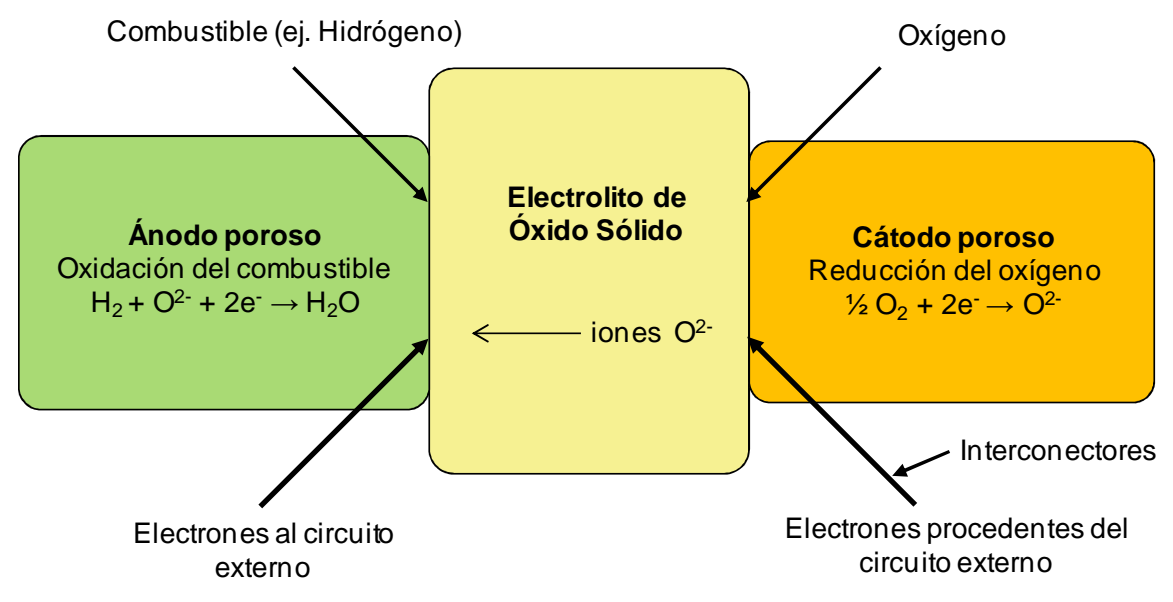

Figura 1.3. Esquema de una celda de combustible de óxido sólido (SOFC).

En condiciones de circuito abierto, con el potencial electroquímico de los iones oxígeno $\left(\mathrm{O}^{2-}\right)$ equilibrado a través del electrolito conductor de aniones, se genera una diferencia de potencial entre el ánodo y el cátodo (potencial termodinámico de la celda o potencial de circuito abierto). Esta diferencia de potencial está relacionada con el cambio neto de la función de Gibbs $(\boldsymbol{\Delta} \boldsymbol{G})$ de la reacción global (1.5) mediante la expresión:

$$
\Delta G=-v F E=-2 F E
$$

siendo:

v: número de electrones que participa en la reacción, dos en el caso que se está considerando las expresiones (1.3) y (1.4).

E: Potencial termodinámico de la celda.

F: $\quad$ Constante de Faraday $=96.480 \mathrm{~J} / \mathrm{V} \cdot \mathrm{mol}$.

De la ecuación (1.14), teniendo en cuenta la ley de Nernst, resulta:

$$
E_{\text {celda }}=-\frac{\Delta G}{2 F}=-\frac{\Delta G^{0}}{2 F}-\frac{R T}{2 F} \ln \left(\frac{p_{H_{2} \mathrm{O}}^{a}}{p_{\mathrm{H}_{2}}^{a} p_{\mathrm{O}_{2}}^{c}{ }^{1 / 2}}\right)=E^{0}+\frac{R T}{2 F} \ln \left(\frac{p_{O_{2}}^{c} p_{\mathrm{H}_{2}}^{a / 2}}{p_{\mathrm{H}_{2} \mathrm{O}}^{a}}\right)
$$

donde:

$\boldsymbol{p}^{c}{ }_{02}$ : Presión parcial de oxígeno en el cátodo (fase gas)

$\boldsymbol{p}_{\text {H2: }}{ }$ : Presión parcial de hidrógeno en el ánodo (fase gas)

$\boldsymbol{p}^{a}{ }_{\text {H2O: }}$ Presión parcial de vapor de agua en el ánodo (fase gas) 
$E^{0}$ : $\quad$ Potencial estándar $=1,229 \mathrm{eV}$

R: $\quad$ Constante de los gases $=8,31 \mathrm{~J} / \mathrm{mol} \cdot \mathrm{K}$

T: $\quad$ Temperatura absoluta $(\mathrm{K})$

\subsubsection{Propiedades del electrolito de las SOFC}

El electrolito de las SOFC debe poseer la conductividad iónica lo más elevada posible y estable con el tiempo a la temperatura habitual de operación, para facilitar el paso de los iones $\mathrm{O}^{2-}$ del cátodo al ánodo ${ }^{15}$ (Figura 1.4), debe ser impermeable a los gases que actúan como combustible y como oxidante, para lo cual es conveniente que tenga una compacidad superior al $95 \%$. Asimismo debe ser estable químicamente, con relación a los materiales que se emplean en el ánodo y el cátodo. Cuando actúa como soporte físico de la celda ha de tener una resistencia mecánica adecuada.

Por otra parte es deseable que tenga una conductividad electrónica despreciable para evitar pérdidas de eficacia como consecuencia del paso de electrones a su través.

\subsubsection{Materiales a utilizar para el electrolito de las pilas SOFC}

Los materiales más utilizados como electrolitos de pilas de combustible son soluciones sólidas basadas en óxidos de los grupos IIIB, IVB o del grupo de los lantánidos. Estas soluciones sólidas pueden cristalizar con estructura de fluorita ${ }^{10}$, de perovskita ${ }^{16,17}$, de perovskita con deficiencia de oxígeno ${ }^{18}$ o de Bimevox ${ }^{19}$ (soluciones sólidas basadas en el óxido de $\mathrm{Bi}$ ).

Al introducir óxidos del grupo IIIB en la estructura de los cristales de un óxido del grupo IVB, se generan vacantes de $\mathrm{O}^{2-}$ (vacantes aniónicas). La presencia de estas vacantes aniónicas proporciona al material una elevada conductividad iónica ya que, a temperatura suficientemente alta, permiten el desplazamiento de los iones $\mathrm{O}^{2-}$ a través de la red cristalina, mediante un mecanismo de transporte consistente en la ocupación secuencial, por dichos iones, de las posiciones vacantes adyacentes (Figura 1.4).

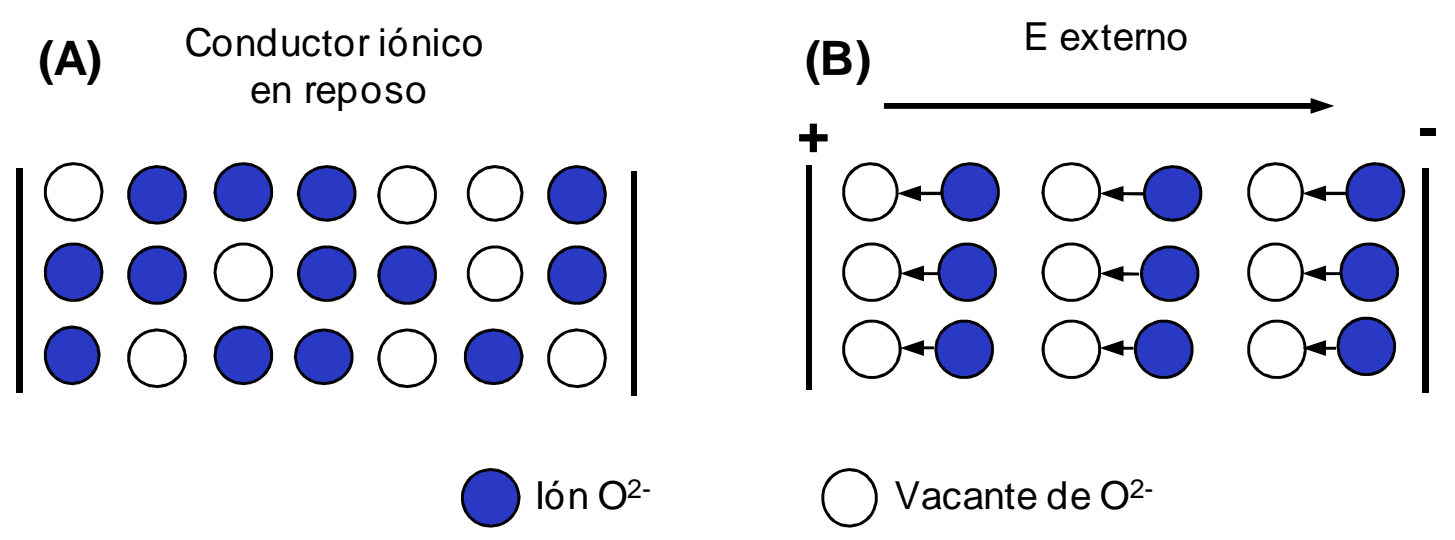

Figura 1.4. Mecanismo de conducción iónica a través de las vacantes de $0^{2-}$ en un monocristal20. 
A modo de ejemplo, a continuación, se pone de manifiesto el efecto que produce la introducción de $\mathrm{Y}_{2} \mathrm{O}_{3}$ en la estructura de cristales de $\mathrm{ZrO}_{2}$. Utilizando la notación de Kröger$V_{\text {Vink }}{ }^{21}$ los cambios que tienen lugar pueden expresarse mediante el esquema siguiente:

$$
\mathrm{Y}_{2} \mathrm{O}_{3} \rightarrow 2 \mathrm{Y}^{\prime}{ }_{\mathrm{Zr}}+\mathrm{VrO}_{2}{ }^{\prime \prime}{ }_{\mathrm{o}}+3 \mathrm{O}_{\mathrm{o}}
$$

Según esta notación, los elementos que se añaden o sustraen a la estructura de un monocristal, se considera que son átomos eléctricamente neutros. Al aplicar este criterio a sistemas iónicos se requiere que, al realizar dicha adición y sustracción, separadamente, se añadan o sustraigan electrones a fin de mantener la neutralidad eléctrica de la red cristalina.

En consecuencia, al introducir una molécula de $\mathrm{Y}_{2} \mathrm{O}_{3}$ en la red cristalina del $\mathrm{ZrO}_{2}$, cada uno de los dos iones $\mathrm{Y}^{3+}$ ocupa una posición que originalmente corresponde a $\mathrm{Zr}^{4+}\left(\mathrm{Y}_{\mathrm{Zr}}^{\prime}\right)$ quedando cada una de esas posiciones con una carga negativa, a la vez que se produce una vacante, con dos cargas positivas, en una posición inicialmente ocupada por un oxígeno (V"o), neutralizándose así la carga, a la vez que quedan tres oxígenos ocupando sus posiciones iniciales en la red.

Entre las soluciones sólidas que reúnen estas características cabe citar las siguientes:

- Circona con estructura cristalina cúbica estabilizada a temperatura ambiente (FSZ), mediante la adición de diferentes óxidos: 12-13\% (molar) de $\mathrm{CaO}$; b) 8-9 \% (molar) de $\mathrm{Y}_{2} \mathrm{O}_{3}$ y $\mathrm{Sc}_{2} \mathrm{O}_{3}$; o c) 8-12\% (molar) de otros óxidos del grupo de los lantánidos ${ }^{22}$.

Estas soluciones sólidas suelen tener valores de la conductividad iónica bastante buenos, en el intervalo de temperatura comprendido entre 873 y $1273 \stackrel{\circ}{\circ} \mathrm{C}$, aunque pueden presentar poca resistencia mecánica.

- Circona estabilizada en su forma tetragonal ${ }^{23}$ (TZP) conteniendo de 2 a $9 \%$ (molar) de $\mathrm{Y}_{2} \mathrm{O}_{3} \mathrm{O}$ de óxidos de tierras raras.

Estas soluciones sólidas poseen mejor resistencia mecánica, tenacidad y resistencia al choque térmico que la circona estabilizada en su forma cúbica, pero sus valores de conductividad iónica son más bajos.

- Ceria dopada con $\operatorname{Pr}$ y $\mathrm{Tb}^{24}$. Esta solución sólida es capaz de mantener la estructura cristalina cúbica en condiciones reductoras. Ahora bien, tiene el inconveniente de que puede llegar a presentar una conducción electrónica demasiado alta para los requerimientos de un electrolito de este tipo.

De todas ellas las más utilizadas hasta hace poco tiempo han sido:

a) Circona estabilizada con $\mathrm{Y}_{2} \mathrm{O}_{3}$.

Hasta finales del siglo XX esta solución sólida fue la más utilizada para la preparación de electrolitos de pilas SOFC. Las fórmulas moleculares más comunes eran: $8 \mathrm{Y}_{2} \mathrm{O}_{3} \cdot 92 \mathrm{ZrO}$ (8YSZ), con estructura cristalina cúbica, con buena conductividad iónica, y $3 \mathrm{Y}_{2} \mathrm{O}_{3} .97 \mathrm{ZrO} \mathrm{r}_{2}$ (T3YSZ), con estructura cristalina tetragonal, con mayor resistencia mecánica que la anterior ${ }^{25,26,27}$. 
Los electrolitos que se obtenían a partir de estos materiales se moldeaban utilizando diferentes técnicas, dependiendo del tipo de celdas a preparar: por prensado unidireccional, por colado en banda, por "sping-coating" para aplicarlos sobre el ánodo de las celdas, etc.

Estos electrolitos reunían todas las propiedades que se requerían, si bien la temperatura de operación tenía que ser moderadamente alta (1173-1273 K) para que la conductividad iónica tuviera un valor aceptable con los espesores de capa entonces empleados (100-150 $\mu \mathrm{m})$. Sólo reduciendo el espesor de la capa de electrolito hasta $9 \mu \mathrm{m}$, con las dificultades que su obtención suponía, se podían conseguir que estos electrolitos tuvieran la conductividad adecuada a temperaturas más bajas (del orden de $923 \mathrm{~K})^{28}$.

\section{b) Circona estabilizada con escandia}

La circona estabilizada con $\mathrm{Sc}_{2} \mathrm{O}_{3}$, en su forma cristalina cúbica, presenta valores de la conductividad iónica más altos, a temperaturas intermedias $(973-1173 \mathrm{~K})$, que la estabilizada con $\mathrm{Y}_{2} \mathrm{O}_{3}{ }^{29,30,31}$, antes mencionada (ver Figura 1.5).

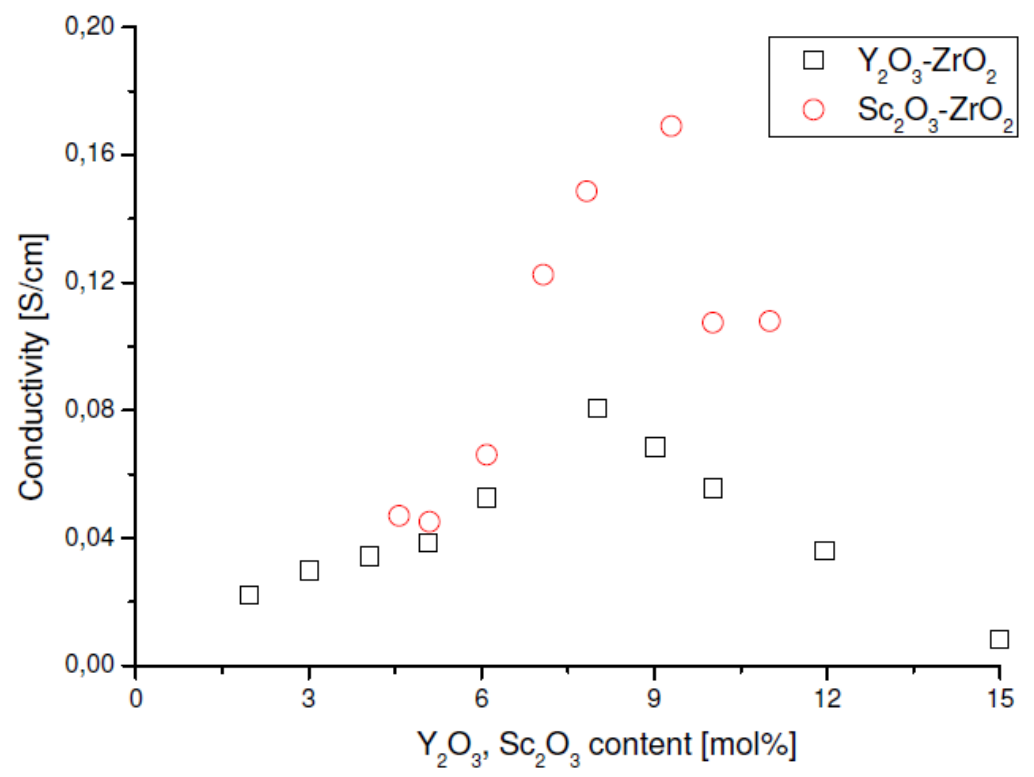

Figura 1.5. Conductividad iónica, a $1123 \mathrm{~K}$, de soluciones sólidas a base de circona en función de la concentración de dopante para los sistemas $\mathrm{Sc}_{2} \mathrm{O}_{3}-\mathrm{ZrO}_{2}$ e $\mathrm{Y}_{2} \mathrm{O}_{3}-\mathrm{ZrO}_{2}{ }^{11}$.

No obstante, las soluciones sólidas que contienen escandio, suelen degradarse más rápidamente que las que contienen $\mathrm{Y}_{2} \mathrm{O}_{3}$, por lo que para tratar de ralentizar este proceso de degradación en ocasiones se añade $\mathrm{Al}_{2} \mathrm{O}_{3}{ }^{32}$.

Durante los últimos años se han incrementado considerablemente los trabajos encaminados a estabilizar y mejorar la conductividad iónica de las soluciones sólidas a base de circona a temperaturas cada vez más bajas ${ }^{33}$, habiéndose encontrado que se obtienen buenos resultados cuando se dopa el $\mathrm{ZrO}_{2}$ con $\mathrm{Y}_{2} \mathrm{O}_{3}$ y $\mathrm{Sc}_{2} \mathrm{O}_{3}{ }^{34,35,36}$ o con $\mathrm{CeO}_{2}$ y $\mathrm{Sc}_{2} \mathrm{O}_{3}{ }^{37,38}$ (Figura 1.6). 


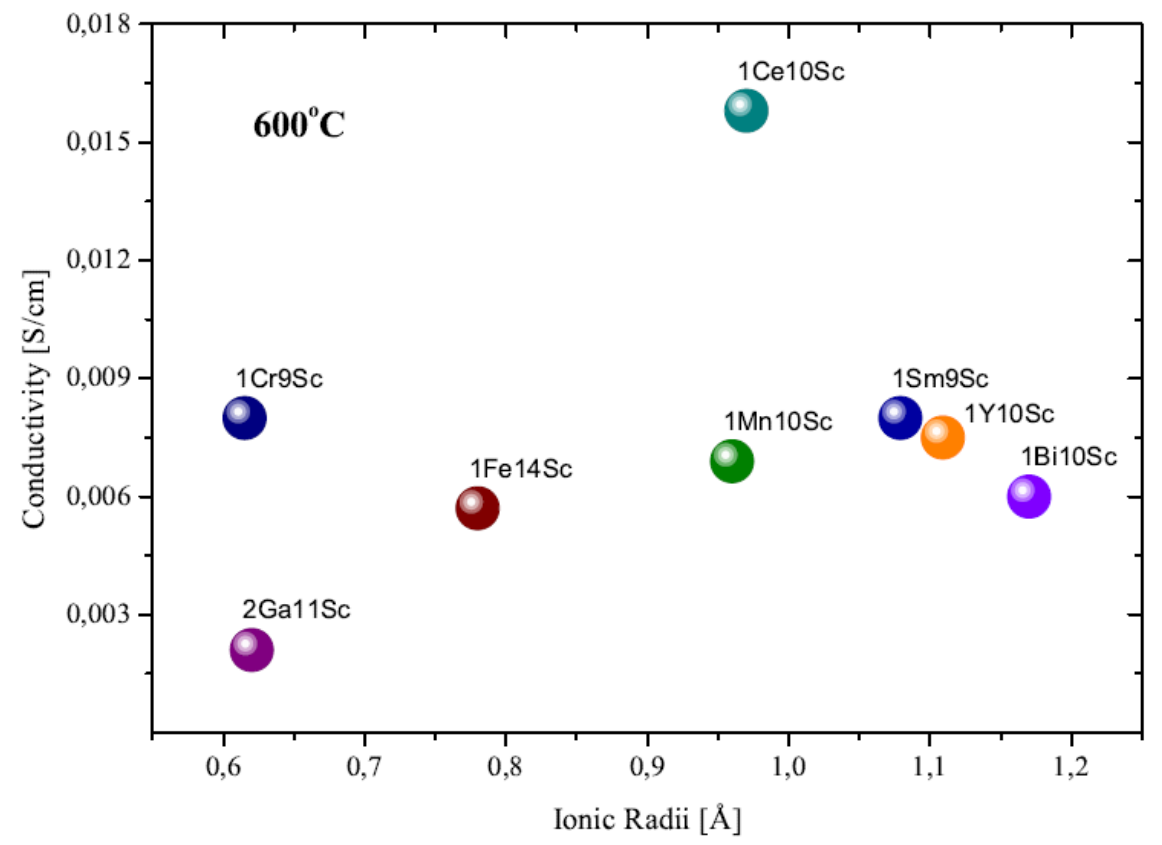

Figura 1.6. Valores de la conductividad a $873 \mathrm{~K}$ de la circona dopada con diferentes aditivos en función del radio iónico del catión codopante ${ }^{34}$.

\subsubsection{Conductividad iónica del electrolito de las SOFC}

La conductividad iónica es una propiedad específica de cada material. Se define como la medida de su capacidad para permitir desplazarse determinados iones a través de su estructura. La conductividad depende de la estructura atómica y molecular del material, así como de otros factores físicos del propio material y de la temperatura.

La conductividad respecto a cualquier ión de un material está relacionada con las variables de las que depende mediante la expresión:

$$
\sigma_{i}=z_{i} \cdot e \cdot c_{i} \cdot \mu_{i}
$$

donde $\boldsymbol{z}_{\boldsymbol{i}}$ es la valencia de la especie química cargada que se transporta, $\boldsymbol{e}$ es la carga, $\boldsymbol{c}_{\boldsymbol{i}}$ es la concentración de dicha especie química (iones $\cdot \mathrm{m}^{-3}$ ) y $\boldsymbol{\mu}_{i}$ su movilidad ${ }^{39}$.

Al aumentar la temperatura se incrementa la movilidad de los elementos estructurales de los materiales por lo que aumenta su conductividad iónica. La relación de dicha propiedad con la temperatura, a temperaturas suficientemente altas, suele adaptarse bastante bien a una correlación tipo Arrhenius, de la forma:

$$
\sigma_{i}=\frac{\sigma_{i 0}}{T} \exp \left[-\frac{E_{i}}{k T}\right]
$$


donde $\boldsymbol{\sigma}_{i 0}$ es un factor pre exponencial, $\boldsymbol{T}$ es la temperatura expresada en $\mathrm{K}, \boldsymbol{E}_{\boldsymbol{i}}$ es una energía aparente de activación (eV) y $\boldsymbol{k}$ la constante de Boltzmann $\left(\boldsymbol{k}=8,6173324 \cdot 10^{-5}\right.$ $\mathrm{eV} / \mathrm{K})$. De la ecuación anterior se deduce que, al representar $\operatorname{In}(\boldsymbol{\sigma} \cdot \boldsymbol{T})$ frente a la inversa de la temperatura $\left(\mathrm{en} \mathrm{K}^{-1}\right)$, debe resultar una línea recta de pendiente $-\boldsymbol{E} / \boldsymbol{k}$, a partir de la que se puede calcular el valor de $\boldsymbol{E}_{\boldsymbol{i}}$.

Ahora bien, cuando el transporte de los iones se realiza simultáneamente por más de un mecanismo, la representación anterior puede ser una línea curva o una quebrada con dos o tres tramos. Esto suele ocurrir cuando los mecanismos de transporte que intervienen tienen distintas energías aparentes de activación. Dependiendo del intervalo de temperatura que se considere, puede predominar uno u otro mecanismo sobre los demás.

\subsubsection{La conductividad iónica en monocristales}

Como se ha indicado anteriormente, la presencia de vacantes aniónicas en un monocristal de $\mathrm{ZrO}_{2}$ dopado con óxidos de elementos de los grupos IIA o IIIB del Sistema Periódico (como por ej. Y, Ce, Sc, Ga, etc. ${ }^{40}$, proporciona al material una cierta conductividad iónica, ya que, a temperatura suficientemente elevada, estas vacantes facilitan el transporte de los iones $\mathrm{O}^{2-}$ a través de la red cristalina, si existe un gradiente de concentraciones de iones $\mathrm{O}^{2-}$ o si se aplica una diferencia de potencial.

Los iones oxígeno se desplazan a través de la estructura del cristal, mediante el mecanismo de transporte antes descrito que se suele denominar de desplazamiento de vacantes, ya que el movimiento de los iones a través de la red del cristal es equivalente al movimiento de vacantes en sentido contrario. Un aumento de las vacantes aniónicas existentes en el cristal suele repercutir en un incremento de la conductividad.

En el caso de monocristales, las ecuaciones (1.16) y (1.17) son bastante representativas del concepto de conductividad iónica y de su variación con la temperatura.

La difusividad iónica puede relacionarse con la carga de los iones, con su movilidad y con la temperatura (en K) mediante la ecuación de Nernst-Einstein ${ }^{39}$.

$$
D_{i}=\mu_{i} \cdot \frac{k T}{e}
$$

Despejando $\mu_{i}$ en la ecuación (1.16) y sustituyendo en la ecuación (1.18) resulta:

$$
D_{i}=\frac{\sigma_{i} k T}{z_{i} e^{2} c_{i}}
$$

De esta expresión se deduce que existe una relación directa entre la difusividad iónica y la correspondiente conductividad. Esta correlación se cumple mejor a temperaturas relativamente elevadas (superiores a $800 \mathrm{~K}$ ) a las que predomina la difusión intrínseca sobre la extrínseca ${ }^{41}$. 


\subsubsection{La conductividad iónica en materiales policristalinos}

El material que constituye los electrolitos que se utilizan en las celdas SOFC (generalmente óxido de circonio o de cerio dopados con lantánidos) consiste en un agregado de microcristales (en adelante granos) separados por espacios de muy pequeño espesor (en adelante límites de grano). Por tanto, el desplazamiento de iones en su seno, no sólo debe tener lugar a través de cada uno de los microcristales que lo constituyen (conducción en el grano), sino también por la superficie de los mismos y por y a través de los espacios intersticiales existentes entre ellos (conducción en los límites de grano). En consecuencia, el flujo de iones a través de dichos materiales, al aplicar un potencial determinado, debe estar influenciado por las resistencias que opongan a su desplazamiento los dos mecanismos (Figura 1.7).

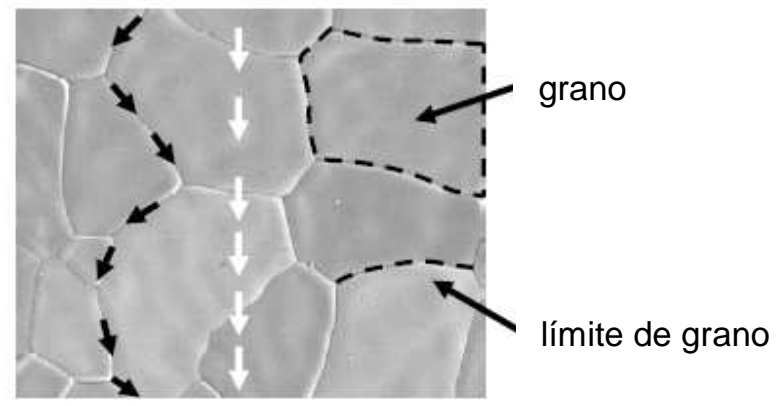

Figura 1.7. Posibles trayectorias de los iones que se desplazan a través de un electrolito de célula SOFC ${ }^{42}$.

La resistencia que opone cada uno de los dos mecanismos citados al desplazamiento de la corriente, está relacionada con la resistividad $\left(\boldsymbol{\rho}_{i}\right)$ o conductividad $\left(\boldsymbol{\sigma}_{i}\right)$ respectiva, mediante la expresión:

$$
R_{i}=\rho_{i} \cdot(L / S)=\left(1 / \sigma_{i}\right) \cdot(L / S)
$$

donde $L$ es el espesor del material, medido en el sentido en que tiene lugar el transporte de los iones, y $\boldsymbol{S}$ es la sección del mismo, en sentido perpendicular a la dirección en que se efectúa dicho desplazamiento. Tanto la resistividad como la conductividad son propiedades intrínsecas del material a través del cual se transportan los mencionados iones.

En el caso de los electrolitos de células SOFC, la propiedad que se suele utilizar para expresar la mayor o menor capacidad del material para el transporte de iones es la conductividad efectiva total $\left(\boldsymbol{\sigma}_{T}\right)$.

Para disponer de una expresión que permita relacionar los valores de la conductividad total del material $\left(\sigma_{T}\right)$ con las conductividades representativas de la contribución de los granos $\left(\sigma_{g}\right)$ y de los límites de grano $\left(\sigma_{l g}\right)$, es preciso proponer previamente un modelo supuestamente representativo de la microestructura y del comportamiento eléctrico del material.

Si además se da la circunstancia de que es posible encontrar un circuito eléctrico representativo o equivalente del modelo propuesto, como el que se describe en el Apartado 1.2.5.2, puede determinarse el valor de la conductividad total y de las conductividades en el grano y en los límites de grano de un material a partir de datos experimentales. 
El modelo más frecuentemente utilizado para representar el transporte de iones a través de la estructura de electrolitos de células SOFC es el denominado "Brick Layer Moder"43,44,45, en el que se considera la microestructura del material como agrupamientos de microcristales de forma cúbica separados por límites planos (Figura 1.8).

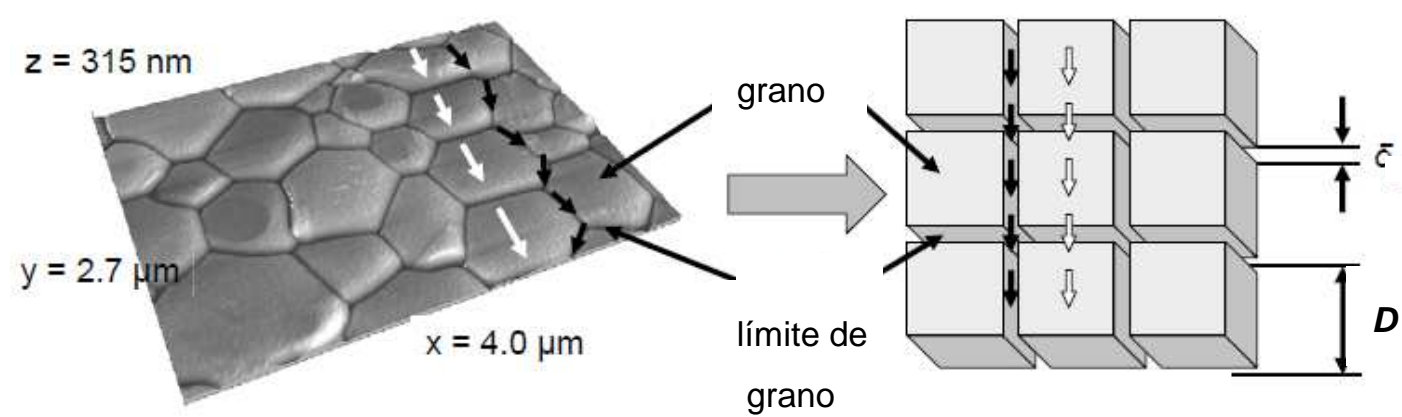

Figura 1.8. Adaptación del Brick Layer Model a la microestructura y trayectoria de los iones en un electrolito de célula SOFC ${ }^{42}$.

En este modelo se considera que los granos son cubos iguales, de lado igual al diámetro medio de grano $(\boldsymbol{D})$, y que la separación entre granos tiene un espesor determinado $(\boldsymbol{\delta})$, siendo $\delta$ mucho más pequeño que $\boldsymbol{D}$, de modo que la fracción volumétrica del espacio existente entre los granos $\left(\boldsymbol{x}_{\boldsymbol{l}}\right)$, en el sólido considerado, se admite que vale:

$$
x_{\mathrm{gg}}=3 \delta / D
$$

Asimismo se considera que el flujo de la corriente es unidimensional, despreciándose la posible curvatura de la trayectoria de la corriente en los vértices de los granos.

En esta hipotética estructura, los dos caminos disponibles para el desplazamiento de la corriente son: a) a través de los granos y de las zonas intersticiales que los separan (límites de grano) según la trayectoria marcada por las flechas blancas; b) a lo largo del espacio intergranular, en el sentido de desplazamiento de la corriente, según la trayectoria marcada por las flechas negras (ver Figura 1.8). Según el valor relativo de la resistencia (expresada como tal o en función de la resistividad o de la conductividad correspondiente) que se oponga al desplazamiento de la corriente por cada camino, su paso se efectuará preferentemente por una u otra trayectoria.

En el caso de los materiales que habitualmente se usan para la confección del electrolito en células SOFC (óxidos de circonio o de cerio dopados con cationes trivalentes $\left(\mathrm{Y}^{3+}, \mathrm{Sc}^{3+}\right.$, $\mathrm{La}^{3+}$, etc.), a las temperaturas elevadas a las que habitualmente suelen operar las SOFC (entre 973 y $1273 \mathrm{~K}$ ) y a las presiones parciales de oxígeno a las que normalmente se opera en el cátodo de las celdas de combustible (alrededor de 0,21 atm), el proceso de conducción eléctrica dominante es el iónico, siendo prácticamente despreciable la conducción electrónica ${ }^{46}$. Por tanto, en estas circunstancias, puede admitirse que la conductividad total coincide prácticamente con la conductividad iónica. 
Utilizando la conductividad como criterio comparativo y admitiendo que el modelo estructural de Brick Layer es suficientemente representativo del proceso, pueden presentarse tres posibilidades:

a) La conductividad a través de los granos $\left(\boldsymbol{\sigma}_{g}\right)$ es mucho mayor que la conductividad específica de los límites de grano $\left(\boldsymbol{\sigma}_{\mathrm{lg}}^{\mathbf{e}}\right)$.

En este caso la conducción a lo largo de los límites de grano, en el sentido de las flechas negras de la Figura 1.8, es prácticamente despreciable, por lo que el transporte de iones se efectúa a través de los granos y de los límites de grano que los separa, en el sentido de las flechas blancas de dicha figura. El comportamiento del sistema puede pues representarse mediante la expresión:

$$
\rho_{T}=\rho_{g}+\rho_{\mathrm{lg}}^{T}=\rho_{g}+(1 / 3) x_{\mathrm{lg}} \rho_{\mathrm{lg}}^{e}
$$

donde $\boldsymbol{\rho}_{T}$ representa la resistividad total de dicho material al transporte de los iones, $\boldsymbol{\rho}_{g}$ la resistividad de los granos, $\boldsymbol{\rho}^{T}{ }_{I g}$ y $\boldsymbol{\rho}^{e}{ }_{l g}$ las resistividades total y específica de los límites de grano, respectivamente, y $\boldsymbol{x}_{\boldsymbol{l g}}$ es la fracción volumétrica del espacio que, en el material considerado, se estima ocupado por los limites de grano. Conviene poner de manifiesto que las propiedades $\boldsymbol{\rho}_{g}$ y $\boldsymbol{\rho}^{T}{ }_{l g}$ se pueden medir directamente, a partir de información experimental. En cambio, la propiedad $\rho^{e}{ }_{l g}$ solamente puede estimarse, a partir de $\boldsymbol{\rho}^{T}{ }_{l g}$, si previamente se establece un modelo representativo de la microestructura del material como, por ejemplo, el de Brick Layer que permita calcular el valor de $\boldsymbol{x}_{\boldsymbol{l g}}$.

$S i$ la ecuación anterior se expresa en función de las respectivas conductividades, resulta:

$$
1 / \sigma_{T}=1 / \sigma_{g}+1 / \sigma_{\mathrm{lg}}^{T}=1 / \sigma_{g}+(1 / 3) x_{\mathrm{lg}}\left(1 / \sigma_{\mathrm{lg}}^{e}\right)
$$

donde el segundo término del segundo miembro representa la inversa de la conductividad total en los límites de grano $\left(\mathbf{1} / \boldsymbol{\sigma}^{T}{ }_{g}\right)$ en el material de que se trata, siendo $\boldsymbol{\sigma}_{l g}{ }_{l g}$ la conductividad específica del límite de grano, de modo que se cumple ${ }^{44,47}$ :

$$
\sigma_{\mathrm{lg}}^{T}=3 \sigma_{\mathrm{lg}}^{e} / x_{\mathrm{lg}}=D \sigma_{\mathrm{lg}}^{e} / \delta
$$

b) La conductividad a través de los granos $\left(\sigma_{g}\right)$ es mucho menor que la conductividad específica en los límites de grano $\left(\boldsymbol{\sigma}^{\boldsymbol{e}}{ }_{\mathrm{g}}\right)$.

En este caso se supone que la conducción se desarrolla preferentemente en el sentido de las flechas negras de la Figura 1.8, aplicándose la relación:

$$
\sigma_{T}=\sigma_{g}+(2 / 3) x_{\mathrm{lg}} \sigma_{\mathrm{lg}}^{e}
$$


Caso de que en el material se cumpliese esta posibilidad, en el diagrama de impedancia aparecería una sola curva, en todo el intervalo de temperaturas de ensayo ${ }^{45}$,

c) Ambas conductividades son del mismo orden de magnitud

Según Näfe ${ }^{48}$, en este caso, las dos trayectorias descritas pueden combinarse en una red que describe las propiedades de los materiales policristalinos para cualquier valor de la relación entre $\sigma_{g}$ y $\boldsymbol{\sigma}_{l g}^{e}$, proponiendo la siguiente relación entre ambas conductividades:

$$
\sigma_{T}=\left[\sigma_{g}^{-1}+\frac{x_{\mathrm{lg}}}{3}\left(\sigma_{\mathrm{lg}}^{e}\right)^{-1}\right]^{-1}+(2 / 3) x_{\mathrm{lg}} \sigma_{\mathrm{lg}}^{e}
$$

Esta última posibilidad no parece demasiado aceptable en el caso de los electrolitos de las células SOFC, ya que la hipótesis de que la corriente fluye por trayectorias separadas, cuando los valores de $\sigma_{g}$ y $\boldsymbol{\sigma}_{l g}^{e}$ son del mismo orden, no parece sostenible ${ }^{45}$.

\subsubsection{Medida de la conductividad iónica de materiales policristalinos}

Uno de los métodos más utilizados para medir la conductividad en sólidos inorgánicos iónicos está basado en el uso de la técnica de la espectroscopía de impedancia compleja ${ }^{45}$.

Este método se basa en la aplicación de un campo eléctrico alterno de frecuencia angular variable y amplitud muy pequeña sobre una muestra del sólido.

Si el comportamiento de la muestra se asimila al de un circuito eléctrico conteniendo resistencias y condensadores, el potencial que se aplica, durante un tiempo $\boldsymbol{t}$, estará relacionado con la amplitud del voltaje aplicado $(\boldsymbol{V})$, con la frecuencia angular $(\boldsymbol{\omega})$ y con el tiempo mediante la expresión:

$$
\tilde{E}(\omega, t)=V^{0} e^{i \omega t}
$$

La intensidad de la corriente que circula a través del circuito, como consecuencia de la aplicación de dicho potencial, vendrá dada por la expresión:

$$
\tilde{I}(\omega, t)=I^{0} e^{i(\omega t+\theta)}
$$

siendo $\boldsymbol{\theta}$ el desfase entre el potencial aplicado y la corriente generada.

La impedancia de un circuito se define como:

$$
\breve{Z}(\omega, t)=\tilde{E}(\omega, t) / \widetilde{I}(\omega . t)
$$


Por tanto, de (1.29), (1.27) y (1.28), haciendo $V^{0} / I^{0}=Z^{0}$, resulta:

$$
Z(\omega, t)=\frac{V^{0} e^{i \omega t}}{l^{0} e^{i(\omega t+\theta)}}=Z^{0} e^{-i \theta}=Z^{0} \cos \theta-i Z^{0} \operatorname{sen} \theta=Z^{\prime}-i Z^{\prime \prime}
$$

Así pues, la impedancia, expresada en forma vectorial, es una magnitud compleja constituida por una componente real y otra imaginaria. La componente real representa la resistencia $\boldsymbol{R}$ del circuito y la imaginaria la reactancia (inductancia más capacitancia).

La representación de la componente imaginaria frente a la componente real en el plano complejo de impedancias, se conoce como Diagrama de Nyquist.

\section{(i) Monocristales}

Si la muestra a la que se aplica el campo eléctrico alterno de frecuencia angular variable es un monocristal de un óxido de naturaleza iónica, en cuya estructura se han generado vacantes por dopado con un óxido de un elemento de valencia inferior, el desplazamiento de iones a su través sólo es posible por un mecanismo de difusión a través de la masa del cristal (bulk diffusion), por desplazamiento de vacantes. Es el caso de monocristales de $\mathrm{ZrO}_{2}$ dopado con óxidos tales como $\mathrm{CaO}, \mathrm{MgO} \circ \mathrm{Y}_{2} \mathrm{O}_{3}{ }^{49,50}$, con los que forma soluciones sólidas sustitucionales.

Cuando se aplica un campo eléctrico alterno, como el indicado más arriba, a un monocristal de la naturaleza descrita, se comporta como si se tratara de un circuito constituido por una resistencia y un condensador, operando en paralelo (circuito $\mathrm{RC}$ ), en el que las limitaciones al flujo de corriente equivalen a la resistencia que opone el cristal al paso de los iones y las interfases electrolito-electrodo se comportan como condensadores (Figura 1.9).

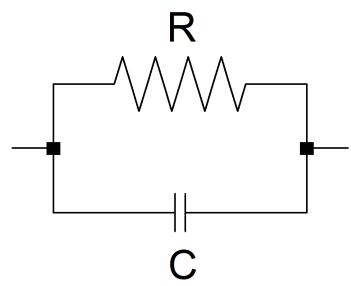

Figura 1.9. Circuito equivalente al comportamiento de un monocristal iónico.

La gráfica que se obtiene al representar, en el plano complejo, los valores que se obtienen experimentalmente de la parte imaginaria de la impedancia ( $\left.\boldsymbol{Z}^{\prime \prime}\right)$ frente a los de la parte real $\left(Z^{\prime}\right)$, correspondientes a distintos valores de la frecuencia angular, es una semicircunferencia con el centro sobre el eje de coordenadas real (abscisas) cuyo diámetro equivale a la resistencia óhmica del material $\left(\boldsymbol{R}_{g}\right)$ (Figura 1.10). 


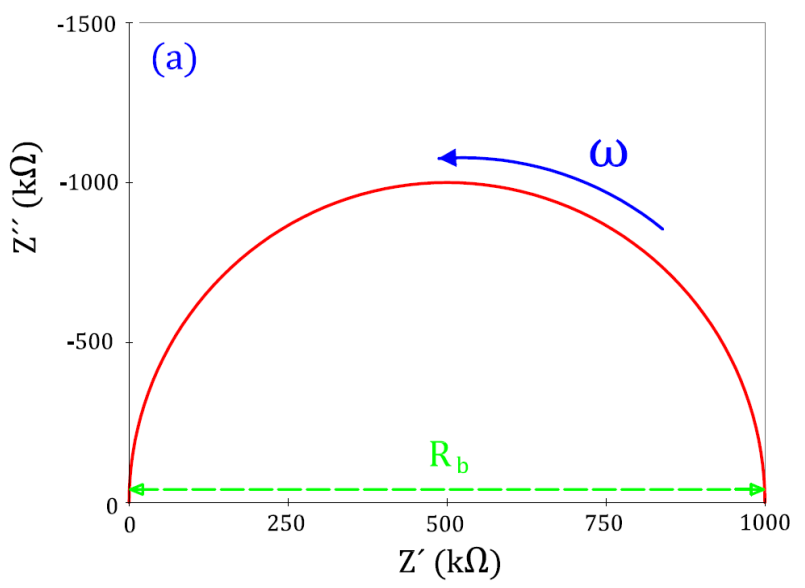

Figura 1.10. Diagrama de Nyquist para un monocristal iónico.

\section{(ii) Sólidos policristalinos}

Como se ha indicado reiteradamente, cuando la muestra a la que se aplica el campo eléctrico es un agregado de monocristales de naturaleza iónica, dopados en la forma antes descrita, los iones se desplazan a través de su estructura por dos mecanismos de transporte diferentes: a través de cada monocristal y por la superficie de los monocristales y los intersticios existentes entre ellos (difusión superficial, desplazamiento por fisuras, límites de grano, etc.). La resistencia que encuentran los iones a desplazarse por los límites de grano es distinta a la que encuentran a través de los monocristales, teniendo asociada también una capacidad diferente.

a) Si se admite que, cuando se aplica un campo eléctrico alterno de frecuencia angular variable a un sólido policristalino, estos dos procesos de transporte de carga actúan como si se desarrollaran en serie, tal como se ha descrito en el apartado 1.2.5.1.(a), el sistema puede asociarse, desde el punto de vista de un circuito equivalente, a un conjunto de dos elementos $\boldsymbol{R} \boldsymbol{C}$ operando en serie, de acuerdo con la representación de la Figura $1.11^{45}$, en la que además se ha añadido un tercer elemento $\boldsymbol{R} \boldsymbol{C}$ representativo del proceso de transporte entre la muestra y los electrodos a través de los que se aplica el campo eléctrico.

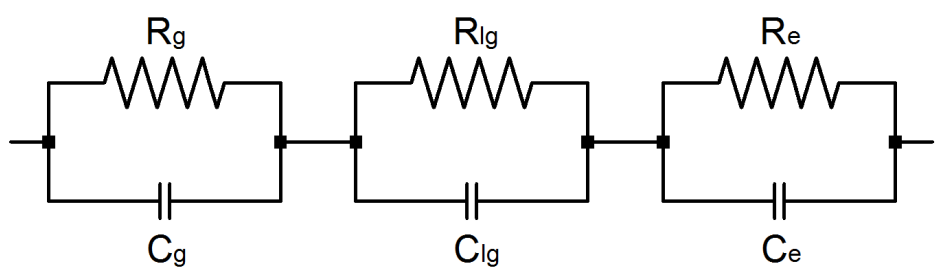

Figura 1.11. Circuito equivalente al comportamiento de un material policristalino en el que el flujo de corriente de efectúa de acuerdo con la posibilidad indicada en 1.2.5.1(a). 
Esto hace que en los espectros de impedancia aparezcan dos arcos característicos del material, uno asociado al desplazamiento de iones por el interior de los monocristales (conducción en el grano) y otro asociado al desplazamiento en los límites de los monocristales (conducción en el límite de grano). Asimismo suelen desarrollarse otros mecanismos de transporte de carga y transporte de materia, a muy baja frecuencia, que ocurren en la interface electrodo/electrolito, con la aparición de un tercer arco en el espectro (Figura 1.12).

En el caso ideal de que, en el Diagrama de Nyquist, aparecieran claramente diferenciadas las semicircunferencias correspondientes a la contribución de cada uno de los dos mecanismos de transporte citados, la resistencia del material al desplazamiento de los iones por cada uno de ellos se podría obtener a partir de la intersección de las respectivas semicircunferencias con el eje real del diagrama.

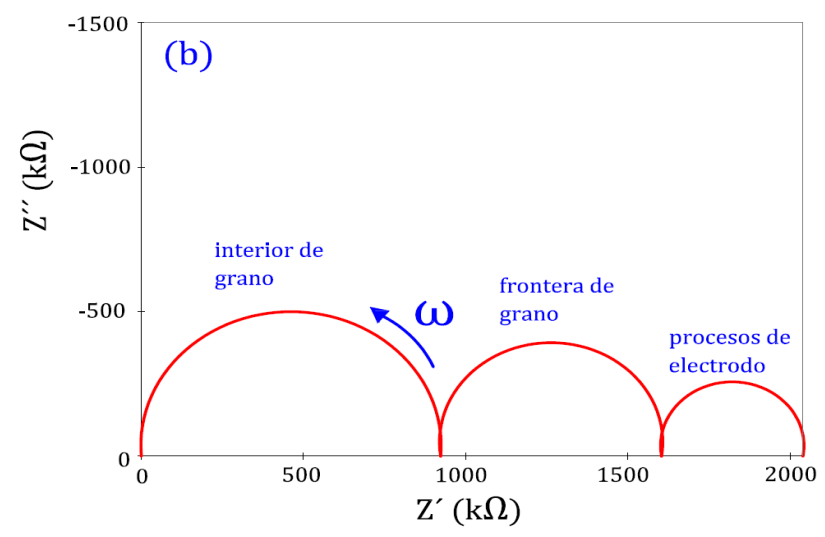

Figura 1.12. Diagrama de Nyquist para un sólido policristalino.

b) Si los dos procesos de transporte de carga a través de un sólido policristalino se desarrollaran en paralelo, tal como se ha descrito en el apartado 1.2.5.1 (b), al aplicar un campo eléctrico alterno de frecuencia angular variable, el sistema se comportaría como si solamente estuviera constituido por un solo elemento $\boldsymbol{R} \boldsymbol{C}$, por lo que únicamente se apreciaría un solo arco en el espectro de impedancias.

En el caso descrito en el apartado a), la capacidad correspondiente a cada mecanismo de transporte de carga $\left(\boldsymbol{C}_{\boldsymbol{i}}\right)$ se puede relacionar con la frecuencia de relajación correspondiente a los respectivos máximos del espectro de impedancia, mediante la siguiente relación:

$$
\omega_{\max }=1 / R_{i} \cdot C_{i}
$$

siendo $\boldsymbol{\omega}_{\max }$ la frecuencia de relajación del proceso y $\boldsymbol{R}$ la resistencia correspondiente.

La frecuencia de relajación de cada mecanismo de transporte considerado suele diferir en varios órdenes de magnitud. Esto hace que se pueda distinguir la contribución de los diferentes mecanismos en el espectro de impedancias. Ahora bien, dado que $\boldsymbol{\omega}_{\max }$ varía fuertemente con la temperatura, en dicho espectro, sólo se podrán visualizar los mecanismos de transporte de carga en los que dicha variable se encuentre dentro del intervalo de frecuencia experimental utilizado en el analizador de impedancias. Debido a 
esto, a altas temperaturas (normalmente superiores a 673-723 K), no es posible apreciar, por separado, las contribuciones individuales, a la resistencia al transporte de carga, de los mecanismos de transporte a través del grano y en el límite de grano. En este caso, sólo es posible calcular la resistencia efectiva global a la que contribuyen ambos mecanismos de transporte.

Debido a que las energías aparentes de activación de los mecanismos de conducción iónica a través de los granos y en los límites de grano son diferentes, la temperatura a la que se efectúa la medida (en adelante temperatura de ensayo $\boldsymbol{T}_{e}$ ) influye notablemente sobre los valores relativos de las conductividades respectivas. Por esa razón, las contribuciones individuales de dichos mecanismos a la resistencia global, en la representación gráfica del Diagrama de Nyquist, sólo se distinguen bien normalmente a temperaturas inferiores a los $673 \mathrm{~K}$. A temperaturas comprendidas entre 673 y $1073 \mathrm{~K}$, aparece únicamente el arco característico del mecanismo de conducción a través del límite de grano. A temperaturas más altas sólo se visualiza la resistencia total, y es prácticamente imposible diferenciar los procesos de transporte en el interior de los monocristales y en el límite de grano (Figuras 1.13 y 1.14$)$.

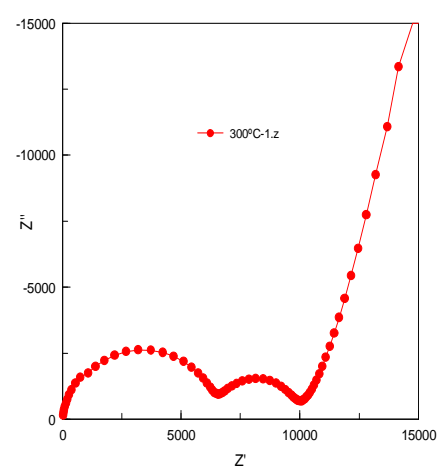

(a)

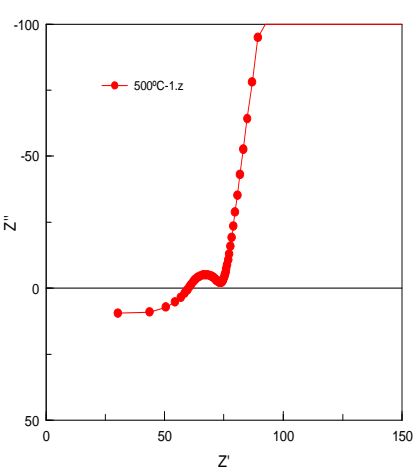

(b)

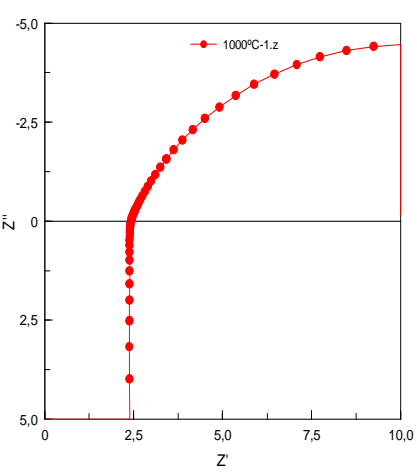

(c)

Figura 1.13. Espectros de impedancia de una muestra de 8YSZ sinterizada a $1773 \mathrm{~K}$ durante 6h., obtenidos a diferentes temperaturas. a) Espectro de $573 \mathrm{~K}$. b) Espectro de $773 \mathrm{~K}$. c) Espectro de $1273 \mathrm{~K}$.

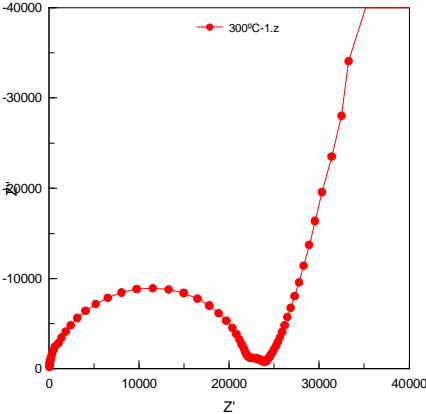

(a)

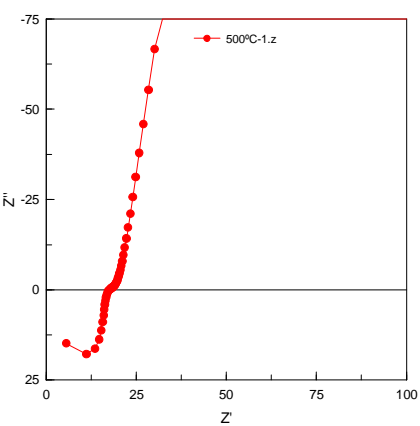

(b)

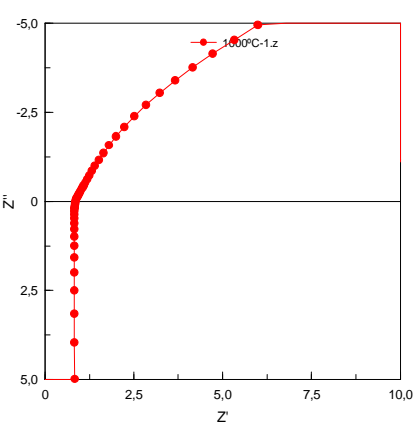

(c)

Figura 1.14. Espectros de impedancia de una muestra de 10Sc1CeSZ sinterizada a 1773 K durante 6 h, obtenidos a diferentes temperaturas. a) Espectro de $573 \mathrm{~K} . \mathrm{b})$ Espectro de $773 \mathrm{~K} . \mathrm{c}$ ) Espectro de $1273 \mathrm{~K}$. 
La asignación de cada semicircunferencia, en el Diagrama de Nyquist, a un determinado mecanismo de conducción se realiza a partir de los valores de la capacidad respectiva. En el trabajo de investigación que se describe en esta Memoria, los valores de la capacidad correspondientes a cada uno de los dos mecanismos de transporte de iones los proporcionaba directamente el dispositivo de medida utilizado.

Para las probetas utilizadas en este trabajo (discos de $1,2 \mathrm{~mm}$ de espesor y de $14 \mathrm{~mm}$ de diámetro) conformadas con la mezcla de composición $\boldsymbol{C}$-II (Tabla 3.2), los mecanismos de conducción por el interior de los monocristales se desarrollaron para valores de la capacidad comprendidos entre $10^{-10}$ y $10^{-11} \mathrm{~F}$, los del límite de grano para valores de la capacidad comprendidos entre $10^{-7}$ y $10^{-9} \mathrm{~F}$ y los de transferencia de carga y polarización de electrodos para valores del orden de $10^{-6} \mathrm{~F}$.

A modo de ejemplo, en la Tabla 1.2 se muestran los valores obtenidos, en este trabajo, para la conductividad iónica, a diferentes temperaturas de ensayo, de una probeta conformada con una muestra de la composición $\boldsymbol{C}$-II (Tabla 3.2), sinterizada a 1673 K durante 6 horas.

\begin{tabular}{|c|c|c|c|}
\hline$T_{e}(\mathrm{~K})$ & $\sigma_{T}(\mathrm{~S} / \mathrm{cm})$ & $\sigma_{g}(\mathrm{~S} / \mathrm{cm})$ & $\sigma_{l g}^{T}(\mathrm{~S} / \mathrm{cm})$ \\
\hline 573 & $4,15 \mathrm{E}-06$ & 4,79E-06 & 3,08E-05 \\
\hline 623 & 3,35E-05 & 3,89E-05 & 2,43E-04 \\
\hline 673 & 2,01E-04 & 2,38E-04 & 1,28E-03 \\
\hline 873 & 1,54E-02 & & \\
\hline 1073 & 7,26E-02 & & \\
\hline 1273 & 1,20E-01 & & \\
\hline
\end{tabular}

Cuando se ajustan los valores experimentales a un modelo del tipo $\mathrm{RC}$ en serie, no siempre se cumple que los procesos tienen el centro del semicírculo en el eje real de las impedancias. A veces, el centro aparece desplazado por debajo del eje real, lo que se debe a que la frecuencia de relajación no tiene un valor único, sino que es una distribución alrededor de un determinado valor. El ángulo de depresión $\boldsymbol{\Phi}$, desplazamiento del centro del arco respecto al eje real, está relacionado con la anchura de la distribución de tiempos de relajación. En estos casos, el modelo clásico de combinación de circuitos $\boldsymbol{R} \boldsymbol{C}$ debe sustituirse por un modelo real de combinaciones $\boldsymbol{R} \boldsymbol{Q}$, en el que $\boldsymbol{Q}$ es un elemento constante de fase, que sólo coincide con la capacidad $\boldsymbol{C}_{\boldsymbol{i}}$ en los casos en los que el exponente que caracteriza el elemento de fase es igual a $1^{51}$.

Así pues, a la hora de ajustar los datos experimentales, la combinación de circuitos $\boldsymbol{R} \boldsymbol{C}$ que se corresponde con un modelo ideal, debe sustituirse por combinaciones $\boldsymbol{R} \boldsymbol{Q}$ de un modelo real. No obstante, hay que tener en cuenta que cuantos más elementos $\boldsymbol{R} \boldsymbol{Q}$ mejor será el ajuste, pero es posible que no tengan un significado físico. 
En consecuencia, siempre se elegirá el modelo que con similar calidad de ajuste, posea menos elementos y éstos deben ser explicables en base a los procesos resistivos del material y de transporte de carga y masa entre el electrolito y los electrodos.

\subsection{Configuración de una pila de combustible}

La generación de una corriente eléctrica con una intensidad considerable requiere el apilamiento de un conjunto de celdas SOFC, formando una estructura en capas o "stack", en la que el ánodo de cada pila debe estar separado del cátodo de la siguiente, impidiendo la mezcla de los gases combustible y oxidante. El material que actúa como separador debe garantizar también una buena conexión eléctrica entre las pilas, por ese motivo recibe en nombre de interconector. Generalmente es una cromita de lantano $\left(\mathrm{LaCrO}_{3}\right)$ dopada con estroncio, calcio y magnesio.

Estos apilamientos son idóneos para las aplicaciones energéticas estacionarias y se presentan como la apuesta de futuro más importante en el intervalo de potencia comprendido entre apenas $1 \mathrm{~kW}$ y varios MW (la potencia de una planta eléctrica).

En el diseño de una pila SOFC es importante que la distribución del combustible y del oxidante sea uniforme en toda la pila y que haya una distribución térmica homogénea para evitar que se generen tensiones, durante la etapa de calentamiento y enfriamiento, entre los componentes de la pila. Además debe de tenerse en cuenta la alta densidad de corriente que debe circular por la pila y que las pérdidas óhmicas por contactos de los componentes de las pilas han de ser lo menores posibles.

En base a estas consideraciones existen cuatro configuraciones para el apilamiento de las celdas, las cuales se diferencian por la forma de la celda, la geometría de los canales de flujo de gases, y la relación tamaño-espesor de los elementos constituyentes. Estos diseños son: plano, tubular, monolítico y segmentado en serie.

i) En el diseño plano las celdas son planas, de geometría rectangular. El espesor de cada una de las láminas que componen la celda unidad puede reducirse convenientemente utilizando técnicas de conformado de materiales de espesor reducido, como el colado en banda o "tape casting", técnicas de proyección térmica por plasma (HPVF), Deposición Física de Vapor (PVD), Deposición Química de Vapor (CVD), etc. Esta reducción de espesor permite disminuir las pérdidas óhmicas. En estos casos es necesaria la incorporación de un material de sellado (por ej. de naturaleza vítrea y/o vitrocerámica) para evitar que se mezclen el combustible y el oxidante.

El diseño plano es el más sencillo y más económico, si bien los costes de producción continúan siendo elevados. Existen dos configuraciones, dependiendo del componente de la celda que actúa como soporte del resto, aportando la resistencia mecánica necesaria para mantener la estructura de la celda (ver Figura 1.15): 

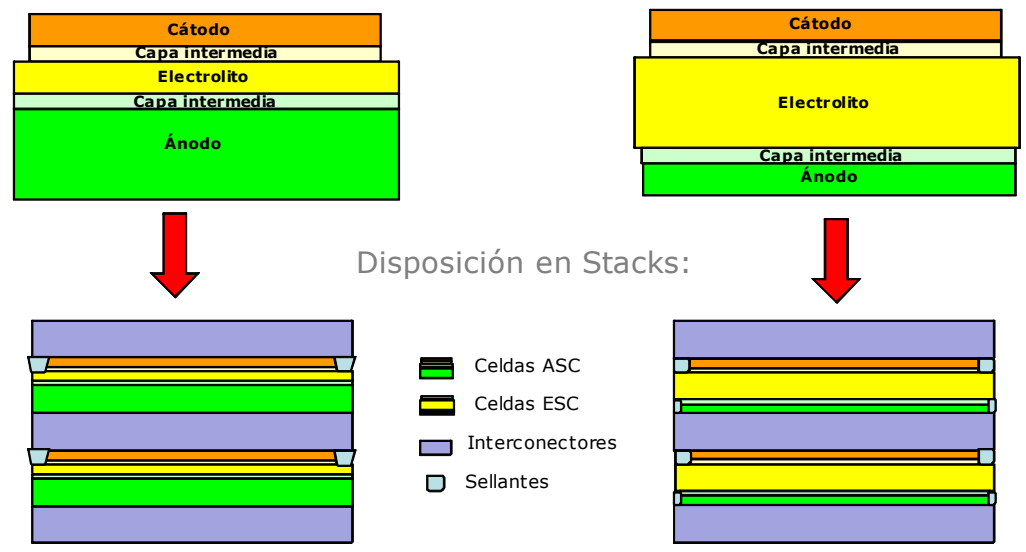

Disposición en Stacks:

Figura 1.15. Tipos de celdas planas y su disposición en stacks.

- Celdas soportadas por el ánodo que es poroso (anode supported cells, ASC). El electrolito se deposita sobre el ánodo formando una capa muy delgada. Este tipo de celdas presenta un mayor espesor total pero tiene una mayor resistencia mecánica que las que se describen a continuación.

- Celdas soportadas por el electrolito (electrolyte supported cells, ESC). Tienen menor espesor que las anteriores. Cuanto más delgada es la capa del electrolito menor es su resistencia ónmica y mayor es la eficacia de la celda. Como contrapartida, en ocasiones pueden resultar excesivamente frágiles.

ii) En el diseño tubular, el cátodo hace de soporte. Un electrolito denso cubre el cátodo, excepto la franja del interconector. El ánodo poroso recubre el electrolito y las celdas se conectan entre sí mediante colectores de corriente de $\mathrm{Ni}$, para formar un stack. Este diseño se muestra en la Figura 1.16 y es el que disfruta de un mayor grado de experiencia y está impulsado principalmente por la empresa multinacional Siemens-Westinghouse. Sin embargo, los costes de producción son muy elevados y esta compañía se ha visto obligada a modificar continuamente sus objetivos. 


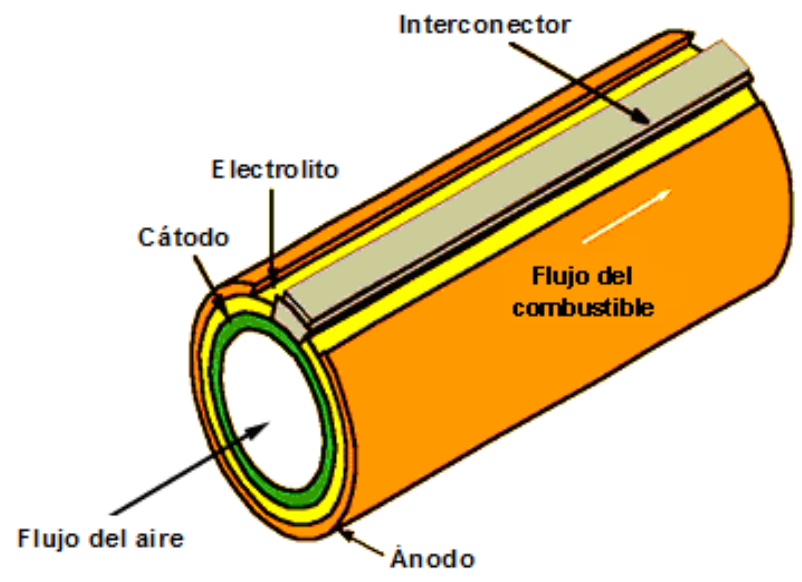

Figura 1.16. Celda SOFC con un diseño tubular ${ }^{52}$.

iii) En el diseño monolítico la triple capa ánodo-electrolito-cátodo está colocada en zig-zag y unidas entre sí por el material de interconector. Según los canales por los que circula el combustible y el oxidante se pueden originar dos configuraciones: de flujo paralelo y de flujo cruzado.

iv) El diseño segmentado viene dado por la unión de numerosos anillos que poseen la configuración básica tubular, pero que van unidos entre sí por el interconector para formar por sí mismos el stack. 


\section{Objetivo y Plan de Trabajo}




\subsection{Objetivo}

El objetivo del trabajo de investigación que se expone en esta Memoria ha sido tratar de obtener láminas de electrolito, de espesor lo más reducido posible (cerca de $80 \mu \mathrm{m}$ ), con suficiente resistencia mecánica para ser utilizadas como soporte en celdas de combustible de óxido sólido, en configuración ESC (electrolyte supported cells), capaces de operar a temperaturas próximas a $873 \mathrm{~K}$, bastante más bajas que las empleadas actualmente en este tipo de celdas (1173-1273 K).

El electrolito de una celda de este tipo, como se ha indicado en la Introducción, ha de permitir la difusión de los iones oxígeno desde el cátodo al ánodo, donde participan en la oxidación electroquímica del hidrógeno, debiendo evitar el paso de electrones a su través, para reducir las pérdidas de eficacia, y ser impermeable a los gases.

Teniendo en cuenta estas premisas, se ha de intentar que la lámina de electrolito tenga las siguientes propiedades:

$\checkmark$ Elevada conductividad iónica (a los iones $\mathrm{O}^{2-}$ ) en el intervalo de temperatura al que se desea que opere la celda, debiendo permanecer estable esta propiedad con el tiempo, para retardar el efecto del envejecimiento. El valor de la conductividad conviene que sea superior a $0,01 \mathrm{~S} / \mathrm{cm}$, a la temperatura de operación.

$\checkmark$ Impermeabilidad a los gases ya que, dado que este componente de la celda actúa como elemento de separación entre el ánodo el cátodo, debe impedir el contacto entre los gases que se introducen en los respectivos compartimentos. Conviene que su porosidad sea prácticamente nula, para evitar el paso de los gases a su través.

$\checkmark$ Estabilidad química. El electrolito está en contacto, por un lado, con el ambiente oxidante del cátodo y, por el otro, con el ambiente reductor del ánodo, por lo que debe ser inerte químicamente a ambas condiciones. Además debe ser física y químicamente compatible con el resto de componentes de la celda, en todo el intervalo de temperatura comprendido entre la temperatura ambiente y la temperatura habitual de operación.

$\checkmark$ Resistencia mecánica adecuada, pues ha de actuar como soporte de la celda.

La conductividad iónica elevada se puede conseguir seleccionando adecuadamente el material a utilizar para su construcción y optimizando la etapa de sinterización a fin de obtener el tamaño de grano más adecuado. La compacidad necesaria para que tenga la máxima impermeabilidad, puede obtenerse optimizando la etapa de conformado y las de tratamiento térmico necesarias para su producción: presinterización y sinterización.

\subsection{Plan de trabajo}

De la fase de revisión bibliográfica previa al inicio del trabajo, se concluyó que el material de partida a utilizar para tratar de obtener un electrolito de las características deseadas debía ser polvo de circona $\left(\mathrm{ZrO}_{2}\right)$ estabilizada, en su forma cristalina cúbica, mediante la adición del elemento o elementos químicos más adecuados para intentar que el producto final tuviera una buena conductividad iónica a temperaturas del orden de los $873 \mathrm{~K}^{34,35}$. La mayor parte de los experimentos se realizaron con probetas obtenidas por conformado de polvo de circona dopada con escandio y cerio, de fórmula molecular $10 \mathrm{Sc}_{2} \mathrm{O}_{3} \cdot 1 \mathrm{CeO}_{2} \cdot 89 \mathrm{ZrO}_{2}$

Para conformar laminas tan delgadas, como se ha indicado más arriba, se decidió utilizar la técnica de colado en banda, procedimiento que permite un cambio de escala relativamente sencillo a la hora pensar en desarrollar el proceso industrialmente. Dada la dificultad de utilizar muestras de producto acabado, moldeado por colado en banda, para determinar la 
conductividad del material por la metodología y equipo utilizados, se moldearon asimismo probetas por prensado unidireccional.

De acuerdo con lo que antecede, se planificó desarrollar el siguiente plan de trabajo:

\subsubsection{Láminas moldeadas por colado en banda}

a) Preparación de una suspensión de partículas de la circona elegida con las características adecuadas

Para ello, se planificó preparar diferentes suspensiones de la circona elegida buscando la fase líquida más adecuada y seleccionando la naturaleza y la proporción de los aditivos orgánicos (dispersantes, plastificantes y ligantes) a emplear para obtener suspensión fácilmente manipulable, a la vez que permitiera moldear por colado en banda láminas de electrolito que después de ser tratadas térmicamente poseyeran las propiedades deseadas. Las láminas coladas debían ser compactas y exentas de defectos superficiales como grumos, poros, grietas, etc., además de ser suficientemente flexibles y poseer la resistencia mecánica adecuada para soportar las operaciones de manipulación posteriores, hasta obtener el producto final.

b) Selección del ciclo térmico más adecuado para el desarrollo de la etapa de eliminación de materia orgánica presente en las láminas coladas en crudo

En esta fase del trabajo, previa a la de sinterización, había que seleccionar el ciclo térmico más adecuado para eliminar, por descomposición térmica, los aditivos orgánicos contenidos en la lámina colada, en crudo, sin que ésta perdiera su integridad (planaridad, ausencia de grietas o fisuras, etc.). Para ello se programó realizar diversos ensayos, probando distintos ciclos de tratamiento térmico, partiendo de la base de que parecía oportuno eliminar en primer lugar el dispersante y los plastificantes y, a continuación, el ligante.

\section{c) Optimización del ciclo térmico de sinterización.}

La optimización del ciclo térmico de sinterización había que plantearla con la finalidad de obtener una lámina de producto acabado que tuviera una porosidad inferior al $5 \%$, la resistencia mecánica adecuada para poder actuar como soporte de los restantes elementos de la celda de combustible y la máxima conductividad iónica posible en el intervalo de temperaturas comprendido entre 873 y $973 \mathrm{~K}$. Para tratar de alcanzar este objetivo, se pensó en realizar varios ensayos de sinterización de las probetas coladas, después de eliminar los aditivos orgánicos, operando a distintas temperaturas y tiempos de residencia, haciendo posteriormente un análisis morfológico del producto resultante y midiendo su conductividad iónica.

d) Puesta a punto de una metodología para medir el tamaño de grano (microcristales de circona dopada) y de la conductividad iónica de las piezas sinterizadas

Dado que parece que parece existir una relación entre la conductividad iónica efectiva de las piezas sinterizadas y el tamaño de grano en las mismas, por la influencia de este último sobre la contribución a dicha propiedad de los mecanismos de transporte de iones a través del grano y en el límite de grano, se consideró que era muy importante tratar de relacionar, en las piezas sinterizadas a diferentes condiciones, la conductividad iónica efectiva global con el tamaño de grano. 


\subsubsection{Probetas conformadas por prensado unidireccional}

Con las láminas sinterizadas sólo se pudo determinar el tamaño de grano, porque al intentar medir la conductividad iónica de las probetas, debido al reducido espesor de las mismas, no se tenía seguridad de que no se produjera contacto entre los electrodos de platino que se habían depositado en ambas caras de las muestras.

Para poder determinar la conductividad iónica del material sinterizado a diferentes condiciones de temperatura y tiempo de residencia, se pensó en conformar, por prensado unidireccional, probetas cilíndricas de mayor espesor que las láminas coladas, evitando así la posibilidad de que se produjera un contacto entre los electrodos al efectuar las medidas. 


\section{Experimental}




\subsection{Materiales}

Las materias primas utilizadas han sido:

$\checkmark$ Circona (óxido de circonio) estabilizada a temperatura ambiente en su forma cúbica mediante la adición de los cationes dopantes Sc y $\mathrm{Ce}$, y de fórmula molecular $10 \mathrm{Sc}_{2} \mathrm{O}_{3} \cdot 1 \mathrm{CeO}_{2} \cdot 89 \mathrm{ZrO}_{2}$ (en adelante $10 \mathrm{Sc} 1 \mathrm{CeSZ}$ ). Se trata de un producto comercial fabricado por la empresa japonesa DKKK (Daiichi Kigenso Kagaku Kogyo Co. Ltd.), suministrado a través de la compañía alemana Sumitomo Deutschland Gmbh, y con muy buenas perspectivas para obtener productos de elevada conductividad iónica.

$\checkmark$ Circona estabilizada a temperatura ambiente en su forma tetragonal mediante la adición de $\mathrm{Y}$, de fórmula molecular $3 \mathrm{Y}_{2} \mathrm{O}_{3} .97 \mathrm{ZrO} \mathrm{ZO}_{2}$ (3YSZ) y fabricada por la compañía japonesa Tosoh. Esta circona, al ser de naturaleza tetragonal puede originar productos con muy buenas propiedades mecánicas. En efecto, la circona tetragonal policristalina posee una resistencia a la flexión comprendida entre 800 y $2.400 \mathrm{MPa}$, mientras que la cúbica tan sólo de $200 \mathrm{MPa}^{54}$.

$\checkmark$ Alúmina (óxido de aluminio) tipo $\alpha\left(\alpha-\mathrm{Al}_{2} \mathrm{O}_{3}\right)$ o corindón, de la firma Sasol. Esta materia prima se ha empleado, como aditivo, para intentar aumentar la resistencia mecánica de las láminas cocidas.

$\checkmark$ Diversos líquidos orgánicos que se han empleado para preparar las suspensiones utilizadas y como disolventes de los aditivos orgánicos ensayados.

$\checkmark$ Diferentes aditivos orgánicos con la misión de actuar como dispersantes de las partículas en las suspensiones o de actuar como plastificantes o ligantes para conferir cierta resistencia mecánica a las láminas coladas, en crudo.

Las propiedades físicas y químicas de dichas materias primas han sido facilitadas por los suministradores, las cuales, en el caso de la circona $10 \mathrm{Sc} 1 \mathrm{CeSZ}$, han sido certificadas para cada uno de los lotes con los que se ha trabajado.

Se ha realizado la identificación de los componentes cristalinos de cada materia prima por DRX. Los difractogramas obtenidos se detallan en las Figuras 3.1 a 3.3.

La circona $10 \mathrm{Sc} 1 \mathrm{CeSZ}$ era predominantemente cúbica, con ligera presencia de circona romboédrica (véase en la Figura 3.1 el hombro que presenta el difractograma en el pico principal de la circona cúbica en torno al ángulo de difracción 29,9 (20)). 


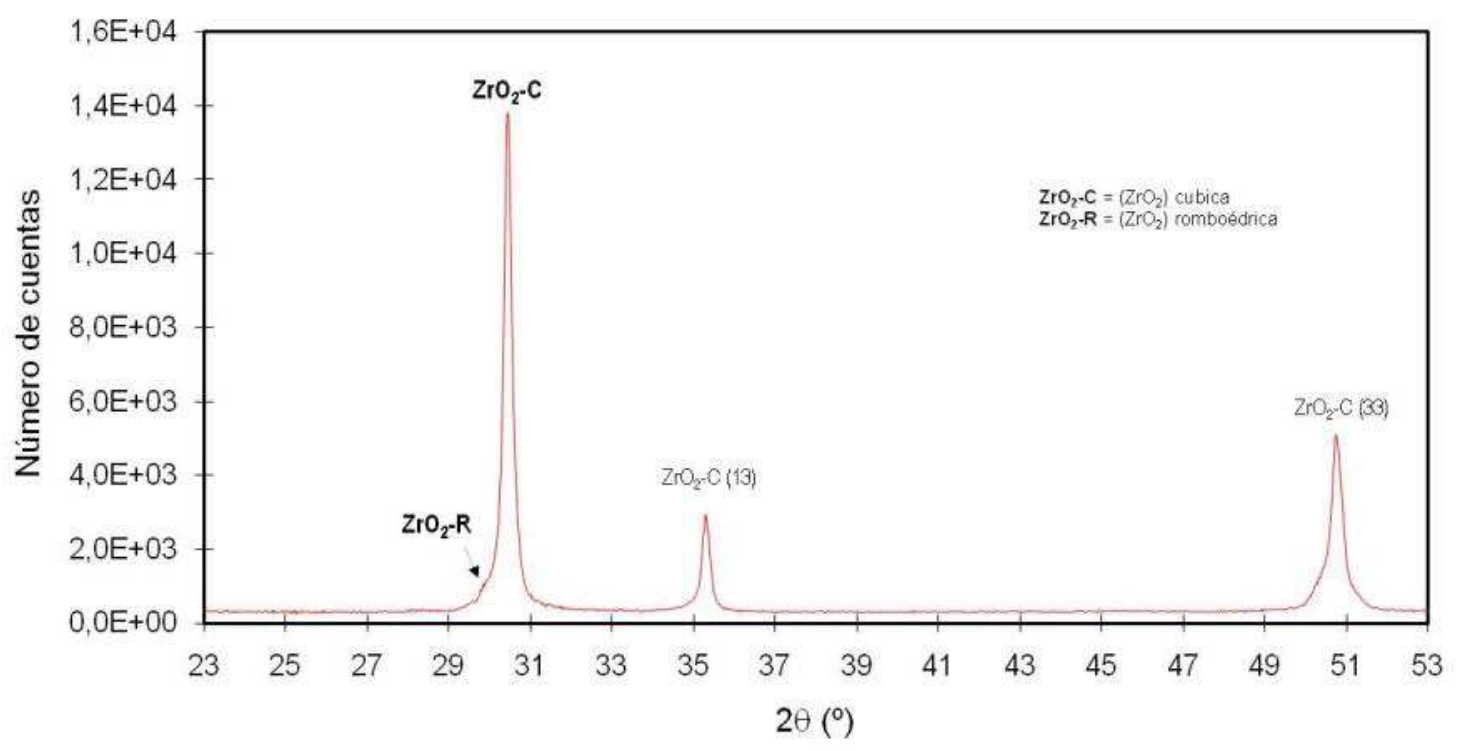

Figura 3.1. Difractograma de la muestra de circona 10Sc1CeSZ.

En la Figura 3.2 se observa que la circona 3YSZ estaba estabilizada en su forma tetragonal, con cantidades importantes de circona monoclínica que es la forma cristalina estable a la temperatura ambiente.

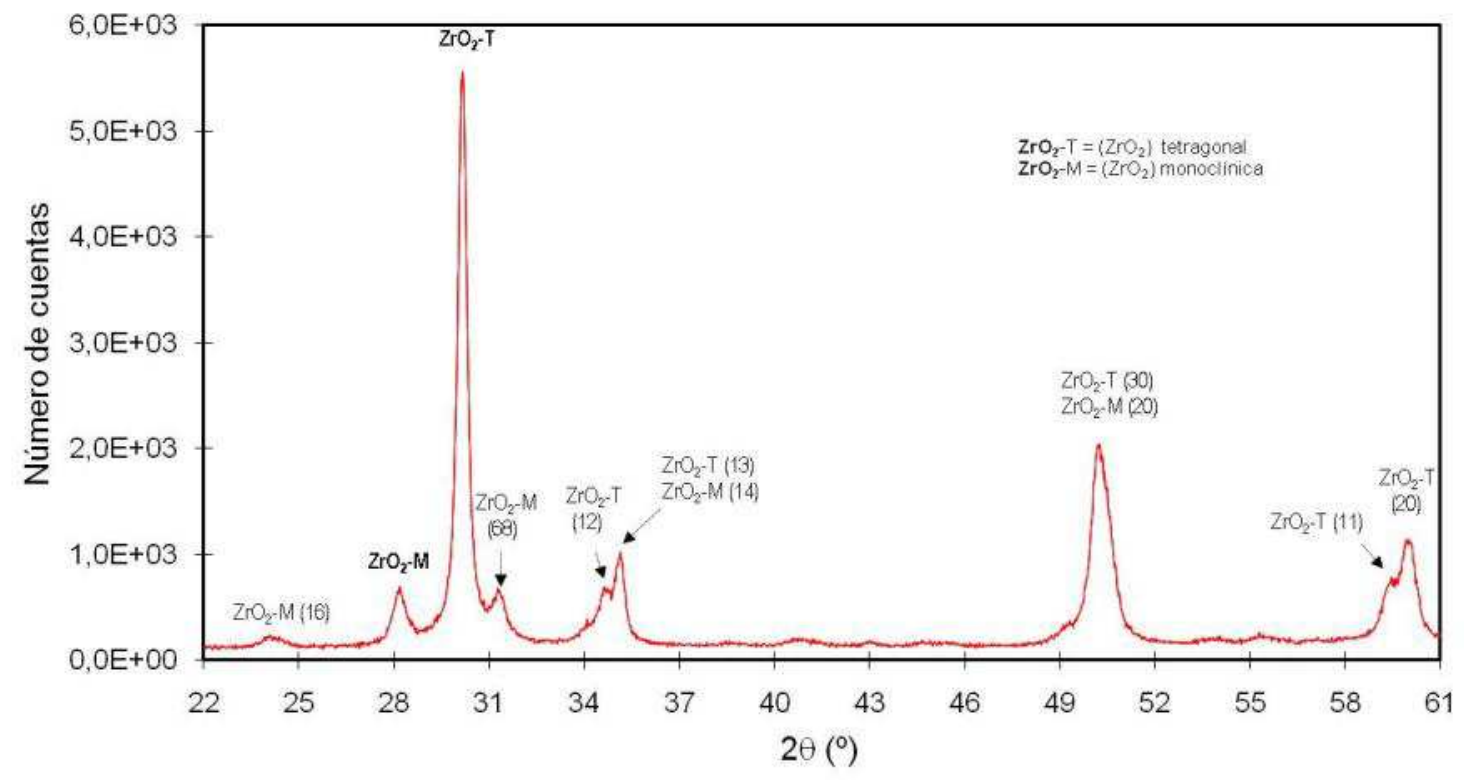

Figura 3.2. Difractograma de la muestra de circona 3YSZ.

En la Figura 3.3 se observa que la alúmina utilizada estaba cristalizada en forma de $\alpha-\mathrm{Al}_{2} \mathrm{O}_{3}$ o corindón $100 \%$ 


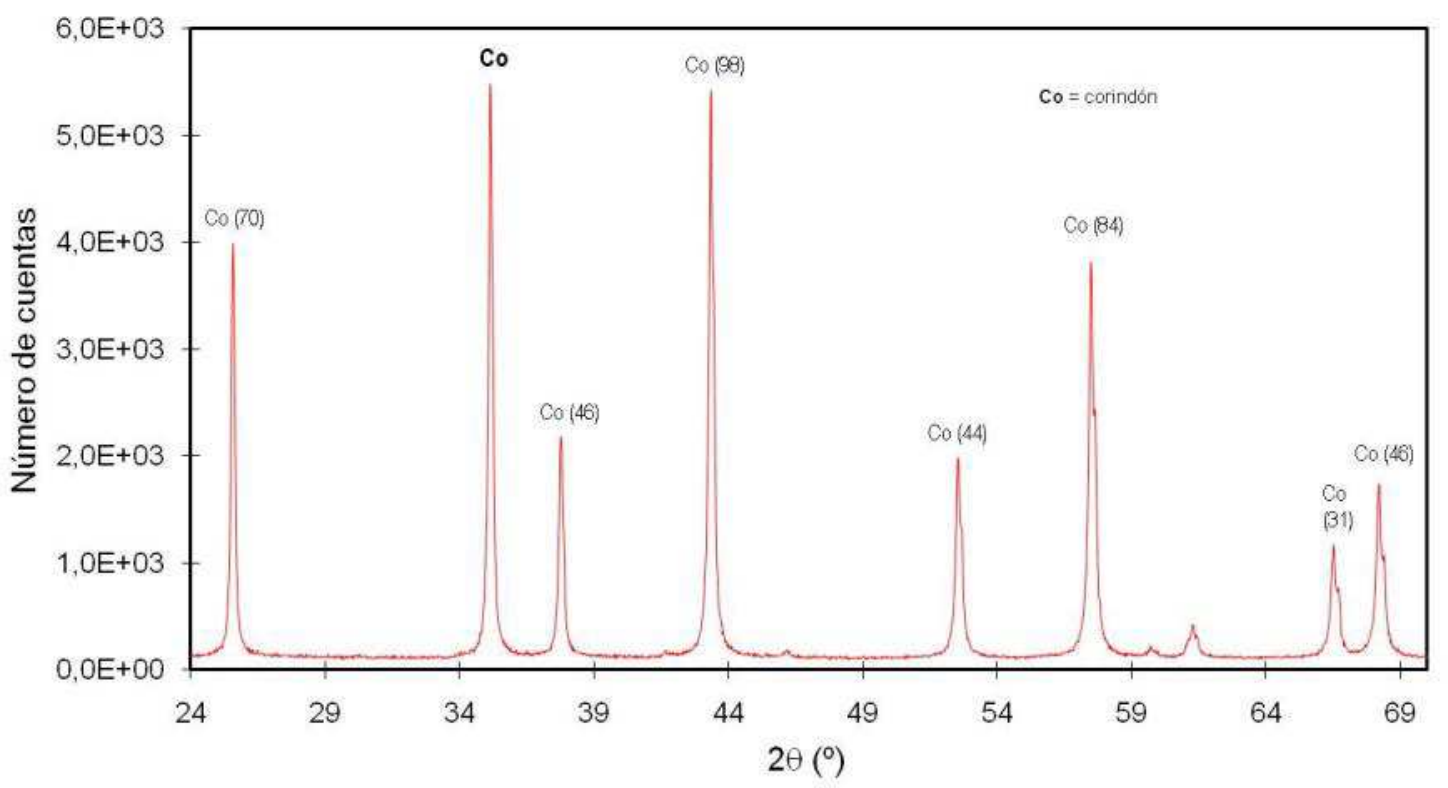

Figura 3.3. Difractograma de la muestra de $\alpha-\mathrm{Al}_{2} \mathrm{O}_{3}$ utilizada.

En las Figuras 3.4 y 3.5 se visualizan el aspecto de los materiales obtenido en el MEB (microscopio electrónico de barrido). Se comprueba que en todos los casos la morfología de las materias primas es muy homogénea.

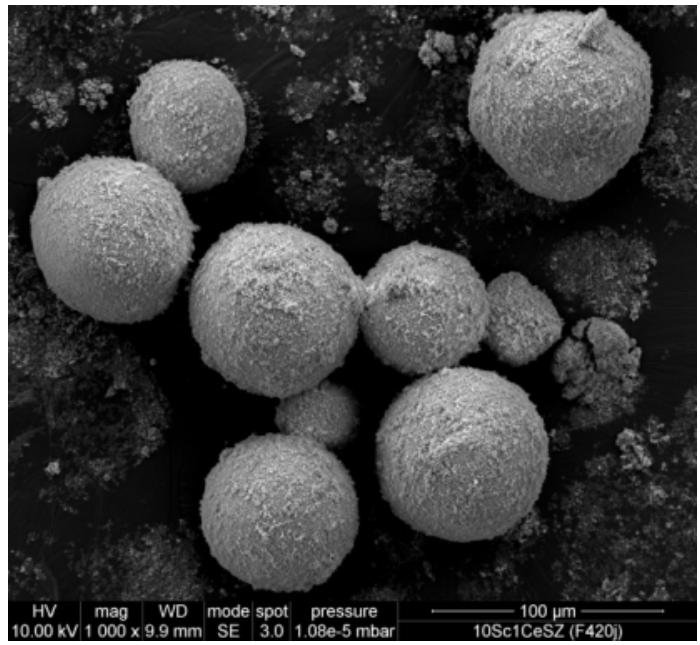

(a)

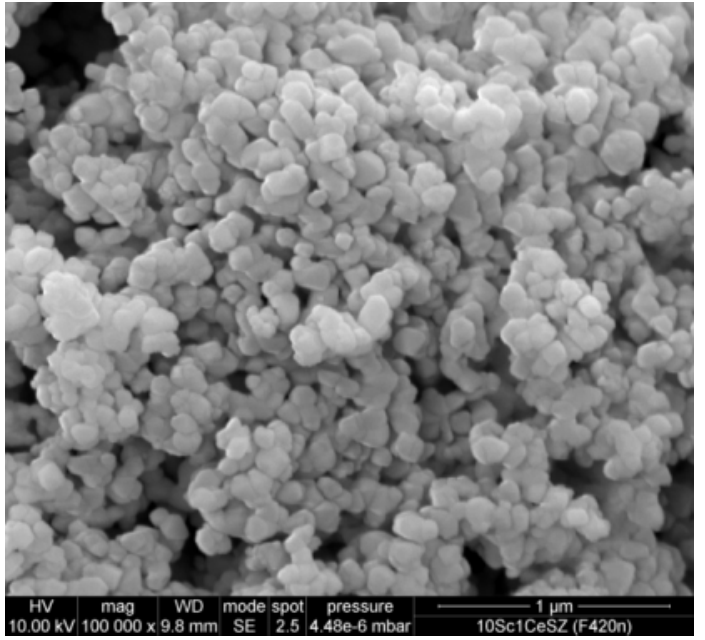

(b)

Figura 3.4. Micrografías MEB de la muestra de circona 10Sc1CeSZ. a) 1.000 x. b) 100.000 x. 


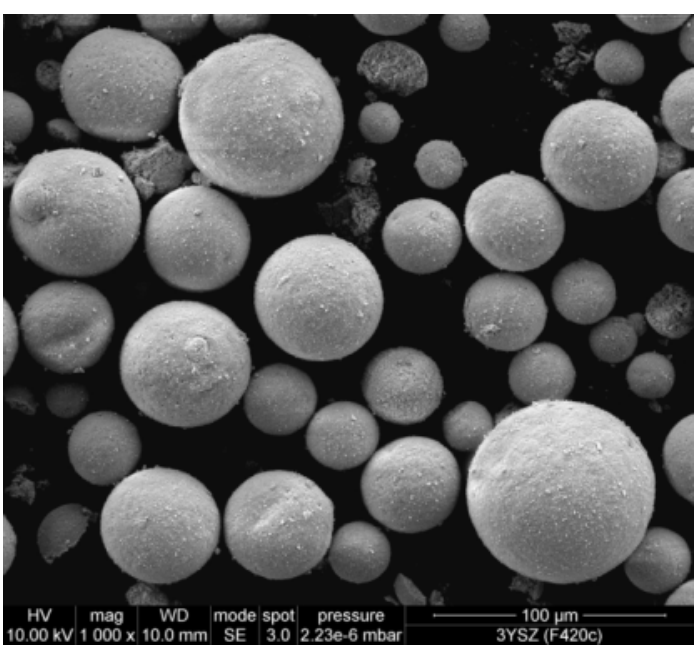

(a)

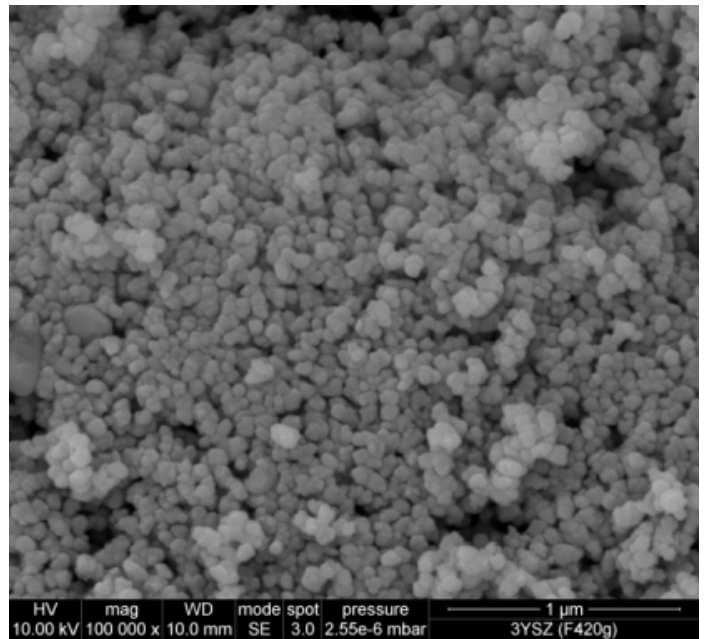

(b)

Figura 3.5. Micrografías MEB de la muestra de circona 3YSZ. a) 1.000 x. b) $100.000 x$.

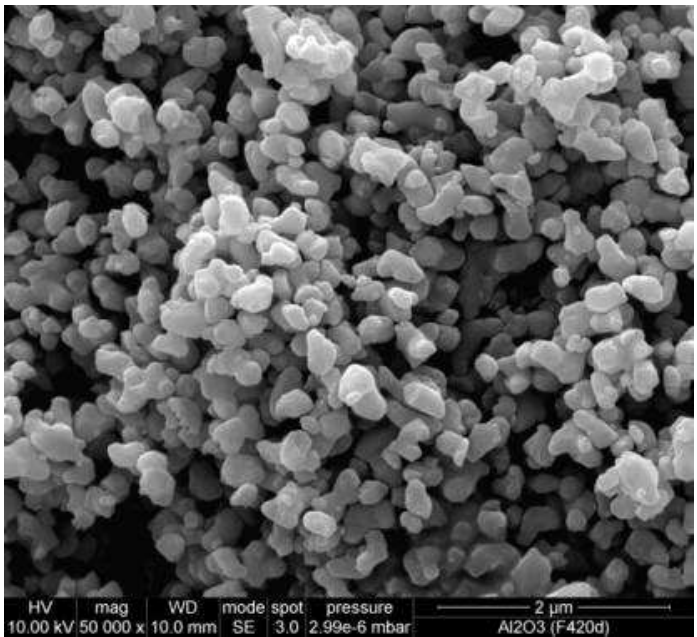

(a)

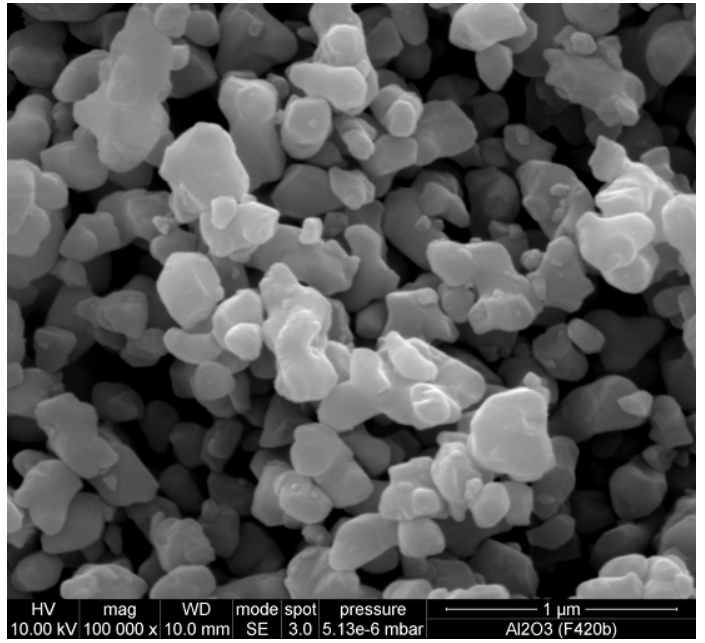

(b)

Figura 3.6. Micrografías MEB de una muestra de $\alpha-\mathrm{Al}_{2} \mathrm{O}_{3}$, a) 50.000 x. b) $100.000 \mathrm{x}$.

En la Tabla 3.1 se muestran los valores de la superficie específica (determinada mediante el método BET), de la densidad real (medida con picnómetro de helio) y del diámetro medio superficial de los microcristales en las partículas iniciales, correspondientes a cada una de las tres materias primas utilizadas para realizar este estudio. 
Tabla 3.1. Propiedades físicas de los materiales de partida

\begin{tabular}{lccc}
\hline & 10Sc1CeSZ & 3YSZ & $\mathbf{\alpha - A l}_{2} \mathrm{O}_{3}$ \\
\hline $\begin{array}{l}\text { Superficie específica }\left(\mathbf{m}^{2} / \mathbf{g}\right) \\
\text { Densidad real }\left(\mathbf{g} / \mathbf{c m}^{3}\right)\end{array}$ & 11 & 15 & 7,9 \\
$\begin{array}{l}\text { Diámetro medio de los } \\
\text { microcristales en las partículas } \\
\text { iniciales }(\boldsymbol{\mu m})\end{array}$ & 5,64 & 5,84 & 3,91 \\
\hline
\end{tabular}

\subsection{Procedimiento Experimental}

A partir de los materiales de partida, se han preparado tres mezclas de composiciones diferentes (ver Tabla 3.2), las cuales se han conformado de dos procedimientos distintos: láminas delgadas conformadas por colado en banda y pastillas moldeadas por prensado unidireccional. Con las láminas coladas se ha desarrollado la fase de optimización del ciclo térmico utilizado para la eliminación de la materia orgánica contenida en las muestras, en crudo, y con las láminas sinterizadas se ha determinado su porosidad y resistencia mecánica, así como el tamaño de los cristales que conforman el agregado cristalino resultante (diámetro medio de grano). Con las muestras prensadas se ha determinado el diámetro medio de grano y se ha medido la conductividad iónica ya que, debido al pequeño espesor de las láminas, no se tenía garantía de que se pudiera medir correctamente dicha propiedad con el equipo utilizado.

El diámetro medio de grano de los materiales sinterizados se determinó con la intención de: a) comprobar si su valor resultaba afectado por el método de conformado de las muestras de partida, cuando se trataban con idéntico ciclo térmico total; b) para ver si existía alguna relación entre los valores de dicha propiedad y los de la conductividad iónica total.

\begin{tabular}{lccc}
\hline \multicolumn{4}{c|}{ Tabla 3.2. Composiciones de las muestras estudiadas (Porcentajes másicos) } \\
\hline & 10Sc1CeSZ & 3YSZ & a-Al2O3 \\
\hline Composición C- I & 100 & -- & -- \\
Composición C- II & 80 & 20 & -- \\
Composición C- III & 98 & -- & 2 \\
\hline
\end{tabular}




\subsubsection{Preparación de las probetas}

\subsubsection{Conformado por prensado unidireccional}

Para la preparación de cada muestra se operaba del modo siguiente: En primer lugar, se preparaba, por un lado, una disolución del polímero PARALOID B-67 en acetona, en la proporción 20-80 (porcentajes másicos).

Seguidamente, se mezclaban $100 \mathrm{~g}$ de polvo, $7 \mathrm{~g}$ del preparado y $100 \mathrm{~g}$ de acetona. El conjunto se molturaba en un molino de bolas planetario, durante $2 \mathrm{~h}$, a una velocidad de 150 r.p.m. Posteriormente se secaba en cabina. El producto resultante se disgregaba y tamizaba a través de un tamiz de $200 \mu \mathrm{m}$ de luz de malla.

Con el polvo resultante del tamizado se prensaban probetas cilíndricas de $1 \mathrm{gr}$ de material usando un molde de $19 \mathrm{~mm}$ de diámetro en máquina de ensayos universales INSTROM con una presión de prensado de $800 \mathrm{~kg} / \mathrm{cm}^{2}$.

En la Figura 3.7 se detalla el montaje experimental utilizado para desarrollar la etapa de prensado.

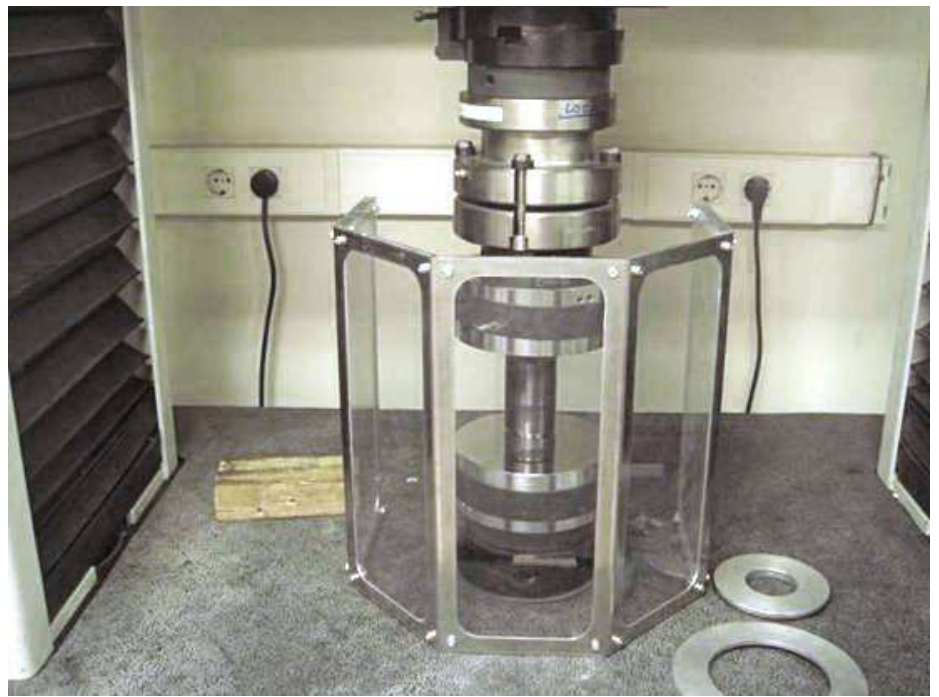

Figura 3.7. Detalle del montaje experimental utilizado para el prensado de las probetas.

Las probetas obtenidas se secaban y, posteriormente se trataban térmicamente, a velocidad de calentamiento constante e igual $120 \mathrm{~K} / \mathrm{h}$, hasta alcanzar las temperaturas máximas de 1573,1673 y $1773 \mathrm{~K}$, a las que se mantenía durante 2, 4 y $6 \mathrm{~h}$. Las pastillas sinterizadas se utilizaron para la determinación de la conductividad iónica, porosidad y tamaño de microcristal.

Las muestras destinadas a la medida de la conductividad iónica se pintaban por ambas caras con pasta de platino, y se secaban en una estufa a $383 \mathrm{~K}$ durante 30 min cada cara. Una vez secas, se trataban térmicamente en un horno eléctrico de laboratorio, primero a velocidad de calentamiento constante e igual a $1200 \mathrm{~K} / \mathrm{h}$, hasta alcanzar $1223 \mathrm{~K}$. Seguidamente se mantenía a esa temperatura durante 60 minutos, enfriándose la muestra dentro del horno. 


\subsubsection{Conformado por colado}

Las láminas se han conformado utilizando la técnica de "Colado en banda" o "Colado en cinta" (Tape casting). El dispositivo que se emplea está provisto de una doble cuchilla (Doctor Blade), que deposita la barbotina (suspensión de la muestra) por un lado y elimina el exceso por el lado opuesto. La deposición se realiza sobre un film de polietileno en movimiento sobre una mesa de colado. Ajustando convenientemente la velocidad de avance del film, la apertura de la ranura de salida y las propiedades de la barbotina (viscosidad y contenido en sólidos), se consigue el espesor de lámina, en crudo, deseado.

Esta técnica se usa para la producción de hojas y láminas delgadas de material cerámico en gran cantidad y a bajo coste, que además pueden ser apiladas y laminadas en estructuras multicapa. Es un proceso continuo en el que la película de espesor controlado se forma cuando una suspensión fluye sobre un sustrato inclinado o bajo una cuchilla. Se utiliza para la obtención de espesores de láminas comprendidos entre $12 \mu \mathrm{m}$ y $3 \mathrm{~mm}$, aunque han llegado a obtenerse espesores de $5 \mu \mathrm{m}$.

Resulta muy difícil obtener piezas cerámicas de tales espesores por otros procedimientos de conformado. Caso de intentar utilizar el prensado en seco unidireccional los principales problemas se presentarían serían el llenado irregular del molde, y/o el desmoldado de las piezas sin rotura. Por otra parte, es prácticamente imposible conformar piezas de esas características por extrusión.

\section{(i) Preparación de las suspensiones}

Se han preparado suspensiones de muestras de las diferentes composiciones preparadas, en mezclas de líquidos orgánicos que, a la vez actuaban como disolventes de los aditivos (dispersantes, ligantes y plastificantes) de naturaleza orgánica ensayados. Se ha procurado que la viscosidad aparente de las suspensiones fuera adecuada para poder desarrollar correctamente la operación de colado.

Se han utilizado dos sistemas de líquidos orgánicos (en adelante se denominaran disolventes) diferentes:

$\checkmark$ Sistema 1: metil etil cetona/isopropanol. Las mezclas se han preparado en la proporción correspondiente a la mezcla azeotrópica y en proporción distinta.

$\checkmark$ Sistema 2: xileno/etanol.

Con ambos sistemas de disolventes se han preparado suspensiones con diferentes contenidos de la muestra de material inorgánico elegido, intentado siempre que la concentración de este fuese lo más alta posible.

Las suspensiones se han homogeneizado utilizando un molino de bolas Pulverisette 5 de la firma Fritsch. Las jarras del molino tenían una capacidad de $500 \mathrm{ml}$, y las bolas de molienda ocupaban el $50 \%$ del volumen útil y eran de $10 \mathrm{~mm}$ de diámetro. Todos los elementos eran de circona. La velocidad de giro utilizada ha sido de 150 r.p.m.

Todas las suspensiones se han preparado en dos fases secuenciales, debido a la adsorción competitiva del dispersante y del ligante sobre las partículas de las muestras de circona empleadas.

En la primera fase se introducía en la jarra del molino la mezcla de disolventes, el dispersante y la muestra de circona elegida y el conjunto se mantenía en agitación durante 6 $\mathrm{h}$. Trascurrido este tiempo se añadía a la suspensión los plastificantes y el ligante, y se sometía de nuevo a agitación durante $16 \mathrm{~h}$. 
Se han probado como dispersantes: terpineol, aceite de pescado de "Aldrich" y aceite de pescado (Blow Menhaden Fish oil Z3) de "Werner G. Smith, Inc".

Como plastificantes tipo I se han usado: Dibutyl phthalate de "Aldrich" (DBT), y SANTICIZER 160 (Butyl Benzyl Phthalate) de "Ferro Corporation".

Como pastificantes tipo II se han probado: Polietilenglicol 400, Polietilenglicol 10.000, Poliglicol 2.000 y UCON 50-HB-2000 de "Dow Chemical Company".

Los ligantes ensayados han sido: Poly (vinyl butyral-co-vinyl alcohol-co-vinyl acetato) (PVB) de "Aldrich" y BUTVAR B-98 (Polyvinyl butyral) de "Solutia, Inc".

Las suspensiones se descargaban del molino y se desaireaban, mediante una bomba de vacío, durante $10 \mathrm{~min}$. La potencia de la bomba de vacío se ajustaba de modo que se evitase la eliminación del disolvente (ver Figura 3.8).

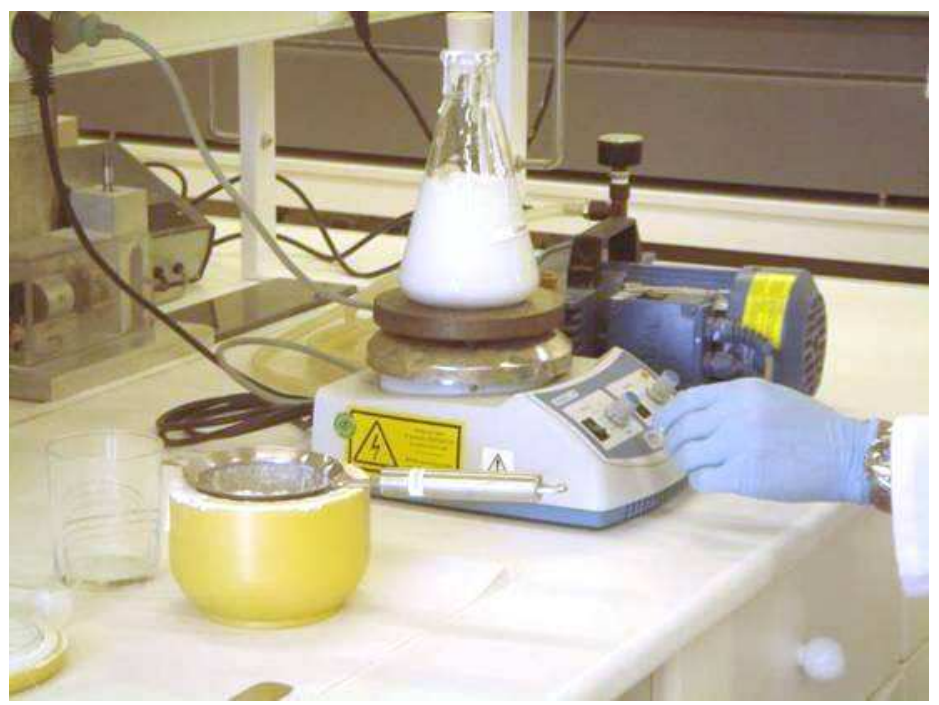

Figura 3.8. Detalle del proceso de desaireación realizado.

La viscosidad de la suspensión se controlaba mediante un viscosímetro rotacional BOHLIN (ver Figura 3.9) y cuando las condicionas reológicas eran las adecuadas se procedía a realizar la etapa de colado sobre un film de polietileno. En aquellos casos en los que las suspensiones eran demasiado viscosas y de difícil desaireación, fue necesario añadir más disolvente previo para poder desarrollar la etapa de colado. 


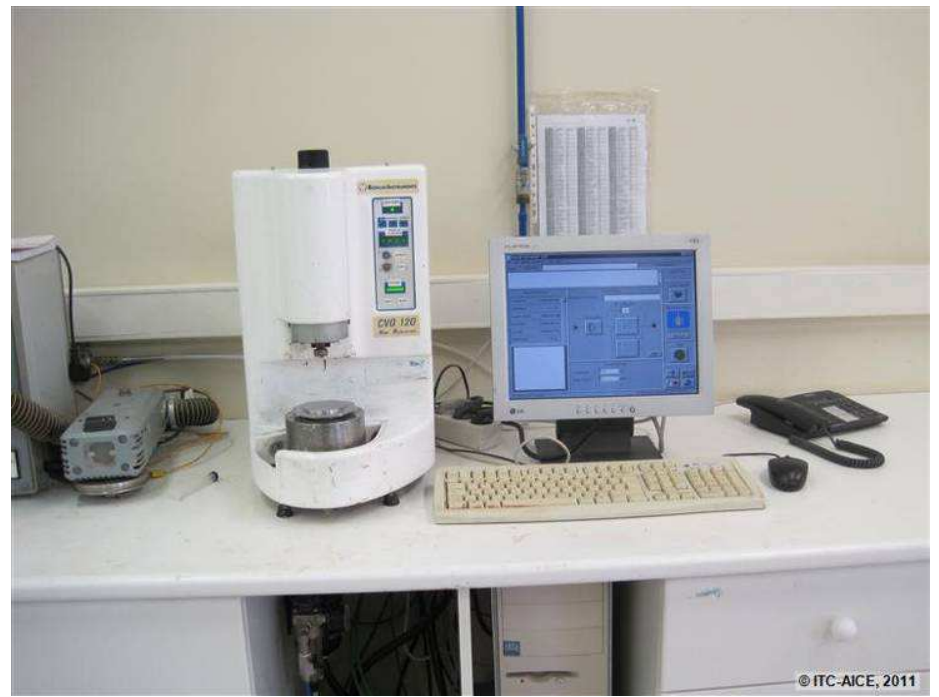

Figura 3.9. Vista del reómetro utilizado.

(ii) Conformado de las láminas

Las suspensiones preparadas de la forma que se indica en el apartado anterior, se depositaban por colado sobre un film de polietileno que avanzaba sobre la mesa del equipo "Doctor Blade" (ver Figuras 3.10 y 3.11).

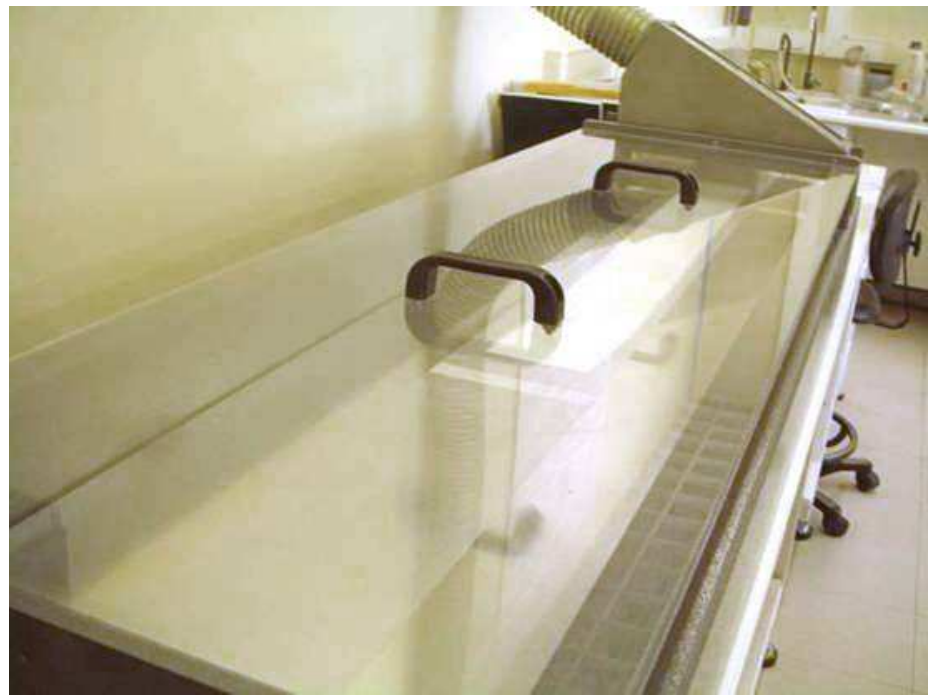

Figura 3.10. Fotografía del dispositivo de colado en banda. 


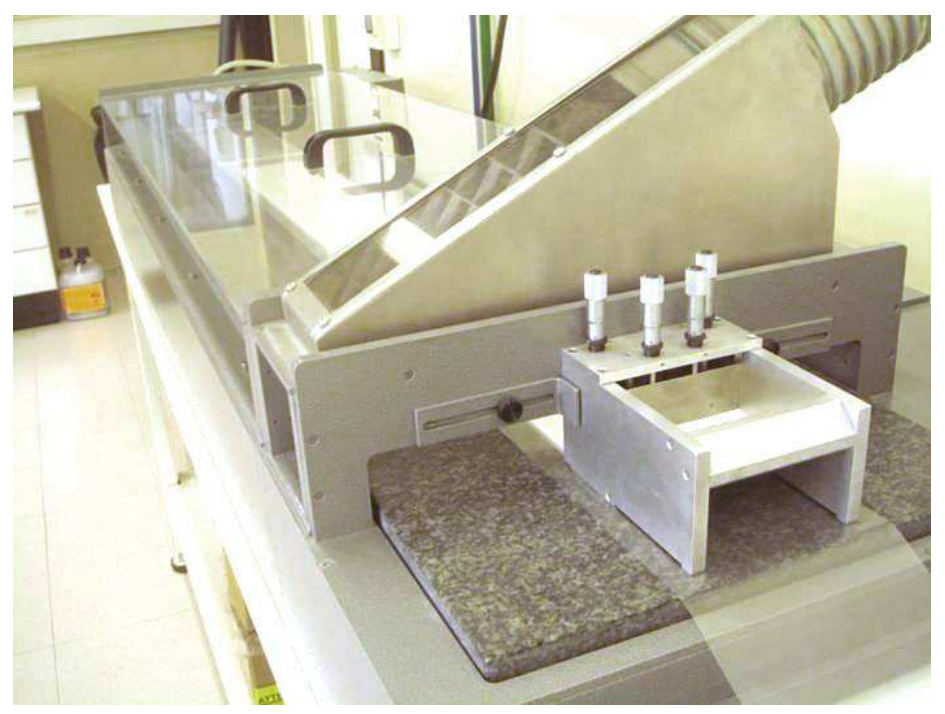

Figura 3.11. Vista del dispositivo de colado en banda. Detalle de la cuchilla de alimentación.

Las condiciones de colado utilizadas han sido las siguientes:

$\checkmark$ Posición de la cuchilla: entre $3 / 4$ y 1 y $1 / 4$ de pulgada.

$\checkmark$ Velocidad de avance del film: $100 \%(0,67 \mathrm{~m} / \mathrm{min})$

$\checkmark$ Temperatura de la mesa: entre Temperatura ambiente y $333 \mathrm{~K}$.

$\checkmark$ Corriente de aire: a temperatura ambiente, con el caudal que suministra el equipo.

El espesor de la lámina cruda estaba condicionado por la posición de la cuchilla, la velocidad de avance del film y el contenido en sólidos de la suspensión que se estaba colando.

Una vez obtenida la lámina cruda se dejaba secar en la mesa de colado durante 24 horas. Transcurrido ese tiempo la lámina se cortaba en piezas cuadradas de $68 \mathrm{~mm}$ de lado (las destinadas a ser incorporadas en otras etapas de preparación de la celda unidad), o en piezas de sección circular de $25 \mathrm{~mm}$ de diámetro (las destinadas a la determinación de la resistencia mecánica).

\subsubsection{Tratamiento térmico}

Las láminas en crudo se sometían a la fase de tratamiento térmico, que constaba de dos etapas diferenciadas: la primera debía diseñarse para eliminar completamente la materia orgánica presente y la segunda para sinterizar la lámina exenta de materia orgánica, manteniendo su forma plana.

La optimización de la etapa de eliminación de la materia orgánica presente en las láminas crudas, fue bastante laboriosa para evitar que se quebraran o agrietaran durante su desarrollo. Finalmente se desarrolló a velocidad de calentamiento muy baja (entre 30 y 60 $\mathrm{K} / \mathrm{h}$ ), hasta una temperatura de $773 \mathrm{~K}$, La etapa de sinterización se realizó utilizando ciclos térmicos de temperatura constante, precalentando las muestras a una velocidad de calentamiento de $120 \mathrm{~K} / \mathrm{h}$ hasta la temperatura elegida. A cada temperatura de sinterización 
se realizaron experimentos para diferentes valores del tiempo de residencia (2, 4 y $6 \mathrm{~h})$. Se ensayaron valores de la temperatura de sinterización comprendidos entre 1573 y $1773 \mathrm{~K}$.

Para asegurar la planaridad de las láminas resultantes de la fase de tratamiento térmico, se colocaron las láminas crudas entre dos piezas planas de refractario (Repton tiles) en configuración tipo sándwich. Estas piezas de refractario debían de reunir las siguientes características:

$\checkmark$ Ser inertes. Cualquier contaminación del refractario sobre la lámina de electrolito podía modificar sus propiedades eléctricas.

$\checkmark$ Tener elevada porosidad abierta. En la etapa de eliminación de materia orgánica, el refractario debía permitir la fácil salida de los gases resultantes de la operación, por lo que debía poseer una permeabilidad alta.

$\checkmark$ Tener un peso adecuado, a fin de efectuar un efecto de planchado sobre la lámina de electrolito durante las dos etapas de la fase de tratamiento térmico, para evitar la pérdida de su planaridad, sin llegar provocar la rotura de la misma.

Se probaron diferentes materiales refractarios con características distintas, de Marketech Int, :

$\checkmark$ Repton 663 Mullite: Densidad Aparente: $2,40 \mathrm{~g} / \mathrm{cm}^{3}$; Densidad real: $3,38 \mathrm{~g} / \mathrm{cm}^{3}$, Porosidad: 29,0 \%, Resistencia mecánica a la flexión $\geq 25,0$ Mpa. CTE, linear 4.00 $\mu \mathrm{m} / \mathrm{m}-\mathrm{K}$ a $573 \mathrm{~K}$ y $5.00 \mu \mathrm{m} / \mathrm{m}-\mathrm{K}$ a $1173 \mathrm{~K}$

$\checkmark$ Repton 632 Mullite: Densidad Aparente: $1,50 \mathrm{~g} / \mathrm{cm}^{3}$, Densidad real: 3,41 g/cm , Porosidad 56,0 \%, Resistencia mecánica a la flexión $\geq 27,0$ Mpa. CTE, linear 4.00 $\mu \mathrm{m} / \mathrm{m}-\mathrm{K}$ a $573 \mathrm{~K}$ y $5.00 \mu \mathrm{m} / \mathrm{m}-\mathrm{K}$ a $1173 \mathrm{~K}$

$\checkmark$ Repton 601 Mullite: Densidad Aparente: $1,00 \mathrm{~g} / \mathrm{cm}^{3}$; Densidad real: $3,33 \mathrm{~g} / \mathrm{cm}^{3}$, Porosidad 70,0 \%, Resistencia mecánica a la flexión $\geq 11,0$ Mpa. CTE, linear 3.80 $\mu \mathrm{m} / \mathrm{m}-\mathrm{K}$ a $573 \mathrm{~K}$ y $5.00 \mu \mathrm{m} / \mathrm{m}-\mathrm{K}$ a $1173 \mathrm{~K}$.

$\checkmark$ Repton 214 Aluminum Oxide Densidad Aparente: $2,60 \mathrm{~g} / \mathrm{cm}^{3}$; Densidad real: 4,00 $\mathrm{g} / \mathrm{cm}^{3}$, Porosidad 35,0 \%; Resistencia mecánica a la flexión $\geq 56,0 \mathrm{MPa}$.

eligiendo finalmente una combinación de piezas $3 \mathrm{~mm}$ de espesor: Repton 214 en la parte de abajo y Repton 632 en la parte de arriba.

\subsubsection{Preparación de las muestras de láminas sinterizadas}

Las muestras destinadas a ser observadas por microscopía electrónica de barrido (MEB) se han preparado a partir de las piezas sinterizadas obtenidas, bien a partir de probetas conformadas por prensado o bien a partir de láminas moldeadas pors colado en banda.

Las probetas conformadas por prensado y sinterizadas se han cortado longitudinalmente y se han embutido en resina utilizando moldes cilíndricos, de modo que la sección de las probetas fuera perpendicular al eje del molde, a fin de que se pudiera pulir para estudiar la microestructura de su sección transversal.

Las láminas sinterizadas, de aproximadamente $80 \mu \mathrm{m}$ de espesor, se han cortado en varios trozos y se han sujetado un mínimo de 5 trozos de cada una con un clip de montaje, teniendo la precaución de colocarlas siempre en la misma posición. Cada conjunto, así montado, se ha colocado en moldes cilíndricos de modo que la sección de las láminas fuera perpendicular al eje del molde, después de añadir la resina, a fin de pulir la pieza cilíndrica por la base para estudiar la microestructura de la sección de las piezas embutidas. 
El material utilizado para embutir las muestras consistía en una mezcla de resina epoxi y endurecedor. El pulido se realizaba de forma secuencial en una máquina Struers.

Las muestras pulidas se colocaban en el MEB y se observaba su microestructura, obteniendo, a continuación, imágenes a 1.500x, 2.200x, 3.000x y 5.000x aumentos, obteniendo un mínimo de 10 imágenes por cada una de ellas. Estas imágenes se utilizaron para determinar la porosidad de las muestras, mediante un programa informático de Análisis de Imagen (Micro Image 4.0, de la firma Olympus).

Posteriormente, se eliminaba la resina de las muestras, mediante corte con sierra y/o fractura y se sometían a un tratamiento térmico para revelar y resaltar los límites de los microcristales (el borde de grano) ${ }^{53,54}$. El tratamiento térmico se realizaba a una velocidad de calentamiento constante e igual a $300 \mathrm{~K} / \mathrm{h}$, hasta una temperatura máxima de $1223 \mathrm{~K}$, permaneciendo a dicha temperatura durante $1 \mathrm{~h}$. Las muestras resultantes de este tratamiento se observaron en el MEB, obteniendo imágenes a: $3.000 x, 10.000 x$ y $20.000 x$ aumentos. Estas imágenes se trataron utilizando el mismo programa informático de Análisis de Imagen empleado anteriormente para determinar la porosidad, pero enfocado, en este caso, a obtener los parámetros que caracterizan el tamaño medio de grano y su distribución (ver Apartado 3.2.4.2), aplicando el método de Jeffries ${ }^{55,56}$.

\subsubsection{Determinación de las propiedades técnicas del producto resultante de la etapa de sinterización}

\subsubsection{Determinación de la porosidad}

En cada muestra se medía la distribución, por tamaño, de los poros y el área correspondiente a cada tamaño de poro. La medida cuantitativa de dichas propiedades, en las muestras cuya porosidad era inferior al $0,5 \%$, no era demasiado fiable para el procedimiento de medida empleado, razón por la que no se han dado resultados cuantitativos para las muestras cuya porosidad era inferior a dicho valor.

Las imágenes se modificaron con el Analizador de Imágenes, para poder realizar un marcado adecuado de los poros, a fin de poder obtener, de la forma más representativa posible, las dos propiedades mencionadas. (Figura 3.12).

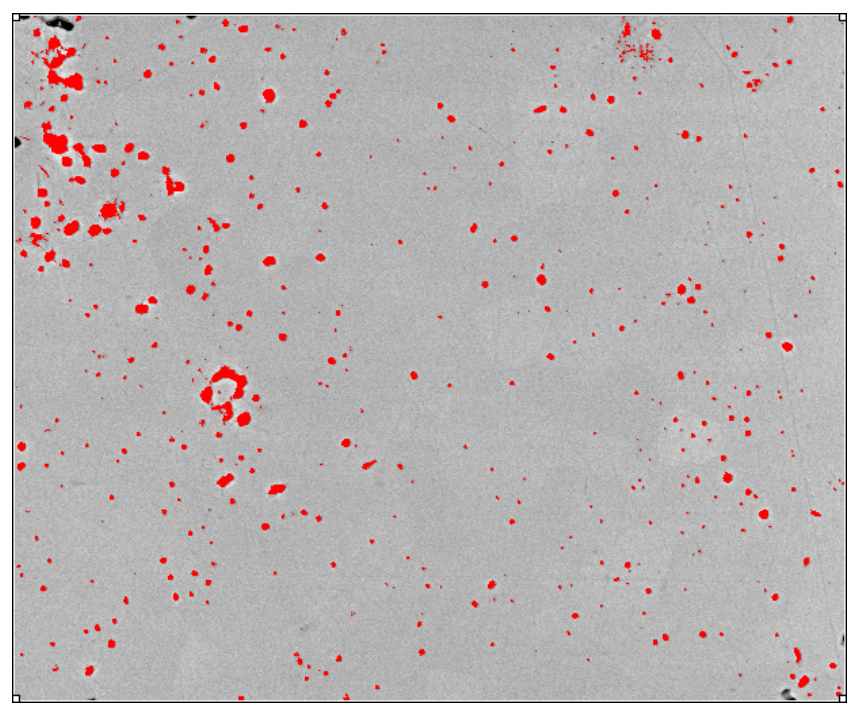

Figura 3.12. Marcado correcto de los poros 
Como medida representativa del tamaño de poro se ha utilizado el "diámetro equivalente" 57 que es el diámetro del círculo cuya área es igual a la de la sección del poro. Por tanto se calculó a partir de la correspondiente medida del área de la sección del poro $\left(\boldsymbol{A}_{p}\right)$, mediante la expresión:

$$
d_{p}=2 \sqrt{\frac{A_{p}}{\pi}}
$$

Los resultados obtenidos se suelen presentar en diagramas con coordenadas semilogaritmicas, de dos modos diferentes ${ }^{57}$ :

- Representando el porcentaje del área de la sección de la muestra considerada que está ocupada por poros de diámetro equivalente igual o inferior a un valor dado, frente al valor de dicho diámetro equivalente (Figura 3.13). Esta representación, admitiendo la existencia de cierta proporcionalidad entre el porcentaje de áreas y el de volúmenes, permite tener una idea aproximada del valor de la porosidad total de cada muestra $\left(\varepsilon_{\text {total }}\right)$.

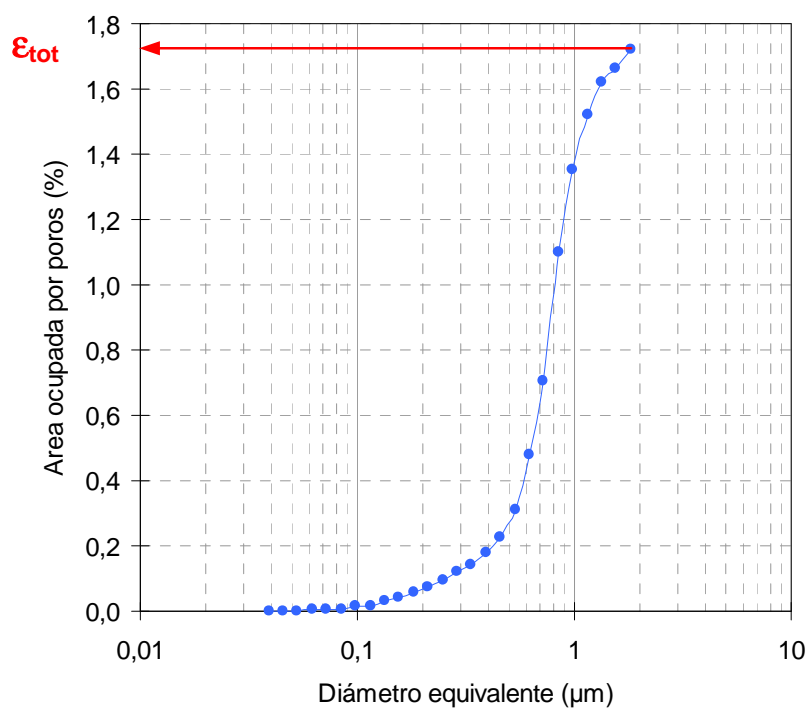

Figura 3.13. Curva de distribución del porcentaje del área de la muestra ocupada por poros

- Representando el porcentaje del área total acumulada de poros que está ocupada por poros de diámetro equivalente igual o inferior a un valor dado, frente al valor de dicho diámetro equivalente (Figura 3.14), se puede determinar el tamaño medio de poro, $\boldsymbol{d}_{50}$, por encima o por debajo del cual se encuentra el $50 \%$ del área ocupada por los poros.

A partir de la representación de la Figura 3.14 se pueden determinar también otros parámetros análogos como $\boldsymbol{d}_{10}, \boldsymbol{d}_{25}, \boldsymbol{d}_{75} 0 \boldsymbol{d}_{90}$. La amplitud de la distribución se calcula mediante los cocientes $d_{75} / d_{25}$ o preferentemente $d_{90} / d_{10}$. 


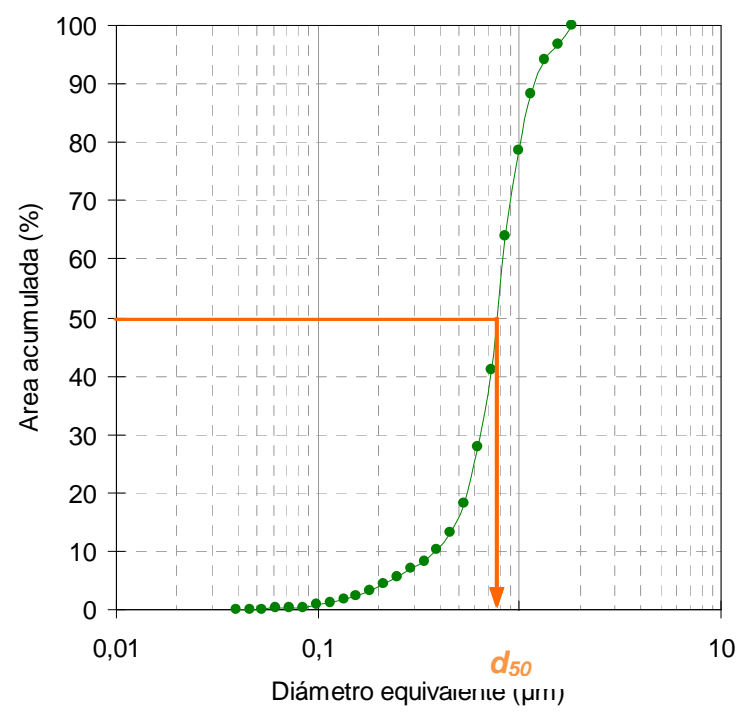

Figura 3.14. Curva de distribución del porcentaje del área acumulada ocupada por los poros.

\subsubsection{Determinación del tamaño de los microcristales (diámetro medio de grano)}

El tamaño de los microcristales en las muestras sinterizadas, expresado como diámetro medio de grano, se determinó a partir de las correspondientes imágenes obtenidas en el MEB, tratadas con el Analizador de Imágenes, aplicando la metodología descrita en el apartado anterior ${ }^{55}$, acondicionadas previamente para tratar que las medidas fueran lo más representativas posible ${ }^{58}$ (Figura 3.15).

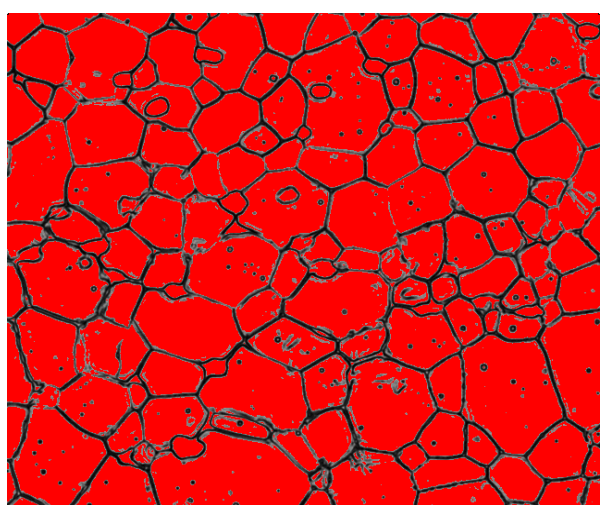

(a)

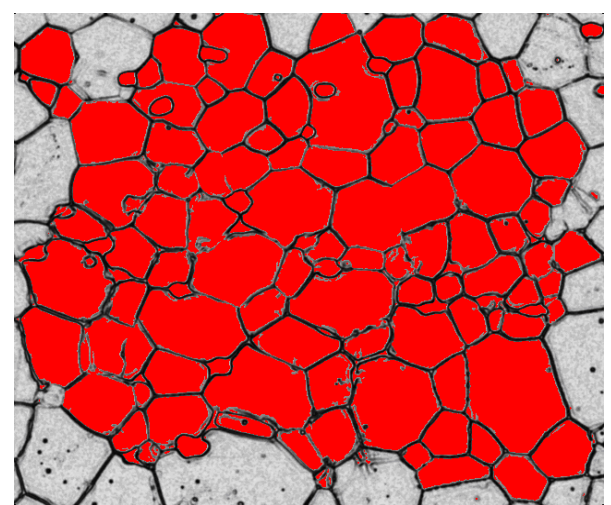

(b)

Figura 3.15. Marcado final de los granos en una misma muestra. a) Sin las opciones "Fill Holes" y "All borders". b) Con las opciones "Fill Holes" y "All Borders". 
La imagen que se aprecia en la Figura 3.15 puede inducir a error al tratar de obtener, a partir de ella, el área del material que está ocupada por los granos, (Figura 3.16) ya que en los materiales policristalinos estudiados no existen monocristales con un área inferior a $0,1 \mu \mathrm{m}^{2}$.

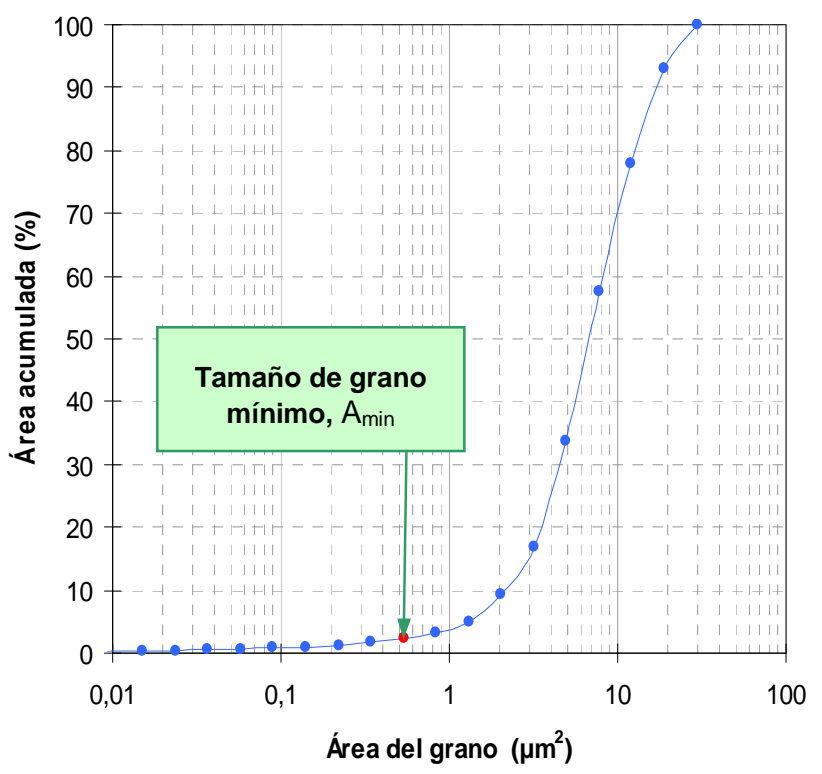

Figura 3.16. Distribución del área acumulada de todos los objetos marcados en la etapa de análisis de imagen.

Se ha comprobado que los objetos más pequeños que se detectan en la imagen, corresponden a los poros de mayor tamaño que no han sido discriminados o partes de algunos granos no marcados completamente. Esto último se aprecia especialmente en las muestras sinterizadas y atacadas térmicamente a menor temperatura (Figura 3.17).

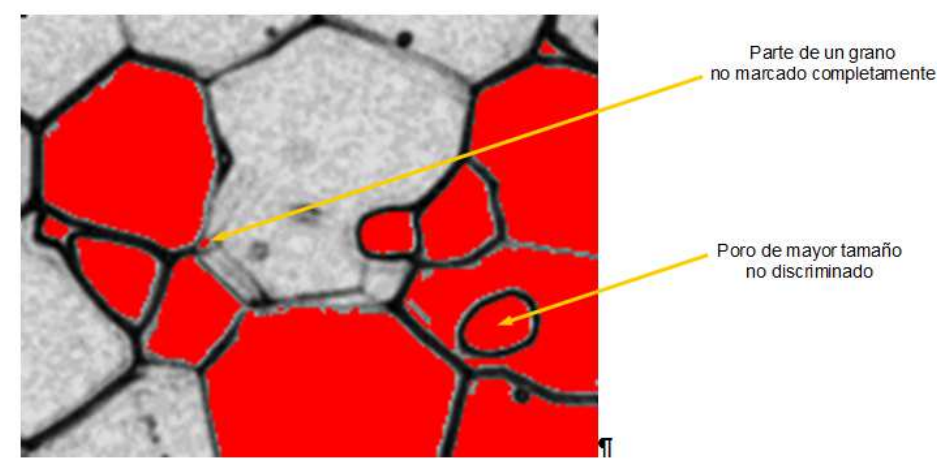

Figura 3.17. Objetos marcados en la etapa de análisis de imagen que no son granos.

La forma más sencilla de eliminar los objetos que conducen a error es determinar, en la representación gráfica de la Figura 3.16, a qué valor del área de grano se produce un primer cambio significativo de la pendiente. Dicho valor $\left(A_{\min }\right)$ está normalmente por encima de 0,5 $\mu \mathrm{m}^{2}$ y el valor de su ordenada, según se ha observado a lo largo de este trabajo, suele ser 
muy próximo al de la porosidad total del material. Dicha magnitud se ha de determinar antes de efectuar el revelado del límite de los monocristales que se hace por tratamiento térmico.

Mediante un filtrado se eliminan todos los objetos de la imagen con un área inferior a la correspondiente al tamaño de microcristal mínimo detectado $\left(\boldsymbol{A}_{\min }\right)$, y se representa de nuevo la distribución del área acumulada de los objetos resultante, en función del área del microcristal (grano). En la Figura 3.18 se muestra esta nueva representación que se ha realizado a partir de los datos con los que se construyó la gráfica de la Figura 3.16.

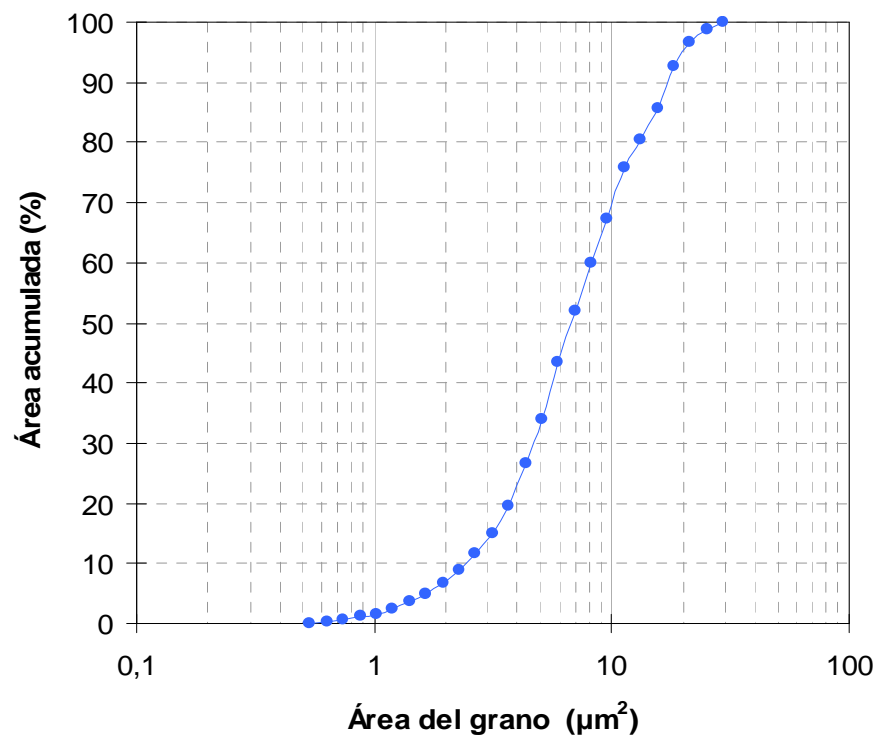

Figura 3.18. Distribución del área acumulada ocupada por los monocristales de la muestra correspondiente a las Figuras 3.15 y 3.16.

El método descrito permitió obtener una curva de distribución más representativa del valor del área acumulada ocupada por los microcristales.

Ahora bien, el tamaño de cada microcristal se suele expresar como el diámetro que tendría un círculo con la misma área que la sección de dicho microcristal en la imagen. De acuerdo con esta definición, dicho diámetro se puede calcular mediante la expresión:

$$
D_{g}=2 \sqrt{\frac{A_{g}}{\pi}}
$$

Donde $\boldsymbol{A}_{g}$ es el área de grano representada en el eje de abscisas de las gráficas de las Figuras 3.16 y 3.18 .

Por tanto, la representación gráfica de la distribución del área acumulada de los monocristales en función del diámetro de grano tiene la forma que se muestra en la Figura 3.19.

A partir de esta representación se puede determinar el diámetro equivalente medio $\left(\boldsymbol{D}_{50}\right)$ del conjunto de cristales que conforman la muestra considerada, que es aquel por encima o por debajo del cual se encuentra el $50 \%$ del área de la imagen ocupada por los microcristales. 


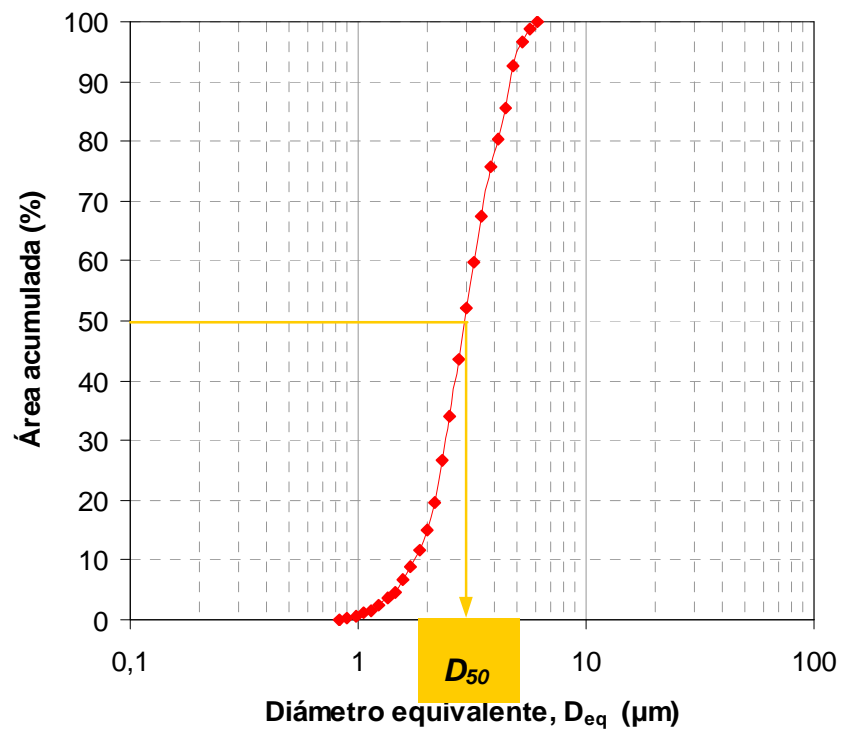

Figura 3.19. Distribución del área acumulada de los monocristales en función del diámetro de grano.

\subsubsection{Medida de la conductividad iónica}

La determinación de la conductividad se realizó por el método de impedancias complejas. Las medidas de impedancia se realizaron con un Analizador de Impedancias Solartrom 1260 , al que se le adaptó un portamuestras para probetas sólidas y un horno tubular (Figura 3.20).

El portamuestras utilizado consistía en una celda de medida con dos puntos de contacto, y cuatro hilos, construida para asegurar que la resistencia que se determinaba, en cada caso, sólo correspondía a la muestra analizada, sin ninguna contribución óhmica asociada a los hilos de medida empleados en las conexiones (Figura 3.21).

La muestra se alojaba en el portamuestras y se sujetaba, por ambos lados, mediante unas varillas de alúmina (varillas de ajuste en la Figura 3.21) por cuyo interior discurrían los hilos de platino que contactaban, por cada lado, con la muestra. 


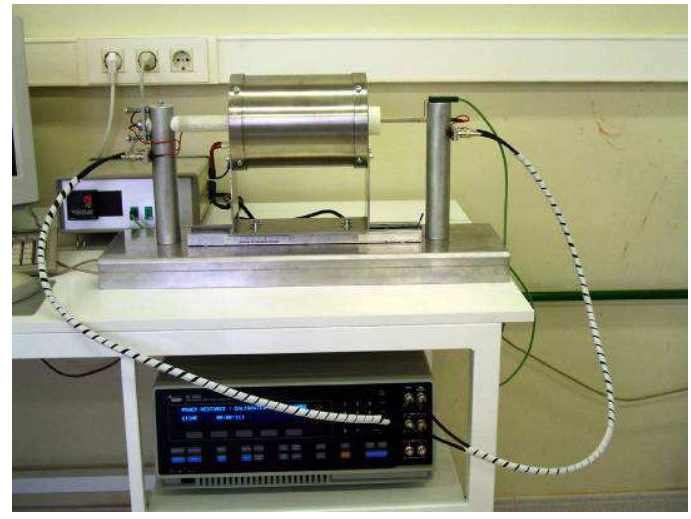

(a)

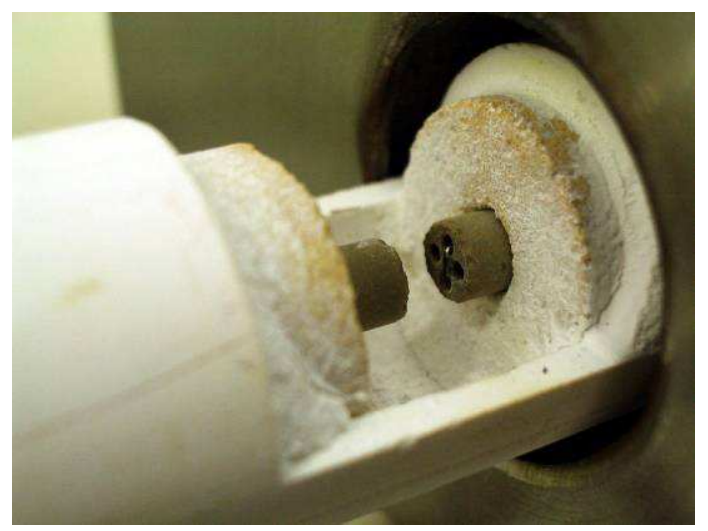

(c)

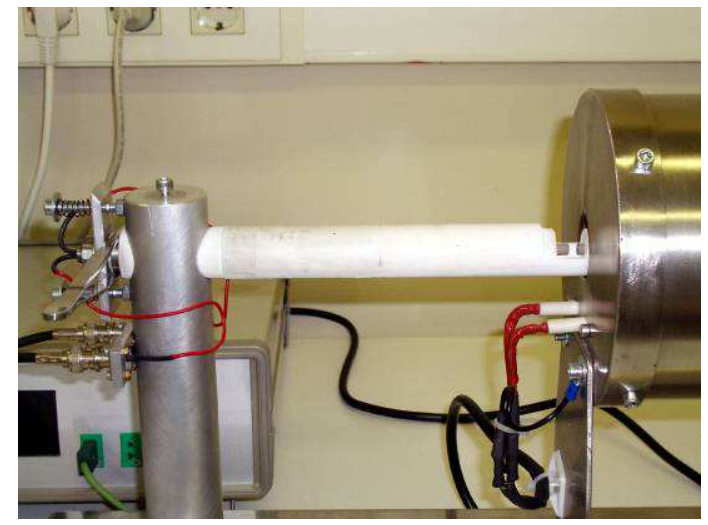

(b)

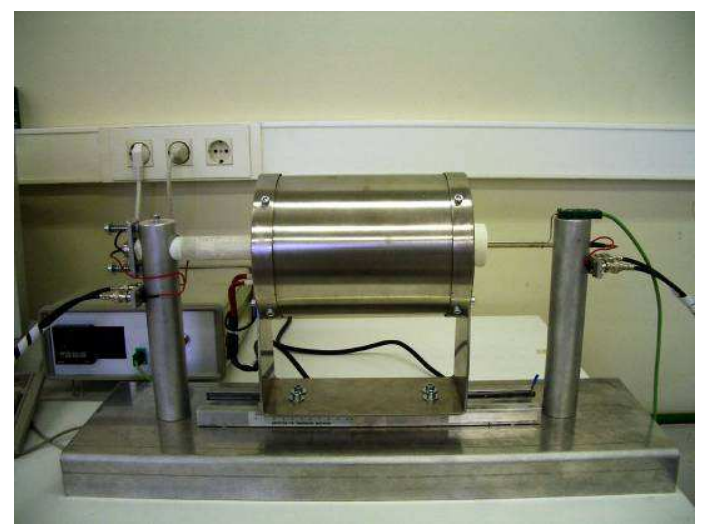

(d)

Figura 3.20. Vistas del analizador de impedancias utilizado. a) Vista general del montaje: analizador portamuestras y horno; b) Vista del portamuestras; c) Detalle del portamuestras; d) Vista del horno tubular.

Las medidas se realizaron a las condiciones atmosféricas. El intervalo de frecuencias utilizado estuvo comprendido entre $10^{2} \mathrm{~Hz} \mathrm{y} 10^{7} \mathrm{~Hz}$. El valor de perturbación aplicado fue de $100 \mathrm{mV}$. Cada experimento se desarrolló desde $573 \mathrm{~K}$ hasta $1273 \mathrm{~K}$ realizando medidas cada $50 \mathrm{~K}$. Una vez alcanzada la temperatura deseada en la muestra, ésta se mantenía durante un tiempo de estabilización de $600 \mathrm{~s}$ antes de realizar la medida, y cada medida se repetía dos veces. Se obtuvieron los espectros de impedancia de cada muestra a cada una de las temperaturas elegidas, a partir de los cuales se determinaron las conductividades asignadas a cada mecanismo de conducción mediante el modelo RC, así como la conductividad total de cada muestra, utilizando el programa ZView2, que permite el ajuste de los diagramas de impedancia. 


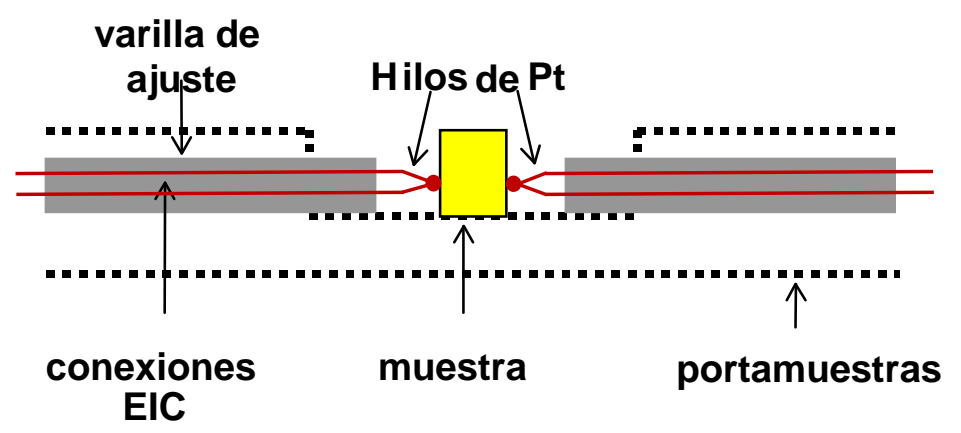

Figura 3.21. Esquema del interior del portamuestras con la celda de medida de cuatro hilos.

La forma de los diagramas de impedancia obtenidos para un mismo conductor iónico policristalino, a distintas temperaturas, difiere considerablemente.

A temperaturas bajas (inferiores a $673 \mathrm{~K}$ ) la resistencia del grano suele ser lo suficientemente elevada para que su frecuencia de relajación sea baja y se pueda visualizar la correspondiente curva en el diagrama de impedancias obtenido. En consecuencia, se pueden separar bastante bien los tres mecanismos, descritos en el Apartado 1.2.3.3, por los que se produce el transporte de carga en un conductor iónico policristalino (en el interior de los granos, en los límites de grano y por polarización de los electrodos).

En la Figura 3.22 se muestra un diagrama obtenido a $573 \mathrm{~K}$. Se observan únicamente los semicírculos característicos de los procesos de transporte de iones en el interior de los granos y en los límites de grano, debido a que la frecuencia de relajación del proceso de electrodos es tan baja que está fuera del límite inferior del equipo de medida utilizado.

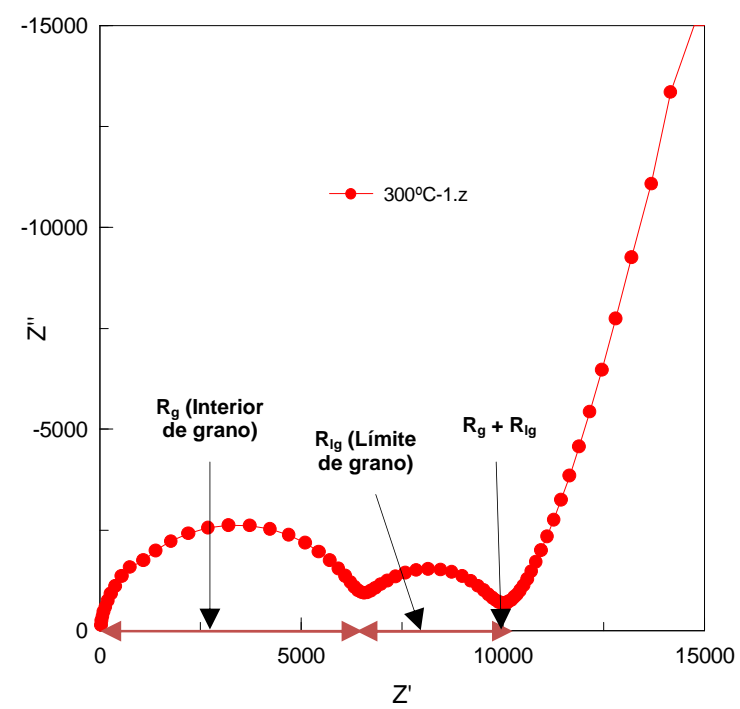

Figura 3.22. Espectro de impedancias de 8YSZ obtenido a $573 \mathrm{~K}$. 
A temperaturas mayores de $673 \mathrm{~K}$, cuando la impedancia de las SOFC comienza a ser muy baja, el valor que se mide está afectado por la inductancia y la resistencia parásita del cableado y de la celda ${ }^{59}$. Mientras la resistencia parasitaria se puede eliminar totalmente, la inductancia $n^{60}$ e incluso con la disposición del electrodo de cuatro puntas, modifica los espectros obtenidos a estas temperaturas. Las Figuras 3.23 y 3.24 muestran los espectros de impedancia a 773 y $1273 \mathrm{~K}$ respectivamente. La inductancia deforma primero el semicírculo de altas frecuencias, que desaparece, y después el de frecuencias intermedias, que se deforma y desaparece también a temperaturas más elevadas (Figura 3.24).

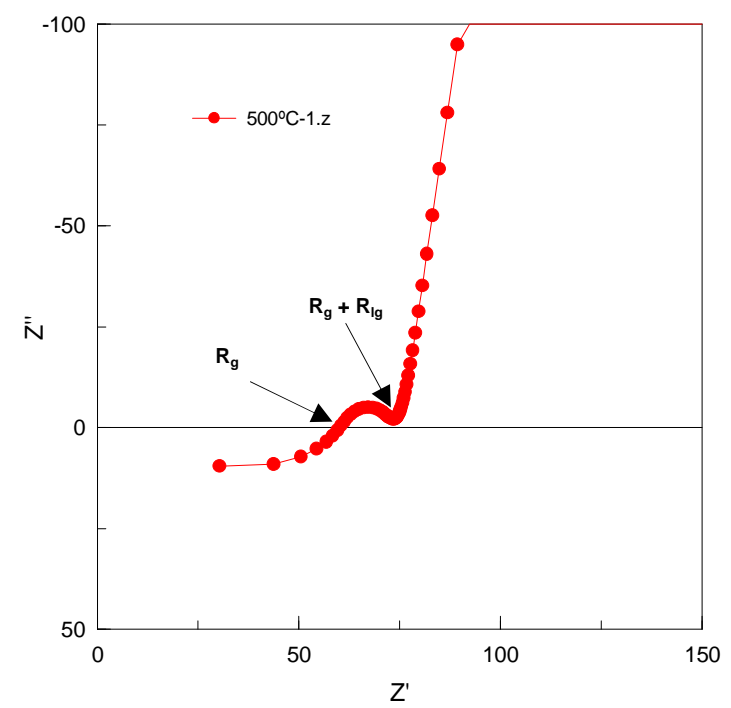

Figura 3.23. Espectro de impedancias de 8YSZ obtenido a $773 \mathrm{~K}$.

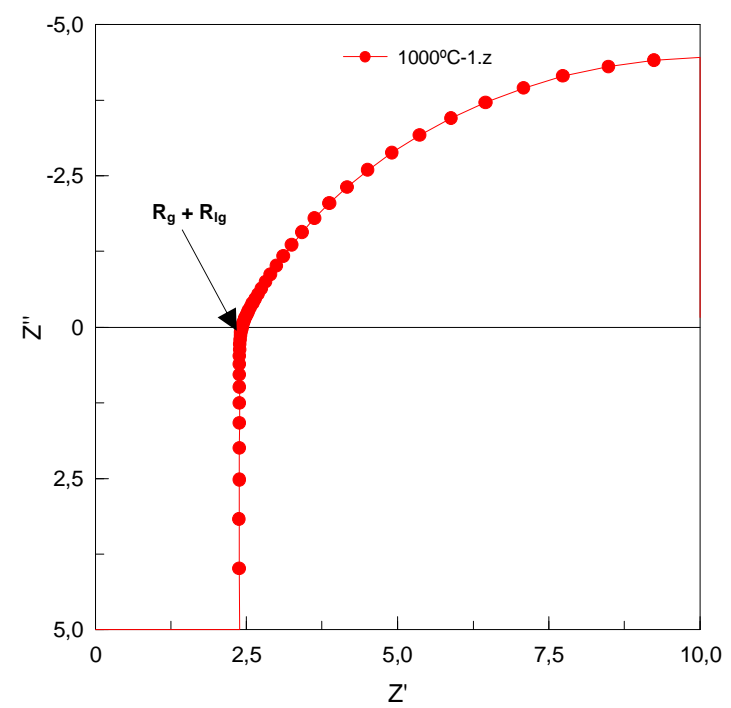

Figura 3.24. Espectro de impedancias de 8YSZ obtenido a $1273 \mathrm{~K}$. 
Para interpretar los resultados a temperaturas bajas e intermedias, cuando el semicírculo correspondiente al límite de grano aún no ha desaparecido se ha utilizado el programa ZView2 con el modelo que se muestra en la Figura 3.25, donde $\boldsymbol{L}_{\boldsymbol{i}}$ es la inductancia del circuito, $\boldsymbol{R}_{g}$ y $\boldsymbol{C P E}_{g}$ son la resistencia y el elemento constante de fase del interior del grano, $\boldsymbol{R}_{l g}$ y $\boldsymbol{C P E _ { l g }}$ son la resistencia y el elemento constante de fase del límite de grano y Wo es un elemento de Warburg abierto que simula el electrodo.

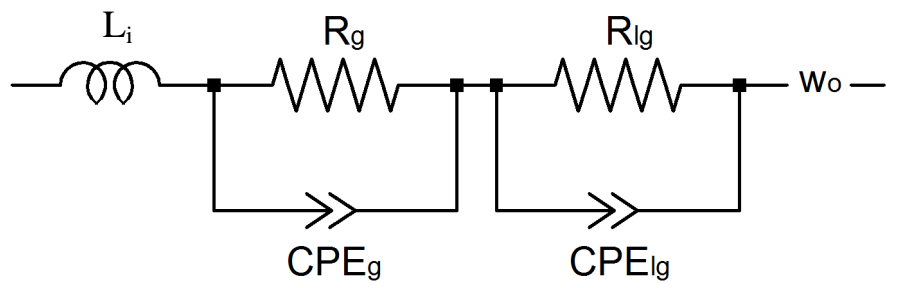

Figura 3.25. Modelo utilizado para ajustar los datos de impedancia a temperaturas bajas e intermedias, cuando el semicírculo correspondiente al bode de grano aún no ha desaparecido.

Se ha utilizado el elemento constante de fase sugerido por Macdowals para ajustar los resultados debido a que los semicírculos no tienen su centro en el eje de abscisas. EI CPE se encuentra a menudo en los estudios de la impedancia de electrolitos sólidos y de la interfacie sólido-sólido ${ }^{61,62,63,64}$. La impedancia del CPE se expresa en función de los parámetros $\alpha$ y $\mathbf{Q}$ como:

$$
Z_{C P E}=\frac{1}{(j \omega)^{\alpha} Q}
$$

Cuando $\alpha=1$ el sistema está descrito por una única constante de tiempo y el parámetro $\boldsymbol{Q}$ tiene unidades de capacitancia, en otro caso, $\boldsymbol{Q}$ es la pseudocapacitancia, con unidades de $\mathrm{s}^{\alpha} / \Omega \mathrm{cm}^{2}$ ó $\mathrm{Fs}^{(\alpha-1)} / \mathrm{cm}^{2} .{ }^{65}$ La capacitancia real del sistema puede calcularse $\mathrm{como}^{66}$ :

$$
C_{i}=\frac{\left(R_{i} \cdot Q_{i}\right)^{1 / \alpha}}{R_{i}}
$$

Se considera que el origen físico del CPE es una distribución de constantes de tiempo en la muestra que puede ocurrir a lo largo de la superficie del electrodo o en la dirección normal al electrodo ${ }^{67}$. Puede ser consecuencia de una distribución de propiedades físicas que incluye estructura, reactividad, constantes dieléctricas y resistividad. En general, salvo para los materiales más densos, las muestras policristalinas siempre muestran alguna dispersión anómala de frecuencias ${ }^{68}$. Una aproximación para modelizar la CPE es asumir que se origina de una distribución superficial de constantes de tiempo mientras que la resistencia óhmica y la resistencia a la transferencia de carga se mantienen uniformes. La dispersión de constantes de tiempo, por tanto, se asume que se debe a una distribución de las capacitancias $^{69}$.

El electrodo se ha modelizado con un elemento de Warburg abierto (dado que es el que mejor representa la zona de la impedancia contigua al semicírculo del borde de grano) que puede indicar se produce la difusión de $\mathrm{O}^{2-}$ en el electrodo plano ${ }^{63}$. En cualquier caso, el 
ajuste del electrodo no resulta interesante por sí mismo sino únicamente para garantizar la mejor correlación posible del modelo en la zona de bajas frecuencias del semicírculo del borde de grano.

Por último, se ha introducido en el modelo una inductancia en serie con los otros procesos ${ }^{62}$, que se encarga de reproducir la respuesta parasitaria del cableado del electrodo. Se ha supuesto que, con la configuración adoptada, la resistencia del circuito es despreciable; en caso contrario, podría aumentar el valor aparente de la resistencia de la probeta ${ }^{70}$.

A temperaturas bajas e intermedias; los valores proporcionados para la resistencia de interior y borde de grano han sido los obtenidos de los ajustes al modelo, sin embargo, a temperaturas altas (superiores a $773 \mathrm{~K}$ ) se pierden los semicírculos y sólo se visualiza la resistencia total (suma de las resistencias correspondientes a las contribuciones de los mecanismos de conducción a través de los granos y de los límites de grano) como el único corte de la gráfica de impedancias con el eje de abscisas (Figura 3.24). Por tanto, a temperaturas altas, la conductividad de las probetas se ha determinado a partir del corte del espectro de impedancias con el eje de abscisas ${ }^{64,71}$.

\subsubsection{Determinación de la Resistencia Mecánica a la Flexión de las láminas sinterizadas}

La Resistencia Mecánica a la Flexión de las láminas sinterizadas se determinó por el método de "ball-on-ring", a partir de ensayos de flexión biaxial ${ }^{72}$. Los ensayos se realizaron en una máquina universal de ensayos mecánicos (Instron).

El dispositivo de medida constaba de un soporte de acero, con un orificio central, sobre el cual debe situarse la probeta a ensayar. Sobre ésta, se aplicaba una carga, mediante un "punzón", que, en la parte de contacto con la probeta, tiene forma redondeada, y que se desplaza a una velocidad constante de $1 \mathrm{~mm} / \mathrm{min}$ (Figura 3.26).

En el ensayo se determina la Fuerza de Rotura de cada muestra, y a partir de su valor se calcula la Resistencia a la Flexión.
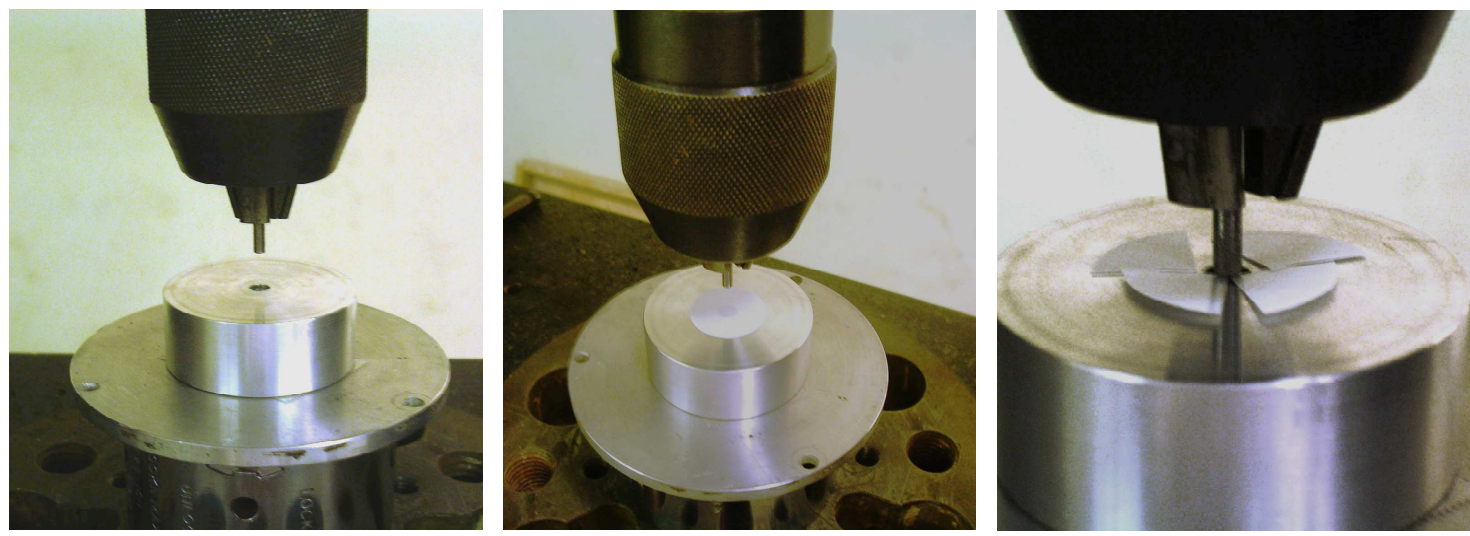

Figura 3.26. Esquema del dispositivo de medida de la Resistencia a la Flexión por el método de ball-on-ring. 
La expresión que se utilizó para el cálculo de la resistencia mecánica a la flexión fue la propuesta por Sheety:

$$
R M=\frac{3 \cdot F(1+v)}{4 \cdot \pi \cdot e^{2}}\left[1+2 \cdot \ln \frac{R_{a}}{b}+\frac{(1-v)}{(1+v)} \cdot\left(1-\frac{b^{2}}{2 \cdot R_{a}^{2}}\right) \cdot \frac{R_{a}^{2}}{R^{2}}\right]
$$

donde:

RM: Resistencia mecánica $(\mathrm{Pa})$

F: $\quad$ Carga aplicada (N)

e: $\quad$ Espesor de la probeta $(m)$

$v$ : Coeficiente de Poisson del material de la probeta

b: $\quad$ Radio del área de carga (radio de contacto de la bola de carga con la superficie de la probeta) (m)

$\boldsymbol{R}$ : $\quad$ Radio de la probeta $(\mathrm{m})$

$\boldsymbol{R}_{a}$ : Radio del soporte (m) (hueco donde se introduce el "punzón") 
“... agua descompuesta sin duda por la electricidad y que llegará a ser entonces una fuerza poderosa y manejable". Julio Verne, La Isla Misteriosa (1875).

\section{Resultados}


La investigación realizada ha constado de varias fases diferenciadas, pero relacionadas entre sí:

a) Preparación de suspensiones de la muestra de circona seleccionada con las características adecuadas para poder conformar a partir de ellas, por colado en banda, láminas crudas con las propiedades deseadas;

b) Descomposición térmica de la materia orgánica contenida en las láminas crudas y secas, seleccionando un ciclo térmico que conduzca a la mínima porosidad posible en las láminas tratadas;

c) Sinterización a temperatura elevada de la lámina resultante de la eliminación de los aditivos orgánicos;

d) Medida de la porosidad, tamaño de grano y conductividad en las muestras sinterizadas seleccionadas.

Ante la dificultad de preparar muestras para medir la conductividad a partir de las láminas sinterizadas, por su pequeño espesor, se utilizaron probetas conformadas por prensado unidireccional a partir de la misma muestra de circona. Estas probetas se sinterizaban exactamente a las mismas condiciones de temperatura y tiempo que las correspondientes láminas y en ellas se determinaban las propiedades indicadas en el apartado d) del párrafo anterior.

A continuación se exponen los resultados obtenidos en cada una de las fases.

\subsection{Experimentos previos}

Para tratar de optimizar el desarrollo de las dos primeras fases indicadas era preciso determinar si las propiedades de las láminas producto de las mismas, tanto en crudo, como en seco, así como después de someterlas al tratamiento térmico necesario para eliminar la materia orgánica que contenían y para sinterizarlas, eran las adecuadas en lo que a textura y porosidad se refiere. Es decir, si las láminas obtenidas, en cada una de estas dos fases, poseían la planaridad, compactación y porosidad requeridas en el producto que después se sometería a la fase final de sinterización.

Para diseñar un ciclo de tratamiento térmico no optimizado pero que fuera efectivo para poder establecer comparaciones entre las laminas, obtenidas como resultado de cada una de las dos primeras fases, que visualmente presentaran un aspecto prometedor, se realizó un ensayo de $A T D-T G$ de una lámina colada, en seco, obtenida partiendo de una suspensión de una muestra de la circona $\boldsymbol{C}$-I, conteniendo los aditivos orgánicos que habrían de eliminarse posteriormente. El ensayo se realizó con una muestra de una lámina colada obtenida a partir de la suspensión C-I-9 (Apartado 4.2.1). La muestra se trató, en condiciones no isotérmicas en atmosfera de aire, utilizando una velocidad de calentamiento de $120 \mathrm{~K} / \mathrm{h}$, hasta alcanzar los $1623 \mathrm{~K}$. Asimismo se consideró interesante tratar térmicamente en un microscopio de calefacción, utilizando el mismo ciclo térmico, una muestra de idéntica composición para observar los posibles cambios que, de forma cualitativa, pudiera experimentar con la temperatura, durante la fase de sinterización.

\subsubsection{Ensayos de ATD-TG}

Se realizó un ensayo con una muestra de lámina colada seca, tras haber eliminado completamente el disolvente. Esta muestra contenía $100 \mathrm{~g}$ de la circona $\boldsymbol{C}-\mathrm{I}, 4 \mathrm{~g}$ de MFO, 2,7 $\mathrm{g}$ de DBT, $7 \mathrm{~g}$ de PEG 400 y $20 \mathrm{~g}$ de PVB (lámina seca obtenida a partir de la suspensión $\boldsymbol{C}$ - 
I-15, Tabla 4.2) por lo que los compuestos orgánicos a eliminar, durante el ensayo de ATD$T G$, suponían alrededor de un $25 \%$ de la masa total de la muestra.

En el diagrama TG obtenido (Figura 4.1), se observan claramente dos tramos de pérdida de peso de la muestra, los cuales se corresponden con dos picos diferenciados en la curva DTG, uno más ancho, con el valor máximo a $556 \mathrm{~K}$ debido a la eliminación de todos los aditivos orgánicos, excepto el PEG 400, y otro más estrecho con el valor máximo a $644 \mathrm{~K}$ debido a la combustión del PEG 400 y que termina alrededor de los $723 \mathrm{~K}$. El diagrama ATD de la Figura 4.2 confirma los resultados obtenidos en el diagrama TG.

Además en dichos diagramas no se observan otros picos a temperaturas más elevadas, ni de pérdida de masa, ni de cambios de fase, lo que indicaría que durante la etapa de sinterización no hay transformaciones de la circona de partida a otras fases cristalinas.

Esta última circunstancia se comprobó al realizar un ensayo de $D R X$ de una muestra de la misma composición que la anterior, a la que previamente se le había eliminado la materia orgánica y se había sinterizado a $1773 \mathrm{~K}$ (Figura 4.3).

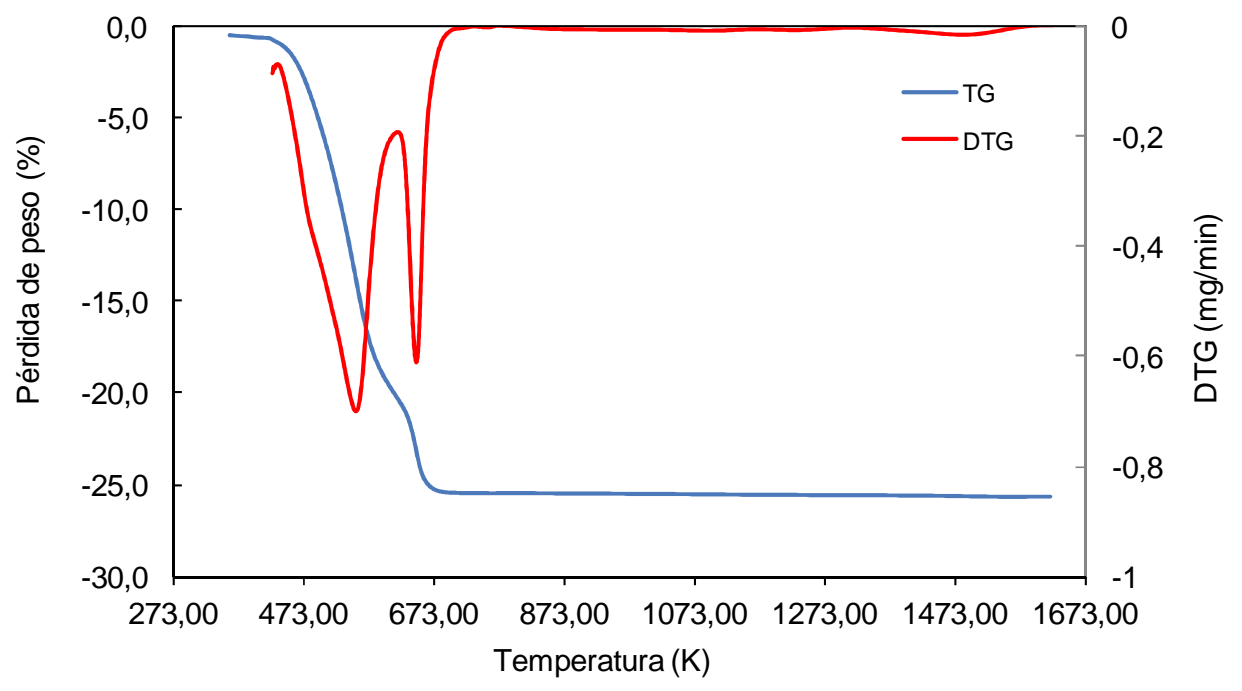

Figura 4.1. Análisis termogravimétrico de la lámina obtenida con la muestra C-I, más aditivos orgánicos.

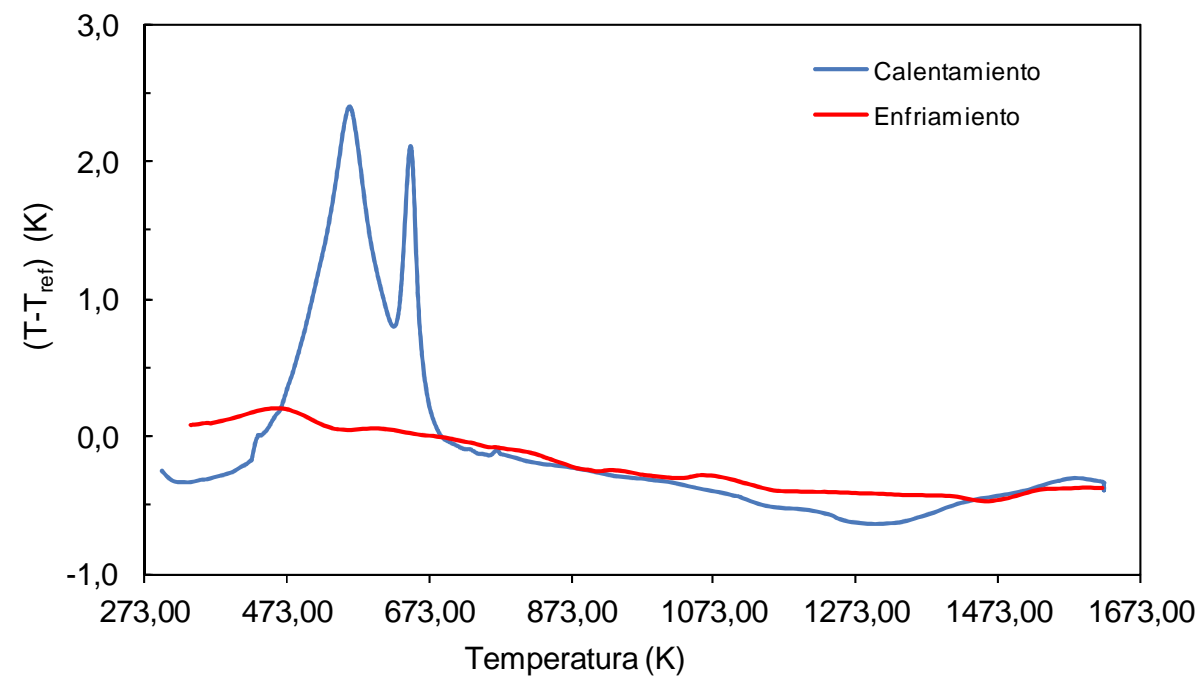

Figura 4.2. Análisis térmico diferencial de la lámina obtenida con la muestra C-I, más aditivos orgánicos. 


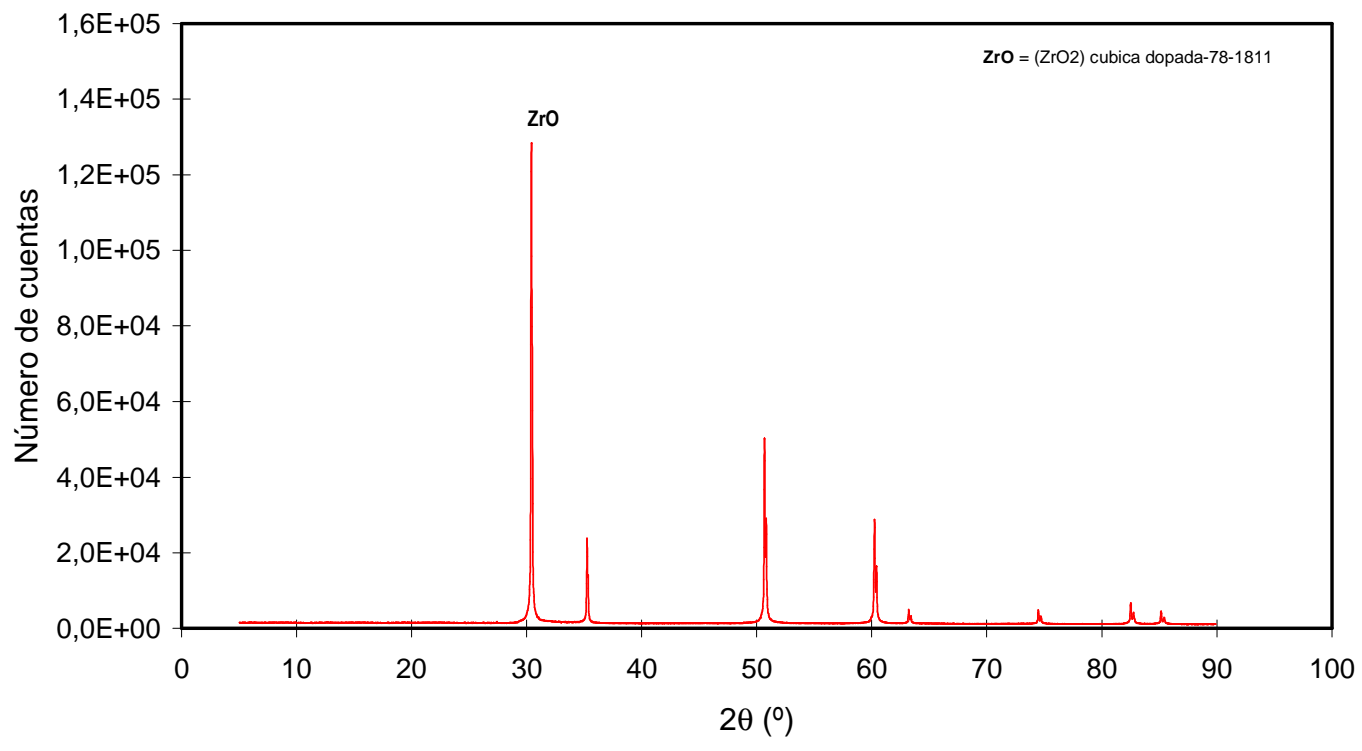

Figura 4.3. Difractograma de la muestra C-I sinterizada a $1773 \mathrm{~K}$ durante 60 minutos.

\subsubsection{Ensayos con el Microscopio de calefacción}

Para contrastar la información suministrada por los ensayos de ATD-TG, se efectuaron ensayos, en un microscopio de calefacción, con una probeta prensada de igual composición que la lámina seca obtenida a partir de la suspensión C-I-15 (Tabla 4.2). En la Figura 4.4 se han representado los resultados obtenidos en la forma Contracción lineal (\%) versus Temperatura.

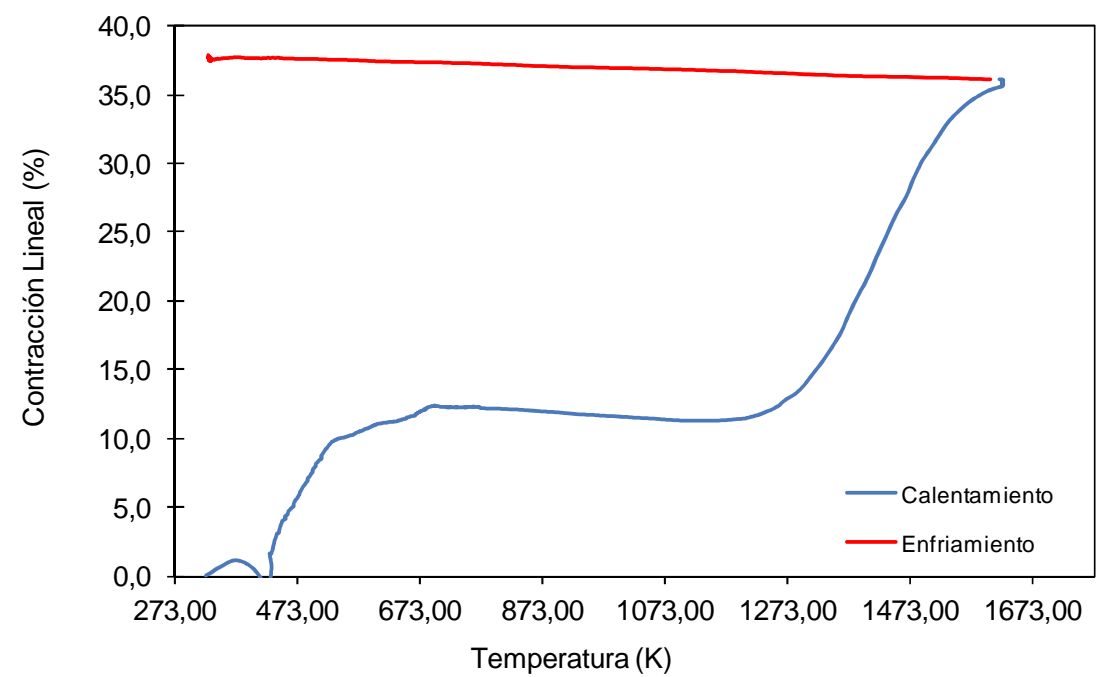

Figura 4.4. Contracción de la probeta preparada con la composición C-I-15 en función de la temperatura. 
Como puede apreciarse, se produce una primera contracción acentuada, como consecuencia de la fase de eliminación de materia orgánica, que alcanza su valor máximo $(8.4 \%)$ a $758 \mathrm{~K}$. Después la contracción se paraliza y la probeta expande ligeramente hasta los $1164 \mathrm{~K}$, temperatura a la que comienza de nuevo a contraer, debido a que se inicia la fase de sinterización, hasta llegar a los $1623 \mathrm{~K}$, a la que se alcanza una contracción del $28.4 \%$.

De los ensayos anteriormente descritos se deduce que la fase de eliminación de los componentes orgánicos contenidos en las muestras secas (tanto láminas coladas, como probetas prensadas) ha terminado entre 723 y $748 \mathrm{~K}$, a la velocidad de calentamiento utilizada $(120 \mathrm{~K} / \mathrm{h})$.

\subsection{Optimización de las suspensiones de circona}

El objetivo de esta parte del trabajo fue preparar una suspensión de la circona (barbotina) elegida que permitiera conformar laminas de dicho material, por colado en banda, con una buena textura y la menor porosidad en crudo posible, a fin de facilitar que durante la etapa de sinterización se pudiera obtener un producto con compacidad muy próxima a la unidad.

La técnica del colado en banda proporciona una superficie lisa, un control preciso de las dimensiones y, si los aditivos están optimizados, una resistencia mecánica, en crudo, adecuada para poder manipular las láminas resultantes ${ }^{73}$. Los componentes imprescindibles en el proceso de colado en banda son: el líquido de partida que sirve de base a la suspensión y de disolvente de los aditivos orgánicos, que en adelante, se denominará "el disolvente", un dispersante, un ligante, plastificantes ${ }^{74} \mathrm{y}$, en algunas ocasiones, un homogeneizador.

Algunos de los factores más importantes a considerar cuando se ha de seleccionar un sistema ligante-dispersante-disolvente son: la compatibilidad química de dichos componentes, la solubilidad del ligante, los aditivos en la fase líquida y la viscosidad de la suspensión. En el colado en banda, se prefiere utilizar una mezcla de dos disolventes a trabajar con un líquido puro, porque la solubilidad de los polímeros es generalmente mayor en un sistema mixto optimizado que en cualquier disolvente ${ }^{75}$. Las características de los disolventes a elegir dependerán de la naturaleza de los aditivos empleados para estabilizar la suspensión y para conferir la resistencia mecánica adecuada a la pieza colada en crudo.

La función del dispersante es mantener las partículas de circona en suspensión estable, habitualmente generando impedimentos estéricos para que las partículas se aproximen ${ }^{76}$. A medida que el disolvente se evapora durante el secado de la banda, el dispersante permite que las partículas se reorganicen para formar una lámina cruda densamente empaquetada.

Los dispersantes más efectivos y conocidos que se utilizan para la circona son el Menhaden fish oil y el éster fosfato; el terpineol se utiliza también como dispersante en tintas de serigrafía $^{77,78,79}$. El uso de estos dispersantes presenta algunos problemas. La composición y el estado de oxidación del Menhaden fish oil varía con la procedencia ${ }^{80}$. El éster fosfato no se piroliza hasta llegar a $1073 \mathrm{~K}$, con el consiguiente alargamiento del tiempo necesario para eliminar la materia orgánica de la pieza colada y, en ocasiones, algo de fósforo residual queda en la pieza que puede reducir significativamente las propiedades eléctricas del producto sinterizado ${ }^{81}$. Además, los ligantes (que son generalmente polímeros de elevada masa molecular) tienen tendencia a adsorberse sobre la superficie de la partícula y, por tanto, a interferir con la adsorción del dispersante ${ }^{81}$. Esta competición en la adsorción de los dos aditivos empeora considerablemente la efectividad de la dispersión y, en consecuencia, la estabilidad de la suspensión.

El ligante se añade a la suspensión para incrementar la adherencia entre las partículas de la pieza colada cruda y, por tanto, su resistencia mecánica a fin de evitar la formación de 
grietas $^{82}$. El poli(vinilbutiral), PVB, es el más comúnmente utilizado para el colado en banda. Su baja velocidad de pirolisis, de hecho, ofrece la ventaja de proporcionarle resistencia durante el periodo de eliminación de materia orgánica (burn-out) ${ }^{81}$. Además, el PVB puede ayudar a mejorar la dispersión de las partículas de circona ${ }^{83,84}$. El PVB es soluble en alcoholes, éteres glicólicos y ciertas mezclas de disolventes polares y apolares.

Los plastificantes son generalmente sustancias orgánicas con una masa molecular menor que la del ligante. La función del plastificante es disminuir la rigidez del ligante cuando se seca la pieza colada (por ejemplo, reducir la $T_{g}$ del ligante), aumentando de este modo la flexibilidad en crudo de la lámina resultante ${ }^{85}$. Para aquellos procesos de conformado en los que el ligante se introduce ya disuelto, el plastificante debe ser soluble en el mismo disolvente utilizado para disolver el ligante. En la pieza cruda, el ligante y el plastificante se encuentran mezclados homogéneamente. Las moléculas de plastificante se introducen entre las cadenas poliméricas del ligante impidiendo que se alineen y reducen la fortaleza del enlace de van der Waals entre cadenas adyacentes, produciendo el reblandecimiento del ligante. Ahora bien, por el contrario reduce la resistencia mecánica ${ }^{86}$.

Siguiendo el procedimiento recomendado en la bibliografía ${ }^{79,82}$, la suspensión conviene prepararla en dos etapas, debido a la adsorción competitiva del dispersante y del ligante sobre las partículas de la muestra sólida. En una primera etapa, se añade el dispersante al disolvente, seguido por la circona. La suspensión se moltura en un molino de bolas durante $6 \mathrm{~h}$ para romper los aglomerados débiles. Entonces se añade el ligante y los plastificantes y se sigue molturando durante $18 \mathrm{~h}$ más.

Tras desairear la suspensión a vacío y antes de colar en banda, se controlaba su viscosidad aparente. En principio, cuando más bajo es el valor de la viscosidad aparente mayor grado de desaglomeración ${ }^{87}$ y estabilidad cabe esperar para la suspensión. Por otra parte, conviene que la concentración de sólidos en la suspensión sea lo más alta posible, para obtener piezas suficientemente compactas ya que, cuanto mayor sea su densidad menor será la contracción final de las mismas.

La viscosidad de la suspensión debe ser lo más baja posible para proporcionarle un flujo fácil en la cuchilla del dispositivo de colado ${ }^{88}$. Es importante controlarla, puesto que es de esperar que una baja viscosidad se traduzca en un menor espesor de la capa colada. Hay que tener en cuenta, sin embargo, que la viscosidad es una propiedad compleja, y a menos que el fluido tenga un comportamiento newtoniano, no es constante y depende de la velocidad de deformación. En el caso de consignar un único valor de la viscosidad aparente, a los efectos de establecer comparaciones, éste debería ser el correspondiente al gradiente de velocidad de $100 \mathrm{~s}^{-1}$ que es el que se considera más representativo para la operación de conformado por colado en banda ${ }^{89}$.

Una vez se obtiene la lámina colada, se deja secar en la misma mesa de colado. La etapa de secado es crítica porque cualquier defecto que aparezca en una lámina seca (grietas, pinchados, huellas, etc.), se reflejará posteriormente en la pieza sinterizada. Además, las láminas secas deben conservarse completamente planas sin que aparezca ninguna curvatura en los bordes. Cuando una lámina colada, en seco, tiene buen aspecto superficial, normalmente no presenta ningún defecto tras las etapas de descomposición térmica de aditivos orgánicos y de sinterización. Por tanto, la primera caracterización a realizar de las piezas coladas debe ser visual. Las láminas secas, además de ser completamente planas, deben estar exentas de defectos superficiales, tales como: poros, balsitas, pinchados, cráteres, pequeños cuarteos, etc.

Con todas las suspensiones ensayadas, se han obtenido láminas crudas, pero sólo las láminas en las que no se apreciaba visualmente defectos se han cortado en piezas y se han tratado térmicamente. Dicho tratamiento térmico consistió en desarrollar, en primer lugar, la etapa de eliminación de materia orgánica a una velocidad de calentamiento de $120 \mathrm{~K} / \mathrm{h}$, hasta alcanzar los $773 \mathrm{~K}$, temperatura a la que, según los ensayos de ATD-TG y la curva de 
contracción lineal-temperatura obtenidas en el Apartado 4.1, se debía haber eliminado completamente la materia orgánica contenida inicialmente en las muestras. Tras esta fase se realizaba una segunda inspección visual de la calidad de la lámina terminada, desechando las que se consideraban inadecuadas. Las piezas que habían mantenido la planaridad y la textura sin agrietarse, se sometían a otro tratamiento térmico a la misma velocidad de calentamiento hasta alcanzar los 1623 ó 1673 K. Finalmente se volvían a valorar visualmente, seleccionando las que parecían más adecuadas para la realización de la tercera fase de sinterización.

\subsubsection{Ensayos utilizando una mezcla de metil etil cetona e isopropanol como disolvente}

\subsubsection{Ensayos realizados utilizando terpineol como dispersante}

Maitia y Rajenderb ${ }^{90}$, utilizando una mezcla de metil etil cetona (MEK) e isopropanol (ISOPROL) como disolvente, propusieron la utilización de terpineol, como dispersante, para el colado de suspensiones de polvo de circona estabilizada con itria. Según estos investigadores, las láminas coladas, obtenidas utilizando este componente como dispersante, tenían una densidad más alta, tanto en crudo como después de sinterizadas, que las obtenidas empleando MFO o éster fosfato como dispersantes. Además, el uso de terpineol requería menos proporción de ligante y conducía a láminas más flexibles en seco.

En consecuencia, se decidió realizar los primeros ensayos con suspensiones de polvo de la muestra $\boldsymbol{C}$-I, utilizando como disolvente una mezcla no azeotrópica de MEK e ISOPROL, en proporción 60:40 en masa, y terpineol como dispersante. A la suspensión así preparada se añadía, en una segunda etapa, DBT y PEG 400, como plastificantes y PVB como ligante.

La composición de las suspensiones preparadas se detalla en la Tabla 4.1. En dicha tabla, $\mathrm{w}_{\mathrm{Zr}}$ es la fracción másica de circona dopada (Composición $\boldsymbol{C}$-I) en la suspensión.

\begin{tabular}{|c|c|c|c|c|c|c|c|c|}
\hline Suspensión & $\mathbf{w}_{\mathrm{zr}}$ & $\begin{array}{c}\text { MEK } \\
(\mathrm{g})\end{array}$ & $\begin{array}{c}\text { ISOPR. } \\
\text { (g) }\end{array}$ & $\begin{array}{l}C-I \\
(\mathrm{~g})\end{array}$ & $\begin{array}{l}\text { Terpin. } \\
\text { (g) }\end{array}$ & $\begin{array}{c}\text { DBT } \\
(\mathrm{g})\end{array}$ & $\begin{array}{c}\text { PEG } \\
400 \\
(\mathrm{~g})\end{array}$ & $\begin{array}{l}\text { PVB } \\
\text { (g) }\end{array}$ \\
\hline$C-I-1$ & 0.65 & 19.3 & 12.6 & 100 & 2.8 & 10.7 & 4.8 & 4.0 \\
\hline$C-1-2$ & 0.61 & 22.4 & 14.6 & 100 & 4.0 & 12.0 & 6,1 & 5.0 \\
\hline$C-I-3$ & 0.60 & 22.4 & 14.6 & 100 & 4.0 & 13.0 & 7.0 & 5.0 \\
\hline
\end{tabular}

El aspecto de las capas coladas obtenidas se representa en la Figura 4.5.

La lámina resultante del colado de la suspensión $\mathbf{C}$-I-1 presentaba grietas en crudo, antes de secarse, por lo que se decidió disminuir su contenido en circona y aumentar el contenido en terpineol, plastificantes y ligante. 
La lámina cruda obtenida a partir de la suspensión $\mathbf{C}$-I-2 había mejorado en lo que a textura se refiere, aunque estaba ligeramente curvada. Al secarla presentó grietas.
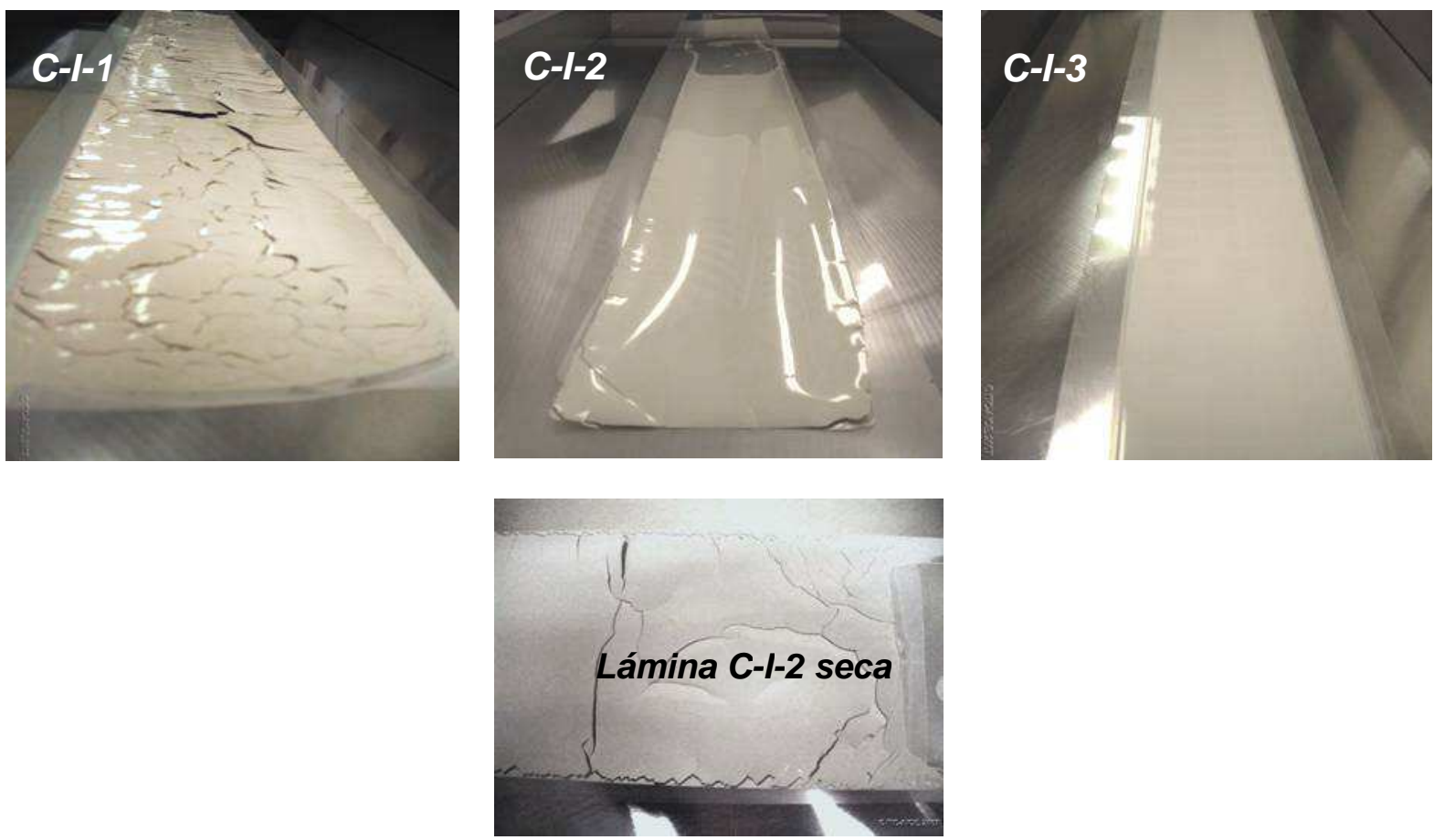

Figura 4.5. Aspecto de las láminas crudas obtenidas por colado de las suspensiones C-I-1 a C-I-3.

Finalmente se ensayó con una suspensión (C-I-3) algo más rica en plastificantes. En este caso la lámina colada estaba exenta de defectos apreciables visualmente tanto en crudo como seca. Al tratarla térmicamente para eliminar la materia orgánica se formaron varias grietas (Figura 4.6).

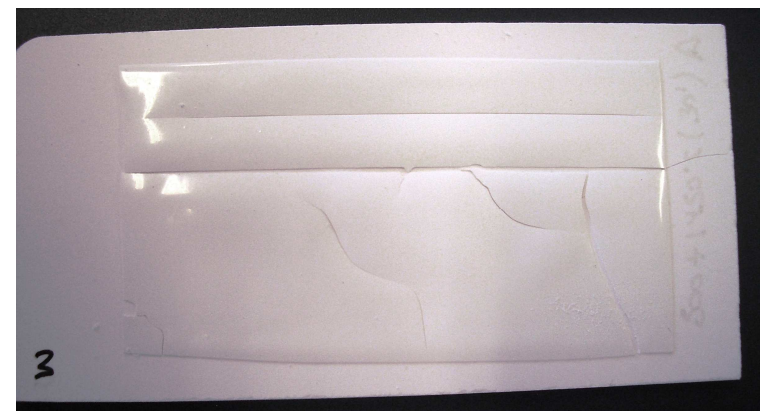

Figura 4.6. Aspecto de la lámina resultante de la suspensión C-I-3 tras la eliminación de la materia orgánica.

A fin de comprobar si el dispersante utilizado no era el más adecuado, se preparó una suspensión, conteniendo como único aditivo el dispersante, en la misma proporción que en la suspensión $\mathbf{C}-\mathbf{I}-\mathbf{3}$, y otra conteniendo todos los aditivos antes descritos para dicha 
suspensión. Con una y otra se moldearon sendas láminas coladas que se desecaron, observando su microestructura por MEB. Los resultados se muestran en las Figuras 4.7 y 4.8.
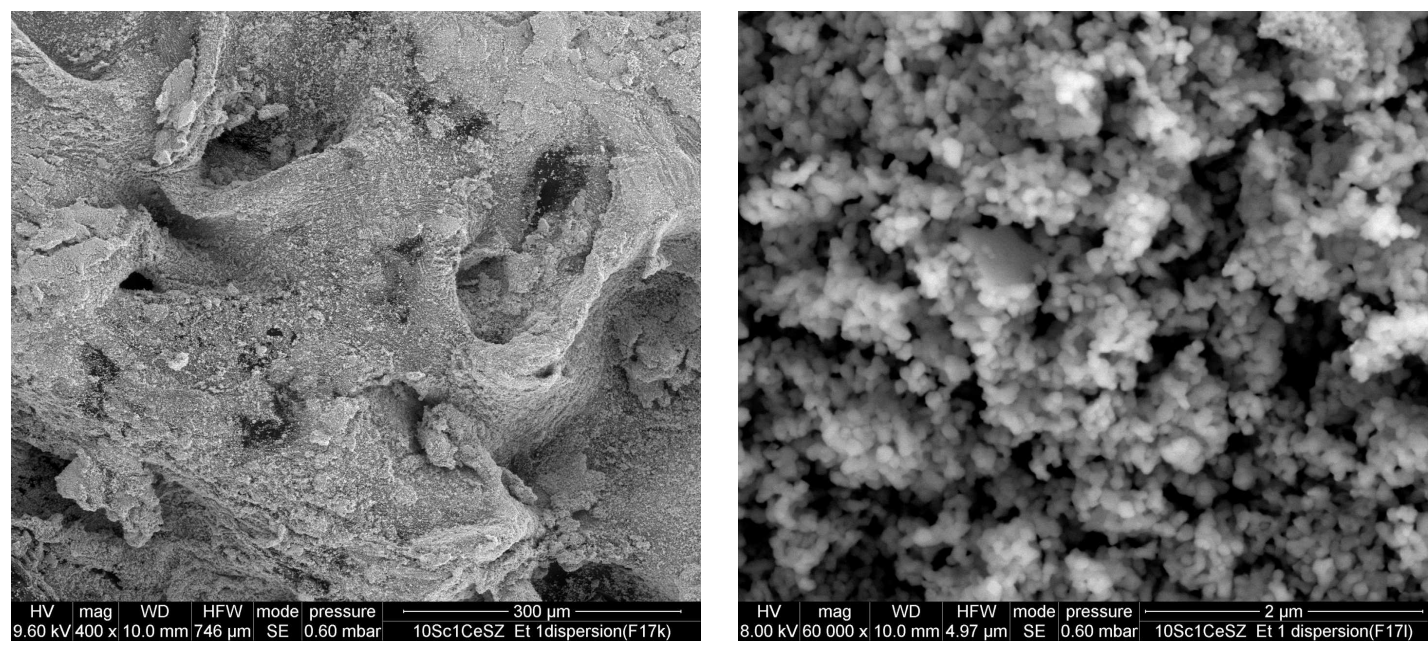

Figura 4.7. Microestructura de la lámina seca obtenida de la suspensión conteniendo terpineol como único aditivo.
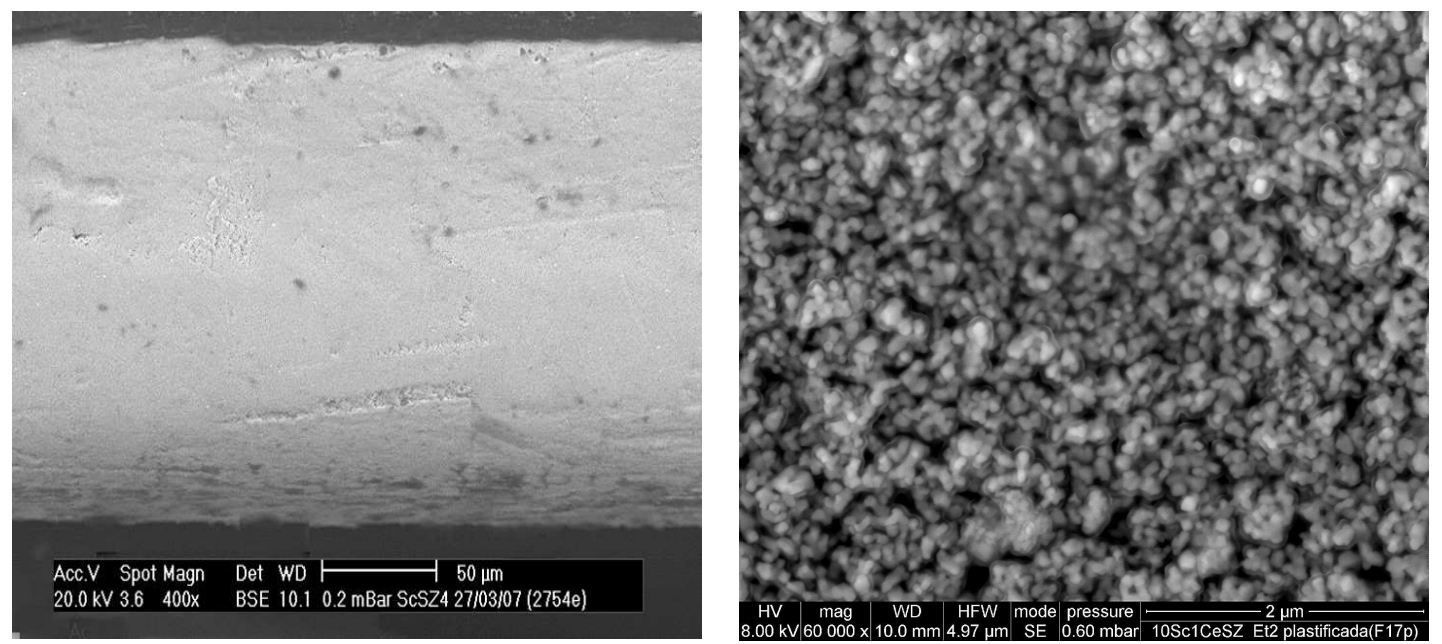

Figura 4.8. Microestructura de la lámina seca obtenida de la suspensión C-I-3.

Como puede apreciarse la lámina seca resultante del colado de la suspensión cuyo único aditivo era el terpineol presenta una considerable porosidad, con poros cuyo tamaño oscila entre unos $2 \mu \mathrm{m}$ hasta $300 \mu \mathrm{m}$. En cambio, la lámina resultante del colado de la suspensión $\boldsymbol{C}-\mathbf{I}-\mathbf{3}$, sólo presenta poros de pequeño tamaño. 
Esta diferencia entre las microestructuras de las dos láminas parecía indicar que el terpineol no era el dispersante idóneo para las suspensiones de polvo de la muestra $\boldsymbol{C}$ - $\boldsymbol{I}$ y que era posible que el plastificante o el ligante pudieran estar actuando, en parte, también como desfloculantes de las partículas de circona. En consecuencia, se decidió modificar el dispersante para tratar de mejorar la calidad de las láminas coladas en seco, antes de proceder a desarrollar la fase de sinterización.

\subsubsection{Ensayos realizados utilizando Menhanden Fish Oil de Aldritch (MFO) como dispersante.}

Según varias referencias localizadas en la revisión bibliográfica ${ }^{91,92,93,94}$ otro dispersante que había resultado efectivo para suspensiones de circona era el aceite de pescado (menhaden fish oil, MFO).

Utilizando este producto como agente dispersante, se realizó un primer ensayo tomando como composición de partida la de la suspensión $\boldsymbol{C}$-I-3, pero sustituyendo el terpineol por MFO (Suspensión C-I-4, Tabla 4.2).

\begin{tabular}{|c|c|c|c|c|c|c|c|c|}
\hline Suspensión & $w_{z r}$ & $\begin{array}{c}\text { MEK } \\
(\mathrm{g})\end{array}$ & $\begin{array}{c}\text { ISOPR. } \\
\text { (g) }\end{array}$ & $\begin{array}{l}C-I \\
(\mathrm{~g})\end{array}$ & $\begin{array}{c}\text { MFO } \\
(\mathrm{g})\end{array}$ & $\begin{array}{c}\text { DBT } \\
\text { (g) }\end{array}$ & $\begin{array}{c}\text { PEG } \\
400 \\
(\mathrm{~g})\end{array}$ & $\begin{array}{c}\text { PVB } \\
\text { (g) }\end{array}$ \\
\hline$C-I-4$ & 0,60 & 22,4 & 14,6 & 100 & 4,0 & 13,0 & 7,0 & 5,0 \\
\hline$C-I-5$ & 0,58 & 26,0 & 16,9 & 100 & 4,0 & 13,0 & 7,0 & 5,0 \\
\hline$C-I-6$ & 0,51 & 40,4 & 26,3 & 100 & 4,0 & 3,7 & 7,0 & 16,0 \\
\hline$C-I-7$ & 0,51 & 40,4 & 26,3 & 100 & 4,0 & 2,7 & 7,0 & 17,0 \\
\hline$C-I-8$ & 0,51 & 44,8 & 29,2 & 100 & 4,0 & 2,6 & 1,3 & 20,0 \\
\hline$C-I-9$ & 0,49 & 42,1 & 27,4 & 100 & 4,0 & 2,7 & 7,0 & 20,0 \\
\hline$C-I-10$ & 0,47 & 49,6 & 32,3 & 100 & 4,0 & 2,7 & 7,0 & 15,0 \\
\hline$C-I-11$ & 0,47 & 49,6 & 32,3 & 100 & 4,0 & 2,7 & 7,0 & 17,0 \\
\hline$C-I-12$ & 0,46 & 51,6 & 33,6 & 100 & 4,0 & 2,7 & 7,0 & 20,0 \\
\hline$C-I-13$ & 0,45 & 51,6 & 33,6 & 100 & 4,0 & 2,7 & 7,5 & 21,0 \\
\hline$C-I-14$ & 0,45 & 53,7 & 35,0 & 100 & 4,0 & 2,7 & 7,0 & 20,0 \\
\hline$C-I-15$ & 0,43 & 60,6 & 39,4 & 100 & 4,0 & 2,7 & 7,0 & 20,0 \\
\hline$C-I-16$ & 0,43 & 60,6 & 39,4 & 100 & 4,0 & 2,7 & 7,5 & 20,0 \\
\hline$C-I-17$ & 0,41 & 68,3 & 44,5 & 100 & 4,0 & 2,7 & 7,0 & 15,0 \\
\hline
\end{tabular}


Con la suspensión $\boldsymbol{C}$-I-4 se obtenía una lámina colada en crudo aceptable pero al secarla presentaba pinchados (Figura 4.9).

El problema se intentó resolver aumentando el contenido en disolvente (suspensión C-I5). En este caso la lámina colada tenía buen aspecto, tanto en crudo como en seco, pero al someterla a la fase de eliminación de los aditivos orgánicos se agrietaba.

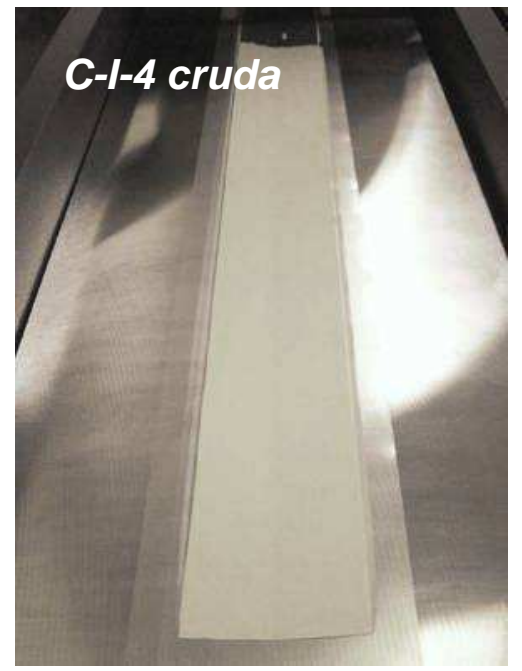

\section{C-I-4 seca}
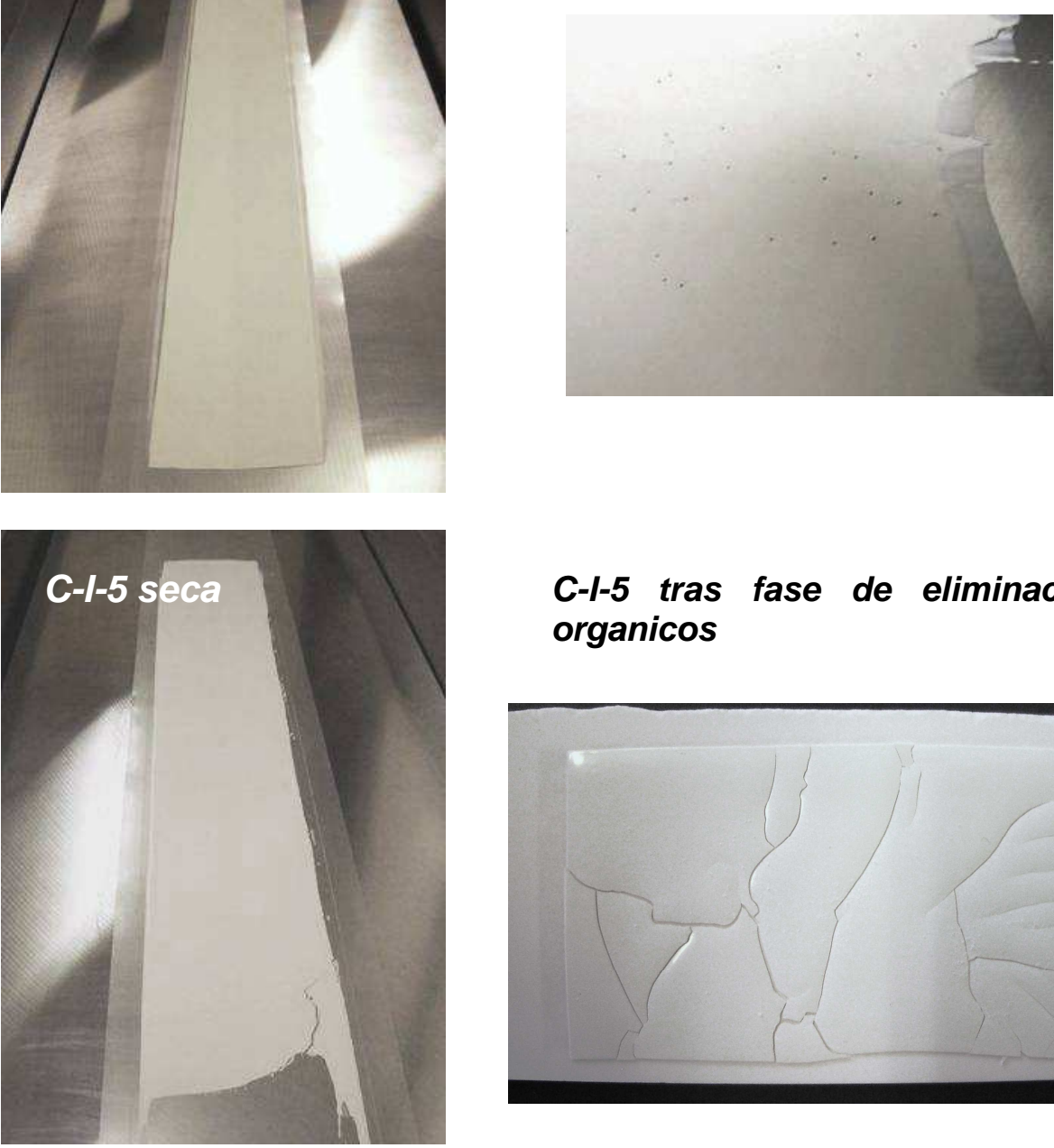

\section{C-I-5 tras fase de eliminación organicos}

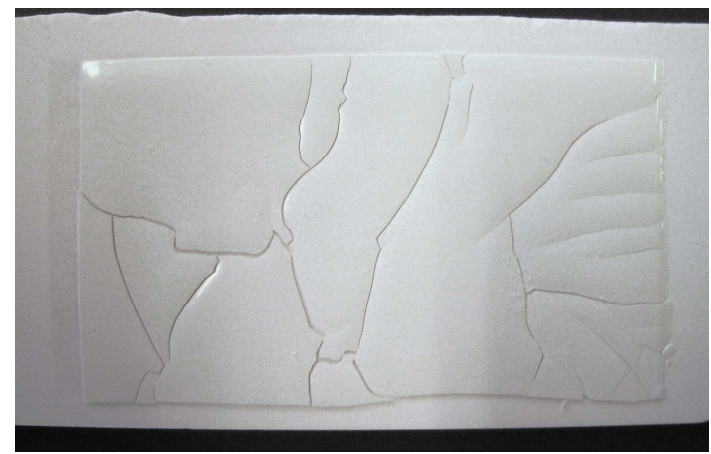

Figura 4.9. Aspecto de las láminas obtenidas con las suspensiones C-I-4 y C-I-5.

Seguidamente se ensayó aumentar el contenido en ligante (PVB) y disminuir el contenido en plastificante (DBT) de la suspensión (Suspensión C-I-6). Asimismo se aumentó progresivamente la proporción de disolvente para obtener suspensiones más diluidas en $\boldsymbol{C}$-I, a fin de compensar el aumento de valor de la viscosidad aparente de la misma que se produciría al aumentar la proporción de PVB.

En las Figuras 4.10 y 4.11 se ha representado, para cada una de las suspensiones ensayadas, la variación de la viscosidad aparente frente al gradiente de velocidad. 


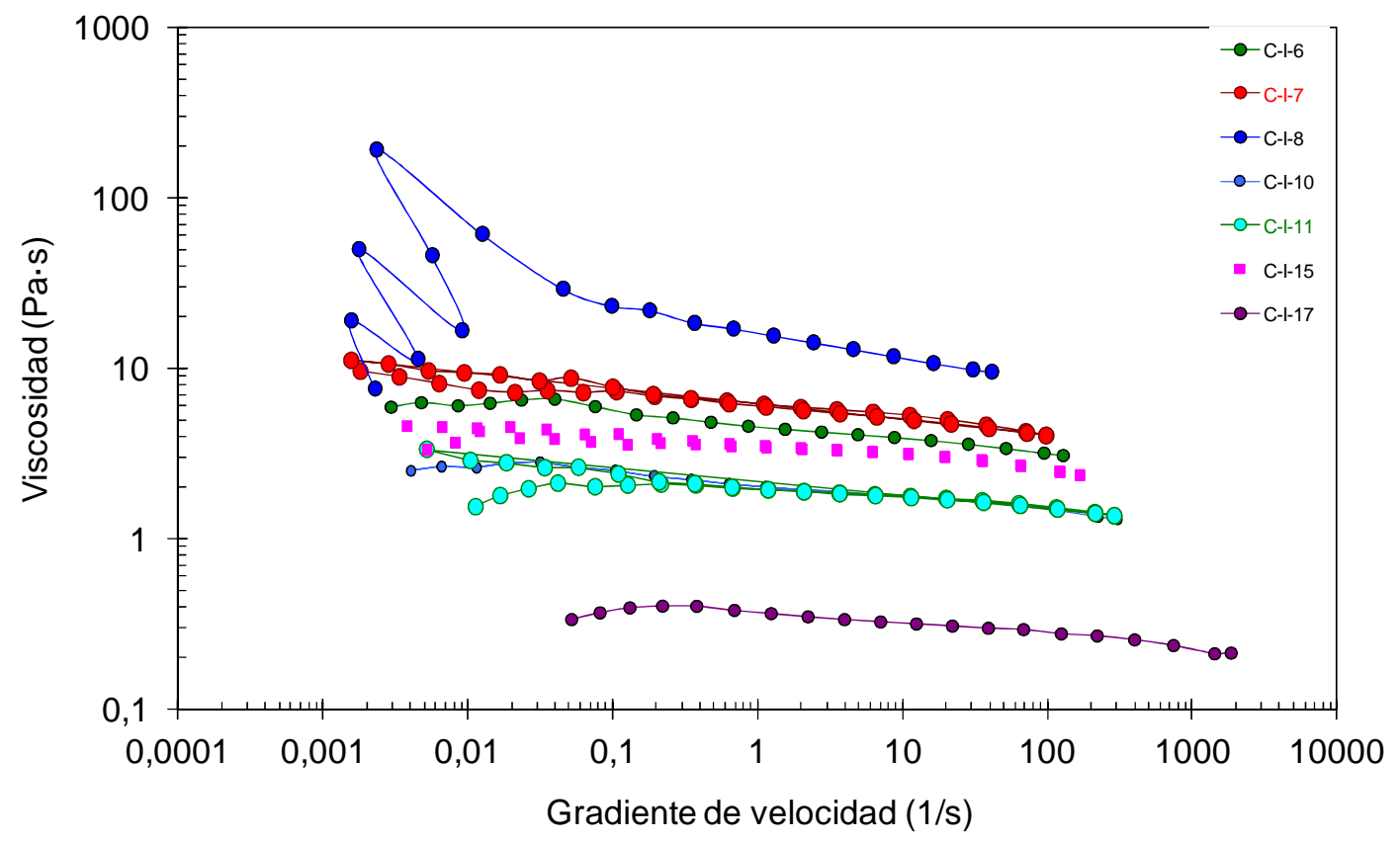

Figura 4.10. Variación de la viscosidad aparente de las suspensiones ensayadas con el gradiente de velocidad.

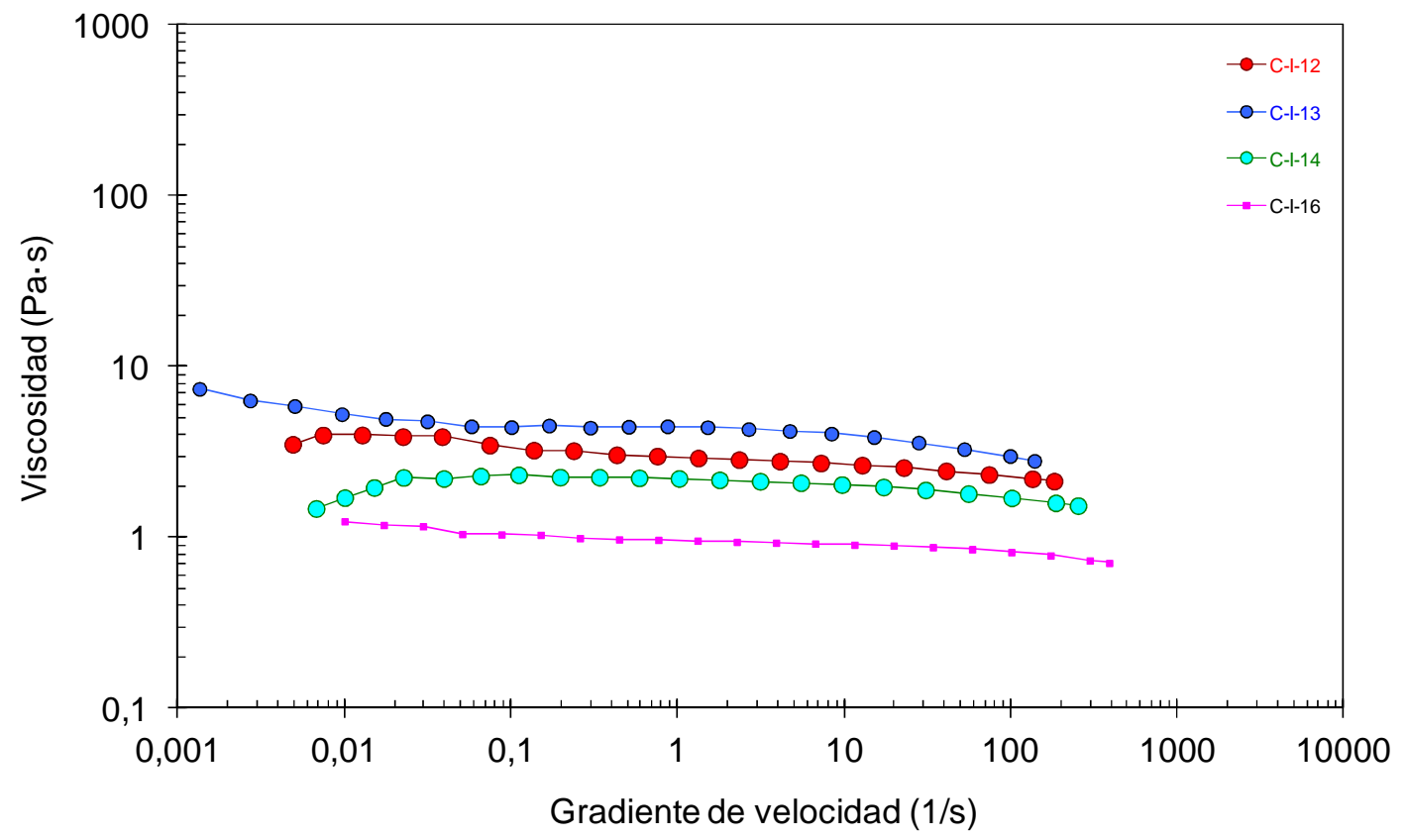

Figura 4.11. Variación de la viscosidad aparente de las suspensiones ensayadas con el gradiente de velocidad. 
En las Tablas 4.3 y 4.4 se muestra el valor de la viscosidad cinemática aparente correspondiente a un gradiente de velocidad de $100 \mathrm{~s}^{-1}\left(\boldsymbol{\eta}_{100}\right)$ de cada una de las suspensiones que se detallan en la Tabla 4.2. Siguiendo las recomendaciones de ciertos autores $^{95,96,97}$, las suspensiones ensayadas se prepararon procurando que el valor de su viscosidad aparente, para un gradiente de velocidad de $100 \mathrm{~s}^{-1}$, se mantuviera dentro del intervalo de 1 a 4 Pa.s. o muy próximo.

\begin{tabular}{|c|c|c|}
\hline Suspensión & $\eta_{100}($ Pa.s) & Aspecto visual de la lámina en crudo \\
\hline$C-I-6$ & 3,35 & Lisa con pliegue en borde \\
\hline$C-I-7$ & 4,26 & Algunos pliegues \\
\hline$C-I-8$ & 8,02 & Totalmente doblada: convexa \\
\hline$C-I-9$ & 5,40 & Lisa con pliegues en los bordes \\
\hline$C-I-10$ & 1,55 & Algo convexa; muchos pliegues \\
\hline$C-I-11$ & 1,54 & Lisa, se levantan los bordes \\
\hline$C-I-12$ & 2,38 & Lisa; muy ligero alzamiento del borde \\
\hline
\end{tabular}

En las fotos de las Figuras 4.12 y 4.13 puede apreciarse el aspecto visual de cada una de las suspensiones preparadas, lo que da una idea cualitativa de la calidad de las mismas. Asimismo, en la última columna de las Tablas 4.3 y 4.4 se hace un breve comentario sobre dicho aspecto.

De dichas figuras y comentarios se deduce que, de las suspensiones ensayadas, sólo las $\boldsymbol{C}$ I-12 a $\boldsymbol{C}$-I-16, conteniendo una fracción másica de $\boldsymbol{C}$-I comprendida entre 0,43 y 0,46 y un contenido en PVB del orden de $20 \mathrm{~g}$, de MFO de $4 \mathrm{~g}$, de DBT de 2,7 $\mathrm{g}$ y de PEG de $7 \mathrm{~g}$, por cada $100 \mathrm{~g}$ de $\boldsymbol{C}-\boldsymbol{I}$, fueron las que condujeron a laminas coladas, en crudo y en seco, homogéneas y sin defectos. 

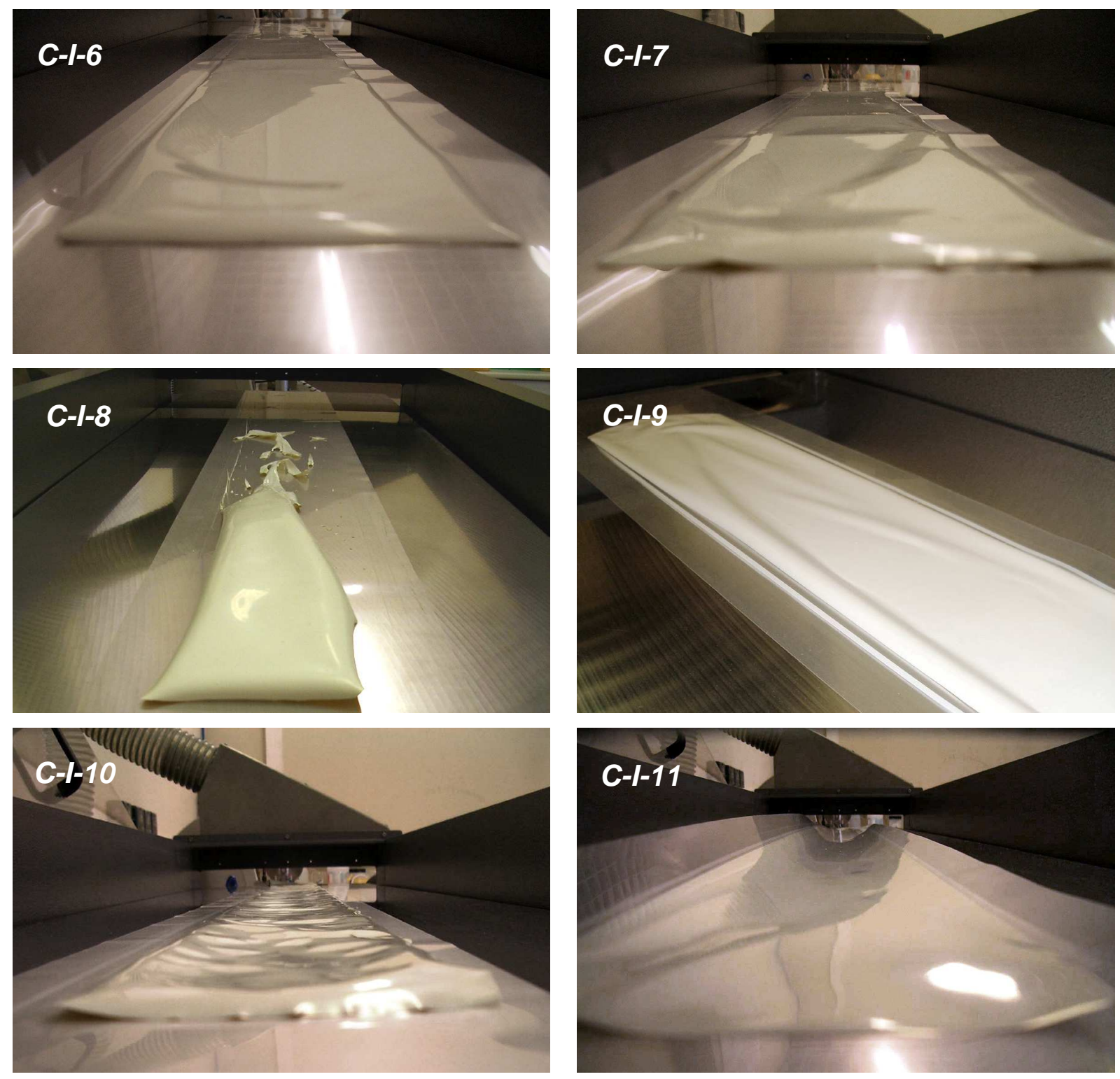

Figura 4.12. Aspecto visual de las láminas coladas, en crudo, obtenidas a partir de las suspensiones C-I-6 a C-I11. 

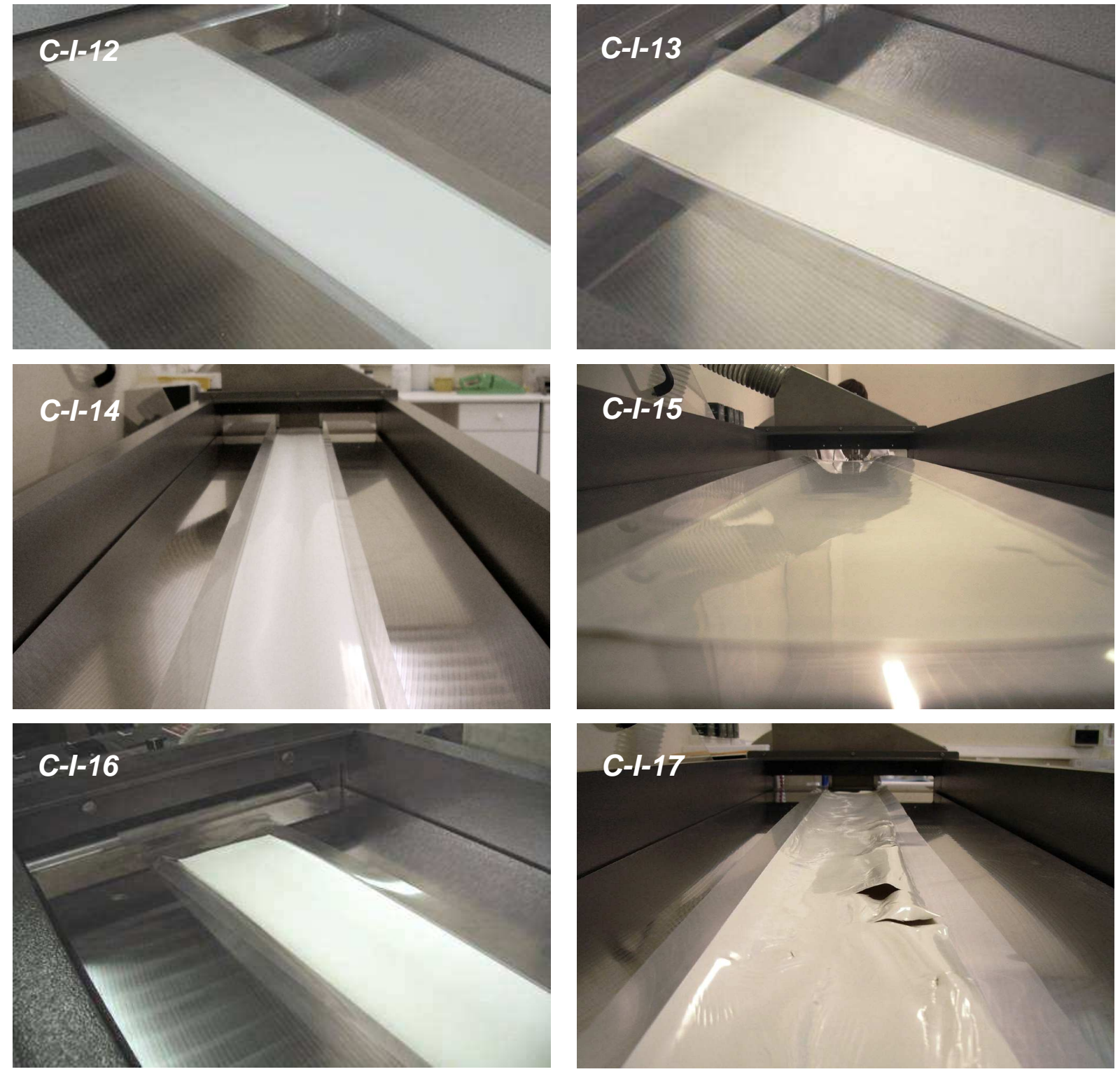

Figura 4.13. Aspecto visual de las láminas coladas, en crudo, obtenidas a partir de las suspensiones C-I-12 a CI-17.

Tras someter las láminas correspondientes a las suspensiones $\boldsymbol{C}$-I-12 a $\boldsymbol{C}$-I-16 a las fases de tratamiento térmico, en la forma indicada anteriormente para eliminar componentes orgánicos y para sinterizarlas, se obtuvieron las piezas cuyo aspecto se representa en la Figura 4.14. De su aspecto se concluyó que la lámina resultante del colado de la suspensión C-I-12 debía desecharse, ya que la pieza resultante de su tratamiento térmico estaba agrietada. 
Tabla 4.4. Valor de $\eta_{100}$ de las suspensiones $C-I-13$ a $C$-I-17 y aspecto visual de las respectivas láminas coladas en crudo

\begin{tabular}{ccl} 
Suspensión & $\eta_{100}($ Pa.s) & \multicolumn{1}{c}{ Aspecto visual de la lámina en crudo } \\
\hline $\boldsymbol{C}-I-13$ & 3,04 & Lisa; muy ligero alzamiento del borde \\
$\boldsymbol{C}-\mathrm{I}-14$ & 1,88 & Lisa; muy ligero alzamiento del borde \\
$\boldsymbol{C}-\mathrm{I}-15$ & 0,95 & Lisa; muy ligero alzamiento del borde \\
$\boldsymbol{C}-\mathrm{I}-16$ & 0,79 & Lisa; bordes más alzados \\
$\boldsymbol{C}-\boldsymbol{I - 1 7}$ & 0,27 & Pliegues y roturas \\
\hline
\end{tabular}

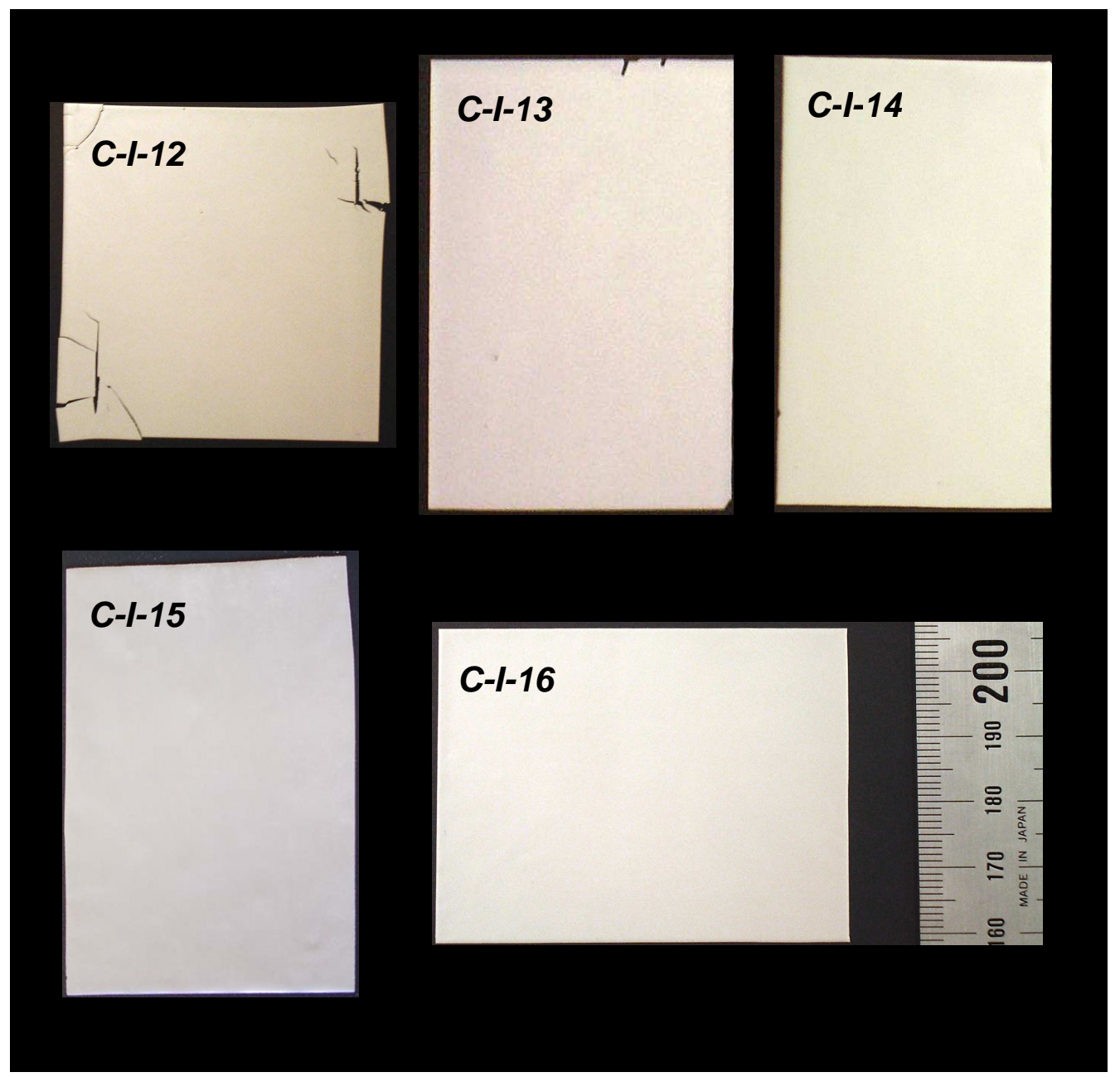

Figura 4.14. Aspecto de las piezas sinterizadas obtenidas por tratamiento térmico de las láminas coladas. 


\subsubsection{Efecto de la proporción de dispersante (MFO).}

Para estudiar la posible influencia de la proporción de dispersante se prepararon tres nuevas suspensiones, aumentando la proporción de MFO de 4 a $8 \mathrm{~g}$ por cada $100 \mathrm{~g}$ de $\boldsymbol{C}$-I. La composición de las suspensiones preparadas se muestra en la Tabla 4.5, junto con la de la C-I-14, ya estudiada.

El aspecto visual de las láminas coladas crudas se muestra en la Figura 4.15. Como puede apreciarse no presentan ninguna diferencia significativa respecto a la lámina colada obtenida a partir de la suspensión $\boldsymbol{C}-\mathbf{I - 1 4}$.

\begin{tabular}{cccccccccc}
\hline \multicolumn{10}{|c|}{ Tabla 4.5. Composiciones de las suspensiones conteniendo distinta proporción de } \\
MFO
\end{tabular}
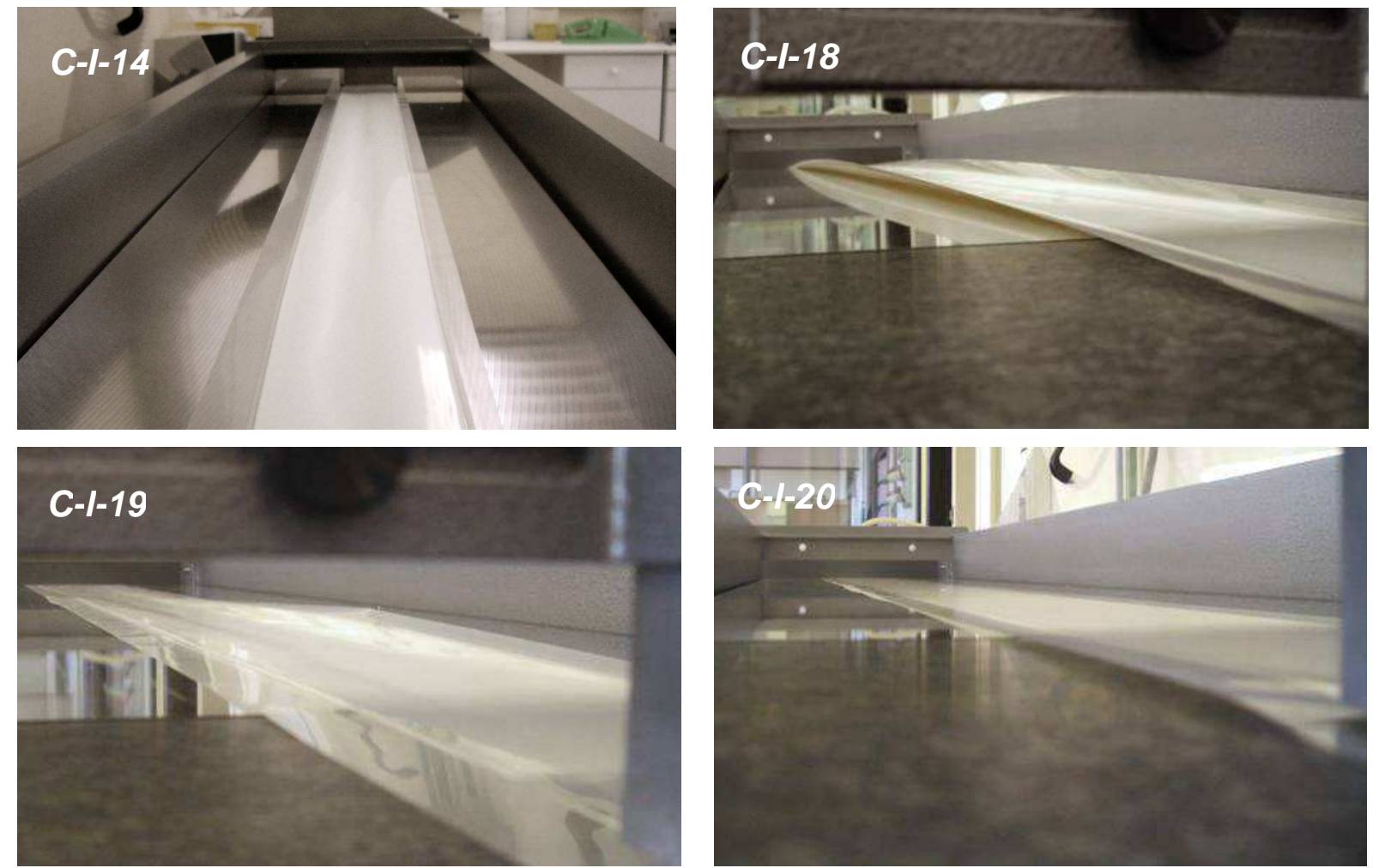

Figura 4.15. Aspecto de las láminas coladas, en crudo obtenidas variando la proporción de MFO. 
En la Figura 4.16 se ha representado, para cada una de las suspensiones ensayadas, la variación de la viscosidad aparente frente al gradiente de velocidad.

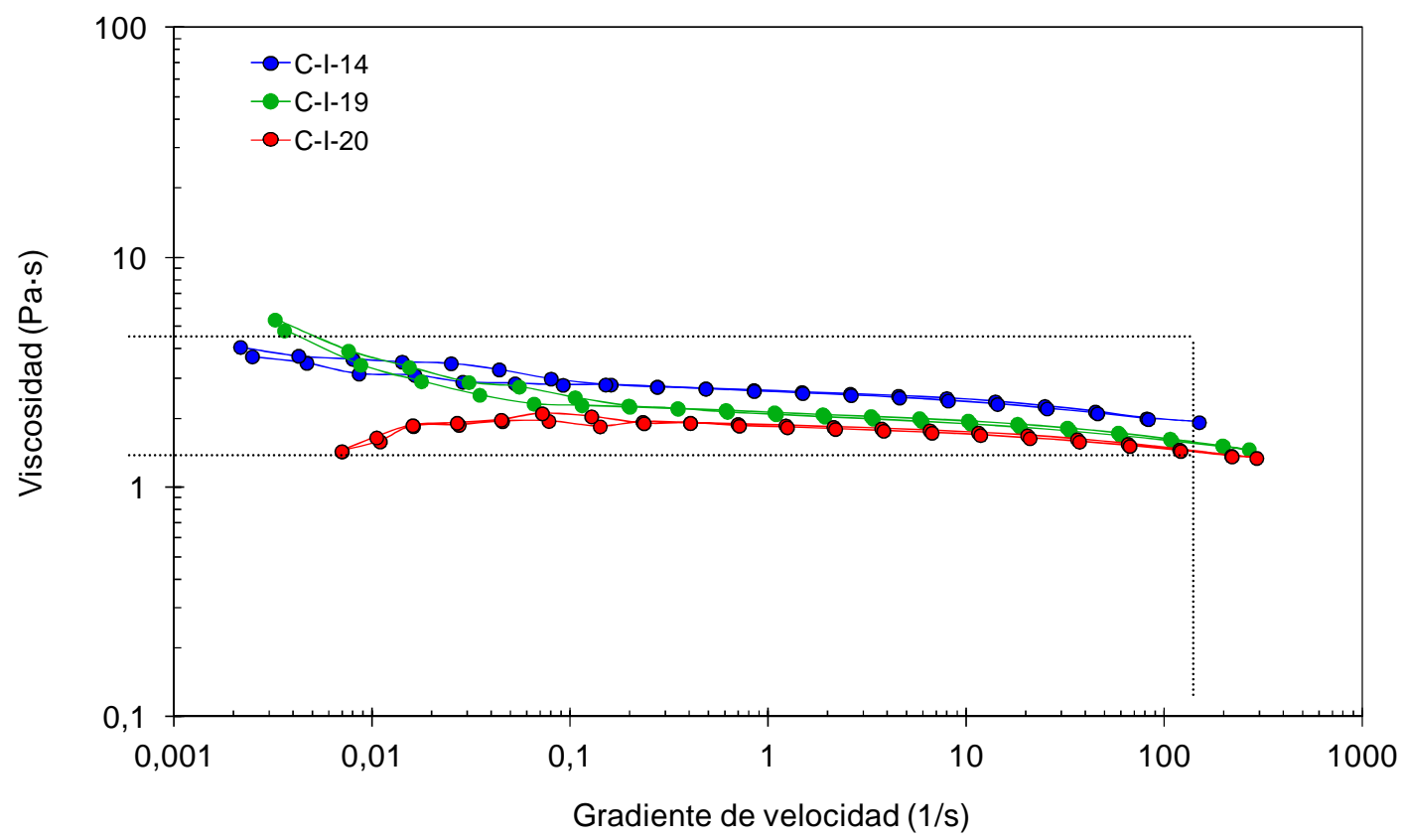

Figura 4.16. Evolución de la viscosidad de las suspensiones tras la etapa II de preparación, al modificar la proporción de MFO añadido.

En la Tabla 4.6 se muestra el valor de $\eta_{100}$ de las suspensiones estudiadas y se comenta el aspecto de la lámina colada a partir de cada una de ellas (Figura 4.16), así como el de dichas láminas después de eliminar la materia orgánica y sinterizarlas a $1673 \mathrm{~K}$, durante $6 \mathrm{~h}$.

\begin{tabular}{ccc}
\hline Tabla 4.6. Valor de $\eta_{100}$ de las suspensiones $C$-I-14 y $C-I-18$ a $C-I-20$ y aspecto visual de \\
las respectivas láminas coladas en crudo y en cocido
\end{tabular}

Al comparar el aspecto de las láminas sinterizadas (Figura 4.17) se aprecia que el aumento de la proporción de MFO, por encima de 4,5 g MFO/100 g de $\boldsymbol{C}$-I, conduce a obtener láminas sinterizadas agrietadas y recogidas $(\boldsymbol{C}-\mathbf{I - 1 9})$ o que se pegan al soporte refractario (C-I-20). En consecuencia se decidió utilizar valores de la relación másica $\mathrm{MFO} / \boldsymbol{C}-\boldsymbol{I}$, del orden de 4-4,5 g de MFO/100 g de $\boldsymbol{C}$-I pues, por los resultados obtenidos, no está justificado 
el empleo de una mayor proporción de dicho componente que, además de aumentar la proporción de materia orgánica en la lámina colada, supondría un aumento del coste de materias primas.

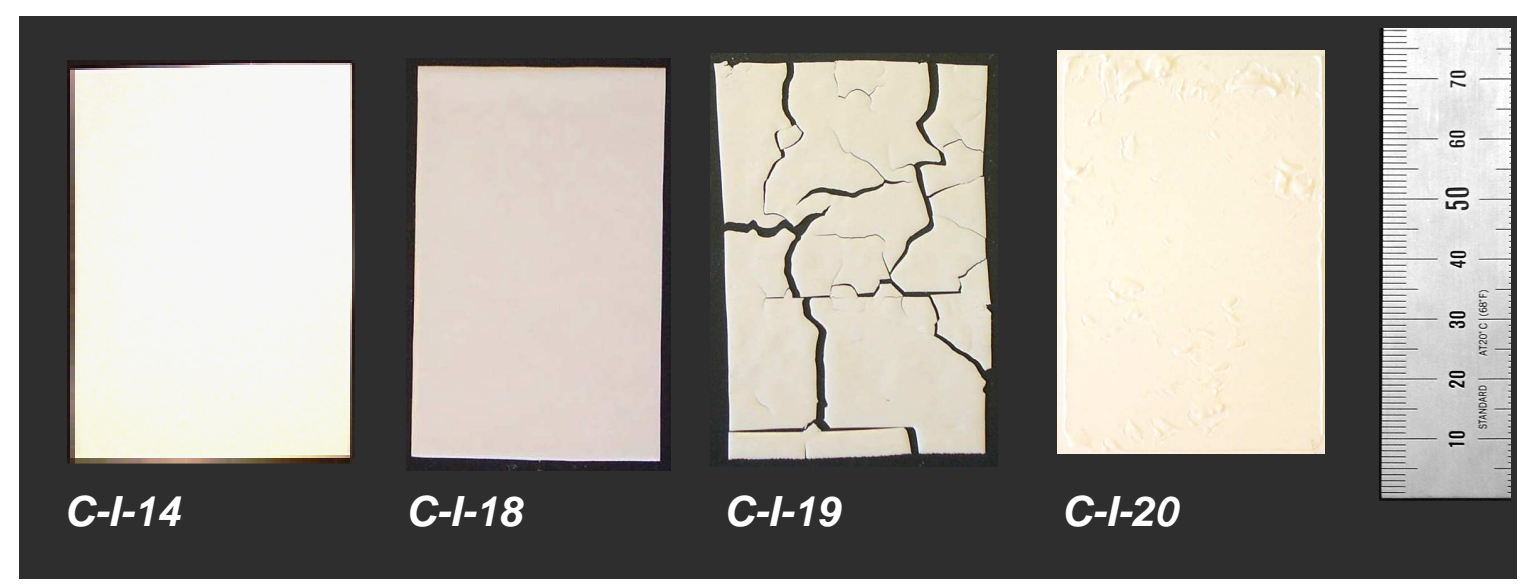

Figura 4.17. Aspecto de las láminas sinterizadas obtenidas variando la proporción de MFO.

\subsubsection{Efecto de la relación MEK/Isopropanol en el disolvente.}

A fin de comprobar la influencia de la composición del disolvente sobre la calidad de las láminas coladas, se prepararon tres suspensiones con aproximadamente el mismo contenido en $\boldsymbol{C}-\boldsymbol{I}$, pero modificando las proporciones de MEK e isopropanol en la mezcla. La Tabla 4.7 detalla la composición de las suspensiones y la Figura 4.18 muestra el aspecto de las capas coladas en crudo.

\begin{tabular}{|c|c|c|c|c|c|c|c|c|}
\hline Suspensión & $\mathbf{w}_{\mathbf{Z r}}$ & $\begin{array}{c}\text { MEK } \\
\text { (g) }\end{array}$ & $\begin{array}{c}\text { ISOPR. } \\
\text { (g) }\end{array}$ & $\begin{array}{l}C-I \\
(\mathrm{~g})\end{array}$ & $\begin{array}{l}\text { MFO } \\
\text { (g) }\end{array}$ & $\begin{array}{c}\text { DBT } \\
\text { (g) }\end{array}$ & $\begin{array}{c}\text { PEG } \\
400 \\
(\mathrm{~g})\end{array}$ & $\begin{array}{l}\text { PVB } \\
\text { (g) }\end{array}$ \\
\hline$C-I-14$ & 0,45 & 53,7 & 35,0 & 100 & 4 & 2,7 & 7 & 20 \\
\hline$C-I-21$ & 0,45 & 61,3 & 27,4 & 100 & 4 & 2,7 & 7 & 20 \\
\hline$C-I-22$ & 0,45 & 35,0 & 53,7 & 100 & 4 & 2,7 & 7 & 20 \\
\hline$C-I-23$ & 0,45 & 28,4 & 60,3 & 100 & 4 & 2,7 & 7 & 20 \\
\hline
\end{tabular}



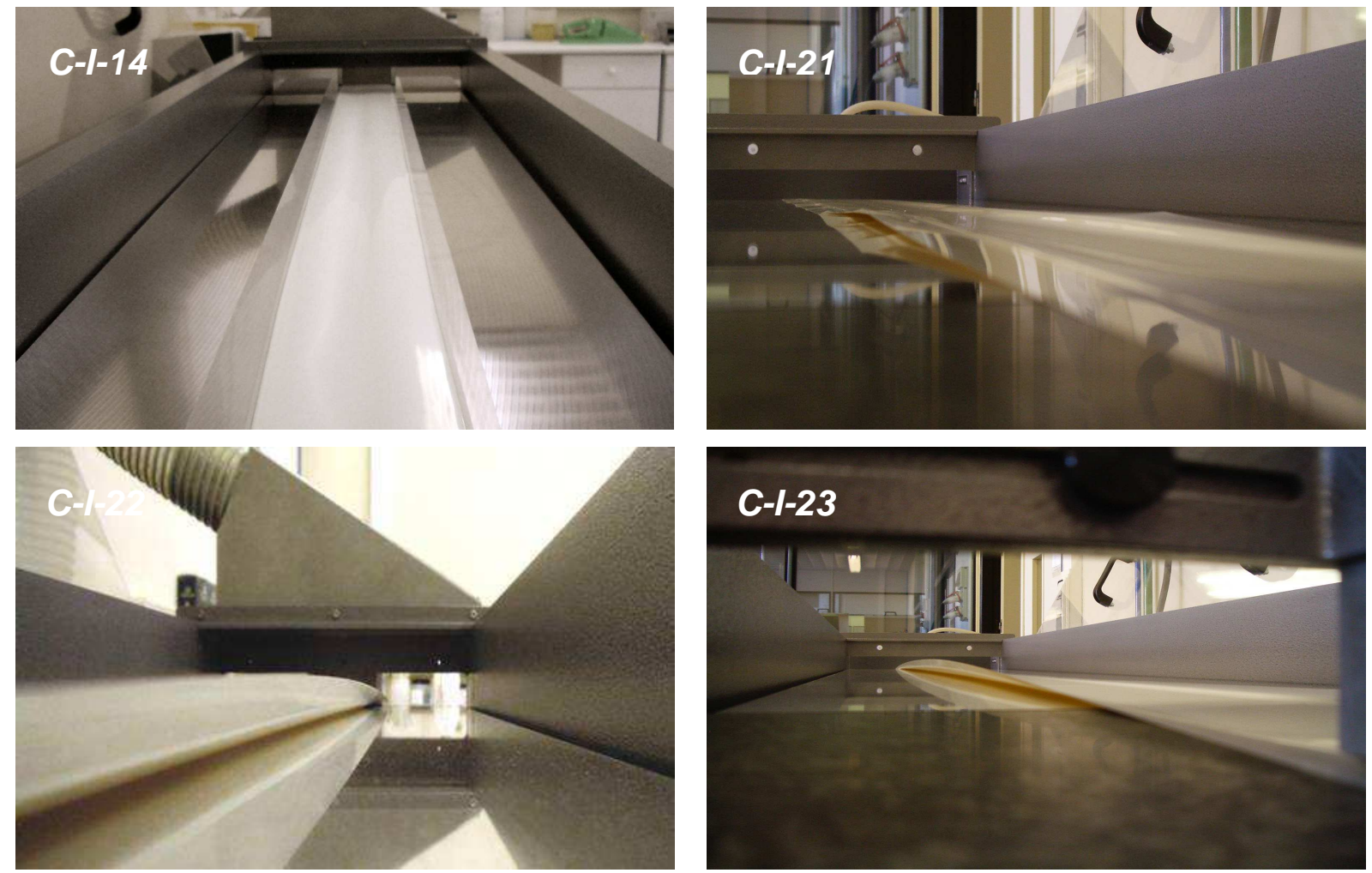

Figura 4.18. Aspecto de las láminas coladas, en crudo, obtenidas variando la relación de MEK/Isopropanol en el disolvente.

En la Tabla 4.8 se muestran los valores de la $\eta_{100}$ y se comenta el aspecto de las láminas coladas en crudo. Como puede apreciarse, la lámina obtenida a partir de la suspensión $\boldsymbol{C}$-I21 es lisa y plana, muy parecida a las obtenidas con la $C$-I-14. En cambio las láminas obtenidas a partir de las suspensiones $\boldsymbol{C}-\mathbf{I - 2 2}$ y $\boldsymbol{C}-\mathbf{I}-23$, con menor contenido en MEK, son lisas pero cóncavas, con los bordes levantados. El aspecto de las láminas sinterizadas fue aceptable en los tres casos, por lo que no se muestra gráficamente.

Tabla 4.8. Valor de $\eta_{100}$ de las suspensiones $C-I-14$ y $C-I-21$ a $C$-I-23 y aspecto visual de las respectivas láminas coladas en crudo y en cocido

\begin{tabular}{ccl} 
Suspensión & $\eta_{100}($ Pa.s) & \multicolumn{1}{c}{ Aspecto visual de la lámina en crudo y sinterizada } \\
\hline $\boldsymbol{C}$-I-14 & 1,88 & Lisa; ligero alzamiento del borde tras sinterizado \\
$\boldsymbol{C}-I-21$ & 1,47 & Lisa y plana, en crudo y después de sinterizar \\
$\boldsymbol{C}-I-22$ & 1,51 & Lisa pero cóncava, bordes alzados \\
$\boldsymbol{C}-\mathrm{I}-23$ & 2,75 & Lisa pero cóncava, bordes alzados \\
\hline
\end{tabular}




\subsubsection{Características de las suspensiones idóneas}

De cuanto antecede se deduce que las suspensiones que conducen a la obtención de láminas coladas crudas que, en principio, se consideran adecuadas para ser sometidas a las etapas de eliminación de materia orgánica y sinterización han de tener una fracción másica de $\boldsymbol{C}$ - $\boldsymbol{I}$ comprendida entre $\mathbf{0 , 4 3}$ y $\mathbf{0 , 4 6}$, MEK e ISOPROL han de estar en una proporción de aproximadamente 60/40 en el disolvente de partida y han de contener, entre 4-4,5 g de MFO, 2,7 g de DBT, $7 \mathrm{~g}$ de PEG 400 y $20-21 \mathrm{~g}$ de PVB, por cada $100 \mathrm{~g}$ de $\boldsymbol{C}-\boldsymbol{l}$.

Al estudiar el comportamiento reológico de las suspensiones que reunían estas características (C-I-12 a $\boldsymbol{C}$-l-16), se observó que, en todas ellas, el valor de $\boldsymbol{\eta}_{100}$ estaba comprendido entre 1 y $3 \mathrm{~Pa}$.s, de acuerdo con lo sugerido por algunos investigadores ${ }^{95,96,97}$.

Partiendo del supuesto de que el valor de esta propiedad de las suspensiones era un factor determinante en lo referente a la calidad de las láminas coladas que se obtuvieran a partir de las mismas, se pensó en la posibilidad de obtener una correlación entre dicha propiedad y la composición de las suspensiones, con vistas a disponer de una herramienta que permitiera modificar la proporción de los componentes de las mismas manteniendo el valor de $\boldsymbol{\eta}_{100}$ dentro de los límites indicados.

\subsubsection{Ensayos utilizando una mezcla de xileno-etanol como disolvente}

La fracción másica de $\boldsymbol{C}$-I en las laminas coladas secas (exentas de disolvente), obtenidas a partir de las suspensiones descritas en el Apartado 4.2.1 que, en principio, se han considerado más adecuadas (las procedentes de las suspensiones $\boldsymbol{C}$-I-12 a $\boldsymbol{C}$-l-16), era del orden de $100 /(100+4+2,7+7+20)=0,75$, es decir contenían un $25 \%$, en masa, de materia orgánica que había de ser eliminada antes de proceder a desarrollar la fase de sinterización. Como consecuencia, las láminas resultantes de la fase de eliminación de materia orgánica presentaban una cierta porosidad residual, como se verá en el Apartado 4.3, circunstancia que convenía reducir, antes de desarrollar la fase de sinterización, a fin de obtener piezas terminadas con la menor porosidad posible.

Por ello, se consideró oportuno, partiendo de la experiencia adquirida al desarrollar el estudio descrito en el Apartado 4.2.1, ensayar otro disolvente de entre los recomendados en la bibliografía para sistemas análogos, que condujera a moldear láminas coladas secas de $\boldsymbol{C}-\boldsymbol{I}$, con menor contenido en aditivos orgánicos que las obtenidas con el sistema MEKISOPROL, en especial del componente PVB que se encontraba en una proporción elevada en las suspensiones que conducían a láminas coladas con las propiedades deseadas.

Según la bibliografía consultada ${ }^{74,90}$, las mezclas de alcoholes con compuestos aromáticos se consideran buenos disolventes para este tipo de sistemas. En estos casos, es preferible utilizar alcohol con un cierto contenido en agua. La presencia de agua proporciona menor viscosidad a las suspensiones que cuando se utiliza alcohol absoluto. Los puntos de menor viscosidad de la mezcla suelen encontrarse en los alrededores del 50\% alcohol- $50 \%$ aromático, en proporción másica ${ }^{74,90}$.

\subsubsection{Optimización de la composición de las suspensiones preparadas con mezclas xilleno-etanol al 50\%, en masa.}

De acuerdo con lo indicado en el párrafo anterior se procedió a preparar una serie de suspensiones utilizando como disolvente una mezcla de xileno-etanol al $50 \%$, en masa.

En la Tabla 4.9 se muestran las composiciones de las suspensiones preparadas, que tienen fracciones másicas de $\boldsymbol{C}$-I bastante más elevadas que las preparadas con la mezcla de 
disolventes ensayada en el apartado anterior. Las suspensiones se han ido preparando empezando con proporciones bastante bajas de aditivos orgánicos a fin de reducir, en lo posible, el porcentaje de estos en las láminas coladas secas para tratar de obtener una porosidad lo más baja posible en la etapa de presinterización o eliminación de materia orgánica, previa a la de sinterización. Poco a poco se ha ido aumentando la proporción de dichos componentes hasta que se han obtenido láminas coladas con las características deseadas. En primer lugar se ha ensayado la efectividad del plastificante PEG 400.

\begin{tabular}{cccccccccc}
\hline \multicolumn{10}{|c}{ Tabla 4.9. Composiciones de las suspensiones preparadas usando PEG 400 como } \\
plastificante
\end{tabular}

En la Tabla 4.10 se muestran los valores experimentales de $\eta_{100}$ de las suspensiones estudiadas, así como un breve comentario sobre el aspecto visual de las láminas crudas resultantes del colado de las mismas (Figura 4.21). Como puede apreciarse, todas las láminas crudas obtenidas en este primer intento presentaban grietas, por lo que se optó por sustituir el PEG 400 por plastificantes más efectivos, como PEG 10000 o PEG 2000 para tratar de mejorar la calidad de las mismas manteniendo la fracción másica de $\boldsymbol{C}$-I alrededor de 0,6 .

\begin{tabular}{ccl}
\hline Tabla 4.10. Valor de $\begin{array}{c}\eta_{100} \text { de las suspensiones } C-I-24 \text { a } C-I-27 \text { y aspecto visual de las } \\
\text { respectivas láminas coladas en crudo y en cocido }\end{array}$ \\
\hline Suspensión & $\eta_{100}$ (Pa.s) & \multicolumn{1}{c}{ Aspecto visual de la lámina en crudo y sinterizada } \\
\hline C-I-24 & 0,541 & Totalmente descamada \\
C-I-25 & 0,782 & Una grieta central que se ramifica \\
C-I-26 & 1,433 & Muy descamada \\
C-I-27 & 0,753 & Una grieta central muy ramificada \\
\hline
\end{tabular}



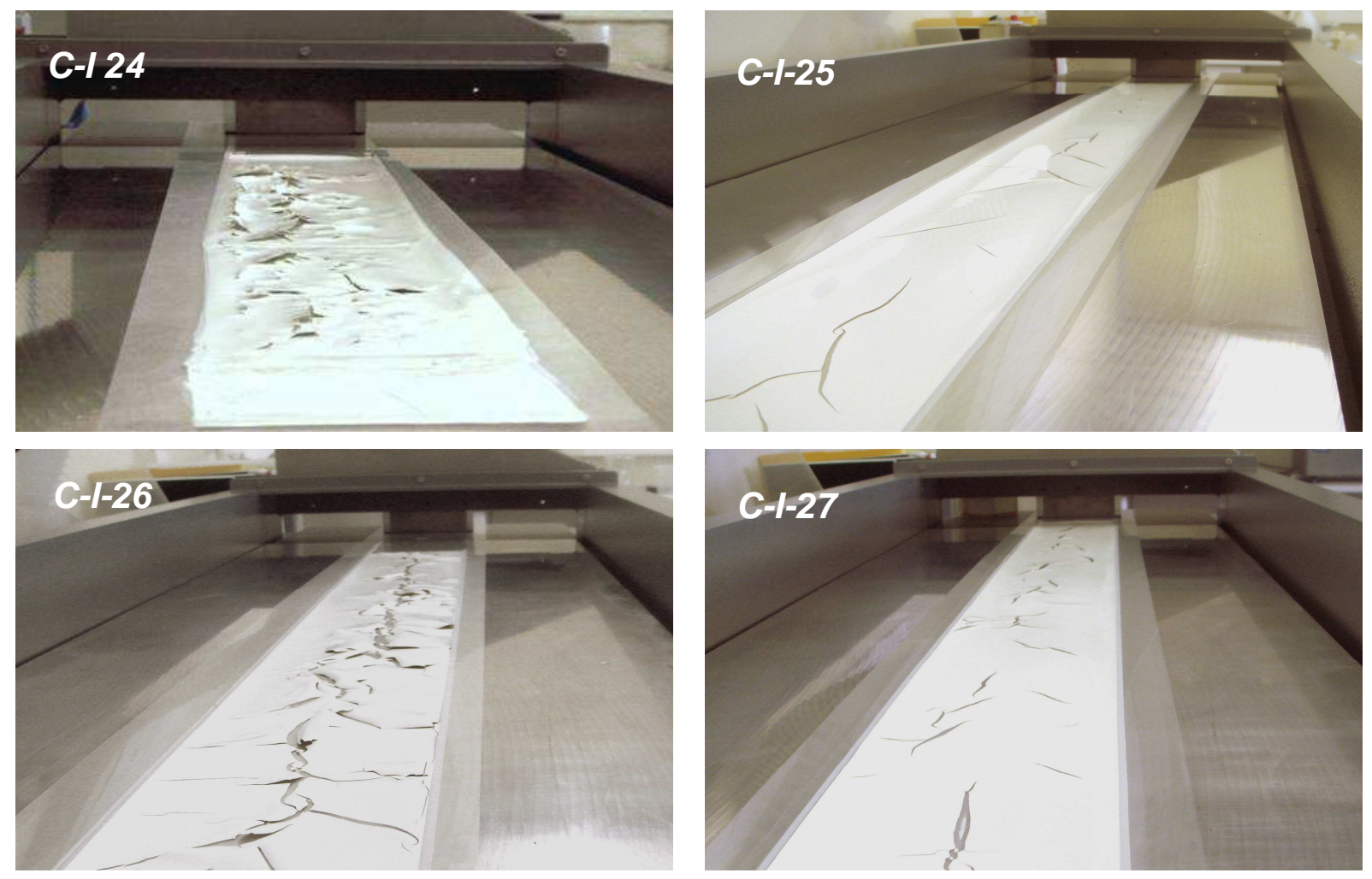

Figura 4.21. Aspecto de las láminas coladas, en crudo, preparadas utilizando PEG 400 como plastificante.

En las Tablas 4.11 y 4.12 se muestra las composiciones de las suspensiones que se han ido preparando con los plastificantes PEG 10000 y PEG 2000, respectivamente, con vistas a tratar de optimizar las características de las láminas coladas, partiendo del mínimo contenido posible de aditivos orgánicos en la suspensión.

Tabla 4.11. Composiciones de las suspensiones preparadas usando PEG 10000 como plastificante

\begin{tabular}{|c|c|c|c|c|c|c|c|c|}
\hline Suspensión & $\mathbf{w}_{\mathrm{Zr}}$ & $\begin{array}{c}\text { Xileno } \\
(\mathrm{g})\end{array}$ & $\begin{array}{l}\text { Etanol } \\
\text { (g) }\end{array}$ & $\begin{array}{l}C-I \\
(g)\end{array}$ & $\begin{array}{l}\text { MFO } \\
\text { (g) }\end{array}$ & $\begin{array}{l}\text { DBT } \\
\text { (g) }\end{array}$ & $\begin{array}{c}P E G \\
10000 \\
(\mathrm{~g})\end{array}$ & $\begin{array}{l}\text { PVB } \\
\text { (g) }\end{array}$ \\
\hline$C-I-28$ & 0,625 & 24,72 & 24,72 & 100 & 2 & 2,5 & 0,7 & 5 \\
\hline C-I-29 & 0,615 & 24,72 & 24,72 & 100 & 2 & 2,5 & 1,5 & 7 \\
\hline$C-1-30$ & 0,603 & 24,72 & 24,72 & 100 & 3 & 5,0 & 1,5 & 7 \\
\hline$C-I-31$ & 0,560 & 32,76 & 32,62 & 100 & 3 & 5,0 & 1,5 & 7 \\
\hline$C-I-32$ & 0,600 & 24,72 & 24,72 & 100 & 3 & 5,0 & 2,0 & 7 \\
\hline C-II-33 & 0,602 & 24,72 & 24,72 & 100 & 3 & 5,0 & 1,5 & 7 \\
\hline$C-I I-34$ & 0,584 & 26,92 & 26,92 & 100 & 3 & 6,0 & 1,5 & 7 \\
\hline
\end{tabular}




\begin{tabular}{cccccccccc}
\hline \multicolumn{10}{c}{ Tabla 4.12. Composiciones de las suspensiones preparadas usando PEG 2000 como } \\
plastificante \\
\hline \multirow{2}{*}{ Suspensión } & $\mathbf{w}_{\mathrm{Zr}}$ & $\begin{array}{c}\text { Xileno } \\
(\mathbf{g})\end{array}$ & $\begin{array}{c}\text { Etanol } \\
(\mathbf{g})\end{array}$ & $\begin{array}{c}\text { C-I } \\
(\mathbf{g})\end{array}$ & $\begin{array}{c}\text { MFO } \\
(\mathbf{g})\end{array}$ & $\begin{array}{c}\text { DBT } \\
(\mathbf{g})\end{array}$ & $\begin{array}{c}\text { PEG } \\
\mathbf{2 0 0 0} \\
(\mathbf{g})\end{array}$ & $\begin{array}{c}\text { PVB } \\
(\mathbf{g})\end{array}$ \\
\hline C-I-35 & 0,597 & 24,72 & 24,72 & 100 & 3 & 6,0 & 2,0 & 7 \\
C-II-36 & 0,597 & 24.72 & 24.72 & 100 & 3 & 6,0 & 2,0 & 7 \\
\hline
\end{tabular}

En las Figuras 4.22 y 4.23 se observa el aspecto de las láminas obtenidas por colado en banda, con los dos nuevos plastificantes ensayados y en la Tabla 4.13 se muestran los valores experimentales de $\eta_{100}$ de las respectivas suspensiones y un breve comentario sobre el aspecto visual de las láminas crudas resultantes del colado de las mismas.

\begin{tabular}{c|cl}
\hline \multicolumn{3}{|c|}{ Tabla 4.13. Valor de $\begin{array}{r}\eta_{100} \text { de las suspensiones } \text { C-I-28 a C-II-36 y aspecto visual de las } \\
\text { respectivas láminas coladas en crudo }\end{array}$} \\
\hline Suspensión & $\eta_{100}$ (Pa.s) & Aspecto visual \\
\hline C-I-28 & 0,478 & Capa con roturas y grietas \\
C-I-29 & 1,250 & Diferencias de espesor, grietas \\
C-I-30 & 1,047 & Buen aspecto; ligeramente cóncava, pinchados \\
C-I-31 & 0,210 & Una grieta central \\
C-II-33 & 1,178 & Lisa pero cóncava; bordes muy alzados \\
C-II-34 & 0,730 & Buen aspecto, cóncava \\
C-I-32 & 0,983 & Buen aspecto, plana, pinchados \\
C-I-35 & 0,925 & Lisa con ligera concavidad, buen aspecto \\
C-II-36 & 0,914 & Ondulaciones superficiales; ligera concavidad, pinchados \\
\hline
\end{tabular}



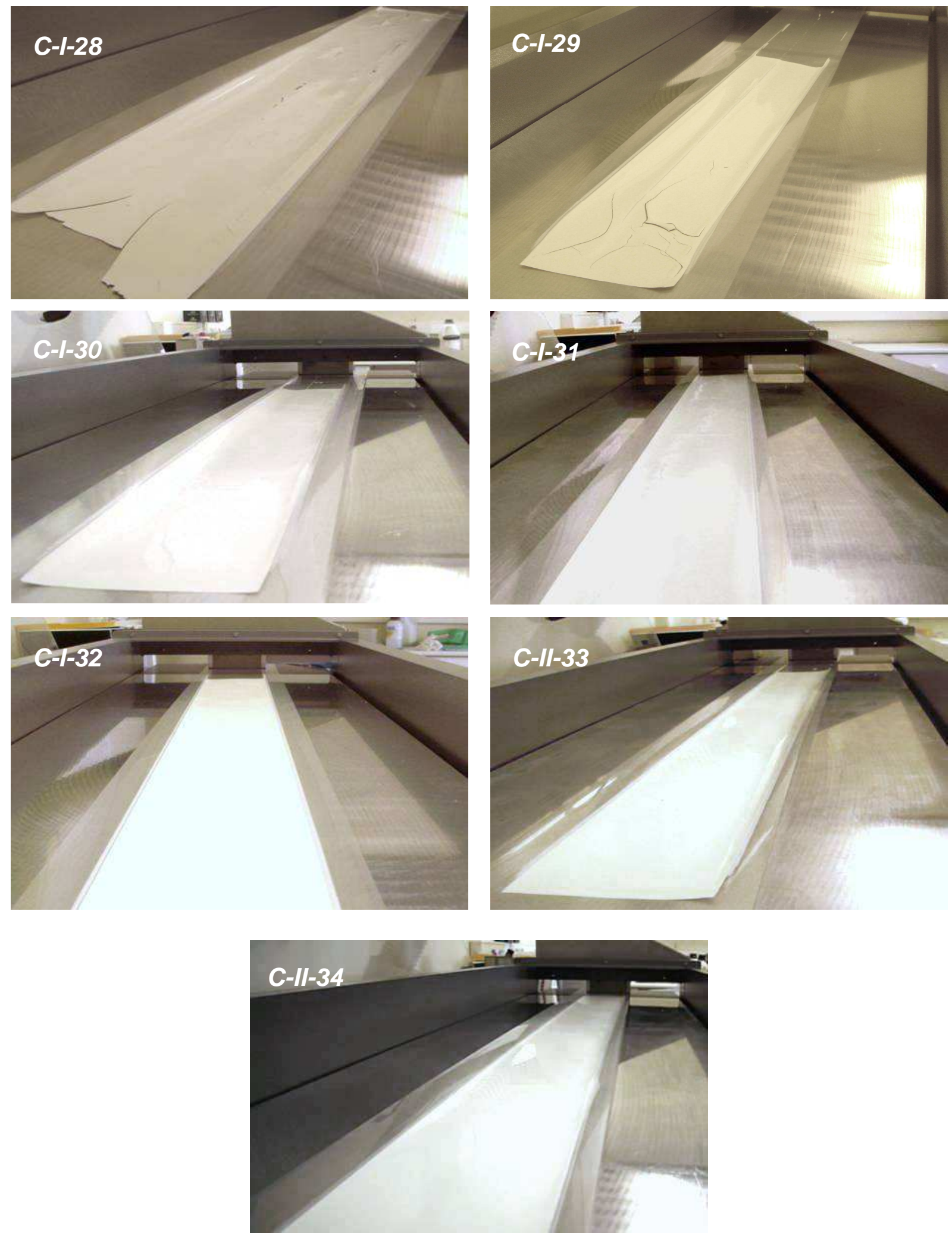

Figura 4.22. Capas coladas obtenidas en el sistema Xileno/Etanol, con PEG 10000. 

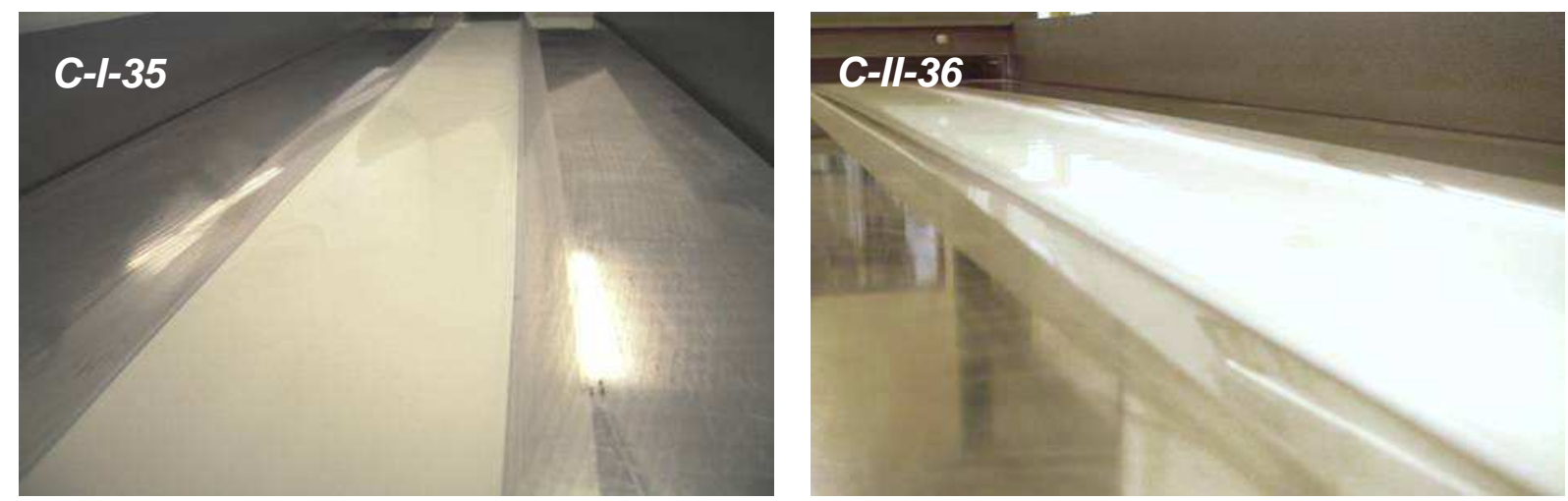

Figura 4.23. Láminas coladas obtenidas con el sistema Xileno/Etanol, con PEG 2000.

Como puede apreciarse en las fotos que se presentan en las figuras antes indicadas y por los comentarios del aspecto visual contenidos en las Tablas 4.10 y 4.13 , los mejores resultados se obtuvieron a partir de las suspensiones $C$-I-32 y C-I-35 (esta última la mejor). A la vista de la composición de la suspensión $\boldsymbol{C}$-I-35, se llega a la conclusión de que al utilizar este nuevo sistema de disolventes, en la lámina seca, se ha reducido considerablemente el contenido en aditivos orgánicos que se han de eliminar posteriormente durante la etapa de tratamiento térmico, previa a la sinterización. Esta circunstancia debe conducir, en principio, a que se obtenga menor porosidad en la lámina resultante de desarrollar la etapa de presinterización, lo cual es un buen punto de partida para reducir la porosidad de la lámina sinterizada.

\subsubsection{Optimización de la composición de las suspensiones preparadas con mezclas xileno-etanol en la proporción másica 40-60.}

A fin de tratar de disminuir, en lo posible, la proporción de xileno en la mezcla, dado que es más caro que el etanol y, además, se ha de manejar con precaución por sus propiedades cancerígenas, se prepararon cinco suspensiones, tomando como punto de partida la fracción másica de componente inorgánico y la proporción de aditivos de la suspensión $\boldsymbol{C}$-I35 (suspensión $\boldsymbol{C}$-I-37).

En la Tabla 4.14 se indica la composición de las suspensiones preparadas y en la Tabla 4.15 se proporcionan los correspondientes valores de $\boldsymbol{\eta}_{100}$ y se comenta el aspecto de las láminas coladas resultantes que se muestra en las fotografías de la Figura 4.24.

A la vista de los resultados obtenidos se concluye que las láminas crudas resultantes tienen peor aspecto que la obtenida a partir de la suspensión $\boldsymbol{C}-\mathbf{I}-35$. Este resultado parece confirmar la idea inicial de que las mezclas de los dos componentes del disolvente, en la proporción 50:50 en masa es, en este caso, la que conduce a mejores resultados entre las posibilidades estudiadas. 


\begin{tabular}{|c|c|c|c|c|c|c|c|c|}
\hline Suspensión & $\mathbf{w}_{\mathrm{Zr}}$ & $\begin{array}{l}\text { Xileno } \\
\text { (g) }\end{array}$ & $\begin{array}{l}\text { Etanol } \\
(\mathrm{g})\end{array}$ & $\begin{array}{l}C-I \\
(\mathrm{~g})\end{array}$ & $\begin{array}{l}\text { MFO } \\
\text { (g) }\end{array}$ & $\begin{array}{l}\text { DBT } \\
\text { (g) }\end{array}$ & $\begin{array}{c}P E G \\
10000 \\
(\mathrm{~g})\end{array}$ & $\begin{array}{l}\text { PVB } \\
\text { (g) }\end{array}$ \\
\hline$C-I-37$ & 0,600 & 19,77 & 29,66 & 100 & 3 & 6 & 2,0 & 7 \\
\hline$C-1-38$ & 0,580 & 21,54 & 32,31 & 100 & 3 & 7 & 1,5 & 7 \\
\hline$C-I-39$ & 0,577 & 21,54 & 32,31 & 100 & 3 & 7 & 2 & 7,5 \\
\hline$C-I-40$ & 0,593 & 20,61 & 30,91 & 100 & 3 & 5 & 2 & 7 \\
\hline$C-I-41$ & 0,552 & 24,72 & 24,72 & 100 & 3 & 6,0 & 2,0 & 7 \\
\hline
\end{tabular}

Tabla 4.15. Valor de $\eta_{100}$ de las suspensiones $C-I-37$ a $C-I-41$ y aspecto visual de las respectivas láminas coladas en crudo

\begin{tabular}{ccl} 
Suspensión & $\eta_{100}($ Pa.s) & \multicolumn{1}{c}{ Aspecto visual } \\
\hline $\boldsymbol{C}-\mathrm{I}-\mathbf{3 7}$ & 1,320 & Lisa, plana con pinchados de burbujas \\
$\boldsymbol{C}-\mathrm{I}-\mathbf{3 8}$ & 0,740 & Lisa, plana, algún pinchado \\
$\boldsymbol{C}-\mathrm{I}-\mathbf{3 9}$ & 0,973 & Curvatura cóncava muy pronunciada, pinchados \\
$\boldsymbol{C}-\mathrm{I}-\mathbf{4 0}$ & 1,020 & Lisa, con pinchados \\
$\boldsymbol{C}-\mathrm{I}-\mathbf{4 1}$ & 0,383 & Curvatura cóncava, grieta central \\
\hline
\end{tabular}

De cuanto antecede se deduce que al utilizar como disolvente y suspensionante la mezcla xileno-etanol, al $50 \%$ en masa, se ha conseguido aumentar la fracción másica de componente inorgánico $(\boldsymbol{C}-I)$ en las suspensiones desde 0,43-0,46 a 0,60, reduciendo, en consecuencia, el contenido en aditivos orgánicos (MFO, DBT, PEG, PVB) de las láminas coladas y secas (una vez eliminado el disolvente por evaporación) alrededor de un $65 \%$, en unidades másicas. En efecto, se pasa de un contenido de una fracción másica de aditivos orgánicos en las láminas crudas y secas coladas a partir de las suspensiones $C$-I-12 a $C$-I16 (Sistema MEK-ISOPROL) de 0,25 a otra de 0,15 en las láminas secas obtenidas a partir de la suspensión $\boldsymbol{C}$-I-35 (Sistema xileno-ETOH). Por ello, se eligió finalmente la suspensión C-I-35 para colar las láminas que, después de tratarlas térmicamente para eliminar los aditivos orgánicos, se habían de someter a la etapa de sinterización, a diferentes temperaturas y tiempos de residencia, para estudiar la variación de la resistencia mecánica a la flexión y la evolución del tamaño de grano. 

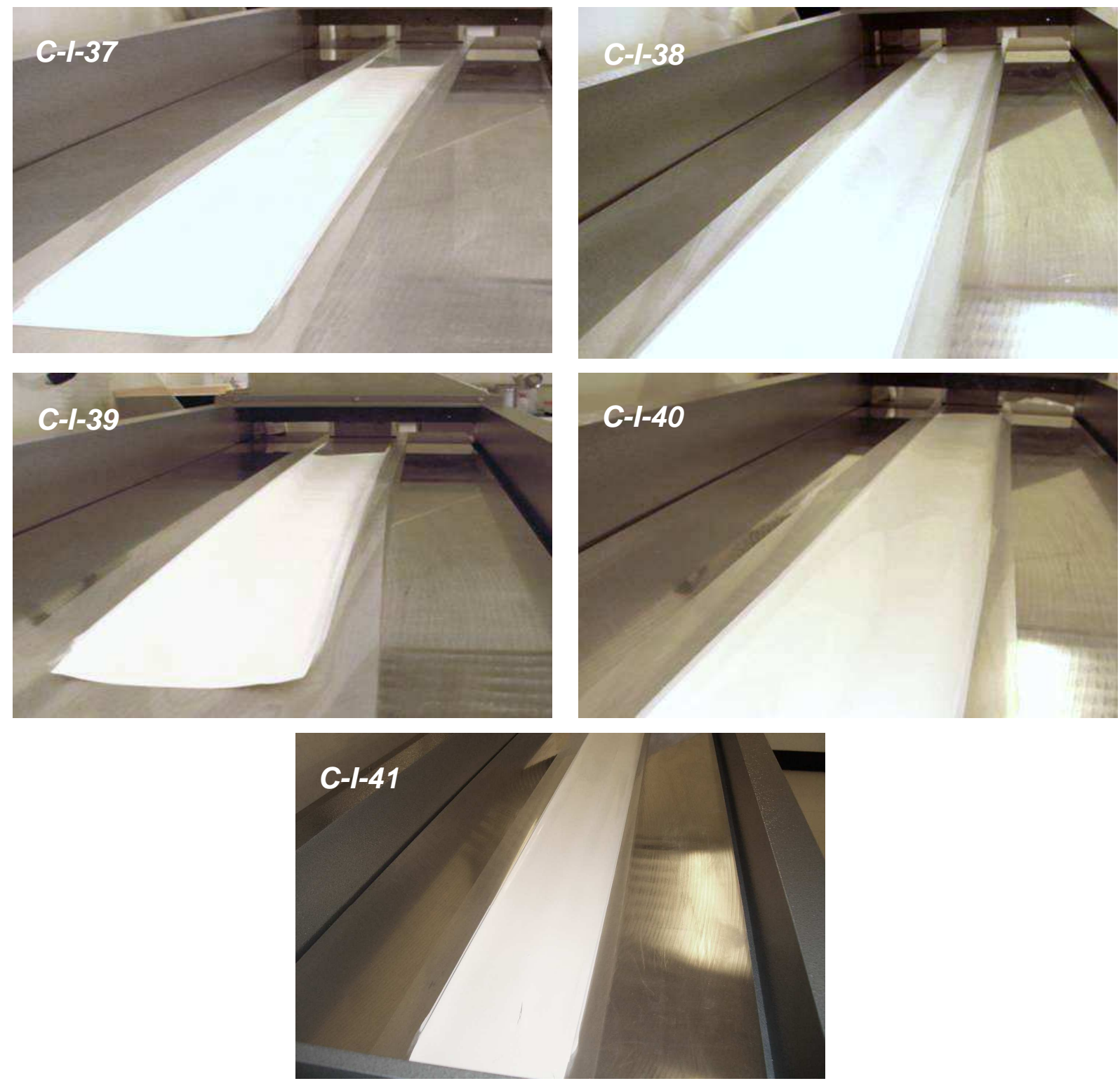

Figura 4.24. Láminas coladas obtenidas con el sistema Xileno/Etanol, con PEG 10000 o 2000. 


\subsection{Optimización de la etapa de eliminación de la materia orgánica contenida en las láminas coladas: Selección de la velocidad de calentamiento y de la temperatura máxima idóneas}

\subsubsection{Criterio de selección: Aspecto visual de la lámina resultante}

Dado que, tanto los resultados de los ensayos de ATD-TG (Apartado 4.1.1) como los realizados con el microscopio de calefacción (Apartado 4.1.2) mostraban que la eliminación de los aditivos orgánicos se completaba entre 723 y $748 \mathrm{~K}$, a la velocidad de calentamiento utilizada $(120 \mathrm{~K} / \mathrm{h})$, se programó desarrollar los primeros ensayos, para tratar de eliminar la materia orgánica de las láminas coladas en una estufa de temperatura programada, operando a dicha velocidad de calentamiento hasta alcanzar diferentes temperaturas inferiores a $873 \mathrm{~K}$, en presencia de aire.

La primera fase del estudio se realizó utilizando láminas secas moldeadas por colado de la suspensión $\boldsymbol{C}-\mathbf{I}-15$, que eran las de mayor calidad que se habían obtenido utilizando el sistema de disolventes MEK-ISOPROL.

Las láminas secas se depositaban sobre una placa de material refractario para ser tratadas térmicamente, en las condiciones antes indicadas. Finalizada esta etapa, se analizaba visualmente el aspecto (planaridad, compactación y posible formación de grietas) de las láminas resultantes.

En la Figura 5.25 se nuestra el aspecto de las láminas resultantes del tratamiento térmico descrito, utilizando una velocidad de calentamiento de $120 \mathrm{~K} / \mathrm{h}$, hasta alcanzar diferentes temperaturas máximas comprendidas entre 573 y $873 \mathrm{~K}$.

La lámina tratada hasta $573 \mathrm{~K}$ adquirió una coloración negruzca, debido a la coquización de parte de la materia orgánica que se deseaba eliminar y que, a las condiciones a las que se efectuó el experimento, no llegó a oxidarse.

En la lámina tratada hasta $673 \mathrm{~K}$ se había eliminado prácticamente casi todo el carbono que confería la coloración negra a la lámina anterior y, finalmente, en la lámina tratada hasta 773 K se había eliminado completamente toda la materia orgánica, presentando una coloración blanca.

La lámina calentada hasta $873 \mathrm{~K}$ se agrietó, por lo que se decidió no superar los $773 \mathrm{~K}$ en el desarrollo de esta etapa.

Debido a que las láminas obtenidas no poseían la planaridad deseada (ver fotos de la Figura 4.25) se pensó en reducir la velocidad de calentamiento para ver si mejoraba esta propiedad. Se realizaron ensayos a velocidades de calentamiento de $60 \mathrm{~K} / \mathrm{h}$ y $30 \mathrm{~K} / \mathrm{h}$. 


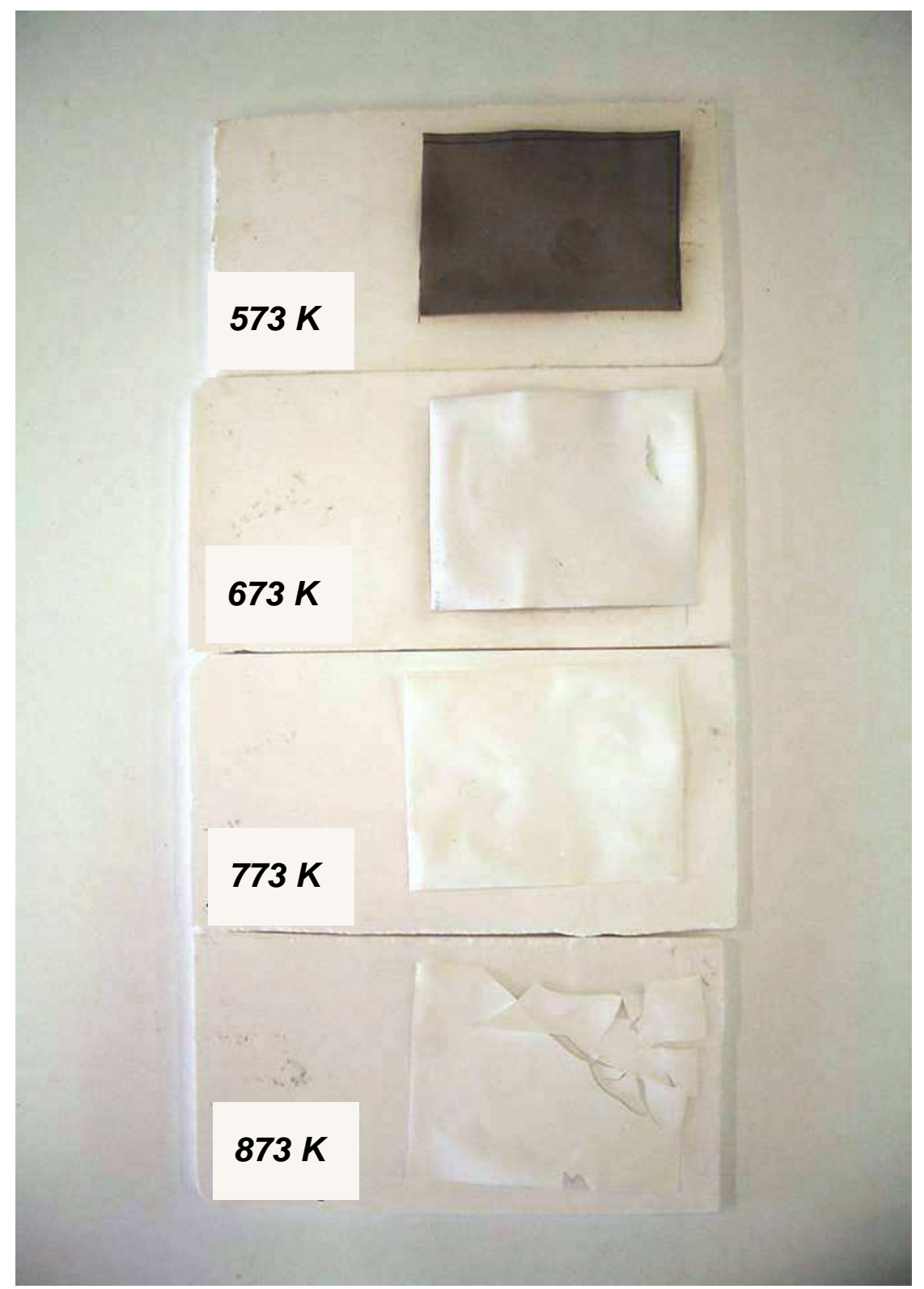

Figura 4.25. Aspecto de las láminas tratadas a una velocidad de calentamiento de $120 \mathrm{~K} / \mathrm{h}$, hasta distintas temperaturas máximas. 


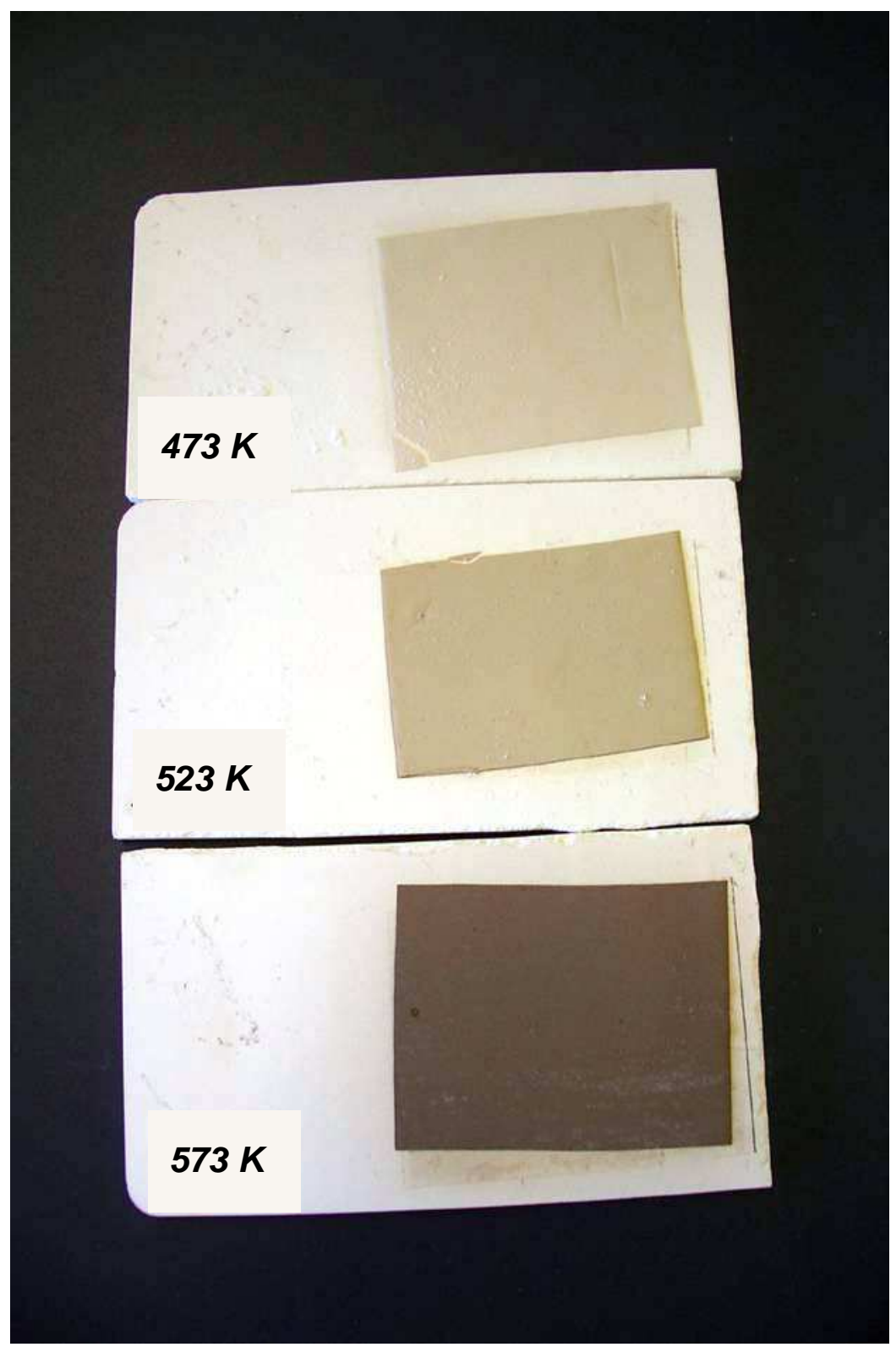

Figura 4.26. Aspecto de las láminas tratadas a una velocidad de calentamiento de $30 \mathrm{~K} / \mathrm{h}$, hasta distintas temperaturas máximas. 

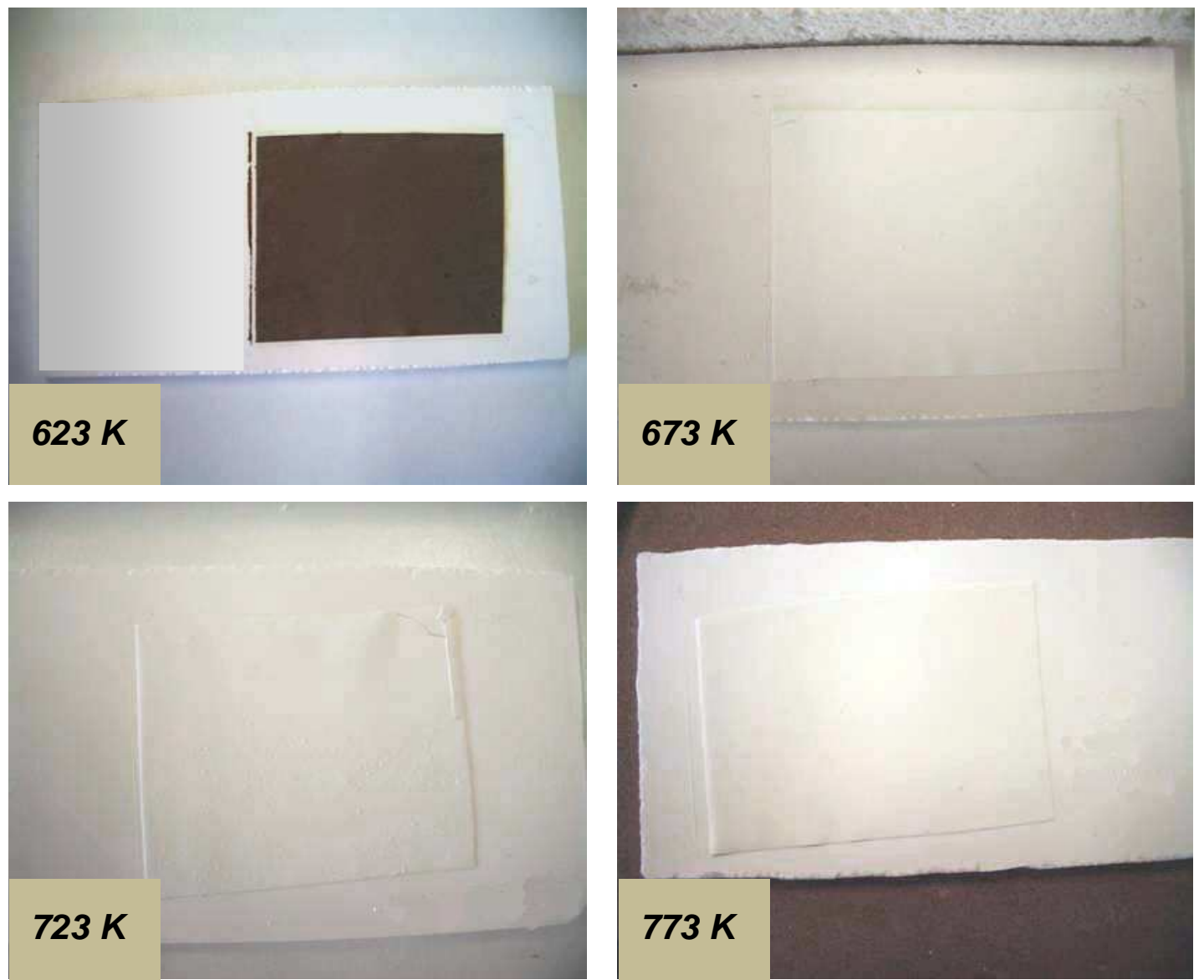

Figura 4.27. Aspecto de las láminas tratadas a una velocidad de calentamiento de $30 \mathrm{~K} / \mathrm{h}$, hasta distintas temperaturas máximas.

Las láminas resultantes de efectuar el tratamiento térmico para eliminar la materia orgánica a la velocidad de calentamiento de $60 \mathrm{~K} / \mathrm{h}$ resultaron más planas que las obtenidas a 120 $\mathrm{K} / \mathrm{h}$, pero aún presentaban algún defecto en ese aspecto por lo que se decidió ensayar una velocidad de calentamiento aún más baja $(30 \mathrm{~K} / \mathrm{h})$.

En las Figuras 4.26 y 4.27 , se muestran las fotografías de las láminas resultantes de eliminar la materia orgánica utilizando una velocidad de calentamiento de $30 \mathrm{~K} / \mathrm{h}$. Como puede apreciarse, en este caso, se ha mantenido la planaridad de las láminas después del tratamiento térmico. Visualmente pudo apreciarse que, entre 673 y $723 \mathrm{~K}$, se había eliminado toda la materia orgánica, ya que habían desaparecido los residuos de carbón que oscurecían las láminas tratadas hasta temperaturas más bajas (623 K), de acuerdo con los resultados obtenidos al operar a la velocidad de calentamiento de $120 \mathrm{~K} / \mathrm{h}$, tanto al efectuar el tratamiento térmico en horno, como en el estudio termogravimétrico realizado (Apartado 4.1.1). En consecuencia, se decidió desarrollar la etapa de eliminación de materia orgánica utilizando una velocidad de calentamiento de $30 \mathrm{~K} / \mathrm{h}$, hasta alcanzar la temperatura de 773 $\mathrm{K}$.

\subsubsection{Criterio de selección: Porosidad de la lámina resultante.}

Con fines orientativos, se comparó, en primer lugar, la microestructura de la sección transversal de una lámina obtenida a partir de la suspensión $C$-I-15 que se había tratado 
térmicamente con una velocidad de calentamiento de $30 \mathrm{~K} / \mathrm{h}$, hasta $773 \mathrm{~K}$, con la microestructura de la sección transversal de la misma lámina después de someterla a un ciclo térmico adicional consistente en elevar la temperatura de la estufa progresivamente desde $553 \mathrm{~K}$ hasta $1723 \mathrm{~K}$, utilizando una velocidad de calentamiento de $120 \mathrm{~K} / \mathrm{h}$, manteniendo luego la temperatura constante e igual a $1723 \mathrm{~K}$, durante 30 min (Figura 4.28), con vistas a observar los cambios que se producían durante esta segunda etapa.
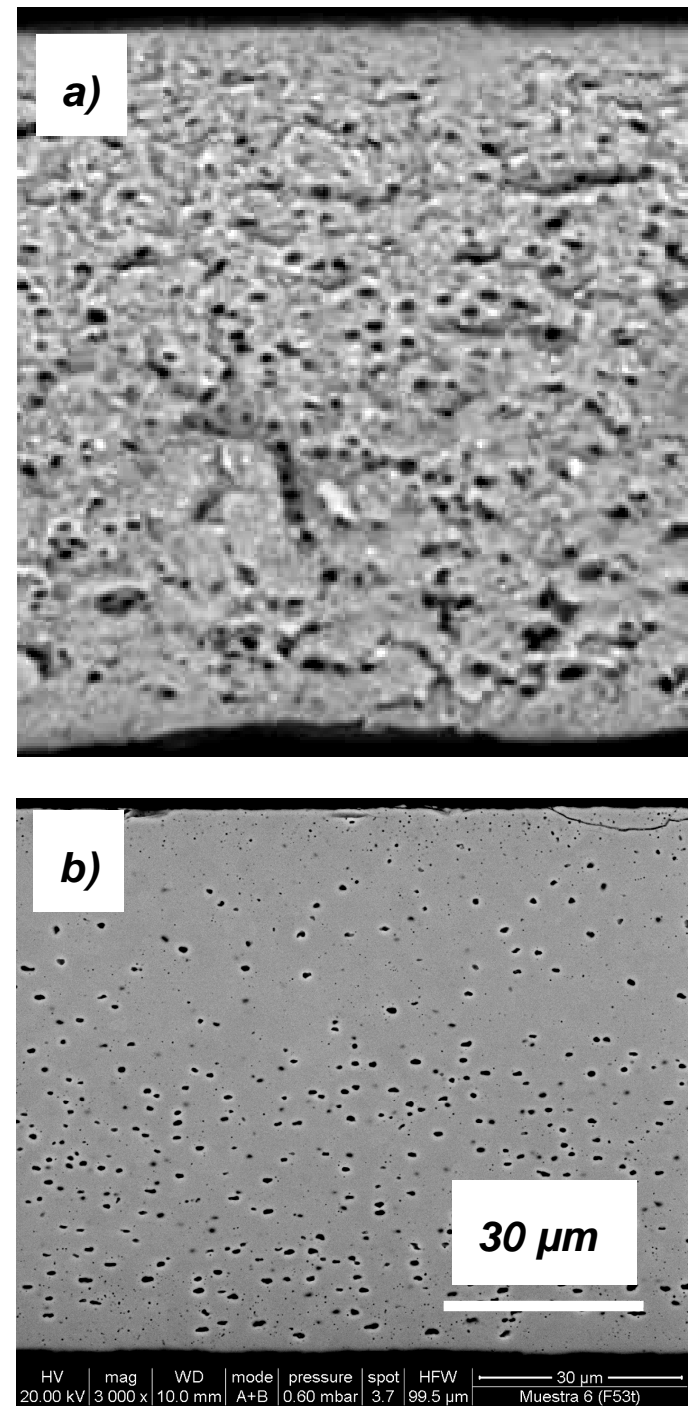

Figura 4.28. a) Microestructura de la sección de la lámina después de la etapa de eliminación de la materia orgánica; b) Microestructura de la sección de la lámina tras tratarla térmicamente a 1723 K durante 30 minutos.

De la comparación de las micrografías que se muestran en la Figura 4.28 se dedujo que la distribución de poros era muy similar en la lámina pretratada hasta $773 \mathrm{~K}$, y en la sometida, con posterioridad, al ciclo térmico indicado en el párrafo anterior, aun cuando los poros de ésta última eran de tamaño considerablemente menor. 
La morfología de los poros de mayor diámetro era también muy similar en ambas láminas. Los poros tenían forma elíptica, con el eje mayor paralelo a la superficie de colado y secado.

Dado el paralelismo observado entre $773 \mathrm{~K}$ y las sinterizadas, al someterlas posteriormente al ciclo térmico descrito, se pensó utilizar la porosidad de estas últimas como criterio comparativo para seleccionar el límite máximo de temperatura, más conveniente, de la etapa de eliminación de materia orgánica.

Para ello, partiendo asimismo de láminas coladas obtenidas a partir de la suspensión $\boldsymbol{C}-\mathbf{I - 1 5}$, se realizaron tres series de experimentos en los que se desarrolló la etapa de eliminación de materia orgánica a la velocidad de calentamiento seleccionada anteriormente de $30 \mathrm{~K} / \mathrm{h}$, hasta alcanzar diferentes temperaturas máximas $(673,723$ y $773 \mathrm{~K})$, situadas en la zona donde, según los resultados del ensayo de $A T D-T G$, parecía que se habían eliminado totalmente los aditivos orgánicos (Apartado 4.1.1). Las láminas resultantes se sometieron posteriormente al ciclo térmico adicional de sinterización a $1723 \mathrm{~K}$ durante $30 \mathrm{~min}$, determinando la microestructura porosa de las respectivas secciones. En la Tabla 4.16 se muestran los resultados obtenidos de porosidad $(\varepsilon)$ y diámetro medio de poro $\left(\boldsymbol{d}_{50}\right)$ de las láminas, en la Figura 4.29 el aspecto de su microestructura y en la Figura 4.30 las distribuciones de los tamaños de poros determinadas a partir de las microfotografías.

\begin{tabular}{|c|c|c|}
\hline $\begin{array}{l}\text { Temp. Máx. de } \\
\text { eliminación (K) }\end{array}$ & $\varepsilon(\%)$ & $d_{50}(\mu \mathrm{m})$ \\
\hline 673 & 2,8 & 0,75 \\
\hline 723 & 2,6 & 0,74 \\
\hline 773 & 2,4 & 0,75 \\
\hline
\end{tabular}
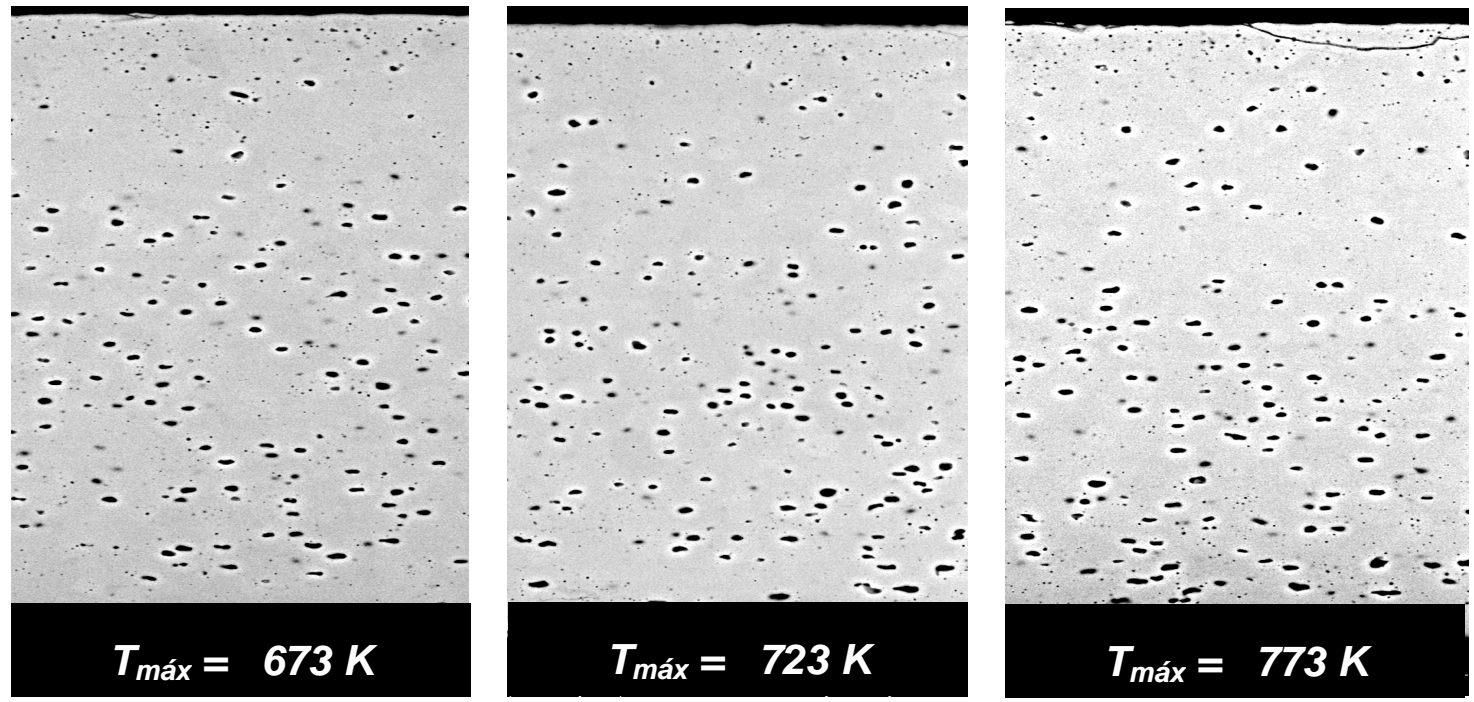

Figura 4.29. Microestructura de las láminas obtenidas a partir de la suspensión C-I-15 tras la eliminación de materia orgánica hasta diferentes temperaturas y la sinterización a $1723 \mathrm{~K}$ durante 30 min. 


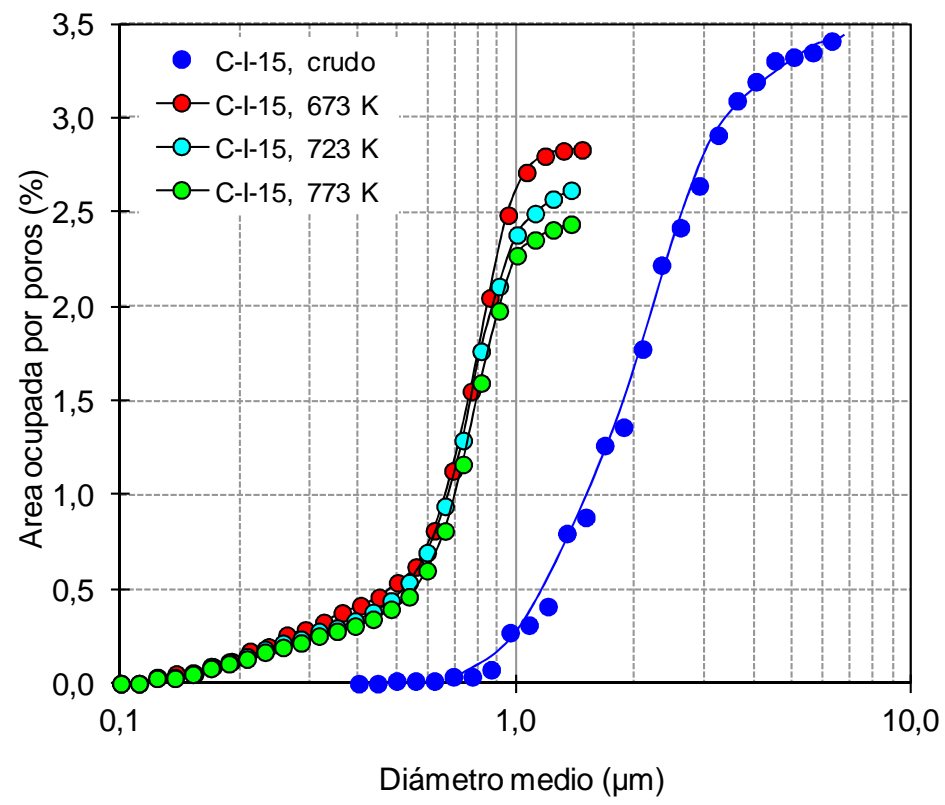

Figura 4.30. Comparación de las Distribuciones de tamaño de poro en las secciones de las láminas de probetas cruda y tratadas a distintas temperaturas de eliminación de orgánicos y cocidas a $1723 \mathrm{~K}$.

La comparación de las imágenes de la Figura 4.29 no permitió obtener ninguna conclusión, ya que aparentemente son prácticamente iguales. En cambio, los valores de la porosidad $(\boldsymbol{\varepsilon})$ de la Tabla 4.16 y las representaciones de la Figura 4.30 sugirieron la conveniencia de establecer $773 \mathrm{~K}$ como límite de temperatura de la etapa de eliminación de la materia orgánica dado que, aun cuando las diferencias no eran significativas y estaban dentro del margen de error, dicha temperatura límite conducía a la porosidad más baja en la lámina tratada y una de las características deseables en las láminas sinterizadas era que su porosidad fuera nula o lo más reducida posible.

\subsubsection{Montaje utilizado para conseguir mantener la planaridad de las láminas durante el desarrollo de las etapas de eliminación de materia orgánica y de sinterización.}

Al desarrollar la etapa de tratamiento térmico entre 773 y $1723 \mathrm{~K}$, manteniendo luego las muestras a dicha temperatura durante media hora, se observó que, en algunos casos, las láminas perdían la deseada planaridad. En consecuencia, se pensó desarrollar tanto la etapa anterior de eliminación de materia orgánica, como la de sinterización, colocando las láminas secas entre dos piezas planas de material refractario muy poroso (Repton tiles), para facilitar la evacuación de los gases resultantes de la descomposición de la materia orgánica, formando como una especie de sándwich, a fin de tratar de evitar la pérdida de planaridad de las láminas durante esta fase de su procesado.

En la Figura 4.31 se muestra un esquema del dispositivo utilizado para mantener la planaridad de las láminas durante las etapas de tratamiento térmico. 


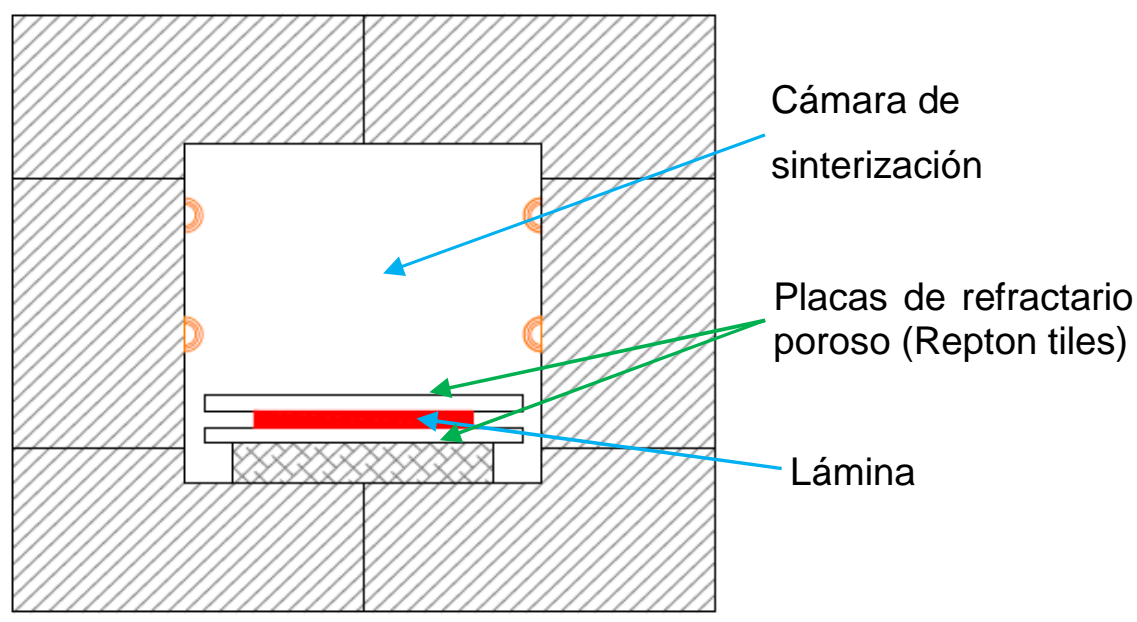

Figura 4.31. Esquema del montaje utilizado para mejorar la planaridad de las láminas durante su tratamiento térmico.

En la Figura 4.32 se muestra el aspecto de las láminas, coladas a partir de la suspensión $\boldsymbol{C}$ 1-15, que resultaron de la ejecución consecutiva de las dos etapas de tratamiento térmico (eliminación de aditivos orgánicos y sinterización) utilizando las placas de material refractario que condujeron al mejor resultado: combinación de 632 (arriba) y T214 (debajo).
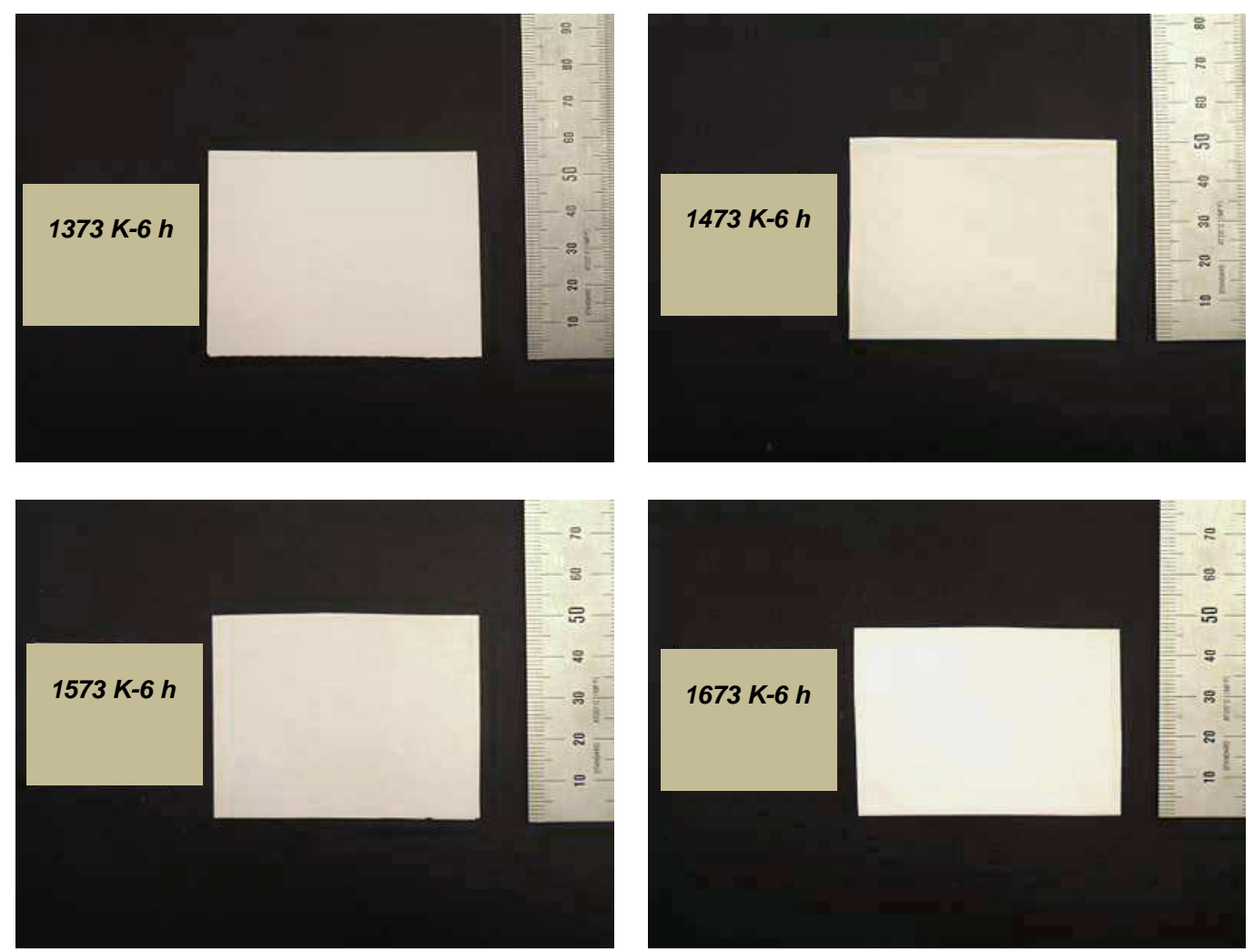

Figura 4.32. Aspecto de las láminas resultantes del tratamiento térmico realizado insertándolas entre dos placas de material refractario poroso: 632-T214. 


\subsection{Etapa de sinterización.}

Como se ha indicado reiteradamente, el material resultante de la etapa de sinterización debía poseer una porosidad lo más baja posible (al menos inferior al 5\%), la resistencia mecánica adecuada para poder actuar como soporte de los restantes elementos de la celda de combustible y la máxima conductividad iónica posible, en el intervalo de temperaturas comprendido entre 873 y $973 \mathrm{~K}$.

Ahora bien, como se ha comentado en el Apartado 2.2.2, no se tenía ninguna garantía de que las medidas de la conductividad iónica obtenidas a partir de las láminas sinterizadas fueran correctas. En consecuencia, partiendo de láminas coladas secas, se decidió estudiar solamente la influencia de las condiciones a las que se desarrollaba la fase de sinterización sobre la compactación (o porosidad) y sobre el tamaño de grano desarrollado.

Para determinar la conductividad iónica del material sinterizado, a diferentes condiciones de temperatura y tiempo de residencia, se partió de probetas cilíndricas, moldeadas por prensado unidireccional, de mayor espesor que las láminas coladas, evitando así la posibilidad de que se produjera un contacto entre los electrodos del dispositivo empleado, al efectuar las medidas. En las probetas sinterizadas se determinó asimismo la porosidad y el tamaño medio de grano.

Posteriormente se comparó la porosidad y el tamaño medio de grano de las láminas sinterizadas, para las que se había obtenido la porosidad más baja, con las correspondientes propiedades obtenidas a partir de probetas prensadas sometidas al mismo tratamiento térmico, a fin de comprobar si eran del mismo orden. Dado que la conductividad iónica de estos materiales está íntimamente relacionada con su tamaño de grano y podría estar algo influenciada por su porosidad, se pensó que, si dichas propiedades llegaban a ser similares en las láminas menos porosas y en las probetas prensadas sinterizadas, las medidas de conductividad iónica realizadas con muestras de probetas prensadas serían bastante representativas del valor de dicha propiedad que tendrían las laminas coladas de estructura similar.

Conviene poner de manifiesto que el calentamiento de las muestras, una vez eliminada la materia orgánica, hasta las temperaturas de sinterización seleccionadas $(1473,1573,1673$ y $1773 \mathrm{~K}$ ), no se efectuó instantáneamente, sino a una velocidad de calentamiento constante de $120 \mathrm{~K} / \mathrm{h}$, para evitar agrietamientos o roturas motivadas por un cambio brusco de temperatura, en el caso de las láminas conformadas por colado. El mismo ciclo térmico se utilizó para sinterizar las probetas prensadas, a fin de someterlas al mismo tratamiento que a las láminas.

En consecuencia, antes de alcanzar la temperatura de sinterización elegida, las muestras estaban sometidas, durante un tiempo superior a diecinueve horas, a temperaturas crecientes que, al sobrepasar los $1173 \mathrm{~K}$ debían influir sobre el desarrollo del proceso de sinterización (ver Figura 4.4, Apartado 4.1.2).

Los posibles cambios producidos en las muestras, durante dichos periodos de calentamiento, no se han podido estimar experimentalmente. Por tanto, los valores del tiempo de residencia que se dan a continuación son los de permanencia de las muestras a cada una de las temperaturas de sinterización elegidas, medidos desde el momento en que se alcanzaron los correspondientes valores preestablecidos.

Todo ello se tendrá en cuenta en los apartados correspondientes, al interpretar los resultados obtenidos. 


\subsubsection{Experimentos con láminas coladas.}

\subsubsection{Influencia del ciclo térmico de sinterización sobre la porosidad de las láminas resultantes.}

Al tratar térmicamente láminas coladas a partir de la suspensión $C$-I-15, utilizando el ciclo térmico descrito en el Apartado 4.3.2 (hasta la temperatura máxima de $1723 \mathrm{~K}$ ), se había llegado a obtener láminas sinterizadas con porosidad inferior al 3 \% (Figura 4.29).

A la vista de estos resultados se planificó la realización de una serie de experimentos de sinterización sometiendo las laminas pretratadas hasta $773 \mathrm{~K}$ (para eliminar los aditivos orgánicos) a una velocidad de calentamiento de $120 \mathrm{~K} / \mathrm{h}$ desde $773 \mathrm{~K}$ hasta cuatro temperaturas diferentes $(1473,1573,1673$ y $1773 \mathrm{~K}$ ) manteniendo luego las muestras durante periodos de 2, 4 y 6 horas a dichas temperaturas que, en adelante, se denominaran temperaturas de sinterización $\left(\boldsymbol{T}_{\boldsymbol{S}}\right)$. En cada experimento se determinó la porosidad $(\boldsymbol{\varepsilon})$ y el diámetro medio de poro $\left(\boldsymbol{d}_{50}\right)$ de las láminas resultantes.

Estos experimentos se realizaron con láminas coladas a partir de la suspensión $\mathbf{C}-\mathbf{I}-15$ (obtenida usando como disolvente MEK-Isopropanol) y con láminas coladas a partir de la suspensión C-I-35 (obtenida usando como disolvente xileno-etanol).

(i) Experimentos de sinterización con láminas coladas a partir de suspensiones en mezclas de MEK-Isopropanol.

Para realizar esta serie de experimentos se eligió láminas coladas a partir de la suspensión $\boldsymbol{C}$-I-15, porque al someterlas a la etapa de eliminación de materia orgánica habían conservado la planaridad, poseyendo además una porosidad suficientemente baja (Apartados 4.3.1 y 4.3.2).

En la Tabla 4.17 se muestra el valor del tiempo de residencia de las muestras a cada temperatura de sinterización ensayada, así como los valores de la contracción lineal $(\boldsymbol{C L})$, de la porosidad $(\boldsymbol{\varepsilon})$ y del diámetro medio de poro $\left(\boldsymbol{d}_{50}\right)$ de las láminas resultantes de cada ensayo realizado.

Con objeto de apreciar mejor la influencia de las condiciones de sinterización sobre la contracción lineal experimentada por las láminas sinterizadas resultantes de cada experimento realizado, en la Figura 4.33 se ha representado los valores de dicha propiedad frente al tiempo de residencia, para cada una de las temperaturas de sinterización ensayadas.

En dicha figura se observa que el valor de la contracción lineal de las láminas sinterizadas a diferentes condiciones difiere muy poco, ya que está comprendida entre 27,7 y 29,3\%. Esa diferencia aún es menor si se consideran los resultados correspondientes a las tres temperaturas de sinterización más altas (1573, 1673 y 773 K).

Estos resultados están de acuerdo con los obtenidos en el Apartado 4.1 (Figura 4.4), donde se aprecia que, a partir de $1473 \mathrm{~K}$, la variación de la contracción lineal con la temperatura se reduce considerablemente, alcanzando un valor prácticamente constante a partir de $1573 \mathrm{~K}$. 


\begin{tabular}{|c|c|c|c|c|}
\hline $\begin{array}{l}\text { Temperatura de } \\
\text { sinterización (K) }\end{array}$ & $\begin{array}{c}\text { tiempo de } \\
\underset{\text { (h) }}{\text { residencia a } T_{S}}\end{array}$ & CL (\%) & $\varepsilon(\%)$ & $\begin{array}{c}d_{50} \\
(\mu \mathrm{m})\end{array}$ \\
\hline \multirow[t]{3}{*}{1473} & 2 & 27,7 & 5,68 & 0,24 \\
\hline & 4 & 28,3 & 3,37 & 0,23 \\
\hline & 6 & 28,6 & 2,56 & 0,50 \\
\hline \multirow[t]{3}{*}{1573} & 2 & 28,8 & 1,85 & 0,57 \\
\hline & 4 & 28,9 & 1,39 & 0,61 \\
\hline & 6 & 29,3 & 2,14 & 0,78 \\
\hline \multirow[t]{3}{*}{1673} & 2 & 28,6 & 1,27 & 0,53 \\
\hline & 4 & 28,6 & 1,17 & 0,58 \\
\hline & 6 & 29,2 & 1,80 & 0,77 \\
\hline \multirow[t]{3}{*}{1773} & 2 & 29,2 & 2,22 & 0,88 \\
\hline & 4 & 29,2 & 2,18 & 0,86 \\
\hline & 6 & 29,3 & 2,40 & 0,91 \\
\hline
\end{tabular}

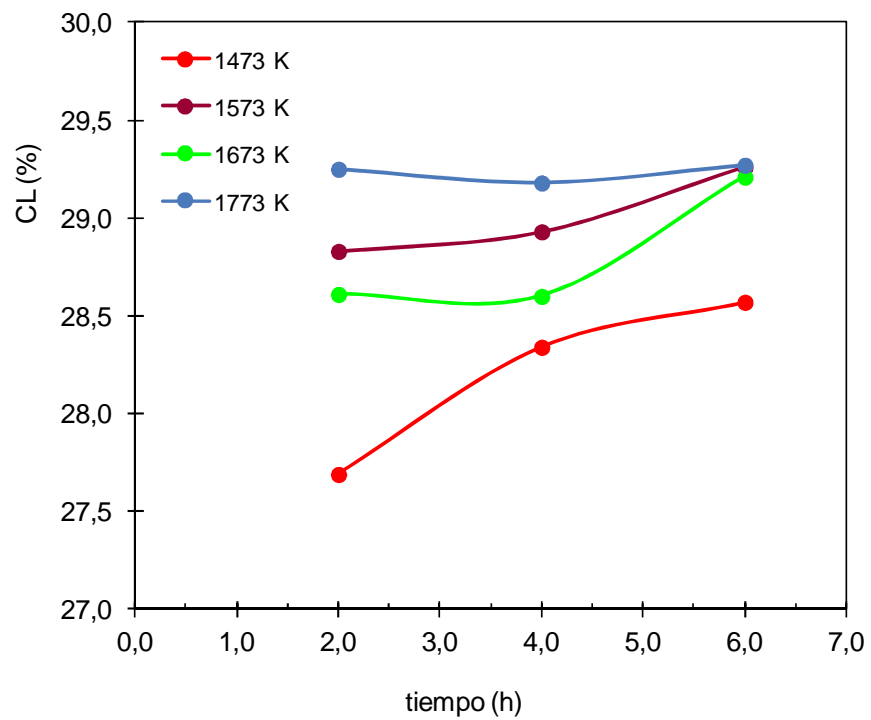

Figura 4.33. Contracción lineal de las probetas obtenidas a las diferentes temperaturas de sinterización y tiempos de residencia ensayados. 
En efecto, las muestras resultantes de los ensayos realizados a $1773 \mathrm{~K}$, a diferentes tiempos de residencia, han experimentado prácticamente la misma contracción lineal y en las láminas obtenidas en los experimentos efectuados a 1573 y $1673 \mathrm{~K}$, la contracción lineal apenas varía por estar muy próxima ya al valor máximo hacia el que evoluciona al aumentar el valor del tiempo de residencia.

En lo que se refiere a la porosidad de las láminas sinterizadas, en las Figuras 4.34 y 4.35 se ha representado el área ocupada por los poros frente al tamaño medio de poro, para cada una de las láminas sinterizadas obtenidas a las diferentes condiciones de operación ensayadas (temperatura de sinterización y tiempo de residencia a dicha temperatura).

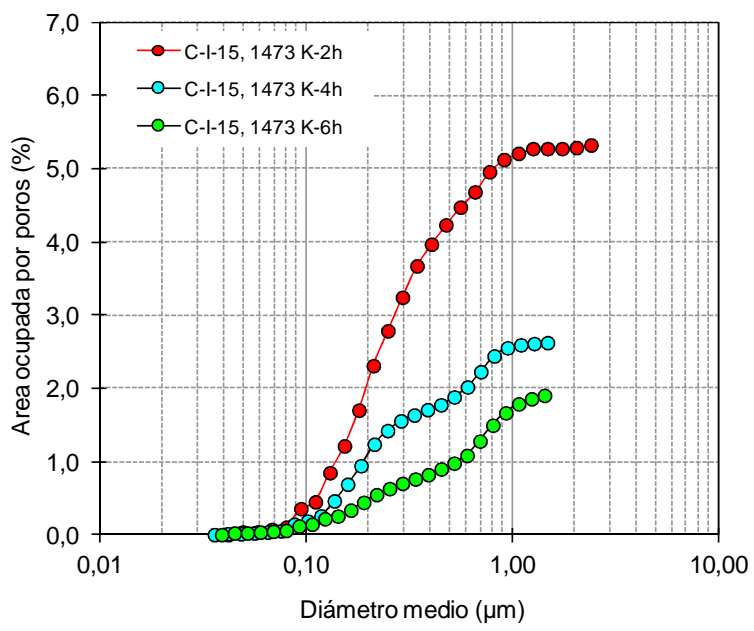

(a)

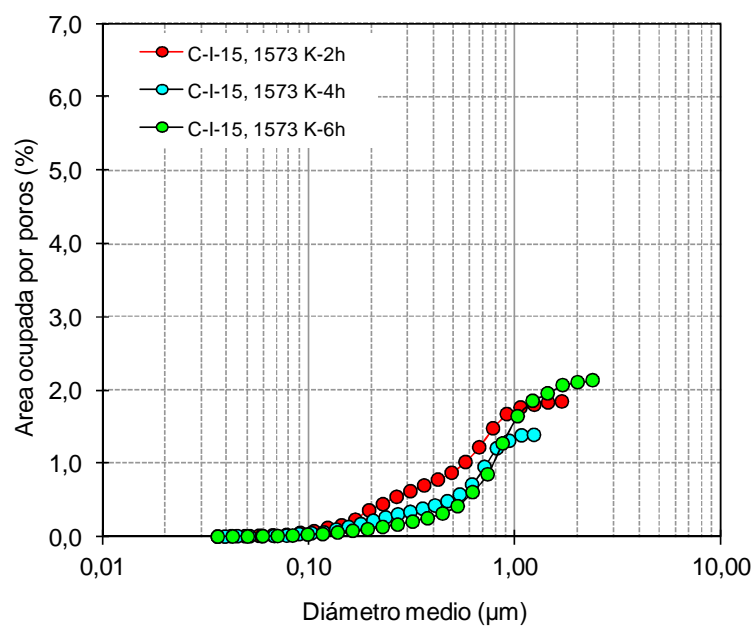

(b)

Figura 4.34. Representación del área ocupada por poros de distinto tamaño en las láminas sinterizadas a diferentes tiempos de residencia. (a) Láminas sinterizadas a $1473 \mathrm{~K}$; (b) Láminas sinterizadas a $1573 \mathrm{~K}$.

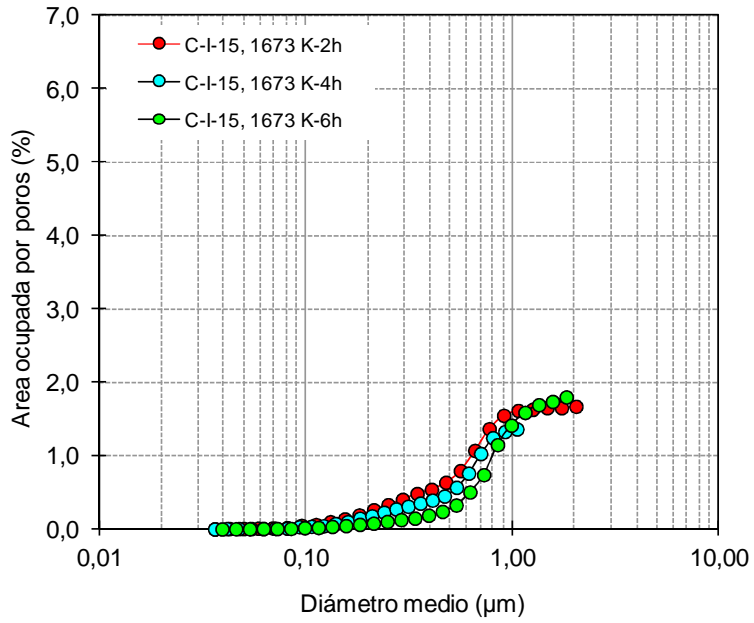

(a)

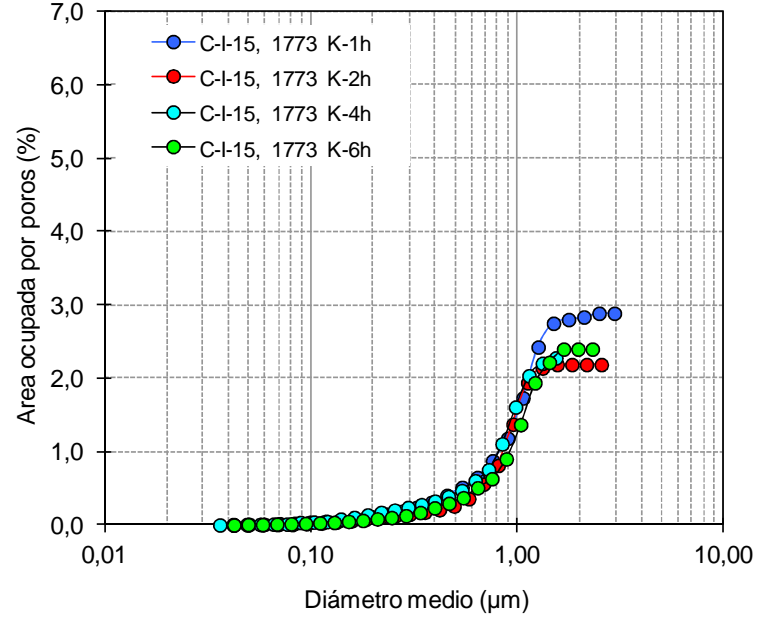

(b)

Figura 4.35. Representación del área ocupada por poros de distinto tamaño en las láminas sinterizadas a diferentes tiempos de residencia. (a) Láminas sinterizadas a 1673 K; (b) Láminas sinterizadas a $1773 \mathrm{~K}$. 
En las cuatro representaciones se ha utilizado la misma escala en el eje de ordenadas a fin de visualizar rápidamente, de forma cualitativa, las diferencias de comportamiento de las muestras estudiadas.

En la Figura 4.36 se ha representado los valores de la porosidad frente al tiempo de residencia, para cada una de las temperaturas de sinterización ensayadas.

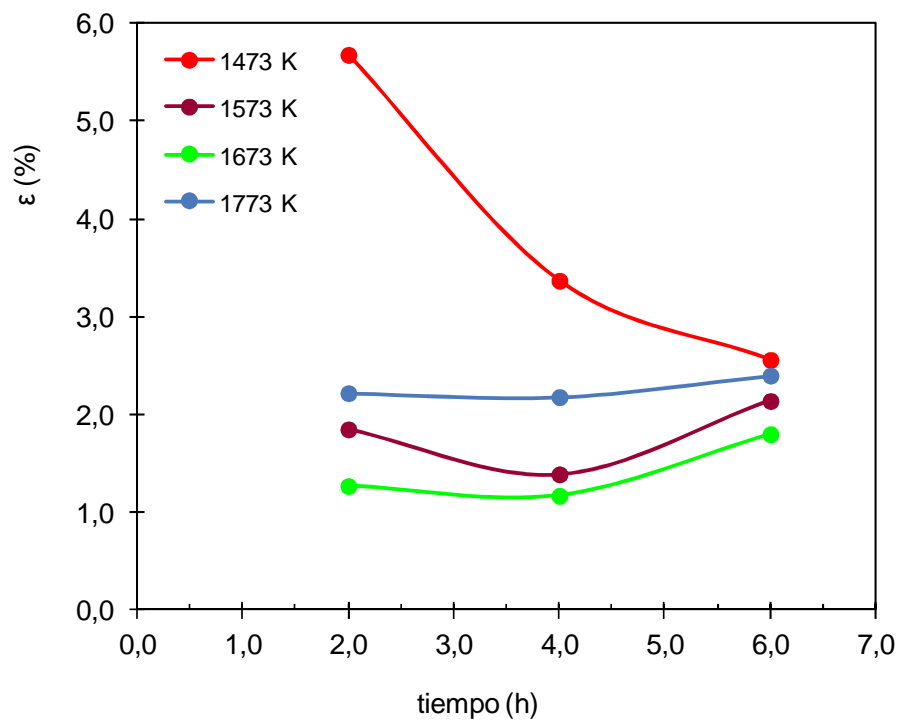

Figura 4.36. Porosidad de las probetas obtenidas a las diferentes temperaturas de sinterización y tiempos de residencia ensayados.

De la observación de las representaciones de las Figuras 4.34 a 4.36 se deduce lo siguiente:

a) A todas las condiciones de sinterización ensayadas, excepto a $1473 \mathrm{~K}$ y tiempo de residencia de 2 horas, se obtienen valores de la porosidad inferiores al $5 \%$, valor mínimo que se había considerado necesario alcanzar.

b) En las láminas resultantes de los experimentos realizados a las temperaturas de sinterización de 1673 y 1773 K, la porosidad mínima, inferior al 1,5\%, se alcanza para tiempos de residencia de 4 horas.

c) La porosidad más baja obtenida corresponde a las láminas sinterizadas a $1673 \mathrm{~K}$, con un tiempo de residencia de 2 a $4 \mathrm{~h}$.

El aspecto visual de la sección transversal de dichas láminas puede apreciarse en la Figura 4.37. A las mismas conclusiones se llega, de forma cualitativa, al observar dichas imágenes. 


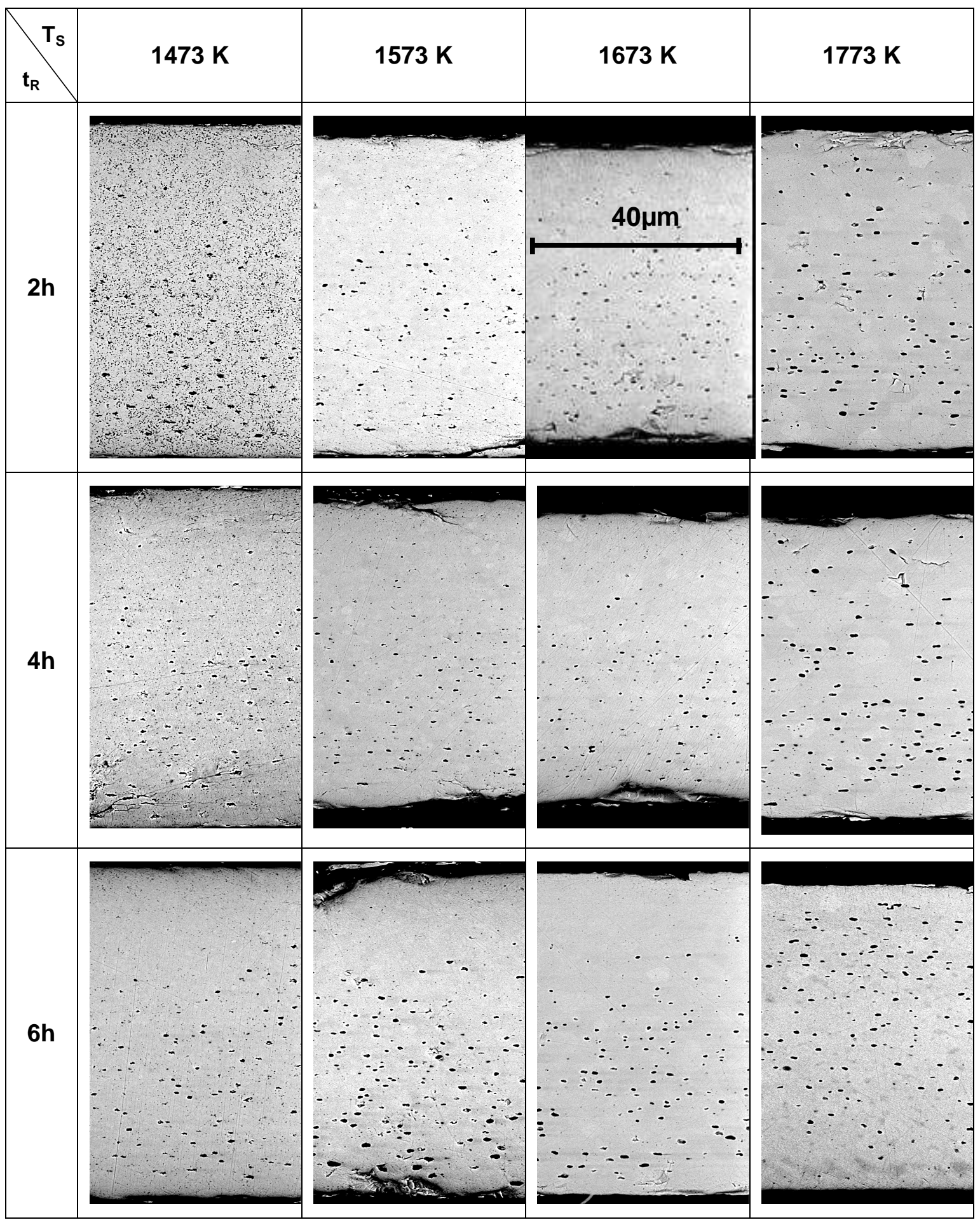

Figura 4.37. Micrografías de la sección transversal de láminas sinterizadas utilizando los distintos ciclos térmicos estudiados. 
(ii) Experimentos de sinterización con láminas coladas a partir de suspensiones en mezclas de Xileno-Etanol.

Aún cuando en las muestras sinterizadas a partir de láminas coladas de la suspensión $\boldsymbol{C}$-I15 , a que se hace referencia en el apartado anterior, se habían alcanzado ya valores de la porosidad del orden del $1,17 \%$, que eran bastante más bajos que el límite máximo del $5 \%$ que se había fijado como indispensable para un electrolito de una celda SOFC, se consideró conveniente realizar un conjunto de experimentos análogos utilizando láminas coladas a partir de la suspensión $\boldsymbol{C}$-I-35, puesto que, al tener un contenido mucho menor de aditivos orgánicos que la $\boldsymbol{C}-\mathbf{I - 1 5}$, como se ha indicado anteriormente, podía conducir a porosidades más bajas que las descritas en el apartado anterior.

Las láminas obtenidas a partir de la suspensión $\boldsymbol{C}$-I-35, tras eliminar los aditivos orgánicos, se sometieron a los mismos ciclos térmicos que las obtenidas a partir de la suspensión $\boldsymbol{C}$-I15.

En las Figuras 4.38 y 4.39 se ha representado el área ocupada por los poros frente al tamaño medio de poro, para cada una de las láminas sinterizadas a las diferentes condiciones de operación ensayadas (temperatura de sinterización y tiempo de residencia a dicha temperatura).

En la Tabla 4.18 se muestran los valores de la porosidad $(\varepsilon)$ y del diámetro medio de poro $\left(\boldsymbol{d}_{50}\right)$ de las láminas, determinados a partir de dichas representaciones.

\begin{tabular}{cccc}
\hline $\begin{array}{c}\text { Tabla 4.18. Láminas coladas a partir de la suspensión } \\
\text { Porosidad y diámetro medio de poro de las muestras resultantes de } \\
\text { cada ciclo térmico ensayado }\end{array}$ \\
\hline $\begin{array}{c}\text { Temperatura de } \\
\text { sinterización (K) }\end{array}$ & $\begin{array}{c}\text { tiempo de } \\
\text { residencia a } \mathbf{T}_{\mathbf{s}} \\
\text { (h) }\end{array}$ & $\varepsilon(\%)$ & $\begin{array}{c}\mathbf{d}_{50} \\
(\boldsymbol{\mu} \mathrm{m})\end{array}$ \\
\hline $\mathbf{1 4 7 3}$ & 2 & 6,42 & 0,34 \\
& 4 & 6,05 & 0,34 \\
& 6 & 0,75 & 0,30 \\
\hline 1573 & 2 & 0,23 & 0,22 \\
& 4 & 0,20 & 0,20 \\
& 6 & 0,20 & 0,21 \\
\hline 1673 & 2 & 0,35 & 0,22 \\
& 4 & 0,17 & 0,21 \\
& 6 & 0,10 & 0,18 \\
\hline 1773 & 2 & 0,15 & 0,24 \\
& 4 & 0,10 & 0,28 \\
& 6 & 0,11 & 0,26 \\
\hline
\end{tabular}




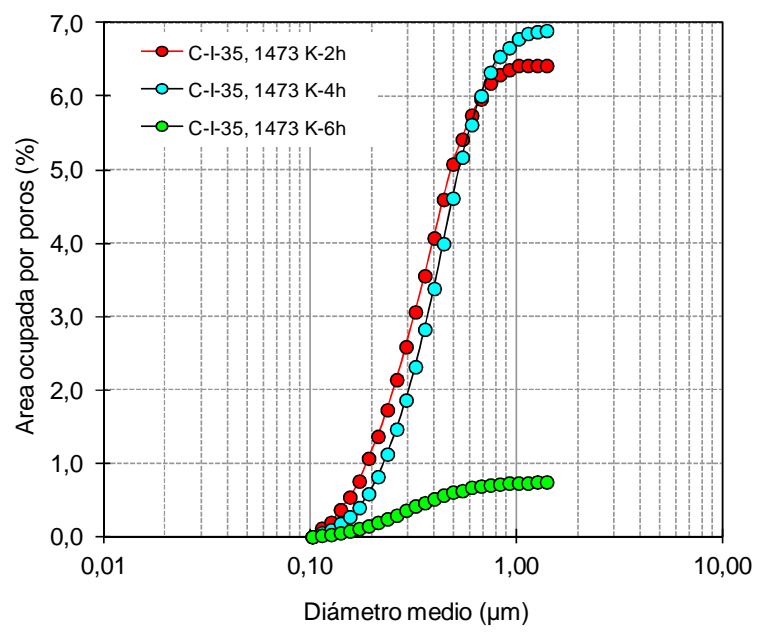

(a)

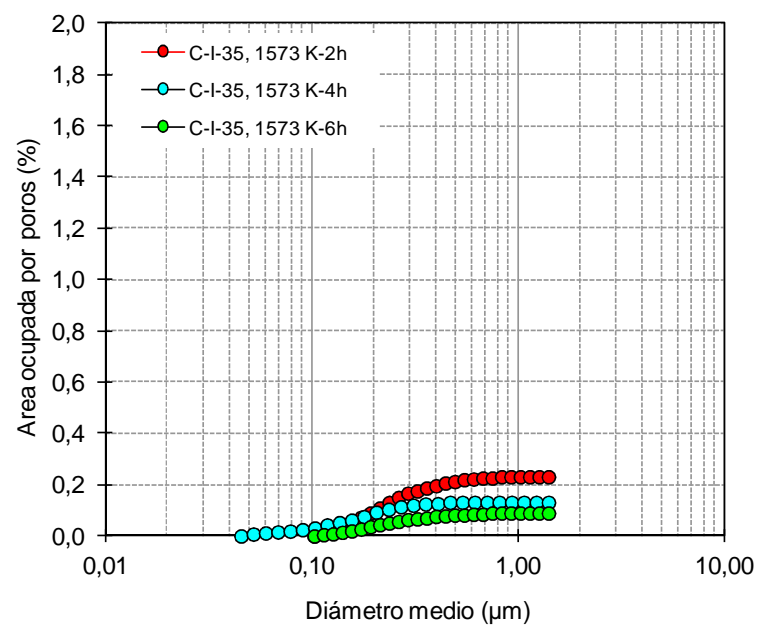

(b)

Figura 4.38. Representación del área ocupada por poros de distinto tamaño en las láminas sinterizadas a diferentes tiempos de residencia. (a)Láminas sinterizadas a 1473 K; (b) Láminas sinterizadas a 1573 K.

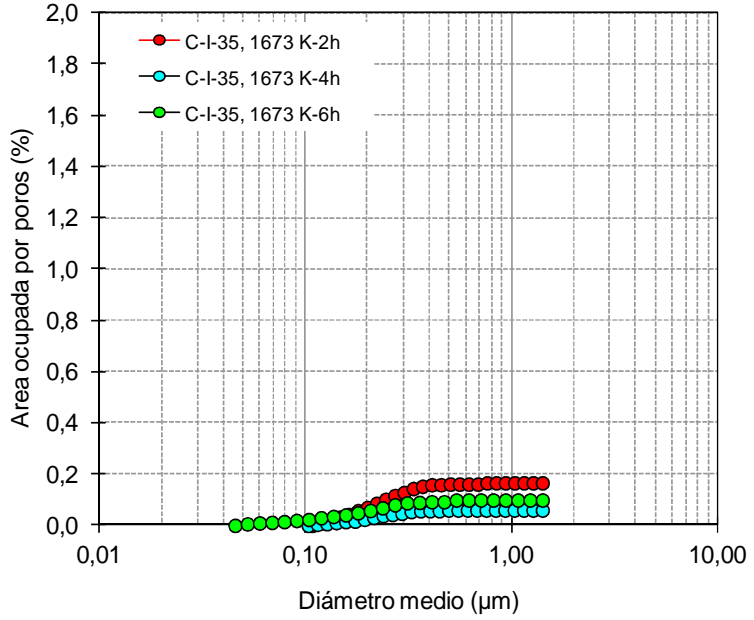

(a)

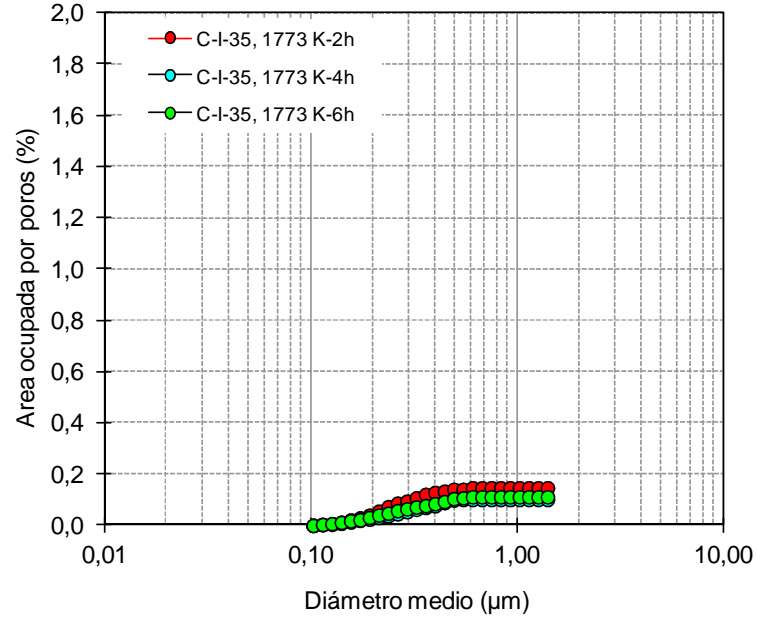

(b)

Figura 4.39. Representación del área ocupada por poros de distinto tamaño en las láminas sinterizadas a diferentes tiempos de residencia. (a) Láminas sinterizadas a $1673 \mathrm{~K}$. (b) Láminas sinterizadas a $1773 \mathrm{~K}$.

En la Figura 4.40 se ha representado los valores de la porosidad $(\boldsymbol{\varepsilon})$ en función del tiempo de residencia a cada temperatura de sinterización ensayada. 


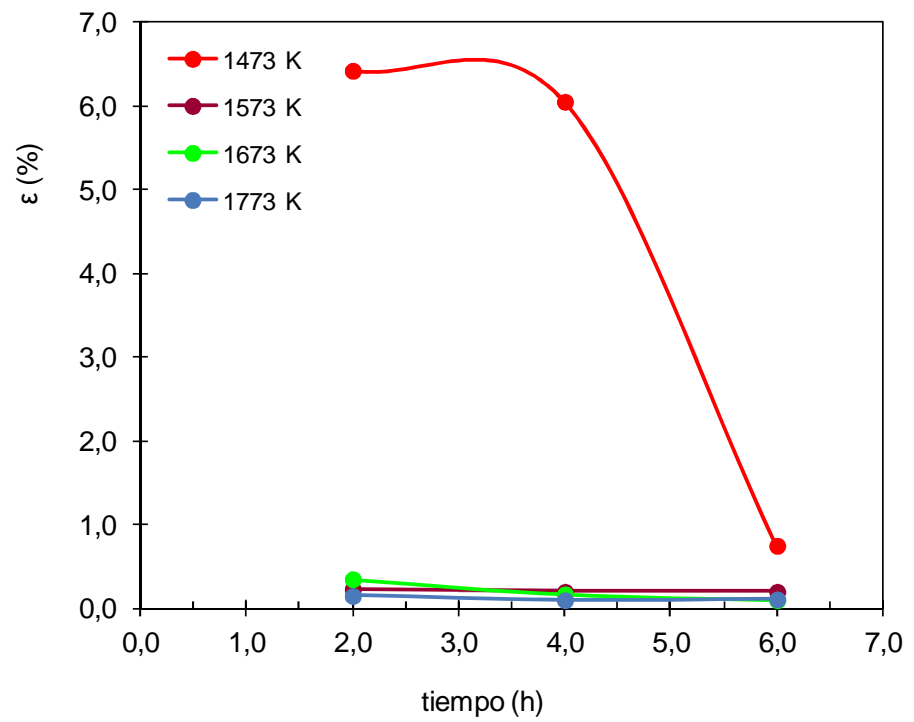

Figura 4.40. Porosidad de las probetas obtenidas a las diferentes temperaturas de sinterización y tiempos de residencia ensayados.

En la Figura 4.41 puede apreciarse visualmente el aspecto de la sección transversal de dichas láminas. Dichas imágenes confirman los resultados mostrados en las Figuras 4.38 a 4.40 .

De la observación de la Tabla 4.18 y de las citadas figuras se deduce lo siguiente:

a) Los valores de la porosidad obtenidos son del orden de diez a veinte veces (según la temperatura de sinterización y el tiempo de residencia que se considere) más pequeños que los resultantes de las laminas conformadas con la suspensión $\boldsymbol{C}$-I-15 tratadas a las mismas condiciones.

b) Los valores más bajos de la porosidad $(0,10-0,11 \%)$ se obtuvieron para las láminas sinterizadas a $1673 \mathrm{~K}$ (seis horas) y $1773 \mathrm{~K}$ (cuatro y seis horas). En estos casos, puede admitirse que las láminas resultantes están prácticamente exentas de porosidad.

Este resultado, como se esperaba, es coherente con el hecho de que las láminas secas, coladas a partir de la suspensión $\boldsymbol{C}$-I-35, poseen un contenido bastante más bajo de materia orgánica que las obtenidas a partir de la suspensión $C-I-15$ y, en consecuencia, se partió de una estructura más compacta al iniciar la etapa de sinterización. 


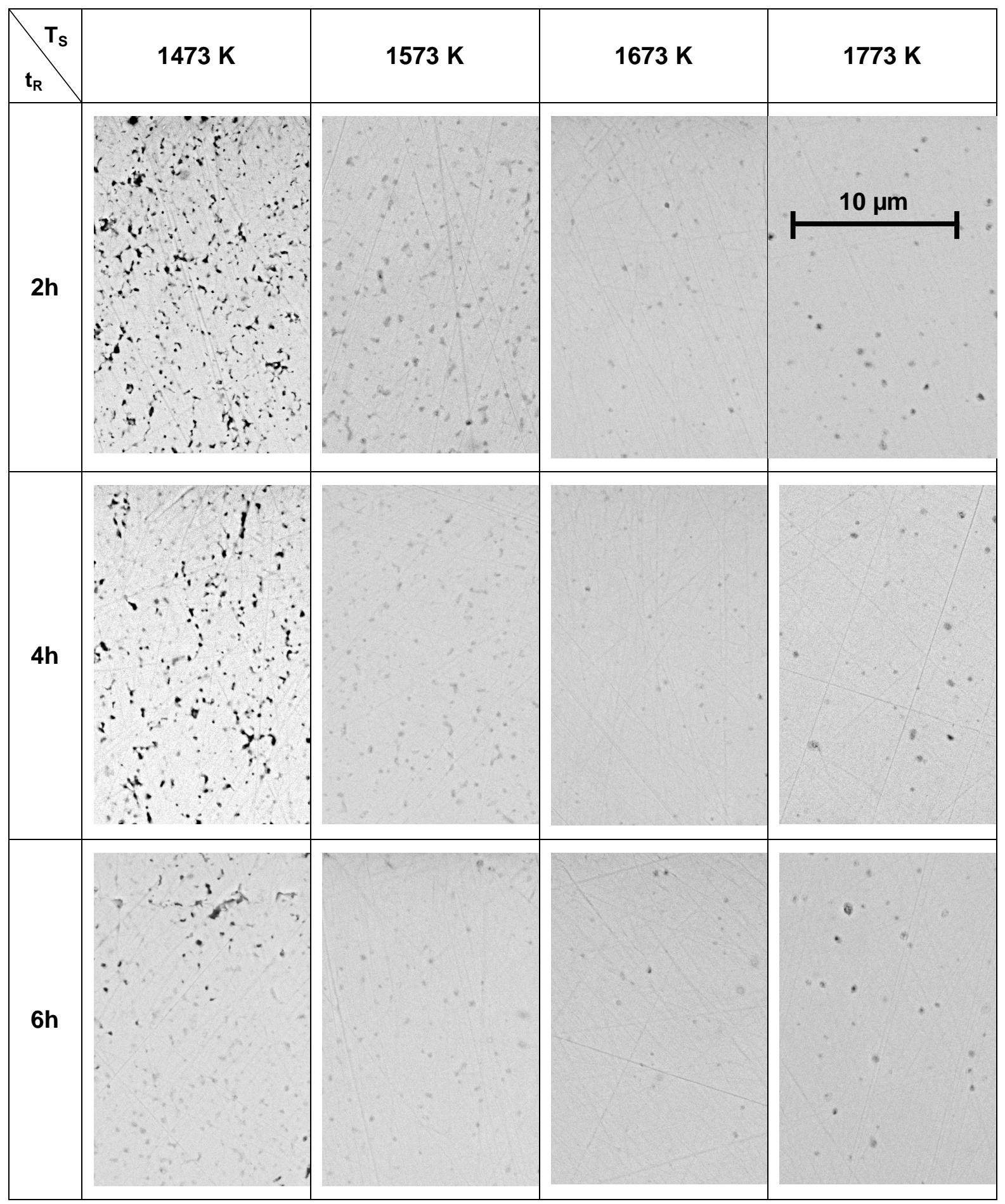

Figura 4.41. Micrografías mostrando los poros de una sección transversal de las láminas sinterizadas utilizando los distintos ciclos térmicos estudiados. 


\subsubsection{Influencia del ciclo térmico de sinterización sobre el diámetro medio de grano de las láminas resultantes.}

En muestras de las láminas sinterizadas, utilizando los ciclos térmicos descritos en el segundo párrafo del Apartado 4.4.1.1, se determinó la distribución de tamaño de grano que se describe en los dos apartados que se exponen a continuación.

\section{(i) Láminas obtenidas a partir de la suspensión C-I-15 (Apartado 4.4.1.1.(i))}

Las curvas de distribución del área acumulada ocupada por los granos en función del diámetro medio de grano, correspondientes a las láminas resultantes de la sinterización a las temperaturas de $1673 \mathrm{~K}$ y $1773 \mathrm{~K}$ y a los tres tiempos de residencia estudiados, se muestran en las representaciones de la Figura 4.42.

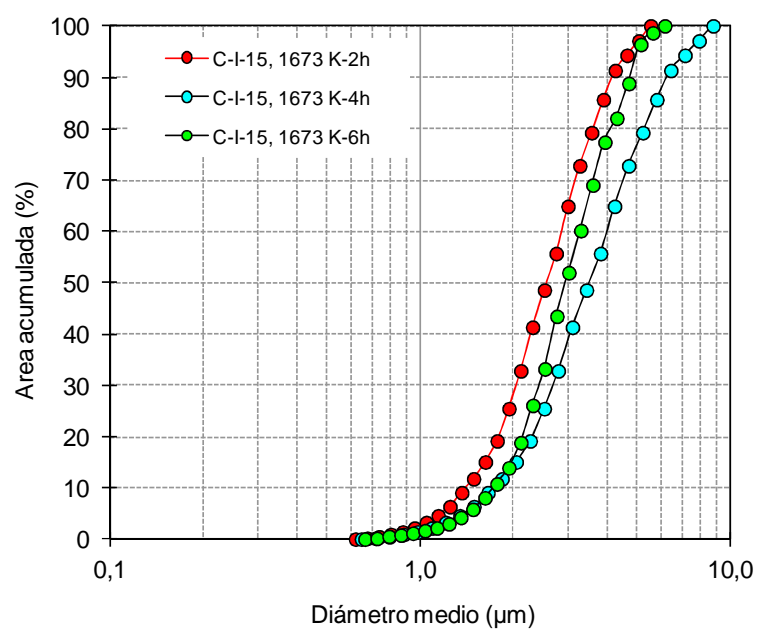

(a)

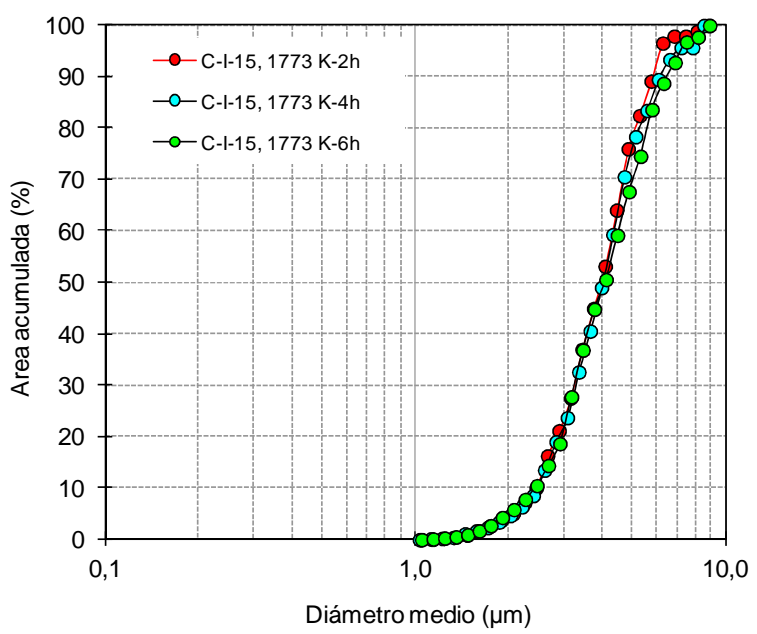

(b)

Figura 4.42. Representación del área acumulada ocupada por los granos frente a su diámetro medio para distintas temperaturas de sinterización y tiempos de residencia. (a) Láminas sinterizadas a $1673 \mathrm{~K}$. (b) Láminas sinterizadas a $1773 \mathrm{~K}$.

En la Figura 4.43 se muestra la misma representación para láminas sinterizadas a las tres temperaturas ensayadas, para un tiempo de residencia de 6 horas.

En la Tabla 4.19 se detalla el valor del diámetro medio de grano $\left(\boldsymbol{D}_{50}\right)$ correspondiente a cada muestra estudiada.

Como puede apreciarse en dicha tabla, en las muestras resultantes de los experimentos realizados a 1673 y $1773 \mathrm{~K}$, el tamaño medio de grano aumenta al aumentar la temperatura de sinterización y el tiempo de residencia. 


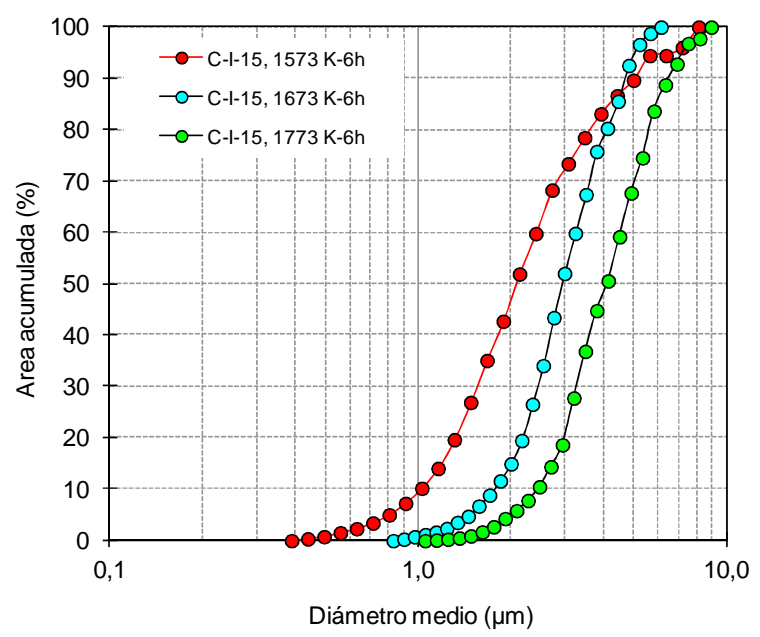

Figura 4.43. Representación del porcentaje de área acumulada ocupada por los granos frente a su diámetro medio. Láminas sinterizadas, con un tiempo de residencia de 6 horas, a las tres temperaturas de sinterización estudiadas.

\begin{tabular}{|ccc}
\hline $\begin{array}{c}\text { Tabla 4.19. Láminas coladas de la suspensión } \\
\text { medio de grano de las muestras resultantes de cada ciclo } \\
\text { térmico ensayado }\end{array}$ \\
\hline $\begin{array}{c}\text { Temperatura de } \\
\text { sinterización }(\mathrm{K})\end{array}$ & $\begin{array}{c}\text { tiempo de } \\
\text { residencia a } \mathrm{T}_{\mathrm{S}}(\mathrm{h})\end{array}$ & $\begin{array}{c}\mathrm{D}_{50} \\
(\boldsymbol{\mu} \mathrm{m})\end{array}$ \\
\hline $\mathbf{1 5 7 3}$ & 2 & --- \\
& 4 & --- \\
& 6 & 1,8 \\
\hline 1673 & 2 & 2,56 \\
& 4 & 2,95 \\
& 6 & 3,20 \\
\hline 1773 & 1 & --- \\
& 2 & 3,60 \\
& 4 & 4,04 \\
& 6 & 4,40 \\
\hline
\end{tabular}

\section{(ii) Láminas obtenidas a partir de la suspensión C-I-35 (Apartado 4.4.1.1.(ii))}

En las Figuras 4.44 y 4.45 se han representado las curvas de distribución del área acumulada ocupada por los granos en función del diámetro medio de grano, correspondientes a las láminas sinterizadas a las cuatro temperaturas $(1473,1573,1673$ y $1773 \mathrm{~K})$ y los tres tiempos de residencia estudiados (2, 4 y 6 h). 


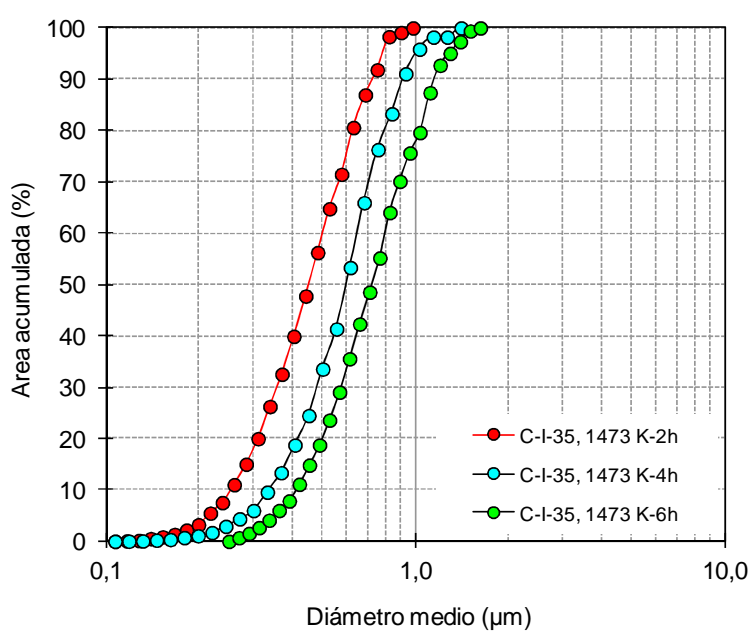

(a)

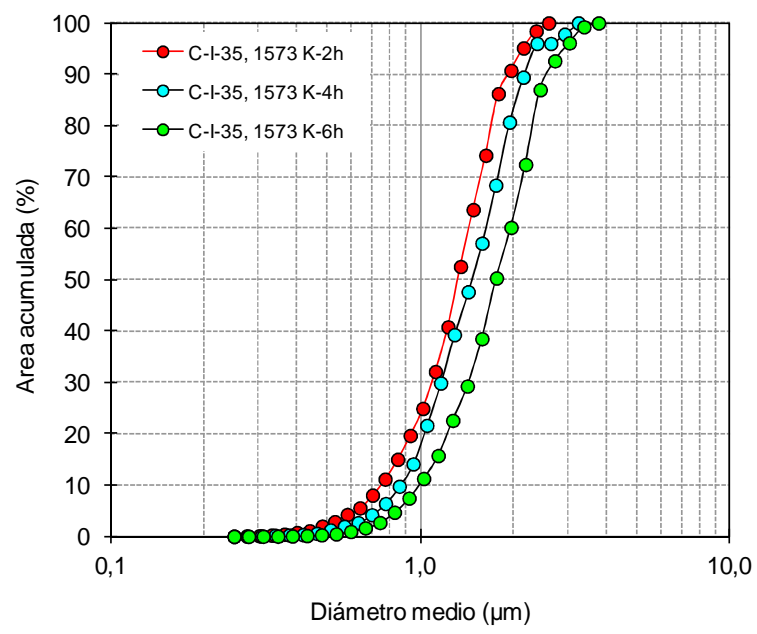

(b)

Figura 4.44. Representación del área acumulada ocupada por los granos frente a su diámetro medio, para distintos tiempos de residencia. (a) Láminas sinterizadas a $1473 \mathrm{~K}$. (b) Láminas sinterizadas a $1573 \mathrm{~K}$.

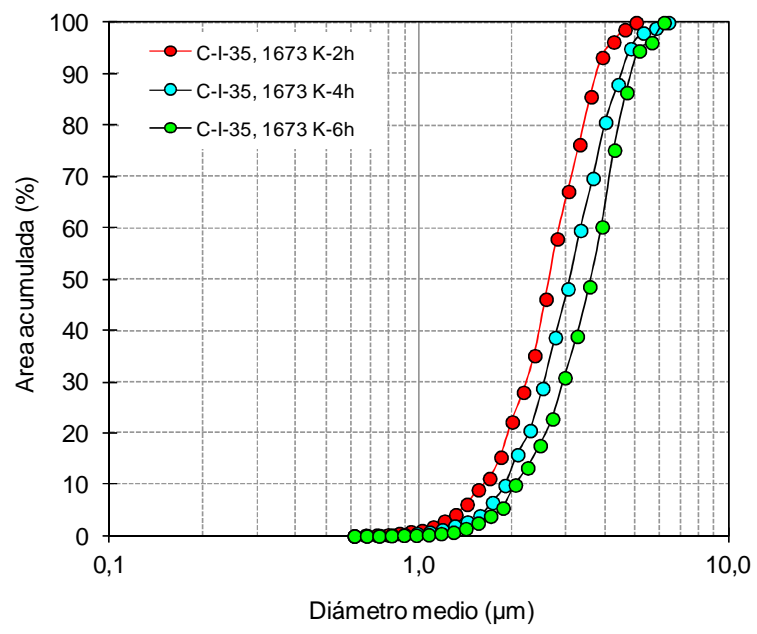

(a)

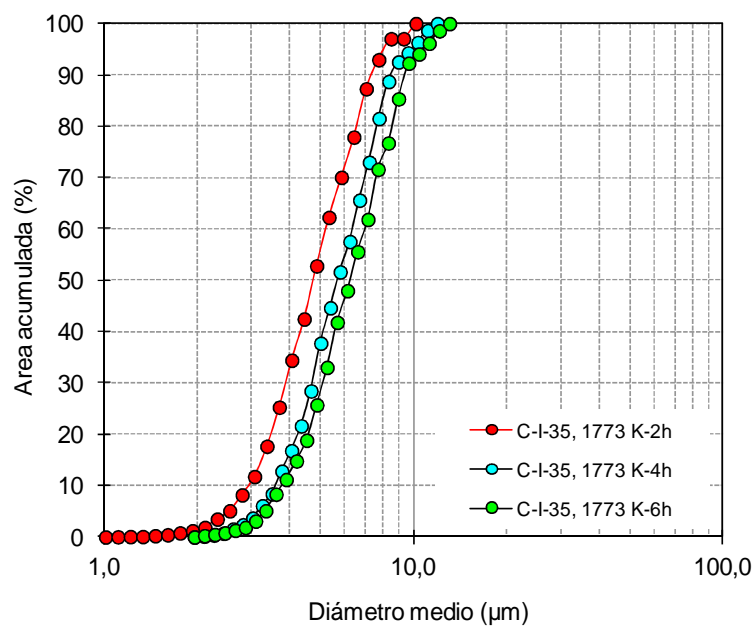

(b)

Figura 4.45. Representación del área acumulada ocupada por los granos frente a su diámetro medio, para distintos tiempos de residencia. (a) Láminas sinterizadas a $1673 \mathrm{~K}$. (b) Láminas sinterizadas a $1773 \mathrm{~K}$.

En las Figuras 4.46 a 4.49 se muestra, a modo de ilustración, un conjunto de imágenes (obtenidas en el MEB) representativas de la forma y de la evolución del tamaño de grano, en la superficie de las láminas sinterizadas, con la temperatura de sinterización y el tiempo de residencia estudiados (las microfotografías están realizadas con el mismo número de aumentos por lo que son comparables visualmente). 


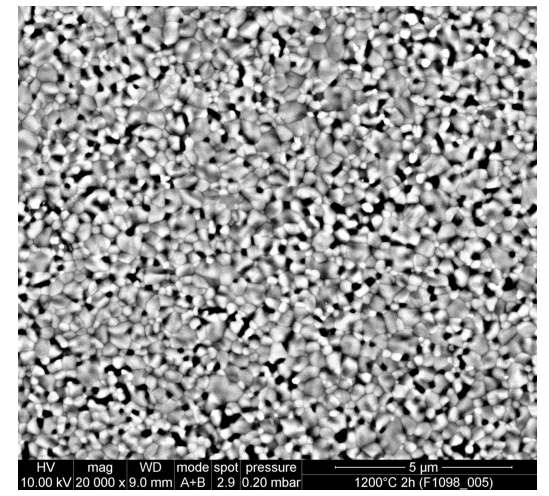

$t=2 h$

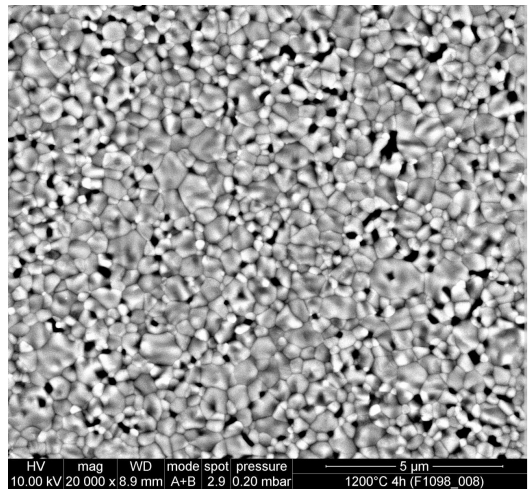

$t=4 h$

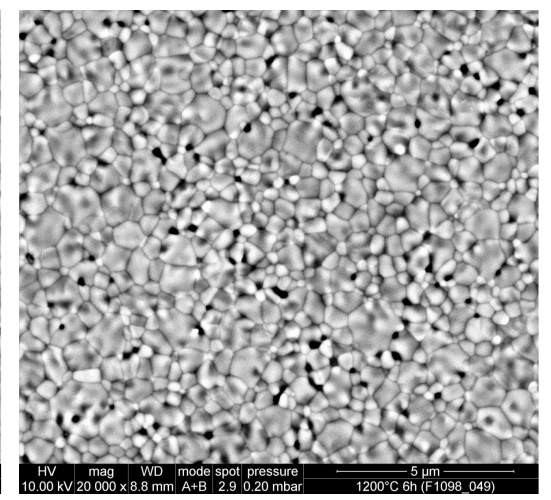

$t=6 h$

Figura 4.46. Micrografías de la superficie de las láminas sinterizadas a 1473 K, para tigual a 2, 4 y 6 h mostrando la evolución del tamaño de los granos.

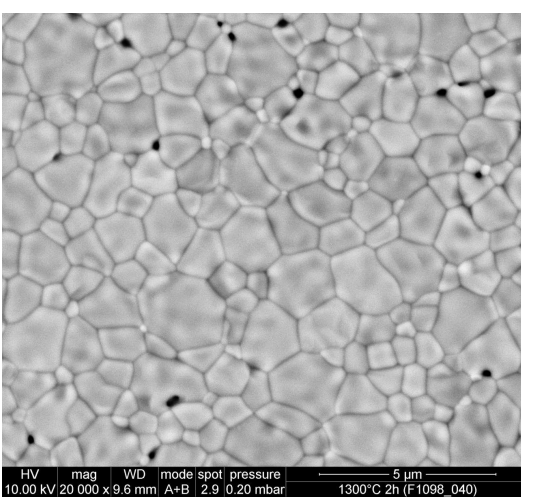

$t=2 h$

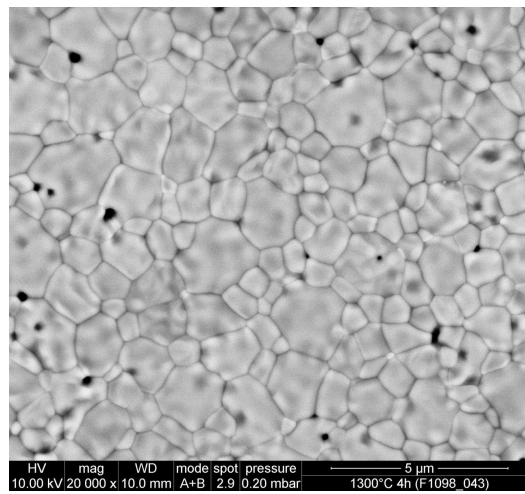

$t=4 h$

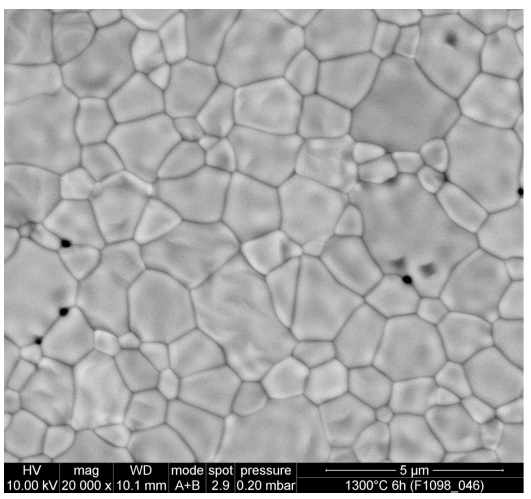

$t=6 h$

Figura 4.47. Micrografías de la superficie de las láminas sinterizadas a 1573 K, para t igual a 2, 4 y 6 h mostrando la evolución del tamaño de los granos.

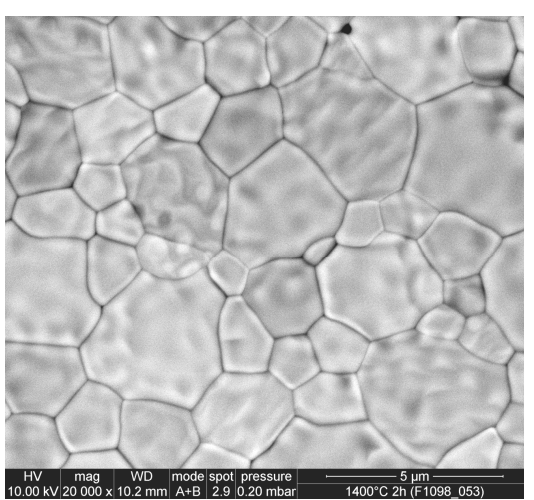

$t=2 h$

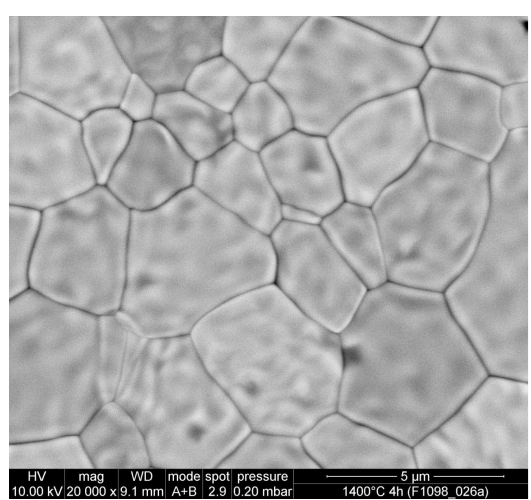

$t=4 h$

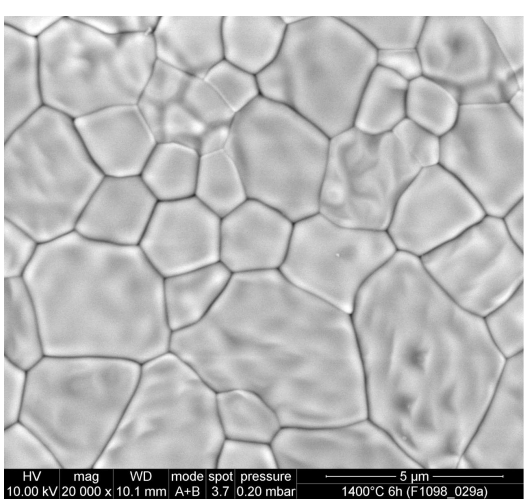

$t=6 h$

Figura 4.48. Micrografías de la superficie de las láminas sinterizadas a 1673 K, para tigual a 2, 4 y 6 h mostrando la evolución del tamaño de los granos. 


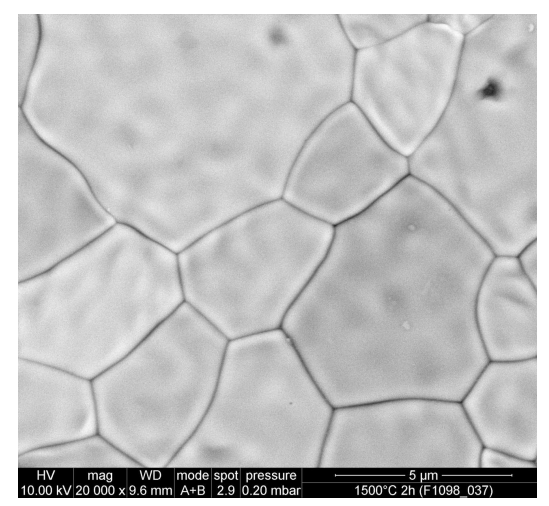

$t=2 h$

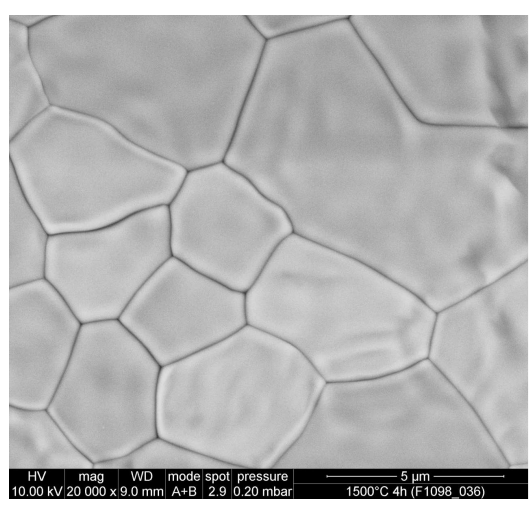

$t=4 h$

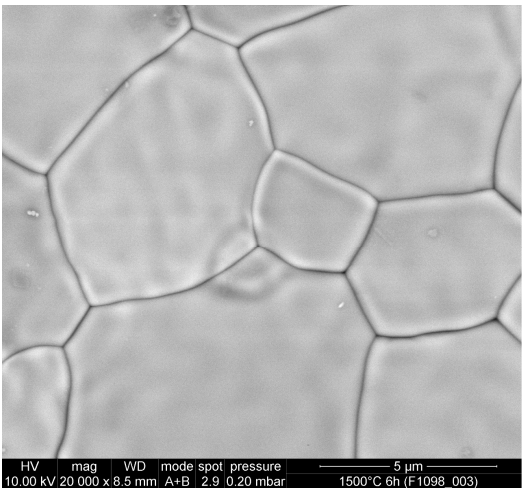

$t=6 h$

Figura 4.49. Micrografías de la superficie de las láminas sinterizadas a 1773 K, para tigual a 2, 4 y $6 \mathrm{~h}$ mostrando la evolución del tamaño de los granos.

\begin{tabular}{|ccc}
\hline $\begin{array}{l}\text { Tabla 4.20. Láminas coladas de la suspensión } C-I-35 . \text { Diámetro } \\
\text { medio de grano de las muestras resultantes de cada ciclo } \\
\text { térmico ensayado }\end{array}$ \\
\hline $\begin{array}{c}\text { Temperatura de } \\
\text { sinterización (K) }\end{array}$ & $\begin{array}{c}\text { tiempo de } \\
\text { residencia } \\
\text { a } \text { T }_{\mathbf{S}} \text { (min) }\end{array}$ & $\begin{array}{c}\mathrm{D}_{50} \\
(\boldsymbol{\mu m})\end{array}$ \\
\hline 1473 & 2 & 0,46 \\
& 4 & 0,59 \\
& 6 & 0,66 \\
\hline 1573 & 2 & 1,32 \\
& 4 & 1,52 \\
& 6 & 1,76 \\
\hline 1673 & 2 & 2,65 \\
& 4 & 3,06 \\
& 6 & 3,50 \\
\hline 1773 & 2 & 4,75 \\
& 4 & 5,71 \\
& 6 & 6,30 \\
\hline
\end{tabular}

Como puede apreciarse en las Figuras 4.44 a 4.49 y en la Tabla 4.20, el diámetro medio de grano aumenta con la temperatura y el tiempo de residencia. 


\subsubsection{Resistencia mecánica de las láminas sinterizadas}

La resistencia mecánica de las láminas sinterizadas únicamente se determinó con láminas obtenidas a partir de la suspensión C-I-35 sinterizadas a $1673 \mathrm{~K}$ durante seis horas.

Utilizando la metodología descrita en el Apartado 3.2.4.4 se obtuvo un valor de $121 \mathrm{MPa}$.

Los resultados de las medidas realizadas se muestran en el Apartado 8.2 del Apéndice

\subsubsection{Experimentos con probetas prensadas}

Las probetas prensadas a partir de la composición $\boldsymbol{C}$-I, se sometieron a los mismos ciclos térmicos (para eliminar previamente el aditivo orgánico y para proceder posteriormente a su sinterización) que las láminas obtenidas a partir de las suspensiones $\mathbf{C}-\mathbf{I - 1 5}$ y $\mathbf{C}-\mathbf{I}-\mathbf{3 5}$, antes descritos.

En este caso se operó solamente a las temperaturas de sinterización de 1573, 1673 y 1773 $\mathrm{K}$, con tiempos de residencia de 2,4 y 6 horas, excepto a la temperatura más alta, en la que se realizaron también experimentos para un tiempo de residencia de $1 \mathrm{~h}$.

Como en el caso de las láminas, en cada experimento de sinterización, se determinó la porosidad y el diámetro medio de poro $\left(\boldsymbol{d}_{50}\right)$, así como el diámetro medio de grano $\left(\boldsymbol{D}_{50}\right)$ de las probetas resultantes.

\subsubsection{Influencia del ciclo térmico de sinterización sobre la porosidad de las probetas resultantes.}

En las Figuras 4.50 y 4.51 se ha representado el área ocupada por los poros frente al diámetro medio de poro, para cada una de las probetas sinterizadas a las condiciones de operación estudiadas (temperatura de sinterización y tiempo de residencia a dicha temperatura).

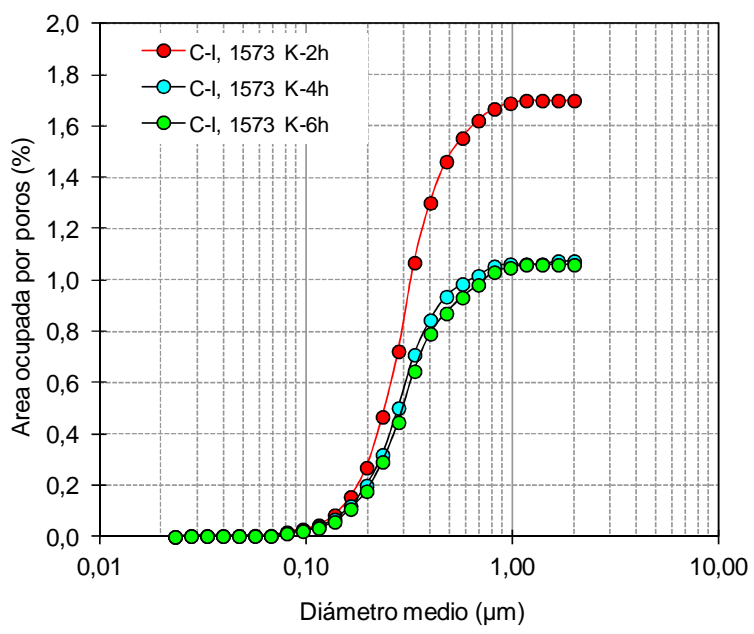

(a)

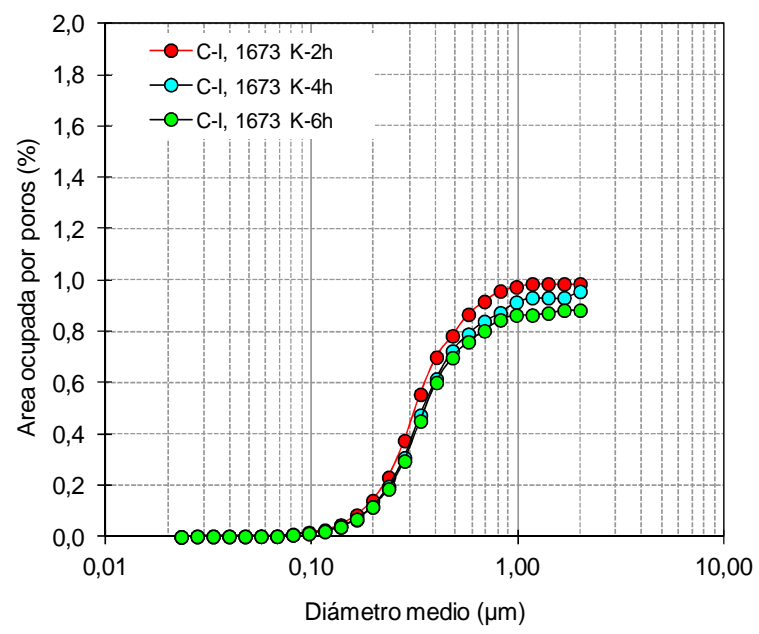

(b)

Figura 4.50. Representación del área ocupada por poros de distinto tamaño en las piezas prensadas sinterizadas, a diferentes tiempos de residencia. (a) Probetas sinterizadas a $1573 \mathrm{~K}$. (b) Probetas sinterizadas a $1673 \mathrm{~K}$. 


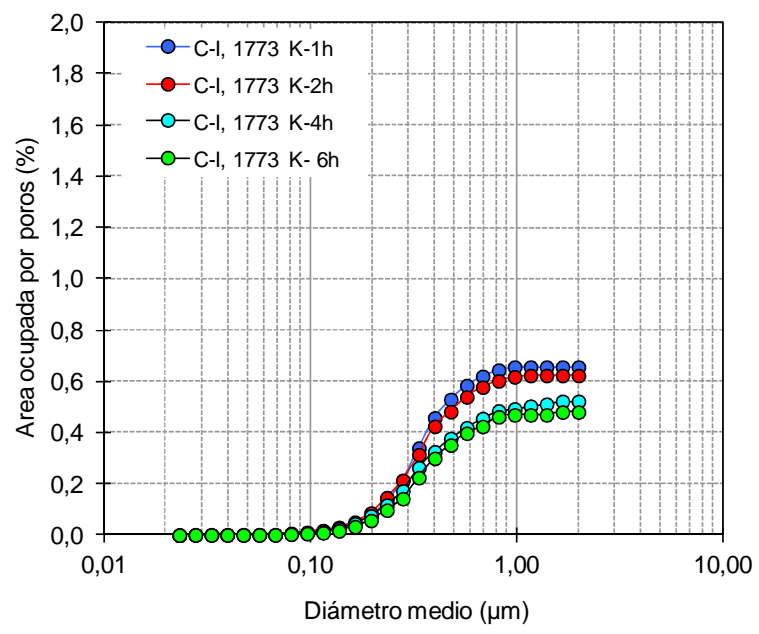

Figura 4.51. Representación del área ocupada por poros de distinto tamaño en las piezas prensadas sinterizadas, a diferentes tiempos de residencia, a la temperatura de $1773 \mathrm{~K}$.

En la Tabla 4.21 se muestran los valores de la porosidad $(\varepsilon)$ y del diámetro medio de poro $\left(\boldsymbol{d}_{50}\right)$ de las probetas, determinados a partir de dichas representaciones.

\begin{tabular}{|c|c|c|c|}
\hline $\begin{array}{l}\text { Temperatura de } \\
\text { sinterización }(\mathrm{K})\end{array}$ & $\begin{array}{c}\text { tiempo de } \\
\text { residencia a } \mathrm{T}_{\mathrm{S}} \\
\text { (min) }\end{array}$ & $\varepsilon(\%)$ & $\begin{array}{l}d_{50} \\
(\mu \mathrm{m})\end{array}$ \\
\hline \multirow[t]{3}{*}{1573} & 2 & 1,70 & 0,30 \\
\hline & 4 & 1,07 & 0,29 \\
\hline & 6 & 1,06 & 0,30 \\
\hline \multirow[t]{3}{*}{1673} & 2 & 0,99 & 0,32 \\
\hline & 4 & 0,96 & 0,34 \\
\hline & 6 & 0,88 & 0,33 \\
\hline \multirow[t]{4}{*}{1773} & 1 & 0,66 & 0,33 \\
\hline & 2 & 0,62 & 0,33 \\
\hline & 4 & 0,52 & 0,34 \\
\hline & 6 & 0,48 & 0,35 \\
\hline
\end{tabular}

De la observación de las Figuras 4.50 y 4.51 y de los valores de la Tabla 4.21 , se deduce que: 
a) La porosidad de las probetas sinterizadas disminuye a medida que aumenta la temperatura de sinterización y el tiempo de residencia.

b) Las probetas con menor porosidad fueron las obtenidas a la temperatura de sinterización de $1773 \mathrm{~K}$.

c) El valor más bajo de la porosidad $(0,48 \%)$ se obtuvo para la probeta sinterizada a $1773 \mathrm{~K}$, durante un tiempo de residencia de seis horas.

\subsubsection{Influencia del ciclo térmico de sinterización sobre el diámetro medio de grano de las probetas resultantes.}

En las probetas sinterizadas a las que se hace referencia en el apartado anterior se determinó la distribución de tamaño de grano.

Las curvas de distribución del área acumulada ocupada por los granos en función del diámetro equivalente de grano, correspondientes a las probetas resultantes de la sinterización a las diferentes condiciones de temperatura y tiempos de residencia estudiados, se muestran en las Figuras 4.52 y 4.53.

En la Tabla 4.22 se muestra el valor del diámetro medio de grano $\left(\boldsymbol{D}_{50}\right)$ correspondiente a cada muestra estudiada, obtenido a partir de las representaciones de dichas figuras.

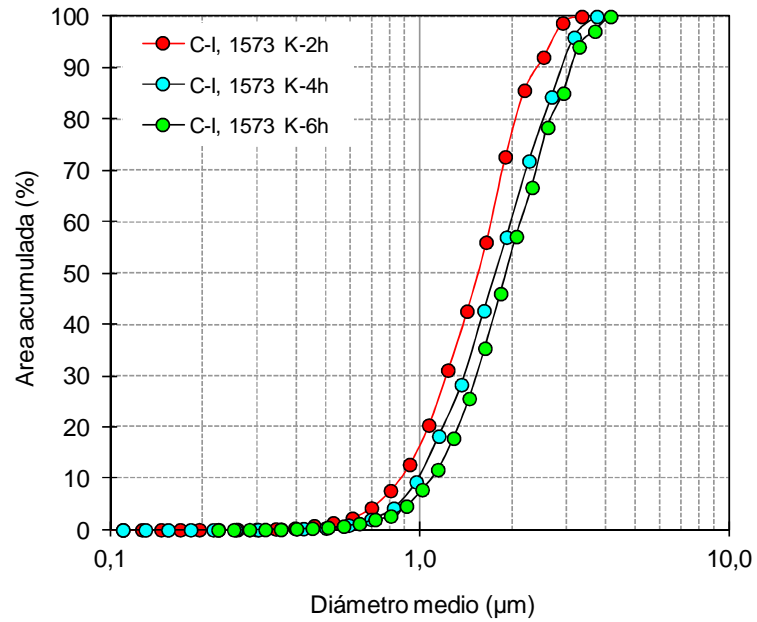

(a)

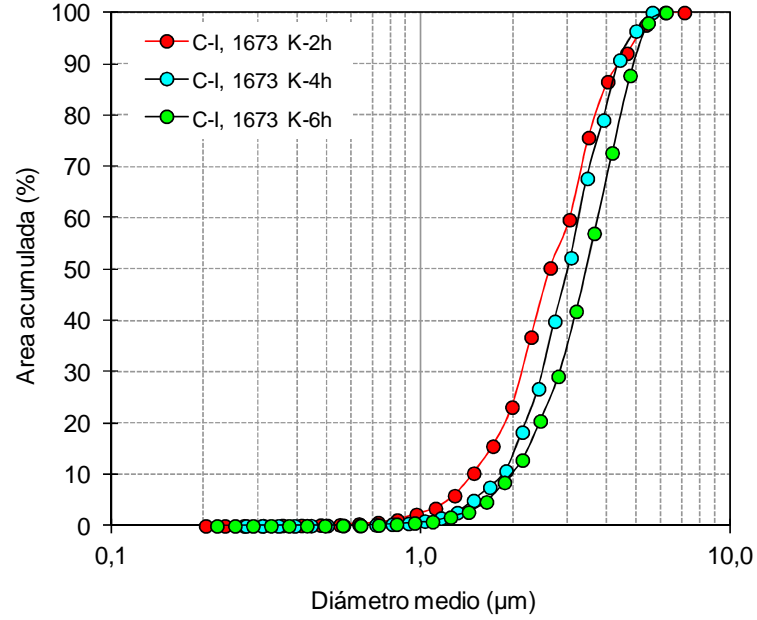

(b)

Figura 4.52. Representación del porcentaje de área acumulada ocupada por los granos frente a su diámetro medio. (a) Probetas sinterizadas a 1573 K. (b) Probetas sinterizadas a 1673 K. 


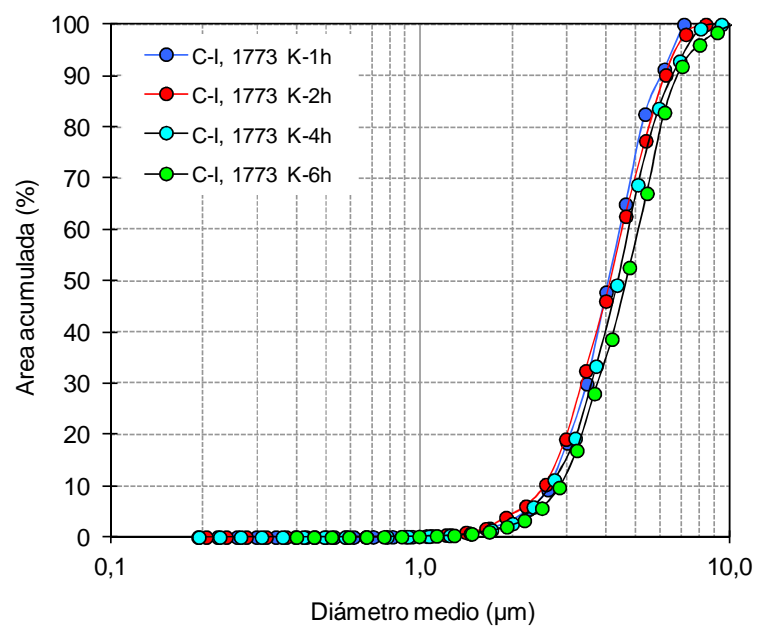

Figura 4.53. Representación del porcentaje de área acumulada ocupada por los granos frente a su diámetro medio. Probetas sinterizadas a 1773 K para distintos tiempos de residencia.

\begin{tabular}{|c|c|c|}
\hline $\begin{array}{l}\text { Temperatura de } \\
\text { sinterización }(\mathrm{K})\end{array}$ & $\begin{array}{c}\text { Tiempo de } \\
\text { residencia a } T_{S}(h)\end{array}$ & $\begin{array}{l}D_{50} \\
(\mu \mathrm{m})\end{array}$ \\
\hline \multirow[t]{3}{*}{1573} & 2 & 1,52 \\
\hline & 4 & 1,74 \\
\hline & 6 & 1,91 \\
\hline \multirow[t]{3}{*}{1673} & 2 & 2,70 \\
\hline & 4 & 3,01 \\
\hline & 6 & 3,30 \\
\hline \multirow[t]{4}{*}{1773} & 1 & 3,40 \\
\hline & 2 & 3,80 \\
\hline & 4 & 4,30 \\
\hline & 6 & 4,70 \\
\hline
\end{tabular}

También en este caso, el tamaño medio de grano aumenta con la temperatura de sinterización y el tiempo de residencia. 


\subsubsection{Influencia del ciclo térmico de sinterización sobre la conductividad iónica de las probetas resultantes.}

Para disponer de una expresión que permita relacionar los valores de la conductividad total del material con las conductividades representativas de la contribución de los granos y de los límites de grano, es preciso proponer previamente un modelo supuestamente representativo de la microestructura y del comportamiento eléctrico del material.

El modelo más frecuentemente utilizado para representar el transporte de iones a través de la estructura de electrolitos de células SOFC es el denominado "Brick Layer Model"43,44,45 por lo que todos los cálculos y la discusión de los mismos que se desarrollen en adelante se basaran en la utilización de dicho modelo que ha sido descrito en el Apartado 1.2.5.1.

Las resistencias eléctricas correspondientes al interior de los granos y a los límites de grano, a partir de las cuales se han calculado las resistividades y las conductividades respectivas mediante la ecuación (1.20), se determinaron a partir del espectro de impedancias obtenido con un Analizador de Impedancias SOLARTROM 1260 (Apartados 1.2.5.2.(ii) y 3.2.4.3).

Como se ha indicado en el Apartado 1.2.3, en los materiales que habitualmente se usan para la confección del electrolito en celdas SOFC (óxidos de circonio o de cerio dopados con cationes trivalentes $\left(\mathrm{Y}^{3+}, \mathrm{Sc}^{3+}, \mathrm{La}^{3+}\right.$, etc.), a las temperaturas elevadas a las que suelen operar (entre 973 y $1273 \mathrm{~K}$ ) y a las presiones parciales de oxígeno a las que normalmente se emplean en el cátodo de las celdas de combustible (alrededor de 0,21 atm), el proceso de conducción eléctrica dominante es el iónico, siendo prácticamente despreciable la conducción electrónica ${ }^{98,99}$. Por tanto, cuando se opera en estas condiciones, puede admitirse que las conductividades medidas coinciden prácticamente con las respectivas conductividades iónicas.

Antes de abordar la medida de las conductividades de las muestras preparadas era necesario saber si las variaciones de presión parcial de oxígeno, en el ambiente en el que se desarrollaban las medidas, podía afectar cuantitativamente a las mismas, aún cuando todas ellas se realizaron en presencia de aire, por tanto los valores de la $\mathrm{p}_{\mathrm{O} 2}$ oscilaban alrededor de $21 \mathrm{kPa}$.

Las conductividades iónicas, en el interior de grano y en los límites de grano, de circona estabilizada con óxidos de escandio y co-dopada con óxidos de cerio e itrio han sido estudiadas recientemente, en el intervalo de temperaturas de ensayo de $573-973 \mathrm{~K}$ y de presiones parciales de oxígeno comprendidas entre $10^{-22}$ y $100 \mathrm{kPa}(\mathrm{a} 973 \mathrm{~K})^{99,101,}$.

En los experimentos realizados con las composiciones que contenían óxidos de cerio y de itrio como dopantes, a la temperatura de ensayo de $973 \mathrm{~K}$, se observó que las conductividades medidas no resultaban afectadas por la presión parcial de oxígeno, en el intervalo de valores de dicha variable de operación comprendido entre $10^{-13}$ y $100 \mathrm{kPa}$. En todas las muestras que contenían óxido de cerio se observó una sensible disminución de la conductividad total $\left(\boldsymbol{\sigma}_{T}\right)$ y en el interior de los granos $\left(\boldsymbol{\sigma}_{g}\right)$ cuando se operó a presiones parciales de oxígeno inferiores a $10^{-13} \mathrm{kPa}^{98}$.

En cambio, como se muestra en la Figura 4.54, en los experimentos realizados por el grupo de investigación de la Escuela de Química de la Universidad de St. Andrews, operando a la misma temperatura de ensayo de $973 \mathrm{~K}$, con una muestra de análoga composición a la $\boldsymbol{C}$-I $(10 S c 1 C e 89 Z r)$ utilizada en esta investigación ${ }^{100}$, no se apreció influencia alguna en todo el intervalo de valores de la presión parcial de oxígeno estudiada (entre $10^{-20}$ y $100 \mathrm{kPa}$ ). En la grafica que se adjunta se ha expresado en bares la presión parcial del oxígeno, respetando la representación original de los autores. 


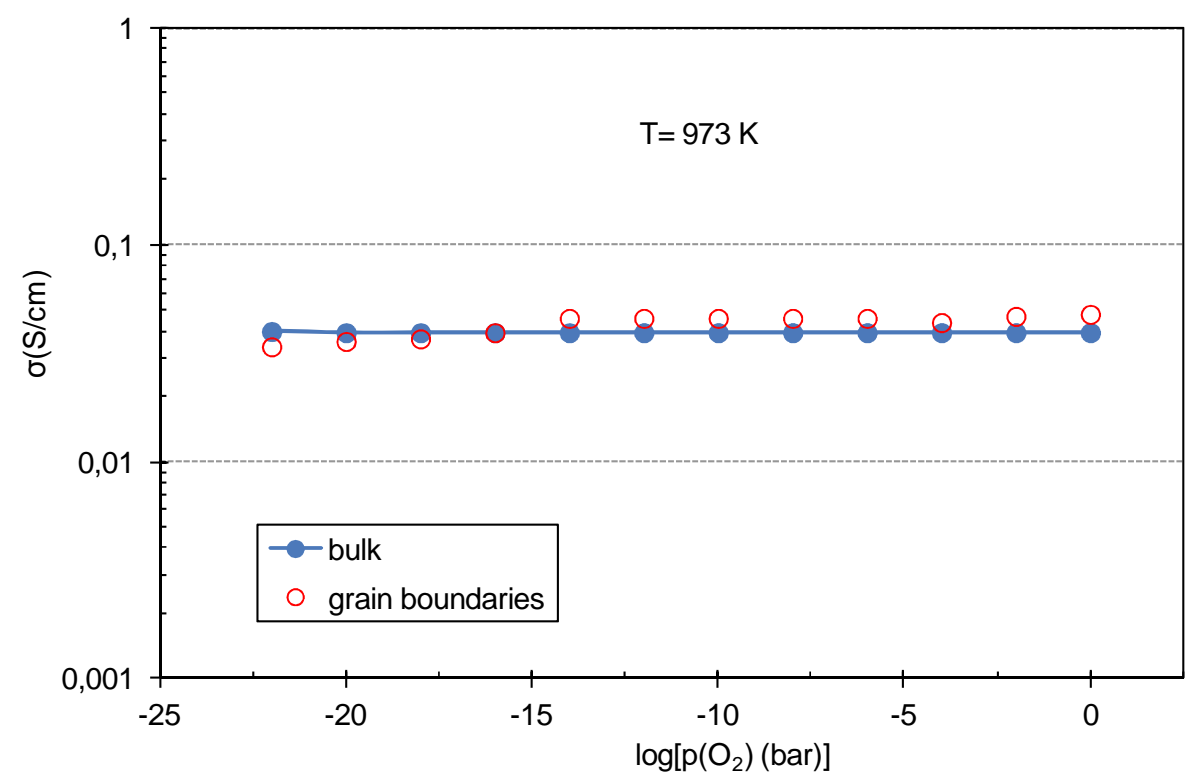

Figura 4.54. Variación de la conductividad en el interior de los granos y en los límites de grano frente a la presión parcial de oxígeno (en bar), en una muestra de composición 10Sc1Ce89SZr, análoga a la C-I, medidas a la temperatura de ensayo de $973 \mathrm{~K}^{100 .}$

Dado que, según la bibliografía consultada ${ }^{18}$, las pequeñas variaciones de la presión parcial de oxígeno en el ambiente en el que se realizaba las medidas de impedancia (alrededor de $21 \mathrm{kPa}$ ) no tenían influencia sobre el valor de dichas medidas, se procedió a la realización de las mismas con muestras de las probetas prensadas sinterizadas a las diez condiciones de operación estudiadas.

Con cada muestra se realizaron medidas, cada $50 \mathrm{~K}$ de temperatura, en el intervalo comprendido entre $573 \mathrm{~K}$ y $1273 \mathrm{~K}$. Los valores obtenidos para la resistividad correspondiente al interior de los granos $\left(\boldsymbol{\rho}_{g}\right)$, a los límites de grano $\left(\boldsymbol{\rho}_{l g}\right)$ y la resistividad total $\left.\left(\boldsymbol{\rho}_{T}\right)\right)$, así como los respectivos valores de la conductividad $\left(\boldsymbol{\sigma}_{g}, \boldsymbol{\sigma}_{I g}\right.$ y $\left.\boldsymbol{\sigma}_{T}\right)$, obtenidos a partir de las medidas realizadas, se muestran en las Tablas 8.1 a 8.10 del Apéndice 8.1.1.

En la Tabla 4.23 se muestran los valores medios de la conductividad total obtenidos, a las quince temperaturas de ensayo estudiadas, para las diez muestras estudiadas. 
Tabla 4.23. Probetas prensadas de composición $C-I$ sinterizadas a diferentes condiciones de temperatura $\left(T_{s}\right)$ y tiempo de residencia $(t)$. Variación de la conductividad total $\left(\sigma_{T}\right)(S / c m)$ con $T_{S}$, $t$ y la temperatura de ensayo $\left(T_{e}\right)$

\begin{tabular}{|c|c|c|c|c|c|c|c|c|c|c|}
\hline \multirow{2}{*}{$\frac{T_{S}}{t_{R}(h)}$} & \multicolumn{3}{|c|}{$1573 \mathrm{~K}$} & \multicolumn{3}{|c|}{$1673 \mathrm{~K}$} & \multicolumn{4}{|c|}{1773 K } \\
\hline & $2 \mathrm{~h}$ & $4 \mathrm{~h}$ & $6 \mathrm{~h}$ & $2 \mathrm{~h}$ & $4 \mathrm{~h}$ & $6 \mathrm{~h}$ & $1 \mathrm{~h}$ & $2 \mathrm{~h}$ & $4 \mathrm{~h}$ & $6 \mathrm{~h}$ \\
\hline \multicolumn{11}{|l|}{$T_{e}(K)$} \\
\hline 573 & $2,66 \mathrm{E}-6$ & 2,73E-6 & $2,74 \mathrm{E}-6$ & $2,82 \mathrm{E}-6$ & $2,85 \mathrm{E}-6$ & 2,92E-6 & $2,91 \mathrm{E}-6$ & $2,90 \mathrm{E}-6$ & $2,90 \mathrm{E}-6$ & 2,92E-6 \\
\hline 623 & $2,65 E-5$ & $2,70 \mathrm{E}-5$ & $2,80 \mathrm{E}-5$ & 2,82E-5 & $2,92 \mathrm{E}-5$ & $2,89 \mathrm{E}-5$ & 2,89E-5 & $2,92 \mathrm{E}-5$ & $2,90 \mathrm{E}-5$ & $2,93 \mathrm{E}-5$ \\
\hline 673 & $1,99 \mathrm{E}-4$ & $2,05 \mathrm{E}-4$ & $2,09 \mathrm{E}-4$ & $2,17 \mathrm{E}-4$ & $2,20 \mathrm{E}-4$ & $2,21 \mathrm{E}-4$ & $2,26 \mathrm{E}-4$ & $2,24 \mathrm{E}-4$ & $2,30 \mathrm{E}-4$ & $2,32 \mathrm{E}-4$ \\
\hline 723 & $1,01 \mathrm{E}-3$ & $1,05 \mathrm{E}-3$ & $1,08 \mathrm{E}-3$ & $1,11 \mathrm{E}-3$ & $1,15 \mathrm{E}-3$ & $1,14 \mathrm{E}-3$ & $1,15 \mathrm{E}-3$ & $1,15 \mathrm{E}-3$ & $1,16 \mathrm{E}-3$ & $1,18 \mathrm{E}-3$ \\
\hline 773 & $3,30 \mathrm{E}-3$ & $3,60 \mathrm{E}-3$ & $3,87 \mathrm{E}-3$ & $3,96 \mathrm{E}-3$ & $4,01 \mathrm{E}-3$ & $3,95 \mathrm{E}-3$ & 4,06E-3 & 4,07E-3 & $4,20 \mathrm{E}-3$ & $4,20 \mathrm{E}-3$ \\
\hline 823 & $7,20 \mathrm{E}-3$ & $8,49 \mathrm{E}-3$ & $9,62 \mathrm{E}-3$ & $1,04 \mathrm{E}-2$ & $1,06 \mathrm{E}-2$ & $1,00 \mathrm{E}-2$ & $1,04 \mathrm{E}-2$ & $1,09 \mathrm{E}-2$ & 1,03E-2 & $1,10 \mathrm{E}-2$ \\
\hline 873 & 1,21E-2 & 1,56E-2 & $1,90 \mathrm{E}-2$ & $2,15 \mathrm{E}-2$ & $2,16 \mathrm{E}-2$ & $2,10 \mathrm{E}-2$ & $2,15 E-2$ & $2,06 \mathrm{E}-2$ & $2,15 \mathrm{E}-2$ & $2,20 \mathrm{E}-2$ \\
\hline 923 & 1,68E-2 & 2,33E-2 & $3,13 \mathrm{E}-2$ & 3,69E-2 & $3,74 \mathrm{E}-2$ & $3,63 \mathrm{E}-2$ & $3,46 \mathrm{E}-2$ & $3,61 \mathrm{E}-2$ & 3,77E-2 & $3,84 \mathrm{E}-2$ \\
\hline 973 & 2,06E-2 & $3,04 \mathrm{E}-2$ & 4,43E-2 & 5,55E-2 & 5,63E-2 & $5,47 \mathrm{E}-2$ & 5,27E-2 & 5,53E-2 & $5,74 \mathrm{E}-2$ & 5,74E-2 \\
\hline 1023 & 2,37E-2 & $3,64 \mathrm{E}-2$ & $5,63 \mathrm{E}-2$ & $7,59 \mathrm{E}-2$ & $7,61 \mathrm{E}-2$ & $7,41 \mathrm{E}-2$ & $7,22 \mathrm{E}-2$ & $7,59 \mathrm{E}-2$ & $7,70 \mathrm{E}-2$ & 7,71E02 \\
\hline 1073 & $2,61 \mathrm{E}-2$ & $4,15 \mathrm{E}-2$ & $6,63 \mathrm{E}-2$ & $9,45 \mathrm{E}-2$ & $9,54 \mathrm{E}-2$ & $9,32 \mathrm{E}-2$ & $9,16 \mathrm{E}-2$ & $9,84 \mathrm{E}-2$ & $9,95 \mathrm{E}-2$ & $9,95 \mathrm{E}-2$ \\
\hline 1123 & 2,81E-2 & $4,51 \mathrm{E}-2$ & $7,52 \mathrm{E}-2$ & $1,11 \mathrm{E}-1$ & $1,14 \mathrm{E}-1$ & $1,11 \mathrm{E}-1$ & $1,11 \mathrm{E}-1$ & $1,13 \mathrm{E}-1$ & $1,17 \mathrm{E}-1$ & $1,16 \mathrm{E}-1$ \\
\hline 1173 & 2,96E-2 & 4,76E-2 & $8,20 \mathrm{E}-2$ & 1,28E-1 & $1,28 \mathrm{E}-1$ & $1,29 \mathrm{E}-1$ & $1,29 \mathrm{E}-1$ & $1,31 \mathrm{E}-1$ & $1,30 \mathrm{E}-1$ & $1,29 \mathrm{E}-1$ \\
\hline 1223 & $3,09 \mathrm{E}-2$ & $4,88 \mathrm{E}-2$ & $8,74 \mathrm{E}-2$ & $1,41 \mathrm{E}-1$ & $1,41 \mathrm{E}-1$ & $1,43 \mathrm{E}-1$ & $1,45 \mathrm{E}-1$ & $1,46 \mathrm{E}-1$ & $1,48 \mathrm{E}-1$ & $1,47 \mathrm{E}-1$ \\
\hline 1273 & $3,14 \mathrm{E}-2$ & $4,86 \mathrm{E}-2$ & $9.09 \mathrm{E}-2$ & $1.52 \mathrm{E}-1$ & $1,54 \mathrm{E}-1$ & $1.56 \mathrm{E}-1$ & $1.57 \mathrm{E}-1$ & $1.58 \mathrm{E}-1$ & $1.61 \mathrm{E}-1$ & $1,60 \mathrm{E}-1$ \\
\hline
\end{tabular}




\subsubsection{Probetas conformadas a partir de la composición C-II}

En la composición $\boldsymbol{C}$-I la circona estaba cristalizada en su forma cúbica.

Para tratar de mejorar la resistencia mecánica de las láminas de electrolito sinterizadas se confeccionaron láminas a partir de la composición $\boldsymbol{C}$-II, constituida por una mezcla conteniendo un $80 \%$, en masa, de $10 \mathrm{Sc} 1 \mathrm{Ce} 89 \mathrm{Zr}$ y un $20 \%$ de $3 \mathrm{Y}_{2} \mathrm{O}_{3} .97 \mathrm{ZrO}_{2}$, en la que la circona estaba estabilizada en su forma tetragonal por la adición del $\mathrm{Y}^{23,29}$ (Apartado 3.2). Dado que la circona tetragonal policristalina posee una resistencia a la flexión (entre 800 y $2.400 \mathrm{MPa}$ ) bastante más elevada que la circona cristalizada en el sistema cúbico (del orden de $200 \mathrm{MPa})^{54}$, se consideró interesante estudiar como variaban las propiedades de las muestras sinterizadas con esta mezcla.

La información bibliográfica de que se disponía ${ }^{23,54}$ respecto al componente $3 \mathrm{Y}_{2} \mathrm{O}_{3} .97 \mathrm{ZrO} \mathrm{r}_{2}$ hacía pensar que, con las muestras conformadas a partir de la composición $\boldsymbol{C}$-II, se obtendrían conductividades algo inferiores a las resultantes para las probetas sinterizadas a partir de la composición $\boldsymbol{C}$-I. Ahora bien, si la diferencia era reducida, la mejora que podía obtenerse en lo referente a la resistencia mecánica de las láminas sinterizadas quizá pudiera compensar la pequeña disminución de la conductividad.

\subsubsection{Conductividades}

Para los cálculos de la conductividad, con esta composición, se conformaron probetas por prensado utilizando los mismos aditivos orgánicos que se habían empleado con la composición $\boldsymbol{C}$-I. Estas probetas se trataron con el ciclo térmico óptimo, reiteradamente descrito, hasta la temperatura de $1673 \mathrm{~K}$ a la que se mantuvieron durante 2, 4 y 6 horas respectivamente, determinando luego las conductividades a las mismas temperaturas de ensayo utilizadas con la composición $\boldsymbol{C}$-I. Todo ello a efectos de comparar los resultados con los obtenidos a partir de la composición $\boldsymbol{C}$-I sinterizada a las mismas condiciones de operación. Se eligieron estas condiciones de sinterización porque, con la composición $\boldsymbol{C}$-I, se había alcanzado ya el valor máximo posible de la conductividad (alrededor de 0,021 $\mathrm{S} / \mathrm{cm})$.

Los valores de la resistividad correspondiente al interior de los granos $\left(\boldsymbol{\rho}_{g}\right)$, a los límites de grano $\left(\boldsymbol{\rho}_{I g}\right)$ y la resistividad total $\left(\boldsymbol{\rho}_{T}\right)$, así como los respectivos valores de la conductividad $\left(\boldsymbol{\sigma}_{g}, \boldsymbol{\sigma}_{\mathrm{Ig}} \boldsymbol{y} \boldsymbol{\sigma}_{T}\right)$, obtenidos a partir de las medidas realizadas con las muestras ensayadas, se detallan en la Tabla 8.11 (Apéndice 8.1.2).

En la Tabla 4.24 se muestran los valores medios de $\sigma_{T}$, obtenidos de las probetas prensadas de composición $\boldsymbol{C}$-II sinterizadas a $1673 \mathrm{~K}$ durante diferentes tiempos de residencia $\left(\boldsymbol{t}_{\boldsymbol{R}}\right)$. 


\begin{tabular}{|c|c|c|c|}
\hline$T_{S}$ & & $1673 \mathrm{~K}$ & \\
\hline$t_{R}(h)$ & $2 \mathrm{~h}$ & $4 h$ & $6 \mathrm{~h}$ \\
\hline \multicolumn{4}{|l|}{$\mathrm{T}_{\mathrm{e}}(\mathrm{K})$} \\
\hline 573 & 4,03E-06 & 3,95E-06 & $4,15 \mathrm{E}-06$ \\
\hline 623 & 3,20E-05 & 3,16E-05 & $3,35 E-05$ \\
\hline 673 & 1,96E-04 & $1,90 \mathrm{E}-04$ & $2,01 \mathrm{E}-04$ \\
\hline 723 & 8,44E-04 & 8,04E-04 & $8,55 \mathrm{E}-04$ \\
\hline 773 & 2,75E-03 & 2,61E-03 & $2,78 \mathrm{E}-03$ \\
\hline 823 & 6,98E-03 & $6,80 \mathrm{E}-03$ & $7,28 \mathrm{E}-03$ \\
\hline 873 & 1,44E-02 & 1,48E-02 & 1,54E-02 \\
\hline 923 & 2,43E-02 & 2,69E-02 & $2,75 \mathrm{E}-02$ \\
\hline 973 & 3,55E-02 & 4,26E-02 & $4,23 E-02$ \\
\hline 1023 & 4,65E-02 & 6,03E-02 & $5,80 \mathrm{E}-02$ \\
\hline 1073 & 5,69E-02 & 7,86E-02 & $7,26 \mathrm{E}-02$ \\
\hline 1123 & 6,72E-02 & 9,58E-02 & 8,59E-02 \\
\hline 1173 & 7,58E-02 & $1,10 \mathrm{E}-01$ & $9,99 \mathrm{E}-02$ \\
\hline 1223 & 8,40E-02 & 1,24E-01 & $1,11 \mathrm{E}-01$ \\
\hline 1273 & $9,12 \mathrm{E}-02$ & 1,34E-01 & $1,20 \mathrm{E}-01$ \\
\hline
\end{tabular}

\subsubsection{Diámetro medio de grano}

En la Tabla 4.25 se muestra el valor del diámetro medio de grano $\left(\boldsymbol{D}_{50}\right)$ correspondiente a las muestras obtenidas con la composición $\boldsymbol{C}$-II, obtenido a partir de láminas preparadas por colado en banda con dicha composición y sinterizadas en la forma habitual (Figura 4.55). 


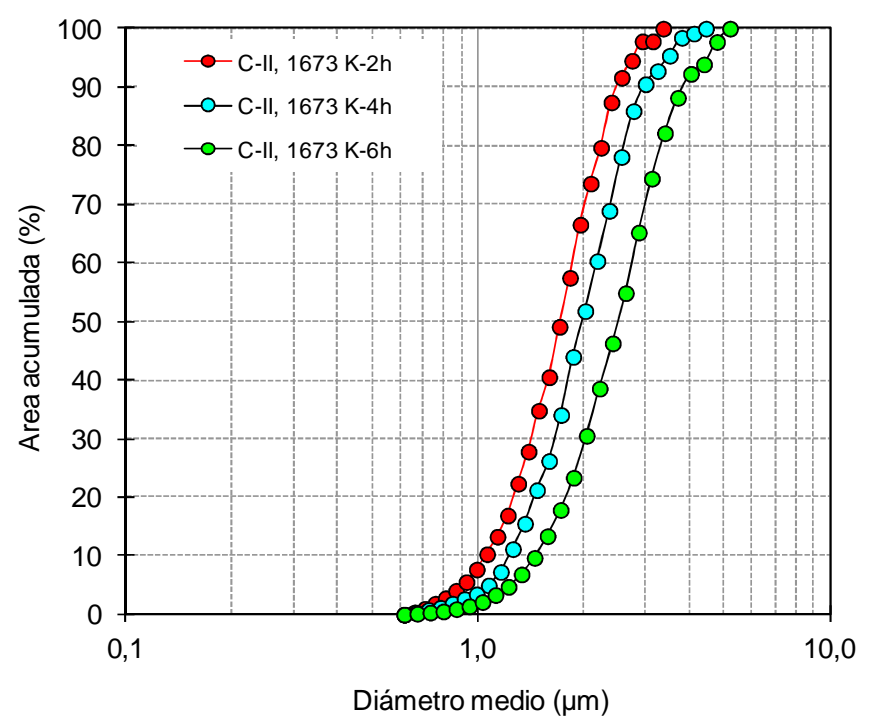

Figura 4.55. Representación del porcentaje de área acumulada ocupada por los granos frente a su diámetro medio. Probetas sinterizadas a 1673 K para distintos tiempos de residencia.

\begin{tabular}{|c|c|c|}
\hline $\begin{array}{l}\text { Temperatura de } \\
\text { sinterización }(K)\end{array}$ & $\begin{array}{c}\text { Tiempo de } \\
\text { residencia a } T_{S}(h)\end{array}$ & $\begin{array}{l}D_{50} \\
(\mu \mathrm{m})\end{array}$ \\
\hline \multirow[t]{3}{*}{1673} & 2 & 1,71 \\
\hline & 4 & 1,98 \\
\hline & 6 & 2,48 \\
\hline
\end{tabular}

\subsubsection{Resistencia mecánica de las láminas coladas sinterizadas}

Para determinar la resistencia mecánica de este material se conformaron láminas, por colado, a partir de suspensiones que tenían una proporción de disolvente y de aditivos orgánicos idéntica a la de la suspensión C-I-35. Las láminas coladas se sinterizaron utilizando el ciclo térmico correspondiente a la temperatura de $1673 \mathrm{~K}$ y tiempo de residencia de seis horas.

Utilizando la metodología descrita en el Apartado 3.2.4.4 se obtuvo un valor de $147 \mathrm{MPa}$.

Los resultados de las medidas realizadas se muestran en el Apartado 8.2 del Apéndice. 


\subsubsection{Probetas conformadas a partir de la composición C-III}

Esta composición también se formuló con la intención de mejorar la resistencia mecánica de las láminas sinterizadas ${ }^{101,102,103}$, sin detrimento de su conductividad iónica. Consistió en una mezcla conteniendo $2 \%$, en masa, de alúmina tipo $\alpha\left(\alpha-\mathrm{Al}_{2} \mathrm{O}_{3}\right)$ y un $98 \%$ de la composición C-I (10Sc1Ce89Zr,). Con esta composición se operó de forma análoga a la descrita para la composición $\boldsymbol{C}$-II, en lo referente a la preparación de las muestras sinterizadas para medir la conductividad y para determinar la resistencia mecánica.

\subsubsection{Conductividades}

Los valores de la resistividad correspondiente al interior de los granos $\left(\boldsymbol{\rho}_{g}\right)$, a los límites de grano $\left(\boldsymbol{\rho}_{I g}\right)$ y la resistividad total $\left(\boldsymbol{\rho}_{T}\right)$, así como los respectivos valores de la conductividad $\left(\boldsymbol{\sigma}_{g}, \boldsymbol{\sigma}_{\lg } \boldsymbol{y} \boldsymbol{\sigma}_{T}\right)$, obtenidos a partir de las medidas realizadas con las muestras ensayadas, se detallan en la Tabla 8.12 del Apéndice 8.1.3.

En la Tabla 4.26 se muestran los valores medios de $\sigma_{T}$, obtenidos, a las diferentes temperaturas de ensayo estudiadas, para las muestras sinterizadas a $1673 \mathrm{~K}$, con tiempos de residencia de 4 y $6 \mathrm{~h}$. Se observa que las conductividades obtenidas son menores que para el caso de las muestras preparadas con $\boldsymbol{C}$-I, aunque ligeramente superiores a las obtenidas con $\boldsymbol{C}$-II. 


\begin{tabular}{|c|c|c|}
\hline$T_{S}$ & \multicolumn{2}{|c|}{$1673 \mathrm{~K}$} \\
\hline$t_{R}(h)$ & $4 h$ & $6 \mathrm{~h}$ \\
\hline$T_{e}(K)$ & & \\
\hline 573 & $2,14 \mathrm{E}-06$ & $2,24 \mathrm{E}-06$ \\
\hline 623 & 2,03E-05 & 2,08E-05 \\
\hline 673 & 1,59E-04 & 1,63E-04 \\
\hline 723 & 7,96E-04 & 8,17E-04 \\
\hline 773 & 2,81E-03 & 2,87E-03 \\
\hline 823 & $7,56 \mathrm{E}-03$ & 7,65E-03 \\
\hline 873 & 1,60E-02 & 1,62E-02 \\
\hline 923 & 2,85E-02 & 2,86E-02 \\
\hline 973 & 4,37E-02 & 4,43E-02 \\
\hline 1023 & $6,05 E-02$ & 6,17E-02 \\
\hline 1073 & 7,71E-02 & 7,81E-02 \\
\hline 1123 & $9,23 \mathrm{E}-02$ & $9,33 \mathrm{E}-02$ \\
\hline 1173 & $1,05 \mathrm{E}-01$ & $1,06 \mathrm{E}-01$ \\
\hline 1223 & $1,16 \mathrm{E}-01$ & 1,17E-01 \\
\hline 1273 & $1,24 \mathrm{E}-01$ & $1,26 \mathrm{E}-01$ \\
\hline
\end{tabular}

\subsubsection{Diámetro medio de grano}

En la Tabla 4.27 se muestra el valor del diámetro medio de grano $\left(\boldsymbol{D}_{50}\right)$ correspondiente a las muestras obtenidas con la composición $\boldsymbol{C}$-III, obtenido a partir de láminas preparadas por colado en banda con dicha composición y sinterizadas en la forma habitual (Figura 4.56). 


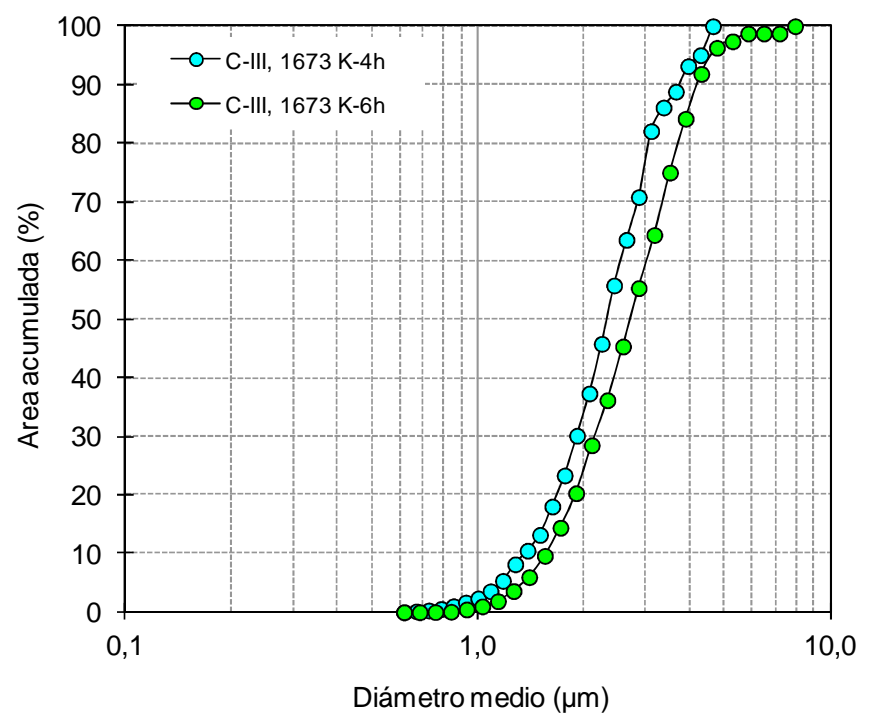

Figura 4.56. Representación del porcentaje de área acumulada ocupada por los granos frente a su diámetro medio. Probetas sinterizadas a 1673 K para distintos tiempos de residencia.

\begin{tabular}{|c|c|c|}
\hline $\begin{array}{l}\text { Temperatura de } \\
\text { sinterización }(K)\end{array}$ & $\begin{array}{l}\text { Tiempo de } \\
\text { residencia a } T_{S}(h)\end{array}$ & $\begin{array}{r}D_{50} \\
(\mu \mathrm{m})\end{array}$ \\
\hline \multirow[t]{2}{*}{1673} & 4 & 2,32 \\
\hline & 6 & 2,68 \\
\hline
\end{tabular}

En la Figura 4.57 se visualiza una microfotografía obtenida en el MEB representativa de la microestructura de la muestra en la que se aprecia cómo se sitúa la alúmina en los límites de los granos de circona (superficie negra). Estos resultados concuerdan con lo observado por otros investigadores ${ }^{103}$. 


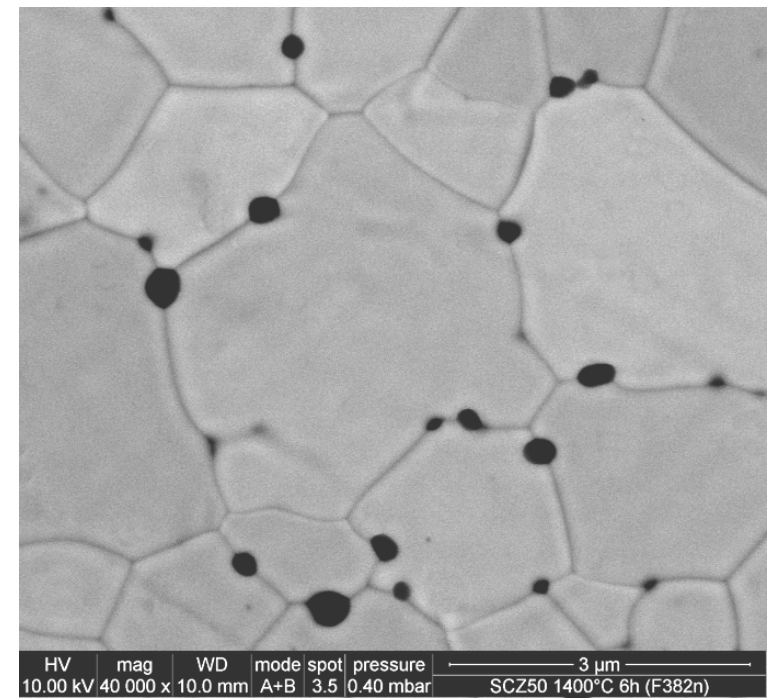

Figura 4.57. Aspecto de la microestructura de la lámina preparada con la composición C-III sinterizada a la temperatura de $1673 \mathrm{~K}$ durante $6 \mathrm{~h}$.

\subsubsection{Resistencia mecánica de láminas coladas sinterizadas}

Para determinar la resistencia mecánica de este material, también en este caso, se conformaron láminas, por colado, a partir de suspensiones que tenían una proporción de disolvente y de aditivos orgánicos idéntica a la de la suspensión $\boldsymbol{C}$-I-35. Las láminas coladas se sinterizaron, asimismo, utilizando el ciclo térmico correspondiente a la temperatura de $1673 \mathrm{~K}$ y tiempo de residencia de seis horas.

Utilizando la metodología descrita en el Apartado 3.2.4.4 se obtuvo un valor de $139 \mathrm{MPa}$.

Los resultados de las medidas realizadas se muestran en el Apartado 8.2 del Apéndice. 
"Creo que, cuando estén agotados los yacimientos de hulla, se producirá el calor con el agua. El agua es el calor del porvenir". Julio Verne, La Isla Misteriosa (1875).

\section{Discusión de los Resultados}




\subsection{Composición C-I. Comparación de las propiedades estructurales de las piezas resultantes de sinterizar, a diferentes valores de $T_{S}$ y $t_{R}$, las láminas coladas y las probetas prensadas.}

\subsubsection{Valores de la porosidad $(\varepsilon)$ y del diámetro medio de poro $\left(d_{50}\right)$}

En las Tablas 5.1 y 5.2 se comparan los valores de la porosidad $(\boldsymbol{\varepsilon})$ y del diámetro medio de poro $\boldsymbol{d}_{50}(\mu \mathrm{m})$ obtenidos para los tres tipos de piezas sinterizadas estudiados (Tablas 4.17, 4.18 y 4.21 ), a las temperaturas de sinterización y a los tiempos de residencia ensayados.

Como puede apreciarse, todas las muestras estudiadas tienen porosidades bastante inferiores al 5\% (porosidad máxima recomendable), en todo el intervalo de condiciones de operación estudiado.

A las temperaturas de sinterización de 1573, 1673 y $1773 \mathrm{~K}$, los valores más bajos de la porosidad corresponden a las muestras de las láminas $C$-I-35 y los más altos a las muestras de las láminas $\mathbf{C}-\mathbf{I - 1 5}$.

La porosidad de las piezas prensadas tiene valores intermedios entre las de las de los dos tipos de láminas estudiados, siendo bastante más próxima a las de las láminas C-I-35 en el caso de las muestras sinterizadas a $1773 \mathrm{~K}$.

Tabla 5.1. Composición $C-I$. Comparación de los valores de la porosidad $\varepsilon$ (\% en volumen de poro) de las muestras resultantes de sinterizar las láminas coladas a partir de las suspensiones $C-I-15$ y $C-I-35$ y las piezas prensadas a las temperaturas de sinterización y tiempos de residencia ensayados

\begin{tabular}{ccccc}
\hline$T_{\mathbf{S}}(\mathrm{K})$ & $\mathbf{t}_{\mathbf{R}}(\mathbf{h})$ & $\begin{array}{c}\text { Láminas } \\
\mathbf{C}-\mathrm{I}-15\end{array}$ & $\begin{array}{c}\text { Láminas } \\
\mathbf{C}-\mathrm{I}-35\end{array}$ & $\begin{array}{c}\text { Piezas } \\
\text { prensadas }\end{array}$ \\
\hline 1473 & 2 & 5,68 & 6,42 & - \\
& 4 & 3,37 & 6,05 & - \\
& 6 & 2,56 & 0,75 & - \\
\hline 1573 & 2 & 1,85 & 0,23 & 1,70 \\
& 4 & 1,39 & 0,20 & 1,07 \\
& 6 & 2,14 & 0,20 & 1,06 \\
\hline \multirow{2}{*}{1673} & 2 & 1,27 & 0,35 & 0,99 \\
& 4 & 1,17 & 0,17 & 0,96 \\
& 6 & 1,80 & 0,10 & 0,88 \\
\hline \multirow{2}{*}{1773} & 1 & - & - & 0,66 \\
& 2 & 2,22 & 0,15 & 0,62 \\
& 4 & 2,18 & 0,10 & 0,52 \\
& 6 & 2,40 & 0,11 & 0,48 \\
\hline
\end{tabular}


Como puede apreciarse, la porosidad de las probetas prensadas sinterizadas resultó ser igual o inferior al 1,1\% (excepto en uno de los ensayos). A estos valores tan bajos de dicha propiedad, es posible admitir que las pequeñas diferencias existentes, en valor absoluto, entre la porosidad de las muestras sinterizadas obtenidas a partir de las láminas coladas de la suspensión $\mathbf{C}-\mathbf{I}-35$ y de las probetas prensadas, no deben influir significativamente sobre el valor de las respectivas conductividades iónicas.

A una misma conclusión se llega al comparar los valores del diámetro medio de poro correspondientes a dichas muestras, que tienen valores prácticamente coincidentes (Tabla 5.2).

En consecuencia, se puede admitir que las medidas de la conductividad que se efectúen con las muestras sinterizadas de las probetas prensadas, serán suficientemente representativas de la conductividad de las muestras sinterizadas de las láminas coladas de la suspensión $\boldsymbol{C}-\mathrm{I}-35$, ya que no fue posible determinar dicha propiedad directamente sobre ellas por las dificultades indicadas anteriormente (Apartado 2.2.2).

\begin{tabular}{|c|c|c|c|c|}
\hline $\mathrm{T}_{\mathrm{S}}(\mathrm{K})$ & $t_{R}(h)$ & $\begin{array}{l}\text { Láminas } \\
\text { C-I-15 }\end{array}$ & $\begin{array}{c}\text { Láminas } \\
\text { C-I-35 }\end{array}$ & $\begin{array}{c}\text { Piezas } \\
\text { prensadas }\end{array}$ \\
\hline \multirow[t]{3}{*}{1473} & 2 & 0,24 & 0,34 & - \\
\hline & 4 & 0,23 & 0,34 & - \\
\hline & 6 & 0,50 & 0,30 & - \\
\hline \multirow[t]{3}{*}{1573} & 2 & 0,57 & 0,22 & 0,30 \\
\hline & 4 & 0,61 & 0,20 & 0,29 \\
\hline & 6 & 0,78 & 0,21 & 0,30 \\
\hline \multirow[t]{3}{*}{1673} & 2 & 0,53 & 0,22 & 0,32 \\
\hline & 4 & 0,58 & 0,21 & 0,34 \\
\hline & 6 & 0,77 & 0,18 & 0,33 \\
\hline \multirow[t]{4}{*}{1773} & 1 & - & - & 0,33 \\
\hline & 2 & 0,88 & 0,24 & 0,33 \\
\hline & 4 & 0,86 & 0,28 & 0,34 \\
\hline & 6 & 0,91 & 0,26 & 0,35 \\
\hline
\end{tabular}

\subsubsection{Valores del diámetro medio de grano}

En la Tabla 5.3 se muestran los valores del diámetro medio de grano de las muestras resultantes de sinterizar las láminas coladas a partir de las suspensiones $C$-I-15 y C-I-35 y las probetas prensadas, a las diferentes temperaturas de sinterización y tiempos de residencia ensayados. 
Tabla 5.3. Composición $C$-I. Comparación de los valores del diámetro medio de grano D $(\mu \mathrm{m})$ de las muestras resultantes de sinterizar las láminas coladas a partir de las suspensiones $C-I-15$ y $C-I-35$ y las piezas prensadas, a las temperaturas de sinterización y tiempos de residencia ensayados

\begin{tabular}{|c|c|c|c|c|}
\hline $\mathrm{T}_{\mathrm{S}}(\mathrm{K})$ & $t_{R}(h)$ & $\begin{array}{l}\text { Láminas } \\
\text { C-I-15 }\end{array}$ & $\begin{array}{c}\text { Láminas } \\
\text { C-I-35 }\end{array}$ & $\begin{array}{c}\text { Piezas } \\
\text { prensadas }\end{array}$ \\
\hline \multirow[t]{3}{*}{1473} & 2 & -- & 0,46 & -- \\
\hline & 4 & -- & 0,59 & -- \\
\hline & 6 & -- & 0,66 & -- \\
\hline \multirow[t]{3}{*}{1573} & 2 & -- & 1,32 & 1,52 \\
\hline & 4 & -- & 1,49 & 1,74 \\
\hline & 6 & 1,95 & 1,76 & 1,91 \\
\hline \multirow[t]{3}{*}{1673} & 2 & 2,56 & 2,65 & 2,70 \\
\hline & 4 & 2,95 & 3,06 & 3,01 \\
\hline & 6 & 3,20 & 3,50 & 3,30 \\
\hline \multirow[t]{4}{*}{1773} & 1 & -- & -- & 3,40 \\
\hline & 2 & 3,60 & 4,75 & 3,80 \\
\hline & 4 & 4,04 & 5,71 & 4,30 \\
\hline & 6 & 4,40 & 6,30 & 4,70 \\
\hline
\end{tabular}

Como puede apreciarse, los valores del diámetro medio de grano obtenidos para los tres tipos de muestra estudiados (láminas $\boldsymbol{C}-\mathbf{I}-15$, láminas $\boldsymbol{C}-\mathbf{I}-35$ y piezas prensadas), correspondientes a unas mismas condiciones de operación $\left(\boldsymbol{T}_{S} \boldsymbol{y} \boldsymbol{t}_{R}\right)$, difieren muy poco en todo el intervalo de condiciones de operación ensayado. Por tanto, en principio, puede esperarse que estas pequeñas diferencias no influyan significativamente sobre el valor de las respectivas conductividades iónicas.

En todo caso, cuando más adelante se comparen las conductividades iónicas de las probetas prensadas sinterizadas, a diferentes condiciones de operación, medidas a distintas temperaturas de ensayo, se dispondrá de una información adicional que, posiblemente, permita emitir un juicio más concreto sobre el grado en que las pequeñas diferencias observadas, entre los valores del diámetro medio de grano de las muestras estudiadas, puede afectar al valor de las respectivas conductividades.

\subsubsection{Variación de la porosidad y el diámetro medio de poro con la temperatura de sinterización y el tiempo de residencia}

\subsubsection{Porosidad}

Los resultados expuestos en la Tabla 5.1 se han representado gráficamente en las Figuras 5.1.(a) a 5.1.(c). 


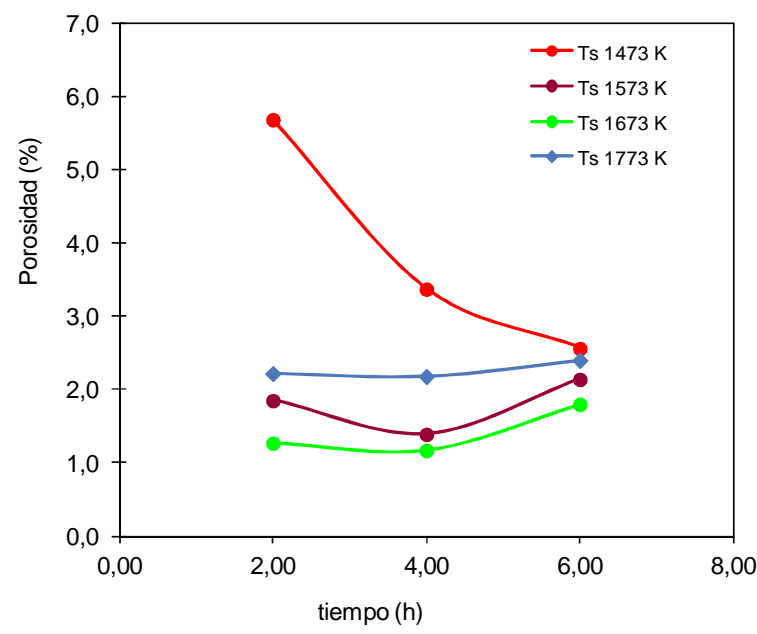

(a)

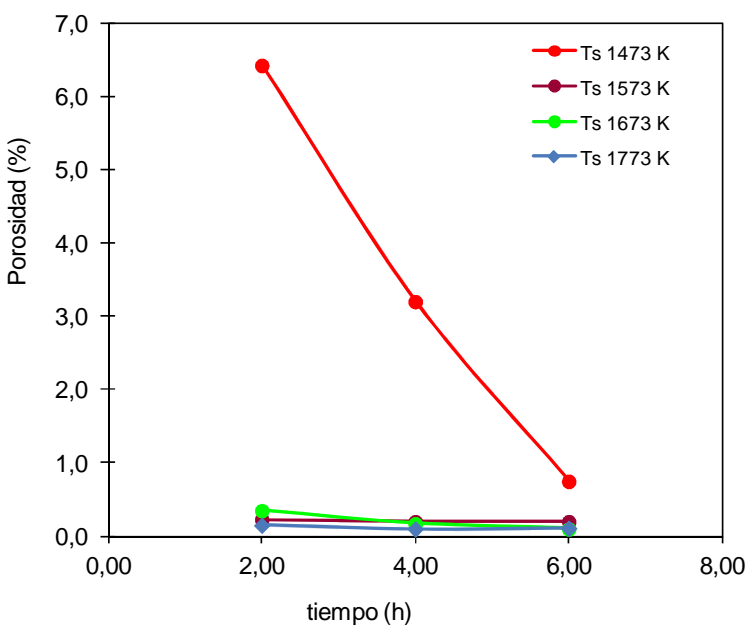

(b)

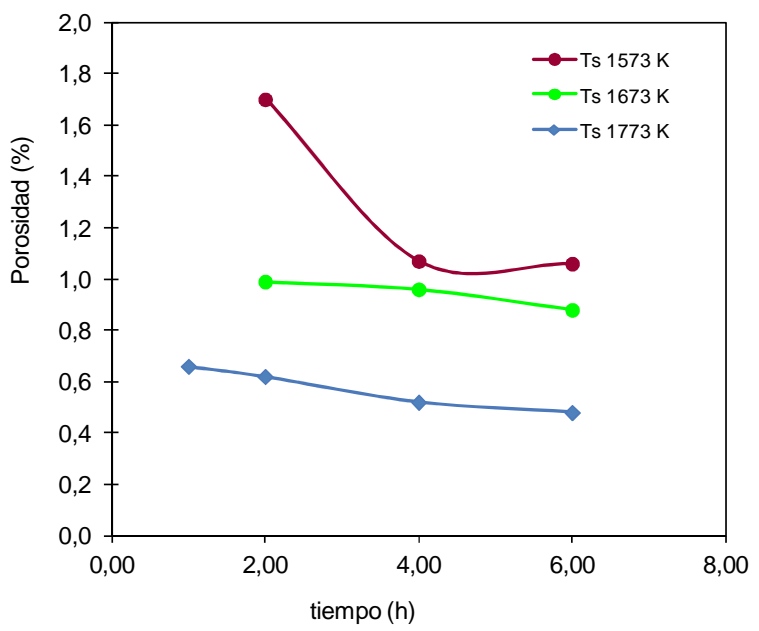

(c)

Figura 5.1. (a) Láminas C-I-15; (b) Láminas C-I-35; (c) Piezas prensadas

Como puede apreciarse, en el caso de las muestras correspondientes a las láminas $C-I-35$ y a las piezas prensadas, para un determinado valor del tiempo de residencia, la porosidad disminuye al aumentar la temperatura de sinterización. Esta variación ya es muy pequeña en las muestras sinterizadas a temperatura superior a $1473 \mathrm{~K}$, de acuerdo con otros estudios realizados materiales análogos ${ }^{37,104}$.

Asimismo disminuye la porosidad de dichas muestras al aumentar el tiempo de residencia. Esta disminución es muy pequeña cuando los valores de la porosidad son del orden del $1 \%$ o inferiores.

En cambio, las muestras correspondientes a las láminas $\boldsymbol{C}$-I-15, presentan un comportamiento algo diferente. La porosidad disminuye con la temperatura de sinterización a las tres temperaturas más bajas estudiadas, aumentando en cambio apreciablemente en 
el caso de la muestra sinterizada a $1773 \mathrm{~K}$. Por otra parte, dicha propiedad apenas disminuye o se mantiene prácticamente constante al aumentar el tiempo de residencia entre 2 y $4 \mathrm{~h}$, aumentando ligeramente para valores de esta variable a $6 \mathrm{~h}$.

\subsubsection{Diámetro medio de poro}

Los resultados expuestos en la Tabla 5.2 se han representado en las Figuras 5.2.(a) a (c).

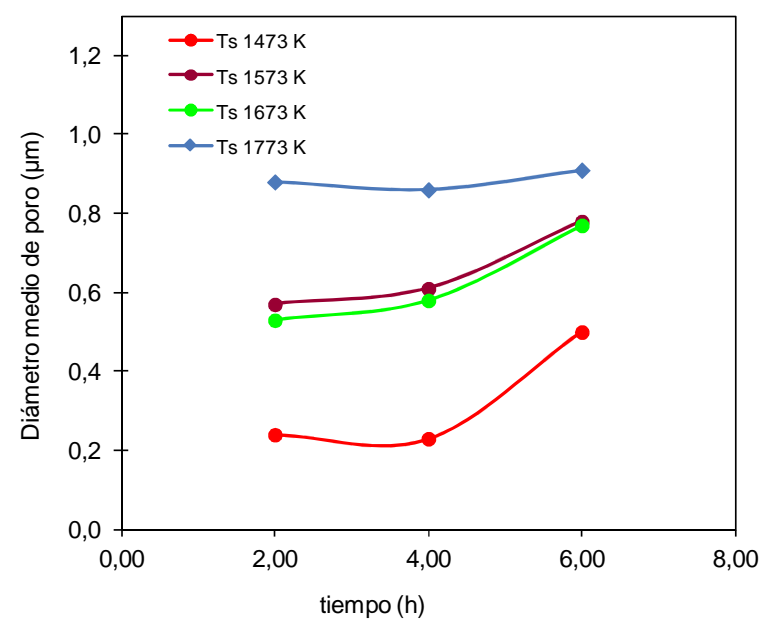

(a)

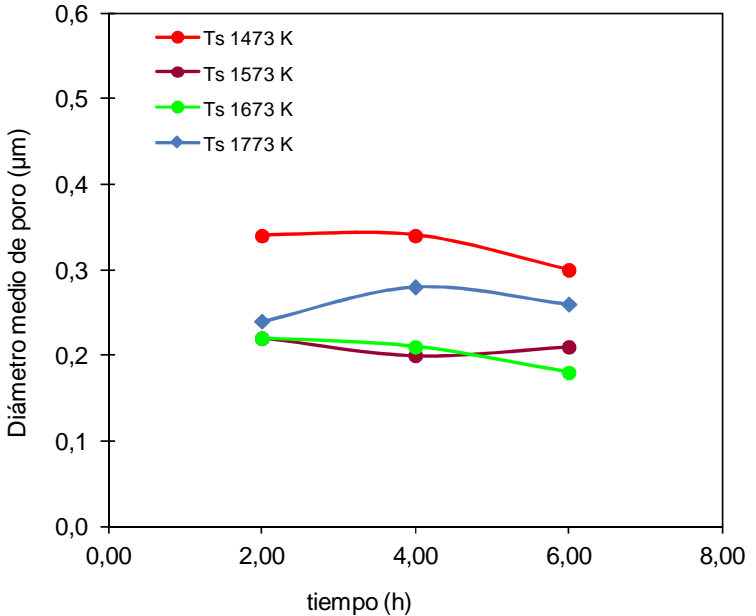

(b)

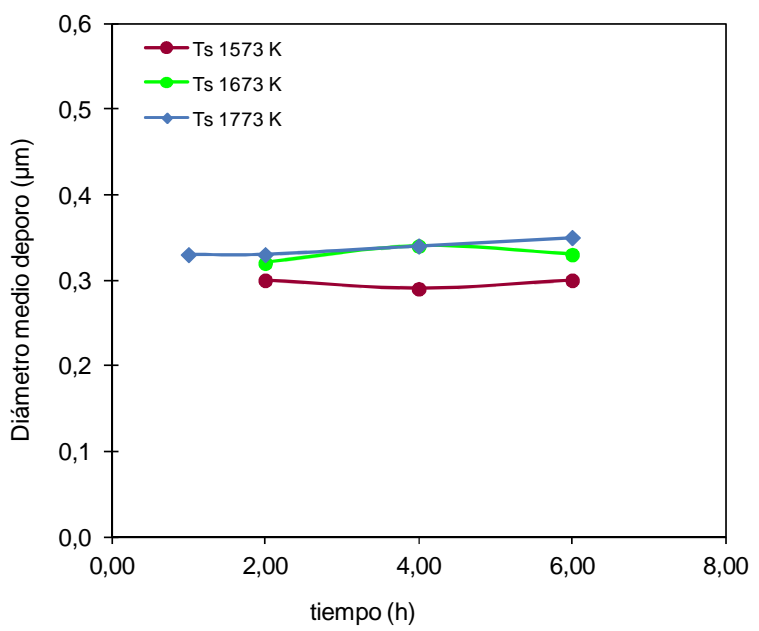

(c)

Figura 5.2. (a) Láminas C-I-15; (b) Láminas C-I-35; (c) Piezas prensadas 
En dichas representaciones gráficas se aprecia que el diámetro medio de poro aumenta ligeramente con el tiempo de residencia en las muestras de las láminas $\boldsymbol{C - I - 1 5}$, mientras que apenas disminuye o se mantiene prácticamente invariable en las muestras de las láminas $\boldsymbol{C}$ I-35 y de las probetas prensadas, para las que dicha propiedad tiene un valor similar, aunque es algo más bajo en el caso de las muestras de las láminas C-I-35.

\subsubsection{Estudio cinético del crecimiento de grano. Variación del diámetro medio de grano con la temperatura de sinterización y el tiempo de residencia}

En este Apartado sólo se han incluido los resultados obtenidos con las muestras sinterizadas de las probetas prensadas y de las láminas coladas a partir de la suspensión $\boldsymbol{C}$ I-35.

Se ha considerado oportuno realizar este estudio con los datos experimentales de tamaño de grano correspondientes a las muestras sinterizadas de las probetas prensadas, porque estas muestras eran las que se iban a utilizar posteriormente para el estudio de la conductividad iónica, a fin de disponer de información sobre ambas propiedades, por si tenían alguna relación.

Por otra parte y a efectos comparativos, dado que en la práctica industrial (por su reducido espesor) se han moldear las piezas de electrolito por colado en banda, se ha estudiado el comportamiento de los datos experimentales de las muestras sinterizadas procedentes de las láminas coladas a partir de la suspensión $\mathbf{C}-\mathbf{I}-35$. Se han elegido estas muestras, porque se dispone de resultados experimentales del diámetro medio de grano para un intervalo de condiciones de operación más amplio que en el caso de las muestras procedentes de la suspensión $\boldsymbol{C}$-I-15 y porque presentaban una porosidad análoga (inferior al $1 \%$ ) a la de las probetas prensadas sinterizadas a las mismas condiciones de operación (ver Tabla 5.3).

Para realizar el estudio cinético del crecimiento de grano se ha partido de la ecuación propuesta por Burke y Turnbull ${ }^{105,106,107}$ modificada:

$$
d D / d t=k_{D} / D^{n}
$$

En la que $\boldsymbol{D}$ representa el diámetro medio de grano, $\boldsymbol{t}$ el tiempo de durante el cual se aplica el tratamiento térmico y $\boldsymbol{k}_{\boldsymbol{D}}$ es un parámetro cinético, que está relacionado con la energía en el límite de grano y con la movilidad del límite de grano de cada material y cuyo valor depende exponencialmente de la temperatura a la que se desarrolla el proceso y del material al que se aplica.

Esta ecuación fue propuesta inicialmente por los mencionados investigadores para interpretar la cinética del crecimiento de grano, en materiales policristalinos ${ }^{106,108}$, con el exponente $\boldsymbol{n}=\mathbf{1}$.

Posteriormente se ha comprobado que, en muchos materiales policristalinos, el crecimiento de grano no sigue exactamente el comportamiento parabólico propuesto por Burke y Turnbull, adaptándose bastante bien a la forma integrada de la ecuación (5.1), cuando se utilizan valores del exponente $\boldsymbol{n}$ que oscilan entre 1 y 3 y, en algunos casos mayores, habiéndose citado casos en que $\boldsymbol{n}=9^{107}$.

Integrando la ecuación $(5,1)$, a temperatura constante ( $\boldsymbol{k}_{\boldsymbol{D}}$ constante), entre límites definidos $\left(D_{1}, t_{1}\right)$ y $\left(D_{2}, t_{2}\right)$ y despejando $D_{2}^{(n+1)}$, resulta: 


$$
D_{2}^{(n+1)}=D_{1}^{(n+1)}+(n+1) k_{D}\left(t_{2}-t_{1}\right)
$$

que sólo puede aplicarse cuando el proceso se desarrolla en condiciones isotérmicas, ya que, como se ha indicado anteriormente, el parámetro $\boldsymbol{k}_{\boldsymbol{D}}$ varía con la temperatura siguiendo un comportamiento de tipo exponencial ${ }^{107}$ representable por una ecuación de la forma:

$$
k_{D}=k_{0} \cdot \exp (-Q / T)
$$

en la que $\boldsymbol{T}$ es la temperatura a la que se trata la muestra, expresada en $\mathrm{K}, \boldsymbol{Q}$ es un parámetro, que se suele asociar al concepto de una energía aparente de activación y que depende del material con el que se está experimentando, expresado asimismo en $\mathrm{K}$, y $\boldsymbol{k}_{\boldsymbol{o}}$ es un factor preexponencial característico de cada material.

Como consecuencia del ciclo térmico utilizado en los experimentos de sinterización realizados, consistente en calentar la muestra desde $298 \mathrm{~K}$ hasta la temperatura de sinterización preestablecida, utilizando una velocidad de calentamiento $(\boldsymbol{\lambda})$ de $120 \mathrm{~K} / \mathrm{h}$, la ecuación integrada (5.2) no se puede aplicar desde las condiciones iniciales $\left(D_{0}=0,097 \mu \mathrm{m}\right.$; $\mathrm{t}_{0}=0 ; \mathrm{T}_{0}=298 \mathrm{~K}$ ). Sólo se podrá aplicar durante la etapa del ciclo de tratamiento térmico que, con cada muestra, se desarrolla, en condiciones isotérmicas, a la temperatura de sinterización seleccionada, a diferentes valores del tiempo de residencia.

Por tanto, en lo que sigue, $\boldsymbol{t}_{1}$ representará el valor del tiempo transcurrido desde que empieza el ciclo de tratamiento térmico hasta que comienza cada etapa del mismo que se desarrolla a temperatura constante. De modo que, en cada experimento, $\boldsymbol{t}_{2}=\boldsymbol{t}_{R}+\boldsymbol{t}_{1}$, siendo $t_{R}$ el correspondiente valor del tiempo de residencia.

Dada la forma en que se han desarrollado los experimentos, se desconoce el valor del diámetro medio de grano $\left(\boldsymbol{D}_{\boldsymbol{1}}\right)$ correspondiente al tiempo de tratamiento térmico $\boldsymbol{t}_{\boldsymbol{1}}$, el cual depende del respectivo valor de $\boldsymbol{T}_{\boldsymbol{S}}$ pues, para cada experimento, se cumple que:

$$
t_{1}=\frac{T_{S}-T_{0}}{\lambda}
$$

donde $\lambda$ es la velocidad de precalentamiento utilizada en todos los experimentos $(120 \mathrm{~K} / \mathrm{h})$ y $\mathrm{T}_{0}=298 \mathrm{~K}$

En efecto, durante la fase de precalentamiento, cuando las muestras alcanzan temperaturas del orden de los $1200 \mathrm{~K}$, debe comenzar el crecimiento de grano ${ }^{37,47}$, por lo que cuando se alcanza la temperatura $\left(\boldsymbol{T}_{1}\right)$ correspondiente a cada valor de $\boldsymbol{t}_{1}$ (comprendida entre $1473 \mathrm{y}$ $1773 \mathrm{~K}$ en los experimentos realizados), el diámetro medio de grano debe ser sensiblemente mayor que el de partida y distinto para cada temperatura de sinterización estudiada.

De acuerdo con la ecuación (5.2), si se representan los resultados experimentales, obtenidos en condiciones isotérmicas, durante cada etapa desarrollada a temperatura constante, en la forma $D_{2}^{(n+1)}$ versus $\left(t_{2}-t_{1}\right) \equiv t_{R}$, en coordenadas rectangulares, debe resultar una recta de pendiente $(\boldsymbol{n + 1}) \cdot \boldsymbol{k}_{\boldsymbol{D}}$, cuando el valor de $\boldsymbol{n}$ empleado sea el idóneo para el material policristalino estudiado. 
Conocido el valor del exponente $\boldsymbol{n}$, se puede calcular el valor del parámetro cinético $\boldsymbol{k}_{\boldsymbol{D}}$, que corresponde a cada temperatura de sinterización estudiada $\left(\boldsymbol{T}_{\boldsymbol{S}}\right)$, a partir del valor de la pendiente de dicha representación gráfica. Los valores de $\boldsymbol{k}_{\boldsymbol{D}}$ obtenidos para cada temperatura de sinterización estudiada deberán adaptarse a una representación tipo Arrhenius, de acuerdo con la ecuación (5.3), obteniendo así los valores de $\boldsymbol{Q}$ y de $\boldsymbol{k}_{\boldsymbol{o}}$ de dicha ecuación.

Si se admite que el valor del exponente $\boldsymbol{n}$ de la ecuación (5.1) no depende de la temperatura a la que se desarrolla el proceso de crecimiento de grano, una posible forma de confirmar la validez de los valores de dicho parámetro cinético, obtenidos al representar los resultados experimentales según las ecuaciones (5.2) y (5.3), sería calculando la variación del diámetro medio de grano, desde las condiciones iniciales $\left(T_{0}=298 \mathrm{~K}\right.$ y $\left.\mathrm{D}_{0}=0,097 \mu \mathrm{m}\right)$ hasta las finales en cada experimento realizado, por integración de la ecuación (5.1), utilizando los valores del exponente $\boldsymbol{n}$, de $\boldsymbol{Q}$ y de $\boldsymbol{k}_{\boldsymbol{0}}$ determinados previamente en la forma descrita en los dos párrafos anteriores.

Para ello, se puede operar en la forma que se describe a continuación.

De las ecuaciones (5.1) y (5.3) resulta:

$$
d D / d t=\frac{k_{0} \exp (-Q / T)}{D^{n}}
$$

Durante el periodo de precalentamiento, que se desarrolla a velocidad de calentamiento $(\boldsymbol{\lambda})$ constante, esta ecuación se puede expresar en función de una sola variable independiente (el tiempo $\boldsymbol{t}$ transcurrido desde que se inicia el ciclo de tratamiento térmico a la temperatura ambiente). En efecto, a partir de la definición de la velocidad de calentamiento $(\boldsymbol{\lambda})$ :

$$
\lambda=\frac{d T}{d t}
$$

separando variables e integrando entre las condiciones de contorno $\left(T_{0}, t=0\right)$ y $(T, t)$, resulta:

$$
T=T_{0}+\lambda t
$$

y de (5.5) y (5.7) resulta:

$$
d D / d t=\frac{k_{0} \exp \left[-\frac{Q}{\left(T_{0}+\lambda t\right)}\right]}{D^{n}}
$$

Conocidos el valor de $\boldsymbol{n}$ y los de $\boldsymbol{Q}$ y $\boldsymbol{k}_{\boldsymbol{0}}$, para cada ciclo térmico y tipo de muestra estudiados, se puede integrar la ecuación (5.8), por un método numérico, desde las condiciones de operación iniciales del ciclo térmico $\left(T_{0}=298 \mathrm{~K} ; t_{0}=0 \mathrm{~h}\right.$ y $\left.D_{0}=0,097 \mu \mathrm{m}\right)$ 
hasta el tiempo $\boldsymbol{t}_{1}$, correspondiente al inicio de la etapa a temperatura constante a la temperatura de sinterización de que se trate, obteniendo así la evolución del valor del diámetro medio de grano con el tiempo transcurrido, así como su valor al final de esta etapa $\left(\boldsymbol{D}_{1}\right)$ de duración $\boldsymbol{t}_{1}$ horas. Para cada temperatura de sinterización estudiada, el tiempo $\boldsymbol{t}_{\boldsymbol{1}} \mathrm{se}$ calculará mediante la ecuación (5.4).

Seguidamente, a partir de las condiciones de contorno $\left(\boldsymbol{D}_{1}, \boldsymbol{t}_{1}\right)$, obtenidas en la forma indicada, y conocido el valor del parámetro $\boldsymbol{k}_{\boldsymbol{D}}$ a la respectiva temperatura de sinterización, calculado mediante la ecuación (5.3) con los valores de $\boldsymbol{Q}$ y $\boldsymbol{k}_{\boldsymbol{0}}$ obtenidos, se puede integrar la ecuación (5.5) hasta el valor del tiempo $\boldsymbol{t}_{2}=\boldsymbol{t}_{\boldsymbol{1}}+\boldsymbol{t}_{R}$ correspondiente a cada experimento.

Los resultados de la integración consecutiva de las ecuaciones (5.8) y (5.5) se pueden representar en coordenadas rectangulares en la forma $D=f(t)$, junto con los datos experimentales, comprobando hasta qué punto la ecuación (5.1) y las que se han derivado de ésta se adaptan a dichos datos.

En lo que sigue, se aplicará la metodología descrita a los datos experimentales resultantes de la sinterización de las láminas coladas a partir de la suspensión $\boldsymbol{C}$-I-35 y de las probetas moldeadas por prensado a partir de la composición $\boldsymbol{C}$-I.

\subsubsection{Muestras sinterizadas a partir de las láminas coladas con la suspensión C-I-35}

En la Figura 5.3 se ha representado los valores del diámetro medio de grano, obtenidos a las cuatro temperaturas de sinterización ensayadas $(1473,1573,1673$ y $1773 \mathrm{~K}$ ), frente al correspondiente valor del tiempo de residencia $(2,4$ y $6 \mathrm{~h}$ ) a dichas temperaturas (Tabla 5.3).

Las líneas obtenidas son ligeramente curvas, cóncavas hacia el eje de abscisas, y de pendiente positiva.

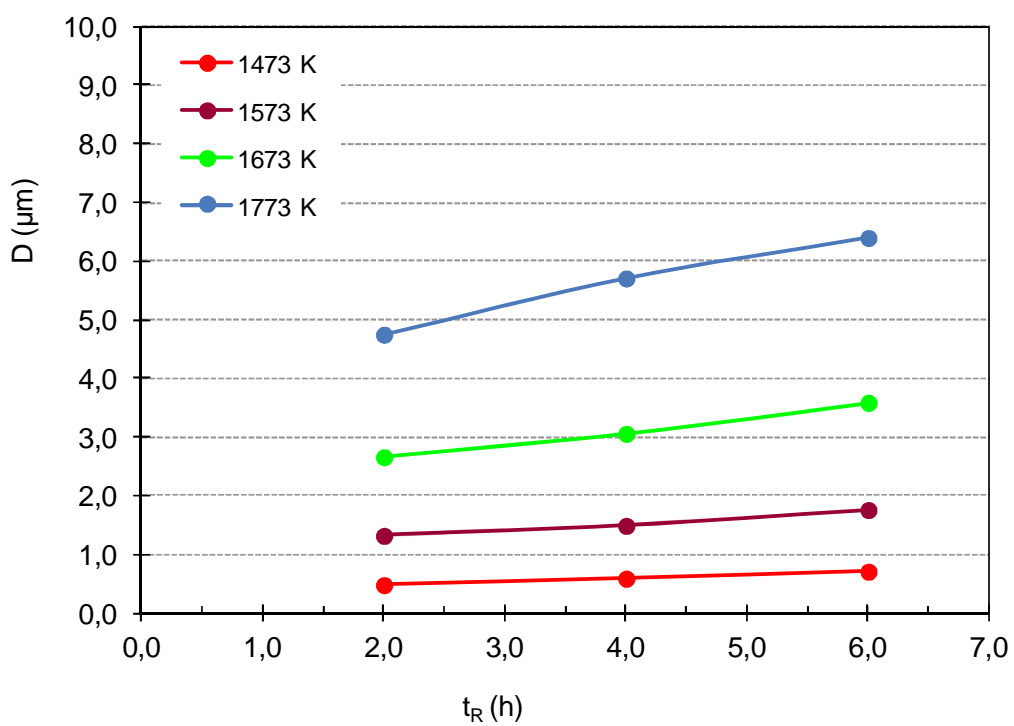

Figura 5.3. Láminas sinterizadas de la suspensión C-I-35. Variación del diámetro medio grano con la temperatura de sinterización y el tiempo de residencia. 
Al representar estos datos de acuerdo con la ecuación (5.2) se obtuvieron líneas rectas con coeficientes de correlación superiores a 0,96 para valores del exponente $\boldsymbol{n}$ de dicha ecuación comprendidos entre 2 y 4 , todos ellos además prácticamente iguales.

Dado que para trazar las correspondientes líneas rectas sólo se disponía de tres valores experimentales del diámetro medio de grano, a cada temperatura de sinterización estudiada, para decidir qué valor de dicho exponente era más adecuado se utilizó un criterio adicional: se integró por el método de Runge-Kutta de cuarto orden las ecuaciones (5.8) y (5.5), en la forma descrita anteriormente, comparando los resultados obtenidos con los experimentales. La mejor concordancia se obtuvo al utilizar el valor de $\boldsymbol{n}=\mathbf{3 , 5}$.

En la Figura 5.4 se han representado los valores de $\boldsymbol{D}^{4,5}$ frente a $\boldsymbol{t}_{R}=\boldsymbol{t}_{2}-\boldsymbol{t}_{1}$, de acuerdo con la ecuación (5.2), para las cuatro temperaturas de sinterización estudiadas. En la Tabla 5.4 se detallan los valores del parámetro $\boldsymbol{k}_{\boldsymbol{D}}$ obtenidos de las correspondientes representaciones los cuales se han representado, a su vez, en la forma $\boldsymbol{I n} \boldsymbol{k}_{\boldsymbol{D}}$ frente a la recíproca de la temperatura de sinterización en la Figura 5.5. Como puede apreciarse, los coeficientes de correlación obtenidos son muy buenos.

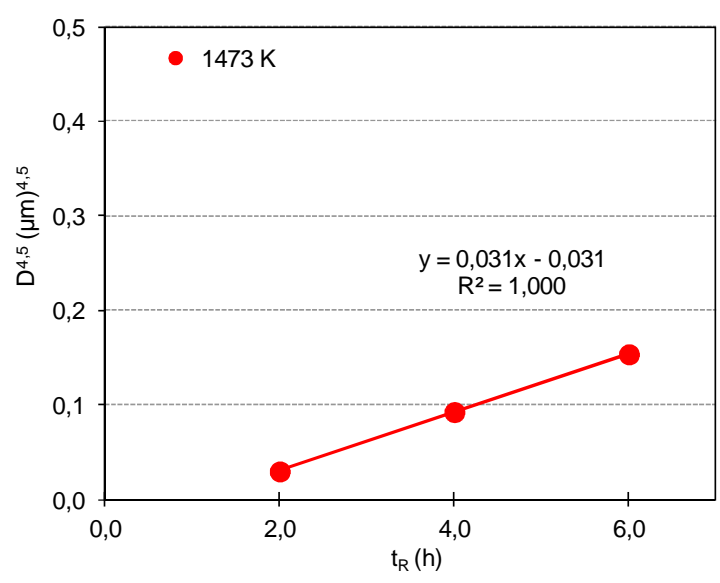

(a)

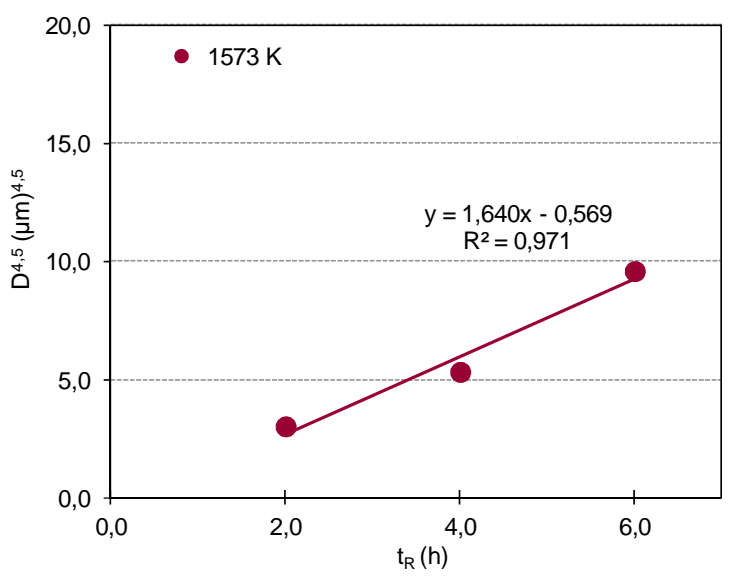

(b)

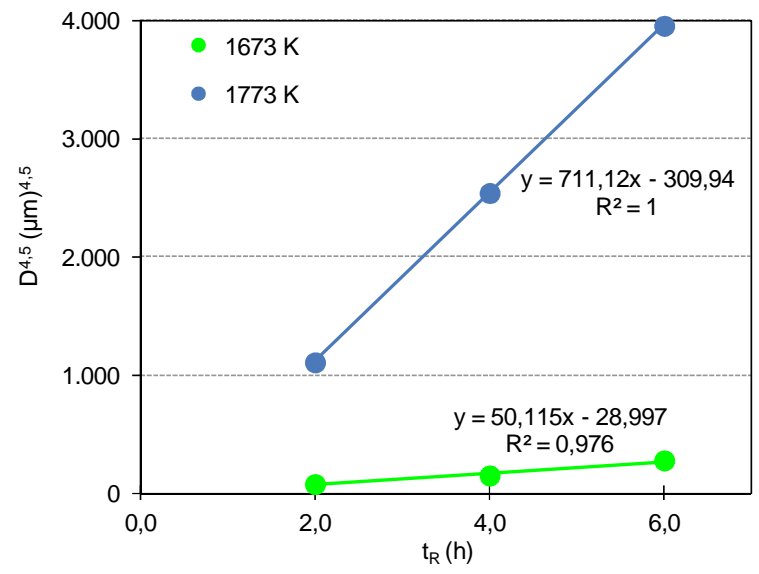

(c)

Figura 5.4. Representación de los datos experimentales de $D$ en función de $t_{R}$, de acuerdo con la ecuación (5.2). (a) $T_{s}=1473 \mathrm{~K}$; (b) $T_{s}=1573 \mathrm{~K}$; (c) $T_{s}=1673$ y $1773 \mathrm{~K}$. 
Tabla 5.4. Variación de la constante $k_{\mathrm{D}}$ de la ecuación (5.3) con la temperatura de tratamiento térmico

\begin{tabular}{|c|c|c|c|c|c|}
\hline $\mathbf{T}_{\mathrm{S}}(\mathrm{K})$ & $1 / T_{S}\left(K^{-1}\right)$ & $k_{D}(n+1)=4,5 k$ & $k_{D}(\exp )$ & In $k_{D}(\exp )$ & $k_{D}($ calc) \\
\hline 1473 & 6,79E-04 & 0,031 & 0,007 & $-4,978$ & 0,0076 \\
\hline 1573 & 6,36E-04 & 1,64 & 0,364 & $-1,009$ & 0,336 \\
\hline 1673 & 5,98E-04 & 50 & 11,11 & 2,408 & 9,44 \\
\hline 1773 & 5,64E-04 & 711 & 158,00 & 5,063 & 182,24 \\
\hline
\end{tabular}

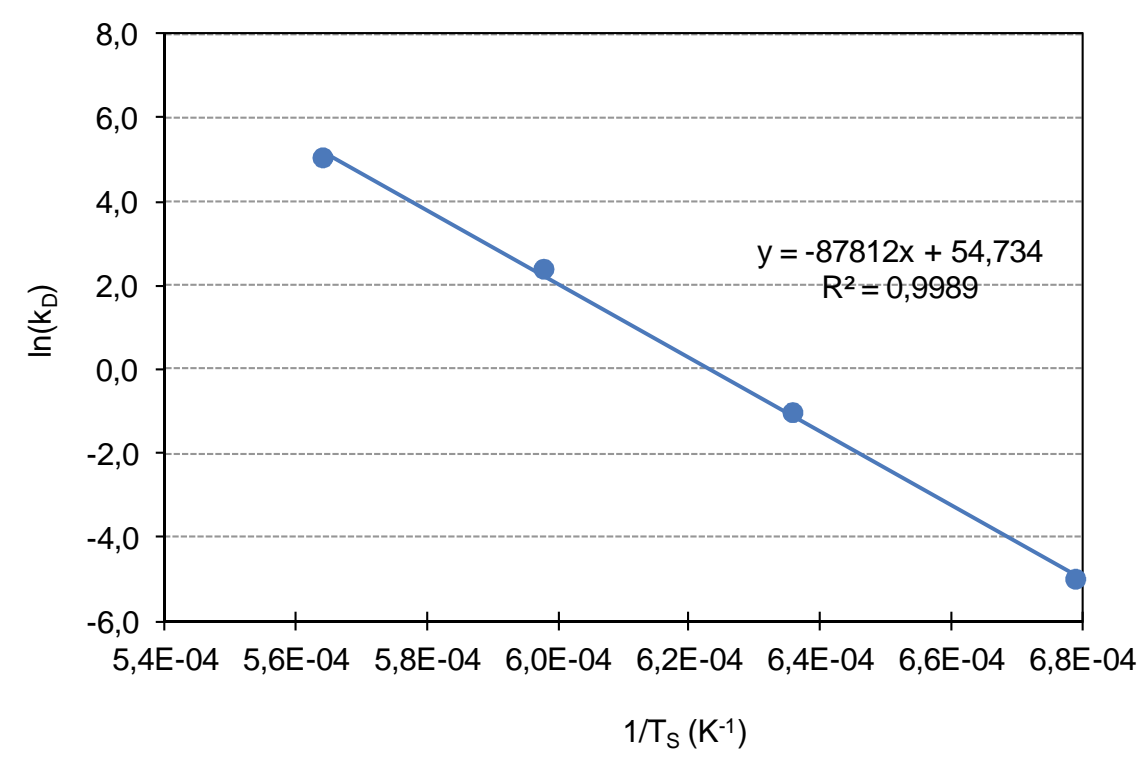

Figura 5.5. Representación del ln kb frente a 1/Ts, de acuerdo con la ecuación (5.3)

De la representación de la figura 5.5 se deduce que la variación del parámetro $\boldsymbol{k}_{\boldsymbol{D}}$ con la temperatura, en el caso de las muestras sinterizadas correspondientes a las láminas coladas a partir de la suspensión $\boldsymbol{C}$-I-35 se adapta bien a la ecuación (5.3), haciendo $\boldsymbol{Q}=$ 87812 y $k_{0}=5,898 \cdot 10^{23}$.

Finalmente, la ecuación (5.8) puesta en la forma:

$$
d D / d t=\frac{5,898 \cdot 10^{23} \exp \left[-\frac{87812}{(298+120 t)}\right]}{D^{3,5}}
$$


se integró desde las condiciones iniciales $\left(t_{0}=0 h ; D_{0}=0,097 \mu \mathrm{m}\right)$ hasta el tiempo $t_{1}$, calculado para cada valor de $\boldsymbol{T}_{\boldsymbol{s}}$ mediante la ecuación (5.4) puesta en la forma:

$$
t_{1}=\frac{T_{S}-298}{120}
$$

Los valores resultantes de $\boldsymbol{t}_{1}$ fueron: 9,$79 ; 10,63 ; 11,46$ y $12,29 \mathrm{~h}$ para las temperaturas de sinterización de 1473; 1573; 1673 y 1773 K respectivamente.

En la Tabla 5.5 se muestran los valores del diámetro medio de grano obtenidos en los experimentos realizados junto con el valor del tiempo de tratamiento térmico correspondiente, calculado teniendo en cuenta que $\boldsymbol{t}_{2}=\boldsymbol{t}_{1}+\boldsymbol{t}_{R}$, en cada caso.

Tabla 5.5. Valores de $t_{2}=t_{1}+t_{R}$ y de los correspondientes $D_{2}$ experimentales $(\mu m)$ a las diferentes condiciones de operación ensayadas

\begin{tabular}{|c|c|c|c|c|c|c|c|}
\hline \multicolumn{2}{|c|}{$T_{S}=1473 \mathrm{~K}$} & \multicolumn{2}{|c|}{$T_{S}=1573 \mathrm{~K}$} & \multicolumn{2}{|c|}{$T_{S}=1673 \mathrm{~K}$} & \multicolumn{2}{|c|}{$T_{S}=1773 \mathrm{~K}$} \\
\hline$t_{2}(h)$ & $D_{2} \exp$ & $t_{2}(h)$ & $D_{2} \exp$ & $t_{2}(h)$ & $D_{2} \exp$ & $t_{2}(h)$ & $D_{2} \exp$ \\
\hline 12,63 & 1,32 & 11,79 & 0,46 & 13,46 & 2,65 & 14,29 & 4,75 \\
\hline 14,63 & 1,52 & 13,79 & 0,59 & 15,46 & 3,06 & 16,29 & 5,71 \\
\hline 16,63 & 1,76 & 15,79 & 0,66 & 17,46 & 3,50 & 18,29 & 6,30 \\
\hline
\end{tabular}

En la Tabla 5.6 se detalla la variación del diámetro medio de grano con el tiempo de tratamiento térmico de las muestras y con la temperatura del horno, calculada a partir de las ecuaciones (5.9), (5.7) y (5.5). La ecuación (5.9) se ha integrado desde $\boldsymbol{t}_{0}=0$ hasta el correspondiente valor de $\boldsymbol{t}_{\boldsymbol{1}}$. La ecuación (5.7) se ha utilizado con $\boldsymbol{\lambda}=120 \mathrm{~K} / \mathrm{h}$ para calcular la variación de temperatura en el horno que se supone muy próxima a la de la muestra, dado que se ha utilizado una muy baja velocidad de calentamiento, y la ecuación (5.5) se ha integrado desde $\boldsymbol{t}_{1}$ al respectivo valor de $\boldsymbol{t}_{2}$, sustituyendo la constante $\boldsymbol{k}_{D}$ por su valor calculado a partir de la ecuación (5.3) sustituyendo en ella los valores de $\boldsymbol{Q}$ y de $\boldsymbol{k}_{\boldsymbol{o}}$ obtenidos anteriormente a partir de los datos experimentales (valores de la última columna de la Tabla 5.4.

De estos resultados se deduce, tal como se había supuesto, que el crecimiento de grano se inicia a temperaturas del orden de los $1250 \mathrm{~K}$, por lo que para el tiempo $\boldsymbol{t}_{1}$ correspondiente al inicio de las etapas a temperatura constante (temperatura de sinterización), en todos los ciclos térmicos estudiados, el diámetro medio de grano es sensiblemente mayor que el inicial, tanto más cuanto más alta es la temperatura de sinterización. 


\begin{tabular}{|c|c|c|c|c|c|c|c|c|c|c|c|}
\hline \multicolumn{3}{|c|}{$T_{S}=1473 \mathrm{~K}$} & \multicolumn{3}{|c|}{$T_{S}=1573 \mathrm{~K}$} & \multicolumn{3}{|c|}{$T_{S}=1673 \mathrm{~K}$} & \multicolumn{3}{|c|}{$T_{S}=1773 \mathrm{~K}$} \\
\hline$t(h)$ & $\mathrm{T}(\mathrm{K})$ & $\begin{array}{c}\text { D calc } \\
(\mu \mathrm{m})\end{array}$ & $t(h)$ & $\mathbf{T}(\mathrm{K})$ & $\begin{array}{c}\text { D calc } \\
(\mu \mathrm{m})\end{array}$ & $t(h)$ & $\mathrm{T}(\mathrm{K})$ & $\begin{array}{c}\text { D calc } \\
(\mu \mathrm{m})\end{array}$ & $t(h)$ & $\mathrm{T}(\mathrm{K})$ & $\begin{array}{c}\text { D calc } \\
(\mu \mathrm{m})\end{array}$ \\
\hline 0 & 298 & 0,097 & 0 & 298 & 0,097 & 0 & 298 & 0,097 & 0 & 298 & 0,097 \\
\hline 2 & 538 & 0,097 & 2 & 538 & 0,097 & 2 & 538 & 0,097 & 2 & 538 & 0,097 \\
\hline 4 & 778 & 0,097 & 4 & 778 & 0,097 & 4 & 778 & 0,097 & 4 & 778 & 0,097 \\
\hline 6 & 1018 & 0,097 & 6 & 1018 & 0,097 & 6 & 1018 & 0,097 & 6 & 1018 & 0,097 \\
\hline 8 & 1258 & 0,097 & 8 & 1258 & 0,097 & 8 & 1258 & 0,097 & 8 & 1258 & 0,097 \\
\hline 9,79 & 1473 & 0,30 & 10 & 1498 & 0,44 & 10 & 1498 & 0,44 & 10 & 1498 & 0,44 \\
\hline 11,79 & 1473 & 0,55 & 10,63 & 1573 & 0,66 & 11,46 & 1673 & 1,70 & 12,29 & 1773 & 3,28 \\
\hline 13,79 & 1473 & 0,64 & 12,63 & 1573 & 1,32 & 13,46 & 1673 & 2,85 & 14,29 & 1773 & 5,18 \\
\hline \multirow[t]{2}{*}{15,79} & 1473 & 0,69 & 14,63 & 1573 & 1,53 & 15,46 & 1673 & 3,29 & 16,29 & 1773 & 5,95 \\
\hline & & & 16,63 & 1573 & 1,67 & 17,46 & 1673 & 3,58 & 18,29 & 1773 & 6,48 \\
\hline
\end{tabular}

En la Figura 5.6 se han representado los valores de $\boldsymbol{D}_{50}$ calculados que se detallan en la Tabla 5.6 y los experimentales que se muestran en la Tabla 5.5 frente a los respectivos valores del tiempo de duración del correspondiente ciclo térmico. Como puede apreciarse, la ecuación (5.1) con las variantes introducidas y la información obtenida a partir de los resultados experimentales, se adapta razonablemente bien a éstos, con el exponente $\boldsymbol{n}=$ 3,5 .

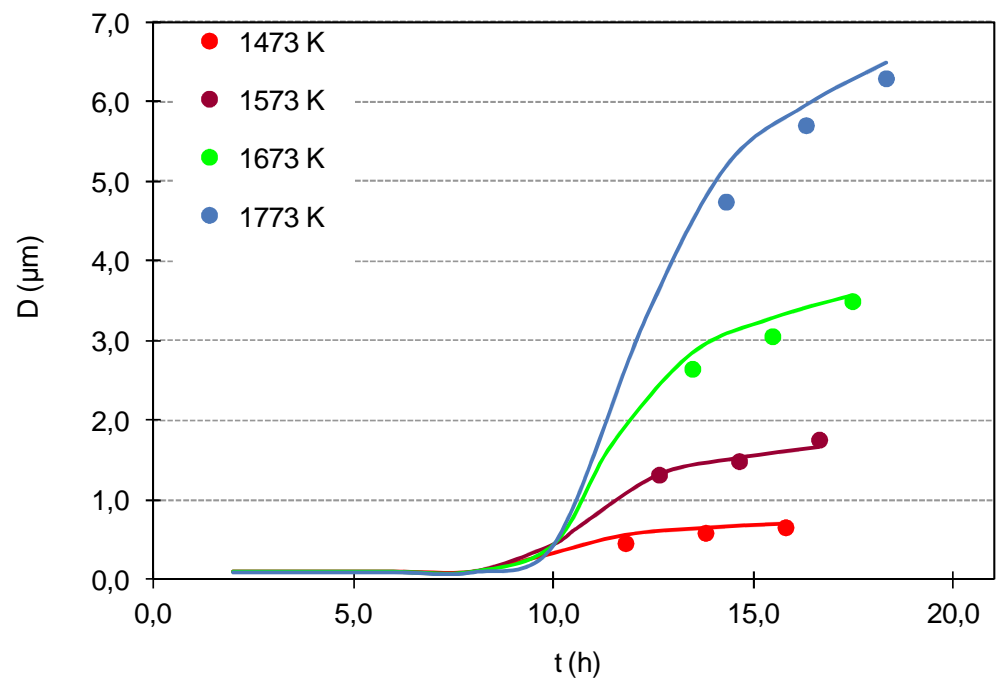

Figura 5.6. Variación del diámetro medio de grano con el tiempo de tratamiento térmico, calculada con las ecuaciones (5.9) y (5.5) con $n=3,5$. Comparación con los datos experimentales obtenidos a las cuatro temperaturas de sinterización ensayadas y diferentes valores del tiempo de residencia. 


\subsubsection{Piezas prensadas}

En la Figura 5.7 se ha representado los valores del diámetro medio de grano, obtenidos a las tres temperaturas de sinterización ensayadas $(1573,1673$ y $1773 \mathrm{~K})$, frente al correspondiente valor del tiempo de residencia $\left(1,2,4\right.$ y $6 \mathrm{~h}$ para $\mathrm{T}_{\mathrm{S}}=1773 \mathrm{~K}$ y 2,4 y $6 \mathrm{~h}$ a 1573 y 1673 K) (Tabla 5.3). Las líneas obtenidas son ligeramente curvas, cóncavas hacia el eje de abscisas, y de pendiente positiva como en el caso de las láminas estudiadas en el apartado anterior.

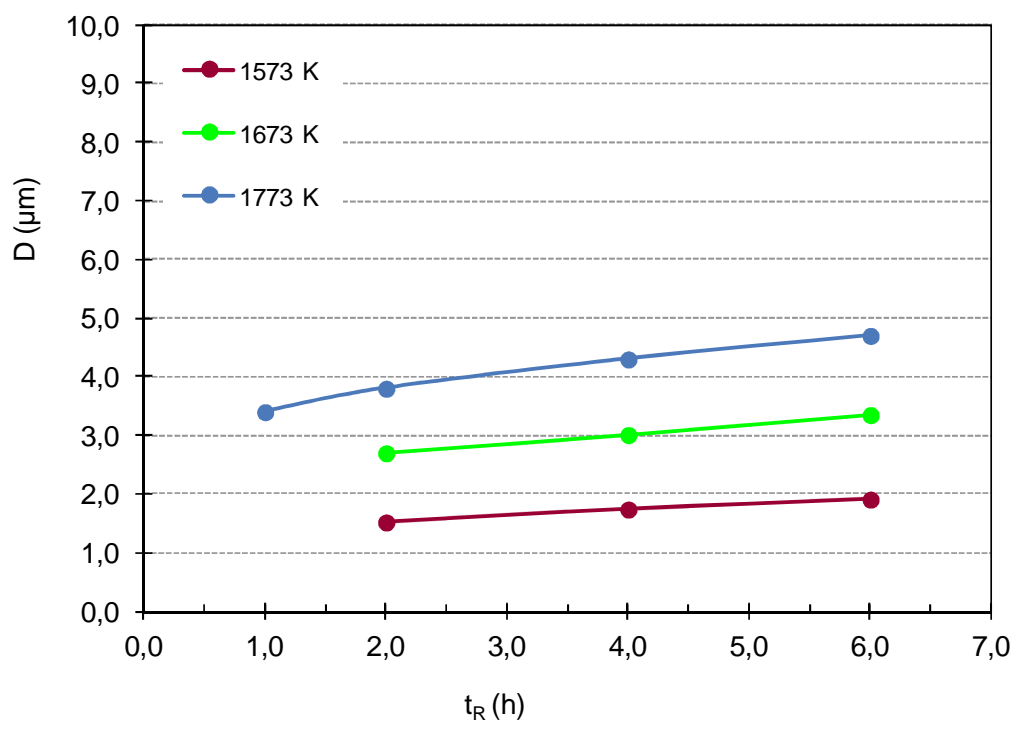

Figura 5.7. Piezas prensadas de la composición C-I. Variación del diámetro medio grano con la temperatura de sinterización y el tiempo de residencia.

Al operar en la forma descrita en el caso de láminas coladas se obtuvieron muy buenos coeficientes de correlación, al representarlos de acuerdo con la ecuación (5.2), y la mejor concordancia entre los resultados experimentales y los calculados mediante las ecuaciones (5.5) y (5.8), aplicadas en la forma descrita anteriormente, para el valor del exponente $n$ de la ecuación (5.1) igual a 3,5, propuesto para las láminas asimismo en el Apartado 5.3.1.

En la Figura 5.8 se han representado, según la ecuación (5.2), los valores de $\boldsymbol{D}^{4,5}$ frente a $\boldsymbol{t}_{\boldsymbol{R}}$, para las tres temperaturas de sinterización estudiadas.

En la Tabla 5.7 se detallan los valores del parámetro $\boldsymbol{k}_{\boldsymbol{D}}$ obtenidos de las correspondientes representaciones, los cuales se han representado, a su vez, en la forma In $\boldsymbol{k}_{\boldsymbol{D}}$ frente a la reciproca de la temperatura de sinterización en la Figura 5.9. Como puede apreciarse, los coeficientes de correlación obtenidos son muy buenos. 


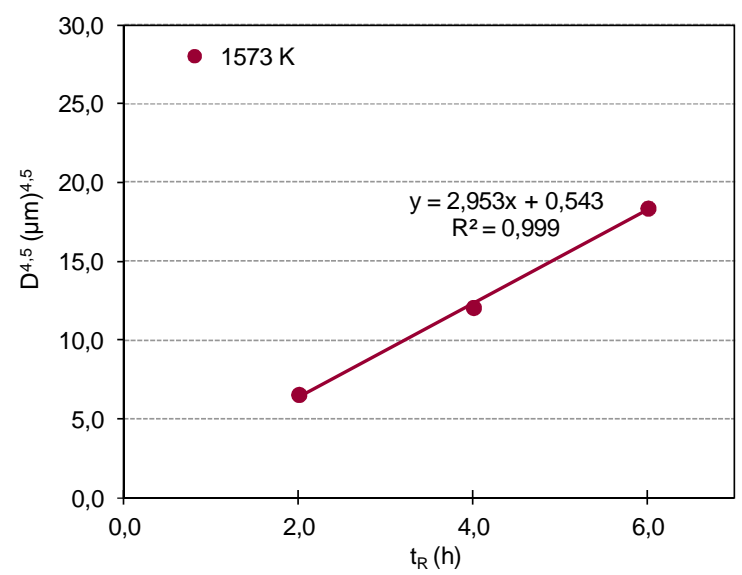

(a)

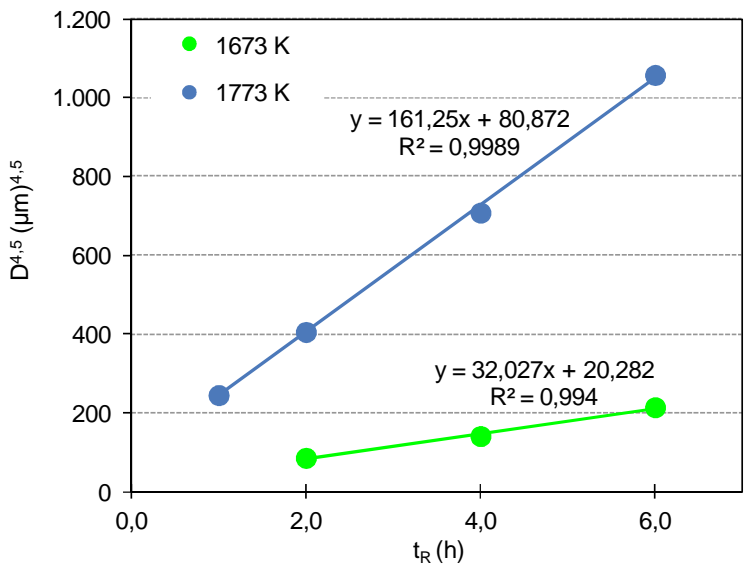

(b)

Figura 5.8. Representación de los datos experimentales de $D$ en función de $t_{R}$, de acuerdo con la ecuación (5.2). (a) $T_{s}=1573 \mathrm{~K}$; (b) $T_{s}=1673$ y $1773 \mathrm{~K}$.

Tabla 5.7. Variación de la constante $k_{D}$ de la ecuación (5.3) con la temperatura de tratamiento térmico

\begin{tabular}{|c|c|c|c|c|c|}
\hline $\mathrm{T}_{\mathrm{S}}(\mathrm{K})$ & $1 / T_{S}\left(K^{-1}\right)$ & $k_{D}(n+1)=4,5 k_{D}$ & $k_{D}(\exp )$ & $\ln k_{D}(\exp )$ & $k_{D}$ (calc) \\
\hline 1573 & 6,36E-04 & 2,95 & 0,66 & $-0,42$ & 0,710 \\
\hline 1673 & 5,98E-04 & 32,03 & 7,12 & 1,96 & 5,960 \\
\hline 1773 & 5,64E-04 & 161,25 & 35,83 & 3,58 & 39,320 \\
\hline
\end{tabular}

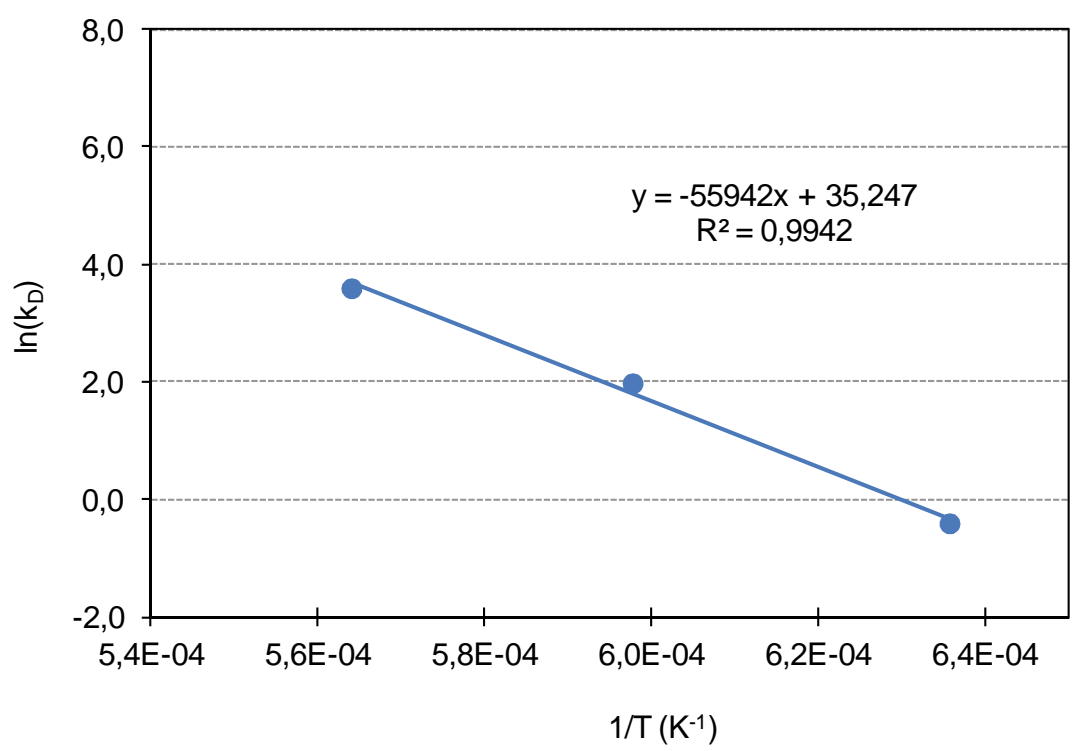

Figura 5.9. Representación del ln $k_{D}$ frente a $1 / T_{S}$, de acuerdo con la ecuación (5.3). 


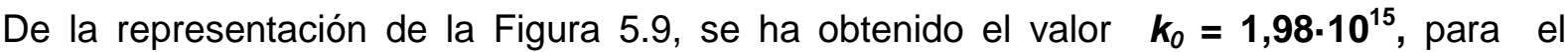
coeficiente preexponencial, y $\mathbf{5 5 9 4 2}$ para el parámetro $\boldsymbol{Q}$ de la ecuación (5.3).

Operando con la ecuación (5.8), puesta en la forma:

$$
d D / d t=\frac{1,984 \cdot 10^{15} \exp \left[-\frac{55942}{(298+120 t)}\right]}{D^{3,5}}
$$

Calculando los valores de $\boldsymbol{t}_{1}$ con la ecuación (5.10), resultaron los valores 10,$63 ; 11,46$ y $12,29 \mathrm{~h}$ para las temperaturas de sinterización de 1573, 1673 y $1773 \mathrm{~K}$ respectivamente.

En la Tabla 5.8 se muestran los valores del diámetro medio de grano obtenidos en los experimentos realizados, junto con el valor del tiempo de tratamiento térmico correspondiente, calculado teniendo en cuenta que $\boldsymbol{t}_{2}=\boldsymbol{t}_{1}+\boldsymbol{t}_{R}$, en cada caso.

\begin{tabular}{|c|c|c|c|c|c|}
\hline \multicolumn{2}{|c|}{$\mathrm{T}_{\mathrm{S}}=1573 \mathrm{~K}$} & \multicolumn{2}{|c|}{$T_{S}=1673 \mathrm{~K}$} & \multicolumn{2}{|c|}{$\mathrm{T}_{\mathrm{S}}=1773 \mathrm{~K}$} \\
\hline$t_{2}(h)$ & $D_{2} \exp$ & $t_{2}(h)$ & $D_{2} \exp$ & $t_{2}(h)$ & $D_{2} \exp$ \\
\hline & & & & 13,29 & 3,4 \\
\hline 12,63 & 1,52 & 13,46 & 2,7 & 14,29 & 3,8 \\
\hline 14,63 & 1,74 & 15,46 & 3,01 & 16,29 & 4,3 \\
\hline 16,63 & 1,91 & 17,46 & 3,35 & 18,29 & 4,7 \\
\hline
\end{tabular}

Operando en la forma descrita en el apartado anterior, se han obtenido las valores calculados del diámetro medio de grano correspondiente a diferentes valores del tiempo de tratamiento térmico de las muestras y de la temperatura del horno.

También, en este caso, el crecimiento de grano empieza sobre los $1450 \mathrm{~K}$, por lo que se puede hacer la misma observación sobre el tamaño de grano, al comienzo de cada tramo a temperatura constante, que se ha hecho en el apartado anterior. 


\begin{tabular}{|c|c|c|c|c|c|c|c|c|}
\hline \multicolumn{3}{|c|}{$\mathrm{T}_{\mathrm{S}}=1573 \mathrm{~K}$} & \multicolumn{3}{|c|}{$T_{S}=1673 \mathrm{~K}$} & \multicolumn{3}{|c|}{$T_{S}=1773 \mathrm{~K}$} \\
\hline$t(h)$ & $\mathrm{T}(\mathrm{K})$ & $\begin{array}{c}\text { D calc } \\
(\mu \mathrm{m})\end{array}$ & $t(h)$ & $\mathrm{T}(\mathrm{K})$ & $\begin{array}{c}\text { D calc } \\
(\mu \mathrm{m})\end{array}$ & $t(h)$ & $\mathrm{T}(\mathrm{K})$ & $\begin{array}{c}\text { D calc } \\
(\mu \mathrm{m})\end{array}$ \\
\hline 0 & 298 & 0,097 & 0 & 298 & 0,097 & 0 & 298 & 0,097 \\
\hline 2 & 538 & 0,097 & 2 & 538 & 0,097 & 2 & 538 & 0,097 \\
\hline 4 & 778 & 0,097 & 4 & 778 & 0,097 & 4 & 778 & 0,097 \\
\hline 6 & 1018 & 0,097 & 6 & 1018 & 0,097 & 6 & 1018 & 0,097 \\
\hline 8 & 1258 & 0,14 & 8 & 1258 & 0,14 & 8 & 1258 & 0,14 \\
\hline 10 & 1498 & 0,70 & 10 & 1498 & 0,70 & 10 & 1498 & 0,70 \\
\hline 10,63 & 1573 & 0,92 & 11,46 & 1673 & 1,70 & 12,29 & 1773 & 2,60 \\
\hline 12,63 & 1573 & 1,52 & 13,46 & 1673 & 2,62 & 13,29 & 1773 & 3,38 \\
\hline 14,63 & 1573 & 1,76 & 15,46 & 1673 & 3,01 & 14,29 & 1773 & 3,80 \\
\hline 16,63 & 1573 & 1,92 & 17,46 & 1673 & 3,27 & 16,29 & 1773 & 4,33 \\
\hline & & & & & & 18,29 & 1773 & 4,70 \\
\hline
\end{tabular}

En la Figura 5.10 se han representado los valores de $\boldsymbol{D}$ calculados, que se muestran en la Tabla 5.9 y los experimentales que se muestran en la Tabla 5.8 frente a los respectivos valores del tiempo de duración del correspondiente ciclo térmico.

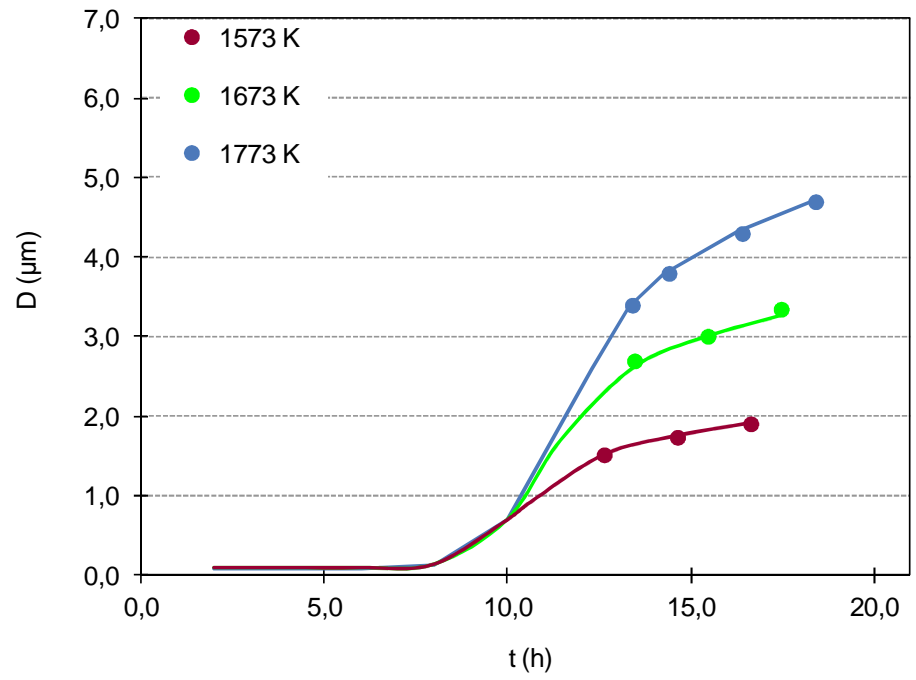

Figura 5.10. Variación del diámetro medio de grano con el tiempo de tratamiento térmico, calculada con las ecuaciones (5.9) y (5.5) con $n=3,5$. Comparación con los datos experimentales obtenidos a las tres temperaturas de sinterización ensayadas y diferentes valores del tiempo de residencia. 
Como puede apreciarse, en este caso, mediante la ecuación (5.1), con las variantes introducidas y la información obtenida a partir de los correspondientes resultados experimentales, se pueden reproducir muy bien dichos resultados, asimismo con el exponente $\boldsymbol{n}=\mathbf{3 , 5}$.

La metodología desarrollada y las ecuaciones propuestas pueden permitir optimizar el ciclo de tratamiento térmico necesario para obtener un producto final con un diámetro medio de grano determinado. Esto cobraría aún mayor interés en el caso de que, en el material estudiado, exista una relación entre la conductividad iónica y el tamaño de grano, posibilidad que se tratará en el Apartado 5.4.

\subsubsection{Variación de la conductividad total con la temperatura de sinterización y el tiempo de residencia}

En la Tabla 5.10 se muestran los valores de la conductividad total, medida a diferentes temperaturas de ensayo $\left(\boldsymbol{T}_{e}\right)$, de las probetas sinterizadas utilizando los distintos ciclos térmicos reiteradamente descritos que han finalizado con etapas a temperatura constante (Ts), durante un cierto tiempo de residencia $\left(\boldsymbol{t}_{\boldsymbol{R}}\right)$, junto con los correspondientes valores del diámetro medio de grano.

En el Apartado 2.1 se puso de manifiesto que uno de los objetivos del trabajo a desarrollar era conseguir un producto final que poseyera una conductividad iónica total, a la temperatura de ensayo de $873 \mathrm{~K}$, lo más elevada posible (superior a 0,015 S/cm), con la finalidad de utilizarlo como electrolito en celdas de combustible de óxido sólido, que operaran a unas condiciones de temperatura bastante más bajas (entre 873 y $973 \mathrm{~K}$ ) que las que se emplean actualmente (entre 1173 y $1273 \mathrm{~K}$ ).

Como puede apreciarse en la Tabla 5.10, las conductividades totales de las muestras procesadas hasta las temperaturas máximas de sinterización de 1673 y $1773 \mathrm{~K}$, son del orden de 0,021 a $0,022 \mathrm{~S} / \mathrm{cm}$ a la temperatura de ensayo de $873 \mathrm{~K}$ y del orden de $0,056 \mathrm{a}$ $0,059 \mathrm{~S} / \mathrm{cm}$ a $973 \mathrm{~K}$.

Estos valores son del mismo orden o mayores que la mayoría de los valores propuestos, hasta ahora, por otros investigadores para electrolitos basados en las propiedades del óxido de circonio dopado con óxidos de escandio, de cerio o de itrio.

En efecto, en la bibliografía consultada, se citan valores de la conductividad total, a las temperaturas de ensayo de $873 \mathrm{~K}$, del orden de entre 0,003 y $0,015 \mathrm{~S} / \mathrm{cm}^{99,109,110,111 .}$ 
Tabla 5.10. Probetas prensadas de la Composición $C$-I. Valores experimentales de la conductividad total $\left(\sigma_{T}\right)(S / \mathrm{cm})$ obtenidos a diferentes valores de la temperatura de ensayo $\left(T_{e}\right)$, junto con las condiciones de operación $\left(T_{s} y t_{R}\right)$ utilizadas para sinterizarlas y los valores de los correspondientes diámetros medios de grano

\begin{tabular}{|c|c|c|c|c|c|c|c|c|c|c|}
\hline \multirow{2}{*}{$\frac{T_{S}}{t_{R}(h)}$} & \multicolumn{3}{|c|}{1573 K } & \multicolumn{3}{|c|}{$1673 \mathrm{~K}$} & \multicolumn{4}{|c|}{$1773 \mathrm{~K}$} \\
\hline & $2 \mathrm{~h}$ & $4 \mathrm{~h}$ & $6 \mathrm{~h}$ & $2 \mathrm{~h}$ & $4 \mathrm{~h}$ & $6 \mathrm{~h}$ & $1 \mathrm{~h}$ & $2 \mathrm{~h}$ & $4 \mathrm{~h}$ & $6 \mathrm{~h}$ \\
\hline \multicolumn{11}{|l|}{$T_{e}(K)$} \\
\hline 573 & $2,66 \mathrm{E}-6$ & 2,73E-6 & $2,74 \mathrm{E}-6$ & $2,82 \mathrm{E}-6$ & $2,85 \mathrm{E}-6$ & 2,92E-6 & 2,91E-6 & $2,90 \mathrm{E}-6$ & $2,90 \mathrm{E}-6$ & 2,92E-6 \\
\hline 623 & $2,65 E-5$ & $2,70 \mathrm{E}-5$ & $2,80 \mathrm{E}-5$ & $2,82 \mathrm{E}-5$ & $2,92 \mathrm{E}-5$ & 2,89E-5 & $2,89 E-5$ & $2,92 \mathrm{E}-5$ & $2,90 \mathrm{E}-5$ & $2,93 \mathrm{E}-5$ \\
\hline 673 & $1,99 \mathrm{E}-4$ & $2,05 \mathrm{E}-4$ & $2,09 \mathrm{E}-4$ & $2,17 \mathrm{E}-4$ & $2,20 \mathrm{E}-4$ & $2,21 \mathrm{E}-4$ & $2,26 \mathrm{E}-4$ & $2,24 \mathrm{E}-4$ & $2,30 \mathrm{E}-4$ & $2,32 \mathrm{E}-4$ \\
\hline 723 & $1,01 \mathrm{E}-3$ & $1,05 \mathrm{E}-3$ & $1,08 \mathrm{E}-3$ & $1,11 \mathrm{E}-3$ & $1,15 \mathrm{E}-3$ & $1,14 \mathrm{E}-3$ & $1,15 \mathrm{E}-3$ & $1,15 \mathrm{E}-3$ & $1,16 \mathrm{E}-3$ & $1,18 \mathrm{E}-3$ \\
\hline 773 & $3,30 \mathrm{E}-3$ & $3,60 \mathrm{E}-3$ & $3,87 \mathrm{E}-3$ & $3,96 \mathrm{E}-3$ & $4,01 \mathrm{E}-3$ & $3,95 \mathrm{E}-3$ & $4,06 \mathrm{E}-3$ & $4,07 \mathrm{E}-3$ & $4,20 \mathrm{E}-3$ & $4,20 \mathrm{E}-3$ \\
\hline 823 & $7,20 \mathrm{E}-3$ & $8,49 \mathrm{E}-3$ & $9,62 \mathrm{E}-3$ & $1,04 \mathrm{E}-2$ & $1,06 \mathrm{E}-2$ & $1,00 \mathrm{E}-2$ & $1,04 \mathrm{E}-2$ & $1,09 \mathrm{E}-2$ & 1,03E-2 & $1,10 \mathrm{E}-2$ \\
\hline 873 & $1,21 \mathrm{E}-2$ & $1,56 \mathrm{E}-2$ & $1,90 \mathrm{E}-2$ & $2,15 \mathrm{E}-2$ & $2,16 \mathrm{E}-2$ & $2,10 \mathrm{E}-2$ & $2,15 \mathrm{E}-2$ & $2,06 \mathrm{E}-2$ & $2,15 \mathrm{E}-2$ & $2,20 \mathrm{E}-2$ \\
\hline 923 & $1,68 \mathrm{E}-2$ & 2,33E-2 & $3,13 \mathrm{E}-2$ & $3,69 \mathrm{E}-2$ & $3,74 \mathrm{E}-2$ & 3,63E-2 & $3,46 \mathrm{E}-2$ & $3,61 \mathrm{E}-2$ & 3,77E-2 & $3,84 \mathrm{E}-2$ \\
\hline 973 & $2,06 \mathrm{E}-2$ & $3,04 \mathrm{E}-2$ & $4,43 \mathrm{E}-2$ & $5,55 \mathrm{E}-2$ & $5,63 \mathrm{E}-2$ & $5,47 \mathrm{E}-2$ & $5,27 \mathrm{E}-2$ & $5,53 \mathrm{E}-2$ & $5,74 \mathrm{E}-2$ & $5,74 \mathrm{E}-2$ \\
\hline 1023 & $2,37 \mathrm{E}-2$ & $3,64 \mathrm{E}-2$ & 5,63E-2 & $7,59 \mathrm{E}-2$ & $7,61 \mathrm{E}-2$ & $7,41 \mathrm{E}-2$ & $7,22 \mathrm{E}-2$ & $7,59 \mathrm{E}-2$ & $7,70 \mathrm{E}-2$ & 7,71E02 \\
\hline 1073 & 2,61E-2 & $4,15 \mathrm{E}-2$ & $6,63 \mathrm{E}-2$ & $9,45 \mathrm{E}-2$ & $9,54 \mathrm{E}-2$ & $9,32 \mathrm{E}-2$ & $9,16 \mathrm{E}-2$ & $9,84 \mathrm{E}-2$ & $9,95 \mathrm{E}-2$ & $9,95 \mathrm{E}-2$ \\
\hline 1123 & $2,81 \mathrm{E}-2$ & $4,51 \mathrm{E}-2$ & $7,52 \mathrm{E}-2$ & $1,11 \mathrm{E}-1$ & $1,14 \mathrm{E}-1$ & $1,11 \mathrm{E}-1$ & $1,11 \mathrm{E}-1$ & $1,13 \mathrm{E}-1$ & 1,17E-1 & $1,16 \mathrm{E}-1$ \\
\hline 1173 & $2,96 \mathrm{E}-2$ & $4,76 \mathrm{E}-2$ & $8,20 \mathrm{E}-2$ & $1,28 \mathrm{E}-1$ & $1,28 \mathrm{E}-1$ & $1,29 \mathrm{E}-1$ & $1,29 \mathrm{E}-1$ & $1,31 \mathrm{E}-1$ & $1,30 \mathrm{E}-1$ & $1,29 \mathrm{E}-1$ \\
\hline 1223 & $3,09 \mathrm{E}-2$ & $4,88 \mathrm{E}-2$ & 8,74E-2 & $1,41 \mathrm{E}-1$ & $1,41 \mathrm{E}-1$ & $1,43 \mathrm{E}-1$ & $1,45 \mathrm{E}-1$ & $1,46 \mathrm{E}-1$ & $1,48 \mathrm{E}-1$ & $1,47 \mathrm{E}-1$ \\
\hline 1273 & $3,14 \mathrm{E}-2$ & $4,86 \mathrm{E}-2$ & 9,09E-2 & $1,52 \mathrm{E}-1$ & $1,54 \mathrm{E}-1$ & $1,56 \mathrm{E}-1$ & $1,57 \mathrm{E}-1$ & $1,58 \mathrm{E}-1$ & $1,61 \mathrm{E}-1$ & $1,60 \mathrm{E}-1$ \\
\hline$\underset{(\mu \mathrm{m})}{\mathrm{D}}$ & 1,52 & 1,74 & 1,91 & 2,70 & 3,01 & 3,30 & 3,40 & 3,80 & 4,30 & 4,70 \\
\hline
\end{tabular}

Por otra parte, el hecho de que utilizando los dos ciclos térmicos más cortos desarrollados hasta las temperaturas máximas de sinterización de $1673 \mathrm{~K}\left(\boldsymbol{t}_{R}=2 \mathrm{~h}\right)$ y $1773 \mathrm{~K}\left(\boldsymbol{t}_{\boldsymbol{R}}=1 \mathrm{~h}\right)$, se hayan obtenido muestras que poseen ya prácticamente el valor máximo alcanzado por la conductividad iónica total, a las temperaturas de ensayo de $873 \mathrm{~K}(0,0215 \mathrm{~S} / \mathrm{cm})$ y de $973 \mathrm{~K}$ $(0,056 \mathrm{~S} / \mathrm{cm})$, supone una información muy interesante, por lo que puede suponer un ahorro de energía, al diseñar el ciclo térmico a utilizar industrialmente para obtener un electrolito de esta naturaleza con la máxima conductividad iónica total posible, a dichas temperaturas de ensayo. 


\subsubsection{Variación de la conductividad total con la temperatura de ensayo $\left(T_{e}\right)$}

Partiendo de los datos experimentales que se detallan la Tabla 5.10, en la Figura 5.11 se ha representado, en coordenadas rectangulares, la conductividad total de las muestras frente a la temperatura de ensayo $\left(\boldsymbol{T}_{\boldsymbol{e}}\right)$, para cada valor del diámetro medio de grano obtenido.

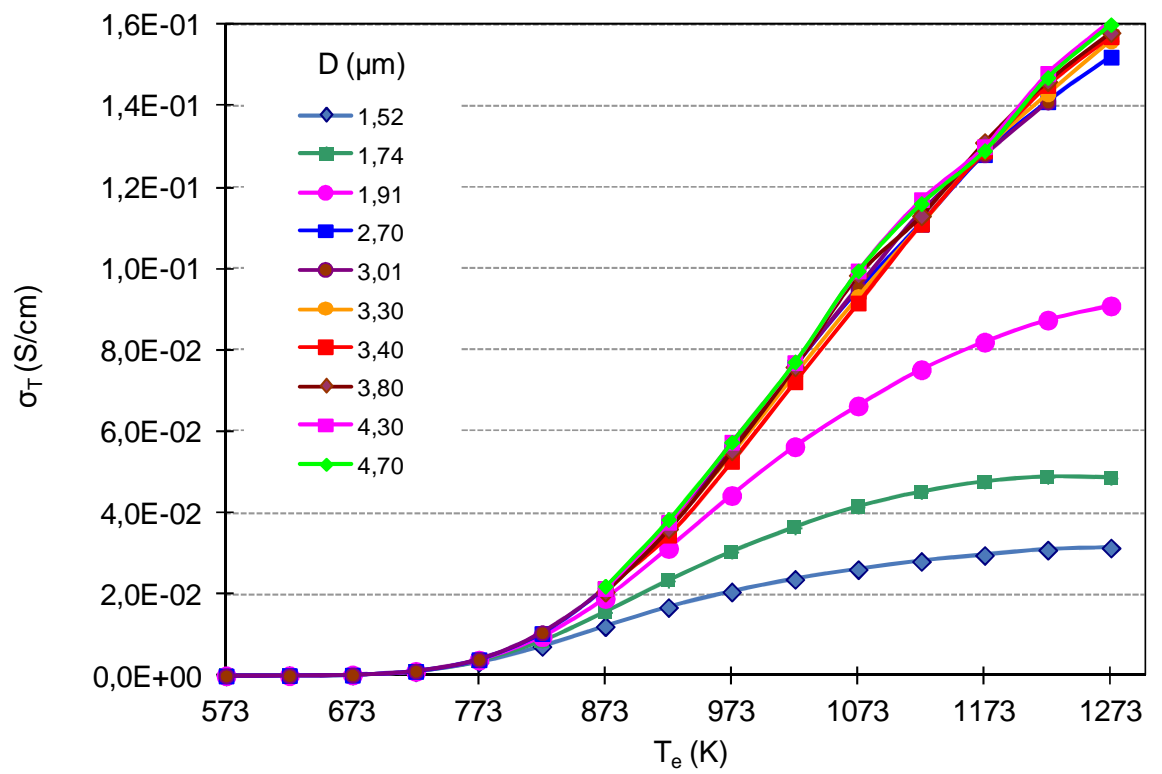

Figura 5.11. Variación de la conductividad total con la temperatura de ensayo $\left(T_{e}\right)$ y con el diámetro medio de grano ( $\mu \mathrm{m})$.

Como puede apreciarse, para temperaturas de ensayo superiores a $773 \mathrm{~K}$, la conductividad total disminuye considerablemente cuando se reduce el tamaño medio de grano, para valores de esta propiedad inferiores a 2,7 $\mu \mathrm{m}$. Esta circunstancia se tratará con detalle en el Apartado 5.4.1.2.

Separando variables en la ecuación (1.17) y hallando logaritmos neperianos resulta:

$$
\ln \left(\sigma_{T} \cdot T_{e}\right)=\ln \sigma_{0}^{T}-\frac{E}{k T_{e}}
$$

Tal como se indicó en el Apartado 1.2.4, en la Figura 5.12 se han representado los datos experimentales en la forma $\boldsymbol{I n}\left(\boldsymbol{\sigma}_{T^{*}} \boldsymbol{T}_{e}\right)$ versus $\left(\mathbf{1} / \boldsymbol{T}_{e}\right)$.

Se observa que se obtienen líneas curvas, debido a la amplitud del intervalo de valores de $\boldsymbol{T}_{\boldsymbol{e}}$ estudiado. Las correlaciones de tipo exponencial de esta naturaleza se suelen cumplir sólo para intervalos de temperatura de 200 a $300 \mathrm{~K}$.

La forma curva de estas representaciones en el intervalo de valores de $T_{e}$ estudiado, coincide con los resultados obtenidos por varios investigadores que han trabajado con 
materiales a base de circona, con la composición utilizada en este trabajo o muy parecida $^{25,104}$.

También en esta representación se aprecia que para temperaturas de ensayo superiores a $773 \mathrm{~K}$, la conductividad total disminuye cuando lo hace el tamaño de grano, para valores del mismo inferiores a $2,7 \mu \mathrm{m}$.

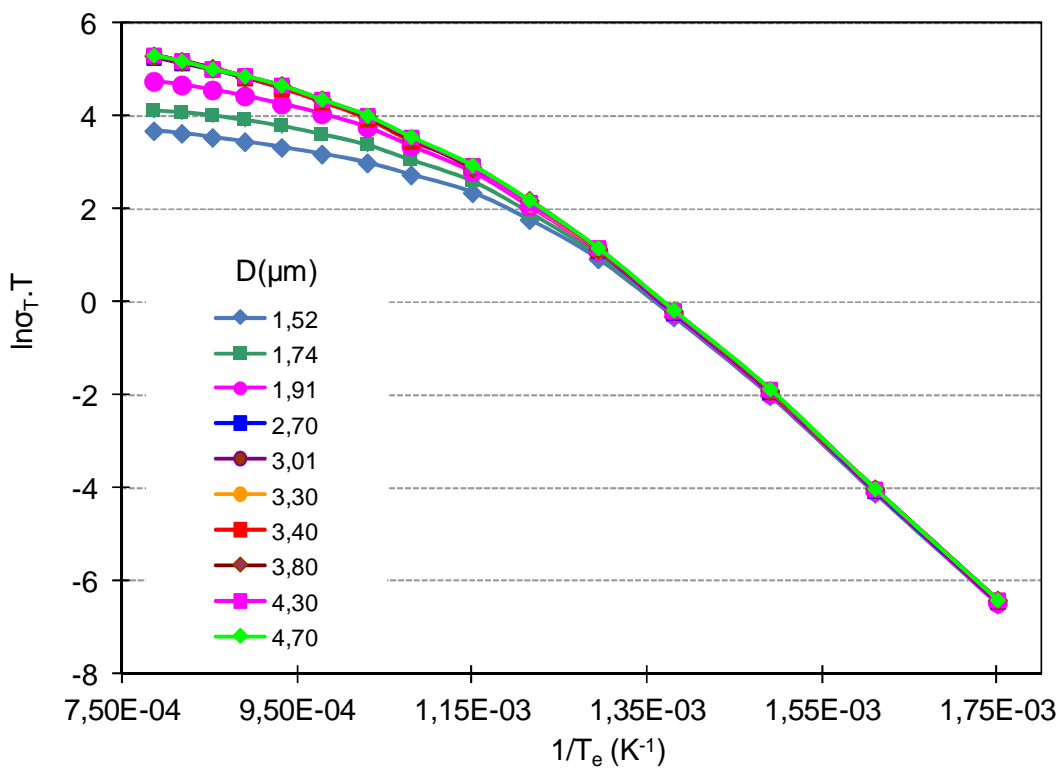

Figura 5.12. Variación de la conductividad total con la temperatura de ensayo ( $T_{e}$ ) y con el diámetro medio de grano (ecuación (5.12)).

Para tratar de ajustar parte de los resultados a una línea recta, mediante la ecuación (5.12), se ha reducido el intervalo de valores de $T_{e}$ a considerar.

En la Figura 5.13 se ha efectuado la representación de la Figura 5.12 sólo para el intervalo de temperatura de ensayo comprendido entre 573 y $773 \mathrm{~K}$, ambas inclusive.

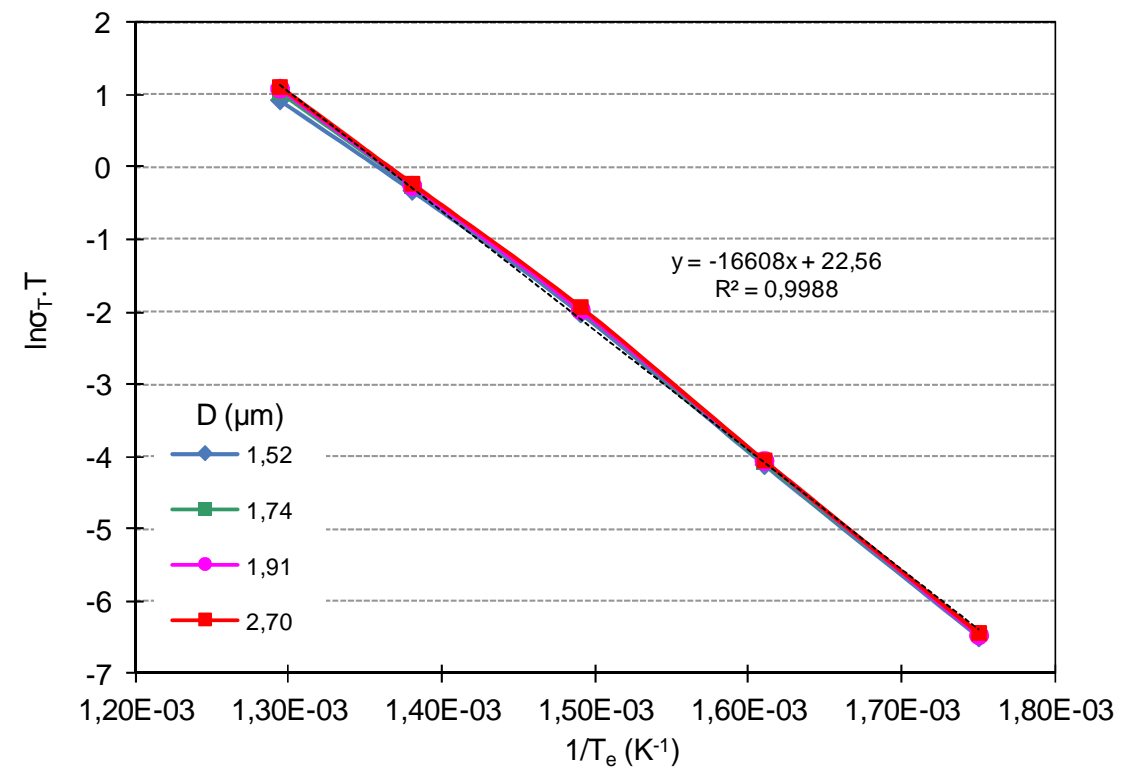

Figura 5.13. Variación de la conductividad total con el diámetro medio de grano y la temperatura de ensayo ( $\left.T_{e}\right)$, en el intervalo de valores de $T_{e} \leq 773 \mathrm{~K}$. 
Se observa que, casi coinciden las representaciones obtenidas para todos los tamaños de grano determinados en los experimentos realizados, de modo que puede afirmarse que, en el intervalo de temperaturas de ensayo comprendido entre 573 y $773 \mathrm{~K}$, el tamaño medio de grano no influye prácticamente sobre los valores de la conductividad iónica total.

Ajustando todos los resultados a una línea recta única se obtiene la ecuación:

$$
\sigma_{T} \cdot T_{e}=6,276 \cdot 10^{9} \cdot \exp \left(-16608 / T_{e}\right)
$$

Si se considera que, en este caso, $16608=\boldsymbol{E}_{i} / \boldsymbol{k}$, según la ecuación (1.17), teniendo en cuenta que la constante de Boltzman vale $\boldsymbol{k}=8,6173324 \cdot 10^{-5} \mathrm{eV}$, resulta un valor para la energía aparente de activación de $\boldsymbol{E}_{\boldsymbol{i}}=1,43 \mathrm{eV}$. Este valor es del mismo orden que los propuestos por otros investigadores ${ }^{100,112}$ para materiales análogos, en el tramo de temperaturas de ensayo considerado.

En la Figura 5.14, dicha representación se ha realizado para el intervalo de temperaturas de ensayo comprendido entre 973 y $1273 \mathrm{~K}$. En este caso, al tratar de ajustar los datos a líneas rectas, se han obtenido cuatro ecuaciones diferentes para los diámetros medios de grano de 1,$52 ; 1,74 ; 1,92$ y $2,70 \mu \mathrm{m}$, de pendientes: $-2842,5 ;-3050,9 ;-4040,6$ y $-5213,1$, respectivamente.

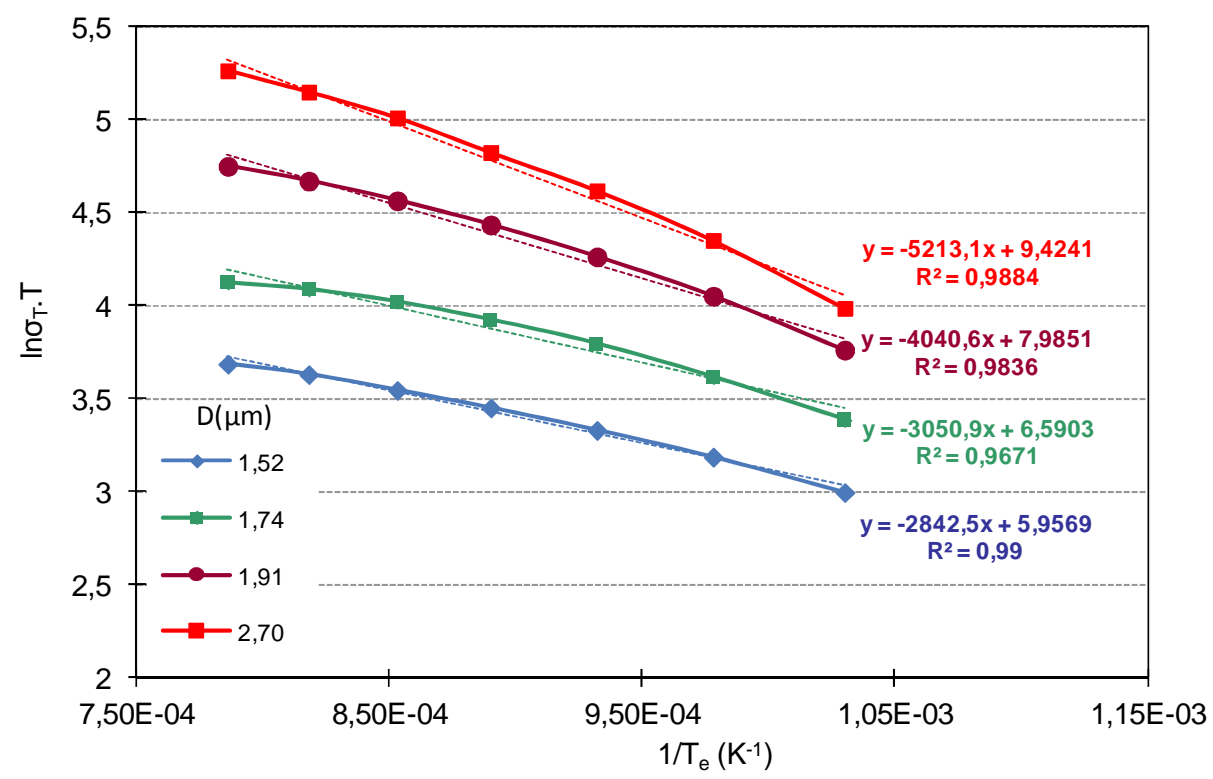

Figura 5.14. Variación de la conductividad total con la temperatura de ensayo ( $\left.T_{e}\right)$ y con el diámetro medio de grano.

A partir de estas pendientes se han obtenido los siguientes valores de las energías aparentes de activación: 0,245 eV; 0,263 eV; 0,348 eV y 0,449 eV respectivamente.

No se ha incluido, en esta última representación, los valores de las conductividades totales correspondientes a los tamaños de grano superiores a 2,70 $\mu \mathrm{m}$, porque son tan próximas a las obtenidas para dicho diámetro medio de grano que prácticamente coinciden (ver Tabla 5.10). 
De los resultados de las representaciones anteriores se deduce lo siguiente:

a) En el intervalo de temperaturas de ensayo comprendido entre 573 y $773 \mathrm{~K}$, la conductividad total apenas resulta influenciada por el tamaño de grano, ya que las líneas representativas correspondientes a los diferentes valores de dicha propiedad estudiados prácticamente coinciden.

b) En el intervalo de temperaturas de ensayo comprendido entre 773 y $1273 \mathrm{~K}$, la conductividad total está fuertemente influenciada por el diámetro medio de grano, para valores del mismo inferiores a 2,7 $\mu \mathrm{m}$, dentro del error experimental cometido.

\subsubsection{Variación de la conductividad total con el diámetro medio de grano}

A lo largo del Apartado anterior, se ha puesto de manifiesto que, cuando el valor del diámetro medio de grano es inferior a 2,7 $\mu \mathrm{m}$, la conductividad iónica total de las muestras procesadas disminuye al disminuir el tamaño de grano, en el intervalo de temperaturas de ensayo comprendido entre 773 y $1273 \mathrm{~K}$.

Para tratar de obtener mayor información acerca de dicha dependencia, en las gráficas de las Figuras 5.15 se han representado los valores experimentales de la conductividad total de las muestras procesadas (círculos, rombos, cuadrados, triángulos, etc.), frente al diámetro medio de grano de las mismas, para cada una de las temperaturas de ensayo estudiadas (Tabla 5.9).

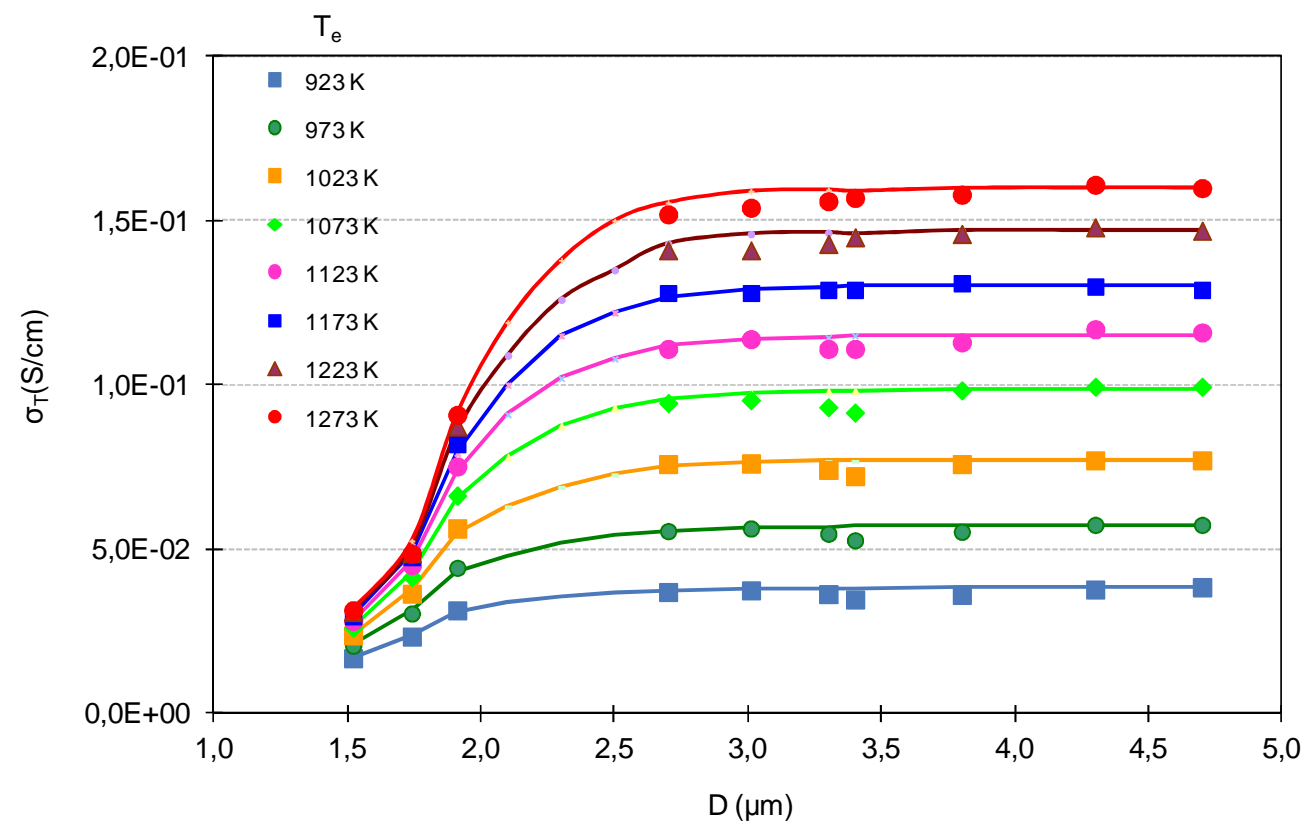

(a) 


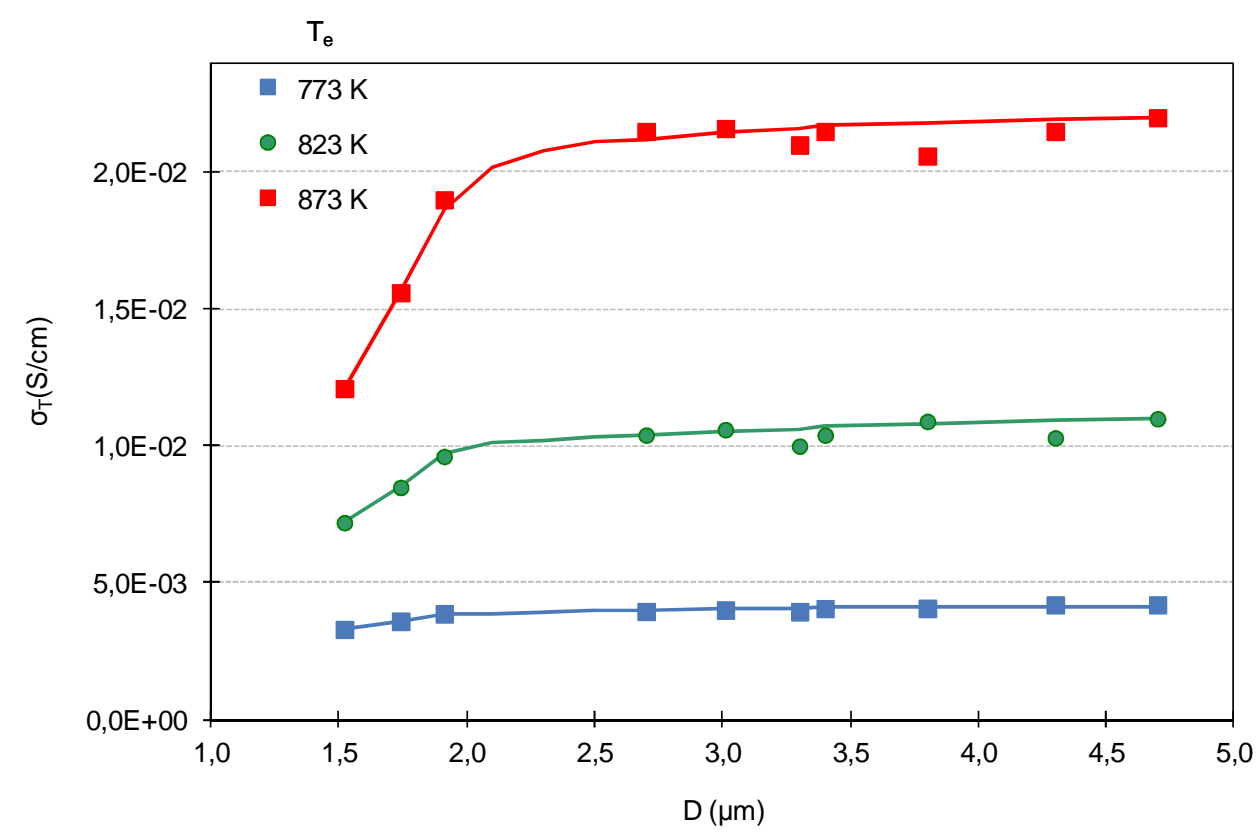

(b)

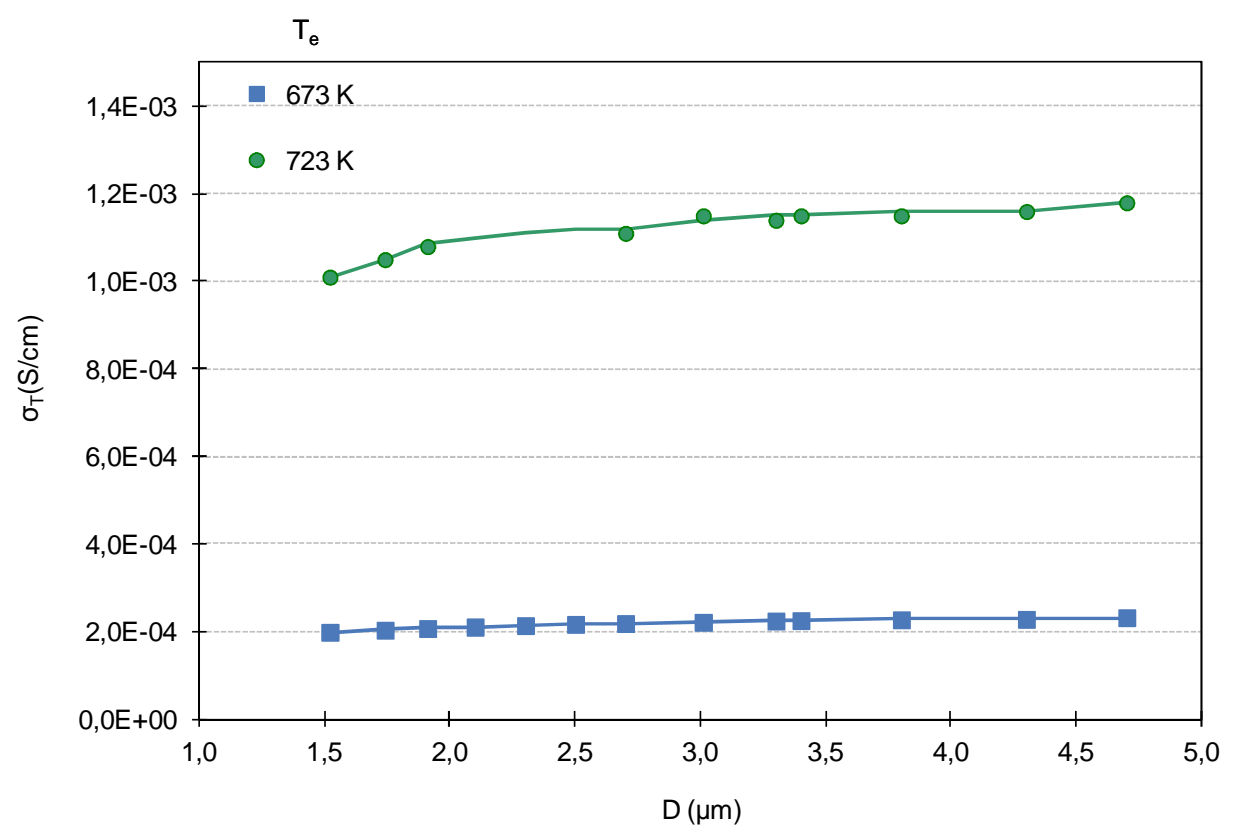

(c) 


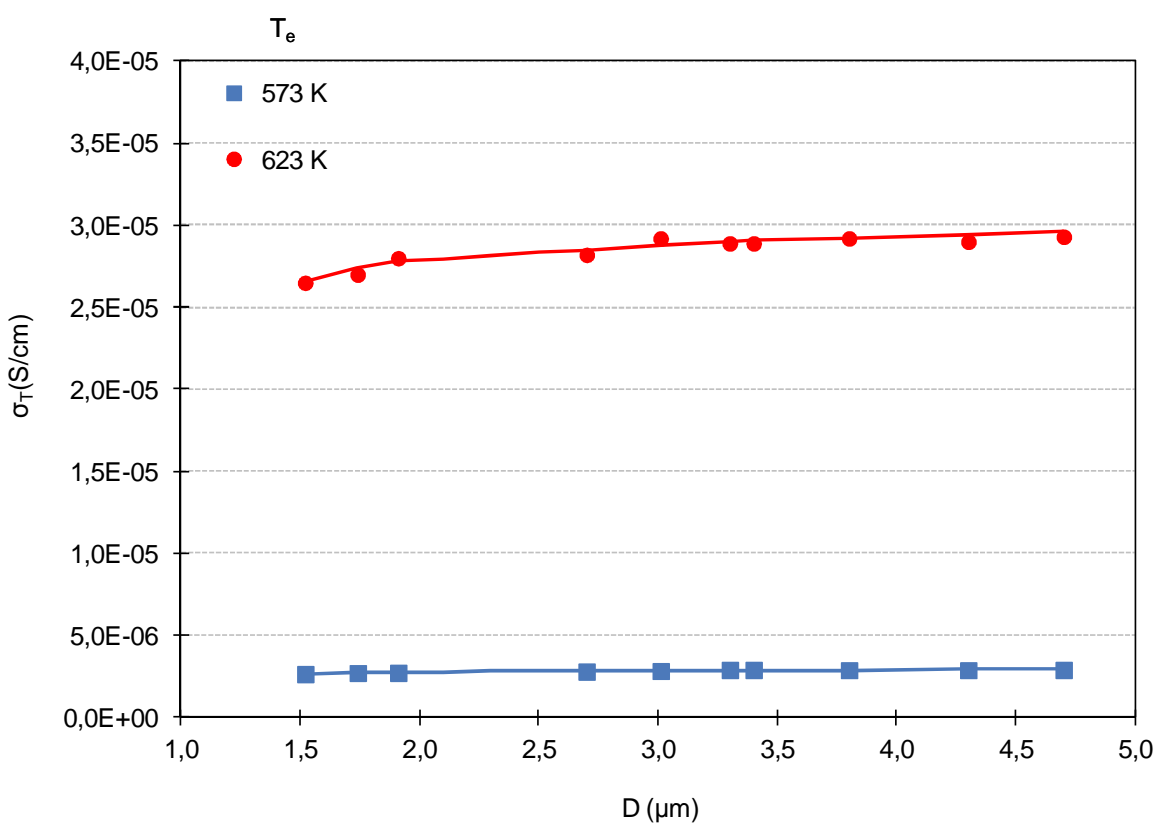

(d)

Figura 5.15. Variación de la conductividad total con la temperatura de ensayo $\left(T_{e}\right)$ y con el diámetro medio de grano.

Como puede apreciarse, a todas las temperaturas de ensayo estudiadas, la conductividad iónica total aumenta con el diámetro medio de grano, según una trayectoria de tipo sigmoideo, hasta valores de éste comprendidos entre 2,7 y 3,01 $\mu \mathrm{m}$. Por encima de estos valores, y a partir del valor máximo se ralentiza dicho crecimiento progresivamente hasta alcanzar un valor prácticamente constante.

Este comportamiento se aprecia mejor en las representaciones correspondientes a las temperaturas de ensayo más elevadas (823 a $1273 \mathrm{~K}$ ).

El aumento de la conductividad iónica total con el tamaño de grano, dentro del intervalo mencionado, ha sido también observado por C. Peters, en electrolitos de circona estabilizada con itria ${ }^{112}$, en el intervalo de valores del diámetro medio de grano comprendidos entre 0,005 y $0,782 \mu \mathrm{m}$, y por Lee $^{37}$ para circona estabilizada con escandio y cerio, en el mismo intervalo de tamaños de grano. Además Lee también detalla la ralentización del crecimiento observada.

Si se admite que, en principio, la relación entre la conductividad total en los límites de grano y el diámetro medio de grano puede expresarse mediante la ecuación (1.23):

$$
\sigma_{\mathrm{lg}}^{T}=D \sigma_{\mathrm{lg}}^{e} / \delta
$$

y se tienen en cuenta el primer y segundo miembros de la ecuación (1.22), puede escribirse:

$$
1 / \sigma_{T}=1 / \sigma_{g}+\delta / D \sigma_{\mathrm{lg}}^{e}
$$


o también:

$$
\sigma_{T}=\left(1 / \sigma_{g}+\delta / D \sigma_{\lg }^{e}\right)^{-1}
$$

que relaciona la conductividad total con la conductividad en el interior del grano, con el diámetro medio del mismo y con $\delta$ y $\sigma_{l g}^{e}$ que se han definido en el Apartado 1.2.5.1.

Poniendo la ecuación anterior en función de las correspondientes resistividades, resulta (ver ecuación (1.21)):

$$
\rho_{T}=\rho_{g}+\rho_{\mathrm{lg}}^{T}=\rho_{g}+\delta / D \sigma_{\mathrm{lg}}^{e}
$$

Ahora bien, la conductividad iónica en el interior de grano $\left(\sigma_{g}\right)$, a cada temperatura de ensayo, no debe variar con el tamaño del mismo, ya que únicamente debe depender de la naturaleza del material ${ }^{33,104,113}$. Por otra parte, según estas dos últimas ecuaciones, al aumentar el diámetro medio de grano debe disminuir la resistividad eléctrica total o aumentar la conductividad iónica total del material policristalino.

De acuerdo con esto, la forma de las representaciones de la Figura 5.15 parece indicar que, a partir de valores del diámetro medio de grano próximos a 2,7 $\mu \mathrm{m}$, el valor del segundo término del segundo miembro de las ecuaciones (5.14) y (5.15) llega a hacerse progresivamente tan pequeño frente al valor del primero que, tanto la resistividad eléctrica total, como la conductividad total, tienden paulatinamente a alcanzar los respectivos valores de la resistividad y de la conductividad en el interior de grano. En lo que sigue se tratará de confirmar esta hipótesis.

Ahora bien, para algunas de las temperaturas de ensayo estudiadas puede apreciarse una cierta dispersión de los puntos representativos de los correspondientes datos experimentales, como consecuencia de desordenadas fluctuaciones presumiblemente debidas al inevitable error del que están afectadas las medidas realizadas.

Para reducir o eliminar la influencia de esta dispersión sobre el procesado de los resultados, que se tenía previsto efectuar a continuación, se procedió a efectuar una interpolación entre los puntos representativos de los datos experimentales, a fin de obtener curvas de trazado suave ${ }^{114}$. Para ello se utilizaron dos modelos de crecimiento de los habitualmente empleados para correlacionar representaciones gráficas de forma sigmoidea ${ }^{114}$. Uno de ellos se empleó para el intervalo de valores del diámetro medio de grano comprendidos entre 1,52 y $1,91 \mu \mathrm{m}$, el otro para el intervalo de valores de $\boldsymbol{D}$ superiores a $1,91 \mu \mathrm{m}$.

Los valores de la conductividad total, resultado de dicha interpolación, se detallan en la Tabla 5.11 y se han representado en forma de líneas continuas, junto con los puntos experimentales, en las representaciones de la Figura 5.16. 
Tabla 5.11. Probetas prensadas de la Composición $C-I$. Valores experimentales de la conductividad total $\left(\sigma_{T}\right)(S / \mathrm{cm})$ calculados por interpolación de los experimentales que se muestran en la tabla 5.9

\begin{tabular}{|c|c|c|c|c|c|c|c|c|c|c|}
\hline \multirow{2}{*}{$\frac{T_{S}}{t_{R}(h)}$} & \multicolumn{3}{|c|}{$1573 \mathrm{~K}$} & \multicolumn{3}{|c|}{$1673 \mathrm{~K}$} & \multicolumn{4}{|c|}{1773 K } \\
\hline & $2 \mathrm{~h}$ & $4 \mathrm{~h}$ & $6 \mathrm{~h}$ & $2 \mathrm{~h}$ & $4 \mathrm{~h}$ & $6 \mathrm{~h}$ & $1 \mathrm{~h}$ & $2 \mathrm{~h}$ & $4 \mathrm{~h}$ & $6 \mathrm{~h}$ \\
\hline \multicolumn{11}{|l|}{$T_{e}(K)$} \\
\hline 573 & $2,66 \mathrm{E}-6$ & $2,71 \mathrm{E}-6$ & $2,74 \mathrm{E}-6$ & $2,85 \mathrm{E}-6$ & $2,88 \mathrm{E}-6$ & $2,89 \mathrm{E}-6$ & $2,89 \mathrm{E}-6$ & $2,90 \mathrm{E}-6$ & $2,91 \mathrm{E}-6$ & $2,92 \mathrm{E}-6$ \\
\hline 623 & $2,65 E-5$ & $2,74 \mathrm{E}-5$ & $2,78 \mathrm{E}-5$ & $2,85 E-5$ & $2,88 \mathrm{E}-5$ & $2,90 \mathrm{E}-5$ & $2,91 \mathrm{E}-5$ & $2,92 \mathrm{E}-5$ & $2,94 \mathrm{E}-5$ & $2,96 \mathrm{E}-5$ \\
\hline 673 & $1,99 \mathrm{E}-4$ & $2,04 \mathrm{E}-4$ & $2,08 \mathrm{E}-4$ & $2,19 \mathrm{E}-4$ & $2,22 \mathrm{E}-4$ & $2,25 \mathrm{E}-4$ & $2,26 \mathrm{E}-4$ & $2,28 \mathrm{E}-4$ & $2,29 E-4$ & $2,32 \mathrm{E}-4$ \\
\hline 723 & $1,01 \mathrm{E}-3$ & $1,05 \mathrm{E}-3$ & $1,09 \mathrm{E}-3$ & $1,12 \mathrm{E}-3$ & $1,14 \mathrm{E}-3$ & $1,15 \mathrm{E}-3$ & $1,15 \mathrm{E}-3$ & $1,16 \mathrm{E}-3$ & $1,16 \mathrm{E}-3$ & $1,18 \mathrm{E}-3$ \\
\hline 773 & $3,30 \mathrm{E}-3$ & $3,55 \mathrm{E}-3$ & $3,84 \mathrm{E}-3$ & $4,00 \mathrm{E}-3$ & $4,04 \mathrm{E}-3$ & $4,08 \mathrm{E}-3$ & $4,11 \mathrm{E}-3$ & $4,12 \mathrm{E}-3$ & $4,14 \mathrm{E}-3$ & $4,15 \mathrm{E}-3$ \\
\hline 823 & $7,20 \mathrm{E}-3$ & $8,50 \mathrm{E}-3$ & $9,70 \mathrm{E}-3$ & $1,04 \mathrm{E}-2$ & $1,05 \mathrm{E}-2$ & $1,06 \mathrm{E}-2$ & 1,07E-2 & $1,08 \mathrm{E}-2$ & $1,09 \mathrm{E}-2$ & $1,10 \mathrm{E}-2$ \\
\hline 873 & $1,21 \mathrm{E}-2$ & 1,56E-2 & $1,86 \mathrm{E}-2$ & 2,12E-2 & $2,15 \mathrm{E}-2$ & $2,16 \mathrm{E}-2$ & 2,17E-2 & $2,18 \mathrm{E}-2$ & $2,19 \mathrm{E}-2$ & $2,20 \mathrm{E}-2$ \\
\hline 923 & $1,68 \mathrm{E}-2$ & $2,40 \mathrm{E}-2$ & $3,07 \mathrm{E}-2$ & 3,73E-2 & $3,78 \mathrm{E}-2$ & $3,80 \mathrm{E}-2$ & $3,81 \mathrm{E}-2$ & $3,82 \mathrm{E}-2$ & $3,83 \mathrm{E}-2$ & $3,84 \mathrm{E}-2$ \\
\hline 973 & $2,06 \mathrm{E}-2$ & $3,16 \mathrm{E}-2$ & $4,30 \mathrm{E}-2$ & $5,56 \mathrm{E}-2$ & $5,65 \mathrm{E}-2$ & $5,68 \mathrm{E}-2$ & $5,69 \mathrm{E}-2$ & $5,70 \mathrm{E}-2$ & $5,70 \mathrm{E}-2$ & $5,70 \mathrm{E}-2$ \\
\hline 1023 & $2,37 \mathrm{E}-2$ & 3,77E-2 & $5,48 \mathrm{E}-2$ & $7,50 \mathrm{E}-2$ & $7,63 \mathrm{E}-2$ & $7,68 \mathrm{E}-2$ & $7,69 \mathrm{E}-2$ & $7,70 \mathrm{E}-2$ & $7,71 \mathrm{E}-2$ & $7,72 \mathrm{E}-2$ \\
\hline 1073 & 2,61E-2 & $4,29 \mathrm{E}-2$ & $6,55 \mathrm{E}-2$ & $9,57 \mathrm{E}-2$ & $9,75 \mathrm{E}-2$ & $9,81 \mathrm{E}-2$ & $9,82 \mathrm{E}-2$ & $9,84 \mathrm{E}-2$ & $9,85 \mathrm{E}-2$ & $9,85 \mathrm{E}-2$ \\
\hline 1123 & $2,81 \mathrm{E}-2$ & $4,68 \mathrm{E}-2$ & $7,34 \mathrm{E}-2$ & $1,12 \mathrm{E}-1$ & $1,14 \mathrm{E}-1$ & $1,15 \mathrm{E}-1$ & $1,15 \mathrm{E}-1$ & $1,15 \mathrm{E}-1$ & $1,15 \mathrm{E}-1$ & $1,15 \mathrm{E}-1$ \\
\hline 1173 & $2,96 \mathrm{E}-2$ & $4,90 \mathrm{E}-2$ & $7,92 \mathrm{E}-2$ & $1,27 \mathrm{E}-1$ & $1,29 \mathrm{E}-1$ & $1,30 \mathrm{E}-1$ & $1,30 \mathrm{E}-1$ & $1,30 \mathrm{E}-1$ & $1,30 \mathrm{E}-1$ & $1,30 \mathrm{E}-1$ \\
\hline 1223 & $3,09 \mathrm{E}-2$ & $5,10 \mathrm{E}-2$ & $8,60 \mathrm{E}-2$ & $1,43 \mathrm{E}-1$ & $1,46 \mathrm{E}-1$ & $1,46 \mathrm{E}-1$ & $1,46 \mathrm{E}-1$ & $1,47 \mathrm{E}-1$ & $1,47 \mathrm{E}-1$ & $1,47 \mathrm{E}-1$ \\
\hline 1273 & $3,14 \mathrm{E}-2$ & $5,25 \mathrm{E}-2$ & $9,10 \mathrm{E}-2$ & $1,56 \mathrm{E}-1$ & $1,59 \mathrm{E}-1$ & $1,59 \mathrm{E}-1$ & $1,59 \mathrm{E}-1$ & $1,60 \mathrm{E}-1$ & $1,60 \mathrm{E}-1$ & $1,60 \mathrm{E}-1$ \\
\hline$\underset{(\mu \mathrm{m})}{\mathrm{D}}$ & 1,52 & 1,74 & 1,91 & 2,70 & 3,01 & 3,30 & 3,40 & 3,80 & 4,30 & 4,70 \\
\hline
\end{tabular}




\subsubsection{Interpretación de los resultados obtenidos en base al Modelo de Brick Layer. Contribución de la conductividad en el interior de grano y en los límites de grano al valor de la conductividad total.}

5.1.5.3.1. Valores experimentales de la conductividad en el interior de grano y en los límites de grano.

Dadas las limitaciones del procedimiento empleado para la medida de las conductividades iónicas de las muestras sinterizadas de las probetas prensadas, sólo fue posible determinar experimentalmente, con ciertas garantías, las conductividades en el interior de grano y en los límites de grano en el intervalo de temperaturas de ensayo comprendido entre 573 y 723 $\mathrm{K}$.

En las Tablas 5.12 y 5.13 se muestran los valores que se han determinado experimentalmente (Tablas 8.1 a 8.10 del Apéndice) de la conductividad en el interior de grano $\left(\boldsymbol{\sigma}_{g}\right)$ y en los límites de grano $\left(\boldsymbol{\sigma}^{T}{ }_{l g}\right)$.

\begin{tabular}{|c|c|c|c|c|c|c|c|c|c|c|}
\hline $\mathbf{T}_{\mathrm{S}}$ & & 1573 K & & & 1673 K & & & 177 & $3 \mathrm{~K}$ & \\
\hline$t_{R}(h)$ & $2 \mathrm{~h}$ & $4 \mathrm{~h}$ & $6 \mathrm{~h}$ & $2 \mathrm{~h}$ & $4 \mathrm{~h}$ & $6 \mathrm{~h}$ & $1 \mathrm{~h}$ & $2 \mathrm{~h}$ & $4 \mathrm{~h}$ & $6 \mathrm{~h}$ \\
\hline \multicolumn{11}{|l|}{$T_{e}(K)$} \\
\hline 573 & $3,13 \mathrm{E}-6$ & $3,10 \mathrm{E}-6$ & $3,04 \mathrm{E}-6$ & $3,08 \mathrm{E}-6$ & $3,06 \mathrm{E}-6$ & $3,12 \mathrm{E}-6$ & $3,08 \mathrm{E}-6$ & $3,08 \mathrm{E}-6$ & $3,08 \mathrm{E}-6$ & $3,10 \mathrm{E}-6$ \\
\hline 623 & $3,16 \mathrm{E}-5$ & $3,14 \mathrm{E}-5$ & $3,21 \mathrm{E}-5$ & $3,15 E-5$ & $3,18 \mathrm{E}-5$ & $3,12 \mathrm{E}-5$ & $3,16 \mathrm{E}-5$ & $3,16 \mathrm{E}-5$ & $3,13 \mathrm{E}-5$ & $3,16 \mathrm{E}-5$ \\
\hline 673 & $2,63 \mathrm{E}-4$ & $2,67 \mathrm{E}-4$ & $2,73 \mathrm{E}-4$ & $2,68 \mathrm{E}-4$ & $2,67 \mathrm{E}-4$ & $2,64 \mathrm{E}-4$ & $2,67 \mathrm{E}-4$ & $2,65 \mathrm{E}-4$ & $2,62 \mathrm{E}-4$ & $2,66 \mathrm{E}-4$ \\
\hline 723 & $1,48 \mathrm{E}-3$ & $1,47 \mathrm{E}-3$ & $1,49 \mathrm{E}-3$ & $1,46 \mathrm{E}-3$ & $1,47 \mathrm{E}-3$ & $1,44 \mathrm{E}-3$ & $1,42 \mathrm{E}-3$ & $1,44 \mathrm{E}-3$ & $1,43 \mathrm{E}-3$ & $1,44 \mathrm{E}-3$ \\
\hline$\underset{(\mu \mathrm{m})}{D}$ & 1,52 & 1,74 & 1,91 & 2,70 & 3,01 & 3,30 & 3,40 & 3,80 & 4,30 & 4,70 \\
\hline
\end{tabular}

Como puede apreciarse en la Tabla 5.12, a cada temperatura de ensayo que se muestra en dicha tabla, la conductividad en el interior de grano oscila alrededor de los valores medios de dicha propiedad que se detallan en la Tabla 5.14, sin que resulte influenciada por el tamaño de grano de la muestra estudiada, tal como se había supuesto en los últimos párrafos del apartado anterior. Esta no dependencia de la conductividad iónica en el interior de grano con del tamaño del mismo, puede pues, en principio, extrapolarse a los valores de dicha propiedad correspondientes a las temperaturas de ensayo superiores a $723 \mathrm{~K}$, que no se han podido medir experimentalmente. 


\begin{tabular}{|c|c|c|c|c|c|c|c|c|c|c|}
\hline $\mathbf{T}_{\mathrm{s}}$ & & $1573 \mathrm{~K}$ & & & $1673 \mathrm{~K}$ & & & 177 & $3 \mathrm{~K}$ & \\
\hline$t_{R}(h)$ & $2 \mathrm{~h}$ & $4 \mathrm{~h}$ & $6 \mathrm{~h}$ & $2 \mathrm{~h}$ & $4 \mathrm{~h}$ & $6 \mathrm{~h}$ & $1 \mathrm{~h}$ & $2 \mathrm{~h}$ & $4 \mathrm{~h}$ & $6 \mathrm{~h}$ \\
\hline \multicolumn{11}{|l|}{$T_{e}(K)$} \\
\hline 573 & $1,78 \mathrm{E}-5$ & $2,25 \mathrm{E}-5$ & $2,78 \mathrm{E}-5$ & $3,29 \mathrm{E}-5$ & $4,13 E-5$ & $4,62 \mathrm{E}-5$ & $5,06 \mathrm{E}-5$ & $5,05 E-5$ & $5,08 \mathrm{E}-5$ & $5,12 \mathrm{E}-5$ \\
\hline 623 & $1,36 \mathrm{E}-4$ & $1,93 \mathrm{E}-4$ & $2,16 \mathrm{E}-4$ & $2,66 \mathrm{E}-4$ & $3,54 \mathrm{E}-4$ & $3,91 \mathrm{E}-4$ & $3,39 \mathrm{E}-4$ & $3,85 \mathrm{E}-4$ & $3,92 \mathrm{E}-4$ & 3,99E-4 \\
\hline 673 & $7,24 \mathrm{E}-4$ & 8,84E-4 & $9,01 \mathrm{E}-4$ & $1,13 \mathrm{E}-3$ & $1,25 \mathrm{E}-3$ & $1,36 \mathrm{E}-3$ & $1,47 \mathrm{E}-3$ & $1,45 \mathrm{E}-3$ & $1,89 \mathrm{E}-3$ & $1,84 \mathrm{E}-3$ \\
\hline 723 & $3,17 \mathrm{E}-3$ & $3,59 \mathrm{E}-3$ & $3,94 \mathrm{E}-3$ & $4,60 \mathrm{E}-3$ & $5,29 \mathrm{E}-3$ & $5,46 \mathrm{E}-3$ & $6,03 \mathrm{E}-3$ & $5,99 \mathrm{E}-3$ & $6,24 \mathrm{E}-3$ & $6,52 \mathrm{E}-3$ \\
\hline$\underset{(\mu \mathrm{m})}{\mathrm{D}}$ & 1,52 & 1,74 & 1,91 & 2,70 & 3,01 & 3,30 & 3,40 & 3,80 & 4,30 & 4,70 \\
\hline
\end{tabular}

Tabla 5.14. Valores de la conductividad en el interior de grano medidos experimentalmente

\begin{tabular}{cc}
\hline$T_{e}(\mathrm{~K})$ & $\sigma_{g}$ medio $(\mathbf{S} / \mathbf{c m})$ \\
\hline $\mathbf{5 7 3}$ & $3,13 \mathrm{E}-06$ \\
$\mathbf{6 2 3}$ & $3,16 \mathrm{E}-05$ \\
$\mathbf{6 7 3}$ & $2,63 \mathrm{E}-04$ \\
$\mathbf{7 2 3}$ & $1,48 \mathrm{E}-03$ \\
\hline
\end{tabular}

En cambio, en la Tabla 5.13 puede apreciarse que la conductividad en los límites de grano, a cada temperatura de ensayo estudiada, aumenta progresivamente con el diámetro medio de grano, salvo en algún caso, debido a la dispersión de los resultados por el error experimental.

Por otra parte, si se compara la variación de los datos de la conductividad total de la Tabla 5.11 , correspondientes a las cuatro temperaturas de ensayo más bajas, con los valores medios de la conductividad en el interior de grano que se muestran en la Tabla 5.14, puede apreciarse que los valores de la primera son muy próximos y tienden progresivamente a los de la segunda, para los valores más altos del diámetro medio de grano estudiados, tal como se había previsto.

Todos estos resultados están de acuerdo con lo supuesto al comentar las ecuaciones (5.14) y (5.15) en el Apartado 5.4.1.2. 


\subsection{Variación de la conductividad en el interior de grano con la temperatura de ensayo}

Los resultados expuestos en el apartado anterior parecen confirmar que, en el caso del material estudiado y las condiciones de ensayo a que ha sido sometido, la conductividad en el interior de grano es independiente del valor del tamaño de grano.

Por tanto, teniendo en cuenta el razonamiento efectuado en el Apartado 5.4.1.2 basado en las ecuaciones (5.14) y (5.15), visualizando las representaciones de la Figura 5.15 (valores de $\sigma_{T}$ de la Tabla 5.10 en función del tamaño de grano), correspondientes a las temperaturas de ensayo más altas estudiadas, se deduce que cuando $\sigma_{T}$ llega a adquirir un valor prácticamente invariable al aumentar $\boldsymbol{D}$, puede admitirse que se da la circunstancia prevista en dicho razonamiento, por lo que el valor máximo alcanzado por la conductividad total puede aceptarse que coincide con el de la conductividad en el interior de grano a la correspondiente temperatura de ensayo. Este hecho se manifiesta claramente para valores del diámetro medio de grano iguales o algo mayores que 3,01 $\mu \mathrm{m}$ (ver también la Tabla 5.10).

Partiendo de este supuesto, se han obtenido los valores de $\sigma_{g}$ que se detallan en la Tabla 5.14 , para valores de la temperatura de ensayo iguales o mayores que $773 \mathrm{~K}$. En dicha tabla se han incluido asimismo los cuatro valores medios de $\sigma_{g}$ determinados experimentalmente de forma directa, que se muestran en la Tabla 5.13, correspondientes a los valores de la temperatura de ensayo inferiores a $773 \mathrm{~K}$.

En la Figura 5.16 se ha representado los valores de la conductividad en el interior de grano que se muestran en la Tabla 5.15 frente a la correspondiente temperatura de ensayo, en coordenadas rectangulares. 


\begin{tabular}{|c|c|c|}
\hline$T_{e}(\mathrm{~K})$ & $\sigma_{g} \exp$ & $\sigma_{g}$ cal. ec. (5.16) \\
\hline 573 & $3,09 E-06$ & 2,62E-06 \\
\hline 623 & 3,16E-05 & 3,88E-05 \\
\hline 673 & 2,66E-04 & 2,91E-04 \\
\hline 723 & $1,45 E-03$ & 1,45E-03 \\
\hline 773 & $4,50 \mathrm{E}-03$ & 4,36E-03 \\
\hline 823 & 1,15E-02 & 1,05E-02 \\
\hline 873 & 2,22E-02 & 1,99E-02 \\
\hline 923 & $3,85 \mathrm{E}-02$ & 3,61E-02 \\
\hline 973 & 5,72E-02 & 5,22E-02 \\
\hline 1023 & 7,72E-02 & 7,29E-02 \\
\hline 1073 & $9,85 \mathrm{E}-02$ & 9,39E-02 \\
\hline 1123 & $1,15 \mathrm{E}-01$ & 1,14E-01 \\
\hline 1173 & $1,30 \mathrm{E}-01$ & 1,32E-01 \\
\hline 1223 & 1,47E-01 & $1,48 \mathrm{E}-01$ \\
\hline 1273 & $1,60 \mathrm{E}-01$ & $1,60 \mathrm{E}-01$ \\
\hline
\end{tabular}




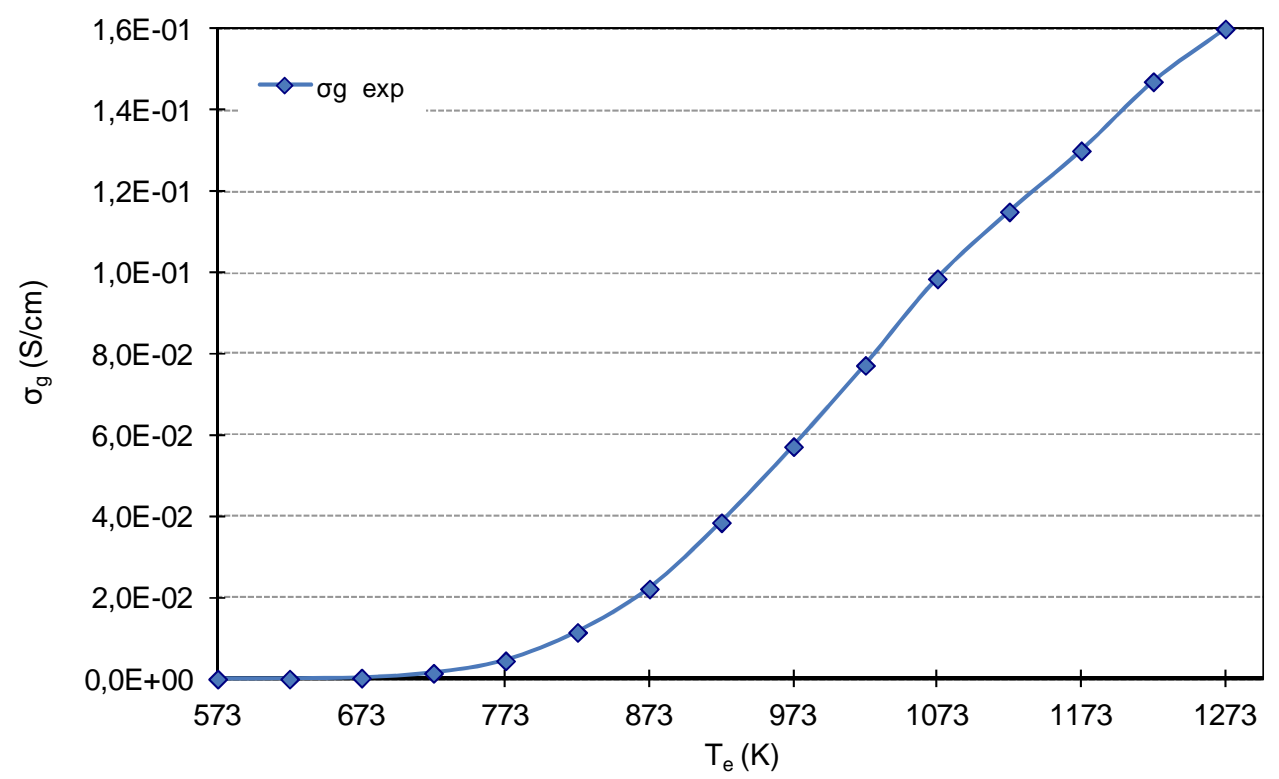

Figura 5.16. Variación de $\left(\sigma_{g}\right) \exp$ con $T_{e}$.

Dada la forma ligeramente sigmoidea de la curva obtenida, para tratar de obtener una expresión analítica representativa de la variación de $\sigma_{g}$ con $T_{e}$, se recurrió a representarlos en la forma In $\boldsymbol{\sigma}_{g}$ frente a $\mathbf{1 / T _ { e }}$, en la Figura 5.17.

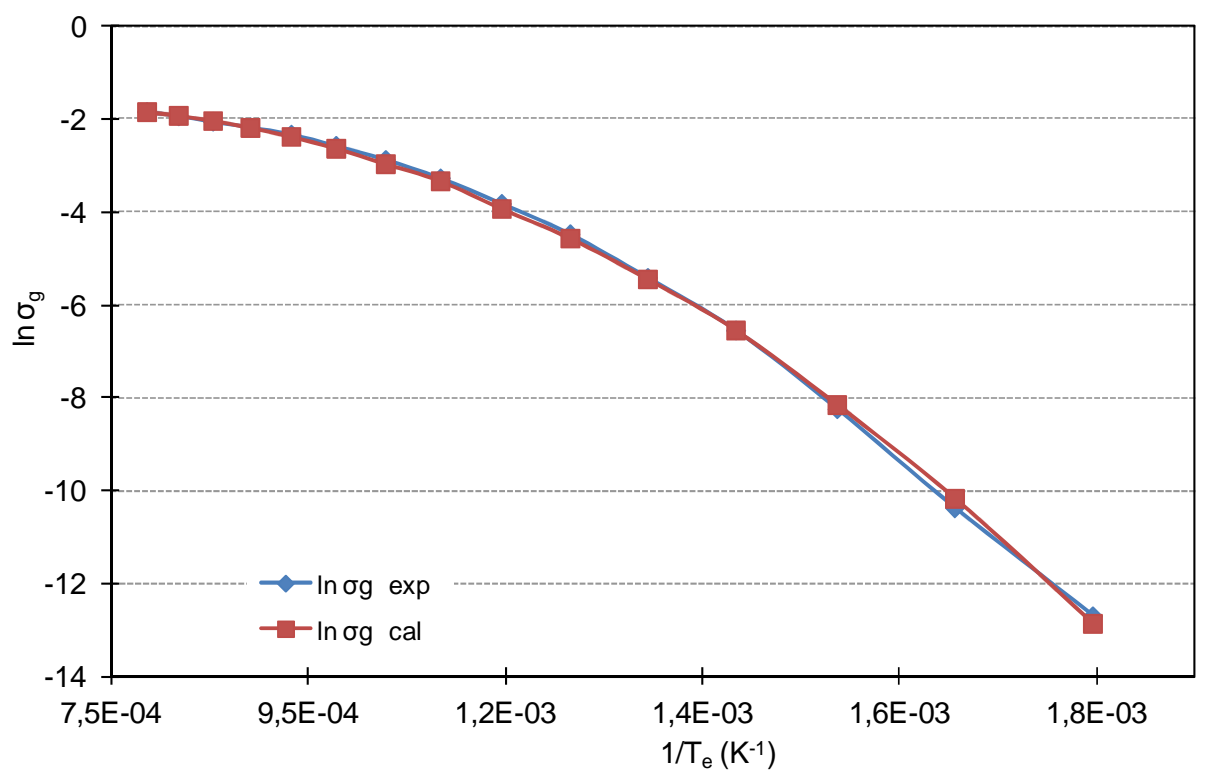

Figura 5.17. Variación con $T_{e}$ de $\left(\sigma_{\mathrm{g}}\right)$ exp y $\left(\sigma_{\mathrm{g}}\right)$ calculados con la ecuación (5.16)

La ecuación que mejor se adaptó a los valores experimentales fue: 


$$
\text { In } \sigma_{g}=12930 / T_{e}-9,56 e 6 / T_{e}^{2}-6,09
$$

con un coeficiente de correlación $R^{2}=0,999$

Esta ecuación puede también escribirse en la forma:

$$
\sigma_{g}=\exp \left(12930 / T_{e}-9560000 / T_{e}^{2}-6,09\right.
$$

Mediante esta ecuación se han calculado los valores de $\left(\sigma_{g}\right)$ calc que se detallan en la tercera columna de la Tabla 5.14, que se han representado en forma de línea continua azul, junto con los puntos (cuadrados) representativos de los valores experimentales, en la Figura 5.17 .

5.1.5.3.3. Variación de la conductividad en los límites de grano $\left(\sigma^{\mathrm{T}} \mathrm{lg}\right)$ con el diámetro medio de grano (D).

(i) Datos experimentales de $\sigma^{\mathrm{T}} \mathrm{lg}$ medidos directamente en el intervalo de valores de $\mathrm{T}_{\mathrm{e}}$ comprendido entre 573 y $623 \mathrm{~K}$.

a) Ajuste de los datos mediante la ecuación (5.12): $\sigma_{\mathrm{lg}}^{T}=D \sigma_{\mathrm{lg}}^{e} / \delta$

A fin de comprobar si los valores de la conductividad total en los límites de grano, determinados experimentalmente en el intervalo de valores de la temperatura de ensayo comprendidos entre 573 y $623 \mathrm{~K}$, se adaptaban a la ecuación (5.12), en la Figura 5.18 se han representado los valores de $\boldsymbol{\sigma}_{l g}^{T}$, que se muestran en la Tabla 5.13 , frente a los correspondientes de $\boldsymbol{D}$.

Como puede apreciarse, los datos experimentales se adaptan bastante bien a líneas rectas, con coeficientes de correlación mayores que 0,95 los correspondientes a las temperaturas de ensayo de 673 y $723 \mathrm{~K}$, de acuerdo con la ecuación (5.12), con la salvedad de que sus ordenadas en el origen son próximas pero distintas de cero (Tabla 5.16). 


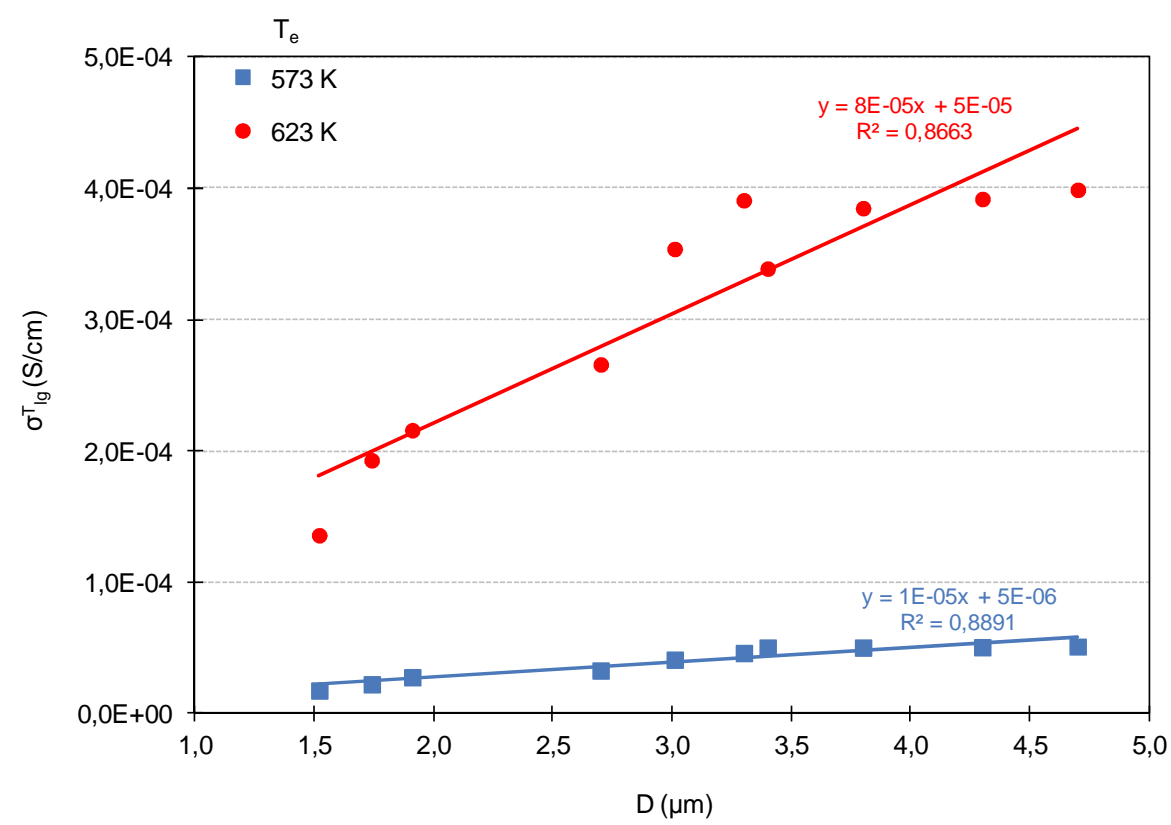

(a)

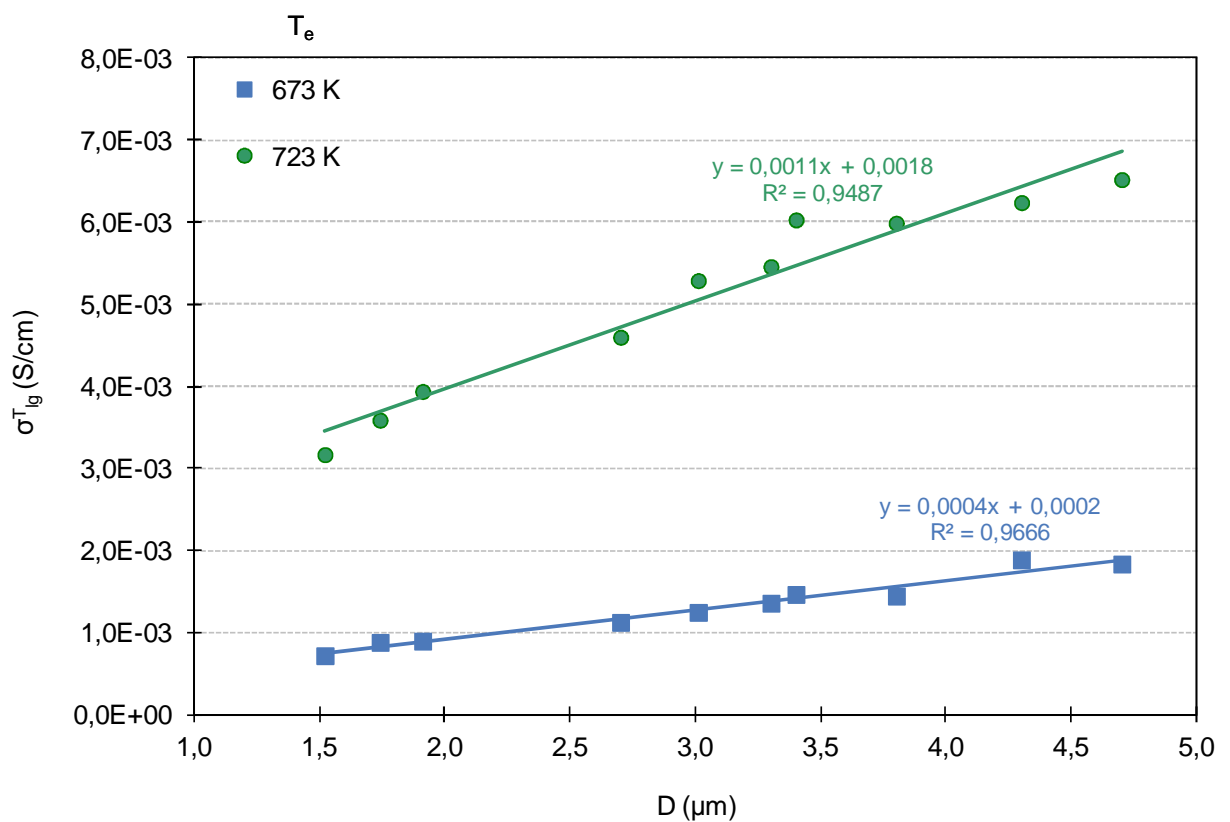

(b)

Figura 5.18. Variación de $\left(\sigma^{\mathrm{T}} \mathrm{lg}\right) \exp$ con $D$

b) Cálculo de la conductividad específica en los límites de grano $\left(\sigma^{e}{ }_{l g}\right)$.

La pendiente de las líneas rectas representadas en la Figura 5.18 (a) y (b), de acuerdo con la ecuación (5.12), debería ser igual a $\boldsymbol{\sigma}_{l g}^{e} / \delta$, siendo $\boldsymbol{\sigma}_{l g}^{e}$ la conductividad específica en los límites de grano ${ }^{43,44,45}$, caso de que dichas rectas pasaran por el origen de coordenadas. En 
la Tabla 5.16 se detallan los valores de dicha razón obtenidos para las cuatro temperaturas indicadas. No se ha calculado el valor de $\sigma_{l g}^{e}$ porque no se conoce exactamente el valor de $\delta$, estando comprendido, según indican algunos investigadores, entre 1 y $10 \mathrm{~nm}^{44,115}$.

Tabla 5.16. Valores de la ordenada en el origen y de la pendiente de la ecuación (5.12), calculados de las representaciones de la Figura 5.18

\begin{tabular}{cccc}
\hline$T_{e}(\mathrm{~K})$ & $\mathbf{1} / \mathbf{T}_{\mathrm{e}}\left(\mathrm{K}^{-1}\right)$ & ord.origen & $\boldsymbol{\sigma}_{\mathrm{lg}}^{\mathrm{e}} / \mathbf{\delta}$ \\
\hline $\mathbf{5 7 3}$ & $1,75 \mathrm{E}-03$ & $5,00 \mathrm{E}-06$ & $1,00 \mathrm{E}-05$ \\
$\mathbf{6 2 3}$ & $1,61 \mathrm{E}-03$ & $1,00 \mathrm{E}-04$ & $8,00 \mathrm{E}-05$ \\
$\mathbf{6 7 3}$ & $1,49 \mathrm{E}-03$ & $2,00 \mathrm{E}-04$ & $4,00 \mathrm{E}-04$ \\
$\mathbf{7 2 3}$ & $1,38 \mathrm{E}-03$ & $1,80 \mathrm{E}-03$ & $1,10 \mathrm{E}-02$ \\
\hline
\end{tabular}

(ii) Valores de $\sigma^{\mathrm{T}} \mathrm{lg}$, en el intervalo de valores de $\mathrm{T}_{\mathrm{e}}$ comprendido entre 773 y $1273 \mathrm{~K}$, calculados a partir de $\sigma_{\mathrm{T}}$ y $\sigma_{\mathrm{g}}$ mediante la ecuación (1.22): $1 / \sigma_{T}=1 / \sigma_{g}+1 / \sigma_{\mathrm{lg}}^{T}$

La metodología empleada para la medida de las conductividades no permite obtener valores fiables de $\sigma_{g}$ y de $\boldsymbol{\sigma}^{T}$ ig para las temperaturas de ensayo de 773 y $823 \mathrm{~K}$ y, para temperaturas de ensayo superiores a $873 \mathrm{~K}$, sólo permite determinar los valores de $\sigma_{T}$.

Para disponer de unos valores fiables de $\sigma^{T}$, en el intervalo de valores de $T_{e} \geq 873 \mathrm{~K}$, se pensó estimarlos a partir de los correspondientes de $\sigma_{T}$, interpolados (Tabla 5.11), y de $\sigma_{g}$, determinados en la forma descrita en el Apartado 5.4.1.3.(ii) (Tabla 5.4), mediante la ecuación (1.22) puesta en la forma:

$$
1 / \sigma_{\mathrm{lg}}^{T}=1 / \sigma_{T}-1 / \sigma_{g}
$$

Los valores de $\boldsymbol{\sigma}^{T}$ ig, obtenidos por este procedimiento, se muestran en la Tabla 5.17, junto con los correspondientes del diámetro medio de grano. 


\begin{tabular}{|c|c|c|c|c|c|c|c|c|c|c|}
\hline$T_{S}$ & & 1573 K & & & $1673 \mathrm{~K}$ & & & 177 & $\mathrm{~K}$ & \\
\hline$t_{R}(h)$ & $2 \mathrm{~h}$ & $4 \mathrm{~h}$ & $6 \mathrm{~h}$ & $2 \mathrm{~h}$ & $4 \mathrm{~h}$ & $6 \mathrm{~h}$ & $1 \mathrm{~h}$ & $2 \mathrm{~h}$ & $4 \mathrm{~h}$ & $6 \mathrm{~h}$ \\
\hline $\begin{array}{c}\mathrm{T}_{\mathrm{e}} \\
(\mathrm{K})\end{array}$ & & & & & & & & & & \\
\hline 773 & $1,24 \mathrm{E}-2$ & $1,68 \mathrm{E}-2$ & $2,62 \mathrm{E}-2$ & $3,60 \mathrm{E}-2$ & $3,95 \mathrm{E}-2$ & 4,37E-2 & $4,74 \mathrm{E}-2$ & $4,88 \mathrm{E}-2$ & $5,17 \mathrm{E}-2$ & $5,34 \mathrm{E}-2$ \\
\hline 823 & $1,93 \mathrm{E}-2$ & $3,26 \mathrm{E}-2$ & $6,20 \mathrm{E}-2$ & $1,18 \mathrm{E}-1$ & $1,21 \mathrm{E}-1$ & $1,35 \mathrm{E}-1$ & $1,54 \mathrm{E}-1$ & $1,77 \mathrm{E}-1$ & $2,09 \mathrm{E}-1$ & $2,53 \mathrm{E}-1$ \\
\hline 873 & $2,66 \mathrm{E}-2$ & $5,25 \mathrm{E}-2$ & $1,15 \mathrm{E}-1$ & $4,71 \mathrm{E}-1$ & $6,35 \mathrm{E}-1$ & $7,99 \mathrm{E}-1$ & $9,63 \mathrm{E}-1$ & $1,21 \mathrm{E}+0$ & $1,62 \mathrm{E}+0$ & $2,44 \mathrm{E}+0$ \\
\hline 923 & $2,98 \mathrm{E}-2$ & $6,37 \mathrm{E}-2$ & $1,52 \mathrm{E}-1$ & $1,20 \mathrm{E}+0$ & $2,08 \mathrm{E}+0$ & $2,93 E+0$ & $3,67 \mathrm{E}+0$ & $4,90 \mathrm{E}+0$ & $7,37 \mathrm{E}+0$ & $1,48 \mathrm{E}+1$ \\
\hline 973 & $3,22 \mathrm{E}-2$ & $7,06 \mathrm{E}-2$ & $1,73 \mathrm{E}-1$ & $1,99 \mathrm{E}+0$ & $4,62 \mathrm{E}+0$ & $8,12 \mathrm{E}+0$ & $1,08 \mathrm{E}+1$ & $1,63 \mathrm{E}+1$ & $1,63 \mathrm{E}+1$ & $1,63 \mathrm{E}+1$ \\
\hline 1023 & $3,42 \mathrm{E}-2$ & $7,37 \mathrm{E}-2$ & $1,89 \mathrm{E}-1$ & $2,63 \mathrm{E}+0$ & $6,85 \mathrm{E}+0$ & $1,48 \mathrm{E}+1$ & $1,98 \mathrm{E}+1$ & $2,97 \mathrm{E}+1$ & $5,95 \mathrm{E}+1$ & - \\
\hline 1073 & $3,55 \mathrm{E}-2$ & $7,60 \mathrm{E}-2$ & $1,96 \mathrm{E}-1$ & $3,37 \mathrm{E}+0$ & $1,00 \mathrm{E}+1$ & $2,15 E+1$ & $3,22 \mathrm{E}+1$ & $9,69 \mathrm{E}+1$ & - & - \\
\hline 1123 & $3,72 \mathrm{E}-2$ & $7,89 \mathrm{E}-2$ & $2,03 \mathrm{E}-1$ & $4,29 \mathrm{E}+0$ & $1,31 \mathrm{E}+1$ & $2,63 E+1$ & - & - & - & - \\
\hline 1173 & $3,83 E-2$ & $7,86 \mathrm{E}-2$ & $2,03 \mathrm{E}-1$ & $4,84 \mathrm{E}+0$ & $1,68 \mathrm{E}+1$ & $3,37 \mathrm{E}+1$ & - & - & - & - \\
\hline 1223 & $3,91 \mathrm{E}-2$ & $7,81 \mathrm{E}-2$ & $2,07 \mathrm{E}-1$ & $5,26 \mathrm{E}+0$ & $2,15 \mathrm{E}+1$ & $3,59 \mathrm{E}+1$ & - & - & - & - \\
\hline 1273 & 3,91E-2 & $7,81 \mathrm{E}-2$ & $2,11 \mathrm{E}-1$ & $5,53 \mathrm{E}+0$ & $2,54 \mathrm{E}+1$ & $4,25 E+1$ & - & - & - & - \\
\hline$\underset{(\mu \mathrm{m})}{\mathrm{D}}$ & 1,52 & 1,74 & 1,91 & 2,70 & 3,01 & 3,30 & 3,40 & 3,80 & 4,30 & 4,70 \\
\hline
\end{tabular}

Las celdas de la tabla en las que no consta ningún dato, corresponden a casos en los que coincidían exactamente los valores de $\sigma_{T}$ y $\boldsymbol{\sigma}_{g}$, por lo que al aplicar la ecuación 5.16 resultaba un valor indeterminado para $\sigma^{T}{ }_{l g}$.
a) Ajuste de los datos mediante la ecuación (5.12): $\sigma_{\mathrm{lg}}^{T}=D \sigma_{\mathrm{lg}}^{e} / \delta$

En la Figura 5.19 se han representado los valores de $\boldsymbol{\sigma}^{T}{ }_{l g}$, que se muestran en la Tabla 5.17, frente a los correspondientes de $\boldsymbol{D}$. 


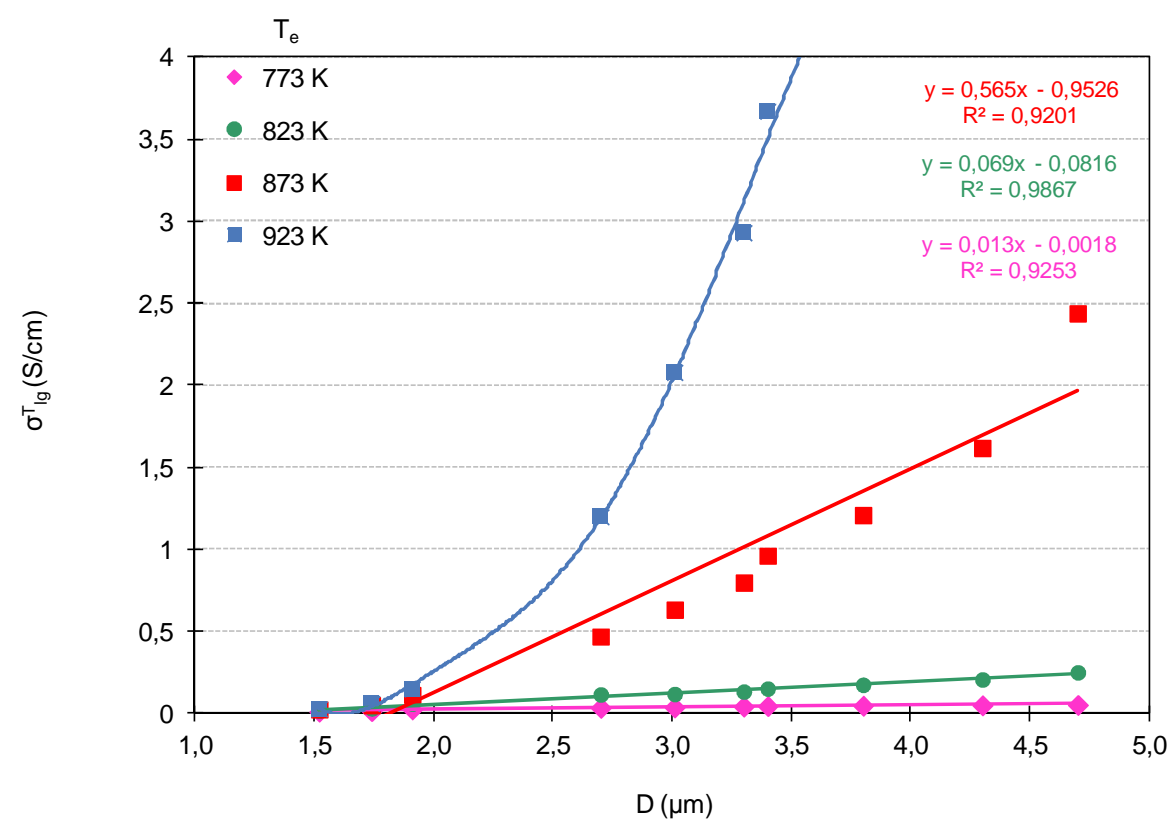

(a)

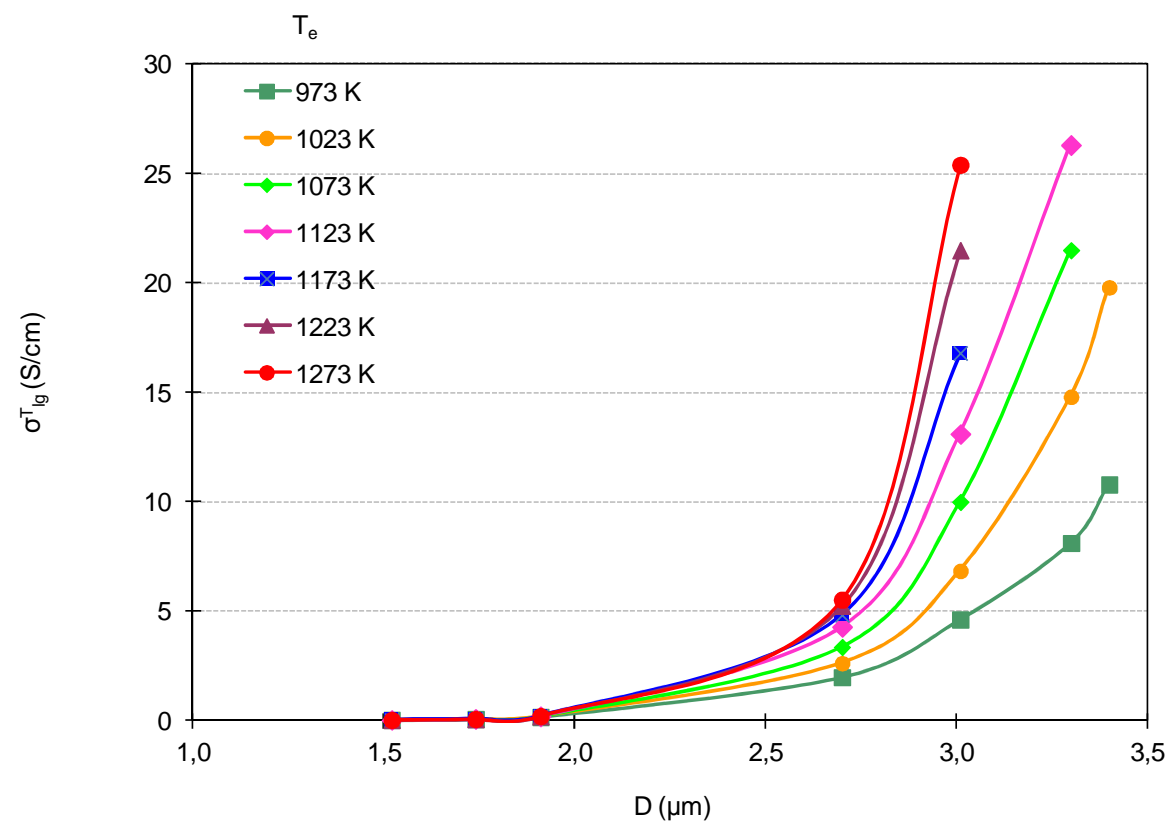

(b)

Figura 5.19. Variación de $\left(\sigma^{\mathrm{T}} \mathrm{lg}\right)$ calc con $D$.

Como puede apreciarse, los valores de $\boldsymbol{\sigma}^{T}{ }_{l g}$ sólo se pudieron adaptar a líneas rectas para las temperaturas de ensayo de 773 a $873 \mathrm{~K}$ (Figura 5.19(a)). Para el resto de valores de $T_{e}$, adoptaron una distribución curva.

Las pendientes de las tres representaciones que se adaptaron a líneas rectas, fueron del orden de 0,013; 0,069 y 0,565 para las temperaturas de ensayo de 773, 823 y $873 \mathrm{~K}$ 
respectivamente. Estos valores, que se han asimilado a los respectivos de $\sigma^{e}{ }_{l g} / \delta$, se han representado, junto con los que se muestran en la Tabla 5.16, en la forma $\ln \left(\sigma^{e}{ }_{l g} / \delta\right)$ frente a $1 / T_{e}$ en la Figura 5.20.

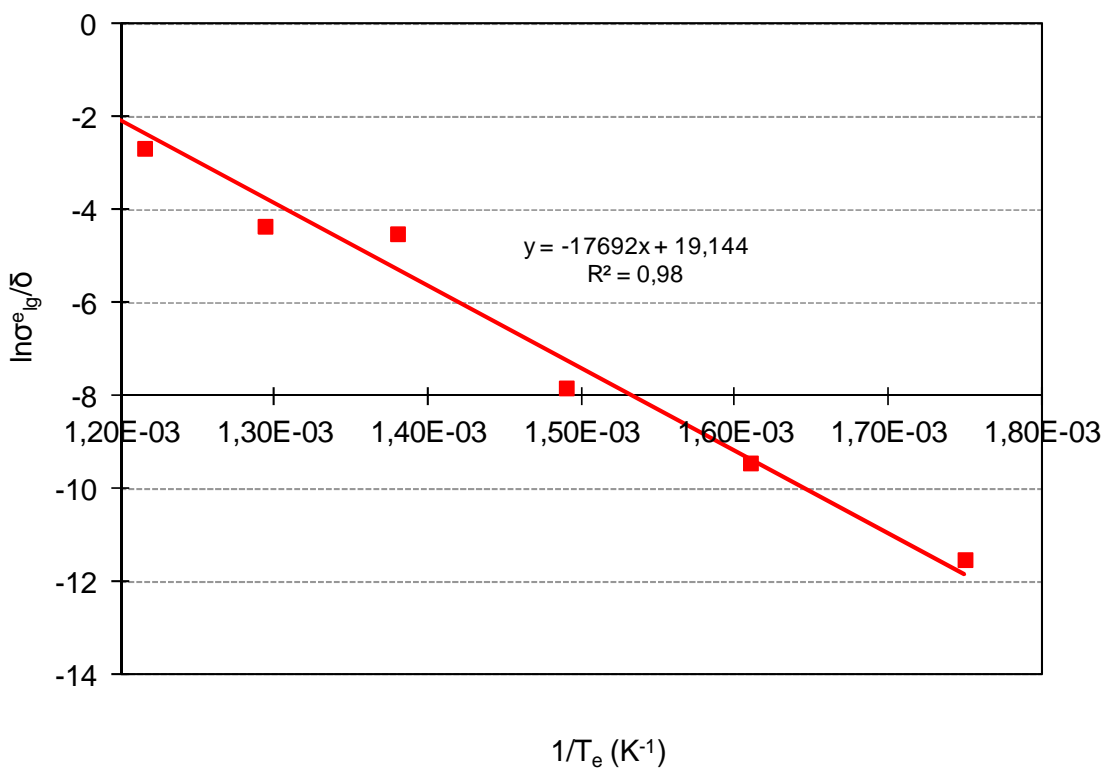

Figura 5.20. Variación de $\sigma^{e}$ lg/ $\delta$ con la temperatura de ensayo.

Se comprueba que los tres puntos representativos de los valores de $\ln \left(\boldsymbol{\sigma}^{e}{ }_{l g} / \delta\right)$, correspondientes a las temperaturas de ensayo 773, 823 y $873 \mathrm{~K}$, se adaptan bastante bien a la recta representativa de la variación exponencial de la razón $\boldsymbol{\sigma}^{e}{ }_{I g} / \boldsymbol{\delta}$ con la inversa de la temperatura de ensayo, correspondiente a los valores de dicha razón obtenidos directamente de los datos de $\boldsymbol{\sigma}^{T}$ Ig medidos experimentalmente (Tabla 5.16). Este resultado parece indicar que la metodología que se ha empleado para calcular los valores de $\boldsymbol{\sigma}^{T}$, para las temperaturas de ensayo iguales o mayores que $773 \mathrm{~K}$, conduce a valores razonables de dicha propiedad del material.

b) Ajuste de la conductividad en los límites de grano (experimental y calculada) a una ecuación exponencial de la forma: $\sigma_{\mathrm{lg}}^{T}=A \cdot \exp (B \cdot D)$

Para correlacionar las representaciones de $\boldsymbol{\sigma}^{T}$ Ig frente a $\boldsymbol{D}$, correspondientes a los valores de $T_{e} \geq 923 \mathrm{~K}$, se ensayaron distintas posibilidades y la ecuación que mejor se adaptó a los valores representados fue de la forma:

$$
\sigma_{\lg }^{T}=A \cdot \exp (B \cdot D)
$$

En las representaciones de la Figura 5.21 se han incluido también las correspondientes a los datos de $\boldsymbol{\sigma}^{T}{ }_{l g}$ determinados directamente, por medida experimental, a las cuatro temperaturas de ensayo más bajas estudiadas (valores de la Tabla 5.13) que, en las 
representaciones de la Figura 5.18 se ajustaron a líneas rectas de ecuación $\sigma_{\mathrm{lg}}^{T}=D \sigma_{\mathrm{lg}}^{e} / \delta$, a efectos comparativos.

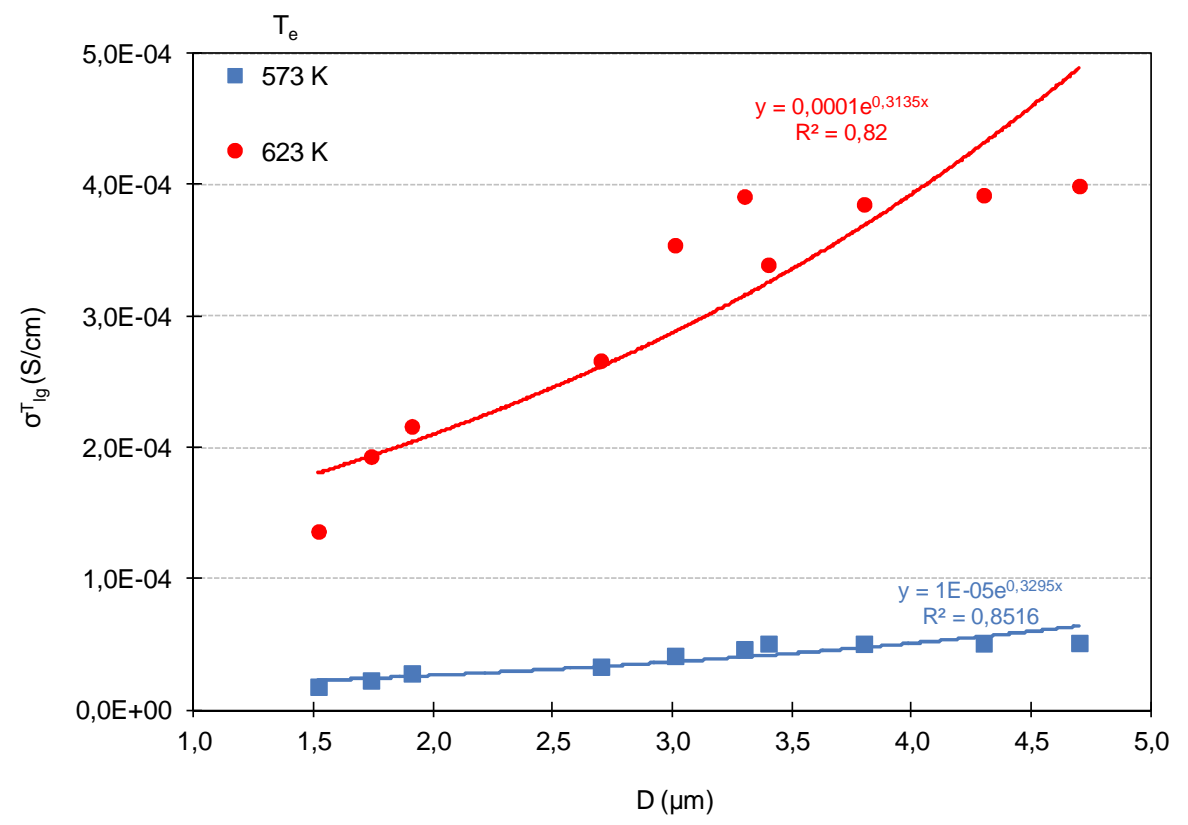

(a)

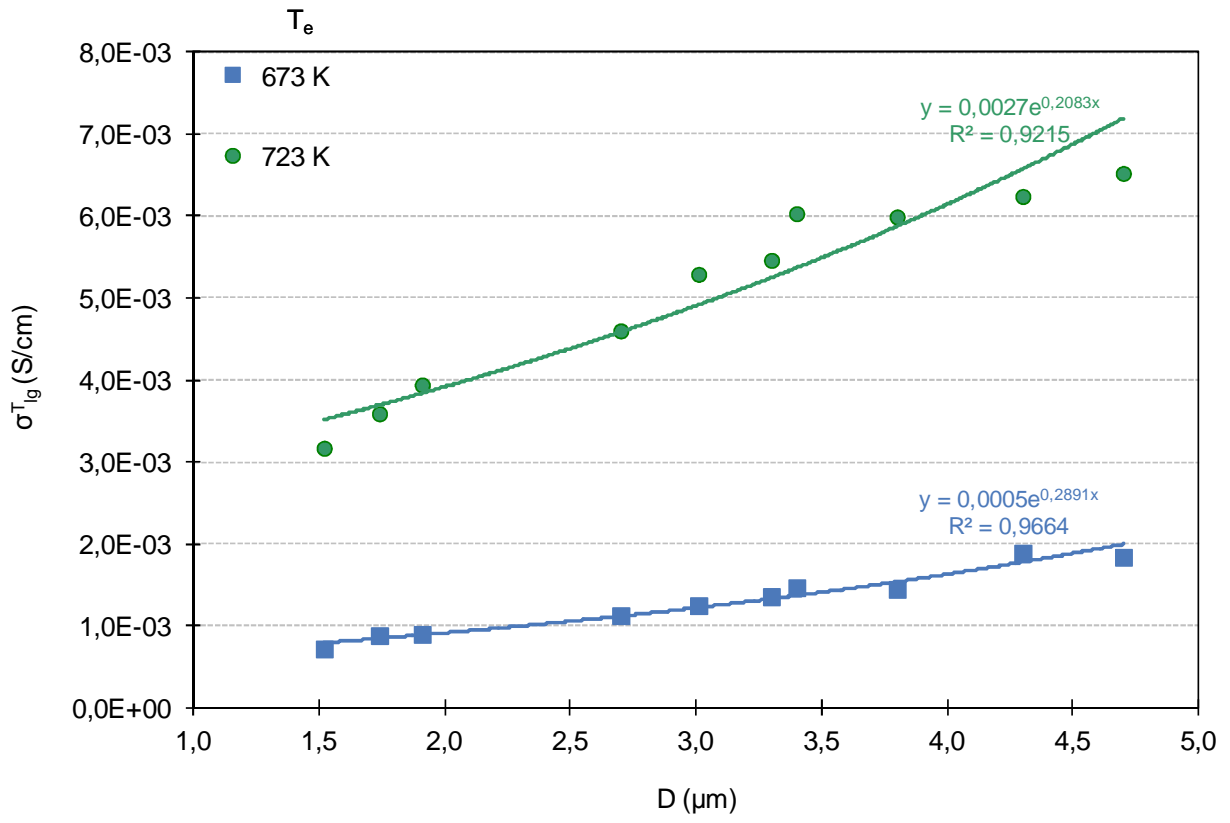

(b) 


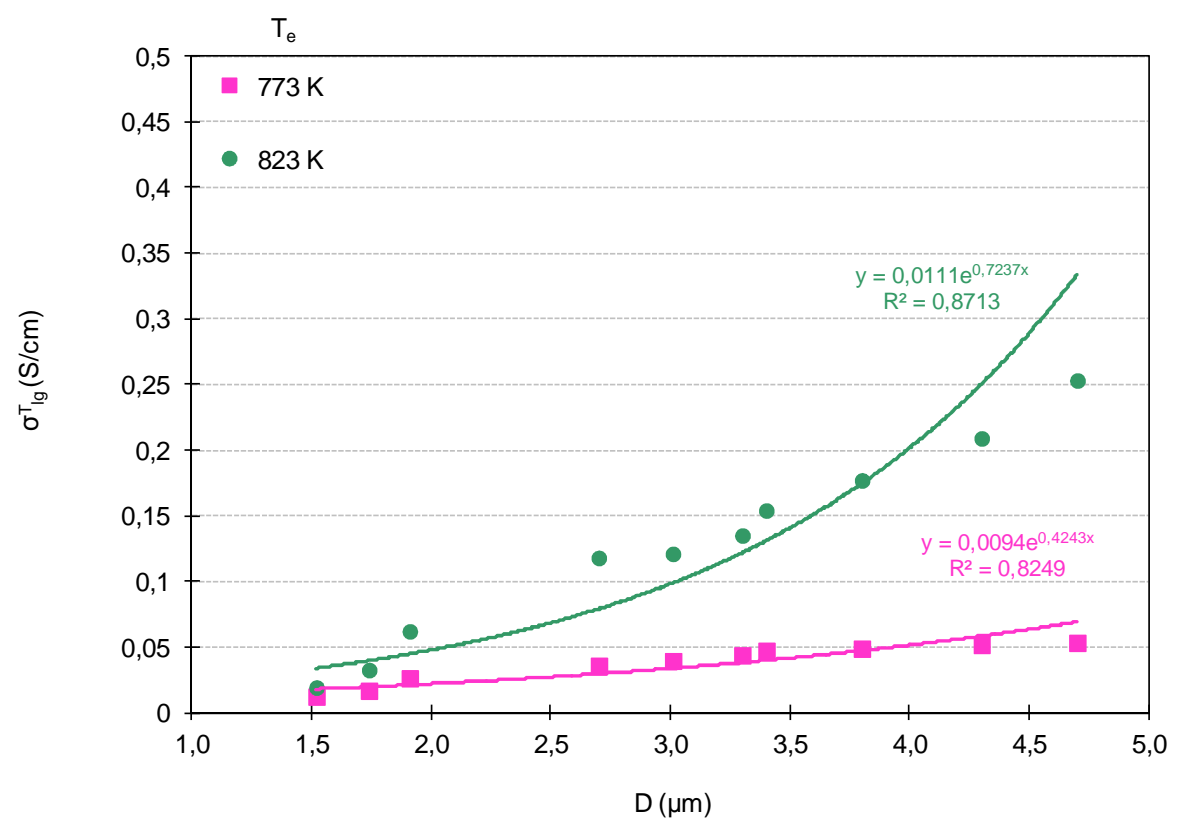

(c)

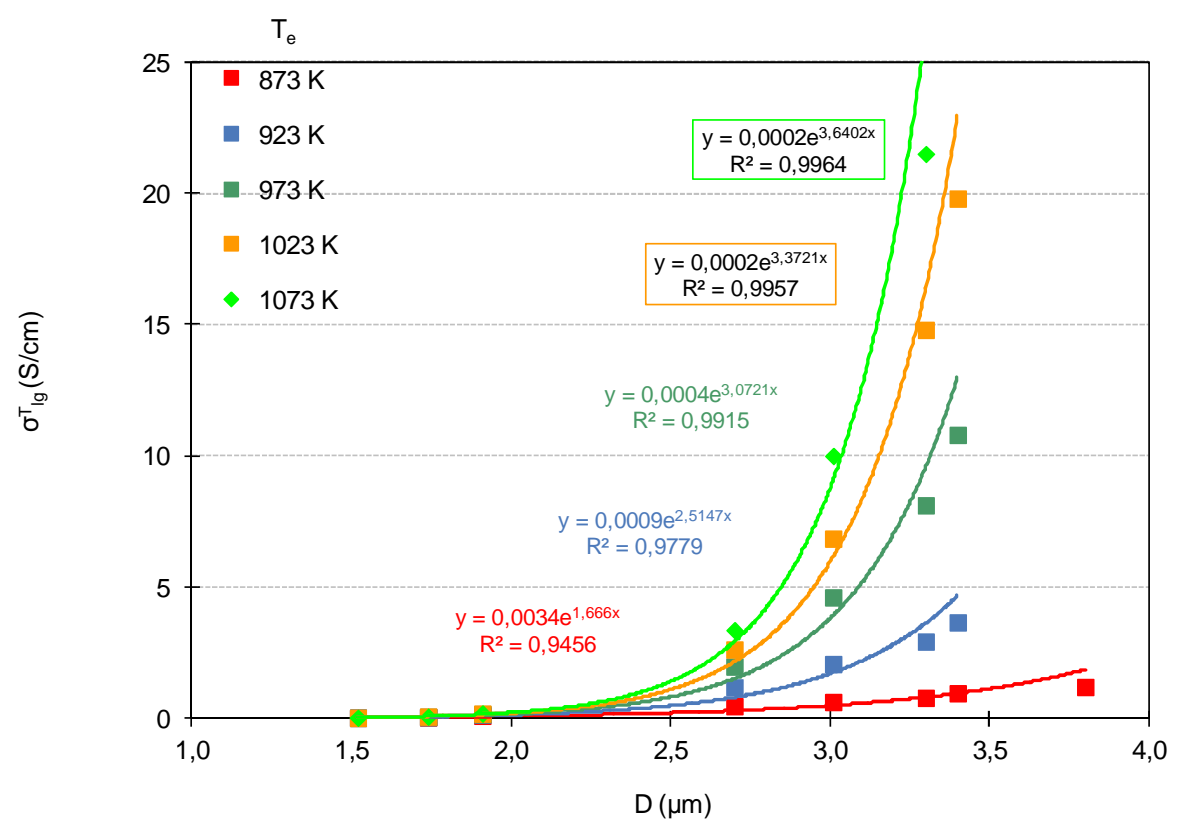

(d) 


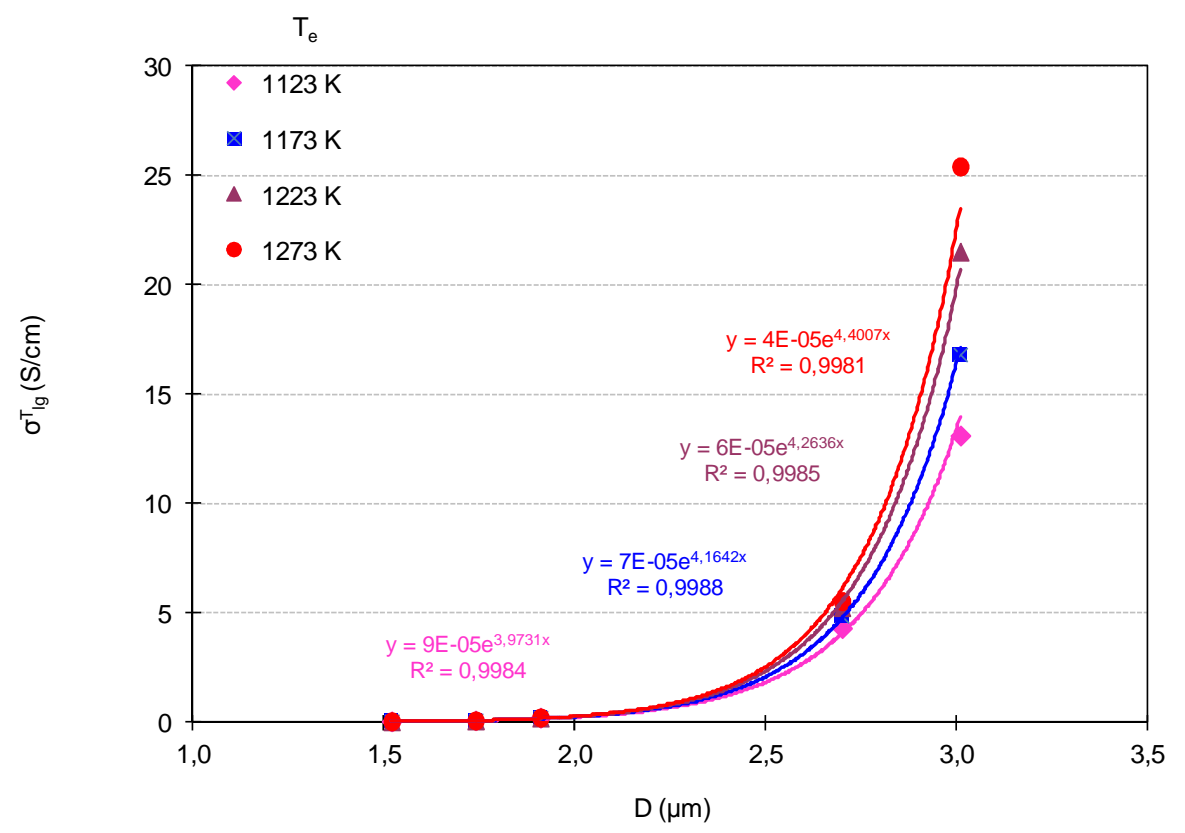

(e)

Figura 5.21. Variación de $\sigma^{T}$ lg con el diámetro medio de grano, para las distintas temperaturas de ensayo estudiadas.

En la Tabla 5.18 se muestran los valores de los parámetros A y B de la ecuación (5.18), obtenidos de las representaciones de la Figura 5.21. 


\begin{tabular}{|c|c|c|}
\hline$T_{e}(\mathrm{~K})$ & A & B \\
\hline 573 & $1,00 \mathrm{E}-05$ & 0,329 \\
\hline 623 & $1,00 \mathrm{E}-04$ & 0,313 \\
\hline 673 & $5,00 \mathrm{E}-04$ & 0,289 \\
\hline 723 & $2,70 \mathrm{E}-03$ & 0,208 \\
\hline 773 & $9,40 \mathrm{E}-03$ & 0,424 \\
\hline 823 & 1,11E-02 & 0,724 \\
\hline 873 & $3,40 \mathrm{E}-04$ & 1,667 \\
\hline 923 & $9,00 \mathrm{E}-04$ & 2,515 \\
\hline 973 & $4,00 \mathrm{E}-04$ & 3,072 \\
\hline 1023 & $2,00 \mathrm{E}-04$ & 3,372 \\
\hline 1073 & 2,00E-04 & 3,640 \\
\hline 1123 & $9,00 \mathrm{E}-05$ & 3,973 \\
\hline 1173 & $7,00 \mathrm{E}-05$ & 4,164 \\
\hline 1223 & $6,00 \mathrm{E}-05$ & 4,264 \\
\hline 1273 & $4,00 \mathrm{E}-05$ & 4,401 \\
\hline
\end{tabular}

5.1.5.3.4. Contribución de la conductividad en el interior de grano y en el límite de grano al valor de la conductividad total

Para tratar de explicar la forma de las representaciones de la conductividad iónica total frente a la temperatura de ensayo, obtenidas para los distintos diámetros medios de grano estudiados (Figuras 5.11 y 5.12), en este apartado se intentará ver el modo en que las conductividades iónicas en los límites de grano y en el interior de grano contribuyen al valor de la conductividad total, condicionando la forma de dichas curvas.

Para ello, se estudiará para cada tamaño de grano obtenido, la forma en que varían con la temperatura de ensayo, no sólo los valores de las conductividades totales, en los límites de grano y en el interior de grano, sino también los valores de las correspondientes resistividades calculadas, en cada caso, como la inversa de la respectiva conductividad.

En las Tablas $5.19,5.20$ y 5.21 se muestran los valores de la resistividad iónica total $\left(\boldsymbol{\rho}_{T}\right)$, de la resistividad en el interior de grano $\left(\boldsymbol{\rho}_{g}\right)$ y de la resistividad en los límites de grano $\left(\boldsymbol{\rho}^{\boldsymbol{T}}{ }_{\text {lg }}\right)$ 
respectivamente. Estos valores se han calculado, como se acaba de indicar, como la inversa de los correspondientes valores de la conductividad iónica que se muestran en las Tablas $5.11,5.15$, y 5.13 y 5.17 respectivamente.

Tabla 5.19. Probetas prensadas de la Composición $C-I$. Valores resistividad total $\left(\rho_{T}\right)$ $(\Omega . c m)$ obtenidos a partir de los valores de la conductividad total $\left(\sigma_{T}\right)$, de la tabla 5.11

\begin{tabular}{|c|c|c|c|c|c|c|c|c|c|c|}
\hline $\mathbf{T}_{\mathrm{s}}$ & \multicolumn{3}{|c|}{$1573 \mathrm{~K}$} & \multicolumn{3}{|c|}{$1673 \mathrm{~K}$} & \multicolumn{4}{|c|}{1773 K } \\
\hline $\begin{array}{c}t_{R} \\
(h)\end{array}$ & $2 \mathrm{~h}$ & $4 \mathrm{~h}$ & $6 \mathrm{~h}$ & $2 \mathrm{~h}$ & $4 \mathrm{~h}$ & $6 \mathrm{~h}$ & $1 \mathrm{~h}$ & $2 \mathrm{~h}$ & $4 \mathrm{~h}$ & $6 \mathrm{~h}$ \\
\hline $\begin{array}{c}T_{e} \\
(K)\end{array}$ & & & & & & & & & & \\
\hline 573 & $3,76 \mathrm{E}+5$ & $3,69 E+5$ & $3,65 E+5$ & $3,51 \mathrm{E}+5$ & $3,47 \mathrm{E}+5$ & $3,46 \mathrm{E}+5$ & $3,46 \mathrm{E}+5$ & $3,45 E+5$ & $3,44 \mathrm{E}+5$ & $3,42 \mathrm{E}+5$ \\
\hline 623 & $3,77 \mathrm{E}+4$ & $3,65 E+4$ & $3,60 \mathrm{E}+4$ & $3,51 \mathrm{E}+4$ & $3,47 \mathrm{E}+4$ & $3,45 E+4$ & $3,44 \mathrm{E}+4$ & $3,42 E+4$ & $3,40 \mathrm{E}+4$ & $3,38 \mathrm{E}+4$ \\
\hline 673 & $5,03 E+3$ & $4,90 \mathrm{E}+3$ & $4,81 E+3$ & $4,57 \mathrm{E}+3$ & $4,50 \mathrm{E}+3$ & $4,44 \mathrm{E}+3$ & $4,42 E+3$ & $4,39 E+3$ & $4,37 \mathrm{E}+3$ & $4,31 \mathrm{E}+3$ \\
\hline 723 & $9,90 \mathrm{E}+2$ & $9,52 \mathrm{E}+2$ & $9,17 \mathrm{E}+2$ & $8,93 \mathrm{E}+2$ & $8,77 \mathrm{E}+2$ & $8,70 \mathrm{E}+2$ & $8,70 E+2$ & $8,62 \mathrm{E}+2$ & $8,62 \mathrm{E}+2$ & $8,47 \mathrm{E}+2$ \\
\hline 773 & $3,03 E+2$ & $2,82 \mathrm{E}+2$ & $2,60 \mathrm{E}+2$ & $2,50 \mathrm{E}+2$ & $2,48 \mathrm{E}+2$ & $2,45 \mathrm{E}+2$ & $2,43 \mathrm{E}+2$ & $2,43 E+2$ & $2,42 \mathrm{E}+2$ & $2,41 \mathrm{E}+2$ \\
\hline 823 & $1,39 \mathrm{E}+2$ & $1,18 \mathrm{E}+2$ & $1,03 \mathrm{E}+2$ & $9,62 \mathrm{E}+1$ & $9,52 \mathrm{E}+1$ & $9,43 \mathrm{E}+1$ & $9,35 \mathrm{E}+1$ & $9,26 \mathrm{E}+1$ & $9,17 \mathrm{E}+1$ & $9,09 \mathrm{E}+1$ \\
\hline 873 & $8,26 \mathrm{E}+1$ & $6,41 E+1$ & $5,38 \mathrm{E}+1$ & $4,72 \mathrm{E}+1$ & $4,65 \mathrm{E}+1$ & $4,63 \mathrm{E}+1$ & $4,61 \mathrm{E}+1$ & $4,59 \mathrm{E}+1$ & $4,57 \mathrm{E}+1$ & $4,55 \mathrm{E}+1$ \\
\hline 923 & $5,95 \mathrm{E}+1$ & $4,17 \mathrm{E}+1$ & $3,26 \mathrm{E}+1$ & $2,68 \mathrm{E}+1$ & $2,65 \mathrm{E}+1$ & $2,63 \mathrm{E}+1$ & $2,62 \mathrm{E}+1$ & $2,62 \mathrm{E}+1$ & $2,61 \mathrm{E}+1$ & $2,60 \mathrm{E}+1$ \\
\hline 973 & $4,85 \mathrm{E}+1$ & $3,16 \mathrm{E}+1$ & $2,33 E+1$ & $1,80 \mathrm{E}+1$ & $1,77 \mathrm{E}+1$ & $1,76 \mathrm{E}+1$ & $1,76 \mathrm{E}+1$ & $1,75 E+1$ & $1,75 \mathrm{E}+1$ & $1,75 \mathrm{E}+1$ \\
\hline 1023 & $4,22 \mathrm{E}+1$ & $2,65 E+1$ & $1,82 \mathrm{E}+1$ & $1,33 \mathrm{E}+1$ & $1,31 \mathrm{E}+1$ & $1,30 \mathrm{E}+1$ & $1,30 \mathrm{E}+1$ & $1,30 \mathrm{E}+1$ & $1,30 \mathrm{E}+1$ & $1,30 \mathrm{E}+1$ \\
\hline 1073 & $3,83 E+1$ & $2,33 E+1$ & $1,53 \mathrm{E}+1$ & $1,04 \mathrm{E}+1$ & $1,03 E+1$ & $1,02 \mathrm{E}+1$ & $1,02 \mathrm{E}+1$ & $1,02 \mathrm{E}+1$ & $1,02 \mathrm{E}+1$ & $1,02 \mathrm{E}+1$ \\
\hline 1123 & $3,56 \mathrm{E}+1$ & $2,14 \mathrm{E}+1$ & $1,36 \mathrm{E}+1$ & $8,93 \mathrm{E}+0$ & $8,77 \mathrm{E}+0$ & $8,70 \mathrm{E}+0$ & $8,70 \mathrm{E}+0$ & $8,70 \mathrm{E}+0$ & $8,70 \mathrm{E}+0$ & $8,70 \mathrm{E}+0$ \\
\hline 1173 & $3,38 \mathrm{E}+1$ & $2,04 \mathrm{E}+1$ & $1,26 \mathrm{E}+1$ & $7,87 \mathrm{E}+0$ & $7,75 \mathrm{E}+0$ & $7,69 \mathrm{E}+0$ & $7,69 \mathrm{E}+0$ & $7,69 \mathrm{E}+0$ & $7,69 \mathrm{E}+0$ & $7,69 \mathrm{E}+0$ \\
\hline 1223 & $3,24 \mathrm{E}+1$ & $1,96 \mathrm{E}+1$ & $1,16 \mathrm{E}+1$ & $6,99 \mathrm{E}+0$ & $6,85 \mathrm{E}+0$ & $6,85 \mathrm{E}+0$ & $6,85 \mathrm{E}+0$ & $6,80 \mathrm{E}+0$ & $6,80 \mathrm{E}+0$ & $6,80 \mathrm{E}+0$ \\
\hline 1273 & $3,18 \mathrm{E}+1$ & $1,90 \mathrm{E}+1$ & $1,10 \mathrm{E}+1$ & $6,41 \mathrm{E}+0$ & $6,29 \mathrm{E}+0$ & $6,29 \mathrm{E}+0$ & $6,29 \mathrm{E}+0$ & $6,25 \mathrm{E}+0$ & $6,25 \mathrm{E}+0$ & $6,25 \mathrm{E}+0$ \\
\hline$\underset{(\mu \mathrm{m})}{\mathrm{D}}$ & 1,52 & 1,74 & 1,91 & 2,70 & 3,01 & 3,30 & 3,40 & 3,80 & 4,30 & 4,70 \\
\hline
\end{tabular}


Tabla 5.20. Probetas prensadas de la Composición $C-I$. Valores resistividad en el interior de grano $\left(\rho_{\mathrm{g}}\right)$ obtenidos a partir de los valores de la conductividad en el interior de grano $\left(\sigma_{\mathrm{g}}\right)$, de la tabla 5.15

\begin{tabular}{cccc}
$\mathrm{T}_{\mathrm{e}}(\mathrm{K})$ & $\rho_{\mathrm{g}}(\Omega . \mathrm{cm})$ & $\mathrm{T}_{\mathrm{e}}(\mathrm{K})$ & $\rho_{\mathrm{g}}(\Omega . \mathbf{c m})$ \\
\hline $\mathbf{5 7 3}$ & $3,24 \mathrm{E}+05$ & $\mathbf{9 7 3}$ & $1,75 \mathrm{E}+01$ \\
$\mathbf{6 2 3}$ & $3,17 \mathrm{E}+04$ & $\mathbf{1 0 2 3}$ & $1,30 \mathrm{E}+01$ \\
$\mathbf{6 7 3}$ & $3,76 \mathrm{E}+03$ & $\mathbf{1 0 7 3}$ & $1,02 \mathrm{E}+01$ \\
$\mathbf{7 2 3}$ & $6,88 \mathrm{E}+02$ & $\mathbf{1 1 2 3}$ & $8,70 \mathrm{E}+00$ \\
$\mathbf{7 7 3}$ & $2,22 \mathrm{E}+02$ & $\mathbf{1 1 7 3}$ & $7,69 \mathrm{E}+00$ \\
$\mathbf{8 2 3}$ & $8,70 \mathrm{E}+01$ & $\mathbf{1 2 2 3}$ & $6,80 \mathrm{E}+00$ \\
$\mathbf{8 7 3}$ & $4,50 \mathrm{E}+01$ & $\mathbf{1 2 7 3}$ & $6,25 \mathrm{E}+00$ \\
$\mathbf{9 2 3}$ & $2,60 \mathrm{E}+01$ & & \\
\hline
\end{tabular}


Tabla 5.21. Probetas prensadas de la Composición $C-I$. Valores de la resistividad los límites de grano $\left(\rho_{\mathrm{lg}}^{\top}\right)(\Omega . \mathrm{cm})$ obtenidos a partir de los valores de la conductividad total en los límites de grano $\left(\sigma_{\mathrm{lg}}^{\mathrm{T}}\right)$, de las tablas 5.13 y 5.17 .

\begin{tabular}{|c|c|c|c|c|c|c|c|c|c|c|}
\hline$T_{S}$ & \multicolumn{3}{|c|}{$1573 \mathrm{~K}$} & \multicolumn{3}{|c|}{$1673 \mathrm{~K}$} & \multicolumn{4}{|c|}{$1773 \mathrm{~K}$} \\
\hline $\begin{array}{c}t_{R} \\
(h)\end{array}$ & $2 \mathrm{~h}$ & $4 \mathrm{~h}$ & $6 \mathrm{~h}$ & $2 \mathrm{~h}$ & $4 \mathrm{~h}$ & $6 \mathrm{~h}$ & $1 \mathrm{~h}$ & $2 \mathrm{~h}$ & $4 \mathrm{~h}$ & $6 \mathrm{~h}$ \\
\hline $\begin{array}{c}T_{e} \\
(\mathrm{~K})\end{array}$ & & & & & & & & & & \\
\hline 573 & $5,62 \mathrm{E}+4$ & $4,44 \mathrm{E}+4$ & $3,60 \mathrm{E}+4$ & $3,24 \mathrm{E}+4$ & $2,42 \mathrm{E}+4$ & $2,16 \mathrm{E}+4$ & $1,98 \mathrm{E}+4$ & $1,98 \mathrm{E}+4$ & $1,97 \mathrm{E}+4$ & $1,95 E+4$ \\
\hline 623 & $7,35 E+3$ & $5,18 \mathrm{E}+3$ & $4,63 E+3$ & $3,76 \mathrm{E}+3$ & $2,73 E+3$ & $2,56 \mathrm{E}+3$ & $2,95 E+3$ & $2,60 E+3$ & $2,55 \mathrm{E}+3$ & $2,51 E+3$ \\
\hline 673 & $1,38 E+3$ & $1,13 E+3$ & $1,11 \mathrm{E}+3$ & $8,87 \mathrm{E}+2$ & $8,00 \mathrm{E}+2$ & $7,37 \mathrm{E}+2$ & $6,80 \mathrm{E}+2$ & $6,90 \mathrm{E}+2$ & $5,29 E+2$ & $5,43 E+2$ \\
\hline 723 & $2,81 \mathrm{E}+2$ & $2,82 \mathrm{E}+2$ & $2,54 \mathrm{E}+2$ & $2,17 \mathrm{E}+2$ & $1,89 \mathrm{E}+2$ & $1,83 \mathrm{E}+2$ & $1,66 \mathrm{E}+2$ & $1,67 \mathrm{E}+2$ & $1,60 \mathrm{E}+2$ & $1,53 \mathrm{E}+2$ \\
\hline 773 & $8,08 \mathrm{E}+1$ & $5,95 \mathrm{E}+1$ & $3,82 \mathrm{E}+1$ & $2,78 \mathrm{E}+1$ & $2,53 \mathrm{E}+1$ & $2,29 \mathrm{E}+1$ & $2,11 \mathrm{E}+1$ & $2,05 \mathrm{E}+1$ & $1,93 \mathrm{E}+1$ & $1,87 \mathrm{E}+1$ \\
\hline 823 & $5,19 E+1$ & $3,07 E+1$ & $1,61 \mathrm{E}+1$ & $9,20 \mathrm{E}+0$ & $8,28 \mathrm{E}+0$ & $7,38 \mathrm{E}+0$ & $6,50 \mathrm{E}+0$ & $5,64 \mathrm{E}+0$ & $4,79 \mathrm{E}+0$ & $3,95 E+0$ \\
\hline 873 & $3,76 \mathrm{E}+1$ & $1,91 E+1$ & $8,72 \mathrm{E}+0$ & $2,12 \mathrm{E}+0$ & $1,47 \mathrm{E}+0$ & $1,25 \mathrm{E}+0$ & $1,04 \mathrm{E}+0$ & $8,27 \mathrm{E}-1$ & $6,17 \mathrm{E}-1$ & $4,10 \mathrm{E}-1$ \\
\hline 923 & $3,35 \mathrm{E}+1$ & $1,57 \mathrm{E}+1$ & $6,60 \mathrm{E}+0$ & $8,36 \mathrm{E}-1$ & $4,81 \mathrm{E}-1$ & $3,42 \mathrm{E}-1$ & $2,73 \mathrm{E}-1$ & $2,04 \mathrm{E}-1$ & $1,36 \mathrm{E}-1$ & $6,76 \mathrm{E}-2$ \\
\hline 973 & $3,11 \mathrm{E}+1$ & $1,42 \mathrm{E}+1$ & $5,77 \mathrm{E}+0$ & $5,03 \mathrm{E}-1$ & $2,17 \mathrm{E}-1$ & $1,23 \mathrm{E}-1$ & $9,22 \mathrm{E}-2$ & $6,13 \mathrm{E}-2$ & $6,13 \mathrm{E}-2$ & $6,13 \mathrm{E}-2$ \\
\hline 1023 & $2,92 \mathrm{E}+1$ & $1,36 \mathrm{E}+1$ & $5,29 \mathrm{E}+0$ & $3,80 \mathrm{E}-1$ & $1,53 \mathrm{E}-1$ & $6,75 \mathrm{E}-2$ & $5,05 \mathrm{E}-2$ & $3,36 \mathrm{E}-2$ & 1,68E-2 & - \\
\hline 1073 & $2,82 E+1$ & $1,32 \mathrm{E}+1$ & $5,11 \mathrm{E}+0$ & $2,97 \mathrm{E}-1$ & $1,04 \mathrm{E}-1$ & $4,14 \mathrm{E}-2$ & $3,10 \mathrm{E}-2$ & 1,03E-2 & - & - \\
\hline 1123 & $2,69 \mathrm{E}+1$ & $1,27 \mathrm{E}+1$ & $4,93 \mathrm{E}+0$ & $2,33 \mathrm{E}-1$ & $7,63 \mathrm{E}-2$ & - & - & - & - & - \\
\hline 1173 & $2,61 E+1$ & $1,27 \mathrm{E}+1$ & $4,93 \mathrm{E}+0$ & $1,82 \mathrm{E}-1$ & 5,96E-2 & - & - & - & - & - \\
\hline 1223 & $2,56 \mathrm{E}+1$ & $1,28 \mathrm{E}+1$ & $4,83 \mathrm{E}+0$ & $1,90 \mathrm{E}-1$ & $4,66 \mathrm{E}-2$ & - & - & - & - & - \\
\hline 1273 & $2,56 \mathrm{E}+1$ & $1,28 \mathrm{E}+1$ & $4,74 \mathrm{E}+0$ & $1,60 \mathrm{E}-1$ & 3,93E-2 & - & - & - & - & - \\
\hline$\underset{(\mu \mathrm{m})}{\text { D }}$ & 1,52 & 1,74 & 1,91 & 2,70 & 3,01 & 3,30 & 3,40 & 3,80 & 4,30 & 4,70 \\
\hline
\end{tabular}

En la Figura 5.22 se ha representado la variación de las resistividades iónicas $\boldsymbol{\rho}_{T}, \boldsymbol{\rho}_{g}$ y $\boldsymbol{\rho}^{\boldsymbol{T}} \mathbf{l g}$, de las Tablas 5.19 a 5.21 , frente a la temperatura de ensayo $\left(\boldsymbol{T}_{e}\right)$, para los valores de los diámetros medios de grano entre 1,52 y $3,3 \mu \mathrm{m}$. No se ha representado para los tamaños de grano mayores ensayados porque no era ya necesario y porque se obtenía bastante dispersión.

En la Figura 5.23 se ha representado las conductividades iónicas $\boldsymbol{\sigma}_{T}, \boldsymbol{\sigma}_{g}$ y $\boldsymbol{\sigma}_{\text {lg }}$, de las Tablas $5.11,5.15$ y 5.13 y 5.17 , frente a los correspondientes valores de la temperatura de ensayo, para el mismo intervalo de valores de los diámetros medios de grano mencionados en el párrafo anterior. 


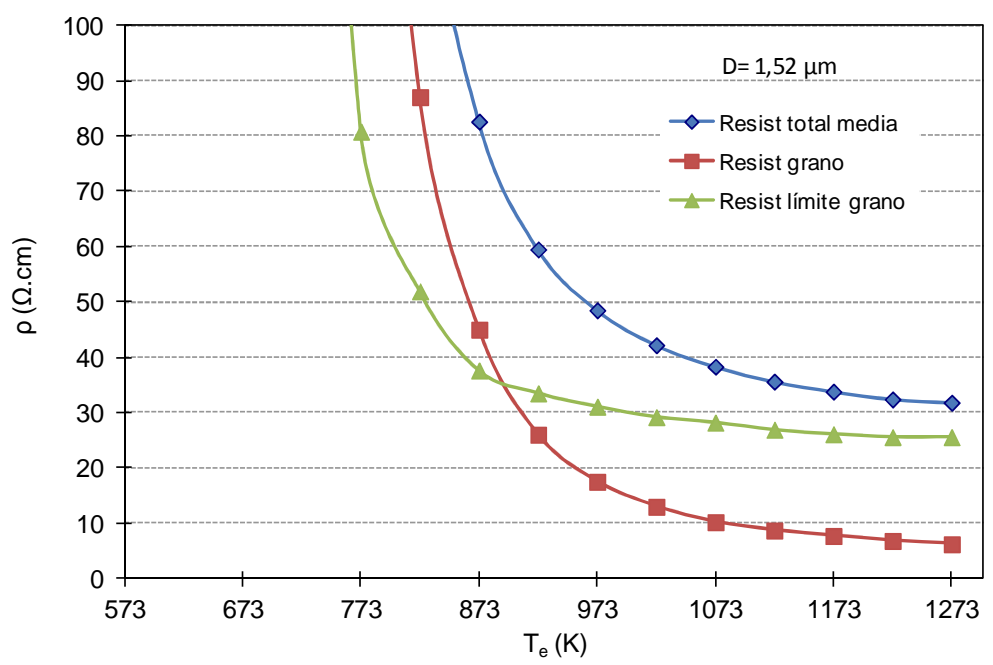

(a)

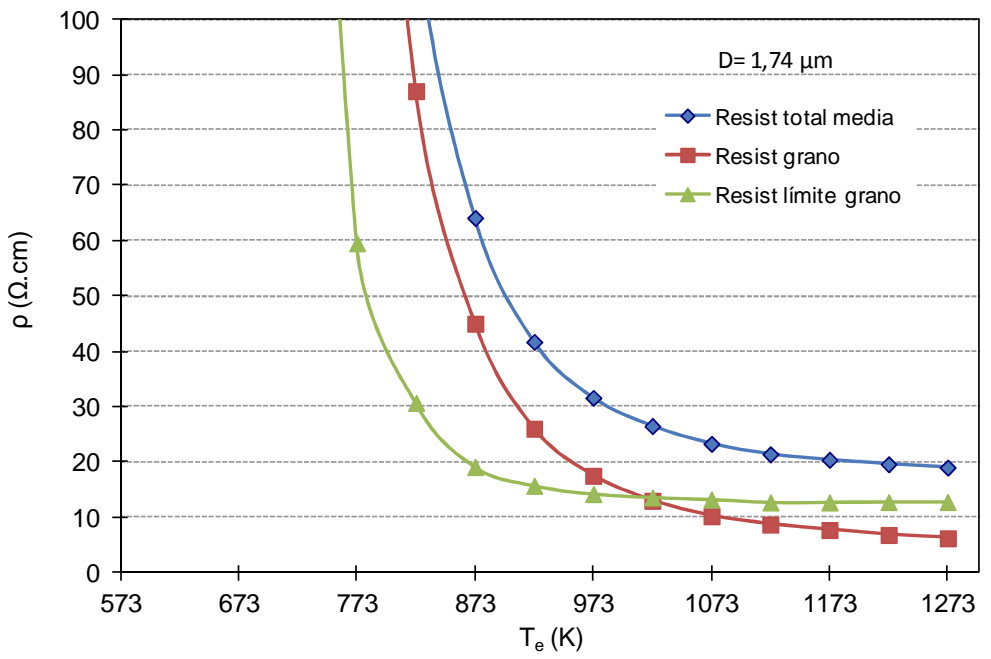

(b)

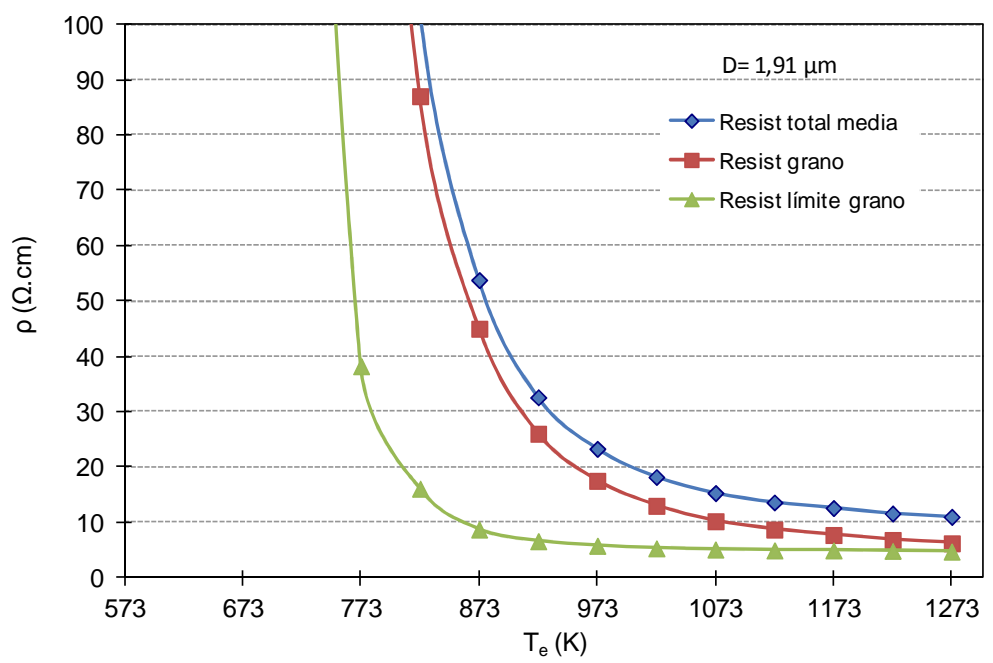

(c) 


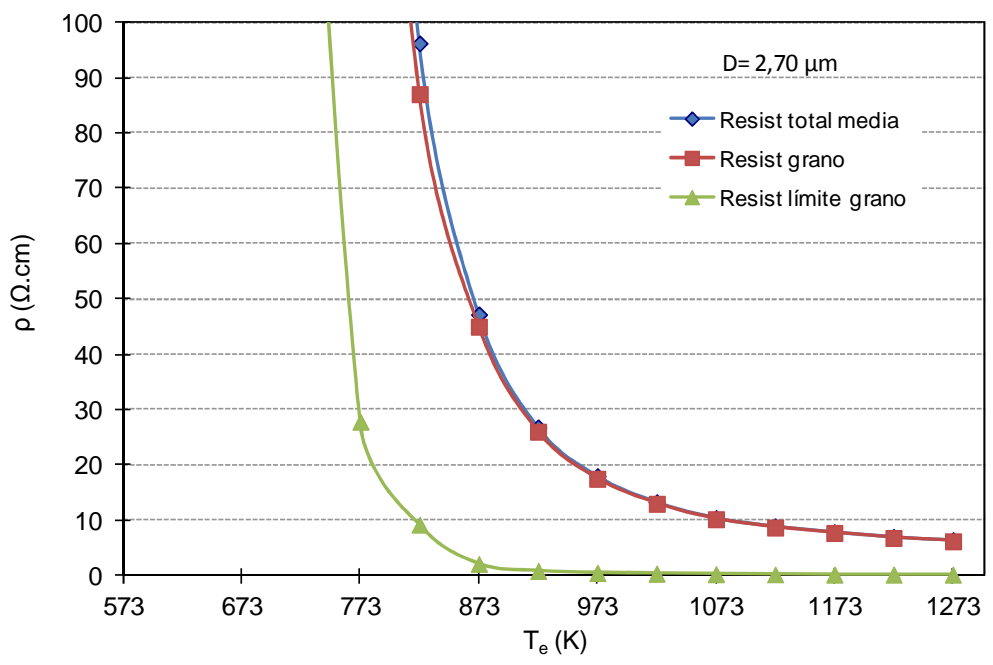

(d)

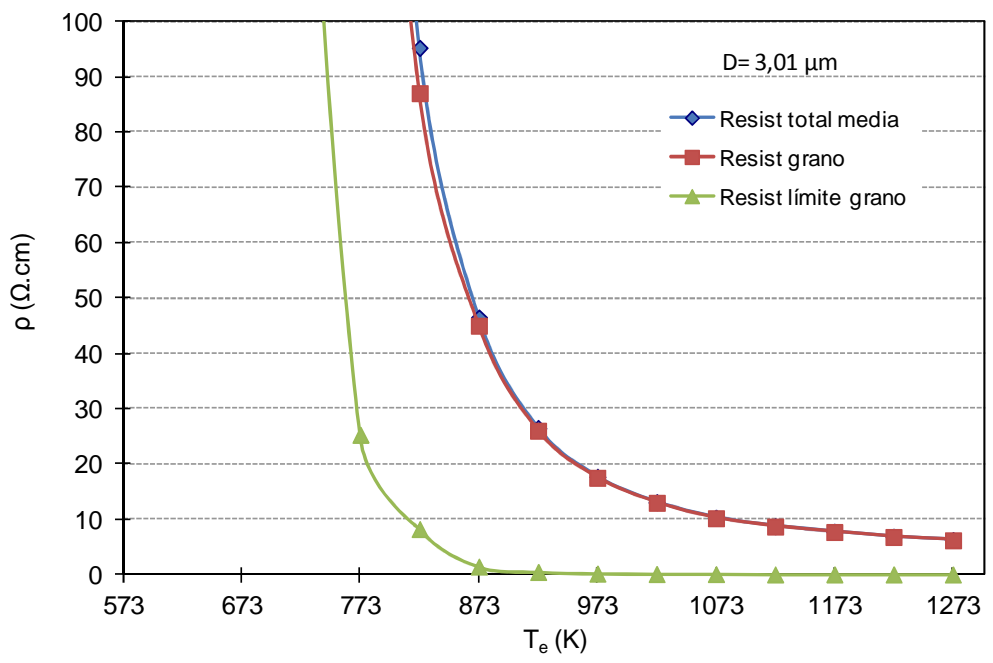

(e)

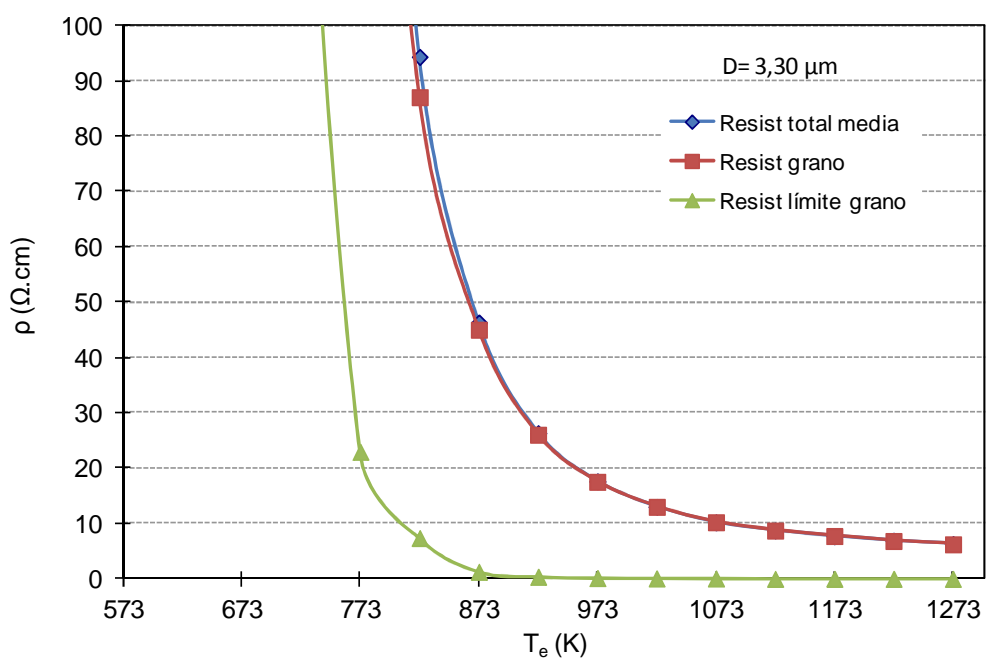

(f)

Figura 5.22. Variación de las resistividades iónicas $\rho_{T}, \rho_{g} y \rho^{T_{l g}}$, con $T_{e}$, para distintos valores de D. 


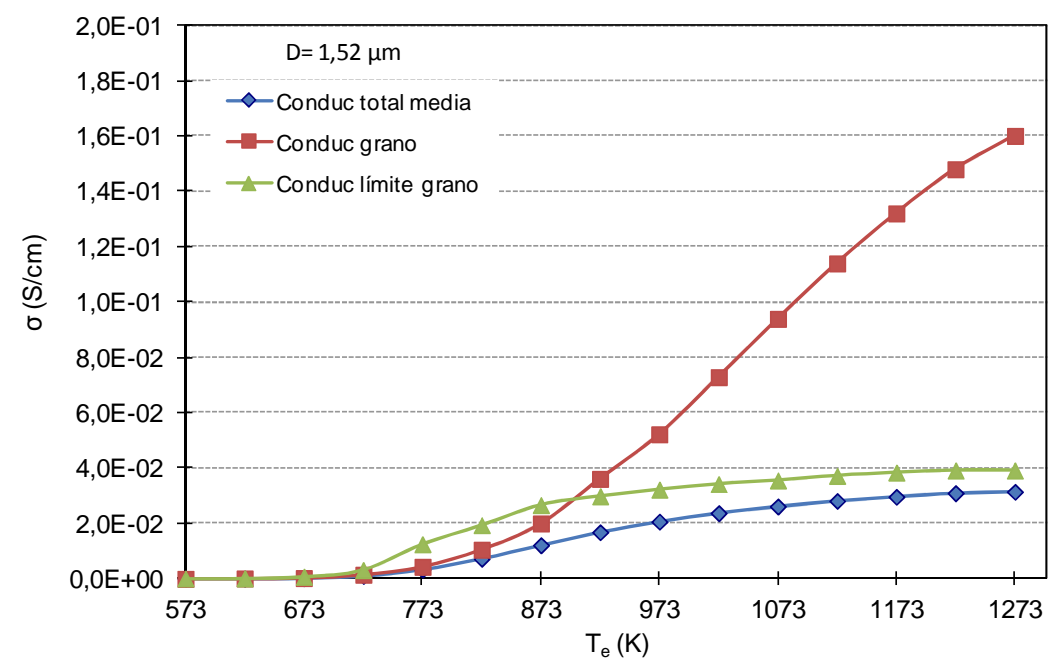

(a)

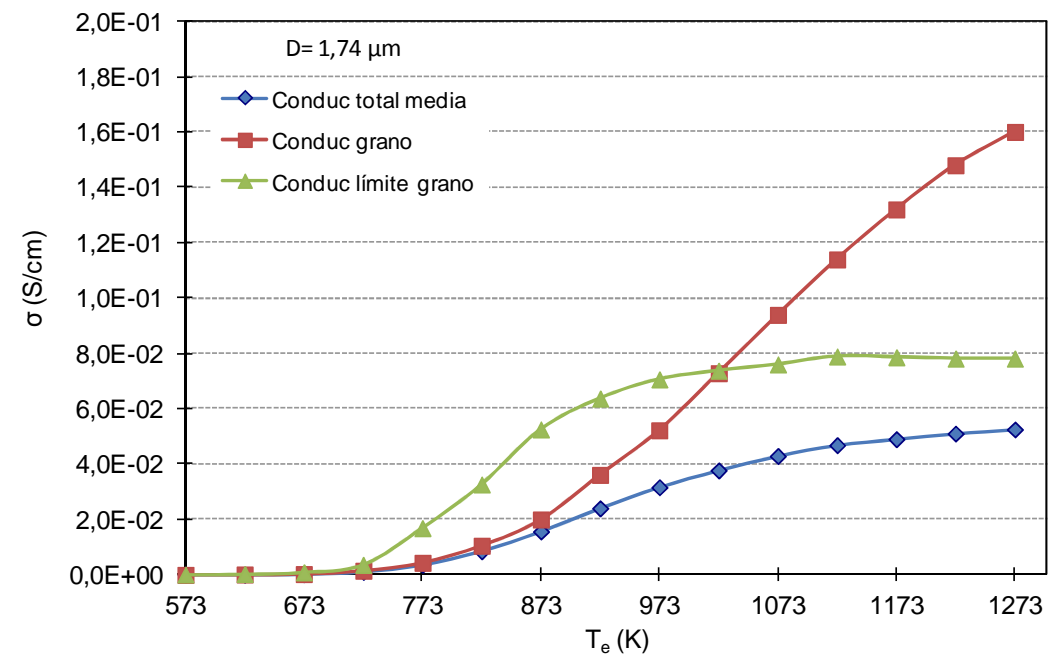

(b)

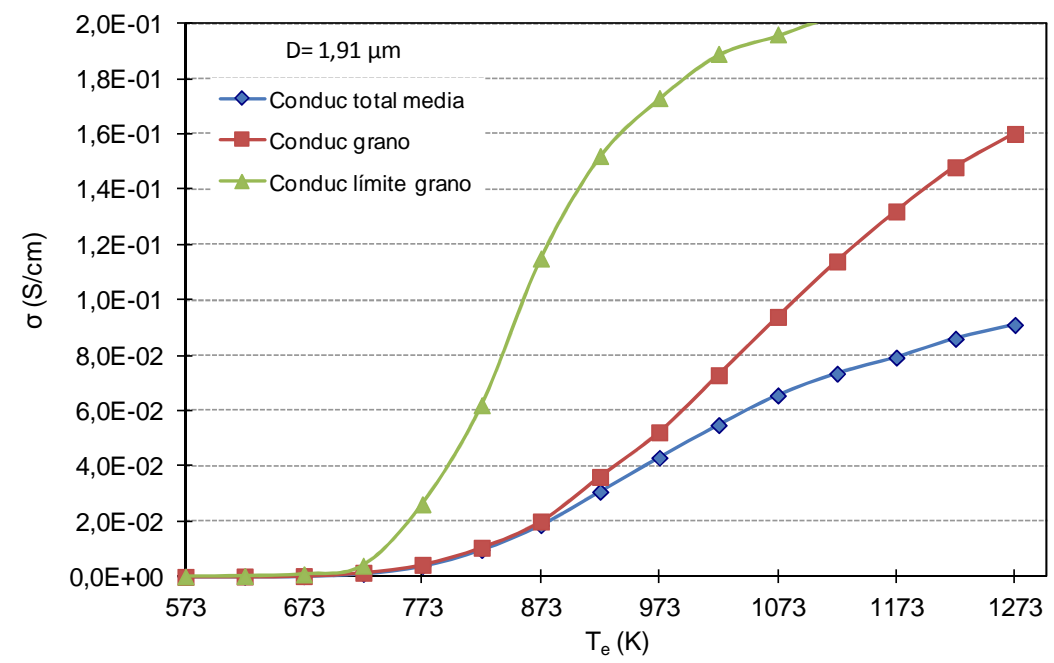

(c) 


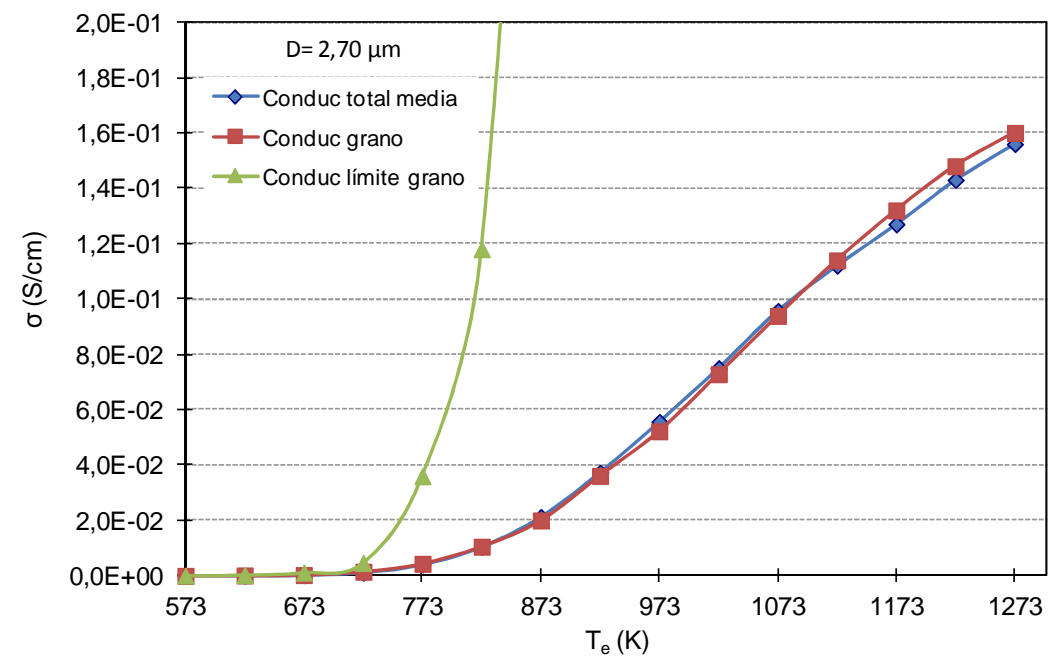

(d)

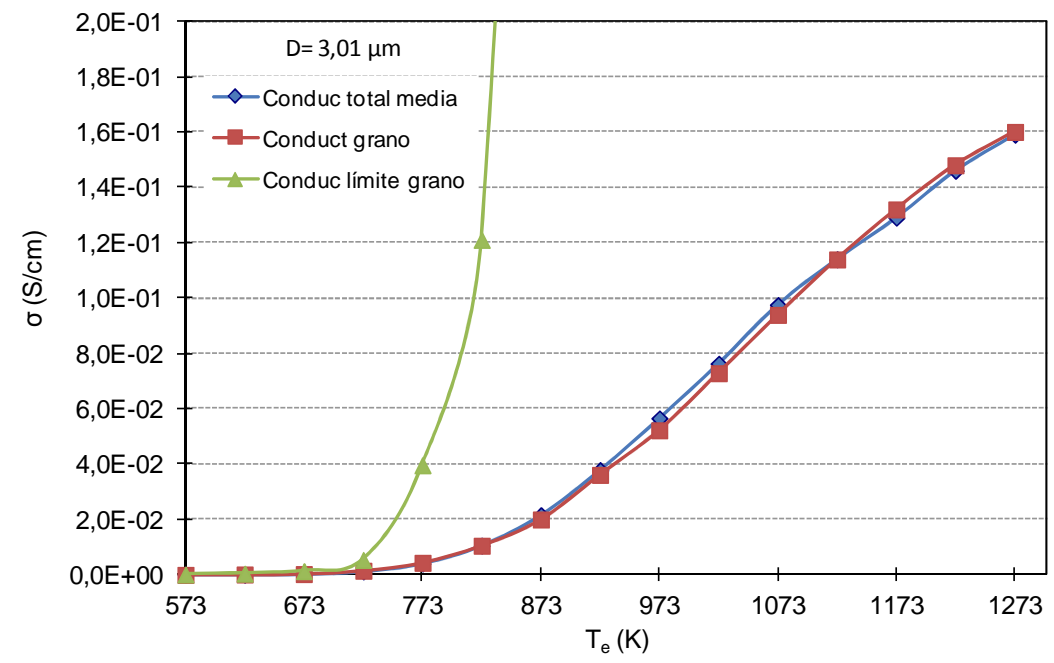

(e)

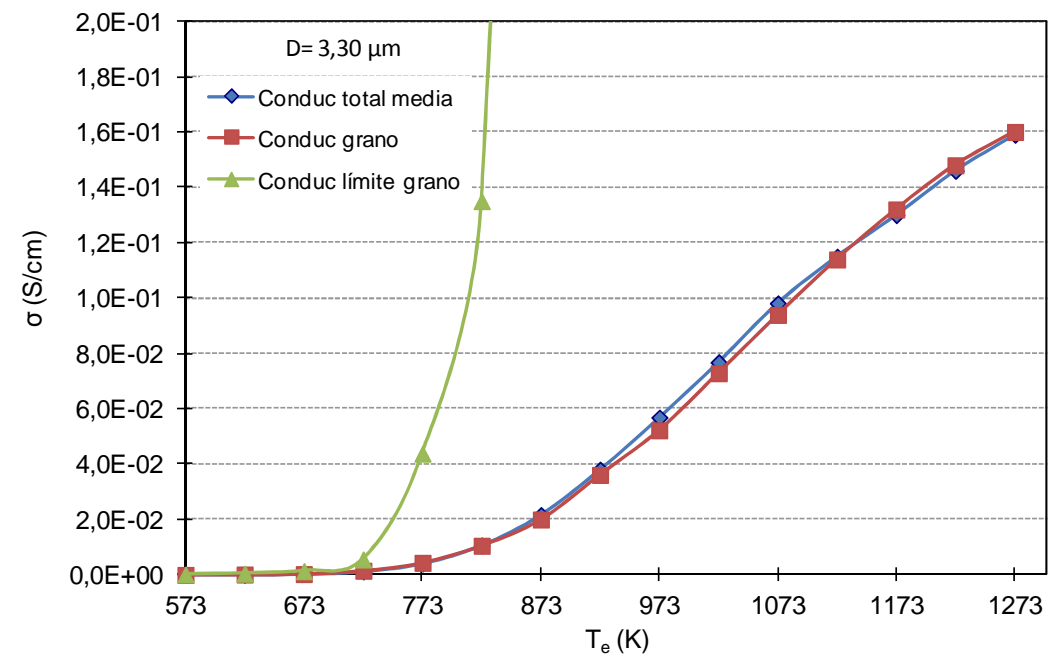

(f)

Figura 5.23. Variación de las conductividades iónicas $\sigma_{T}, \sigma_{g}$ y $\sigma^{T} T_{\text {g, }}$ con $T_{e}$, para distintos valores de $D$. 
Todos los gráficos de la Figura 5.22 se han construido con las mismas escalas, en ambos ejes de coordenadas, a fin de que resulte más fácil establecer comparaciones entre ellos de forma visual.

Al estudiar las representaciones de dicha figura se observa lo siguiente:

La línea representativa de la variación $\boldsymbol{\rho}_{g}$ con $\boldsymbol{T}_{\boldsymbol{e}}$ no cambia de posición al aumentar el diámetro medio de grano ya que, como se ha indicado reiteradamente, se ha observado que la conductividad en el interior de grano permanece prácticamente invariable al aumentar el tamaño de grano.

La línea representativa de la variación de $\boldsymbol{\rho}^{\boldsymbol{T}}{ }_{\mathrm{lg}}$ con $\boldsymbol{T}_{\boldsymbol{e}}$ se va desplazando hacia el eje de abscisas, a medida que aumenta el diámetro de grano, debido a que va disminuyendo el valor de dicha resistividad al aumentar el tamaño de grano.

Condicionada por el comportamiento de $\boldsymbol{\rho}^{\boldsymbol{T}}$ ig, puesto de manifiesto en el subapartado anterior, la línea representativa de la variación de la resistividad total se va desplazando asimismo hacia el eje de abscisas al aumentar el diámetro medio de grano, ya que $\boldsymbol{\rho}_{T}$ es igual a la suma de $\boldsymbol{\rho}_{g}$ y $\boldsymbol{\rho}^{\boldsymbol{T}}{ }_{\mathrm{I}}$, para cada valor de $\boldsymbol{T}_{\mathrm{e}}$. Como consecuencia, la línea representativa de la variación de la resistividad total se va acercando cada vez más a la correspondiente a la resistividad en el interior de grano, coincidiendo finalmente con ella para valores del diámetro medio de grano de $2,7 \mu \mathrm{m}$ o mayores, para los que la resistividad en los límites de grano se hace tan pequeña que su valor es prácticamente despreciable frente al de $\boldsymbol{\rho}_{g}$. Por ello, para valores de $\boldsymbol{D}$ mayores que 2,7 $\mu \mathrm{m}$, las variaciones del diámetro medio de grano no influyen sobre el valor de la resistividad total.

En lo que se refiere a la Figura 5.23, también en este caso, a los efectos de facilitar la comparación visual entre las representaciones correspondientes a los distintos tamaños de grano estudiados, se ha operado con las mismas escalas en todas ellas.

Al estudiar las representaciones de dicha figura se llega a conclusiones que son consecuencia de las observaciones expuestas en los subapartados anteriores, debido a la relación existente entre la conductividad y la resistividad eléctricas del material.

En efecto:

Como es lógico, dada la relación entre $\boldsymbol{\rho}_{g}$ y $\boldsymbol{\sigma}_{g}$, la línea representativa de la variación de esta última con $T_{e}$ tampoco cambia de posición al aumentar el diámetro medio de grano.

Para el tamaño medio de grano más pequeño estudiado, la línea representativa de la variación de $\boldsymbol{\sigma}_{l g}^{T}$ con $T_{e}$, está muy próxima al eje de abscisas, condicionando la posición de la línea representativa de la variación de $\sigma_{T}$, dada la relación entre ambas propiedades y $\boldsymbol{\sigma}_{g}$ (ecuación (1.22)).

A medida que aumenta el tamaño de grano, las líneas representativas de la variación de $\boldsymbol{\sigma}^{T}$ Ig con Te se van alejando, cada vez más, del eje de abscisas, arrastrando, en el mismo sentido, a las líneas correspondientes de $\sigma_{T}$, que progresivamente se van acercando a las de $\sigma_{g}$ hasta prácticamente coincidir con ellas, para el diámetro medio de grano de 2,7 $\mu \mathrm{m}$ y superiores.

Los comentarios expuestos en los subapartados precedentes se basan en la forma de las curvas de distribución de las Figuras 5.22 y 5.23, correspondiente al intervalo de valores de $\boldsymbol{T}_{e} \geq 723 \mathrm{~K}$, que es la temperatura de ensayo a partir de la que constan datos de $\boldsymbol{\rho}_{T}, \boldsymbol{\rho}_{g}$ y $\boldsymbol{\rho}^{T}$ Ig, en las representaciones de la Figura 5.22, y de $\sigma_{T}, \sigma_{g}$ y $\sigma^{T}$, en las representaciones de la Figura 5.23. Asimismo, es la temperatura de ensayo a partir de la que se observa una progresiva separación de las curvas representativas de $\sigma_{T}=1 / \rho_{T}$, al disminuir el diámetro de grano, en las Figuras 5.11 y 5.12 .

No se ha representado la variación de $\boldsymbol{\rho}_{T}, \boldsymbol{\rho}_{g}$ y $\boldsymbol{\rho}^{\boldsymbol{T}}$ lg, en las representaciones de la Figura 5.22 , porque resultan valores muy altos de dichas propiedades para $\mathrm{Te} \leq 723 \mathrm{~K}$, de modo 
que, de haberlos incluido en dichas representaciones, no podrían apreciarse las diferencias existentes en la zona de mayor interés (873 - $973 \mathrm{~K})$, desde el punto de vista de esta investigación, porque salen muy juntos.

En lo que respecta a los valores de $\sigma_{T}, \sigma_{g}$ y $\boldsymbol{\sigma}_{l g}^{T}$, en las representaciones de la Figura 5.23, no puede apreciarse las diferencias existentes entre ellos para temperaturas de ensayo iguales o inferiores a $723 \mathrm{~K}$, porque las correspondientes líneas de distribución aparecen muy juntas, dada la escala de valores que se ha utilizado en el eje de ordenadas, a fin de resaltar las diferencias en la zona de temperatura de $873-973 \mathrm{~K}$ y mayores.

Con la intención de poner de manifiesto la razón por la que en las Figuras 5.11 y 5.12 aparecen prácticamente juntas en este tramo, las líneas representativas de la variación de $\sigma_{T}$ con $\boldsymbol{T}_{e}$ para todos los tamaños de grano estudiados, en la Figura 5.24 se ha representado la variación del logaritmo neperiano de $\sigma_{T}, \sigma_{g}$ y $\sigma^{T}$ frente a $1 / T_{e}$, ya que, mediante esta representación, puede apreciarse lo que sucede en el tramo de temperaturas de ensayo $573-723 \mathrm{~K}$, como se verá a continuación.

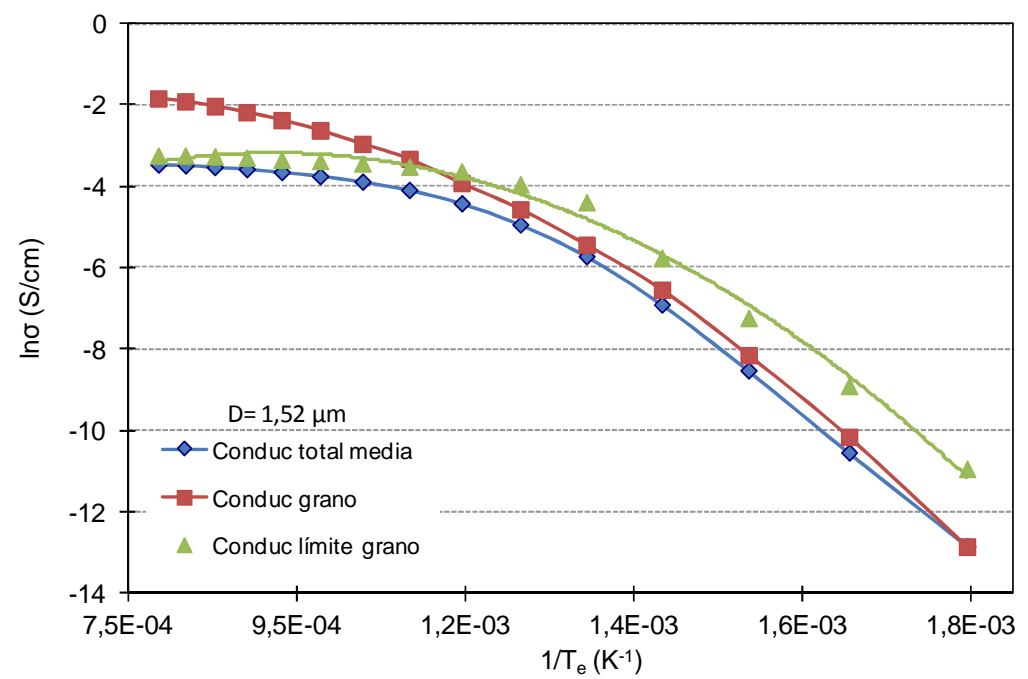

(a)

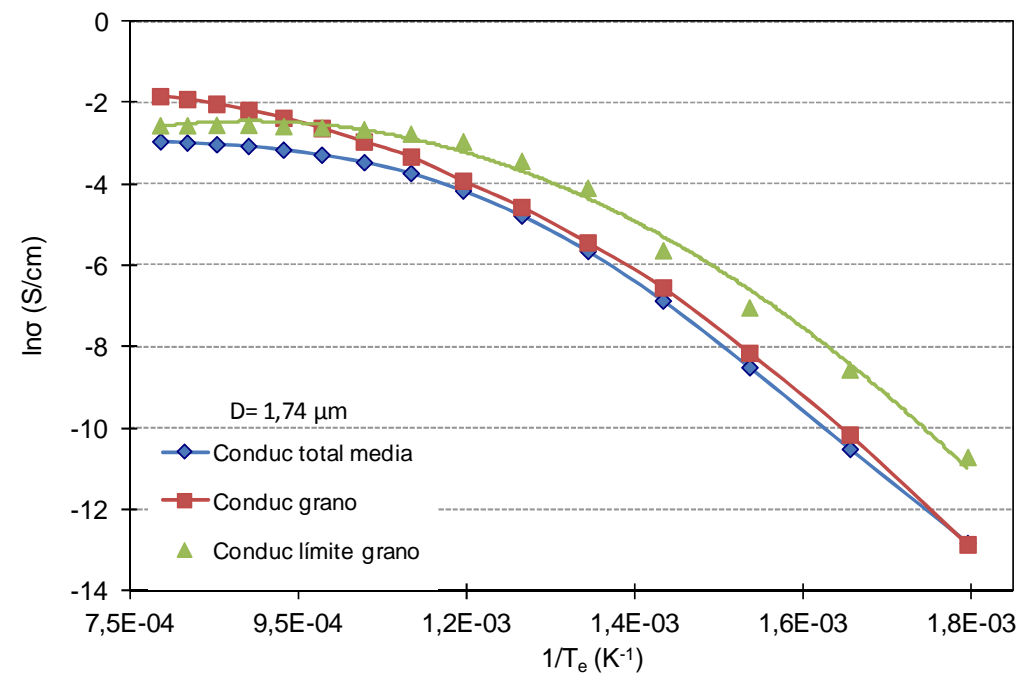

(b) 


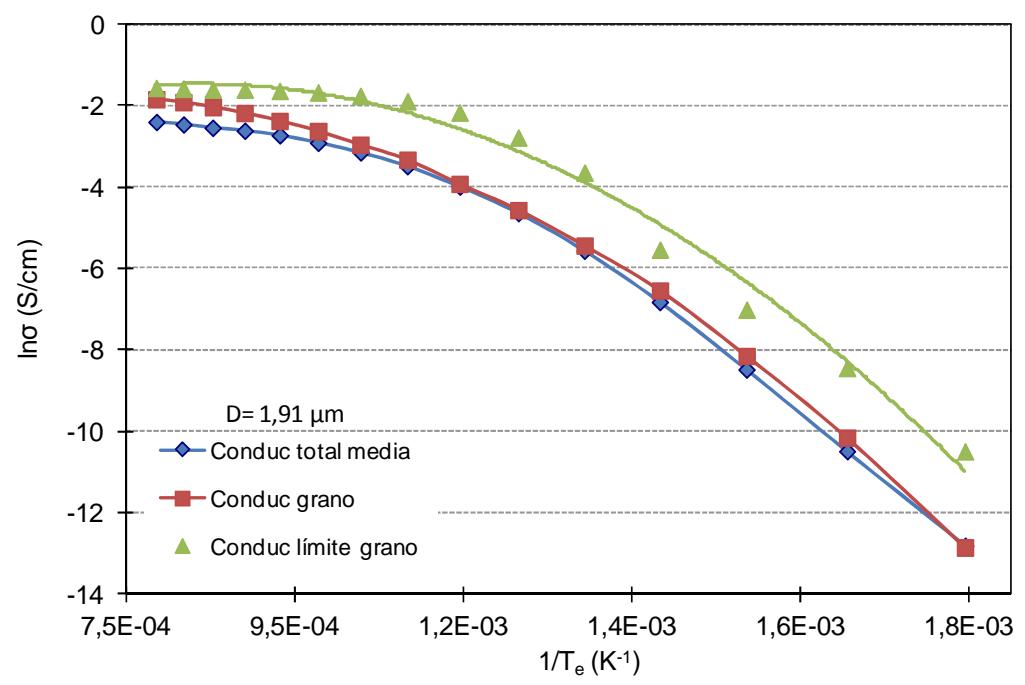

(c)

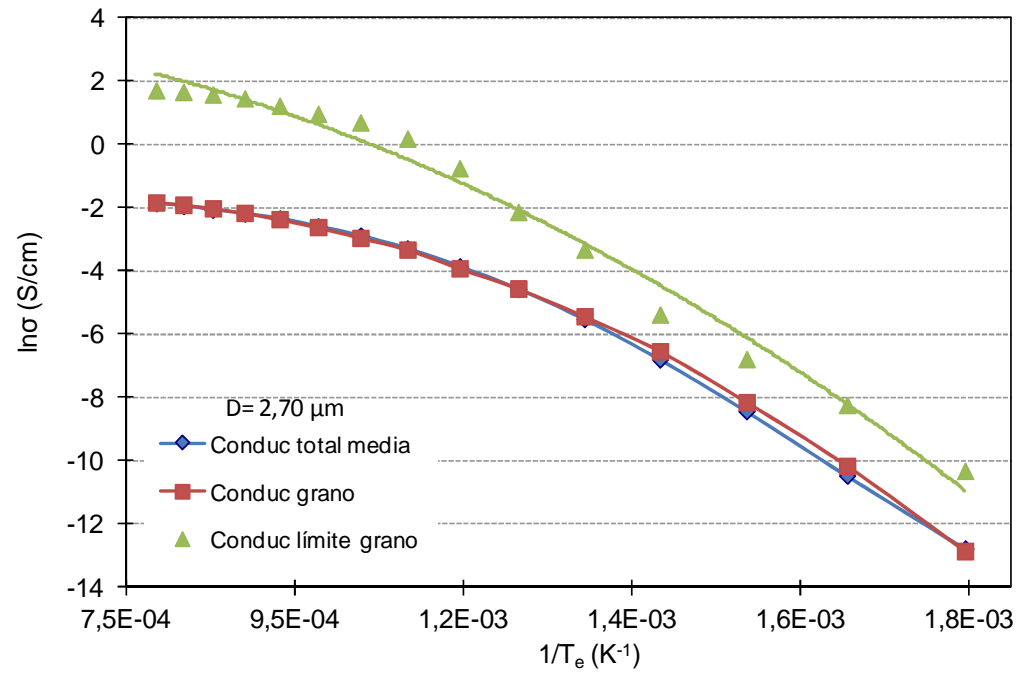

(d)

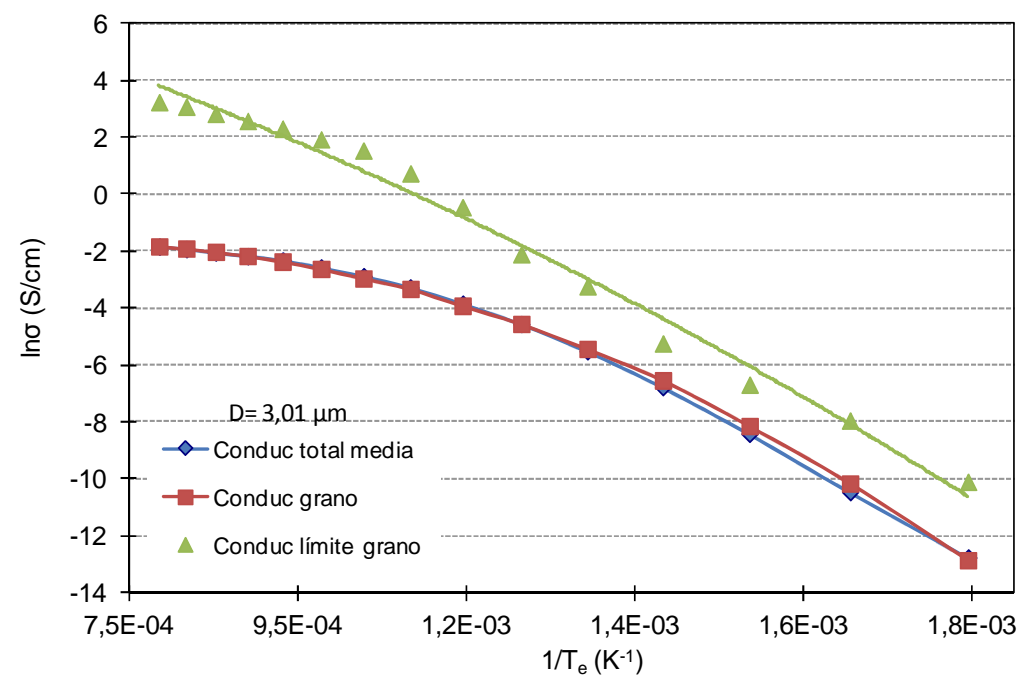

(e)

Figura 5.24. Variación de las conductividades iónicas $\sigma_{T}, \sigma_{g} y \sigma^{T} T_{l}$, con $T_{e}$, para distintos valores de $D$. 
Como puede apreciarse, al observar el comportamiento de las líneas de distribución obtenidas correspondiente a los valores de $1 / T_{e} \geq 1,383 \cdot 10^{-3}$ (los cuatro puntos del extremo de la derecha de las representaciones), para todos los tamaños de grano estudiados, $\boldsymbol{\sigma}^{T}$ es del orden de 100 veces mayor que $\sigma_{g}$ por lo que, de acuerdo con la ecuación (1.22), los valores de $\sigma_{T}$ deben coincidir prácticamente con los de $\sigma_{g}$ en el tramo de temperaturas de ensayo considerado, como así sucede.

Por tanto, dado que el valor de $\sigma_{g}$ no depende del valor del diámetro medio de grano, a cualquier temperatura de ensayo, lo expuesto en el párrafo anterior es la razón por la que para valores de $\boldsymbol{T}_{e}$ inferiores a $723 \mathrm{~K}$, las líneas representativas de la variación de $\sigma_{T}$ con $\boldsymbol{T}$ se superpongan, para todos los valores del diámetro medio de grano, en las representaciones de las Figuras 5.11 y 5.12.

5.1.5.3.5. Reproducción de los resultados experimentales mediante las ecuaciones (1.22), (5.16) y (5.18).

Para completar el estudio realizado sobre las piezas prensadas sinterizadas, obtenidas a partir de la composición $\boldsymbol{C}$-I, se pensó en tratar de reproducir los resultados experimentales partiendo de la ecuación (1.22), que se puede poner en la forma:

$$
\sigma_{T}=\left[\frac{1}{\sigma_{g}}+\frac{1}{\sigma_{\mathrm{lg}}^{T}}\right]^{-1}
$$

Sustituyendo además en ella la conductividad en el interior de grano $\left(\sigma_{g}\right)$ por la ecuación (5.16):

$$
\sigma_{g}=\exp \left(12930 / T_{e}-9560000 / T_{e}^{2}-6,09\right.
$$

que relaciona dicha propiedad con la temperatura de ensayo, y la conductividad total en los límites de grano $\sigma_{\text {Ig }}^{\top}$ por la ecuación (5.18):

$$
\sigma_{\lg }^{T}=A \cdot \exp (B \cdot D)
$$

Sustituyendo en ella, para cada valor de $\boldsymbol{T}_{\boldsymbol{e}}$ considerado, los valores de los parámetros $\boldsymbol{A}$ y $\boldsymbol{B}$ que se detallan en la Tabla 5.18 se han calculado los valores obtenidos para $\sigma_{T}$, a las diferentes condiciones de operación estudiadas. Los resultados se muestran en la Tabla 5.22. Estos valores se han representado en la Figura 5.25 frente a los correspondientes de $\boldsymbol{D}$, para cada temperatura de ensayo estudiada. 


\begin{tabular}{|c|c|c|c|c|c|c|c|}
\hline \multirow{2}{*}{$\begin{array}{c}T_{e}(K) \\
573\end{array}$} & \multirow[b]{2}{*}{$2,60 \mathrm{E}-6$} & \multirow[b]{2}{*}{$2,63 \mathrm{E}-6$} & \multirow[b]{2}{*}{$2,65 \mathrm{E}-6$} & \multirow[b]{2}{*}{$2,68 \mathrm{E}-6$} & \multirow[b]{2}{*}{$2,70 \mathrm{E}-6$} & \multirow[b]{2}{*}{ 2,72E-6 } & \multirow[b]{2}{*}{$2,74 \mathrm{E}-6$} \\
\hline & & & & & & & \\
\hline 623 & 2,64E-5 & $2,67 E-5$ & $2,69 \mathrm{E}-5$ & $2,72 \mathrm{E}-5$ & $2,74 \mathrm{E}-5$ & $2,76 \mathrm{E}-5$ & $2,78 \mathrm{E}-5$ \\
\hline 673 & $1,98 \mathrm{E}-4$ & $2,01 \mathrm{E}-4$ & $2,04 \mathrm{E}-4$ & $2,06 \mathrm{E}-4$ & $2,09 \mathrm{E}-4$ & $2,11 \mathrm{E}-4$ & $2,14 \mathrm{E}-4$ \\
\hline 723 & $1,04 \mathrm{E}-3$ & $1,06 \mathrm{E}-3$ & $1,07 \mathrm{E}-3$ & $1,08 \mathrm{E}-3$ & $1,09 \mathrm{E}-3$ & $1,10 \mathrm{E}-3$ & $1,11 \mathrm{E}-3$ \\
\hline 773 & $3,60 \mathrm{E}-3$ & $3,66 \mathrm{E}-3$ & $3,71 \mathrm{E}-3$ & $3,76 \mathrm{E}-3$ & $3,81 \mathrm{E}-3$ & $3,86 \mathrm{E}-3$ & $3,90 \mathrm{E}-3$ \\
\hline 823 & $8,53 \mathrm{E}-3$ & 8,87E-3 & $9,11 \mathrm{E}-3$ & $9,36 \mathrm{E}-3$ & $9,60 \mathrm{E}-3$ & $9,82 \mathrm{E}-3$ & $1,00 \mathrm{E}-2$ \\
\hline 873 & $1,46 \mathrm{E}-2$ & 1,63E-2 & $1,75 \mathrm{E}-2$ & $1,85 \mathrm{E}-2$ & $1,95 \mathrm{E}-2$ & $2,02 \mathrm{E}-2$ & $2,07 \mathrm{E}-2$ \\
\hline 923 & 1,99E-2 & $2,50 \mathrm{E}-2$ & $2,85 \mathrm{E}-2$ & $3,16 \mathrm{E}-2$ & $3,40 \mathrm{E}-2$ & 3,57E-2 & $3,67 \mathrm{E}-2$ \\
\hline 973 & $2,44 \mathrm{E}-2$ & $3,40 \mathrm{E}-2$ & 4,07E-2 & 4,67E-2 & $5,10 \mathrm{E}-2$ & 5,37E-2 & $5,52 \mathrm{E}-2$ \\
\hline 1023 & 2,34E-2 & $3,69 \mathrm{E}-2$ & $4,78 \mathrm{E}-2$ & $5,83 \mathrm{E}-2$ & $6,62 \mathrm{E}-2$ & $7,12 \mathrm{E}-2$ & $7,40 \mathrm{E}-2$ \\
\hline 1073 & $3,34 \mathrm{E}-2$ & $5,25 \mathrm{E}-2$ & $6,70 \mathrm{E}-2$ & 7,97E-2 & $8,84 \mathrm{E}-2$ & $9,34 \mathrm{E}-2$ & $9,60 \mathrm{E}-2$ \\
\hline 1123 & 2,84E-2 & $5,06 \mathrm{E}-2$ & $6,98 \mathrm{E}-2$ & $8,82 \mathrm{E}-2$ & $1,01 \mathrm{E}-1$ & $1,08 \mathrm{E}-1$ & $1,12 \mathrm{E}-1$ \\
\hline 1173 & $3,01 \mathrm{E}-2$ & 5,59E-2 & 7,87E-2 & $1,00 \mathrm{E}-1$ & $1,15 \mathrm{E}-1$ & $1,23 \mathrm{E}-1$ & $1,27 \mathrm{E}-1$ \\
\hline 1223 & $3,09 \mathrm{E}-2$ & $5,95 \mathrm{E}-2$ & 8,59E-2 & $1,12 \mathrm{E}-1$ & $1,30 \mathrm{E}-1$ & $1,39 \mathrm{E}-1$ & $1,43 \mathrm{E}-1$ \\
\hline 1273 & $2,68 \mathrm{E}-2$ & $5,54 \mathrm{E}-2$ & $8,45 \mathrm{E}-2$ & $1,15 \mathrm{E}-1$ & $1,38 \mathrm{E}-1$ & $1,50 \mathrm{E}-1$ & $1,56 \mathrm{E}-1$ \\
\hline$D(\mu \mathrm{m})$ & 1,52 & 1,74 & 1,91 & 2,1 & 2,3 & 2,5 & 2,7 \\
\hline
\end{tabular}




\begin{tabular}{|c|c|c|c|c|c|c|}
\hline$T_{e}(K)$ & & & & & & \\
\hline 573 & 2,77E-6 & $2,80 \mathrm{E}-6$ & $2,81 \mathrm{E}-6$ & 2,84E-6 & 2,87E-6 & $2,90 \mathrm{E}-6$ \\
\hline 623 & 2,81E-5 & 2,84E-5 & $2,85 \mathrm{E}-5$ & $2,88 \mathrm{E}-5$ & 2,92E-5 & $2,95 \mathrm{E}-5$ \\
\hline 673 & $2,18 \mathrm{E}-4$ & $2,21 \mathrm{E}-4$ & $2,22 \mathrm{E}-4$ & 2,26E-4 & 2,31E-4 & $2,34 \mathrm{E}-4$ \\
\hline 723 & 1,13E-3 & $1,14 \mathrm{E}-3$ & $1,15 \mathrm{E}-3$ & 1,17E-3 & 1,19E-3 & $1,21 \mathrm{E}-3$ \\
\hline 773 & $3,97 \mathrm{E}-3$ & $4,02 \mathrm{E}-3$ & $4,04 \mathrm{E}-3$ & $4,11 \mathrm{E}-3$ & $4,18 \mathrm{E}-3$ & $4,22 \mathrm{E}-3$ \\
\hline 823 & 1,03E-2 & $1,05 \mathrm{E}-2$ & $1,06 \mathrm{E}-2$ & $1,08 \mathrm{E}-2$ & $1,10 \mathrm{E}-2$ & $1,11 \mathrm{E}-2$ \\
\hline 873 & $2,13 \mathrm{E}-2$ & $2,16 \mathrm{E}-2$ & $2,17 \mathrm{E}-2$ & 2,19E-2 & $2,21 \mathrm{E}-2$ & $2,21 \mathrm{E}-2$ \\
\hline 923 & $3,77 \mathrm{E}-2$ & $3,81 \mathrm{E}-2$ & $3,82 \mathrm{E}-2$ & $3,84 \mathrm{E}-2$ & $3,85 \mathrm{E}-2$ & $3,85 \mathrm{E}-2$ \\
\hline 973 & 5,64E-2 & 5,69E-2 & $5,70 \mathrm{E}-2$ & $5,71 \mathrm{E}-2$ & $5,72 \mathrm{E}-2$ & $5,72 \mathrm{E}-2$ \\
\hline 1023 & $7,61 \mathrm{E}-2$ & $7,68 \mathrm{E}-2$ & $7,69 \mathrm{E}-2$ & $7,71 \mathrm{E}-2$ & $7,72 \mathrm{E}-2$ & $7,72 \mathrm{E}-2$ \\
\hline 1073 & $9,77 \mathrm{E}-2$ & $9,82 \mathrm{E}-2$ & $9,83 \mathrm{E}-2$ & $9,85 \mathrm{E}-2$ & $9,85 \mathrm{E}-2$ & $9,85 \mathrm{E}-2$ \\
\hline 1123 & $1,14 \mathrm{E}-1$ & $1,15 \mathrm{E}-1$ & $1,15 \mathrm{E}-1$ & $1,15 \mathrm{E}-1$ & $1,15 \mathrm{E}-1$ & $1,15 \mathrm{E}-1$ \\
\hline 1173 & $1,29 \mathrm{E}-1$ & $1,30 \mathrm{E}-1$ & $1,30 \mathrm{E}-1$ & $1,30 \mathrm{E}-1$ & $1,30 \mathrm{E}-1$ & $1,30 \mathrm{E}-1$ \\
\hline 1223 & $1,46 \mathrm{E}-1$ & $1,47 \mathrm{E}-1$ & $1,47 \mathrm{E}-1$ & $1,47 \mathrm{E}-1$ & $1,47 \mathrm{E}-1$ & $1,47 \mathrm{E}-1$ \\
\hline 1273 & $1,59 \mathrm{E}-1$ & $1,60 \mathrm{E}-1$ & $1,60 \mathrm{E}-1$ & $1,60 \mathrm{E}-1$ & $1,60 \mathrm{E}-1$ & $1,60 \mathrm{E}-1$ \\
\hline$D(\mu \mathrm{m})$ & 3,01 & 3,3 & 3,4 & 3,8 & 4,3 & 4,7 \\
\hline
\end{tabular}




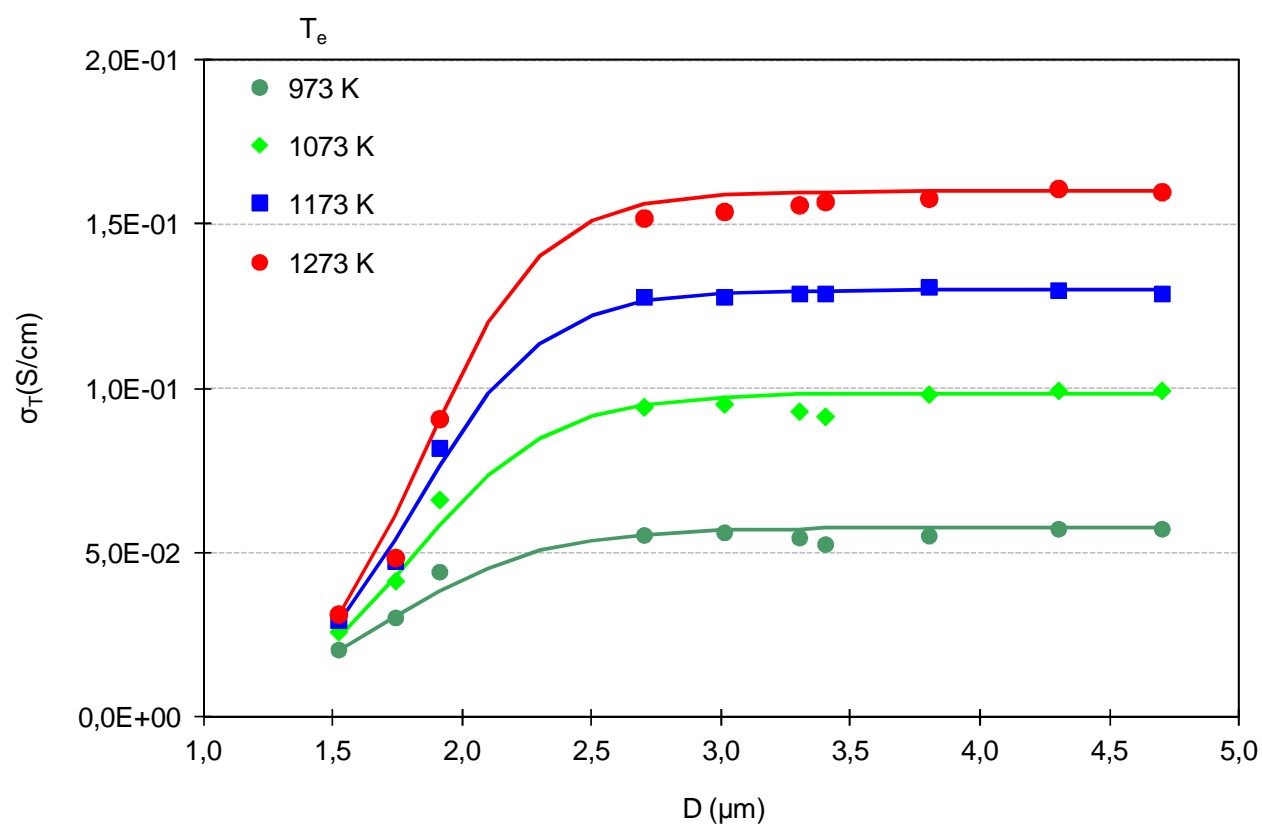

(a)

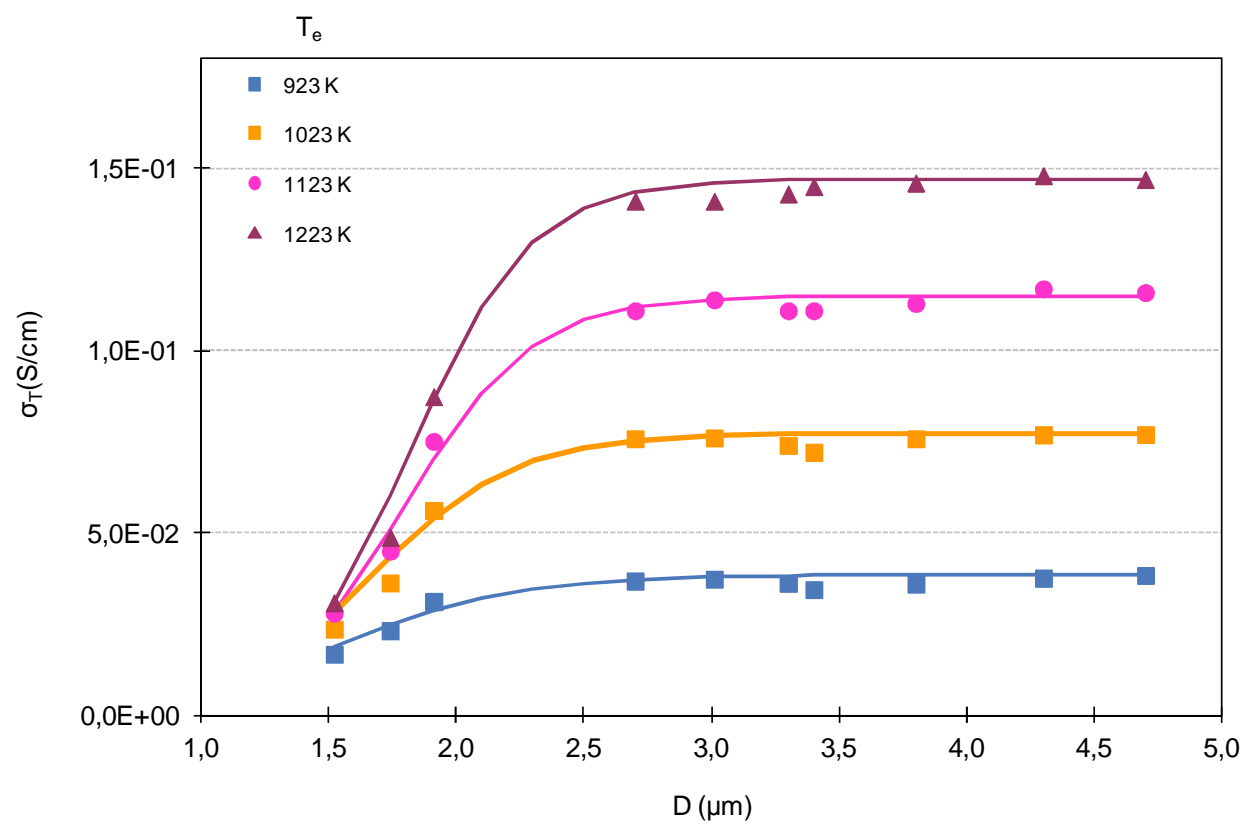

(b) 


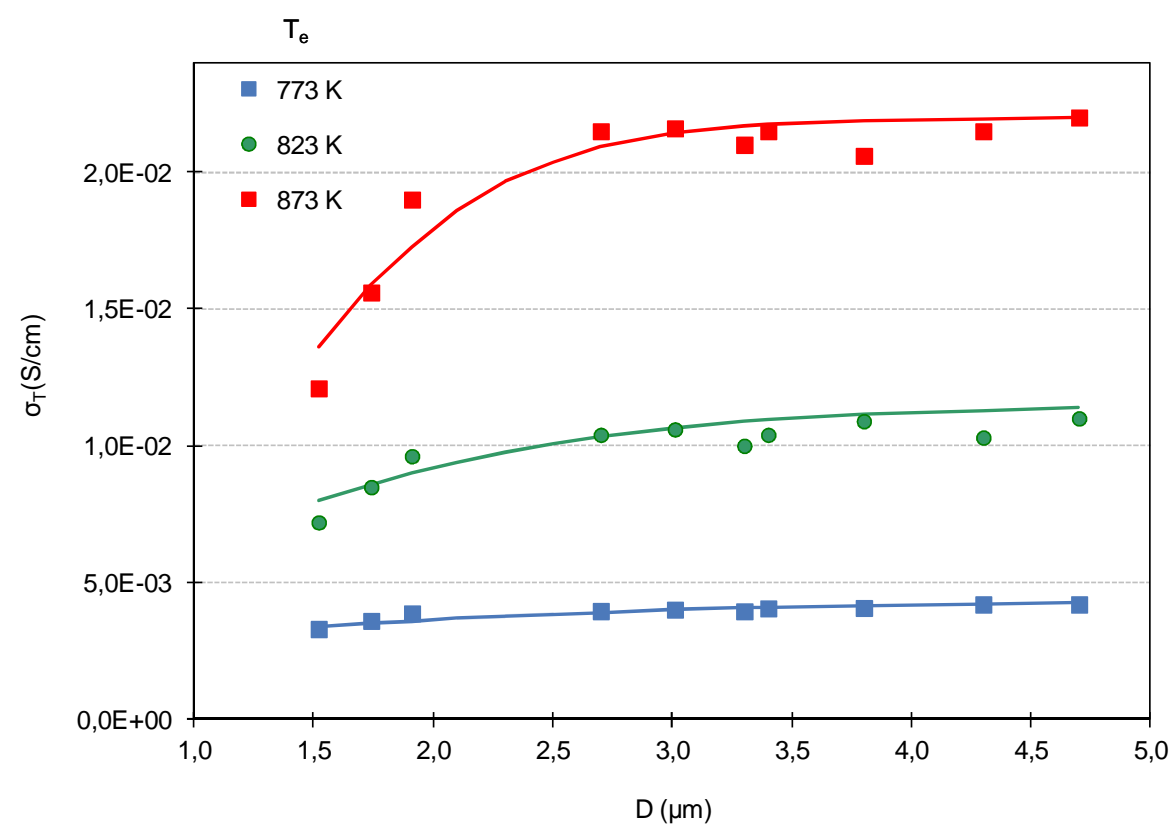

(c)

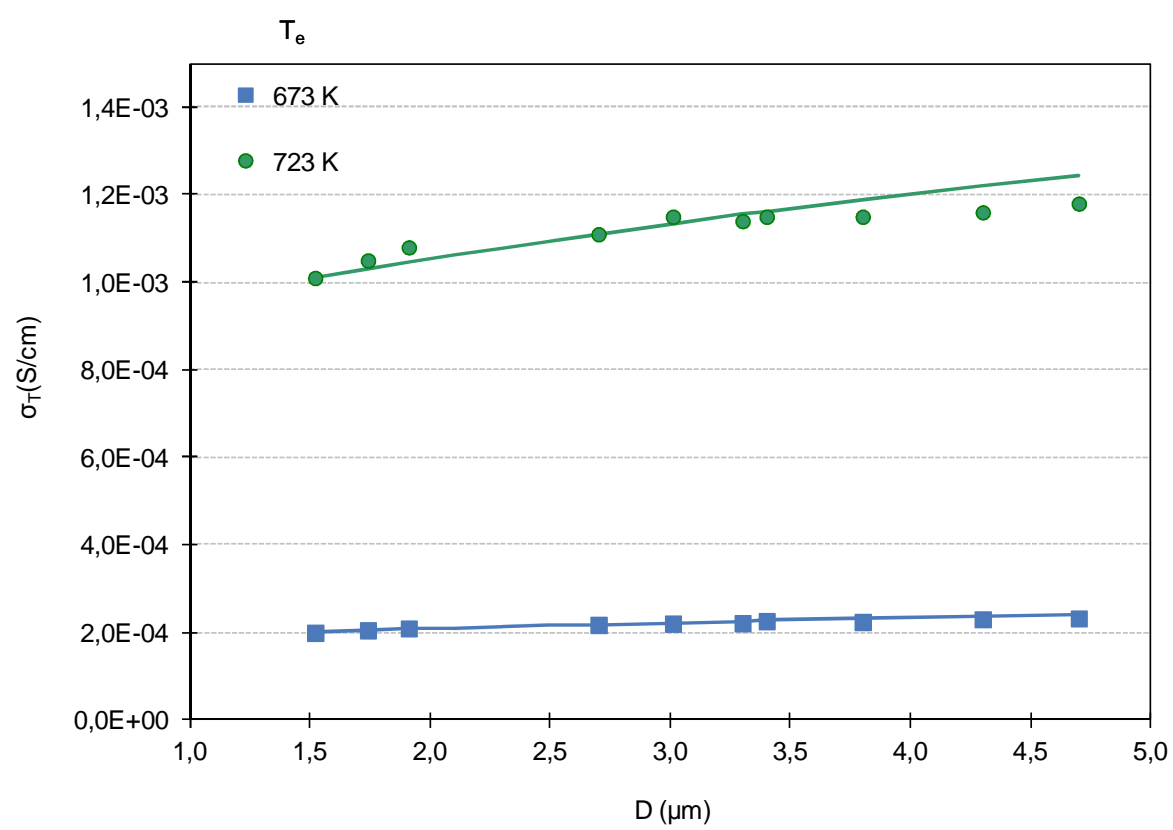

(d) 


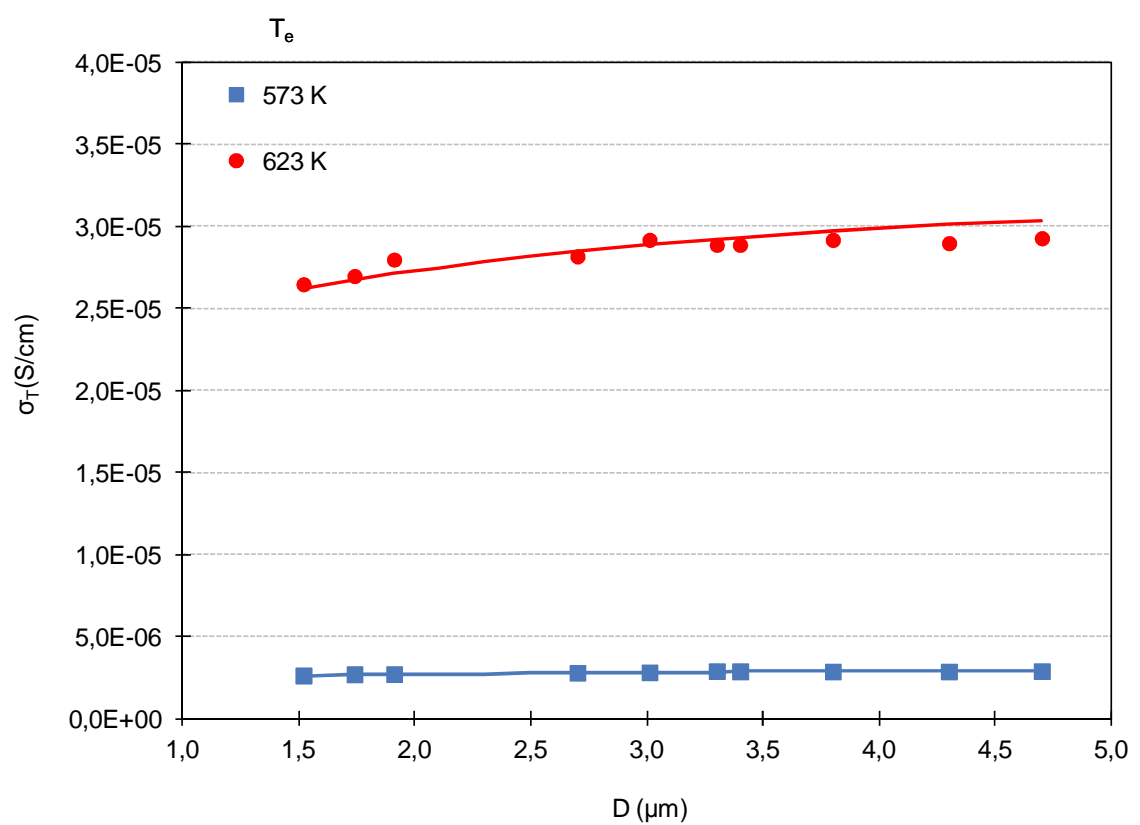

(e)

Figura 5.25. Comparación de los valores de la conductividad iónica total $\left(\sigma_{T}\right)$ calculada con las ecuaciones (1.22), (5.16), (5.18) y Tabla 5.18 (líneas continuas), con los valores experimentales (cuadrados, rombos, etc.) para los distintos valores de $D$ y $T_{e}$.

Como puede apreciarse en las representaciones de la figura anterior, la reproducción de los valores experimentales, con la metodología utilizada, es buena para las temperaturas de ensayo iguales o inferiores a $773 \mathrm{~K}$. Para las temperaturas de ensayo más altas, los valores calculados para valores de $\boldsymbol{D}$ del orden de $2,7 \mu \mathrm{m}$ o superiores, se adaptan asimismo bien a los datos experimentales, pero para los tres valores de $\boldsymbol{D}$ inferiores al indicado la reproductibilidad no es tan buena.

Desde un punto de vista práctico, este resultado podría considerarse satisfactorio, ya que el intervalo de valores de $\boldsymbol{D}$ en el que con el procedimiento utilizado se reproduce peor los datos experimentales es el menos interesante, porque es el que tiene asociados valores más bajos de la conductividad total.

\subsection{Probetas prensadas a partir de la composición $C$-II}

\subsubsection{Conductividades iónicas}

Partiendo de los datos experimentales que se detallan la Tabla 4.24, en la Figura 5.26 se ha representado, en coordenadas rectangulares, los valores de la conductividad total de las tres muestras sinterizadas a $1673 \mathrm{~K}$, durante 2,4 y $6 \mathrm{~h}$, frente a la temperatura de ensayo $\left(\boldsymbol{T}_{\boldsymbol{e}}\right)$. En la Figura 5.27 se han representado los datos experimentales en la forma $\operatorname{In}\left(\sigma_{T} \cdot T_{e}\right)$ versus $\left(\mathbf{1} / \boldsymbol{T}_{e}\right)$. 


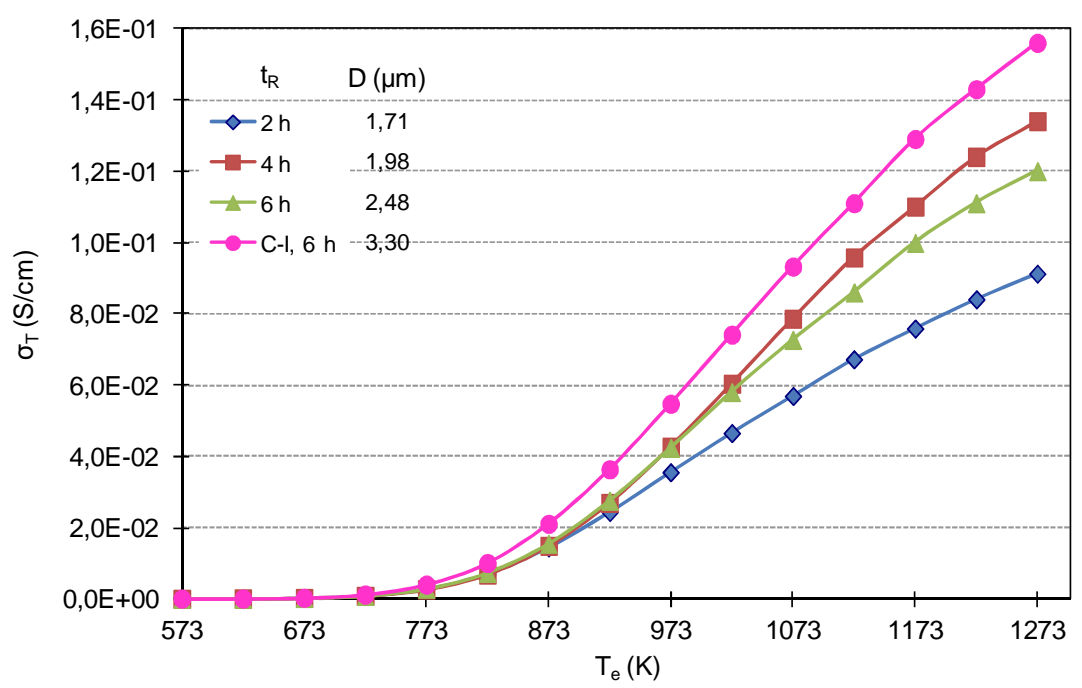

Figura 5.26. Probetas sinterizadas a $1673 \mathrm{~K}$ a diferentes tiempos de residencia. Variación de la conductividad total con la temperatura de ensayo ( $\left.T_{e .}\right)$.

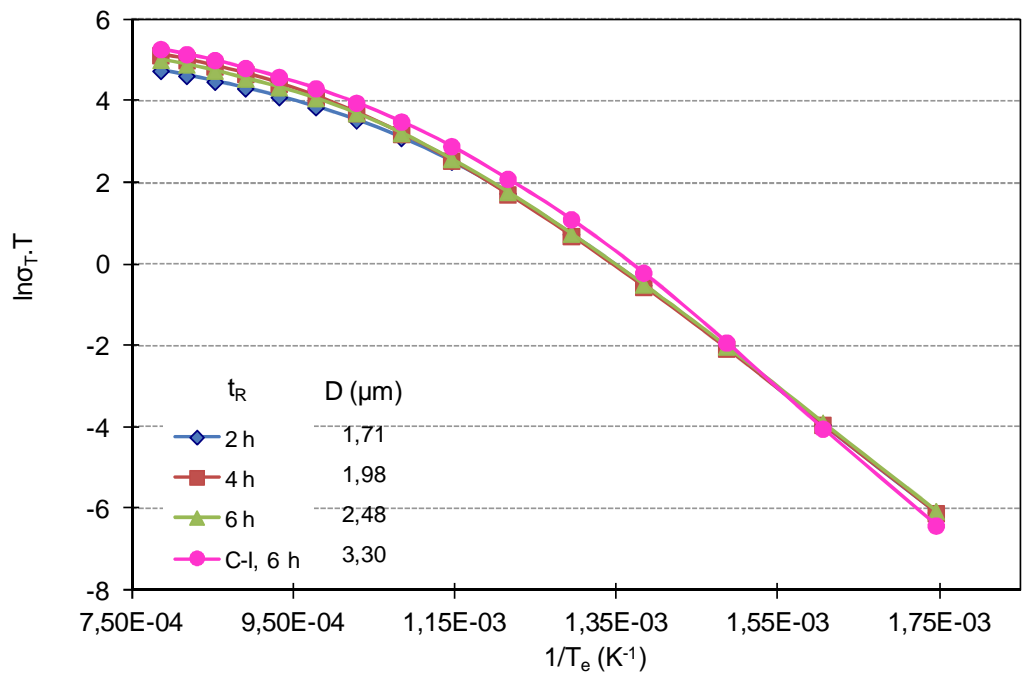

Figura 5.27. Probetas sinterizadas a $1673 \mathrm{~K}$ a diferentes tiempos de residencia. Comparación entre los resultados obtenidos con las muestras de las composiciones $C-I I$ y $C-I$ a $t_{R}=6 h$.

En estas dos representaciones se aprecia que la conductividad total de las muestras de la composición $\boldsymbol{C}$-II es algo menor que la de las muestras de la composición $\boldsymbol{C}$-I. Circunstancia que se manifiesta a partir de $\boldsymbol{T}_{\boldsymbol{e}}=723 \mathrm{~K}$, cumpliéndose en el tramo de mayor interés (873$973 \mathrm{~K})$.

Además, en el intervalo de valores de $T_{e} \geq 823 \mathrm{~K}$, se observa que la conductividad total de las probetas $\boldsymbol{C}$-II aumenta ligeramente con el diámetro medio de grano, de forma amortiguada, ya que la separación entre las curvas correspondientes a los tiempos de 
residencia estudiados se va reduciendo progresivamente al aumentar el tamaño de grano. Este comportamiento está de acuerdo con el observado en el caso de la composición $\boldsymbol{C}$-I.

En efecto, el diámetro medio de la muestra de la composición $\boldsymbol{C}$-II sinterizada con un tiempo de residencia de $6 \mathrm{~h}$ es de 2,48 $\mu \mathrm{m}$. Este tamaño de grano, en las representaciones de la Figura 5.15 correspondientes a la composición $\boldsymbol{C}$-I, todavía está situado en la zona en la que la conductividad total aumenta con dicha propiedad. Por tanto, en el supuesto de que el comportamiento de la composición $\boldsymbol{C}$-II fuera análogo al de la composición $\boldsymbol{C}$-I, en lo que a la variación de la conductividad total con el tamaño de grano y a la variación de éste con la temperatura de sinterización y el tiempo de residencia se refiere, esta circunstancia podría explicar que en el tramo de valores del diámetro medio de grano que se está considerando aumentara la conductividad total con el valor del tamaño de grano.

Por otra parte, en la Figura 5.27, se observa que, en el intervalo de temperaturas de ensayo comprendido entre 573 y $773 \mathrm{~K}$, coinciden prácticamente las representaciones obtenidas para las tres muestras de la composición $\boldsymbol{C}$-II estudiadas. Estos resultados indican que, en dicho tramo de temperaturas de ensayo, el diámetro medio de grano, no influye prácticamente sobre los valores de la conductividad iónica total de las muestras estudiadas. Para este intervalo de temperaturas de ensayo de la Figura 5.27, ajustando los resultados de las tres muestras estudiadas a una línea recta única, resulta la ecuación:

$$
\sigma_{T} \cdot T_{e}=7,888 \cdot 10^{8} \cdot \exp \left(-15198 / T_{e}\right)
$$

Teniendo en cuenta la ecuación (1.17), el valor del exponente de la ecuación anterior y el valor de la constante de Boltzmann, resulta un valor para la energía aparente de activación de $E_{i}=1,31 \mathrm{eV}$. Este valor es ligeramente más pequeño que el obtenido para el mismo tramo de valores de $\boldsymbol{T}_{\boldsymbol{e}}$ para las muestras de la composición $\boldsymbol{C}-\boldsymbol{I}$, (ver Apartado 5.4.1, comentario a la ecuación (5.12)). Esta circunstancia se aprecia visualmente en la mencionada Figura 5.27.

En la Tabla 5.23 se muestran los valores de $\sigma_{g}$ y $\sigma^{T}{ }_{l g}$ de las muestras estudiadas, junto con los de los diámetros medios de grano correspondientes. Como puede apreciarse, al igual que ocurría con las muestras de la composición $\boldsymbol{C}$ - $\boldsymbol{I}$, los valores de $\boldsymbol{\sigma}_{g}$ tampoco varían prácticamente al aumentar el tamaño de grano, a cada temperatura de ensayo estudiada (las pequeñas variaciones se deben al error experimental).

Los valores de $\sigma_{g}$ y $\sigma^{T}$, correspondientes a la muestra sinterizada con un tiempo de residencia de $6 \mathrm{~h}$, se han representado, junto con los de la conductividad total $\left(\boldsymbol{\sigma}_{T}\right)$ en la Figura 5.28, a efectos comparativos. 
Tabla 5.23. Probetas prensadas de la composición C-ll. Valores de $\sigma_{\mathrm{g}}$ y $\boldsymbol{\sigma}^{\top}{ }_{\mathrm{Ig}}$ $(\mathrm{S} / \mathrm{cm})$ de muestras sinterizadas a $1673 \mathrm{~K}$, con tiempos de residencia de 2,4 y 6 $h$, para valores de $T_{e}$ entre 573 y $723 \mathrm{~K}$

\begin{tabular}{|c|c|c|c|c|c|c|}
\hline$t_{R}(h)$ & $2 \mathrm{~h}$ & $2 \mathrm{~h}$ & $4 \mathrm{~h}$ & $4 h$ & $6 \mathrm{~h}$ & $6 \mathrm{~h}$ \\
\hline$T_{e}(K)$ & $\sigma_{g}$ & $\sigma_{l g}^{T}$ & $\sigma_{g}$ & $\sigma_{l g}^{T}$ & $\sigma_{g}$ & $\sigma_{l g}^{T}$ \\
\hline 573 & 4,67E-06 & 2,92E-05 & $4,80 \mathrm{E}-06$ & 2,22E-05 & $4,79 E-06$ & $3,08 \mathrm{E}-05$ \\
\hline 623 & 3,76E-05 & $2,15 \mathrm{E}-04$ & 3,87E-05 & 1,74E-04 & 3,89E-05 & $2,43 \mathrm{E}-04$ \\
\hline 673 & 2,34E-04 & $1,21 \mathrm{E}-03$ & $2,38 \mathrm{E}-04$ & $9,46 \mathrm{E}-04$ & 2,38E-04 & $1,28 \mathrm{E}-03$ \\
\hline 723 & 1,07E-03 & $4,03 E-03$ & 1,07E-03 & $3,21 E-03$ & 1,07E-03 & $4,18 \mathrm{E}-03$ \\
\hline$D(\mu \mathrm{m})$ & 1,71 & 1,71 & 1,98 & 1,98 & 2,48 & 2,48 \\
\hline
\end{tabular}

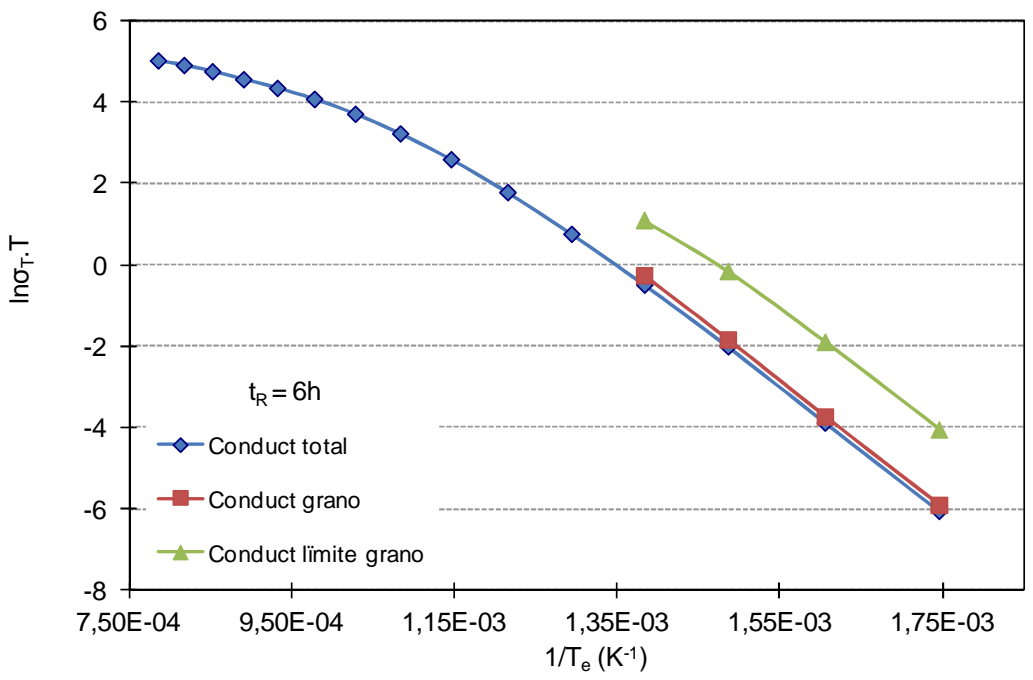

Figura 5.28. Probeta de la composición C-II sinterizada a $1673 \mathrm{~K}$, con $t_{R}=6 \mathrm{~h}$. Variación de $\sigma_{T,} \sigma_{g}$ y $\sigma^{T}$ lg con la temperatura de ensayo $\left(T_{e}\right)$.

Como puede apreciarse, los valores de $\boldsymbol{\sigma}^{T}{ }_{l g}$ son del orden de diez veces mayores que los de $\sigma_{T}$ y $\sigma_{g}$ en el intervalo de temperaturas de ensayo para el que se han podido medir. En consecuencia, en este tramo de valores de $\boldsymbol{T}_{e}$, el valor de $\boldsymbol{\sigma}_{T}$ debe estar condicionado, según la ecuación (1.22) o la (5.19), por el correspondiente valor de $\sigma_{g}$, con el que prácticamente coincide.

Este comportamiento es análogo al descrito anteriormente para las muestras sinterizadas de la composición $\boldsymbol{C}$-I, en el tramo de valores de $\boldsymbol{T}_{\boldsymbol{e}} \leq 723 \mathrm{~K}$ que se está considerando, en el que también los valores de $\sigma_{T}$ prácticamente coinciden con los de $\sigma_{g}$.

De acuerdo con esto, teniendo en cuenta la representación de la Figura 5.26 (b), al comparar los valores de la conductividad en el interior de grano de las probetas de las 
composiciones $\boldsymbol{C}$-I y $\boldsymbol{C}$-II, en dicho tramo de temperaturas de ensayo, mediante una representación de la forma In $\left(\boldsymbol{\sigma}_{g}{ }^{\star} \boldsymbol{T}_{e}\right)$ versus $\left(\mathbf{1} / \boldsymbol{T}_{e}\right)$, la pendiente de la recta correspondiente a la composición $\boldsymbol{C}$-I debería ser algo mayor que la de la recta correspondiente a la composición $\boldsymbol{C}$-II. Esta circunstancia se confirma en la representación que se muestra en la Figura 5.29.

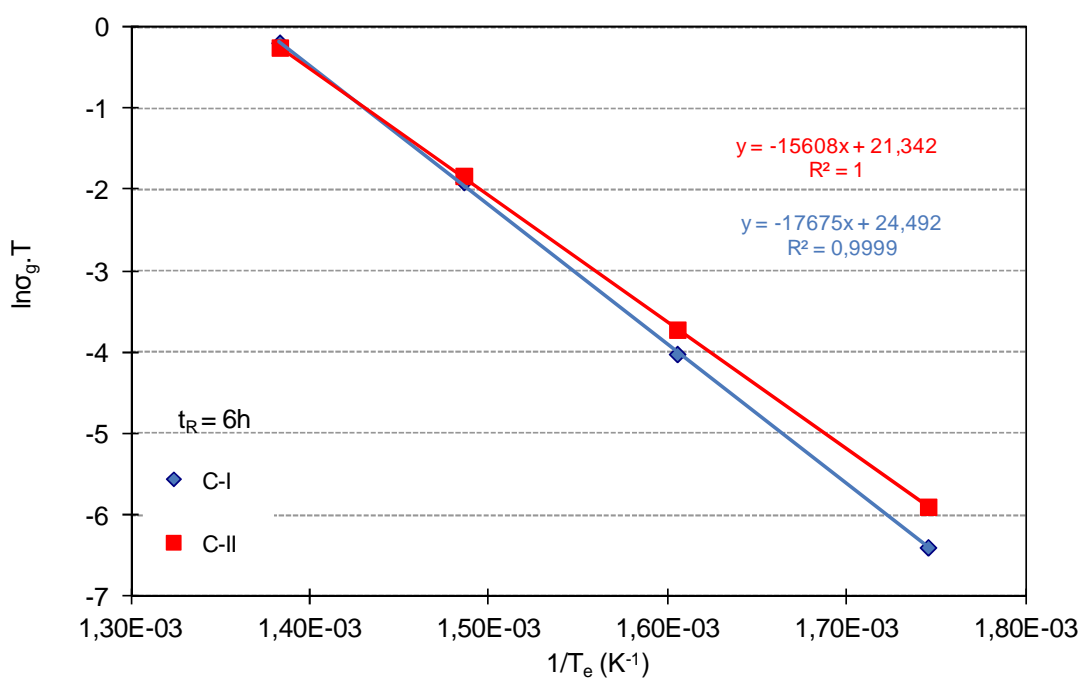

Figura 5.29. Variación, con $T_{e}$, de la conductividad en el interior de grano de las muestras de las composiciones $C$-I y C-II, sinterizadas a $1673 \mathrm{~K}$, en el tramo de valores de $T_{e} \leq 723 \mathrm{~K}$.

\subsubsection{Consideraciones sobre la resistencia mecánica}

El valor de la resistencia mecánica de las láminas sinterizadas a partir de suspensiones de esta composición (145 MPa) es bastante mayor que la de las láminas del mismo espesor obtenidas a partir de la composición $\boldsymbol{C}$-I (121 MPa), circunstancia que se aprecia cualitativamente al manejar las respectivas láminas.

Ahora bien, con la limitada información de que se dispone hasta el momento, se considera que el aumento observado de la resistencia mecánica de las muestras sinterizadas de la composición $\boldsymbol{C}$-II, no compensa la reducción que experimenta la conductividad iónica total a las condiciones de temperatura de ensayo de 873 a $973 \mathrm{~K}$.

En base a la escasa información experimental obtenida en esta investigación sobre las posibilidades de esta composición, se considera que el aumento observado de la resistencia mecánica de las muestras sinterizadas sobre el de las otras dos composiciones estudiadas, podría compensar la reducción que experimenta la conductividad iónica total a las condiciones de temperatura de ensayo de 873 a $973 \mathrm{~K}$, caso de que el electrolito tuviera que operar como soporte del cátodo y el ánodo de una célula de combustible. 


\subsection{Probetas prensadas a partir de la composición C-III}

\subsubsection{Conductividades iónicas}

Partiendo de los datos experimentales que se detallan la Tabla 4.25, en la Figura 5.30 se ha representado, en coordenadas rectangulares, la conductividad total de las dos muestras sinterizadas a $1673 \mathrm{~K}$, durante 4 y $6 \mathrm{~h}$, frente a la temperatura de ensayo $\left(\boldsymbol{T}_{\mathrm{e}}\right)$. En la Figura 5.31 se han representado los datos experimentales en la forma $\operatorname{In}\left(\sigma_{T^{*}} \boldsymbol{T}_{e}\right)$ versus $\left(\mathbf{1} / \boldsymbol{T}_{e}\right)$.

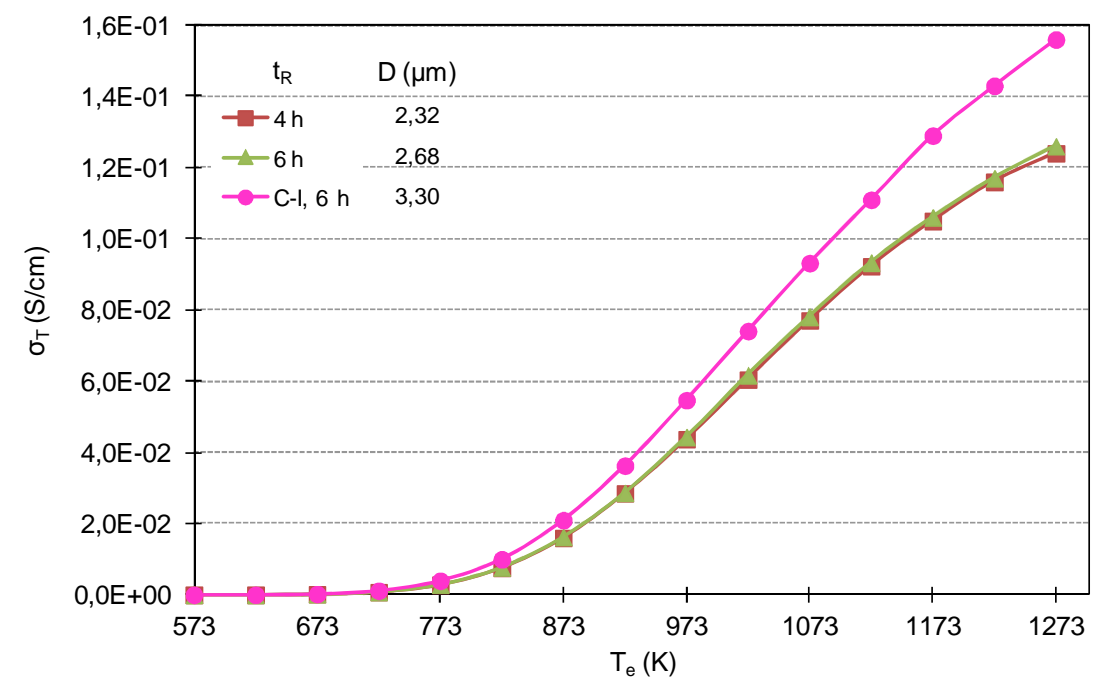

Figura 5.30. Probetas de la composición C-III sinterizadas a 1673 K durante 4 y 6 h. Variación de la conductividad total con la temperatura de ensayo ( $\left.T_{e}.\right)$.

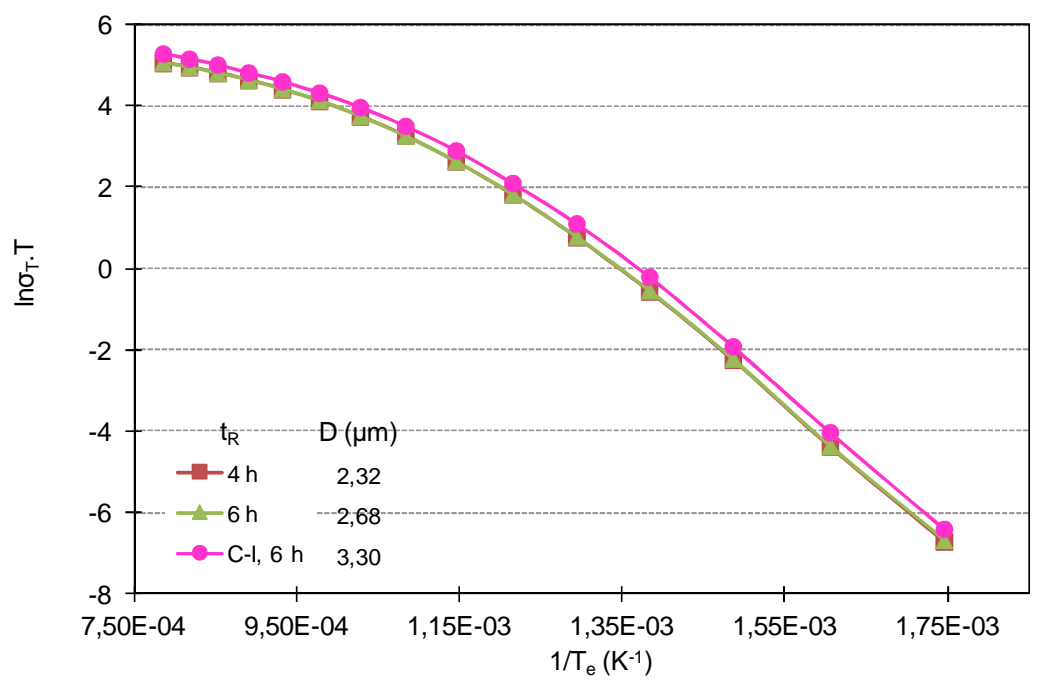

(b)

Figura 5.31. Probetas sinterizadas a 1673 K. Comparación entre los resultados obtenidos con las muestras de las composiciones $C$ - III y $C-I$ a $t_{R}=6 h$. 
Para valores de la temperatura de ensayo mayores que $773 \mathrm{~K}$, el valor de la conductividad iónica total apenas aumenta al aumentar el tiempo de residencia de 4 a 6 horas (Figura 5.30). Este resultado no es de extrañar, si se tiene en cuenta que el valor del diámetro medio de grano de las correspondientes muestras sinterizadas es 2,32 y 2,68 $\mu \mathrm{m}$ respectivamente. En efecto, si se admite que la presencia de la pequeña cantidad de $\alpha$ alúmina añadida, no modifica sensiblemente la relación entre la conductividad total y el tamaño de grano puesta de manifiesto en el caso de la composición $\boldsymbol{C}$-I, es de esperar que la conductividad total apenas varíe con el diámetro medio de grano, cuando el valor de éste se aproxima a los $2,7 \mu \mathrm{m}$.

En el intervalo de valores de $\boldsymbol{T}_{\boldsymbol{e}} \leq 823 \mathrm{~K}$, las representaciones de la variación de la conductividad total de las probetas $\boldsymbol{C}$-III, correspondientes a los dos valores de $\boldsymbol{t}_{\boldsymbol{R}}$ estudiados, prácticamente coinciden, tal como sucedía en el caso de las probetas de la composición $\boldsymbol{C}$-I, para el mismo tramo de valores de $\boldsymbol{t}_{\boldsymbol{R}}$ en los experimentos realizados a la misma temperatura de sinterización. Para este intervalo de temperaturas de ensayo (573 $773 \mathrm{~K}$ ), ajustando los resultados representados en la Figura 5.31, correspondientes a las dos muestras estudiadas, a una línea recta única, resulta la ecuación:

$$
\sigma_{T} \cdot T_{e}=5,952 \cdot 10^{9} \cdot \exp \left(-16720 / T_{e}\right)
$$

Teniendo en cuenta la ecuación (1.17) y el valor de la constante de Boltzmann, expresada en eV, resulta un valor para la energía aparente de activación de $\boldsymbol{E}_{\boldsymbol{i}}=\mathbf{1 , 4 4} \mathrm{eV}$. Este valor es del mismo orden que el obtenido para el mismo tramo de valores de $\boldsymbol{T}_{\boldsymbol{e}}$ para las muestras de la composición $\boldsymbol{C}-\mathbf{I}$, (ver Apartado 5.4.1).

Por ello, al comparar las representaciones de la conductividad total de las muestras de las composiciones $\boldsymbol{C}$-I y $\boldsymbol{C}$-III, sinterizadas a $\boldsymbol{t}_{\boldsymbol{R}}=\mathbf{6} \boldsymbol{h}$, en la Figura 5.31), se observa que las representaciones son prácticamente paralelas, siendo la conductividad total de las muestras de la composición $\boldsymbol{C}$-III ligeramente más baja que la de las correspondientes de la $\boldsymbol{C}$-I.

Estos resultados indican que la adición de a-alúmina a la composición con la que se han confeccionado las probetas $\boldsymbol{C}-\boldsymbol{I}$, reduce ligeramente la conductividad total del material resultante, en todo el intervalo de valores de $T_{e}$ estudiado.

En la Tabla 5.24 se muestran los valores de $\sigma_{g}$ y $\boldsymbol{\sigma}^{T}{ }_{I g}$ de las muestras estudiadas (ver tablas 8.14 y 8.15 del Apendice), junto con los correspondientes valores del diámetro medio de grano. Como puede apreciarse, al igual que ocurría con las muestras de las otras dos composiciones estudiadas, los valores de $\boldsymbol{\sigma}_{g}$ tampoco varían prácticamente, al aumentar el tamaño de grano, a cada temperatura de ensayo estudiada. 


\begin{tabular}{|c|c|c|c|c|}
\hline$t_{R}(h)$ & $4 h$ & $4 h$ & $6 \mathrm{~h}$ & $6 \mathrm{~h}$ \\
\hline $\mathrm{T}_{\mathrm{e}}(\mathrm{K})$ & $\sigma_{g}$ & $\sigma_{l g}^{T}$ & $\sigma_{g}$ & $\sigma_{l g}^{T}$ \\
\hline 573 & $2,40 \mathrm{E}-06$ & 2,03E-05 & 2,44E-06 & $2,75 \mathrm{E}-05$ \\
\hline 623 & 2,31E-05 & 1,71E-04 & 2,31E-05 & 2,15E-04 \\
\hline 673 & 1,87E-04 & 1,06E-03 & 1,86E-04 & 1,30E-03 \\
\hline 723 & 1,02E-03 & 3,63E-03 & 1,01E-03 & $4,20 \mathrm{E}-03$ \\
\hline$D(\mu \mathrm{m})$ & 2,32 & 2,32 & 2,68 & 2,68 \\
\hline
\end{tabular}

Los valores de $\sigma_{g}$ y $\boldsymbol{\sigma}_{\text {Ig }}^{T}$, correspondientes a la muestra sinterizada con un tiempo de residencia de $6 \mathrm{~h}$, se han representado, junto con los de la conductividad total $\left(\boldsymbol{\sigma}_{T}\right)$ en la Figura 5.32, a efectos comparativos.

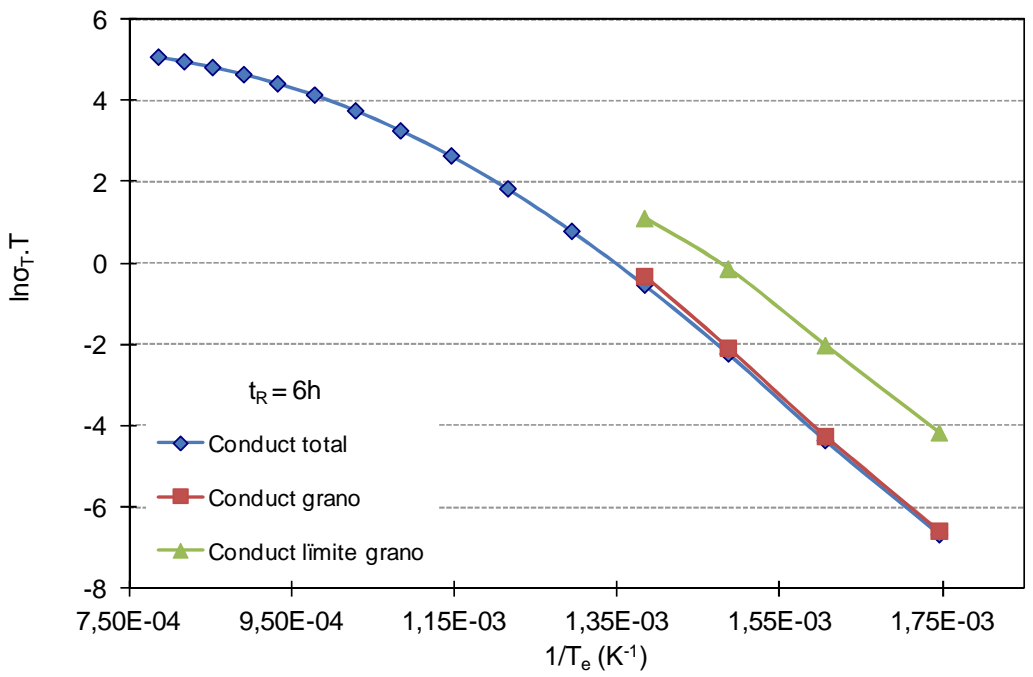

Figura 5.32. Probeta de la composición C-III sinterizada a $1673 \mathrm{~K}$, con $t_{R}=6 \mathrm{~h}$. Variación de $\sigma_{T}, \sigma_{g}$ y $\sigma^{T_{l g}}$ con la temperatura de ensayo $\left(T_{e}\right)$

El hecho de que la conductividad total y la del interior de grano prácticamente coincidan en el tramo de temperaturas de ensayo $573 \leq \mathrm{Te} \leq 773 \mathrm{~K}$, parece indicar que la disminución de la conductividad total observada al añadir un $2 \%$ de a-alúmina a la composición de las probetas $\boldsymbol{C}-\boldsymbol{I}$, se debe a que dicha adición, en realidad, afecta a la conductividad en el 
interior de grano, más que a la presencia de a-alúmina que se ha detectado en los límites de grano (ver Figura 4.57).

La representación de la Figura 5.33, en la que se comparan los valores de la conductividad en el interior de grano de las muestras sinterizadas de composiciones $\boldsymbol{C}$-I y $\boldsymbol{C}$-III, parece confirmar dicha hipótesis.

Este resultado está de acuerdo con el obtenido por otros autores que han investigado la influencia de la adición de alúmina sobre las propiedades de la circona co-dopada con itria ${ }^{116}$ y con escandia y ceria ${ }^{103,103}$ y podría deberse a que una pequeña parte de la alúmina que forma parte de la composición de partida se incorpora a la estructura de los granos (microcristales) de circona, durante el proceso de sinterización y el resto se sitúa en los límites de grano. Aún cuando los radios iónicos del $\mathrm{Al}^{+3}$ y del $\mathrm{Zr}^{+4}$ difieren considerablemente, lo que dificulta la solubilidad de la alúmina en la circona, algo de $\mathrm{Al}^{+3}$ puede incorporarse a la red de los monocristales de circona en muy pequeña proporción ${ }^{117}$

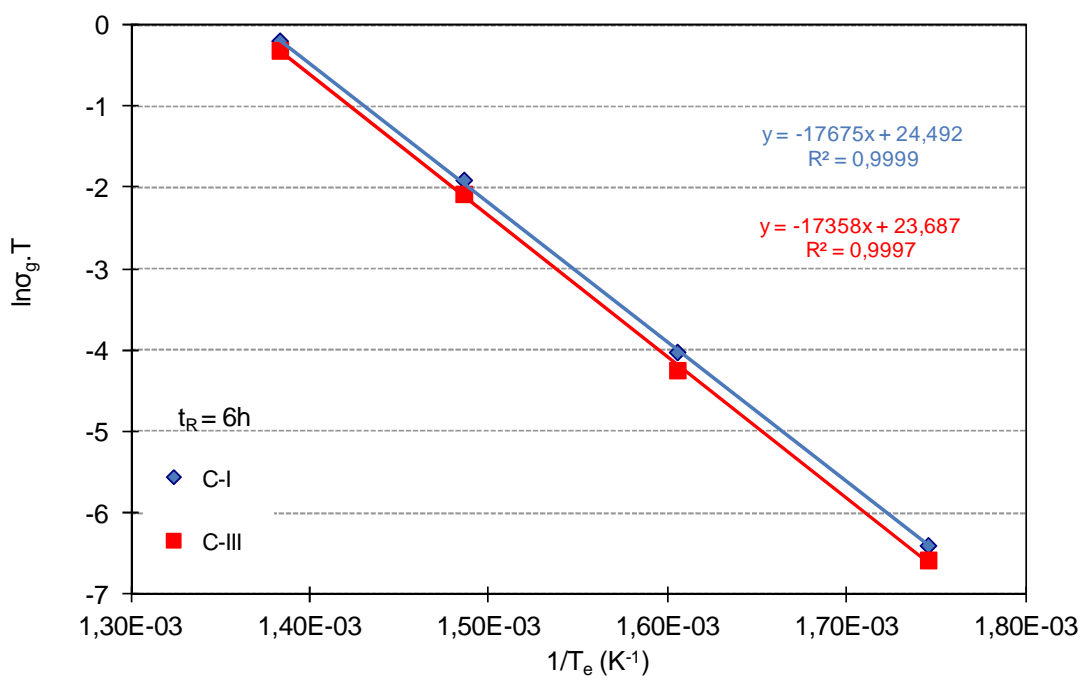

Figura 5.33. Variación, con $T_{e}$, de la conductividad en el interior de grano de las muestras de las composiciones C-I y C-III, sinterizadas a $1673 \mathrm{~K}$, en el tramo de valores de $T_{e} \leq 723 \mathrm{~K}$.

\subsubsection{Consideraciones sobre la resistencia mecánica}

La resistencia mecánica de las láminas sinterizadas a partir de suspensiones de esta composición (139 MPa) es algo mayor que la de las láminas del mismo espesor obtenidas a partir de la composición $\boldsymbol{C}$-I (121 MPa) y menor que la correspondiente a las láminas obtenidas a partir de $\boldsymbol{C}$-II (145 MPa), mientras que la conductividad total es algo más baja que la de las probetas elaboradas con la composición $\boldsymbol{C}$-I, aunque mayor que la resultante para las probetas obtenidas a partir de la composición $\boldsymbol{C}$-II.

Al igual que en el caso de las láminas preparadas a partir de la composición $\boldsymbol{C}$-II se considera que el aumento observado de la resistencia mecánica de las muestras, podría compensar la reducción que experimenta la conductividad iónica total a las condiciones de temperatura de ensayo de 873 a $973 \mathrm{~K}$, caso de que el electrolito tuviera que operar como soporte del cátodo y el ánodo de una célula de combustible. 


\section{Conclusiones}


De los resultados obtenidos durante el desarrollo de los trabajos que se reseñan en esta Memoria, encaminados a tratar de obtener un material para ser utilizado como electrolito en SOFCs, partiendo de circona dopada con escandia y ceria, se han obtenido las siguientes conclusiones:

1. Ensayos realizados con la composición C-I (polvo de circona dopada con escandia y ceria, de composición molar $\left.10 \mathrm{Sc}_{2} \mathrm{O}_{3} .1 \mathrm{CeO}_{2} .89 \mathrm{ZrO}_{2}\right)$.

1.1. De los dos sistemas de líquidos orgánicos ensayados para preparar suspensiones de la composición C-I, susceptibles de ser utilizadas para conformar láminas de espesor reducido (alrededor de $100 \mu \mathrm{m}$ ) por colado en banda, el constituido por la mezcla xileno-etanol, con los aditivos orgánicos (ligantes, plastificantes y dispersantes) descritos para la suspensión $\boldsymbol{C}$-I-35, es el que ha conducido a láminas planas crudas de mayor calidad.

1.2. El ciclo térmico seleccionado para eliminar los aditivos orgánicos contenidos en las láminas crudas obtenidas a partir de la suspensión $C-I-35$, por no afectar a la planaridad de las mismas y conducir a la porosidad más baja en las láminas resultantes $(2,4 \%)$ y un diámetro medio de poro suficientemente pequeño $((0,75$ $\mu \mathrm{m})$, ha consistido en someterlas a una velocidad de calentamiento de $30 \mathrm{~K} / \mathrm{h}$ desde la temperatura ambiente hasta $773 \mathrm{~K}$.

1.3. El tratamiento térmico que se ha considerado más adecuado para desarrollar la etapa de sinterización, ha consistido en someter las láminas, exentas de materia orgánica, a una velocidad de calentamiento de $120 \mathrm{~K} / \mathrm{h}$, hasta alcanzar la temperatura de sinterización deseada, manteniendo luego constante dicha temperatura durante un cierto tiempo $(1,2,4$ o 6 horas) que se ha denominado tiempo de residencia.

1.4. Para evitar que las láminas perdieran planaridad, tanto a lo largo de la etapa de eliminación de materia orgánica, como durante la etapa de sinterización, se decidió colocarlas, entre dos piezas planas de material refractario, de densidad elevada, muy poroso (para facilitar la evacuación de los gases resultantes de la descomposición de la materia orgánica), en configuración tipo sándwich.

1.5. Al determinar la porosidad y el diámetro medio de poro de las láminas obtenidas a partir de la suspensión $\boldsymbol{C}$-I-35, sinterizadas a diferentes condiciones de operación, los valores más bajos de dichas propiedades $\left(\boldsymbol{\varepsilon}=0,10 \%\right.$ y $\boldsymbol{d}_{50}=0,18$ $\mu \mathrm{m})$ se han obtenido para la temperatura de sinterización de $1673 \mathrm{~K}$ y tiempo de residencia de 6 horas. A la vista de estos valores, puede admitirse que las láminas resultantes, en este caso, estaban prácticamente exentas de porosidad.

1.6. Al comparar los valores del tamaño de grano obtenidos para las muestras sinterizadas, a las que se refiere el apartado anterior, se concluye que el diámetro medio de grano aumenta con la temperatura de sinterización y el tiempo de residencia.

1.7. Dado que la etapa de sinterización se inicia con una fase a velocidad de calentamiento de $120 \mathrm{~K} / \mathrm{h}$, hasta alcanzar la temperatura de sinterización preestablecida, que luego se mantiene constante durante diferentes tiempos de residencia, la ecuación integrada que habitualmente se emplea para ajustar los resultados experimentales sólo se puede aplicar al periodo de temperatura constante de cada ciclo. 
Con vistas a determinar la variación del diámetro medio de grano de las muestras, desde su valor inicial $(0,097 \mu \mathrm{m})$ hasta el que adquiere al final de cualquier ciclo térmico desarrollado a una de las temperaturas de sinterización ensayadas, se ha utilizado una ecuación de la forma:

$$
d D / d t=k_{D} / D^{n}
$$

en la que $\boldsymbol{D}$ representa el diámetro medio de grano, $\boldsymbol{t}$ el tiempo transcurrido desde que se inicia el tratamiento térmico de la muestra exenta de materia orgánica (a la temperatura ambiente) y $\boldsymbol{k}_{\boldsymbol{D}}$ es una constante cinética que depende de la temperatura y de la naturaleza del material. Esta ecuación, con un valor de $\boldsymbol{n}=3,5$ y el valor de $\boldsymbol{k}_{\boldsymbol{D}}$ determinado, en cada caso, a partir de los datos experimentales, ha permitido correlacionar con bastante fidelidad dicho resultados.

1.8. Al determinar la porosidad y el diámetro medio de poro de las probetas cilíndricas prensadas, sinterizadas a diferentes condiciones de operación, los valores más bajos de dichas propiedades $\left(\boldsymbol{\varepsilon}=0,48 \%\right.$ y $\left.\boldsymbol{d}_{50}=0,29-0,3 \mu \mathrm{m}\right)$ se han obtenido para las temperaturas de sinterización de $1773 \mathrm{~K}$ (tiempo de residencia de 6 horas) y $1573 \mathrm{~K}$ (tiempo de residencia de 4 y 6 horas).

1.9. En el caso de las probetas cilíndricas sinterizadas, el tamaño medio de grano también aumenta con la temperatura de sinterización y el tiempo de residencia.

1.10. En el caso de las probetas cilíndricas, la ecuación propuesta en el Apartado 1.7, con los valores de la constante cinética $\boldsymbol{k}_{\boldsymbol{D}}$ obtenidos a partir de los datos experimentales correspondientes, ha permitido correlacionar muy bien dichos resultados, utilizando asimismo el exponente $\boldsymbol{n}=\mathbf{3 , 5}$.

1.11. Al comparar los valores de la porosidad, diámetro medio de poro y diámetro medio de grano de las láminas sinterizadas a las que se refieren los Apartados 1.5 a 1.7, de estas Conclusiones, y de las probetas cilíndricas sinterizadas, se ha observado que prácticamente son del mismo orden. Ya que las láminas y las probetas cilíndricas se han conformado a partir de la misma materia prima inorgánica, tanto en lo referente a composición, como a la granulometría. Este resultado permite suponer que los valores de sus respectivas conductividades iónicas deben ser similares.

1.12. En el intervalo de temperaturas de ensayo comprendido entre 573 y $1273 \mathrm{~K}$ se ha medido experimentalmente la conductividad iónica total de las probetas cilíndricas, procesadas a diferentes condiciones de temperatura de sinterización y tiempo de residencia. Dadas las limitaciones inherentes al procedimiento utilizado para la medida de la conductividad, los valores de esta propiedad en los límites de grano y en el interior de grano sólo ha sido posible determinarlos, con cierta garantía, en el intervalo de temperaturas de ensayo comprendido entre 573 y 723 $\mathrm{K}$.

1.13. A las temperaturas de ensayo de 873 y $973 \mathrm{~K}$, se han obtenido unos valores de la conductividad iónica total de 0,0215 y $0,055 \mathrm{~S} / \mathrm{cm}$ respectivamente, con muestras sinterizadas a $1673 \mathrm{~K}$ y un tiempo de residencia de tan sólo 2 horas. Este resultado es muy interesante de cara a optimizar el ciclo térmico a utilizar industrialmente para obtener un electrolito de esta naturaleza, con el mínimo consumo de energía. 
1.14. Los valores máximos de la conductividad total, alcanzados a dichas temperaturas de ensayo $(0,022$ y $0,0574 \mathrm{~S} / \mathrm{cm}$ respectivamente), se han obtenido con las muestras sinterizadas a $1773 \mathrm{~K}$, para un tiempo de residencia de 6 horas. Estos valores son del mismo orden o superiores a los propuestos, hasta ahora, por otros investigadores a las temperaturas de ensayo indicadas, para electrolitos basados en óxido de circonio dopado con óxidos de escandio, cerio o itrio.

1.15. En el intervalo de temperaturas comprendido entre 823 a $1273 \mathrm{~K}$, a cada temperatura de ensayo estudiada, el valor de la conductividad iónica total se reduce sensiblemente al disminuir el diámetro medio de grano, para valores de este último inferiores a 2,7 $\mu \mathrm{m}$, Dicha reducción se acentúa al aumentar la temperatura de ensayo. Para valores del diámetro medio de grano iguales o mayores que 2,7 $\mu \mathrm{m}$, dicha propiedad apenas varía con el tamaño de grano, tendiendo a un valor prácticamente constante, circunstancia que se aprecia sobre todo a las temperaturas de ensayo más altas.

1.16. En el intervalo de temperaturas de ensayo comprendidas entre 573 y $773 \mathrm{~K}$, el tamaño medio de grano apenas influye sobre los valores de la conductividad iónica total.

1.17. Los datos experimentales disponibles de la conductividad en el interior de grano, medidos a las temperaturas de ensayo de $573,623,673$ y $723 \mathrm{~K}$, parecen indicar que dicha propiedad no depende del tamaño de grano.

1.18. A cada temperatura de ensayo, al comparar los valores de la conductividad iónica total con los correspondientes de la conductividad iónica en el interior de grano (determinados experimentalmente), se observa que los primeros son ligeramente más bajos que los segundos, tendiendo progresivamente a alcanzarlos, a medida que aumenta el tamaño de grano.

1.19. Los datos experimentales disponibles de la conductividad en los límites de grano muestran que, aumenta ligeramente con el diámetro medio de grano, siendo sus valores, a cada temperatura de ensayo, bastante mayores que los correspondientes de la conductividad en el interior de grano.

1.20. Al representar gráficamente los datos experimentales de la conductividad total en los límites de grano frente al diámetro de grano, se han ajustado bastante bien a líneas rectas, de acuerdo con lo previsto en el modelo de Brick-Layer. A partir de estas representaciones, ha sido posible calcular los valores de la razón entre la conductividad específica en los límites de grano y el espesor del espacio de separación entre granos, a las temperaturas de ensayo de 573, 623, 673 y $723 \mathrm{~K}$.

1.21. El comportamiento descrito en los Apartados 1.15 a 1.19, de estas Conclusiones, puede explicarse si para valores del diámetro medio de grano mayores que 2,7 $\mu \mathrm{m}$ la conductividad iónica total coincide prácticamente con la conductividad en el interior del grano y si en el intervalo de valores del diámetro medio de grano entre 1,52 y 2,7 $\mu \mathrm{m}$ el valor de la conductividad total está fuertemente influenciado por el de la conductividad en los límites de grano. Para confirmar esta hipótesis, partiendo de la información experimental obtenida y admitiendo que la cinética del proceso se puede explicar mediante el modelo de Brick-Layer, se ha calculado una serie de valores de la conductividad iónica en los límites de grano y en el interior de grano, a diferentes temperaturas de ensayo, en el intervalo comprendido entre 723 y $1273 \mathrm{~K}$, para el que no había sido posible determinar dichas propiedades experimentalmente. Los valores calculados han resultado ser coherentes con los determinados experimentalmente a las temperaturas de ensayo de 573 a $723 \mathrm{~K}$. 
1.22. A partir de los valores calculados y de los determinados experimentalmente de las conductividades iónicas total, en el interior de grano y en los límites de grano, se han calculado los correspondientes de la resistividad eléctrica (en adelante $\rho_{T}$, $\boldsymbol{\rho}_{g}$ y $\boldsymbol{\rho}^{\boldsymbol{T}}{ }_{l g}$ respectivamente). Al representar los valores de estas resistividades frente a los respectivos de la temperatura de ensayo, para cada valor del diámetro medio de grano, se ha observado que en el intervalo comprendido entre 1,52 y 2,7 $\mu \mathrm{m}$, al aumentar el diámetro medio de grano: a) La línea representativa de la variación $\boldsymbol{\rho}_{g}$ con $\boldsymbol{T}_{e}$ no cambia de posición; b) La línea representativa de la variación de $\rho^{T}{ }_{l g}$ con $\boldsymbol{T}_{e}$ se va desplazando hacia el eje de abscisas, debido a que se va reduciendo el valor de dicha resistividad; c) La línea representativa de la variación de la resistividad total se va desplazando asimismo hacia el eje de abscisas, ya que su valor es igual al de la suma de $\rho_{g}$ y $\boldsymbol{\rho}^{T}{ }_{l g}$, para cada $\boldsymbol{T}_{e}$ considerada.

Para el diámetro medio de grano de $2,7 \mu \mathrm{m}$ y mayores, las líneas representativas de $\boldsymbol{\rho}_{T}$ y $\boldsymbol{\rho}_{g}$ prácticamente coinciden, dado el bajo valor relativo de $\boldsymbol{\rho}^{\boldsymbol{T}}{ }_{l g}$ frente al de las otros dos. Por esa razón, para tamaños de grano mayores que 2,7 $\mu \mathrm{m}$, la conductividad iónica total (igual a la inversa de la resistividad eléctrica total) no resulta influenciada por las variaciones del diámetro de grano, coincidiendo prácticamente su valor con el de la conductividad en el interior de grano, confirmándose lo previsto en el Apartado 1.18 de estas Conclusiones.

1.23. La resistencia mecánica de láminas sinterizadas de alrededor de $100 \mu \mathrm{m}$ de espesor fue de $121 \mathrm{MPa}$.

2. Ensayos realizados con la composición $\mathrm{C}$-II $\left(80 \%\right.$ de $10 \mathrm{Sc}_{2} \mathrm{O}_{3} \cdot 1 \mathrm{CeO}_{2} \cdot 89 \mathrm{ZrO}_{2} ; 20 \%$ de $3 \mathrm{Y}_{2} \mathrm{O}_{3} .97 \mathrm{ZrO}_{2}$ ).

2.1. La resistencia mecánica de las láminas de alrededor de $100 \mu \mathrm{m}$ de espesor fue de $147 \mathrm{MPa}$, mayor que la obtenida para las láminas sinterizadas de la composición $\boldsymbol{C}$-I.

2.2. El comportamiento de las muestras de la composición $\boldsymbol{C}$-III, sinterizadas a $1673 \mathrm{~K}$ con tiempos de residencia de 2, 4 y 6 horas, es análogo al descrito anteriormente para las muestras sinterizadas de la composición $\boldsymbol{C}$-I, en lo que a la relación cualitativa entre la conductividad iónica total, en el interior de grano y en los límites de grano se refiere. En efecto, para valores de $\mathrm{Te} \leq 723 \mathrm{~K}$, la conductividad iónica total coincide prácticamente con la conductividad en el interior de grano que, para cada temperatura de ensayo estudiada, no varía prácticamente con el diámetro medio de grano.

2.3. En el intervalo de temperaturas comprendido entre 823 a $1273 \mathrm{~K}$, a cada temperatura de ensayo estudiada, el valor de la conductividad iónica total se reduce al disminuir el diámetro medio de grano, en el intervalo de valores de este último estudiado (entre 1,71 y 2,48 $\mu \mathrm{m}$ ). Este comportamiento es análogo al observado con las muestras sinterizadas de la composición $\boldsymbol{C}$-I.

2.4. A las temperaturas de ensayo de 873 y $973 \mathrm{~K}$, se han obtenido unos valores de la conductividad iónica total de 0,0154 y $0,0426 \mathrm{~S} / \mathrm{cm}$ respectivamente, con muestras sinterizadas a $1673 \mathrm{~K}$ y un tiempo de residencia de 6 horas (diámetro medio de grano de 2,48 $\mu \mathrm{m}$ ). Estos valores de la conductividad total son sensiblemente más bajos que los obtenidos, a las mismas temperaturas de ensayo, con las probetas prensadas de la composición $\boldsymbol{C}-\boldsymbol{I}$, sinterizadas en idénticas condiciones. 
2.5. Dado el pequeño aumento de la conductividad total experimentado por las muestras sinterizadas, al aumentar el tamaño medio de grano de 1,71 a 2,48 $\mu \mathrm{m}$ (de 0,0144 a $0,0154 \mathrm{~S} / \mathrm{cm}$ para la temperatura de ensayo de $873 \mathrm{~K}$ y de 0,0355 a $0,0426 \mathrm{~S} / \mathrm{cm}$ para la de $973 \mathrm{~K}$ ), por el paralelismo entre su comportamiento y el de las muestras sinterizadas a partir de la composición $\boldsymbol{C}$-I, es de esperar que utilizar condiciones de operación más drásticas para su sinterización conduzca a valores límite de la conductividad total algo inferiores a los alcanzados con ésta última, procesada a las mismas condiciones.

2.6. Con la información disponible, el ligero aumento observado de la resistencia mecánica de las muestras sinterizadas de la composición $\boldsymbol{C}$-II, no compensa la reducción que experimenta la conductividad iónica total.

3. Ensayos realizados con la composición C-III (98\% de $10 \mathrm{Sc}_{2} \mathrm{O}_{3} \cdot 1 \mathrm{CeO}_{2} \cdot 89 \mathrm{ZrO}_{2} ; 2 \%$ de $\left.\mathrm{Al}_{2} \mathrm{O}_{3}\right)$.

3.1. La resistencia mecánica de las láminas de alrededor de $100 \mu \mathrm{m}$ de espesor fue de $139 \mathrm{MPa}$, ligeramente mayor que la obtenida para las láminas sinterizadas de la composición $\boldsymbol{C}$-I y menor que las correspondientes a la composicicón $\boldsymbol{C}$-II.

3.2. El comportamiento de las muestras sinterizadas de la composición $\boldsymbol{C}$-III es análogo al descrito anteriormente para las muestras sinterizadas de la Composición $\boldsymbol{C}$-I, en lo que a la relación entre la conductividad iónica total, en el interior de grano y en los límites de grano se refiere. En efecto, en el tramo de valores de $\mathrm{Te} \leq 723 \mathrm{~K}$, la conductividad iónica total coincide también prácticamente con la conductividad en el interior de grano que, a cada temperatura de ensayo estudiada, tampoco varia con el diámetro medio de grano.

3.3. Al comparar la conductividad en el interior de grano de las muestras de las composiciones $\boldsymbol{C}$-I y $\boldsymbol{C}$-II, que corresponde a las temperaturas de ensayo estudiadas inferiores a $723 \mathrm{~K}$, se ha observado una ligera reducción del valor de dicha propiedad. Esta disminución podría deberse a que una pequeña parte del $\mathrm{Al}_{2} \mathrm{O}_{3}$ penetra en la estructura del $10 \mathrm{Sc}_{2} \mathrm{O}_{3} .1 \mathrm{CeO}_{2} \cdot 89 \mathrm{ZrO}$.

3.4. Las microfotografias obtenidas del producto final muestran que la mayor parte de la alúmina de esta composición parece distribuirse en los límites de grano.

3.5. En el intervalo de temperaturas comprendido entre 823 a $1273 \mathrm{~K}$, a cada temperatura de ensayo estudiada, el valor de la conductividad iónica total de las muestras se reduce un poco al disminuir el diámetro medio de grano, en el intervalo de valores de este último estudiado (entre 2,326 y 2,68 $\mu \mathrm{m}$ ). Este comportamiento es asimismo análogo al observado con las muestras sinterizadas de la composición $\boldsymbol{C}$-I en las proximidades de valores del diámetro medio de grano de 2,7 $\mu \mathrm{m}$.

3.6. A las temperaturas de ensayo de 873 y $973 \mathrm{~K}$, se han obtenido unos valores de la conductividad iónica total de 0,0163 y $0,0443 \mathrm{~S} / \mathrm{cm}$ respectivamente, con muestras sinterizadas a $1673 \mathrm{~K}$ y un tiempo de residencia de 6 horas (diámetro medio de grano de 2,68 $\mu \mathrm{m}$ ). Estos valores de la conductividad total son algo más bajos que los obtenidos, a las mismas temperaturas de ensayo, con las probetas prensadas de la composición $\boldsymbol{C}$-I, sinterizadas en idénticas condiciones, aunque un poco más altos que los obtenidos con las probetas de la composición C-II. 
3.7. La conductividad total de las dos muestras estudiadas apenas aumenta a dichas temperaturas de ensayo (de 0,0160 a $0,0162 \mathrm{~S} / \mathrm{cm}$ a $\mathrm{T}_{\mathrm{e}}=873 \mathrm{~K}$ y de $0,0437 \mathrm{a}$ 0,0443 a $T_{e}=973 \mathrm{~K}$ ) al aumentar el diámetro medio de grano de 2,32 a 2,68 $\mu \mathrm{m}$. El hecho de que los dos tamaños de grano estudiados se encuentren en la zona en la que la conductividad total casi no mejora al aumentar el diámetro medio de grano, en el caso de las muestras de la composición $\boldsymbol{C}$-I, hace pensar que no es probable que pueda mejorarse el valor de la conductividad total de las muestras sinterizadas obtenidas a partir de esta composición, a no ser que el mecanismo de conducción de los iones resulte influenciado por la presencia de la alúmina ubicada en los límites de grano. 


\section{Recomendaciones}


La utilización de una mezcla constituida por un $98 \%$ del material inorgánico de partida $\left(10 \mathrm{Sc}_{2} \mathrm{O}_{3} .1 \mathrm{CeO}_{2} .89 \mathrm{ZrO}_{2}\right)$ y un $2 \%$ de a-alúmina, en masa, como materia prima para obtener las láminas de electrolito, ha conducido a conferirles mayor resistencia mecánica que cuando se obtenían a partir de dicho material solamente, a costa de reducir ligeramente la conductividad iónica total, en el limitado intervalo de condiciones de operación estudiado.

Ampliar la información experimental sobre las posibilidades del uso de esta composición sobrepasaba los límites de la tarea que se consideraba objeto de esta Tesis Doctoral, por lo que las conclusiones relacionadas con ella adolecen del defecto de haberse elaborado en base a unos datos muy limitados.

Por esta razón se recomienda ampliar la experimentación realizada con la composición $\boldsymbol{C}$-III - con otra similar (modificando el porcentaje de a-alúmina), a fin disponer de una información experimental más amplia que permita confirmar o rectificar las conclusiones propuestas en relación con las ventajas o inconvenientes de utilizar alúmina como aditivo para elaborar un electrolito basado en el empleo de la circona co-dopada con escandia y ceria que se ha empleado en esta investigación. 


\section{Apéndice}


8.1 Resultados obtenidos al medir las conductividades de las probetas sinterizadas.

\subsubsection{Probetas conformadas a partir de la composición $C$-I}

Tabla 8.1. Valores de resistividades y de conductividades obtenidos, a las diferentes temperaturas de ensayo, para las probetas prensadas de la composición $C$-I sinterizadas a $1573 \mathrm{~K}$, durante 2 horas

\begin{tabular}{|c|c|c|c|c|c|c|}
\hline $\mathrm{Te}(\mathrm{K})$ & $\rho_{\mathrm{T}}(\Omega . \mathrm{cm})$ & $\rho_{\mathrm{g}}(\Omega . \mathrm{cm})$ & $\rho_{\mathrm{lg}}(\Omega . \mathrm{cm})$ & $\sigma_{\mathrm{T}}(\mathrm{S} / \mathrm{cm})$ & $\sigma_{g}\left(S / \mathrm{cm}^{-1}\right)$ & $\sigma_{\mathrm{Ig}}(\mathrm{S} / \mathrm{cm})$ \\
\hline 573 & $3,76 \mathrm{E}+05$ & $3,20 E+05$ & $5,61 E+04$ & 2,66E-06 & 3,13E-06 & 1,78E-05 \\
\hline 623 & $3,90 \mathrm{E}+04$ & $3,17 \mathrm{E}+04$ & $7,34 \mathrm{E}+03$ & 2,56E-05 & 3,16E-05 & 1,36E-04 \\
\hline 673 & $5,18 \mathrm{E}+03$ & $3,80 E+03$ & $1,38 \mathrm{E}+03$ & 1,93E-04 & 2,63E-04 & 7,24E-04 \\
\hline 723 & $9,91 \mathrm{E}+03$ & $6,75 E+02$ & $3,15 E+02$ & 1,01E-04 & 1,48E-03 & 3,17E-03 \\
\hline 773 & $3,03 E+02$ & & & $3,30 \mathrm{E}-03$ & & \\
\hline 823 & $1,39 \mathrm{E}+02$ & & & $7,20 \mathrm{E}-03$ & & \\
\hline 873 & $8,25 \mathrm{E}+01$ & & & 1,21E-02 & & \\
\hline 923 & $5,96 \mathrm{E}+01$ & & & 1,68E-02 & & \\
\hline 973 & $4,85 \mathrm{E}+01$ & & & 2,06E-02 & & \\
\hline 1023 & $4,22 \mathrm{E}+01$ & & & 2,37E-02 & & \\
\hline 1073 & $3,84 \mathrm{E}+01$ & & & 2,61E-02 & & \\
\hline 1123 & $3,57 \mathrm{E}+01$ & & & 2,81E-02 & & \\
\hline 1173 & $3,38 \mathrm{E}+01$ & & & 2,96E-02 & & \\
\hline 1223 & $3,24 \mathrm{E}+01$ & & & 3,09E-02 & & \\
\hline 1273 & $3,18 \mathrm{E}+01$ & & & $3,14 \mathrm{E}-02$ & & \\
\hline
\end{tabular}




\begin{tabular}{|c|c|c|c|c|c|c|}
\hline $\mathrm{Te}(\mathrm{K})$ & $\rho_{\mathrm{T}}(\Omega . \mathrm{cm})$ & $\rho_{\mathrm{g}}(\Omega . \mathrm{cm})$ & $\rho_{\mathrm{Ig}}(\Omega . \mathrm{cm})$ & $\sigma_{\mathrm{T}}(\mathrm{S} / \mathrm{cm})$ & $\sigma_{g}(\mathbf{S} / \mathrm{cm})$ & $\sigma_{\mathrm{Ig}}(\mathrm{S} / \mathrm{cm})$ \\
\hline 573 & $3,66 \mathrm{E}+05$ & $3,22 E+05$ & $4,44 \mathrm{E}+04$ & 2,73E-06 & $3,10 \mathrm{E}-06$ & $2,25 \mathrm{E}-05$ \\
\hline 623 & $3,70 \mathrm{E}+04$ & $3,18 \mathrm{E}+04$ & $5,18 \mathrm{E}+03$ & $2,70 \mathrm{E}-05$ & $3,14 \mathrm{E}-05$ & 1,93E-04 \\
\hline 673 & $4,88 \mathrm{E}+03$ & $3,75 E+03$ & $1,13 \mathrm{E}+03$ & $2,05 E-04$ & 2,67E-04 & 8,84E-04 \\
\hline 723 & $9,57 \mathrm{E}+02$ & $6,79 \mathrm{E}+02$ & $2,79 \mathrm{E}+02$ & $1,05 E-03$ & 1,47E-03 & 3,59E-03 \\
\hline 773 & $2,78 \mathrm{E}+02$ & & & $3,60 \mathrm{E}-03$ & & \\
\hline 823 & $1,18 \mathrm{E}+02$ & & & 8,49E-03 & & \\
\hline 873 & $6,43 E+01$ & & & 1,56E-02 & & \\
\hline 923 & $4,30 \mathrm{E}+01$ & & & 2,33E-02 & & \\
\hline 973 & $3,29 \mathrm{E}+01$ & & & $3,04 \mathrm{E}-02$ & & \\
\hline 1023 & $2,74 \mathrm{E}+01$ & & & 3,64E-02 & & \\
\hline 1073 & $2,41 \mathrm{E}+01$ & & & $4,15 E-02$ & & \\
\hline 1123 & $2,22 \mathrm{E}+01$ & & & 4,51E-02 & & \\
\hline 1173 & $2,10 \mathrm{E}+01$ & & & 4,76E-02 & & \\
\hline 1223 & $2,05 E+01$ & & & 4,88E-02 & & \\
\hline 1273 & $2,06 \mathrm{E}+01$ & & & 4,86E-02 & & \\
\hline
\end{tabular}




\begin{tabular}{|c|c|c|c|c|c|c|}
\hline $\mathrm{Te}(\mathrm{K})$ & $\rho_{\mathrm{T}}(\Omega . \mathrm{cm})$ & $\rho_{\mathrm{g}}(\Omega . \mathrm{cm})$ & $\rho_{\mathrm{Ig}}(\Omega . \mathrm{cm})$ & $\sigma_{\mathrm{T}}(\mathrm{S} / \mathrm{cm})$ & $\sigma_{g}(\mathbf{S} / \mathrm{cm})$ & $\sigma_{\mathrm{Ig}}(\mathrm{S} / \mathrm{cm})$ \\
\hline 573 & $3,65 \mathrm{E}+05$ & $3,29 E+05$ & $3,60 \mathrm{E}+04$ & 2,74E-06 & $3,04 \mathrm{E}-06$ & 2,78E-05 \\
\hline 623 & $3,58 \mathrm{E}+04$ & $3,11 \mathrm{E}+04$ & $4,64 \mathrm{E}+03$ & 2,80E-05 & 3,21E-05 & $2,16 \mathrm{E}-04$ \\
\hline 673 & 4,77E+03 & $3,66 \mathrm{E}+03$ & $1,11 \mathrm{E}+03$ & 2,09E-04 & 2,73E-04 & $9,01 \mathrm{E}-04$ \\
\hline 723 & $9,23 \mathrm{E}+02$ & $6,70 \mathrm{E}+02$ & $2,54 \mathrm{E}+02$ & 1,08E-03 & 1,49E-03 & 3,94E-03 \\
\hline 773 & $2,58 \mathrm{E}+02$ & & & $3,87 E-03$ & & \\
\hline 823 & $1,04 \mathrm{E}+02$ & & & $9,62 \mathrm{E}-03$ & & \\
\hline 873 & $5,26 \mathrm{E}+01$ & & & 1,90E-02 & & \\
\hline 923 & $3,19 \mathrm{E}+01$ & & & $3,13 \mathrm{E}-02$ & & \\
\hline 973 & $2,26 \mathrm{E}+01$ & & & 4,43E-02 & & \\
\hline 1023 & $1,78 \mathrm{E}+01$ & & & 5,63E-02 & & \\
\hline 1073 & $1,51 \mathrm{E}+01$ & & & 6,63E-02 & & \\
\hline 1123 & $1,33 E+01$ & & & 7,52E-02 & & \\
\hline 1173 & $1,22 \mathrm{E}+01$ & & & $8,20 \mathrm{E}-02$ & & \\
\hline 1223 & $1,14 \mathrm{E}+01$ & & & 8,74E-02 & & \\
\hline 1273 & $1,10 \mathrm{E}+01$ & & & 9,09E-02 & & \\
\hline
\end{tabular}




\begin{tabular}{|c|c|c|c|c|c|c|}
\hline $\mathrm{Te}(\mathrm{K})$ & $\rho_{\mathrm{T}}(\Omega . \mathrm{cm})$ & $\rho_{\mathrm{g}}(\Omega . \mathrm{cm})$ & $\rho_{\mathrm{lg}}(\Omega . \mathrm{cm})$ & $\sigma_{\mathrm{T}}(\mathrm{S} / \mathrm{cm})$ & $\sigma_{g}(\mathbf{S} / \mathbf{c m})$ & $\sigma_{\mathrm{lg}}(\mathrm{S} / \mathrm{cm})$ \\
\hline 573 & $3,55 \mathrm{E}+05$ & $3,24 \mathrm{E}+05$ & $3,04 \mathrm{E}+04$ & 2,82E-06 & 3,08E-06 & 3,29E-05 \\
\hline 623 & $3,55 \mathrm{E}+04$ & $3,17 E+04$ & $3,76 \mathrm{E}+03$ & 2,82E-05 & 3,15E-05 & 2,66E-04 \\
\hline 673 & $4,61 \mathrm{E}+03$ & $3,73 E+03$ & $8,87 \mathrm{E}+02$ & 2,17E-04 & 2,68E-04 & 1,13E-03 \\
\hline 723 & $9,03 E+02$ & $6,85 E+02$ & $2,17 \mathrm{E}+02$ & 1,11E-03 & 1,46E-03 & $4,60 \mathrm{E}-03$ \\
\hline 773 & $2,53 \mathrm{E}+02$ & & & 3,96E-03 & & \\
\hline 823 & $9,58 \mathrm{E}+01$ & & & 1,04E-02 & & \\
\hline 873 & $4,65 \mathrm{E}+01$ & & & 2,15E-02 & & \\
\hline 923 & $2,71 \mathrm{E}+01$ & & & 3,69E-02 & & \\
\hline 973 & $1,80 \mathrm{E}+01$ & & & 5,55E-02 & & \\
\hline 1023 & $1,32 \mathrm{E}+01$ & & & 7,59E-02 & & \\
\hline 1073 & $1,06 \mathrm{E}+01$ & & & $9,45 \mathrm{E}-02$ & & \\
\hline 1123 & $8,98 \mathrm{E}+00$ & & & 1,11E-01 & & \\
\hline 1173 & $7,80 \mathrm{E}+00$ & & & 1,28E-01 & & \\
\hline 1223 & $7,10 \mathrm{E}+00$ & & & 1,41E-01 & & \\
\hline 1273 & $6,60 \mathrm{E}+00$ & & & 1,52E-01 & & \\
\hline
\end{tabular}




\begin{tabular}{|c|c|c|c|c|c|c|}
\hline $\mathrm{Te}(\mathrm{K})$ & $\rho_{\mathrm{T}}(\Omega . \mathrm{cm})$ & $\rho_{\mathrm{g}}(\Omega . \mathrm{cm})$ & $\rho_{\mathrm{lg}}(\Omega . \mathrm{cm})$ & $\sigma_{\mathrm{T}}(\mathrm{S} / \mathrm{cm})$ & $\sigma_{g}(\mathbf{S} / \mathbf{c m})$ & $\sigma_{\mathrm{lg}}(\mathrm{S} / \mathrm{cm})$ \\
\hline 573 & $3,51 \mathrm{E}+05$ & $3,27 E+05$ & $2,42 E+04$ & 2,85E-06 & 3,06E-06 & 4,13E-05 \\
\hline 623 & $3,43 E+04$ & $3,14 \mathrm{E}+04$ & $2,83 \mathrm{E}+03$ & 2,92E-05 & 3,18E-05 & 3,54E-04 \\
\hline 673 & $4,54 \mathrm{E}+03$ & $3,74 \mathrm{E}+03$ & $8,00 \mathrm{E}+02$ & 2,20E-04 & 2,67E-04 & $1,25 \mathrm{E}-03$ \\
\hline 723 & $8,71 \mathrm{E}+02$ & $6,82 E+02$ & $1,89 \mathrm{E}+02$ & 1,15E-03 & 1,47E-03 & 5,29E-03 \\
\hline 773 & $2,49 E+02$ & & & 4,01E-03 & & \\
\hline 823 & $9,41 \mathrm{E}+01$ & & & 1,06E-02 & & \\
\hline 873 & $4,63 \mathrm{E}+01$ & & & 2,16E-02 & & \\
\hline 923 & $2,68 \mathrm{E}+01$ & & & 3,74E-02 & & \\
\hline 973 & $1,78 \mathrm{E}+01$ & & & 5,63E-02 & & \\
\hline 1023 & $1,31 \mathrm{E}+01$ & & & 7,61E-02 & & \\
\hline 1073 & $1,05 E+01$ & & & 9,54E-02 & & \\
\hline 1123 & $8,80 \mathrm{E}+00$ & & & 1,14E-01 & & \\
\hline 1173 & $7,81 \mathrm{E}+00$ & & & 1,28E-01 & & \\
\hline 1223 & $7,12 \mathrm{E}+00$ & & & 1,41E-01 & & \\
\hline 1273 & $6,51 \mathrm{E}+00$ & & & 1,54E-01 & & \\
\hline
\end{tabular}




\begin{tabular}{|c|c|c|c|c|c|c|}
\hline $\mathrm{Te}(\mathrm{K})$ & $\rho_{\mathrm{T}}(\Omega . \mathrm{cm})$ & $\rho_{\mathrm{g}}(\Omega . \mathrm{cm})$ & $\rho_{\mathrm{lg}}(\Omega . \mathrm{cm})$ & $\sigma_{\mathrm{T}}(\mathrm{S} / \mathrm{cm})$ & $\sigma_{g}(\mathbf{S} / \mathbf{c m})$ & $\sigma_{\mathrm{lg}}(\mathrm{S} / \mathrm{cm})$ \\
\hline 573 & $3,43 E+05$ & $3,21 E+05$ & $2,16 \mathrm{E}+04$ & 2,92E-06 & 3,12E-06 & 4,62E-05 \\
\hline 623 & $3,46 \mathrm{E}+04$ & $3,20 \mathrm{E}+04$ & $2,56 \mathrm{E}+03$ & 2,89E-05 & 3,12E-05 & 3,91E-04 \\
\hline 673 & $4,52 \mathrm{E}+03$ & $3,79 E+03$ & $7,37 \mathrm{E}+02$ & 2,21E-04 & 2,64E-04 & 1,36E-03 \\
\hline 723 & $8,78 \mathrm{E}+02$ & $6,95 E+02$ & $1,83 \mathrm{E}+02$ & 1,14E-03 & 1,44E-03 & 5,46E-03 \\
\hline 773 & $2,53 \mathrm{E}+02$ & & & 3,95E-03 & & \\
\hline 823 & $9,96 \mathrm{E}+01$ & & & 1,00E-02 & & \\
\hline 873 & $4,76 \mathrm{E}+01$ & & & 2,10E-02 & & \\
\hline 923 & $2,75 \mathrm{E}+01$ & & & 3,63E-02 & & \\
\hline 973 & $1,83 \mathrm{E}+01$ & & & 5,47E-02 & & \\
\hline 1023 & $1,35 \mathrm{E}+01$ & & & 7,41E-02 & & \\
\hline 1073 & $1,07 \mathrm{E}+01$ & & & 9,32E-02 & & \\
\hline 1123 & $9,01 E+00$ & & & 1,11E-01 & & \\
\hline 1173 & $7,75 \mathrm{E}+00$ & & & 1,29E-01 & & \\
\hline 1223 & $6,99 \mathrm{E}+00$ & & & 1,43E-01 & & \\
\hline 1273 & $6,39 \mathrm{E}+00$ & & & 1,56E-01 & & \\
\hline
\end{tabular}


Tabla 8.7. Valores de resistividades y de conductividades obtenidos, a las diferentes temperaturas de ensayo, para las probetas prensadas de la composición C-I sinterizadas a $1773 \mathrm{~K}$, durante 1 hora

\begin{tabular}{|c|c|c|c|c|c|c|}
\hline $\mathrm{Te}(\mathrm{K})$ & $\rho_{\mathrm{T}}(\Omega . \mathrm{cm})$ & $\rho_{g}(\Omega . c m)$ & $\rho_{\mathrm{lg}}(\Omega . \mathrm{cm})$ & $\sigma_{\mathrm{T}}(\mathrm{S} / \mathrm{cm})$ & $\sigma_{g}(S / c m)$ & $\sigma_{\mathrm{lg}}(\mathrm{S} / \mathrm{cm})$ \\
\hline 573 & $3,44 \mathrm{E}+05$ & $3,24 \mathrm{E}+05$ & $1,98 \mathrm{E}+04$ & 2,91E-06 & $3,08 \mathrm{E}-06$ & $5,06 \mathrm{E}-05$ \\
\hline 623 & $3,46 \mathrm{E}+04$ & $3,16 \mathrm{E}+04$ & $2,95 \mathrm{E}+03$ & 2,89E-05 & $3,16 \mathrm{E}-05$ & $3,39 \mathrm{E}-04$ \\
\hline 673 & $4,43 E+03$ & $3,75 \mathrm{E}+03$ & $6,81 E+02$ & 2,26E-04 & 2,67E-04 & 1,47E-03 \\
\hline 723 & $8,68 \mathrm{E}+02$ & $7,02 \mathrm{E}+02$ & 1,66E+02 & 1,15E-03 & 1,42E-03 & 6,03E-03 \\
\hline 773 & $2,46 \mathrm{E}+02$ & & & 4,06E-03 & & \\
\hline 823 & $9,60 \mathrm{E}+01$ & & & 1,04E-02 & & \\
\hline 873 & $4,65 \mathrm{E}+01$ & & & 2,15E-02 & & \\
\hline 923 & $2,89 \mathrm{E}+01$ & & & 3,46E-02 & & \\
\hline 973 & $1,90 \mathrm{E}+01$ & & & 5,27E-02 & & \\
\hline 1023 & $1,38 \mathrm{E}+01$ & & & 7,22E-02 & & \\
\hline 1073 & $1,09 \mathrm{E}+01$ & & & $9,16 \mathrm{E}-02$ & & \\
\hline 1123 & $9,00 \mathrm{E}+00$ & & & $1,11 \mathrm{E}-01$ & & \\
\hline 1173 & $7,76 \mathrm{E}+00$ & & & 1,29E-01 & & \\
\hline 1223 & $6,89 \mathrm{E}+00$ & & & $1,45 \mathrm{E}-01$ & & \\
\hline 1273 & $6,36 \mathrm{E}+00$ & & & 1,57E-01 & & \\
\hline
\end{tabular}




\begin{tabular}{|c|c|c|c|c|c|c|}
\hline $\mathrm{Te}(\mathrm{K})$ & $\rho_{\mathrm{T}}(\Omega . \mathrm{cm})$ & $\rho_{\mathrm{g}}(\Omega . \mathrm{cm})$ & $\rho_{\mathrm{lg}}(\Omega . \mathrm{cm})$ & $\sigma_{\mathrm{T}}(\mathrm{S} / \mathrm{cm})$ & $\sigma_{g}(S / c m)$ & $\sigma_{\mathrm{lg}}(\mathrm{S} / \mathrm{cm})$ \\
\hline 573 & $3,45 \mathrm{E}+05$ & $3,25 E+05$ & $1,98 \mathrm{E}+04$ & 2,90E-06 & 3,08E-06 & 5,05E-05 \\
\hline 623 & $3,42 \mathrm{E}+04$ & $3,16 \mathrm{E}+04$ & $2,60 \mathrm{E}+03$ & 2,92E-05 & 3,16E-05 & 3,85E-04 \\
\hline 673 & $4,46 \mathrm{E}+03$ & $3,77 E+03$ & $6,90 \mathrm{E}+02$ & 2,24E-03 & 2,65E-04 & 1,45E-03 \\
\hline 723 & $8,62 \mathrm{E}+02$ & $6,95 E+02$ & $1,67 \mathrm{E}+02$ & 1,16E-03 & 1,44E-03 & 5,99E-03 \\
\hline 773 & $2,46 \mathrm{E}+02$ & & & 4,07E-03 & & \\
\hline 823 & $9,17 \mathrm{E}+01$ & & & 1,09E-02 & & \\
\hline 873 & $4,84 \mathrm{E}+01$ & & & 2,06E-02 & & \\
\hline 923 & $2,77 \mathrm{E}+01$ & & & 3,61E-02 & & \\
\hline 973 & $1,81 \mathrm{E}+01$ & & & 5,53E-02 & & \\
\hline 1023 & $1,32 \mathrm{E}+01$ & & & 7,59E-02 & & \\
\hline 1073 & $1,02 \mathrm{E}+01$ & & & 9,84E-02 & & \\
\hline 1123 & $8,83 \mathrm{E}+00$ & & & 1,13E-01 & & \\
\hline 1173 & $7,64 \mathrm{E}+00$ & & & 1,31E-01 & & \\
\hline 1223 & $6,86 \mathrm{E}+00$ & & & 1,46E-01 & & \\
\hline 1273 & $6,34 \mathrm{E}+00$ & & & 1,58E-01 & & \\
\hline
\end{tabular}




\begin{tabular}{|c|c|c|c|c|c|c|}
\hline $\mathrm{Te}(\mathrm{K})$ & $\rho_{\mathrm{T}}(\Omega . \mathrm{cm})$ & $\rho_{\mathrm{g}}(\Omega . \mathrm{cm})$ & $\rho_{\mathrm{lg}}(\Omega . \mathrm{cm})$ & $\sigma_{\mathrm{T}}(\mathrm{S} / \mathrm{cm})$ & $\sigma_{g}(\mathbf{S} / \mathrm{cm})$ & $\sigma_{\mathrm{lg}}(\mathrm{S} / \mathrm{cm})$ \\
\hline 573 & $3,45 \mathrm{E}+05$ & $3,25 E+05$ & 1,97E+04 & $2,90 \mathrm{E}-06$ & $3,08 \mathrm{E}-06$ & $5,08 \mathrm{E}-05$ \\
\hline 623 & $3,45 \mathrm{E}+04$ & $3,19 \mathrm{E}+04$ & $2,55 \mathrm{E}+03$ & 2,90E-05 & 3,13E-05 & 3,92E-04 \\
\hline 673 & $4,35 \mathrm{E}+03$ & $3,82 E+03$ & $5,30 \mathrm{E}+02$ & 2,30E-04 & 2,62E-04 & 1,89E-03 \\
\hline 723 & $8,60 \mathrm{E}+02$ & $7,01 \mathrm{E}+02$ & $1,60 \mathrm{E}+02$ & 1,16E-03 & 1,43E-03 & $6,24 \mathrm{E}-03$ \\
\hline 773 & $2,38 \mathrm{E}+02$ & & & $4,20 \mathrm{E}-03$ & & \\
\hline 823 & $9,70 \mathrm{E}+01$ & & & 1,03E-02 & & \\
\hline 873 & $4,65 \mathrm{E}+01$ & & & $2,15 \mathrm{E}-02$ & & \\
\hline 923 & $2,66 \mathrm{E}+01$ & & & 3,77E-02 & & \\
\hline 973 & $1,74 \mathrm{E}+01$ & & & 5,74E-02 & & \\
\hline 1023 & $1,30 \mathrm{E}+01$ & & & $7,70 \mathrm{E}-02$ & & \\
\hline 1073 & $1,00 \mathrm{E}+01$ & & & 9,95E-02 & & \\
\hline 1123 & $8,53 \mathrm{E}+00$ & & & 1,17E-01 & & \\
\hline 1173 & $7,69 \mathrm{E}+00$ & & & $1,30 \mathrm{E}-01$ & & \\
\hline 1223 & $6,77 \mathrm{E}+00$ & & & 1,48E-01 & & \\
\hline 1273 & $6,22 \mathrm{E}+00$ & & & 1,61E-01 & & \\
\hline
\end{tabular}




\begin{tabular}{|c|c|c|c|c|c|c|}
\hline $\mathrm{Te}(\mathrm{K})$ & $\rho_{\mathrm{T}}(\Omega . \mathrm{cm})$ & $\rho_{\mathrm{g}}(\Omega . \mathrm{cm})$ & $\rho_{\mathrm{lg}}(\Omega . \mathrm{cm})$ & $\sigma_{\mathrm{T}}(\mathbf{S} / \mathbf{c m})$ & $\sigma_{\mathrm{g}}(\mathrm{S} / \mathrm{cm})$ & $\sigma_{\mathrm{Ig}}(\mathrm{S} / \mathrm{cm})$ \\
\hline 573 & $3,42 \mathrm{E}+05$ & $3,23 E+05$ & $1,95 \mathrm{E}+04$ & 2,92E-06 & 3,10E-06 & 5,12E-05 \\
\hline 623 & $3,42 \mathrm{E}+04$ & $3,17 \mathrm{E}+04$ & $2,51 \mathrm{E}+03$ & 2,93E-05 & 3,16E-05 & 3,99E-04 \\
\hline 673 & $4,30 \mathrm{E}+03$ & $3,76 \mathrm{E}+03$ & $5,43 E+02$ & 2,32E-04 & 2,66E-04 & 1,84E-03 \\
\hline 723 & $8,48 \mathrm{E}+02$ & $6,95 \mathrm{E}+02$ & $1,53 \mathrm{E}+02$ & 1,18E-03 & 1,44E-03 & 6,52E-03 \\
\hline 773 & $2,38 \mathrm{E}+02$ & & & $4,20 \mathrm{E}-03$ & & \\
\hline 823 & $9,09 \mathrm{E}+01$ & & & 1,10E-02 & & \\
\hline 873 & $4,55 \mathrm{E}+01$ & & & $2,20 \mathrm{E}-02$ & & \\
\hline 923 & $2,60 \mathrm{E}+01$ & & & 3,84E-02 & & \\
\hline 973 & $1,74 \mathrm{E}+01$ & & & $5,74 \mathrm{E}-02$ & & \\
\hline 1023 & $1,30 \mathrm{E}+01$ & & & 7,71E-02 & & \\
\hline 1073 & $1,00 \mathrm{E}+01$ & & & $9,95 \mathrm{E}-02$ & & \\
\hline 1123 & $8,65 \mathrm{E}+00$ & & & $1,16 \mathrm{E}-01$ & & \\
\hline 1173 & $7,74 \mathrm{E}+00$ & & & $1,29 \mathrm{E}-01$ & & \\
\hline 1223 & $6,78 \mathrm{E}+00$ & & & 1,47E-01 & & \\
\hline 1273 & $6,25 \mathrm{E}+00$ & & & 1,60E-01 & & \\
\hline
\end{tabular}


8.1.2 Probetas conformadas a partir de la composición $C$-II

\begin{tabular}{|c|c|c|c|c|c|c|}
\hline $\mathrm{Te}(\mathrm{K})$ & $\rho_{\mathrm{T}}(\Omega . \mathrm{cm})$ & $\rho_{\mathrm{g}}(\Omega . \mathrm{cm})$ & $\rho_{\mathrm{lg}}(\Omega . \mathrm{cm})$ & $\sigma_{\mathrm{T}}(\mathrm{S} / \mathrm{cm})$ & $\sigma_{g}\left(S / \mathbf{c m}^{-1}\right)$ & $\sigma_{\mathrm{lg}}(\mathrm{S} / \mathrm{cm})$ \\
\hline 573 & $2,48 \mathrm{E}+05$ & $2,14 \mathrm{E}+05$ & $3,42 \mathrm{E}+04$ & 4,03E-06 & 4,67E-06 & 2,92E-05 \\
\hline 623 & $3,13 \mathrm{E}+04$ & $2,66 \mathrm{E}+04$ & $4,66 \mathrm{E}+03$ & 3,20E-05 & 3,76E-05 & $2,15 \mathrm{E}-04$ \\
\hline 673 & $5,11 \mathrm{E}+03$ & $4,28 \mathrm{E}+03$ & $8,28 \mathrm{E}+02$ & 1,96E-04 & 2,34E-04 & 1,21E-03 \\
\hline 723 & $1,19 \mathrm{E}+03$ & $9,37 \mathrm{E}+02$ & $2,48 \mathrm{E}+02$ & 8,44E-04 & 1,07E-03 & 4,03E-03 \\
\hline 773 & $3,64 \mathrm{E}+02$ & & & $2,75 \mathrm{E}-03$ & & \\
\hline 823 & $1,43 \mathrm{E}+02$ & & & 6,98E-03 & & \\
\hline 873 & $6,95 \mathrm{E}+01$ & & & 1,44E-02 & & \\
\hline 923 & $4,11 \mathrm{E}+01$ & & & 2,43E-02 & & \\
\hline 973 & $2,82 \mathrm{E}+01$ & & & 3,55E-02 & & \\
\hline 1023 & $2,15 \mathrm{E}+01$ & & & 4,65E-02 & & \\
\hline 1073 & $1,76 \mathrm{E}+01$ & & & 5,69E-02 & & \\
\hline 1123 & $1,49 \mathrm{E}+01$ & & & 6,72E-02 & & \\
\hline 1173 & $1,32 \mathrm{E}+01$ & & & 7,58E-02 & & \\
\hline 1223 & $1,19 \mathrm{E}+01$ & & & 8,40E-02 & & \\
\hline 1273 & $1,10 \mathrm{E}+01$ & & & $9,12 \mathrm{E}-02$ & & \\
\hline
\end{tabular}




\begin{tabular}{|c|c|c|c|c|c|c|}
\hline Te (K) & $\rho_{\mathrm{T}}(\Omega . \mathrm{cm})$ & $\rho_{\mathrm{g}}(\Omega . \mathrm{cm})$ & $\rho_{\mathrm{lg}}(\Omega . \mathrm{cm})$ & $\sigma_{\mathrm{T}}(\mathrm{S} / \mathrm{cm})$ & $\sigma_{\mathrm{g}}(\mathrm{S} / \mathrm{cm})$ & $\sigma_{\mathrm{lg}}(\mathrm{S} / \mathrm{cm})$ \\
\hline 573 & $2,53 \mathrm{E}+05$ & $2,08 \mathrm{E}+05$ & $4,50 \mathrm{E}+04$ & 3,95E-06 & 4,80E-06 & 2,22E-05 \\
\hline 623 & $3,16 \mathrm{E}+04$ & $2,59 \mathrm{E}+04$ & $5,76 \mathrm{E}+03$ & 3,16E-05 & 3,87E-05 & 1,74E-04 \\
\hline 673 & $5,25 \mathrm{E}+03$ & $4,20 \mathrm{E}+03$ & $1,06 \mathrm{E}+03$ & 1,90E-04 & 2,38E-04 & $9,46 \mathrm{E}-04$ \\
\hline 723 & $1,24 \mathrm{E}+03$ & $9,32 \mathrm{E}+02$ & $3,12 \mathrm{E}+02$ & 8,04E-04 & 1,07E-03 & 3,21E-03 \\
\hline 773 & $3,84 \mathrm{E}+02$ & & & 2,61E-03 & & \\
\hline 823 & 1,47E+02 & & & $6,80 \mathrm{E}-03$ & & \\
\hline 873 & $6,77 \mathrm{E}+01$ & & & 1,48E-02 & & \\
\hline 923 & $3,72 \mathrm{E}+01$ & & & 2,69E-02 & & \\
\hline 973 & $2,35 \mathrm{E}+01$ & & & 4,26E-02 & & \\
\hline 1023 & $1,66 \mathrm{E}+01$ & & & $6,03 E-02$ & & \\
\hline 1073 & $1,27 \mathrm{E}+01$ & & & 7,86E-02 & & \\
\hline 1123 & $1,04 \mathrm{E}+01$ & & & 9,58E-02 & & \\
\hline 1173 & $9,05 E+00$ & & & $1,10 \mathrm{E}-01$ & & \\
\hline 1223 & $8,09 E+00$ & & & $1,24 \mathrm{E}-01$ & & \\
\hline 1273 & $7,46 \mathrm{E}+00$ & & & 1,34E-01 & & \\
\hline
\end{tabular}




\begin{tabular}{|c|c|c|c|c|c|c|}
\hline $\mathrm{Te}(\mathrm{K})$ & $\rho_{\mathrm{T}}(\Omega . \mathrm{cm})$ & $\rho_{\mathrm{g}}(\Omega . \mathrm{cm})$ & $\rho_{\mathrm{Ig}}(\Omega . \mathrm{cm})$ & $\sigma_{\mathrm{T}}(\mathrm{S} / \mathrm{cm})$ & $\sigma_{g}(\mathbf{S} / \mathbf{c m})$ & $\sigma_{\mathrm{lg}}(\mathrm{S} / \mathrm{cm})$ \\
\hline 573 & $2,41 \mathrm{E}+05$ & $2,09 E+05$ & $3,25 \mathrm{E}+04$ & $4,15 E-06$ & 4,79E-06 & $3,08 \mathrm{E}-05$ \\
\hline 623 & $2,98 \mathrm{E}+04$ & $2,57 \mathrm{E}+04$ & $4,11 \mathrm{E}+03$ & 3,35E-05 & 3,89E-05 & 2,43E-04 \\
\hline 673 & $4,98 \mathrm{E}+03$ & $4,19 \mathrm{E}+03$ & $7,82 \mathrm{E}+02$ & 2,01E-04 & 2,38E-04 & $1,28 \mathrm{E}-03$ \\
\hline 723 & 1,17E+03 & $9,31 \mathrm{E}+02$ & $2,39 \mathrm{E}+02$ & $8,55 \mathrm{E}-04$ & 1,07E-03 & $4,18 \mathrm{E}-03$ \\
\hline 773 & $3,60 \mathrm{E}+02$ & & & 2,78E-03 & & \\
\hline 823 & 1,37E+02 & & & 7,28E-03 & & \\
\hline 873 & $6,48 \mathrm{E}+01$ & & & 1,54E-02 & & \\
\hline 923 & $3,64 \mathrm{E}+01$ & & & $2,75 E-02$ & & \\
\hline 973 & $2,36 \mathrm{E}+01$ & & & 4,23E-02 & & \\
\hline 1023 & $1,73 \mathrm{E}+01$ & & & 5,80E-02 & & \\
\hline 1073 & $1,38 \mathrm{E}+01$ & & & 7,26E-02 & & \\
\hline 1123 & $1,16 \mathrm{E}+01$ & & & 8,59E-02 & & \\
\hline 1173 & $1,00 \mathrm{E}+01$ & & & 9,99E-02 & & \\
\hline 1223 & $8,98 \mathrm{E}+00$ & & & 1,11E-01 & & \\
\hline 1273 & $8,36 \mathrm{E}+00$ & & & $1,20 \mathrm{E}-01$ & & \\
\hline
\end{tabular}


8.1.3 Probetas conformadas a partir de la composición $C$-III

\begin{tabular}{|c|c|c|c|c|c|c|}
\hline $\mathrm{Te}(\mathrm{K})$ & $\rho_{\mathrm{T}}(\Omega . \mathrm{cm})$ & $\rho_{\mathrm{g}}(\Omega . \mathrm{cm})$ & $\rho_{\mathrm{lg}}(\Omega . \mathrm{cm})$ & $\sigma_{\mathrm{T}}(\mathrm{S} / \mathrm{cm})$ & $\sigma_{g}(\mathbf{S} / \mathbf{c m})$ & $\sigma_{\mathrm{lg}}(\mathrm{S} / \mathrm{cm})$ \\
\hline 573 & 4,67E+05 & $4,17 \mathrm{E}+05$ & $4,93 E+04$ & $2,14 \mathrm{E}-06$ & $2,40 \mathrm{E}-06$ & 2,03E-05 \\
\hline 623 & $4,92 \mathrm{E}+04$ & $4,33 \mathrm{E}+04$ & $5,85 \mathrm{E}+03$ & 2,03E-05 & 2,31E-05 & 1,71E-04 \\
\hline 673 & $6,29 \mathrm{E}+03$ & $5,34 \mathrm{E}+03$ & $9,44 \mathrm{E}+02$ & 1,59E-04 & 1,87E-04 & $1,06 \mathrm{E}-03$ \\
\hline 723 & $1,26 \mathrm{E}+03$ & $9,81 \mathrm{E}+02$ & $2,76 \mathrm{E}+02$ & 7,96E-04 & 1,02E-03 & 3,63E-03 \\
\hline 773 & $3,56 \mathrm{E}+02$ & & & 2,81E-03 & & \\
\hline 823 & $1,32 \mathrm{E}+02$ & & & 7,56E-03 & & \\
\hline 873 & $6,26 \mathrm{E}+01$ & & & 1,60E-02 & & \\
\hline 923 & $3,51 \mathrm{E}+01$ & & & 2,85E-02 & & \\
\hline 973 & $2,29 \mathrm{E}+01$ & & & 4,37E-02 & & \\
\hline 1023 & $1,65 \mathrm{E}+01$ & & & $6,05 \mathrm{E}-02$ & & \\
\hline 1073 & $1,30 \mathrm{E}+01$ & & & 7,71E-02 & & \\
\hline 1123 & $1,08 \mathrm{E}+01$ & & & $9,23 \mathrm{E}-02$ & & \\
\hline 1173 & $9,50 \mathrm{E}+00$ & & & $1,05 \mathrm{E}-01$ & & \\
\hline 1223 & $8,65 \mathrm{E}+00$ & & & 1,16E-01 & & \\
\hline 1273 & $8,06 \mathrm{E}+00$ & & & 1,24E-01 & & \\
\hline
\end{tabular}




\begin{tabular}{|c|c|c|c|c|c|c|}
\hline $\mathrm{Te}(\mathrm{K})$ & $\rho_{\mathrm{T}}(\Omega . \mathrm{cm})$ & $\rho_{\mathrm{g}}(\Omega . \mathrm{cm})$ & $\rho_{\mathrm{lg}}(\Omega . \mathrm{cm})$ & $\sigma_{\mathrm{T}}(\mathrm{S} / \mathrm{cm})$ & $\sigma_{\mathrm{g}}(\mathrm{S} / \mathrm{cm})$ & $\sigma_{\mathrm{Ig}}(\mathrm{S} / \mathrm{cm})$ \\
\hline 573 & 4,47E+05 & $4,11 \mathrm{E}+05$ & $3,64 \mathrm{E}+04$ & 2,24E-06 & $2,44 \mathrm{E}-06$ & $2,75 E-05$ \\
\hline 623 & $4,80 \mathrm{E}+04$ & $4,33 \mathrm{E}+04$ & $4,65 E+03$ & 2,08E-05 & 2,31E-05 & $2,15 \mathrm{E}-04$ \\
\hline 673 & $6,13 \mathrm{E}+03$ & $5,36 \mathrm{E}+03$ & $7,68 \mathrm{E}+02$ & 1,63E-04 & 1,86E-04 & $1,30 \mathrm{E}-03$ \\
\hline 723 & $1,22 \mathrm{E}+03$ & $9,87 \mathrm{E}+02$ & $2,38 \mathrm{E}+02$ & 8,17E-04 & 1,01E-03 & 4,20E-03 \\
\hline 773 & $3,48 \mathrm{E}+02$ & & & 2,87E-03 & & \\
\hline 823 & $1,31 \mathrm{E}+02$ & & & 7,65E-03 & & \\
\hline 873 & $6,17 \mathrm{E}+01$ & & & 1,62E-02 & & \\
\hline 923 & $3,50 \mathrm{E}+01$ & & & 2,86E-02 & & \\
\hline 973 & $2,26 \mathrm{E}+01$ & & & 4,43E-02 & & \\
\hline 1023 & $1,62 \mathrm{E}+01$ & & & 6,17E-02 & & \\
\hline 1073 & $1,28 \mathrm{E}+01$ & & & 7,81E-02 & & \\
\hline 1123 & $1,07 \mathrm{E}+01$ & & & 9,33E-02 & & \\
\hline 1173 & $9,40 \mathrm{E}+00$ & & & 1,06E-01 & & \\
\hline 1223 & $8,54 \mathrm{E}+00$ & & & 1,17E-01 & & \\
\hline 1273 & $7,94 \mathrm{E}+00$ & & & 1,26E-01 & & \\
\hline
\end{tabular}




\subsection{Determinación de la Resistencia Mecánica}

\begin{tabular}{ccc}
\hline \multicolumn{3}{|c}{ Tabla 8.16. Determinación de la RM de las muestras } \\
preparadas con C-I-35 \\
\hline Probeta & Fuerza máxima (N) & RM (MPa) \\
\hline $\mathbf{1}$ & 2,983 & 97 \\
$\mathbf{2}$ & 2,834 & 95 \\
$\mathbf{3}$ & 3,882 & 126 \\
$\mathbf{4}$ & 4,956 & 160 \\
$\mathbf{5}$ & 3,220 & 104 \\
$\mathbf{6}$ & 5,009 & 162 \\
$\mathbf{7}$ & 3,931 & 127 \\
$\mathbf{8}$ & 2,940 & 95 \\
\hline Valor medio & & 121 \\
\hline
\end{tabular}

\begin{tabular}{|ccc}
\hline \multicolumn{3}{|c}{ Tabla 8.17. Determinación de la RM de las muestras } \\
preparadas con C-II \\
\hline Probeta & Fuerza máxima (N) & RM (MPa) \\
\hline $\mathbf{1}$ & 4,449 & 158 \\
$\mathbf{2}$ & 4,214 & 150 \\
$\mathbf{3}$ & 3,891 & 138 \\
$\mathbf{4}$ & 3,165 & 113 \\
$\mathbf{5}$ & 3,426 & 122 \\
$\mathbf{6}$ & 3,831 & 136 \\
$\mathbf{7}$ & 4,836 & 168 \\
$\mathbf{8}$ & 4,724 & 168 \\
$\mathbf{9}$ & 4,076 & 145 \\
$\mathbf{1 0}$ & 4,573 & 163 \\
$\mathbf{1 1}$ & 4,480 & 159 \\
\hline Valor medio & & 147 \\
\hline
\end{tabular}




\begin{tabular}{ccc}
\hline \multicolumn{3}{|c}{ Tabla 8.18. Determinación de la RM de las muestras } \\
preparadas con C-III \\
\hline Probeta & Fuerza máxima (N) & RM (MPa) \\
\hline $\mathbf{1}$ & 2,430 & 136 \\
$\mathbf{2}$ & 3,826 & 129 \\
$\mathbf{3}$ & 2.476 & 138 \\
$\mathbf{4}$ & 2.410 & 134 \\
$\mathbf{5}$ & 4.956 & 160 \\
$\mathbf{6}$ & 3,208 & 97 \\
$\mathbf{7}$ & 4,719 & 155 \\
\hline Valor medio & & 139 \\
\hline
\end{tabular}

8.3 Publicaciones realizadas en el marco de esta investigación (Ver páginas siguientes) 
9 Nomenclatura 


\section{Abreviaturas y siglas}

AC Corriente alterna.

AFC Alkaline Fuel Cell.

ASC Celdas soportadas por el ánodo.

ATD-TG Análisis térmico diferencial - análisis termogravimétrico.

$\mathrm{CPE}_{\mathrm{i}} \quad$ Elemento constante de fase del proceso $\mathrm{i}$, similar a un condensador $(\mathrm{g}=$ interior de grano; lg= límite de grano).

DBT Dibutyl Phtalate o Benzyl butyl phthalate.

DMFC Direct Methanol Fuel Cell.

ESC Celdas soportadas por el electrolito.

PFCA Phosphoric Acid Fuel Cell.

MCFC Melting Carbonate Fuel Cell.

MEK Metil-etil-cetona.

MFO Menhanden Fish Oil.

PEG Polietilenglicol.

PEMFC Polymer Electrolyte / Proton Exchange Membrane Fuel Cell.

PVB Poli(vinilbutiral).

RC Combinación en paralelo de una resistencia y un condensador, equivalente a un círculo en el diagrama de Nyquist.

$\mathrm{RQ}$ Combinación en paralelo de una resistencia y un elemento constante de fase, equivalente a un círculo con el centro deprimido en el diagrama de Nyquist.

SOFC Solid Oxide Fuel Cell.

$3 Y S Z \quad$ Circona dopada con itria, de composición $3 \mathrm{Y}_{2} \mathrm{O}_{3} .97 \mathrm{ZrO}$.

$8 Y S Z \quad$ Circona dopada con itria, de composición $8 \mathrm{Y}_{2} \mathrm{O}_{3} .92 \mathrm{ZrO}_{2}$.

$10 \mathrm{Sc} 1 \mathrm{CeSZ}$ Circona dopada con escandia y ceria de composición $10 \mathrm{Sc}_{2} \mathrm{O}_{3} \cdot 1 \mathrm{CeO}_{2} \cdot 89 \mathrm{ZrO}_{2}$.

\section{Símbolos utilizados}

A Parámetro preexponencial de la ecuación (5.18) $\left(\mathrm{S} \cdot \mathrm{cm}^{-1}\right)$.

$\boldsymbol{A}_{g} \quad$ Área de la sección de un grano medida sobre la imagen, obtenida en el MEB, del material sinterizado $\left(\mu \mathrm{m}^{2}\right)$.

$\boldsymbol{A}_{\boldsymbol{p}} \quad$ Área de la sección de un poro, medida por análisis de imagen $\left(\mu \mathrm{m}^{2}\right)$.

B Parámetro de la ecuación (5.18) $\left(\mu \mathrm{m}^{-1}\right)$.

$\boldsymbol{c}_{\boldsymbol{i}} \quad$ Concentración de la especie química iónica que se transporta en la ecuación (1.16) (iones $\cdot \mathrm{m}^{-3}$ ).

$\boldsymbol{C}_{\boldsymbol{i}} \quad$ Capacitancia de un material $(\mathrm{F})$.

CL Contracción lineal (\%).

$\boldsymbol{d}_{p} \quad$ Diámetro de la sección de un poro, medido por análisis de imagen $(\mu \mathrm{m})$. 
$\boldsymbol{d}_{50} \quad$ Diámetro por encima o por debajo del cual se encuentra el $50 \%$ del área ocupada por los poros.

D Diámetro medio de grano del material $(\mu \mathrm{m})$. Tamaño del grano, calculado como el diámetro del círculo que tiene la misma área que $A_{g}(\mu \mathrm{m})$. Los valores de esta propiedad que se han utilizado en el Apartado 5: "Discusión de los Resultados" corresponden a $\boldsymbol{D}_{50}$.

$D_{i} \quad$ Difusividad iónica $\left(\mathrm{m}^{2} \cdot \mathrm{s}^{-1}\right)$.

$D_{1} \quad$ Diametro medio de grano que corresponde al tiempo de tratamiento térmico $t_{1}$ $(\mu \mathrm{m})$.

$D_{50} \quad$ Diámetro del grano por encima o por debajo del cual se encuentra el $50 \%$ del área ocupada por granos $(\mu \mathrm{m})$.

e Carga del electrón $\left(1,6 \cdot 10^{-19} \mathrm{C}\right)$.

E Voltaje de la celda en equilibrio $(\mathrm{V})$, potencial termodinámico de la celda.

$\boldsymbol{E}^{\prime} \quad$ Voltaje de la celda en operación (V).

$E^{0} \quad$ Potencial reversible en condiciones estándar (1,229 eV).

$\tilde{E}(\omega, t) \quad$ Potencial aplicado a un circuito eléctrico de corriente alterna (V).

$\boldsymbol{E}_{\boldsymbol{i}} \quad$ Energía aparente de activación en la ecuación (1.17), (eV).

$\boldsymbol{F} \quad$ Constante de Faraday $\left(96485,34 \mathrm{C} \cdot \mathrm{mol}^{-1}\right)$.

$\boldsymbol{k} \quad$ Constante de Boltzmann $\left(8,6173324 \cdot 10^{-5} \mathrm{eV} \cdot \mathrm{K}^{-1}\right)$.

$\boldsymbol{k}_{\boldsymbol{D}} \quad$ Parámetro cinético en la ecuación (5.3).

$\boldsymbol{k}_{\boldsymbol{0}} \quad$ Factor pre-exponencial en la ecuación (5.3).

P Amplitud de la intensidad que circula por un circuito eléctrico $(A)$.

$\tau(\omega, t) \quad$ Intensidad que circula por un circuito eléctrico de corriente alterna $(A)$.

$J$

Densidad de corriente producida $\left(A \cdot \mathrm{m}^{-2}\right)$.

$J_{F} \quad$ Densidad de corriente producida si se convirtiera el $100 \%$ de combustible (A.m $\left.{ }^{2}\right)$.

$\mathbf{L} \quad$ Espesor del material, medido en el sentido en que tiene lugar el transporte de los iones $(\mathrm{m})$.

$\boldsymbol{L}_{\boldsymbol{i}} \quad$ Inductancia $(\mathrm{H})$.

$\boldsymbol{n} \quad$ Exponente del tamaño de grano en la ecuación (5.1).

$\boldsymbol{p}_{j}^{c} \quad$ Presión parcial del compuesto j en el cátodo (bar).

$\boldsymbol{p}^{\boldsymbol{a}}{ }_{j} \quad$ Presión parcial del compuesto j en el ánodo (bar), $\mathrm{R}$ constante de los gases, $8,31 \mathrm{~J} \cdot \mathrm{mol}^{-1}$.

$\boldsymbol{Q} \quad$ Parámetro de la ecuación (5.3) (K).

$\boldsymbol{R}_{\boldsymbol{g}} \quad$ Resistencia óhmica del material o resistencia óhmica del interior de grano $(\Omega)$.

$\boldsymbol{R}_{\boldsymbol{i}} \quad$ Resistencia óhmica de un material o proceso al desplazamiento de corriente $(\Omega)$.

$\boldsymbol{R}_{l g} \quad$ Resistencia óhmica del límite de grano $(\Omega)$.

RM Resistencia mecánica (Pa).

$\boldsymbol{S} \quad$ Sección del material, en dirección perpendicular a la del transporte de los iones (m).

$\boldsymbol{t} \quad$ tiempo (h). 
$\boldsymbol{t}_{\boldsymbol{R}} \quad$ tiempo de residencia a la máxima temperatura de sinterización (h).

$\boldsymbol{t}_{1} \quad$ tiempo transcurrido desde que empieza el ciclo de tratamiento térmico hasta que comienza la etapa que se desarrolla a temperatura constante $T_{S}(h)$.

$\boldsymbol{t}_{2} \quad$ tiempo total de tratamiento térmico $(\mathrm{h})$.

$\boldsymbol{T} \quad$ Temperatura expresada en $\mathrm{K}$.

$T_{\boldsymbol{e}} \quad$ Temperatura a la que se mide la conductividad iónica del material (K).

$T_{S} \quad$ Temperatura máxima a la que se sinterizan las probetas de electrolito (K).

$T_{0} \quad$ Temperatura a la que se inicia el proceso de sinterización (K).

$V^{0} \quad$ Amplitud del voltaje aplicado a un circuito eléctrico (V).

$\boldsymbol{w}_{\boldsymbol{Z} r} \quad$ fracción másica de circona en las suspensiones preparadas para el colado en banda.

$\boldsymbol{x}_{\boldsymbol{l g}} \quad$ Fracción volumétrica del material ocupada por los límites de grano.

Valencia de la especie química cargada que se transporta (en la expresión de la conductividad iónica).

$Z^{0} \quad$ Módulo de la impedancia compleja $(\Omega)$.

Z' Componente real de la impedancia $(\Omega)$.

Z" Componente imaginaria de la impedancia $(\Omega)$.

$Z(\omega, t) \quad$ Impedancia compleja de un circuito eléctrico de corriente alterna $(\Omega)$.

$\delta \quad$ espesor del límite de grano $(\mu \mathrm{m})$.

$\Delta G \quad$ Variación de energía libre o función de Gibbs de la reacción química que tiene lugar en la celda $\left(\mathrm{J} \cdot \mathrm{mol}^{-1}\right)$.

$\boldsymbol{\Delta} \boldsymbol{H} \quad$ Variación de entalpía que experimentan las especies electroquímicamente activas disponibles en la celda para generar electricidad $\left(\mathrm{J} \cdot \mathrm{mol}^{-1}\right)$.

$\Delta \boldsymbol{H}_{\text {com }} \quad$ Variación de entalpía que experimenta el conjunto de las especies químicas presentes en la mezcla de gases que se alimenta a la celda $\left(\mathrm{J} \cdot \mathrm{mol}^{-1}\right)$.

$\Delta \boldsymbol{S} \quad$ Variación de entropía en la reacción química que tiene lugar en la celda $\left(\mathrm{J} \cdot \mathrm{mol}^{-1} \cdot \mathrm{K}^{-1}\right)$.

$\boldsymbol{\epsilon}_{E} \quad$ Eficacia electroquímica de una celda de combustible.

$\boldsymbol{\epsilon}_{F C} \quad$ Eficacia total de una celda de combustible.

$\boldsymbol{\epsilon}_{\boldsymbol{J}} \quad$ Eficacia faradaica de una celda de combustible.

$\boldsymbol{\epsilon}_{H} \quad$ Eficacia calorífica de una celda de combustible.

$\boldsymbol{\epsilon}_{T} \quad$ Eficacia termodinámica de una celda de combustible.

$\boldsymbol{\epsilon}_{V} \quad$ Eficacia voltaica de una celda de combustible.

$\varepsilon \quad$ Porosidad total de una muestra, expresada como fracción porcentual de volumen ocupado por poros.

$\boldsymbol{\eta} \quad$ Polarización, diferencia entre el potencial reversible (o potencial de circuito abierto) y el voltaje de la celda (V).

$\eta_{\text {act }} \quad$ Polarización de transferencia de carga o de activación (V).

$\boldsymbol{\eta}_{\text {dif }} \quad$ Polarización de difusión o polarización por concentración (V).

$\eta_{r e} \quad$ Polarización de reacción (V). 


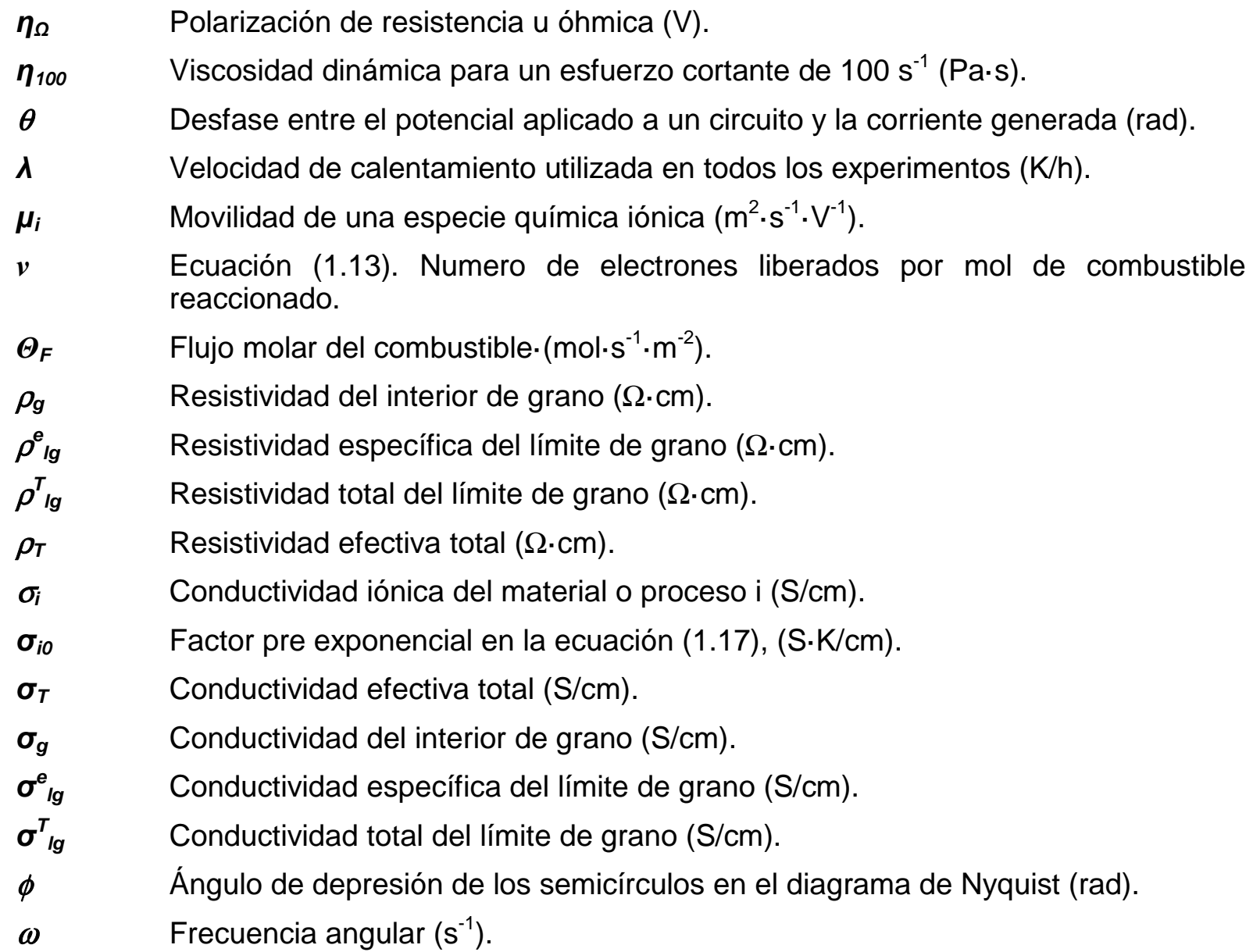




\section{Bibliografía}


1 Aguer Hortal, M.; Miranda Barreras, A.L.: "El Hidrógeno. Fundamento de un futuro equilibrado". Ed. Díaz de Santos, 2007. ISBN: 978-84-7978-809-4.

2 Hoogers, G; Hoogers, H.: "Fuel Cell Technology Handbook" - Edita: CRC Press, 2003. ISBN: 0-8493-0877-1.

${ }^{3}$ Ruiz Morales, J.C; et al: "Pilas de Combustible de Óxidos Sólidos". Centro de la Cultura Popular Canaria, 2008. ISBN: 974-84-7926-567-0.

${ }^{4}$ Lara López, Carlos Javier: "Sellos vitrocerámicos del sistema $\mathrm{RO}-\mathrm{BaO}-\mathrm{SiO}_{2}(\mathrm{R}=\mathrm{Mg}, \mathrm{Zn})$ para pilas de combustible de óxido sólido (SOFC). Tesis Doctoral. Universidad Autónoma de Madrid. Facultad de Ciencias. Instituto de Cerámica y Vidrio. CSIC, Madrid 2006.

${ }^{5}$ Navarro Oliva, Lourdes Maria: "Preparación y evaluación de materiales compuestos cerámicos basados en $\mathrm{ZrO}_{2}-\mathrm{Y}_{2} \mathrm{O}_{3} / \mathrm{Al}_{2} \mathrm{O}_{3}$ como electrolitos sólidos en pilas de combustible". Tesis Doctoral. Universidad de Alcalá de Henares. Facultad de Ciencias Químicas. Instituto de Cerámica y Vidrio. CSIC, Madrid 1994.

${ }^{6}$ Primdahl, S.: "Nickel/Yttria-Stabilised Zirconia Cermet Anodes for Solid Oxide Fuel Cells". Risø Nat. Laboratory, Materials Research Department. Denmark 1999. ISBN: 90-36513375.

7 Steele, B.C.H.; Heinzel, A.: "Materials for fuel-cell technologies". Nature, 414. Nov 2001. Mcmillan Magazines Ltd.

${ }^{8}$ Boer, B.: "SOFC Anodes: Hydrogen oxidation at porous nickel/yttria-stabilised zirconia cermet electrodes". Ph. Thesis. ISBN: 90-36511909. 1998.

${ }^{9}$ Kingery, W.D. et al.: "Oxygen Ion Mobility in Cubic $\mathrm{Zr}_{0,85} \mathrm{Ca}_{0,15} \mathrm{O}_{1,85}$ ". Jour. Amer. Ceram. Soc., 42 (8), 1959, p.393-398.

${ }^{10}$ Goodenough, J.B.: "Oxide-Ion Electrolytes”. Annu. Rev. Mater. Res., 33, 2003, p. 91-128.

${ }^{11}$ Badwal, S.P.S.; Ciacchi, F.T.: "Oxygen-Ion Conducting Electrolyte Materials for Solid Oxide Fuel Cells". Ionics, 6, 2000, p. 1-21.

${ }^{12}$ Ralph, J.M.; Schoeler, A.C.; Krumpelt, M.: "Materials for lower temperature solid oxide fuel cells". Journal of Materials Science, 36(5), 2001, p. 1161-1172.

${ }^{13}$ Yano, M. et al.: "Recent advances in single-chamber solid oxide fuel cells: A review". Solid State lonics, 177, 2007, p. 3351-3359.

14 Singhal, S.C.; Kendall, K.:"High Temperature Solid Oxide Fuel Cells. Fundamentals, Design and Applications". Elsevier, 2003. ISBN: 1856173879.

${ }^{15}$ B.C.H. Steele. J. Mater. Sci., 36, 2001, p. 1053.

${ }^{16}$ Goodenough, J.B., et al.: "Oxide-ion conduction in $\mathrm{Ba}_{2} \mathrm{In}_{2} \mathrm{O}_{5}$ and $\mathrm{Ba}_{3} \mathrm{In}_{2} \mathrm{MO}_{8}(\mathrm{M}=\mathrm{Ce}$, $\mathrm{Hf}$, or Zr)". Solid State Ionics, 44 (1-2), 1990, p. 21-31.

17 Takahashi, T. and Iwahara, H.: "Ionic conduction in perovskite-type oxide solid solution and its application to the solid electrolyte fuel cell". Energy Conversion, 11 (3), 1971, p. 105111.

${ }^{18}$ Mauropey, B.: "Nuevos conductores iónicos para pilas de combustible de óxido sólido: síntesis, caracterización y propiedades eléctricas de los sistemas $\mathrm{Sr}_{2} \mathrm{MNb}_{1-x} \mathrm{Ti}_{\mathrm{x}} \mathrm{O}_{6-\mathrm{x} / 2}$ y $\mathrm{M}_{2 \text { - }}$ ${ }_{x}(\mathrm{Ca}, \mathrm{Sr})_{\times} \mathrm{MgTiO}_{6-\mathrm{x} / 2}(\mathrm{M}=\mathrm{La}, \mathrm{Nd}, \mathrm{Eu}, \mathrm{Y}, \mathrm{Gd}, \mathrm{Yb}, \mathrm{Lu})$. Tesis Doctoral. Universidad CEU San Pablo, Madrid, 2013. 
${ }^{19}$ Takahashi, T. et al.: "Conduction in Bi2O3-based oxide ion conductor under low oxygen pressure. II. Determination of the partial electronic conductivity". Jour. Appl. Electrochem., 7(4), 1977, p. 303-308.

${ }^{20}$ Pérez Coll, D.: "Materiales nanoestructurados a base de ceriapara pilas de combustible: propiedades de transporte iónico y electrónico". Tesis Doctoral. Universidad de La Laguna, 2005. ISBN: 84-7756-682-8.

${ }^{21}$ Kröger, F.A.; Vink, H.J.: "Relations between the Concentrations of Imperfections in Crystalline Solids". Sol. St. Phys., Vol. 3, 1956, p. 307-435.

${ }^{22}$ Subbarao, E.C.: "Advances in Ceramics, Vol.3, Science and Technology of Zirconia"- Ed. A.H. Heuer and L.W. Hobbs. Am. Ceram. Soc. Columbus, 1981, p. 1.

${ }^{23}$ Gupta, T.K. et al.: "Stabilization of tetragonal phase in polycrstalline zirconia". Jour. Mater. Sci., Vol. 12 (12), 1977, p. 2421-2426.

${ }^{24}$ Mogesen, M. et al.: "Physical, chemical and electrochemical properties of pure doped ceria". Solid State Ionics, 129 (1-4), 2000, p. 63-94.

${ }^{25}$ Lee, Y.-K.; Park, J.-W.: "Microstructure and electrical conductivity of yttria-stabilized zirconia electrolyte thin plates produced by the doctor blade method". Jour. Mater. Sci. Lett., 16,1997 , p. $678-682$.

${ }^{26}$ Arachi, Y.; et al.: "Electrical Conductivity of $\mathrm{ZrO}_{2}-\mathrm{Sc}_{2} \mathrm{O}_{3}$ Doped With $\mathrm{HfO}_{2}, \mathrm{CeO}_{2}$, and $\mathrm{Ga}_{2} \mathrm{O}_{3}$.. Jour. Electrochem. Soc., 148(5), 2001, A520-A523.

${ }^{27}$ Yamahara, K.; DeJonghe, L.C., et al.: "Ionic Conductivity of Stabilized Zirconia Networks in composite SOFC Electrodes". LBNL-54801.

${ }^{28}$ Chen, K.; et al.: "Development of yttria-stabilized zirconia thin films via slurry spin coating for intermediate-to-low temperature solid oxide fuel cells". Jour. Pow. Sour., 160, Elsevier 2006, p. 436-438.

${ }^{29}$ Hirano, M.; et al.: "Mechanical and electrical properties of $\mathrm{Sc}_{2} \mathrm{O}_{3}$-doped zirconia ceramics improved by postsintering with HIP". Solid Stat lonics, 133, 2000, p. 1-9.

${ }^{30}$ Hirano, M.; Inagaki, M.: "Improvement of Mechanical and Electrical Properties of ScandiaDoped Zirconia Ceramics by Post-Sintering with Hot Isostatic Pressing". J. Am. Ceram. Soc., 83(10), 2000, p. 2619-21.

${ }^{31}$ Lei, Z. et al.: "Low temperature processing of dense nanocrystalline scandia-doped zirconia (ScSZ) ceramics". Solid State lonics, 176, 2005, p. 2791-2797.

32 Hareing, C.; Roosen, A.; Schichl, H.; Schnöller, M.: "Degradation of the electrical conductivity in stabilized zirconia system. Part II: Scandia-stabilised zirconia". Solid Sta. Ion., 176,2005 , p. 261-268.

33 Politova, T.I.; Irvine, J.T.S.: "Investigation of Scandia-yttria-zirconia system as an electrolyte material for intermediate temperature fuel cells- influenceof yttria content in system $\left(\mathrm{Y}_{2} \mathrm{O}_{3}\right)_{x}\left(\mathrm{Sc}_{2} \mathrm{O}_{3)(11-x)}\left(\mathrm{ZrO}_{2}\right)_{89}\right.$. Solid Sta. Ion., 168, 2994, p. 153-165.

${ }^{34}$ Waqas Bin Najib: "Literature survey of scandia doped zirconia solid electrolyte systems". Risø Nat. Lab. Febr. 2007. Doc. Interno proyecto SOFC 600.

35 Irvine, J.T.S.; Politova, T.; et al.: "Scandia-Zirconia Electrolytes and Electrodes for SOFCs". Full Cell Tecnologies: State and Prerspectives. Springer, 2005, p. 35-47.

${ }^{36}$ Irvine, J.T.S.; Dobson, J.W.; et al.: "Co-doping of scandia- zirconia electrolytes for SOFCs" Faraday Discuss, 134, 2007, p. 41-49. 
${ }^{37}$ Lee, D.-S.; et al.: "Characterization of $\mathrm{ZrO}_{2}$ co-doped with $\mathrm{Sc}_{2} \mathrm{O}_{3}$ and $\mathrm{CeO}_{2}$ electrolyte for application of intermediate temperature SOFCs". Solid Sta. Ion., 176, 2005, p. 33-39.

${ }^{38}$ Wang, Z.; Cheng, M.; et al.: "Structure and impedance of $\mathrm{ZrO}_{2}$ doped with $\mathrm{Sc}_{2} \mathrm{O}_{3}$ and $\mathrm{CeO}_{2}$ ". Mater. Let., 59, 2005, p. 2579-2582.

${ }^{39}$ Gellins, P.J.; Bouwmeester, H.J.M. "Ion and mixed conducting oxides as catalysts". Catalysis Today, 12, 1992, I-105, Elsevier Science Publishers B.V. Amsterdam.

${ }^{40}$ Orliukas, A. et al.: "The relaxation dispersion of the ionic conductivity in cubic zirconias". Solid Stat Ion., 72, 1994, p. 35-38.

${ }^{41}$ Monty, C.: "About Ionic Conductivity/Diffusion Relationships in Yttria Doped Zirconia". lonics, 8, 2002, p. 461.

${ }^{42}$ Peters, C.: "Grain-SizeEffects in Nanoscaled Electrolyte and Cathode Thin Film sfor Solid Oxide Fuel Cells (SOFC). Thesis. Universitat Karlsruhe, 2008.

43 Beekmans, N.M.; Heyne, L.: "Correlation between Impedance, Microstructure and Composition of Calcia-Stabilized Zirconia". Electrochimica Acta, Vol. 2. Pergamon Press. 1976, p. 303-310.

44 Dijk, T.v.; Burggraaf, A.J.: "Grain Boundary Effects on lonic Conductivity in Ceramic $\mathrm{Gd}_{x} \mathrm{Zr}_{1-x} \mathrm{O}_{2-(x / 2)}$ Solid Solutions”. Phys. Stat. Sol. (a) 63, 1981, p. 229.

45 Barsoukov, E.; Macdonald, J.R.: "Impedance Spectroscopy. Theory, Experiment and Applications". John Wiley \& Sons, Inc., Hoboken, New Jersey. 2005. ISBN: 0-471-64749-7.

46 Carvalho, E. et al:: "Investigation of conductivity of $\left(\mathrm{Ce}_{\mathrm{x}} \mathrm{Y}_{0,2-\mathrm{x}}\right) \mathrm{Sc}_{0,6} \mathrm{Zr}_{3,2} \mathrm{O}_{8-\delta}(0<\mathrm{x}<0,2)$ system and its dependence upon oxygen partial pressure". Solid State lonics, 181, 2010, p. 1344-1348.

${ }^{47}$ Martin, M.; Mecartney, M.L.: "Grain boundary ionic conductivityof ytrium stabilized zirconia as a function of silica content and grain size". Solid State lonics, 161, 2003, p. 67-79.

${ }^{48}$ Näfe, $\mathrm{H}$.: "Ionic Conductivity of $\mathrm{ThO}_{2}$ and $\mathrm{ZrO}_{2}$ based Electrolytes between 300 and 2000 K", Solid State Ionics, 13, 1984, p.255-263.

49 Steele, B.C.H.: "Material science and engineering: Theenabling technology for the commercialisation of fuel cell systems". Jour. Mater. Sci., 36, 2001, p. 1053-1068.

${ }^{50}$ Wincewicz, K.C.; et al.: "Taxonomies of SOFC materialand manufacturing alternatives". Jour. Power Sourc., 140, 2005, p. 280.

51 Barsoukov, E., MacDonald, J.R.: "Impedance Spectroscopy Theory, Experiment, and Applications". $2^{\text {nd }}$ ed. John Wiley \& Sons, New Jersey, 2005. p. 87.

${ }^{52}$ Singhal, S.C. MRS Bulletin, March 2000, p. 16-21.

${ }^{53}$ Slepian, R.M.: "Preparation of Stabilized Zirconia for Microscopic Examination". J. Amer. Ceram. Soc. 47 (10), 1964, p. 535.

${ }^{54}$ Taffner, U., Carle, V., et al.: "Preparation and Microstructural Analysis of High-Performance Ceramics". ASM Handbook. Vol 9: Metallography and Microstructures, 2004, p. 1057-1066.

${ }^{55}$ Jeffries, Z., et al. Trans. AIME. Vol. 54, 1916, p. 594-697.

${ }^{56}$ Jeffries, Z., et al. Trans. of the Faraday Soc. Vol. 12, 1916, p. 40-56.

57 Jillaven Katesa, A. et al.: "NIST Recommended Practice Guide: Particle Size Characterization. Special Publication 960-1. Ed. NIST. Washington, 2001. 
58 Engqvist, H.; Uhrenius, B.: "Determination of the average grain size of cemented carbides". International Journal of Refractory Metals \& Hard Materials, 21, 2003, p. 31-35.

59 Vladikova, D. et al.: "Differential impedance analysis of single crystal and polycrystalline yttria stabilized zirconia". Electrochimica Acta 51, 2006, p. 1611-1621.

${ }^{60}$ Barsoukov, E., MacDonald, J.R.: "Impedance Spectroscopy Theory, Experiment, and Applications". $2^{\text {nd }}$ ed. John Wiley \& Sons, New Jersey, 2005. p. 232.

61 Barsoukov, E., MacDonald, J.R.: "Impedance Spectroscopy Theory, Experiment, and Applications". $2^{\text {nd }}$ ed. John Wiley \& Sons, New Jersey, 2005. p. 34.

${ }^{62}$ Gao et al.: "Comparative Study of $\mathrm{Ce}_{0.85} \mathrm{Sm}_{0.075} \mathrm{Nd}_{0.075} \mathrm{O}_{2-\delta}$ electrolyte synthesized by different routes". Journal of Alloys and Compounds 509, 2011, p. 8720-8727.

${ }^{63} \mathrm{~J}$. Xiang et al.: "Influence of pentavalent niobium doping on microstructure and electrical conductivity of oxy-apatite $\mathrm{La}_{10} \mathrm{Si}_{6} \mathrm{O}_{27}$ electrolytes". Electrochimica Acta 153, 2015, p. 287294.

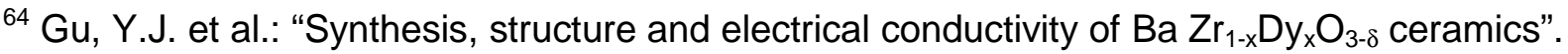
Electrochimica Acta 75, 2012, p. 332-338

${ }^{65}$ M. E. Orazem and B. Tribollet.: "Electrochemical Impedance Spectroscopy". John Wiley \& Sons, Hoboken. NJ, 2008.

${ }^{66}$ C. Sánchez Bautista, A.J. Dos Santos-García, J. Pena Martínez, J. Canales Vázquez, Solid State Ionics, 181, 2010, p. 1665-1673.

${ }^{67}$ Hirschorn, B. et al." Constant-Phase-Element Behavior Caused by Resistivity Distributions in Films". Journal of the Electrochemical Society, 157 (12), 2010, C452-C457.

68 Barsoukov, E., MacDonald, J.R.: "Impedance Spectroscopy Theory, Experiment, and Applications". $2^{\text {nd }}$ ed. John Wiley \& Sons, New Jersey, 2005, p. 73.

${ }^{69}$ G. J. Brug, A. L. G. van den Eeden, M. Sluyters-Rehbach, and J. H. Sluyters. J. Electroanal. Chem., 176, 1974, p. 275.

${ }^{70}$ Raikova, G. et al.: "Inductance correction in impedance studies of solid oxide fuel cells". Bulgarian Chemical Communications, Volume 41, Number 2, 2009, p. 199-206.

${ }^{71}$ Qian, J.: "Chemically stable $\mathrm{BaZr}_{0.7} \mathrm{Pr}_{0.1} \mathrm{Y}_{0.2} \mathrm{O}_{3-\delta}-\mathrm{BaCe}_{0.8} \mathrm{Y}_{0.2} \mathrm{O}_{3-\delta}$ bilayer electrlyte for intermediate temperature solid oxide fuel cells".

72 Simpatico, A. et al.: "Comparison of Hydraulic-Burst and Ball-on-Ring Tests forMeasuring Biaxial Strength". J. Am. Ceram. Soc., 82 (10), 1999, p. 2737-44.

${ }^{73}$ R.E. Mistler, D.J. Shanfield, R.B. Runk: "Ceramic Processing before Firing". Wiley, New York, 1978, p. 411-448.

${ }^{74}$ R.E. Mistler, Am. Ceramic Soc. Bull. 69 (6), 1990, p. 1022-1026.

${ }^{75}$ S. Bhattacharjee*, M. K. Paria, H. S. Maiti: "Polyvinyl butyral as a dispersant for barium titanate in a nonaqueous suspensions".: Journal of Materials Science, 28, 1993, p. 6490-6495.

76 Kurt Mikeska, Roger Cannon, Am. Ceramic Soc. Bull., 9, 1985, p. 164-184.

77 Paul D. Calvert, Ellen S. Tormy, Richard L. Pober, Am. Ceramic Soc. Bull. 65 (4), 1986, p. 669-672.

78 T. Chartier, E. Streicher, P. Booch, Ceramic Bull. 66 (11), 1987, p. 1653-1655. 
79 A.K Maitia, B Rajenderb.: "Terpineol as a dispersant for tape casting yttria stabilized zirconia powder". Materials Science and Engineering: A Volume 333, Issues 1-2, August 2002, p. 35-40.

80 W.R. Cannon, J. R. Morris and K. R. Mikeska, Advances in ceramics, Vol. 19, The American Ceramic Society, Westerville, Ohio, 1987, p. 161.

${ }^{81}$ W. R. Cannon, J. R. Morris and K. R. Mikeskain, Advances in Ceramics, Vol. 26, The American Ceramic Society, Westerville, Ohio, 1989, p. 525.

82 I. Zhitomirsky, A. Petric / Journal of the European Ceramic Society 20, 2000, p. 20552061.

${ }^{83}$ Mikeska, K. and Cannon, W. R.: "Dispersants for tape casting pure barium titanate". Advances in Ceramics. Forming of Ceramics, ed. J. A. Mangels and G. L. Messing. American Ceramic Society, vol. 9, Columbus, OH, 1984, p. 164-183.

84 Jean, J. H., Yeh, S. F. and Chen, C. J.: "Adsorption of poly(vinylbutyral) in nonaqueous ferrite suspensions". J. Mater. Res., 12, 1997, p. 1062-1068.

${ }^{85}$ Moreno, R.: "The role of slip additives in tape-casting technology: part II-binders and plasticizers". American Ceramic Society Bulletin, 71, 1992, p. 1647-1657.

${ }^{86}$ Rahaman, M. N.: "Ceramic Processing and Sintering". $2^{\text {nd }}$ edition. Mascel Dekker Inc., New York, 2003. ISBN: 0-8247-0988-8, pag 359.

${ }^{87}$ T. Chartier, E. Streicher, P. Booch, Ceramic Bull. 66 (11), 1987, p. 1653-1655.

${ }^{88}$ Ramanathan, S.; et al.: "Powder dispersion and aqueous tape casting of YSZ-NiO composite". Jour. Mater. Sci., 39, 2004, p. 3339-3344.

${ }^{89}$ Román Nava, Sophie Guillemet-Fritsch, Juan Aguilar-Garib, Edgar Reyes and Bernard Durand: "The thickness of $\mathrm{BaTiO}_{3}$ tape castings as function of the slip system. Journal of Ceramic Processing Research. Vol. 13 (2), 2012, p. 101-104.

${ }^{90}$ Maitia, A.K.; Rajenderb, B.: "Terpineol as a dispersant for tape casting yttria stabilized zirconia powder". Materials Science and Engineering: A Volume 333, Issues 1-2, August 2002 , p. 35-40.

91 Mistler, R.E.; et al.: "Tape Casting, theory and practice". The Amer. Ceram. Soc., Westerville, OH., 2000. ISBN: 1-57498-029-7.

92 Jang, W.S.; et al.: "Preparation of YSZ/YDC and YSZ/GDC composite electrolytes by the tape casting and sol-gel dip-drawing coating method for low-temperature SOFC". Jour. Mater. Sci., 37, 2002, p. 2535-2541.

${ }^{93}$ Bettge, M.: "Processing of porous electrodes for Solid Oxide Fuel Cells using tape casting and unidirectional freeze-drying". The Florida State University, College of Engineering. Thesis of Department of Mechanical Engineering, 2004.

\footnotetext{
${ }^{94}$ Sholklapper, T. Z.: “Nanostructured Solid Oxide Fuel Cell Electrodes”. Lawrence Berkeley National Laboratory (University of California), 2007. Paper LBNL-63741.

${ }^{95}$ Ianculescu, A. et al.: "BaTiO 3 thick films obtained by tapecasting from powders prepared by the oxalate route". Processing and Application of Ceramics, 3, 1-2, 2009, p. 65-71.

${ }^{96}$ Vihothini, V. et al.: "Optimization of barium titanate nanopowder slip for tape casting". J. Mater. Sci., 41, 2006, p. 7082-7087. DOI: 10.1007/s10853-006-0940-8.

${ }^{97}$ Silvain et al.: "Manufacturing process for thin films made of metal/ceramiccomposite". Pat. №: US 7.871.562 B2. 2011.
} 
${ }^{98}$ Carvalho, E; Irvine, J. T. S.; "Characterisation of conductivity of the $\left(\mathrm{Ce}_{\mathrm{x}} \mathrm{Y}_{0.2-\mathrm{x}}\right) \mathrm{Sc}_{0.6} \mathrm{Zr}_{3.2} \mathrm{O}_{8-\delta}$ $(0 \leq x \leq 0.2)$ system and composition $\mathrm{Ce}_{0.04} \mathrm{Y}_{0.02} \mathrm{Sc}_{0.67} \mathrm{Zr}_{3.27} \mathrm{O}_{7.66}$ as function of time". Cerâmica, 58, 2012, p. 1-7.

${ }^{99}$ Preis, W.; et al.: "Electrical properties of bulk and grain boundaries of scandia-stabilized zirconia co-doped with yttria and ceria". Solid State lonics, 192, 2011, p. 148-152.

100 6o PM, Priority 6.1. Integrated Project: "SOFC 600: Demonstration of SOFC stack technology for operation at $600^{\circ} \mathrm{C}$ ". Documento interno, 2006-2010.

${ }^{101}$ Grosso, R.L. et al. "Ionic conductivity and phase stability of spark plasma sintered scandia and ceria-stabilized zirconia." Solid State lonics, 230, 2013, p. 48-51.

102 Gurauskis, J. et al.: "Alumina-zirconia layered ceramics fabricated by stacking water processed green ceramic tapes”. Jour. Eur. Ceram. Soc., 27, 2007, p. 1387-1394.

${ }^{103}$ Guo, C.X. et al.: "Effect of alumina on the properties of ceria and scandia co-doped zirconia for electrolyte-supported SOFC".Ceram. Int., 39, 2013, p. 9575-9582.

${ }^{104} \mathrm{Xu}, \mathrm{G}$; et al.: "Grain size-dependent electrical conductivity in scandia-stabilized zirconia prepared by a mildurea-based hydrothermal method". Solid State Ionics, 166, 2004, p. 391396.

${ }^{105}$ Burke, J. E.; Turnbull, D., Prog. Metal Phys., 3, 1952, p. 220.

${ }^{106}$ Atkinson, H.V.: "Overview № 65. Theories of normal grain growth in pure single phase systems". Acta Metall., 36 (3), 1988, p. 469-491.

107 Rupp, J.L.M.; et al.: "Microstrain and self-limited grain growth in nanocrystalline ceria ceramics". Acta Materialia, 54, 2006, p. 1721-1730.

108 Powers, J.D.; Glaeser, A.M.: "Grain Boundary Migration in Ceramics". lintience, 6, 1998, p. 23-39.

109 Liu, M. et al.: "Synthesis and characterization of $10 \mathrm{Sc1CeSZ}$ powders prepared by a solid-liquid method for electrolyte-supported solid oxyde fuel cells". Ceramics International 40, 2014, p. 5441-5446.

${ }^{110}$ Kumar, C.N.S., Bauri, R.: "Enhancing the phase stability and ionic conductivity of scandia stabilized zirconia by rare earth co-doping". Journal of Physics and Chemistry of Solids 75, 2014, p. 642-650.

111 Dasari, H.P. et al.: "Synthesis, sintering and conductivity behavior of ceria-doped Scandiastabilized zirconia". Solid State lonics, 263, 2014, p. 103-109.

112 Peters, C.: "Grain-SizeEffects in Nanoscaled Electrolyte and Cathode Thin Film sfor Solid Oxide Fuel Cells (SOFC). Thesis. Universitat Karlsruhe, 2008, p. 64-65.

${ }^{113} \mathrm{Li}$, Y; et al.: "Grain-boundary effect in zirconia stabilized with yttria and calcia by electrical measurements". Materials Science and Engineering, B103, 2003, p. 108-114.

114 Noggle, J.: "Practical Curve Fitting and Data Analysis. Software and self-instruction for scientists and engineers". PTR Prentice-Hall, Inc. New Jersey, 1993. ISBN: 013-677-394-X.

${ }^{115}$ Peters, C.: "Grain-SizeEffects in Nanoscaled Electrolyte and Cathode Thin Film sfor Solid Oxide Fuel Cells (SOFC). Thesis. Universitat Karlsruhe, 2008, p. 97.

116 Tekeli, S.: "Influence of $\alpha-\mathrm{Al}_{2} \mathrm{O}_{3}$ addition on sintering and grain growth behaviour of 8 mol\% $\mathrm{Y}_{2} \mathrm{O}_{3}$-stabilised cubic zirconia $\left(\mathrm{c}-\mathrm{ZrO}_{2}\right)$. Ceramic International, 30, 2004, p. 2203-2209.

117 Guo, X.: "Roles of Alumina in Zirconia for Functional Applications". J. Am. Ceram. Soc., 86, 11, 2003, p. 1867-73. 


